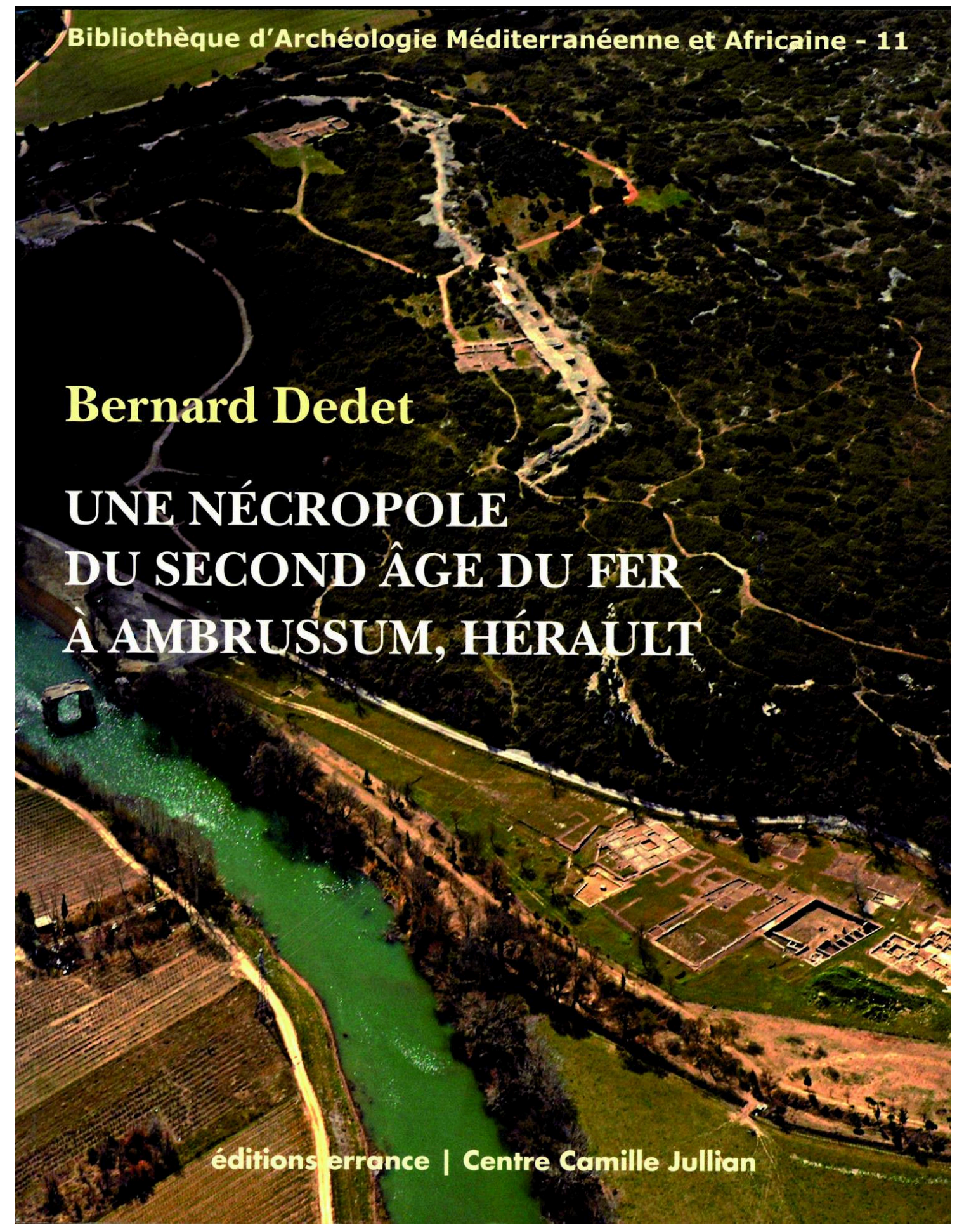




\title{
Une nécropole du second âge du fer à Ambrussum, Hérault
}

\author{
Bernard Dedet (dir.)
}

DOI : 10.4000/books.pccj. 1267

Éditeur : Publications du Centre Camille Jullian, Éditions Errance

Lieu d'édition : Aix-en-Provence

Année d'édition : 2012

Date de mise en ligne : 13 février 2020

Collection : Bibliothèque d'archéologie méditerranéenne et africaine

ISBN électronique : 9782491788001

\section{Cbooks}

http://books.openedition.org

Édition imprimée

Date de publication : 15 mars 2012

ISBN : 9782877724890

Nombre de pages : 282

\section{Référence électronique}

DEDET, Bernard (dir.). Une nécropole du second âge du fer à Ambrussum, Hérault. Nouvelle édition [en ligne]. Aix-en-Provence : Publications du Centre Camille Jullian, 2012 (généré le 03 avril 2020).

Disponible sur Internet : <http://books.openedition.org/pccj/1267>. ISBN : 9782491788001. DOI : https://doi.org/10.4000/books.pccj.1267.

(c) Publications du Centre Camille Jullian, 2012

Conditions d'utilisation :

http://www.openedition.org/6540 


\section{$\mathrm{B}$ ibliothèque d'Archéologie \\ Méditerranéenne et Africaine 11}


Dans la lignée des anciens Travaux du Centre Camille Jullian, la Bibliothèque d'Archéologie Méditerranéenne et Africaine (BiAMA) regroupe des travaux (monographies, actes de colloques, ouvrages collectifs) en relation avec les programmes scientifiques du Centre Camille Jullian, sur l'histoire et l'archéologie de la Gaule méridionale, de l'Afrique du Nord et du bassin méditerranéen. La BiAMA peut comprendre des sous-séries, comme la collection Études massaliètes (EtMassa).

\section{Responsable légal :}

Marie-Brigitte Carre, Directrice du CCJ

Directeur de la publication :

Henri Tréziny

Comité de pilotage :

Xavier Delestre, Marie-Brigitte Carre, Henri Tréziny

Conception graphique et mise en page :

Véronique Gémonet

\section{Comité de lecture :}

$\mathrm{Ph}$. Borgard (CCJ, CNRS), M.-Br. Carre (CCJ, CNRS), X. Delestre (DRAC PACA), D. Garcia (CCJ, Université d'Aix-Marseille), M. Griesheimer (CCJ, Université d'Aix-Marseille), A. Hermary (CCJ, Université d'Aix-Marseille), Ph. Jockey (CCJ, Université d'Aix-Marseille), M. Lombardo (Professeur à l'Université de Lecce), T. S. Loseby (Professeur à l'Université de Sheffield), J.-M. Mignon (Service archéologique départemental du Vaucluse), P. Pomey (CCJ, CNRS), L. Rivet (CCJ, CNRS), J. Sanmarti (Professeur à l'Université de Barcelone), H. Tréziny (CCJ, CNRS), C. Virlouvet (École française de Rome), E. Voutiras (Professeur à l'Université de Thessalonique).

Conseiller scientifique pour ce volume : Stephan Fichtl (CIRA Sud-Est).

(C) 2012 pour tous pays,

Édition Errance, éditeur du groupe Actes Sud,

7 , rue Jean Du Bellay 75004 Paris

Tél. : 0443268582

Fax : 0143293488

Courriel : contact@editions-errance.fr

http://www.libairie-epona.fr

Centre Camille Jullian

Maison Méditerranéenne des Sciences de l'Homme

5 rue du Château de l'Horloge. BP 647, 13094 Aix-en-Provence Cedex 2

ISBN : 978-2-87772-489-0

ISSN : 2101-2849

Illustrations de couverture :

Vue aérienne d'Ambrussum (cliché C. Landes);

Illustration $4^{\text {ème }}$ de couverture :

Pointe de lance (tombe 12) et élément de ceinture (tombe 19) ;

Le loculus de la tombe 23 en cours de fouille (clichés B. Dedet).

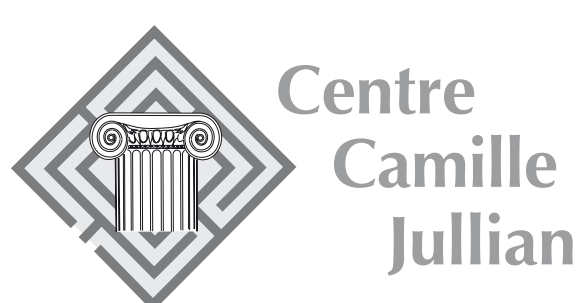

Ouvrage financé par

le Ministère de la Culture et de la Communication

(Direction du Patrimoine, sous-direction de l'Archéologie)

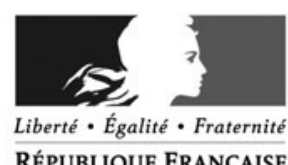

RÉPUBLIQUE FRANÇAISE

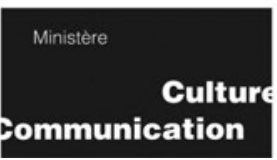

Envoyer les manuscrits à :

Henri Tréziny

Bibliothèque d'Archéologie Méditerranéenne et Africaine

Centre Camille Jullian

Maison Méditerranéenne des Sciences de l'Homme

5 rue du Château de l'Horloge. BP 647,

13094 Aix-en-Provence Cedex 2 


\section{UNE NÉCROPOLE \\ DU SECOND ÂGE DU FER \\ À AMBRUSSUM, HÉRAULT}

Bernard DEDET

avec des contributions de Carine CENZON-SALVAYRE, Aline DURAND, Armelle GARDEISEN, Gael PIQUĖS et Núria ROVIRA 


\section{Sommaire}

Préface (Jean-Luc Fiches)

\section{Introduction}

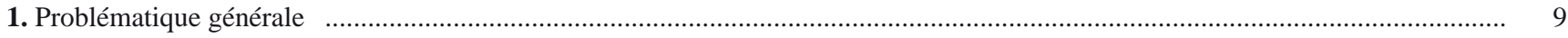

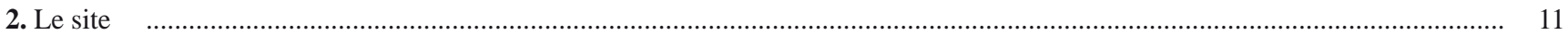

3. Historique des recherches et histoire du site : un oppidum gaulois, sa nécropole et une station routière gallo-romaine $\quad . . . . . . . . . . . . . . . . \quad 14$

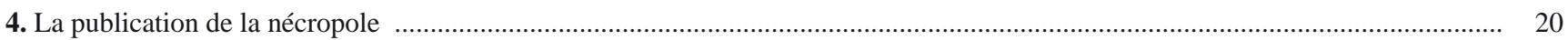

Chapitre 1 : Position stratigraphique et méthode d'étude de la nécropole (fouilles 1999 - 2003)

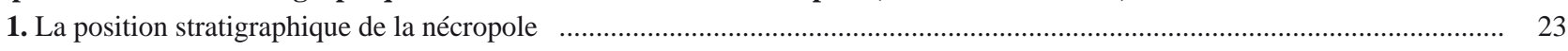

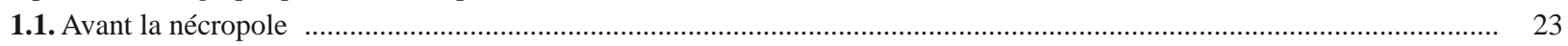

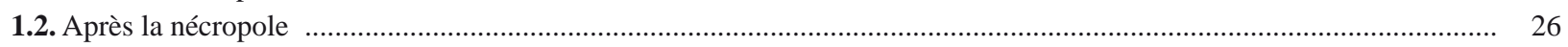

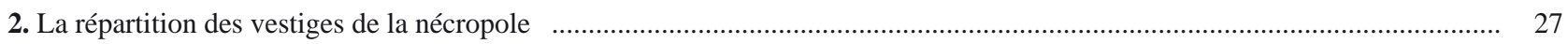

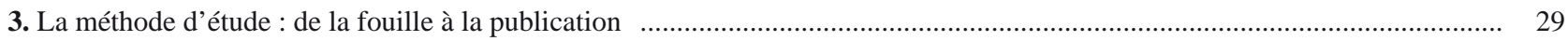

Chapitre 2 : Tombes, structures annexes et sol de la nécropole (fouilles 1999 - 2003)

1. La tombe $\mathrm{T} 10$

2. La tombe T11

3. La tombe $\mathrm{T} 12$

4. La tombe $\mathrm{T} 13$

5. La tombe T14

6. La structure de recouvrement des tombes $\mathrm{T} 12$ et $\mathrm{T} 14$

7. La tombe T15

8. La tombe T16

9. La Tombe T17

10. La tombe $\mathrm{T} 18$

11. La tombe $\mathrm{T} 19$

12. La tombe $\mathrm{T} 20$

13. La tombe $\mathrm{T} 21$

14. La tombe $\mathrm{T} 22$

15. La tombe $\mathrm{T} 23$

16. La structure de recouvrement des tombes $\mathrm{T} 22$ et $\mathrm{T} 23$

17. La tombe $\mathrm{T} 24$

18. La tombe $\mathrm{T} 25$

19. Le niveau de sol de la nécropole

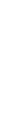


2.2.2. Les objets

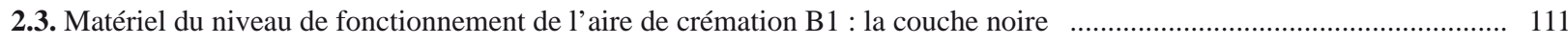

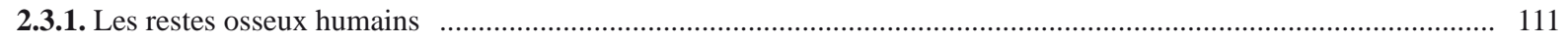

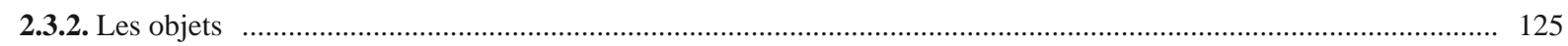

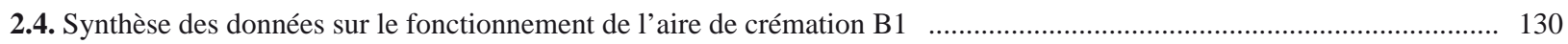

2.4.1. La composition du lot osseux et le nombre d'individus incinérés ................................................................... 130

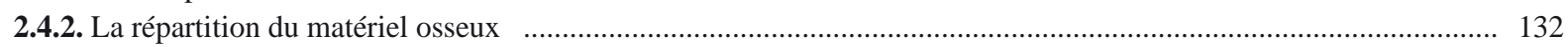

2.4.3. La composition du mobilier et sa répartition ..................................................................................................... 132

3. Conclusion : une aire pour plusieurs crémations séparées, consécutives ou non .......................................................................... 142

Chapitre 4 : Les structures funéraires découvertes dans les sondages 1979-1984 à la lumière des fouilles récentes

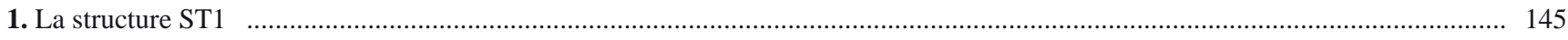

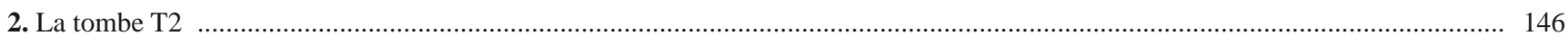

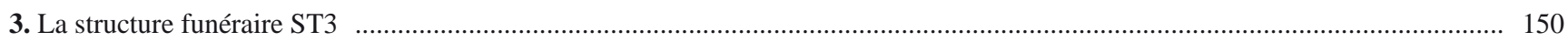

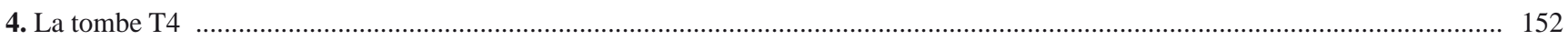

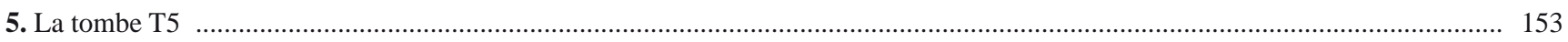

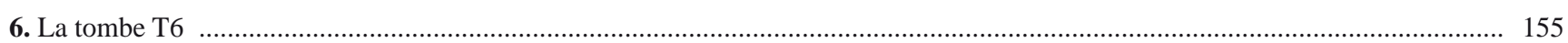

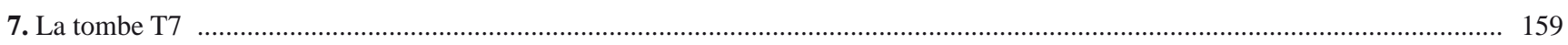

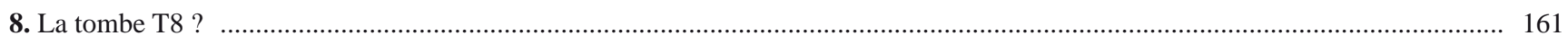

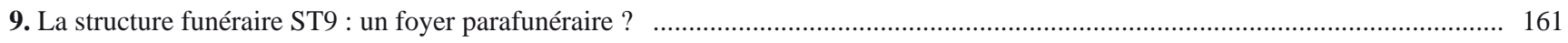

\section{Chapitre 5 : Le mobilier funéraire et son apport à la datation de la nécropole}

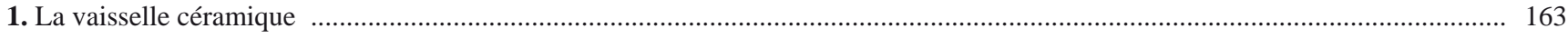

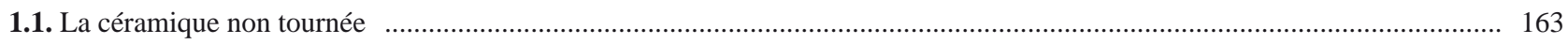

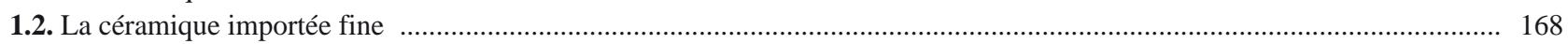

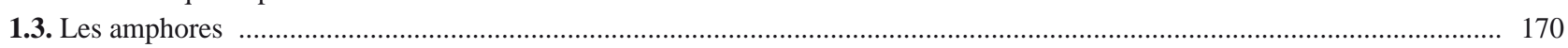

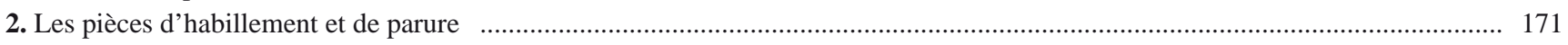

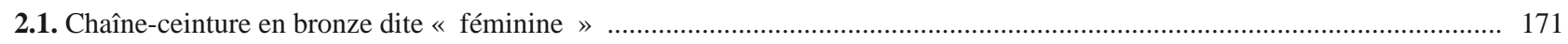

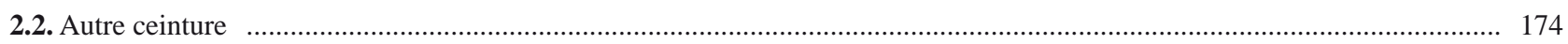

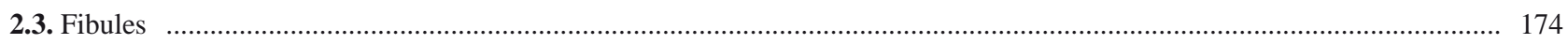

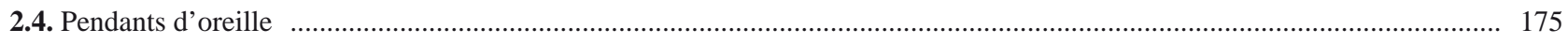

2.5. Torques $\quad$.

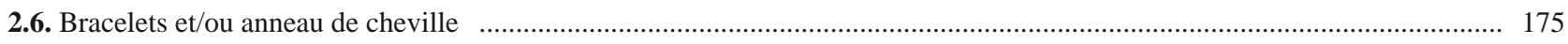

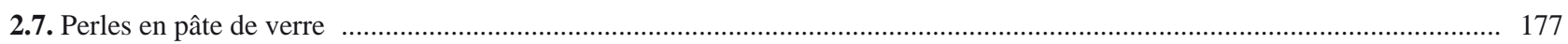

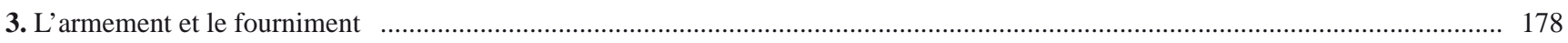

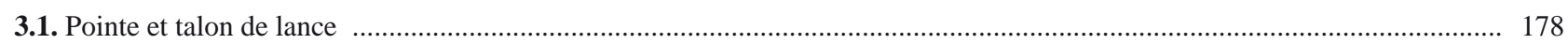

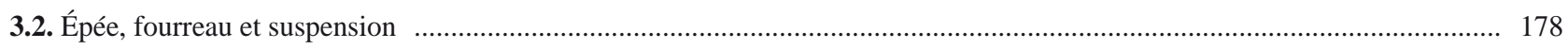

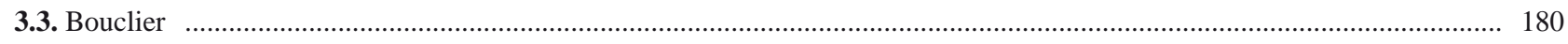

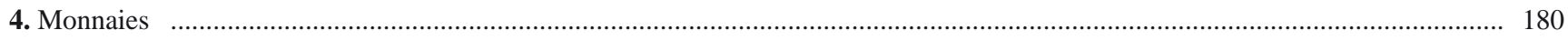

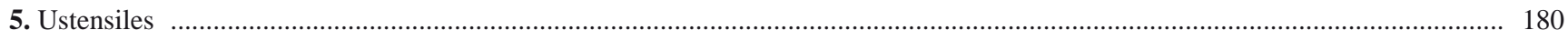

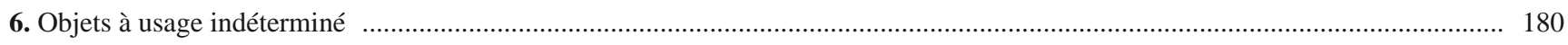

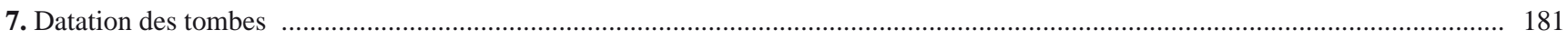

Chapitre 6 : Les pratiques funéraires à Ambrussum : Défunts, traitement des corps et des restes osseux, morphologie des tombes et matériel d'accompagnement

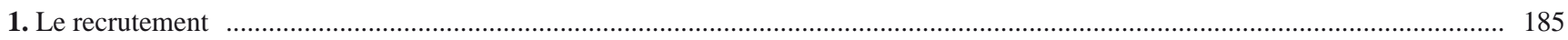

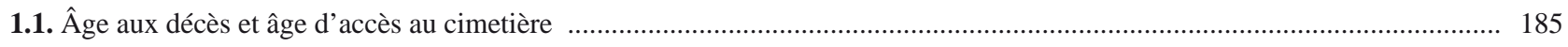

1.2. Homme ou femme, garçon ou fille d'après la symbolique du mobilier ............................................................................. 188

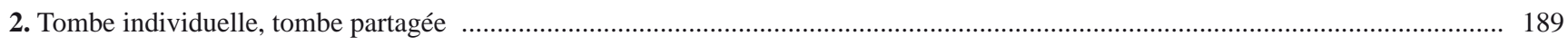

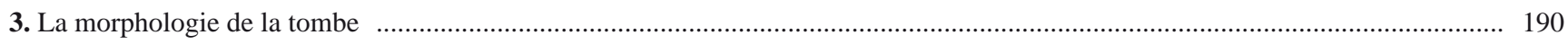

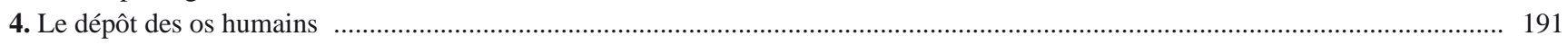

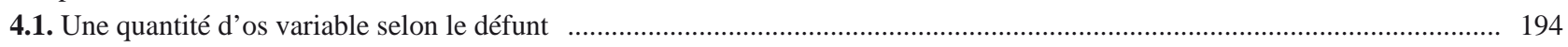

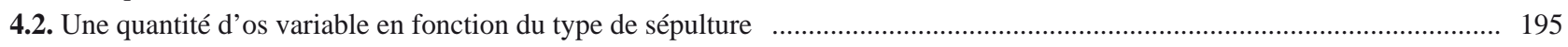

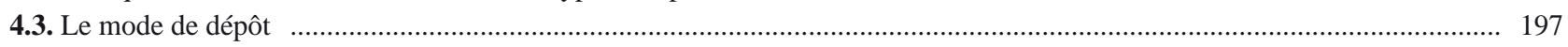

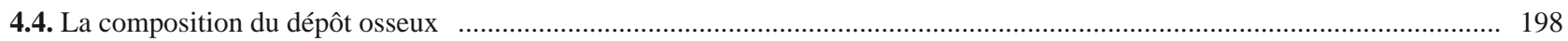


5. Le matériel accompagnant les défunts

5.1. Les objets personnels

5.1.1. Armes et fourniment

5.1.2. Objets de parure et ustensiles spécifiques des tombes sans armement ................................................................ 202

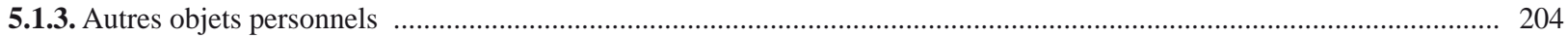

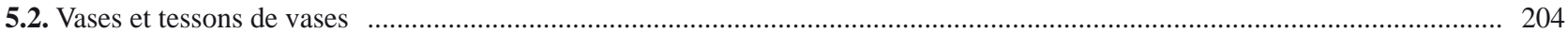

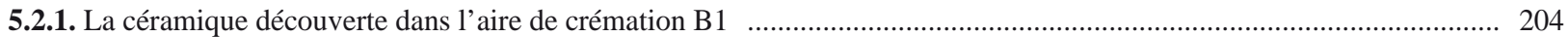

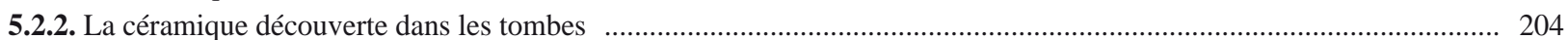

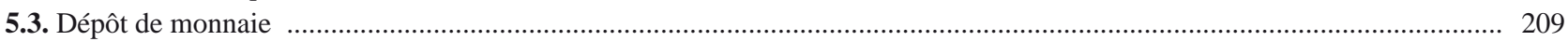

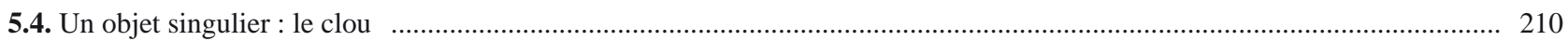

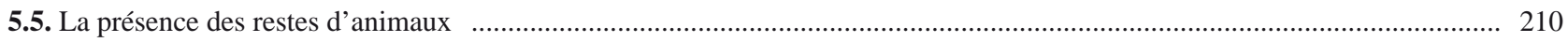

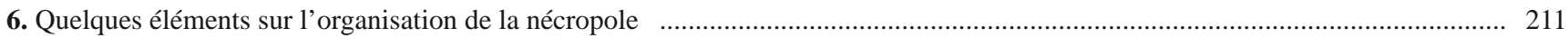

6.1. Bûchers et tombes

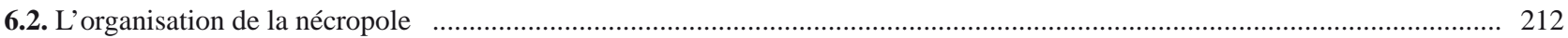

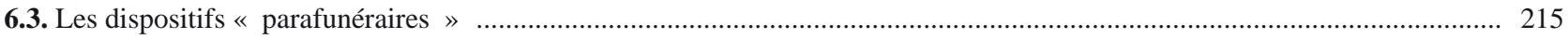

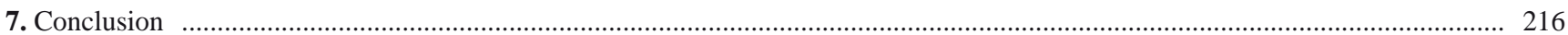

Chapitre 7 : Ambrussum dans le contexte funéraire du Midi méditerranéen au début et au milieu du second Âge du Fer

1. La documentation funéraire contemporaine en Languedoc et en Provence .......................................................................... 219

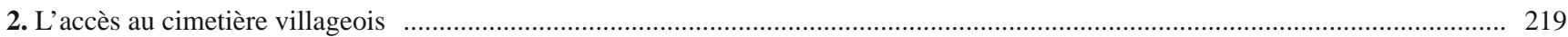

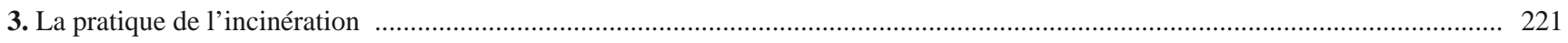

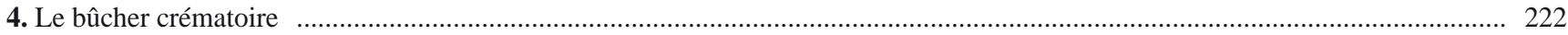

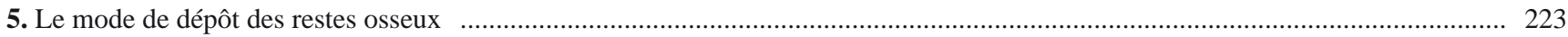

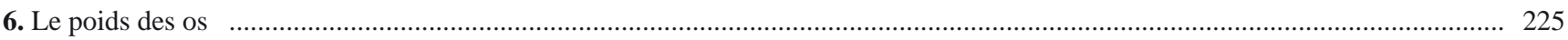

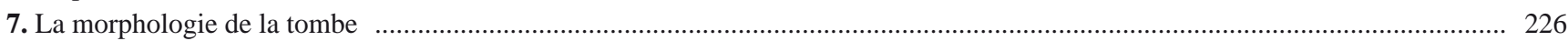

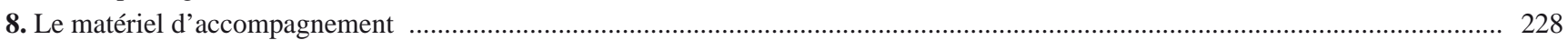

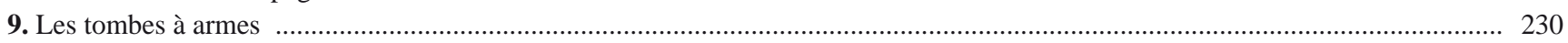

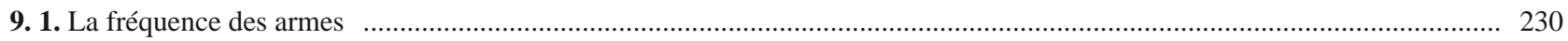

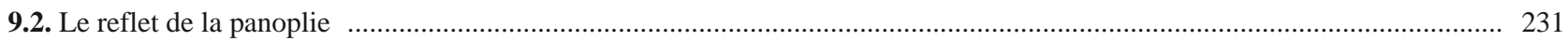

Conclusion générale

Annexe 1 : Analyse anthracologique de l'aire de crémation B1 de la nécropole d'Ambrussum, par Carine Cenzon Salvayre

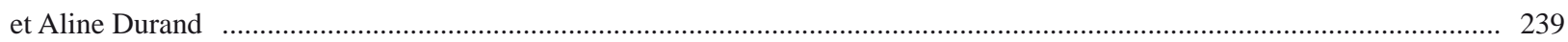

Annexe 2 : Les restes animaux dans les pratiques funéraires à Ambrussum, par Armelle Gardeisen ................................................... 247

Annexe 3 : Les restes de poissons de la nécropole d'Ambrussum, par Gaël Piquès ....................................................................... 265

Annexe 4 : Les restes carpologiques de la nécropole d'Ambrussum : intrusions ou offrandes ? par Núria Rovira ................................ 269 


\section{Préface}

Ambrussum doit sa notoriété aux recherches que nous avons pu y conduire durant quatre décennies : dans les années 1970, la fouille de l'oppidum qui domine le Vidourle a porté sur le rempart gaulois, l'habitat préromain et la ville du Haut-Empire ; depuis 1980, l'exploration a concerné l'agglomération routière gallo-romaine, qui s'est développée en piémont, le long de la voie Domitienne. De manière inattendue, alors que l'oppidum n'a pas fait l'objet de fouilles depuis plus de trente ans, ce sont ces recherches extensives dans le lit majeur du Vidourle qui ont fait progresser la connaissance d'Ambrussum au second Âge du Fer. C'est donc pour moi un grand plaisir d'ouvrir ce livre de Bernard Dedet consacré à un nouveau volet de nos connaissances sur ce site majeur, celui des tombes et des pratiques funéraires des habitants de cet oppidum, un siècle environ avant la conquête de la Gaule transalpine. L'intérêt des découvertes de ce chercheur au début des années 2000 dépasse d'ailleurs largement le cadre local, puisqu'il s'agit d'une des très rares nécropoles actuellement connues du milieu du second Âge du Fer qui concernent le monde indigène du Sud de la France.

Cette nécropole, nous l'avions découverte par surprise, en quelque sorte, quelque vingt-cinq ans plus tôt, lors de la première tranche de travaux développés, entre 1980 et 1985, dans le relais routier gallo-romain. On avait eu alors le souci de rechercher les niveaux d'occupation les plus anciens de la terrasse alluviale, c'est pourquoi des sondages et des fouilles en tranchée furent pratiquées sous l'auberge mise au jour et dans la rue qui la desservait et dont on a rapidement compris qu'il s'agissait de la voie Domitienne. Il faut bien reconnaitre cependant que ces recherches visaient d'abord à recueillir des données sur le paléo-environnement et à retrouver des traces de cultures dans un terroir proche de l'oppidum; elles se sont d'ailleurs révélées fructueuses à cet égard. Mais une première surprise fut de rencontrer, dans tous ces sondages, un niveau d'occupation parfois marqué par un empierrement du sol naturel et comportant le plus souvent une « fosse-foyer », désignée ainsi car on ne soupçonnait pas, tout au long des opérations de terrain, qu'on était en présence de tombes - ce qui explique qu'au terme de la fouille une tranchée ait été réalisée sans plus de précaution à la pelle mécanique pour lire les relations stratigraphiques existant réellement entre les différentes parties de l'îlot. On pensait avoir à faire à un habitat hors les murs que le matériel recueilli permettait alors de dater entre 250 et 175 av. J.-C. Ce n'est, autre surprise, qu'au cours de la préparation de la publication parue en 1989, «L'oppidum d'Ambrussum et son territoire. Fouilles au quartier du Sablas », que l'étude des ossements a révélé qu'il s'agissait de restes humains incinérés, ce qu'il était difficile de soupçonner en l'absence d'ossuaire.

Lorsque la fouille de l'agglomération routière reprit en 1993, priorité fut donnée à la caractérisation des îlots mis au jour sur plus d'un hectare sans qu'il ait été jugé nécessaire de les fouiller jusque dans leur état le plus ancien ; il s'agissait surtout de localiser les différents équipements et services du relais routier gallo-romain pour en dégager l'organisation d'ensemble. Mais en 1998, à l'issue de deux programmes triennaux, d'autres axes de recherche étaient envisagés. Déjà cette année-là, la mise en route d'un projet collectif de géoarchéologie sur la vallée du Vidourle avait permis de réaliser, près du pont romain et perpendiculairement au Vidourle, une tranchée profonde de 5,50 $\mathrm{m}$. On y a distingué dix phases de dérèglement hydrologique, d'ampleur et d'intensités inégales, au cours de l'Antiquité. On y a aussi reconnu, dans le fond, une occupation de la période 275-175 av. J.-C., caractérisée par un mur appareillé, des fosses et des sols aménagés ; ainsi l'habitat a très tôt débordé de l'enceinte pour investir la berge du fleuve dans une période où la plaine présentait un drainage naturel et une stabilité importants.

C'est dans ce contexte qu'il a été décidé d'explorer plus avant le quartier de la nécropole entrevu entre 1980 et 1985. Les sondages pratiqués alors dans la zone 1 étaient restés limités, leur superficie cumulée ne dépassant pas $40 \mathrm{~m}^{2}$. Or, la cour de cet îlot, présenté dans son état augustéen (soit $1 \mathrm{~m}$ seulement au-dessus du sol de la nécropole), offrait un espace de $400 \mathrm{~m}^{2}$ environ dans lequel le niveau funéraire avait été peu touché ; il a donc été 
décidé d'investir ce secteur non bâti et facile d'accès en programmant cinq tranches de travaux de sorte qu'à l'issue de chaque campagne annuelle la partie explorée était remblayée avec les déblais entreposés à proximité.

Mais cette opération n'a pu être engagée et menée à bien que grâce à la compétence et à la disponibilité de Bernard Dedet. Il a conduit la fouille avec la rigueur du spécialiste en archéologie funéraire. Comme en témoigne cet ouvrage, il a assuré lui-même l'analyse minutieuse de la plupart des éléments mis au jour, sachant aussi s'entourer de collaborateurs grâce à qui l'étude la plus complète et la plus précise a pu être réalisée. Si ce quartier de la nécropole d'Ambrussum devient aujourd'hui un site de référence pour l'archéologie funéraire protohistorique du Midi de la France, on le doit à sa connaissance intime de ce domaine de recherche. Mais c'est également grâce à ses qualités pédagogiques, déjà appréciées par les fouilleurs sur le terrain, qu'une partie de l'exposition réalisée dans le bâtiment d'accueil ouvert à l'entrée du site en 2011, permet au public le plus large de comprendre tout l'intérêt de ces traces ténues, révélant des pratiques dont le sens nous échappait naguère.

\section{Jean-Luc FICHES}




\section{Introduction}

\section{Problématique générale}

La découverte de la nécropole de l'oppidum d'Ambrussum en 1981 et la fouille d'une partie de celle-ci entre 1999 et 2003 revêtent une grande importance pour la connaissance des usages funéraires du monde indigène du sud de la France au second Âge du Fer.

Cette portion de cimetière, datée des trois derniers quarts du $\mathrm{III}^{\mathrm{e}} \mathrm{s}$. et des environs de 200 av. J.-C., contribue d'abord à combler une grande lacune. Certes, le Gard et les Bouches-du-Rhône, et tout particulièrement Nîmes et ses alentours ainsi que la région des Alpilles offrent une série relativement bien fournie de sépultures, plus ou moins bien connues selon l'époque de leur mise au jour, mais celles-ci concernent essentiellement la fin de la période, à partir de la création de la province de Narbonnaise vers 123-118 av. J.-C. (Bel et al. 2008 ; Arcelin, Arcelin 1975 ; Marcadal et al. 2003). Aucune sépulture peu ou prou contemporaine de celles d'Ambrussum n'est pour le moment connue en détail en Languedoc oriental, hormis une des tombes de Beaucaire/Les Colombes, aménagée à l'extrême fin du III ${ }^{\mathrm{e}}$ ou au tout début du $\mathrm{II}^{\mathrm{e}} \mathrm{s}$. av. J.-C., et si l'on excepte aussi quelques objets de la fin du IV ${ }^{\mathrm{e}}$ ou de la première moitié du III' ${ }^{\mathrm{e}}$ s. av. J.-C. découverts anciennement à Préville, dans les environs d'Uzès, et que l'on considère comme provenant d'une tombe (Saint-Venant 1897). Cependant une fouille de sauvetage menée en 2008 et 2009 sur le site de Beaucaire/Le Sizen-Collège Vigne par R. Carme et C. Demangeot (société HADES) apportera sous peu une documentation particulièrement importante à ce sujet : elle a permis de mettre au jour 112 tombes datées, pour la plupart, de la seconde moitié du IV et de la première moitié du III ${ }^{\mathrm{e}} \mathrm{s}$. av. J.-C. (Carme, Demangeot 2010 et étude en cours avec la collaboration de M. Py). La sépulture d'un dénommé Atila au Marduel près de Sernhac, incomplètement connue, est légèrement plus récente, du début du $\mathrm{II}^{\mathrm{e}} \mathrm{s}$. av. J.-C. (Py 1983). Et dans ce secteur géographique, les tombes un peu plus anciennes mais se rapportant cependant au second Âge du Fer, sont tout aussi rares, comme celle de Font de la Vie à Saint-Bauzille-de-Montmel, dans l'Hérault, du milieu du Ve s. av. J.-C. (Dedet 1995a) et celle de la Roussillonne à Nîmes, de la fin du IV ${ }^{e}$ ou du début du III s. av. J.-C. (Dedet, Gauthey 2008).

Dans les régions voisines, en Languedoc occidental et en Provence, la documentation utilisable est rare et les données sont le plus souvent encore incomplètes ou en cours d'étude. La nécropole d'Ensérune, en usage depuis le début du $\mathrm{V}^{\mathrm{e}}$ s. au moins jusqu'aux environs de 200 av. J.-C., a été largement explorée (Dubosse 2007) ; mais sur les quelque 520 tombes mises au jour, les deux tiers se prêtent peu à une étude satisfaisante du fait des objectifs de fouilles trop anciennes et du mélange du mobilier, et sur le tiers restant, d'un intérêt plus grand, seulement six sépultures ont été à ce jour publiées intégralement (Schwaller et al. 1995). Toujours dans la partie occidentale du Languedoc, des tombes de la fin du $\mathrm{V}^{\mathrm{e}}$ ou du $\mathrm{IV}^{\mathrm{e}} \mathrm{s}$. ont été repérées aux Oubiels près de Sigean dans l'Aude et, dans l'Hérault, à SaintJulien près de Pézenas et à la Martelle près de Siran, mais elles étaient complètement détruites. Dans cette région, seule la nécropole de Mourrel-Ferrat à Olonzac (Hérault), partiellement fouillée, fournit des données fiables pour la fin du IV et le début du III ${ }^{\mathrm{e}}$ s. av. J.-C. (Janin et al. 2000). Et vers l'ouest au-delà de l'Aude, le bassin aquitain est une totale terra incognita en ce domaine. Rareté et caractère très incomplet de la documentation disponible caractérisent aussi la Provence et les Alpes méridionales, comme les quatre tombes de Cucuron/Les Conques dans le Vaucluse, de la première moitié du IIIe s. av. J.-C.(Dumoulin 1962), ou encore plusieurs découvertes faites au XIX ${ }^{\mathrm{e}} \mathrm{s}$. dans les vallées de l'Ubaye et de la haute-Durance, dont les sépultures des Mâts à Jausiers (Bérard 1997) ou de Peyre-Haute à Guillestre (Ganet 1995) sont les moins mal connues.

Cette carence de données sur le second Âge du Fer est d'autant plus flagrante qu'elle succède à une période où les tombes abondent, depuis les rivages du golfe de Gascogne jusqu'à la frontière italienne. Dans la seule région du 


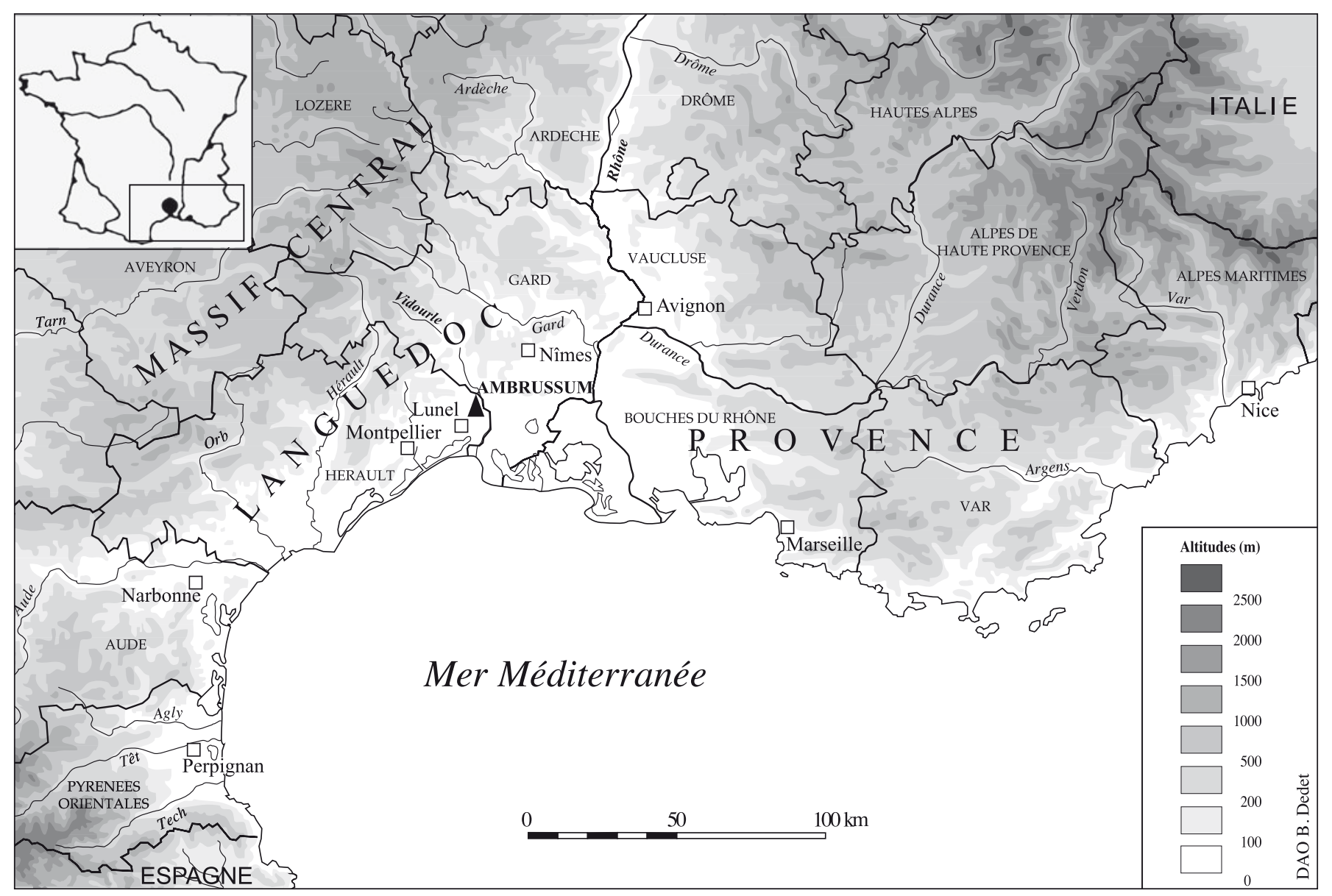

Fig. 1. Localisation d'Ambrussum dans le sud de la France.

Languedoc oriental, ce ne sont pas moins de trois cents tumulus du premier Âge du Fer qui ont été plus ou moins précisément fouillés entre les fleuves Hérault et Rhône. Ce phénomène tumulaire qui connaît un grand développement, pas seulement dans les secteurs de plateaux calcaires des Garrigues où le cantonnaient les recherches traditionnelles (Dedet 1992), mais aussi dans les plaines et les vallées du fait de l'essor de l'archéologie préventive (Dedet, Lisfranc 2005 ; Daveau, Dedet 2010), décline très rapidement dès le commencement du VI ${ }^{\mathrm{e}}$ s. av. J.-C., et disparaît au début du siècle suivant. Ici donc en Languedoc oriental, pour ces quatre siècles courant entre les derniers tumulus et les tombes de la fin du II et du Irr s. av. J.-C., le vide était presque total.

Cette nécropole ne constitue pas seulement un jalon important pour discerner l'évolution des pratiques funéraires en Languedoc oriental et dans le sud de la France à l'Âge du Fer. C'est aussi un des très rares sites protohistoriques régionaux, avec Ensérune, où l'on peut établir la relation entre agglomération des vivants et cimetière. La colline dominant la nécropole de Mourrel-Ferrat porte l'habitat correspondant, mais celui-ci n'a fait l'objet que de sondages limités. Quant aux tombes des Oubiels, elles se situent à la périphérie de l'oppidum de Pech Maho, mais on n'en connaît que des restes mobiliers éparpillés et complètement déconnectés. Ici, à Ambrussum, cette opportunité repose sur des données issues de fouilles récentes, à la fois dans la nécropole et dans l'espace habité par les vivants.

L'habitat protohistorique d'Ambrussum, nom qu'il portait dès le début du principat d'Auguste ${ }^{1}$, au moins, a été partiellement mis au jour sur la colline qui domine immédiatement la nécropole, lors des recherches dirigées par J.-L. Fiches de 1967 à 1979. Ce lieu est d'abord occupé au Néolithique final, puis aux VI et Ve s. av. J.-C.,

1 Il figure sur les quatre gobelets de Vicarello. 
et, entre temps, fréquenté au Bronze final. Mais c'est seulement à la fin du $\mathrm{IV}^{\mathrm{e}} \mathrm{s}$. ou au début du III ${ }^{\mathrm{e}} \mathrm{s}$. av. J.-C. que l'installation humaine devient plus importante et plus structurée, ceinturée par un puissant rempart de pierre sèche, et cet oppidum va continuer à vivre jusqu' au début du $\mathrm{II}^{\mathrm{e}} \mathrm{s}$. ap. J.-C. Un « quartier bas », en fait une station routière le long de la voie Domitia, lui est adjoint dans la seconde moitié du $\mathrm{I}^{\mathrm{er}}$ s. av. J.-C., au pied de la « ville haute » et recouvrant notamment la nécropole protohistorique alors noyée sous les alluvions du Vidourle. Cette ville basse, dont J.-L. Fiches a exhumé les vestiges de 1979 à 2009, tombera à son tour en désuétude dans la deuxième moitié du $\mathrm{IV}^{\mathrm{e}} \mathrm{s}$. ap. J.-C. (Fiches, Mathieu 2002).

\section{Le site}

\subsection{Un lieu de passage exceptionnel}

En Languedoc oriental, à l'extrémité est du département de l'Hérault, à mi-chemin entre Montpellier et Nîmes et aux abords immédiats de la ville de Lunel, Ambrussum jouit d'une situation remarquable, au croisement de deux voies naturelles, l'une reliant de vastes horizons, l'autre d'intérêt plus régional entre l'arrière-pays et le littoral (fig. 1).

L'oppidum se trouve en effet en bordure même du «couloir languedocien », grand axe entre Italie - vallée du Rhône d'un côté, Ibérie - Bassin aquitain de l'autre. Il est sur la première ligne de collines calcaires des Garrigues de Nîmes et du Languedoc oriental, d'altitude ici très modeste, dominant la plaine littorale en sa lisière septentrionale. Ce tracé correspond d'ailleurs, dans cette partie du Languedoc, à celui de la voie à laquelle Domitius Ahenobarbus a laissé son nom en 118-117 av. J.-C. Antérieurement d'après Polybe, sans doute dès le milieu du II' s. av. J.-C., Rome avait déjà borné cette route de milliaires. Celle-ci ne fait que reprendre un itinéraire plus ancien, protohistorique, que qualifie le pseudo-Aristote dans la seconde moitié du III ${ }^{\mathrm{e}} \mathrm{s}$. av. J.-C. : « d'Italie, il y a, dit-on, une route qui mène en Celtique chez les Celtoligures et les Ibères ; on l'appelle voie Hérakléenne ». Et le même auteur rapporte que les chefs indigènes étaient tenus de veiller à la sécurité de ceux qui l'empruntaient.

Cet habitat est aussi bordé par le Vidourle, fleuve côtier ouvrant un axe perpendiculaire à celui de la plaine baslanguedocienne, à travers ces Garrigues qui s'étendent au nord et au nord-ouest jusqu'au pied des Cévennes, à $35 \mathrm{~km}$ de là. À l'opposé, ce cours d'eau permet de gagner la région lagunaire et la mer Méditerranée, distante de $20 \mathrm{~km}$.

\subsection{Une colline, un fleuve, une terrasse}

Le site d'Ambrussum comporte trois éléments topographiques importants et pouvant entraîner d'importantes contraintes pour le groupe humain qui s'y installe (fig. $\mathbf{2}, \mathbf{3}$ et $\mathbf{4}$ ).

Une colline tout d'abord, celle du Devès, qui a fixé l'habitat. C'est un relief calcaire du Valanginien inférieur, culminant à $56 \mathrm{~m}$ d'altitude et formant un amphithéâtre naturel orienté vers le nord-est. Il domine la plaine d'une quarantaine de mètres seulement, mais ses pentes sont abruptes, voire même à-pic en sa partie inférieure, et limitées au nord et au sud par des rochers.

Le Vidourle est un modeste cours d'eau méditerranéen de $85 \mathrm{~km}$ de long, mais il connaît de violentes crues, particulièrement en automne. À travers les Garrigues et avant d'atteindre la plaine littorale, il coule dans une vallée marquée par une succession de petits défilés et de secteurs très amples pouvant atteindre et même dépasser un kilomètre de largeur, comme c'est le cas au niveau d'Ambrussum, entre la colline du Devès et celle qui porte le village de Gallargues-le-Montueux. Sa physionomie actuelle a été profondément modifiée au fil des siècles par des travaux visant à limiter ses inondations dévastatrices. L'examen des photographies aériennes et des sondages ont montré que son lit mineur était beaucoup plus large que l'actuel et qu'il décrivait des courbes et des méandres aujourd'hui abandonnés. L'une de ces courbes est tangente à la colline du Devès. Juste en amont, en rive droite, la terrasse du Sablas, beaucoup moins large qu'aujourd'hui, vient s'achever au niveau de la colline. Désormais, le long de l'oppidum, le cours d'eau longe directement le pied de la colline sans qu'il y ait de terrasse en rive droite 


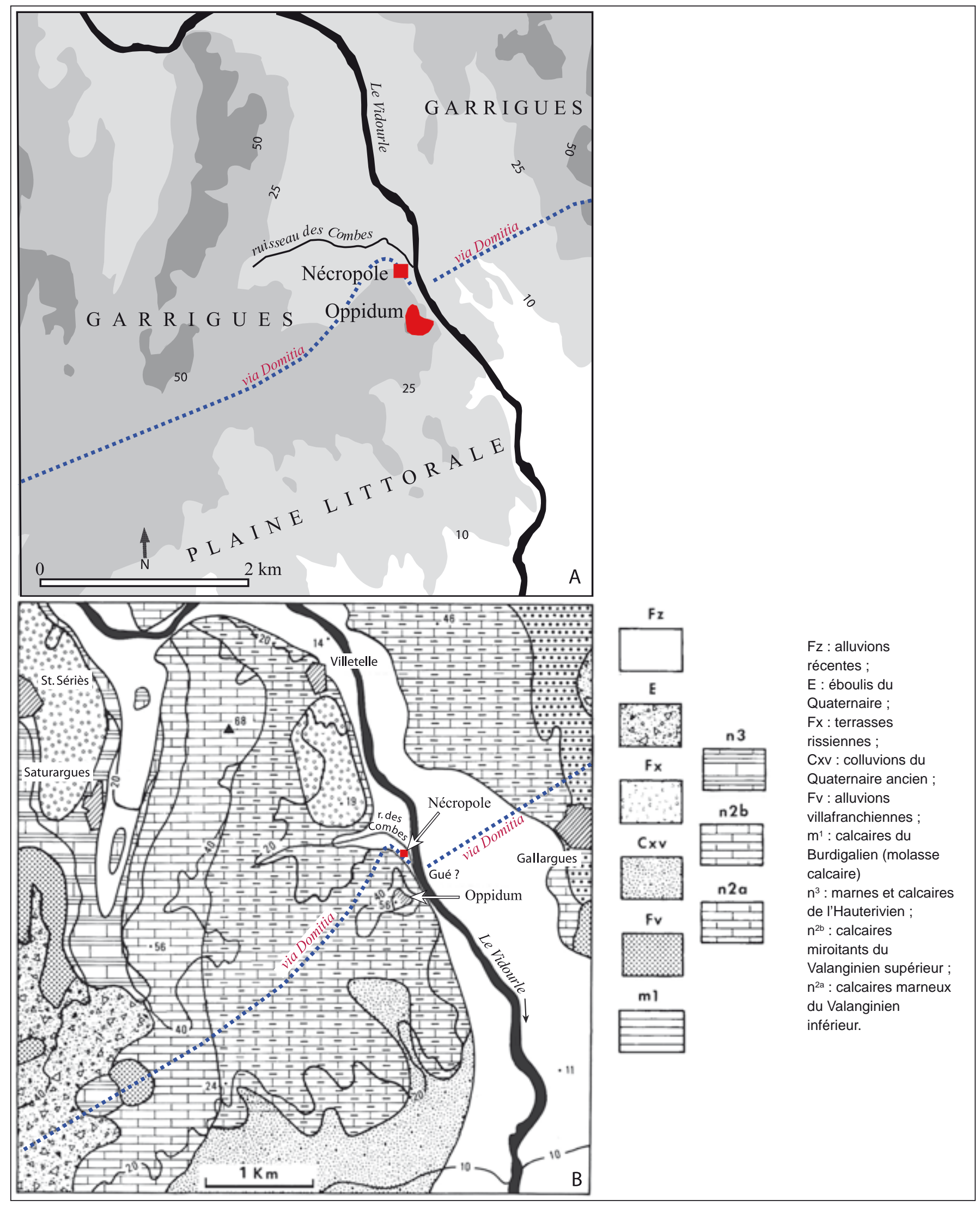

Fig. 2. Situation d'Ambrussum. A : contexte topographique. B : contexte géologique (d'après la feuille de Lunel XXVIII-43 du BRGM au 1/50 000 et P. Poupet). 


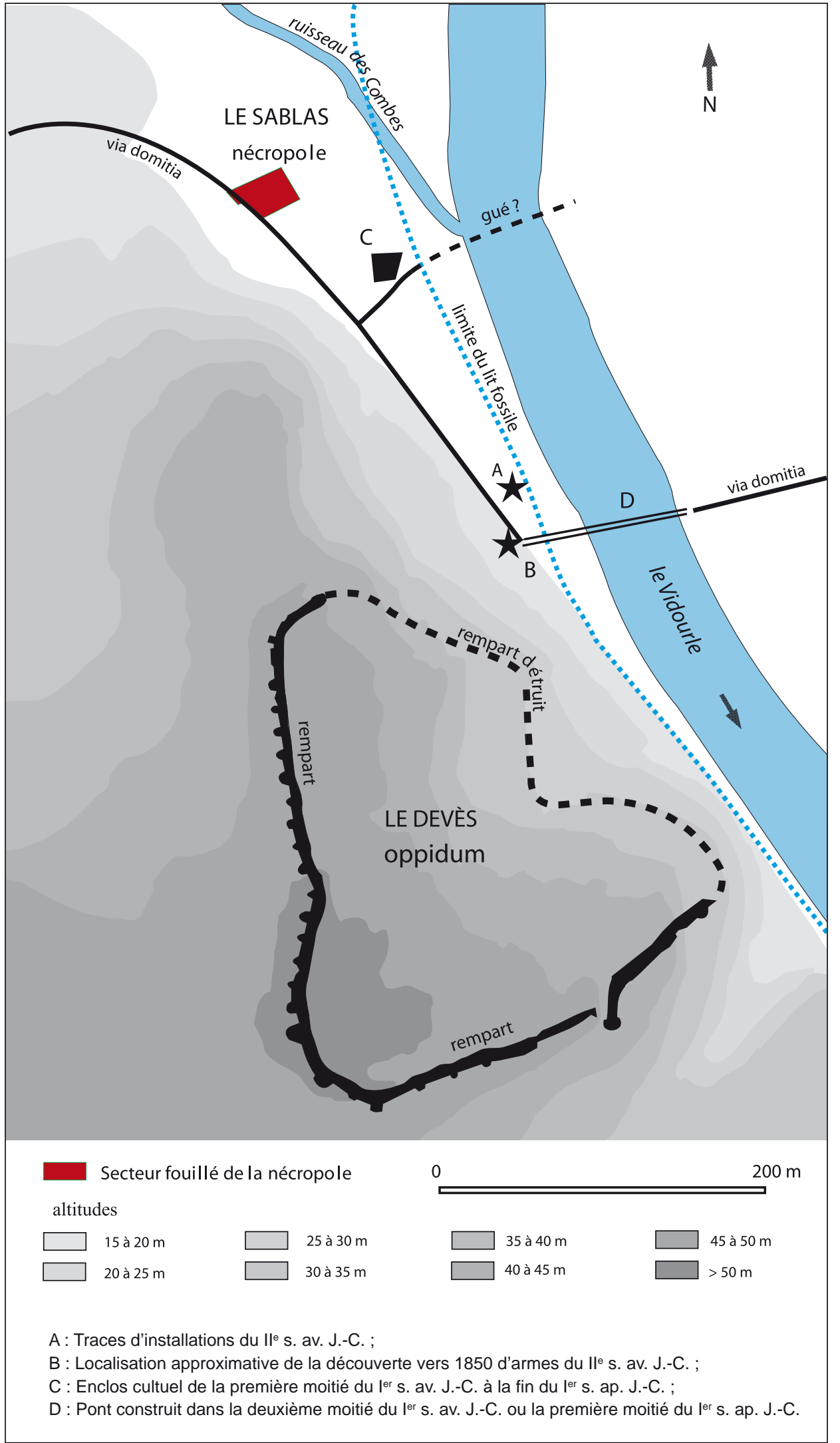

Fig. 3. Site d'Ambrussum : l'oppidum du Devès, la nécropole du Sablas, le Vidourle et la limite occidentale du lit fossile. (DAO B. Dedet, d'après relevés de A. Carrier, J.-L. Fiches, P.-Y. Genty, V. Mathieu, J.-L. Paillet et J.-C. Roux). 
(Poupet dans Fiches dir. 1989, p. 27-29). Ce secteur du Sablas, le «banc de sable » en occitan, juste au nord de la hauteur portant l'habitat, là où le Vidourle dont le lit n'est pas encore contraint sur l'une de ses rives peut s'étaler largement, est donc favorable à l'établissement d'un gué, en fait le dernier possible à proximité de l'oppidum. C'est en ce lieu que fut installée la nécropole de l'habitat protohistorique, du moins le quartier de tombes du III ${ }^{e}$ s. av. J.-C. qui fait l'objet de cette étude (fig. 3 et 4).

D'après les observations sédimentologiques et pédologiques faites par J.-F. Berger sur les coupes ménagées dans les fouilles elles-mêmes ou à l'occasion de tranchées profondes en dehors de celles-ci, cette terrasse témoigne, entre le $\mathrm{V}^{\mathrm{e}} \mathrm{s}$. av. J.-C. et le début du Moyen-Âge, de la succession de phases d'encaissement et de stabilité du lit du cours d'eau ou au contraire de périodes de remontée du plancher fluvial accompagnées d'une recrudescence des crues (Berger et al. 2004). Les $\mathrm{III}^{\mathrm{e}}$ et $\mathrm{II}^{\mathrm{e}} \mathrm{s}$. av. J.-C. connaissent une période d'accalmie hydrologique, le lit fluvial étant alors très encaissé, sans doute de manière plus marquée qu'aujourd'hui, et la plaine présentant un drainage stable, favorable à la formation des sols et à la colonisation des berges. Les sépultures peuvent être alors installées tout près du fleuve. Ultérieurement, à partir du dernier quart du II ${ }^{\mathrm{e}}$ s. av. J.-C. et jusqu'au milieu du $\mathrm{II}^{\mathrm{er}}$ s. ap. J.-C., intervient un épisode de dérèglement, avec exhaussement du plancher fluvial et augmentation du régime des crues, processus qui s'accélère d'ailleurs à partir du milieu du ${ }^{\text {er }}$ s. ap. J.-C. Les tombes implantées auparavant dans le lit majeur sont alors recouvertes, de même que des vestiges d'habitat reconnus plus en aval, dans le secteur du pont romain.

\section{Historique des recherches et histoire du site : un oppidum gaulois, sa nécropole et une station routière gallo-romaine}

Avec son rempart éboulé en pierre sèche, la colline du Devès n'a pas manqué d'attirer très tôt l'attention mais la découverte de la nécropole d'Ambrussum est, en revanche, toute récente.

Une ville antique est identifiée sur la hauteur, dès la première moitié du XVIII ${ }^{\mathrm{e}} \mathrm{s}$. (Ménard 1750, p. 36-37), qui fit l'objet de premières excavations en 1835 par J.-P. Hugues. À la fin du XIX ${ }^{\mathrm{e}}$ s., l'origine préromaine de cet établissement est reconnue (de Saint Venant 1897, p. 507) puis confirmée dans la première décennie du XX ${ }^{\mathrm{e}}$ s.par les fouilles de Grant et Marignan (Fiches, Mathieu 2002, p. 526-527). Deux armes en fer de la fin du second Âge du Fer furent trouvées vers 1850 « à la tête du pont d'Ambrussum, rive droite, c'est-à-dire au pied même de l'escarpement que couronne l'enceinte » : une lance à douille et une épée avec son fourreau (de Saint Venant 1897, p. 507). Ces objets ont disparu et si J. de Saint Venant donne quelques détails sur leur morphologie, il ne les illustre pas. Cependant, selon cet auteur, l'épée est «du type de Saint-Siffret », tombe découverte en 1893 aux environs d'Uzès dont les armes, elles, ont été figurées (ibid., pl. X, p. 484) et qui datent du II s. av. J.-C. Aucune précision sur les conditions de la trouvaille d'Ambrussum n'est connue et l'origine de ces armes reste problématique. Elles pourraient provenir d'une sépulture détruite, mais on peut aussi avoir affaire aux restes d'un dépôt d'offrandes dans un site, la rive d'un cours d'eau, évoquant aussi bien la limite territoriale que le lieu de passage, à l'instar des dépôts d'Auzet et de la Source du Noyer à Roquefort-les-Pins en Provence orientale (Dedet, Marchand 2009).

À partir de 1967, un programme de recherches systématiques débute à Ambrussum, sous la direction de J.-L. Fiches, d'abord jusqu'en 1979, sur la hauteur du Devès, siège de l'oppidum protohistorique, puis, entre 1980 et 1985 et depuis 1993, au pied de celle-ci sur la terrasse du Sablas (fig. 5).

Sur la colline, les travaux ont surtout porté sur l'agglomération des $\mathrm{I}^{\mathrm{er}} \mathrm{s}$. av. et $\mathrm{I}^{\mathrm{er}} \mathrm{s}$. ap. J.-C., portique près de la porte méridionale du rempart, maisons $\mathrm{A}, \mathrm{B}$ et $\mathrm{C}$ et rue principale. Les niveaux d'habitat antérieurs, datés du Néolithique, de la fin du IVe, du III e et du II ${ }^{\mathrm{e}} \mathrm{s}$. av. J.-C. n'ont été fouillés que sur une surface limitée : une habitation d'environ $50 \mathrm{~m}^{2}$ sous la maison gallo-romaine B (Fiches et al. 1976, p. 33-64) et plusieurs sondages, sur une surface cumulée de l'ordre de $50 \mathrm{~m}^{2}$, sous la maison A et à ses abords (Fiches et al. 1979 ; Fiches 1983). Parallèlement ces travaux permettaient de dater la construction de l'enceinte vers la fin du IV ${ }^{\mathrm{e}} \mathrm{s}$. av. J.-C., avec une importante réfection dans la seconde moitié du siècle suivant. (fig. 5).

Dans le quartier bas, c'est une station routière bordant la voie Domitienne qui a été mise au jour, dont l'installation remonte aux environs de 30 av. J.-C. et dont les divers bâtiments, plusieurs fois remaniés, seront abandonnés au 


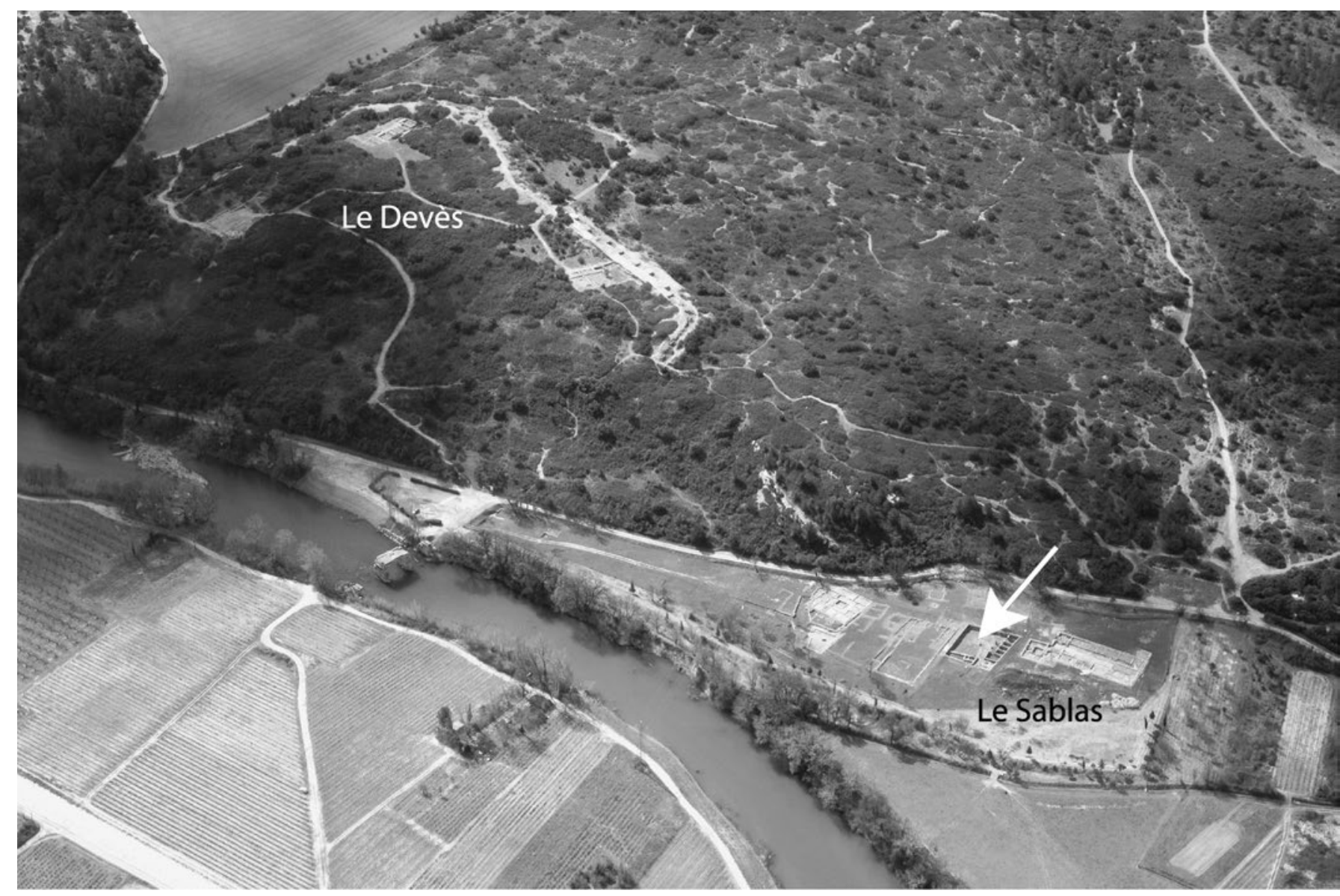

Fig. 4. L'oppidum du Devès, le quartier bas du Sablas et le Vidourle ; vue prise du nord-est (cliché C. Landes) ; la flèche signale la ferme auberge gallo-romaine sous laquelle se trouve le secteur fouillé de la nécropole protohistorique.

milieu du III ${ }^{e}$ s. ap. J.-C. pour les uns, au début du siècle suivant pour d'autres : trois auberges (fig. 5, ${ }^{\circ} 1,4$ et 5 ), une hôtellerie peut-être officielle, organisée et réservée à l'administration $\left(\mathrm{n}^{\circ} 12\right)$, une habitation abritant une forge $\left(n^{\circ} 10\right)$ et un établissement de bains $\left(n^{\circ} 8\right)$. Ce relais routier englobe, au bord même du Vidourle, un petit sanctuaire créé dès la première moitié du $\mathrm{I}^{\mathrm{er}} \mathrm{s}$. av. J.-C. et qui fonctionne jusqu'à la fin du $\mathrm{I}^{\mathrm{er}} \mathrm{s}$. ap. J.-C. (fig. 5, $\mathrm{n}^{\circ} 11$ ). Ce lieu de culte, d'abord simple enclos fossoyé, puis autel maçonné dans une enceinte bâtie, est bordé au sud par une large rue rejoignant la voie Domitienne et se dirigeant vers le lit du fleuve. Peut-être cette voie correspond-elle à un tracé primitif de la Domitienne et conduit-elle à un gué permettant le passage antérieurement à la construction du pont (Fiches et al. 2007). Dans cette optique le sanctuaire aurait pu permettre d'assurer la protection de cette traversée, comme beaucoup plus tard, au Moyen-Âge, une chapelle rurale dédiée à Marie élevée aux abords du vieux pont romain (capella Sancte Marie de Ponte-Ambrosio) atteste une telle préoccupation (Bonnet 1905, p. 295, d'après une bulle du pape Adrien IV citant les possessions du chapitre de Nîmes en 1156).

Ce sont les fouilles dirigées par J.-L. Fiches dans les années 1980 sur ce relais d'étape qui ont occasionné la découverte de la nécropole étudiée ici, et l'implantation des structures bâties de cet établissement a imposé la localisation et la limite des travaux de terrain portant sur cette dernière.

Dans cette ville basse, en dehors de l'enclos cultuel $\mathrm{n}^{\circ} 11$, seule l'auberge $\mathrm{n}^{\circ} 1$ fit l'objet d'une recherche en profondeur. Celle-ci, échelonnée de 1980 à 1985, permit d'atteindre les niveaux les plus anciens et en particulier celui qui correspond à la fondation de l'édifice vers 30 av. J.-C. Pour reconnaître la terrasse alluviale sur laquelle la construction avait été installée, plusieurs sondages profonds furent effectués entre 1981 et 1984 sous ces niveaux ainsi que dans la rue bordant l'îlot à l'ouest. Dans plusieurs salles de cette auberge, les pièces 10, 11, 19, 29 et 36, 


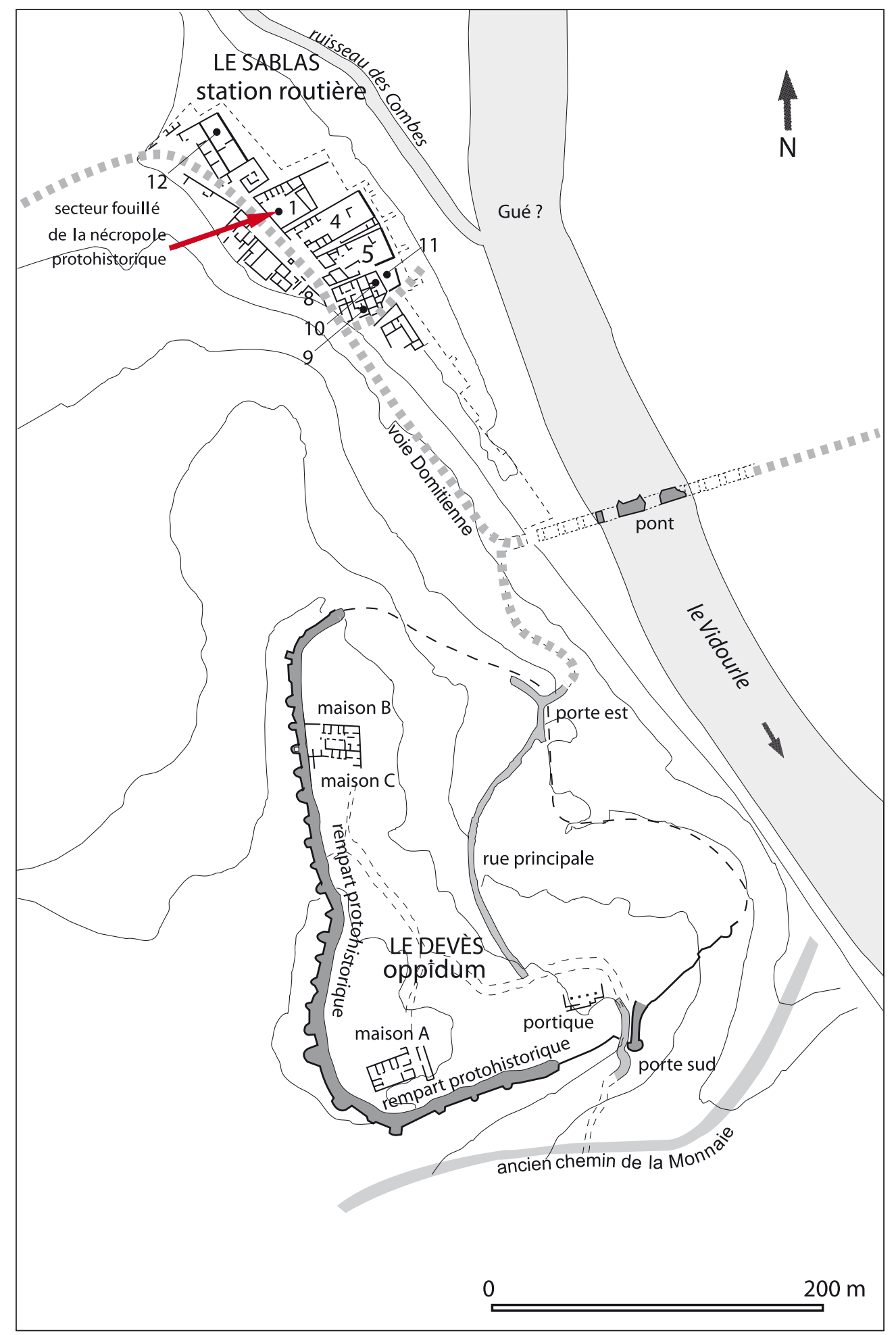

Fig. 5. Plan du rempart édifié à la fin du IVe s. av. J.-C., du pont romain et des vestiges d'époque gallo-romaine mis au jour lors des recherches menées de 1969 à 2007 sur l'oppidum du Devès et dans la station routière du Sablas. Le secteur fouillé de la nécropole se situe dans la cour de l'édifice $n^{\circ} 1$, ferme-auberge bordant une rue identifiée à la voie Domitienne, et dans un sondage effectué sous cette voie à l'extérieur du bâtiment.

4, 5 et 12 : lieux d'étape ; 9 et 10 : habitations ; 11 : enclos cultuel. (DAO Y. Manniez et V. Mathieu, d'après des relevés de A. Carrier, J.-L. Fiches, P.-Y. Genty, J.-L. Paillet et J.-C. Roux). 


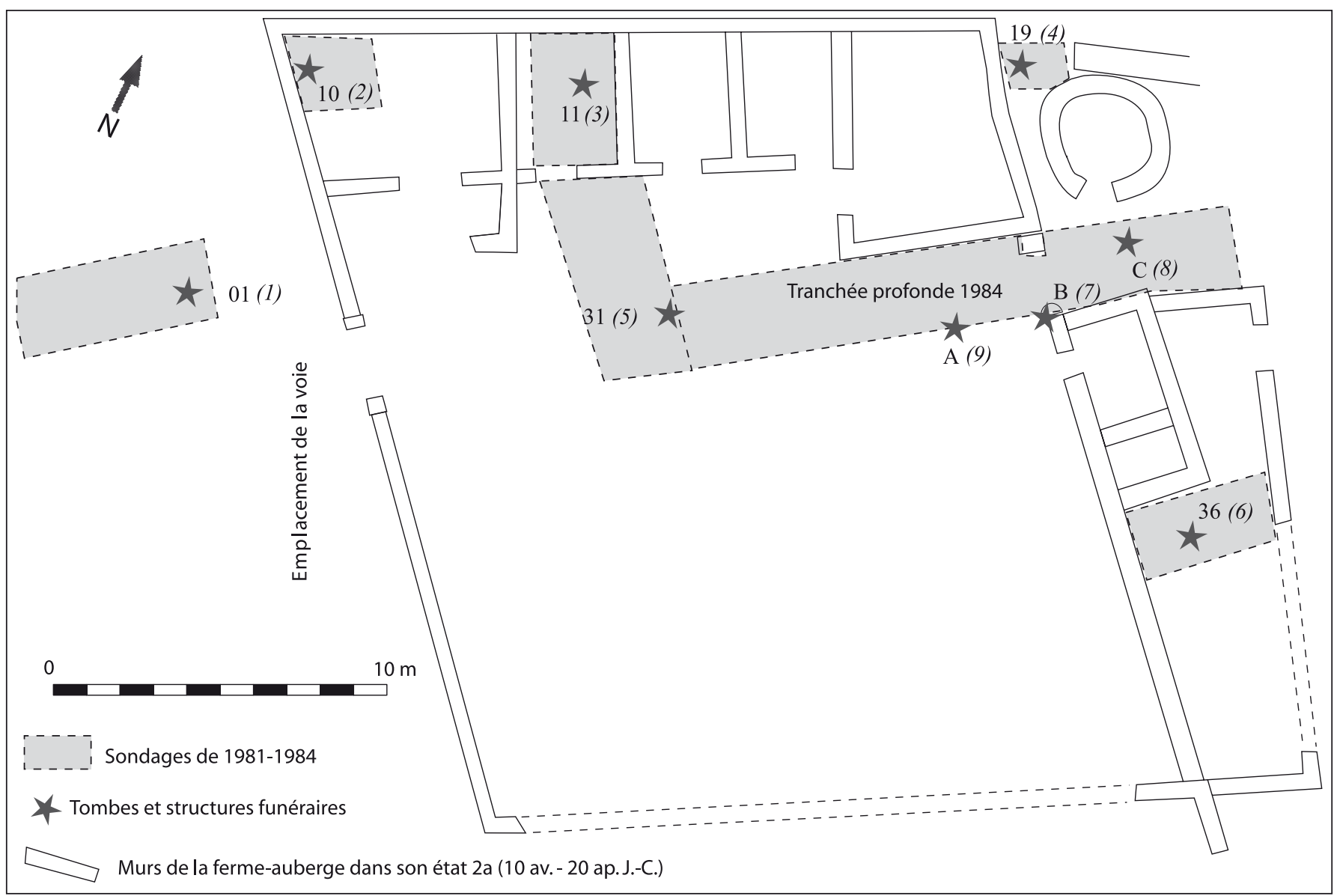

Ferme-auberge $n^{\circ} 1$. Localisation des sondages profonds effectués entre 1981 et 1984 et des structures funéraires mises au jour avec la numérotation de Fiches dir. 1989 et, entre parenthèses, les nouveaux numéros intégrant ces premières découvertes au reste de la portion de nécropole fouillée entre 1999 et 2003 (relevés J.-L. Fiches, DAO V. Mathieu et B. Dedet).

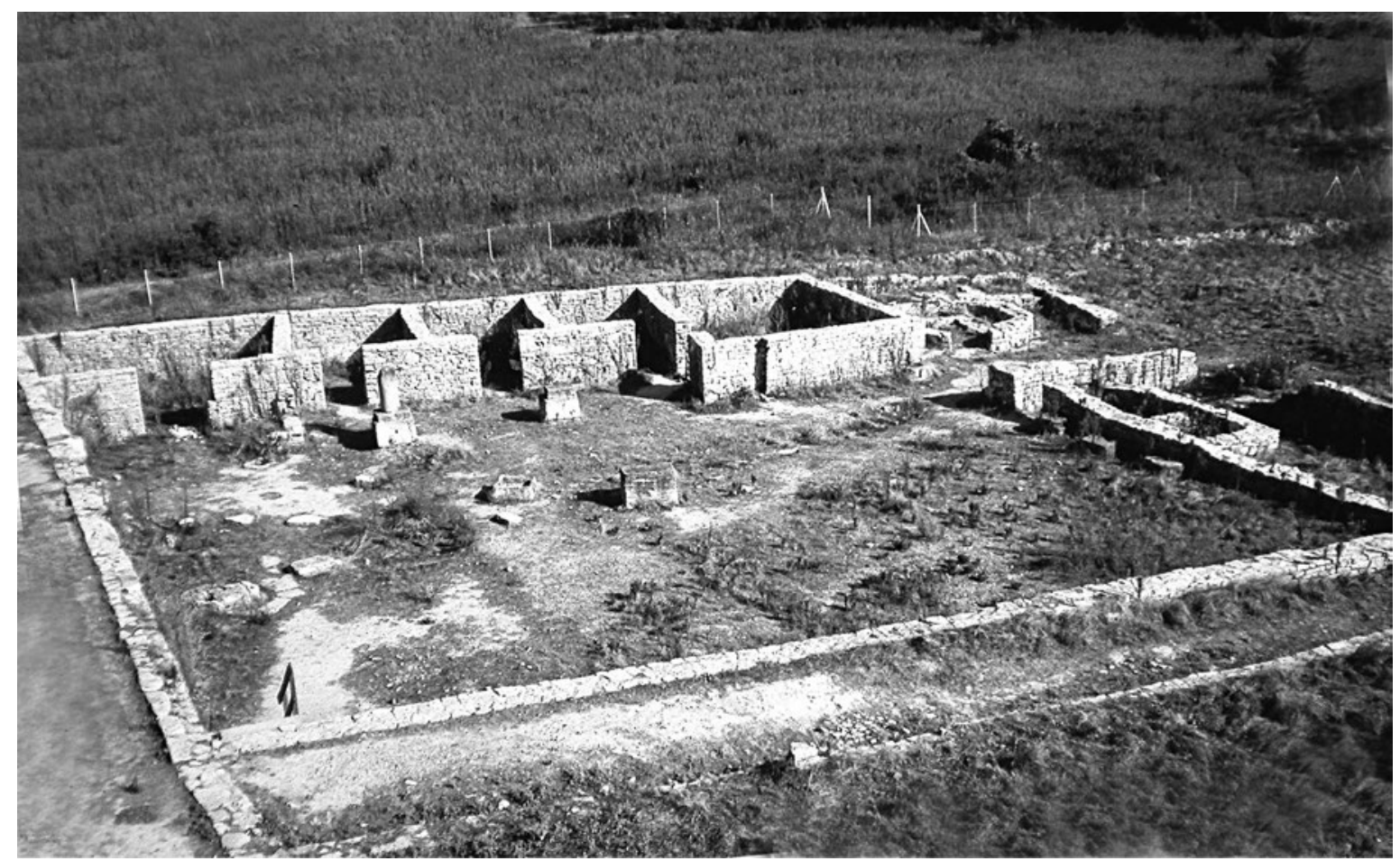

Fig. 6. Fermeauberge $n^{\circ} 1$, après la fouille, présentée au public dans son état $2 a$ (10 av.-20 ap. J.-C.) ; vue prise du sud. Au centre la cour ; au fond et à droite les salles

à gauche la voie. (cliché J.-L. Fiches). 


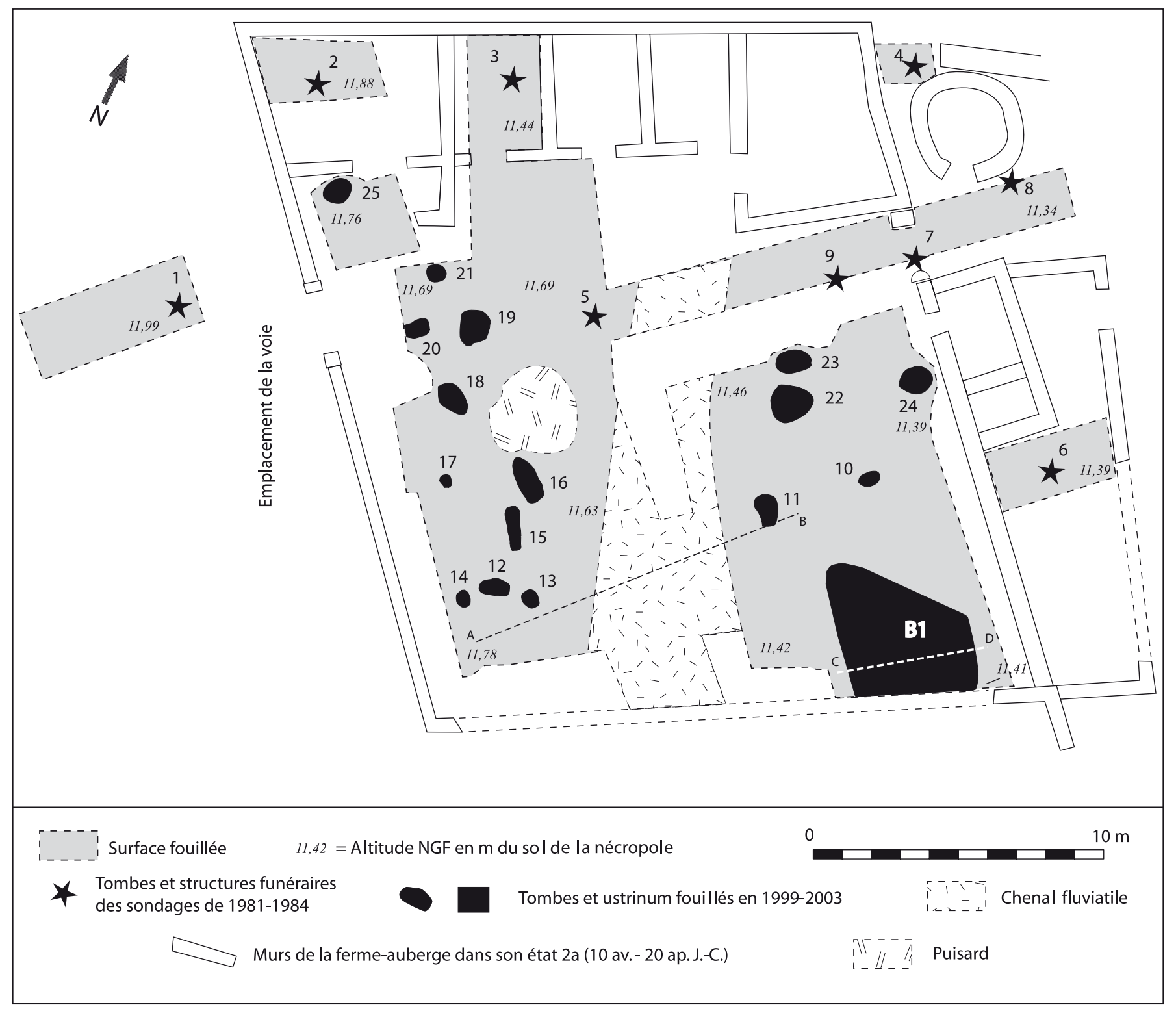

Fig. 7. Plan général du quartier de nécropole fouillée (relevés J.-L. Fiches et B. Dedet ; DAO V. Mathieu et B. Dedet).

comme dans la cour, secteurs 31A, 31B et 31C, ainsi qu'à l'extérieur de l'édifice, dans la rue 01, ces sondages permettaient d'observer à leur base, l'existence de fosses ou de nappes charbonneuses enfermant des os brûlés et un mobilier très fragmenté daté alors de la fin du III au milieu du II ${ }^{e}$ s. av. J.-C. (fig. 6). Lors de la fouille, ces vestiges ne purent être dégagés que très partiellement, dans la partie inférieure de sondages limités et profonds, et ils furent identifiés comme des restes d'habitat. La reconnaissance de tombes ne fut effective que lors de l'étude des os qui suivit, pendant la phase de préparation de la publication de cette auberge dirigée par J.-L. Fiches (Fiches dir. 1989, p. 29-39).

Neuf tombes ou vestiges funéraires étaient alors identifiés, mais, dans cet ouvrage, seuls les os humains furent analysés séparément, par tombe (Duday dans Fiches dir. 1989, p. 30-33), tandis que le reste du matériel était étudié globalement, par catégorie et non par sépulture, charbons de bois (Chabal dans Fiches dir. 1989, p. 33-35), mobilier métallique (Feugère, Tendille dans Fiches dir. 1989, p. 35-36), autres objets et céramiques (Fiches dans Fiches dir. 1989, p. 36-38). Cependant la conclusion soulignait à juste titre l'intérêt de cette découverte, tant au niveau local, celui de la connaissance de l'organisation de l'agglomération d'Ambrussum, qu'au niveau régional, celui des pratiques funéraires du Languedoc oriental (Fiches dans Fiches dir. 1989, p. 38-39). 
Dans les années 1990, un programme de recherche sur les pratiques funéraires protohistoriques se mettait en place en Languedoc. L'occasion se présentait de combler quelque peu la grande lacune qui concernait alors, en ce domaine, le Languedoc oriental pour la première moitié et le milieu du second âge du Fer. Bien entendu, l'existence de la station routière en ce lieu ne permettait pas d'envisager la fouille exhaustive de la nécropole : celle-ci ne pouvait être atteinte que là où les niveaux gallo-romains avaient été entièrement explorés; les murs et les autres structures construits à cette époque, et qu'il convenait de conserver, ne pouvaient que limiter ou fractionner la surface dégagée. Mais il est apparu de première importance de pouvoir préciser la forme et le contenu de ces sépultures, leur datation ainsi que les différents aspects des pratiques funéraires mises en œuvre, de disposer d'une base de données plus étoffée et de pouvoir discerner une éventuelle variabilité sur les plans spatial et temporel. L'emplacement de l'auberge de l'îlot 1 présentait cette opportunité : c'était le seul qui ait alors été fouillé jusqu'aux niveaux correspondant à la fondation de la station routière et la cour de cet édifice offrait un vaste espace de $400 \mathrm{~m}^{2}$, libre de toute structure bâtie, où il était possible de fouiller en extension les couches sous-jacentes (fig. 7).

C'est donc en ce lieu que, de 1999 à 2003 nous avons pu fouiller cette partie de la nécropole, dans le cadre du programme de recherche développé par J.-L. Fiches sur le site de la station routière. Ces nouvelles recherches ont procuré seize nouvelles tombes (T 10 à 25), une aire de crémation (bûcher B1), deux dispositifs annexes ainsi que le sol de circulation du cimetière (fig. 8). La datation de l'ensemble de ces structures entre dans les trois derniers quarts du III s. av. J.-C., et l'étude de cette nouvelle documentation permet aussi de réajuster la datation avancée pour les premières découvertes funéraires des sondages, qui apparaissent tout à fait synchrones des tombes fouillées ensuite.

Évidemment on n'a là qu'une petite part d'une nécropole plus vaste. Aucune limite n'a été atteinte dans le cadre restreint de l'auberge de l'îlot 1 , et un sondage, effectué en profondeur $10 \mathrm{~m}$ à l'ouest de cet édifice, sous la rue (sondage 01), a également révélé une structure funéraire. Cette nécropole peut donc recouvrir un espace beaucoup plus vaste et s'étendre de tous les côtés au-delà du lieu recouvert par ce bâtiment. Elle n'atteignait cependant pas l'emplacement où fut plus tard installé l'enclos cultuel de l'îlot 11, à 50 mètres au sud-est de l'auberge (fig. 3, C). En ce lieu, en effet, un sondage profond a mis au jour, à la surface d'un sol pédologique hydromorphe à $11,17 \mathrm{~m}$ NGF, soit $20 \mathrm{~cm}$ plus bas que celui de la nécropole, un cailloutis assez dense et régulier, des charbons de bois et des tessons. Ces traces d'occupation ont été repérées sur plusieurs mètres carrés ; elles semblent contemporaines de la nécropole exhumée plus au nord mais, en l'absence de tout os humain et objet brûlé, ne paraissent pas s'inscrire dans un contexte funéraire (Fiches et al. 2007, p. 52). Plus loin, à 150 mètres dans la même direction, près du pont romain, dans les niveaux les plus profonds de deux tranchées de reconnaissance effectuées en bordure du fleuve (zones 15 et 16 ; fig. 3, A), ce sont des traces d'habitat datées des trois derniers quarts du III et du premier quart du II ${ }^{\mathrm{e}} \mathrm{s}$. av. J.-C. qui furent mises au jour, notamment un mur et du mobilier céramique (Raynaud et al. 1998, p. 9-10). Ce sont là les deux seuls emplacements du quartier bas où la fouille a atteint le substrat stérile en documents archéologiques. Mais la durée de l'habitat du Devès, au moins quatre siècles entre la structuration de l'oppidum à la fin du $\mathrm{IV}^{\mathrm{e}} \mathrm{s}$. av. J.-C. et son abandon au début du II $\mathrm{e}$ s. après J.-C., laisse bien sûr supposer un vaste cimetière de cette époque ${ }^{2}$. On peut aussi évoquer l'occupation antérieure attestée sur la colline, notamment celle des $\mathrm{VI}^{\mathrm{e}}$ et $\mathrm{V}^{\mathrm{e}} \mathrm{s}$. av. J.-C., mais ce que l'on connaît des pratiques funéraires de cette période en Languedoc oriental semble indiquer alors un traitement solennel de la mort réservé à une minorité d'individus et un mode de groupement des tombes différent de celui qui est mis en place au III ${ }^{\mathrm{e}}$ s. av. J.-C. Seul un accès aux niveaux contemporains de la nécropole situés dans d'autres secteurs de la station routière peut permettre des apports nouveaux en ce domaine ; mais cela reste tributaire de l'état d'avancement des fouilles des bâtiments et des voies de cet établissement et l'exploration des niveaux profonds de celui-ci n'est pas actuellement à l'ordre du jour.

Les études sédimentologiques ont montré que ce secteur de la terrasse alluviale était périodiquement envahi par les eaux fluviales à partir de la première moitié du $\mathrm{II}^{\mathrm{e}} \mathrm{s}$. av. J.-C. C'est donc en fait seulement la nécropole antérieure à cette date qui peut s'y trouver ; les tombes postérieures au milieu du II ${ }^{\mathrm{e}} \mathrm{s}$. av. J.-C. doivent être recherchées ailleurs, dans des zones alors non inondables.

2 Il reste l'interrogation que pose la présence d'armes du $\mathrm{II}^{\mathrm{e}} \mathrm{s}$. av. J.-C. découvertes près du pont romain : celles-ci proviennent-elles de tombes ou d'un dépôt cultuel d'un autre type effectué sur la berge du fleuve ? L'ignorance quant au lieu exact et aux circonstances de cette trouvaille ne facilite pas son interprétation. 


\section{La publication de la nécropole}

En 2003, l'ensemble de la surface du cimetière protohistoriqu e située sous l'auberge de l'îlot 1 était exploré, et aucun autre secteur de la station routière n'est suffisamment fouillé en profondeur pour permettre d'accéder au niveau funéraire ou contemporain de celui-ci, ni ne doit l'être prochainement. Dès lors, la publication de la portion explorée de cette nécropole se justifie amplement, même si, du fait du caractère limité de la surface fouillée, plusieurs aspects comme l'organisation d'ensemble du cimetière et son évolution, la répartition différenciée des tombes en fonction de divers critères naturels ou sociaux ne peuvent être encore abordés sur une base solide. Néanmoins, cette fouille permet un éclairage très circonstancié sur un moment de l'utilisation de ce cimetière et sur les pratiques funéraires des habitants d'Ambrussum dans la seconde moitié du $\mathrm{III}^{\mathrm{e}}$ s. av. J.-C., d'autant que le recouvrement rapide et épais de la nécropole par les alluvions du Vidourle a assuré une bonne conservation et protection des vestiges.

Ce travail reprend aussi l'étude des vestiges funéraires découverts lors des sondages des années 1980-1984, et cela à la lumière des découvertes de 1999-2003. Ces dernières permettent en effet de connaître précisément la forme des tombes et les pratiques mises en œuvre et donc de mieux interpréter les vestiges partiels mis au jour vingt ans plus tôt et d'éclairer les données alors obtenues. C'est pourquoi on examine d'abord les données des fouilles de 1999 à 2003 : la position stratigraphique de la nécropole et la méthode employée pour étudier celle-ci (chapitre 1), puis les structures découvertes à cette occasion, les tombes T10 à T25 $5^{3}$, les dispositifs annexes et le sol de circulation de la nécropole (chapitre 2) et enfin l'aire de crémation B1 (chapitre 3). L'examen de la documentation procurée par les sondages préliminaires, regroupée cette fois tombe par tombe, est repris, cela à la lumière des fouilles ultérieures sur la nécropole, et l'étude du matériel, en particulier céramique, largement complétée (chapitre 4) : il s'agit des structures découvertes dans le secteur 01 (renommée structure ST 1), dans le secteur 10 (tombe 2), dans le secteur 19 (tombes 3 et 4), dans le secteur 31 (tombe 5), dans le secteur 36 (tombe 6) et des fosses $\mathrm{B}, \mathrm{C}$ et du « foyer » A dans le secteur 29 (tombes 7, 8 et 9, respectivement). Le chapitre 5 est consacré au mobilier découvert dans toutes les tombes, les bûchers et sur le sol, par catégories d'objets, et plus spécialement à leur apport pour la datation de cette portion de la nécropole. Le chapitre 6 s'efforce de caractériser les pratiques funéraires mises en œuvre, et leur variabilité en fonction de l'âge et du sexe présumé du défunt. Le chapitre 7, enfin, cherche à replacer ces usages dans le contexte régional. Suivent quatre études spécialisées, portant sur les charbons de bois par Carine Cenzon Salvayre et Aline Durand, la faune vertébrée par Armelle Gardeisen, sur les restes de poissons par Gaël Piquès et celle des graines et fruits carbonisés par Núria Rovira.

\section{Remerciements}

Je remercie vivement Jean-Luc Fiches, directeur de recherche au CNRS, pour sa confiance. Il m'a permis de conduire la fouille du secteur de la nécropole durant ces cinq années, de 1999 à 2003, dans le cadre du programme de fouilles qu'il dirige à Ambrussum depuis la fin des années 1960. J'ai pu bénéficier de toute l'infrastructure du chantier, tant au niveau matériel que financier, et de l'aide de ses proches collaborateurs, Véronique Mathieu, ingénieur au CNRS, et Michiel Gazenbeek, chercheur à l'INRAP. Ma dette est grande aussi envers les étudiants qui ont participé aux différentes campagnes de la nécropole, avec enthousiasme et efficacité, Anne Berthou, Sandrine Bonté, Muriel Brazzolotto, Mélanie Contério, Julie Damaggio, Valérie de Valerio, Myriam Gauthey, Fanny Hubac, Sandrine Jauretche, Florence Martin, Marie Matal, Alexandra Roche, Elsa Sagetat, Angélique Sergent, Sabine Vermillard, Alexandre Boucher, Laurent Kimpinaire, Nicolas Maurel, Alain Vincent-Falquet, sans oublier Thérèse Panouillères, ingénieur de recherche au CNRS. Un grand merci également à Jacques Gauthey, technicien de recherche au CNRS, qui, outre son aide sur le terrain, a mis au net les plans de la campagne de 2000, à Núria Rovira, chercheuse associée au CNRS, qui a réalisé, parfois aidée par des fouilleurs, les opérations de tamisage et de tri des vestiges des refus de tamis, ainsi qu'à Hugues Boisson, chercheur associé au CNRS, pour avoir effectué un certain nombre de dessins de matériel céramique. La restauration du mobilier métallique, essentiellement en fer ou en alliage cuivreux, a été effectuée par le Laboratoire de conservation, restauration et recherches du Centre Archéologique du

3 Cette numérotation prend la suite des 9 structures ou tombes découvertes entre 1980 et 1984. 
Var à Draguignan et mes remerciements vont à Jacques Rebière et Joël Françoise. Merci aussi à Corinne Sanchez et Éric Gailledrat, chercheurs au CNRS, qui ont bien voulu m'aider dans l'identification des différentes catégories de céramiques à vernis noir, et en particulier celle issue des ateliers de Rosas, à Georges Marchand, chercheur associé au CNRS, et à Martine Schwaller, Conservatrice du Patrimoine au SRA, pour leurs précisions sur la nécropole d'Ensérune, à Rémi Carme et à Coralie Demangeot (Société Hadès) pour leurs informations sur celle de Beaucaire/ Le Sizen-Collège Vigne, ainsi qu'à Loïc Buffat (Société Mosaïques Archéologie) pour les renseignements concernant celle de Labruguière/Le Causse dans le Tarn. Merci à Henri Duday (directeur de recherche au CNRS) qui a mis à ma disposition, avant publication, son texte sur les restes humains de la nécropole de la Porta Nocera à Pompéi. Merci enfin à Sylvie Dedet, Jean-Luc Fiches, Stephan Fichtl et Georges Marchand, mes premiers lecteurs, pour les améliorations apportées au manuscrit. 



\section{Chapitre 1}

\section{Position stratigraphique et méthode d'étude de la nécropole (fouilles de 1999 à 2003)}

\section{La position stratigraphique de la nécropole}

\subsection{Avant la nécropole}

$\mathrm{D}$ ans le cadre de l'espace fouillé, la nécropole est aménagée sur un niveau d'alluvions limoneuses de couleur gris jaunâtre à gris vert clair, à nombreuses traces de rouille, un «pseudogley » (Us 17051-17052) (fig. 9). Il s'agit d'une terrasse du lit majeur du Vidourle, asséchée lors d'une phase d'enfoncement du fleuve ${ }^{4}$. Sa surface supérieure constitue le sol de la nécropole (Us 17104), sur lequel reposent l'aire de crémation $\mathrm{B} 1$ et les dispositifs de recouvrement des tombes ${ }^{5}$ et c'est en son sein que sont creusés les loculus de celles-ci. Cette couche 17051-17052 est pratiquement stérile en documents archéologiques. Quelques petits tessons, menus fragments osseux ou charbonneux et petites pierres centimétriques se trouvent bien dans sa partie supérieure, mais il s'agit en fait d'objets qui sont tombés dans d'anciennes fentes de dessiccation. Nous avons pu constater le phénomène durant les fouilles : après arrosage du sol de la nécropole et séchage par le soleil, des prismes se créent en quelques heures, séparés par des interstices atteignant plusieurs centimètres de profondeur et un centimètre à un centimètre et demi de largeur, dans lesquels sont tombés certains des objets ou des os mis au jour sur ce sol.

Cette terrasse n'est pas très ancienne car, dans la moitié orientale de la fouille, environ $10 \mathrm{~cm}$ au-dessous de la surface du cimetière, apparaît un aménagement sans lien avec la nécropole et d'une ampleur certaine (Us 1712517180-17184). C'est une couche à peu près horizontale, reconnue sur plus de $10 \mathrm{~m}$ du nord au sud et $5 \mathrm{~m}$ de l'ouest vers l'est, composée de limon enrobant de la pierraille, galets et éclats de pierres calcaires centimétriques, ainsi que 264 tessons de céramiques, un fragment de vase en

4 Ce niveau correspond à la phase 3 déterminée par J.-F. Berger d'après l'analyse sédimentologique et géo-archéologique des strates (Berger, Fiches, Gazenbeek 2004).

5 Phase 4 de J.-F. Berger (Ibid.). «matière légère ${ }^{6}$ et trois os d'animaux (fig. 9 et $\mathbf{1 0}$ ). Tous ces éléments sont disposés horizontalement. La dimension maximum des tessons est de $7 \times 7 \mathrm{~cm}$.

Le matériel céramique inclus dans cet aménagement Us 17125-17180-17184 comprend différentes catégories.

La mieux représentée, en quantité, est la céramique non tournée, qui compte 255 tessons. Le nombre minimum d'individus ne peut être précisé ; sans toutefois être égal au nombre de tessons, il paraît être cependant élevé. Les fragments de panse ovoïde peignée d'urnes sont majoritaires. De cette forme d'urne figurent aussi deux bords (fig. 10, B, $\mathrm{n}^{\circ} 1$ et 2), un épaulement orné d'une double ligne brisée (fig. 10, $\mathrm{B}, \mathrm{n}^{\circ} 3$ ), deux épaulements décorés d'un rang d'impression associé à une incision horizontale (fig. 10, B, $\mathrm{n}^{\circ} 4$ et 5), ainsi que deux fonds plats dont la panse et le plan de pose portent un peignage (fig. 10, $\mathrm{B}, \mathrm{n}^{\circ} 6$ et 7 ).

Les autres catégories sont très minoritaires :

- six tessons de panse et un de col d'amphore massaliète, à pâte beige à rosée et grosses écailles de mica, appartenant à autant de vases ;

- un petit tesson de vase, fermé semble-t-il, en céramique fine à pâte claire ;

- un petit tesson de dolium indigène.

Dans ce matériel, les éléments permettant d'avancer une datation sont peu précis. Selon les critères de pâte, les tessons d'amphore massaliète ne relèvent pas du début de la production. Ils ne peuvent cependant pas être situés précisément entre le début du $\mathrm{V}^{\mathrm{e}} \mathrm{s}$. et le milieu du II ${ }^{e}$ s. av. J.-C. La céramique non tournée, et en particulier les restes d'urnes ovoïdes, est semblable à celle de l'oppidum du Dévès vers 400 et dans la première moitié du III ${ }^{\mathrm{e}}$ s. av. J.-C., en particulier celle de la couche 4

6 On reprend ici le terme utilisé par C. Lagrand et J.-P. Thalman (1973, p. 54) pour désigner des récipients légers, modelés dans une argile mêlée à une certaine quantité de paille hachée en menus morceaux. 


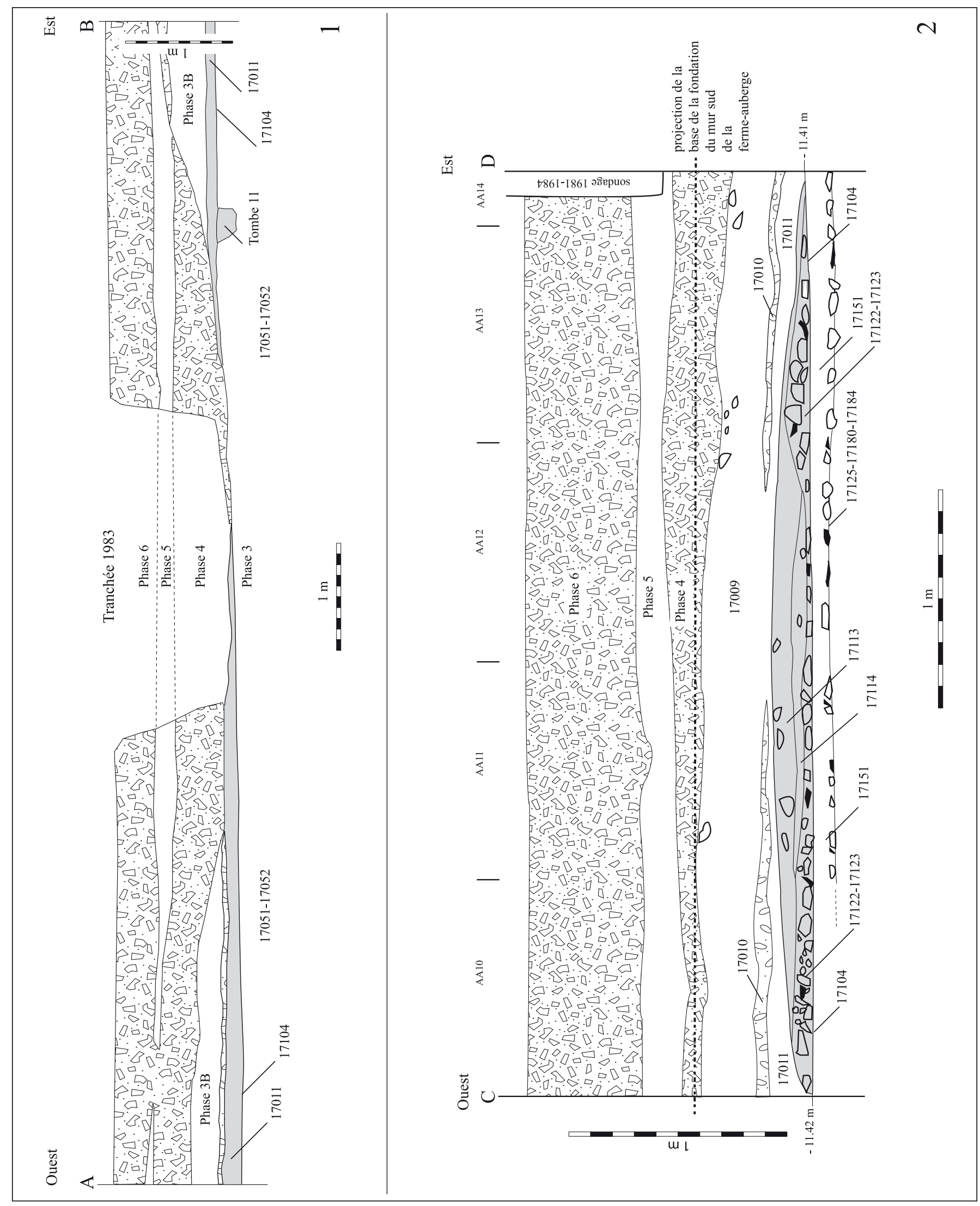

Fig. 9. Coupes stratigraphiques des niveaux inférieurs de la ferme-auberge $n^{\circ} 1.1$ - coupe ouest-est entre les points $A$ et $B$ de la fig. 8, d'après J.-F. Berger ; 2 - coupe ouest-est entre les points C et D de la fig. 8. 


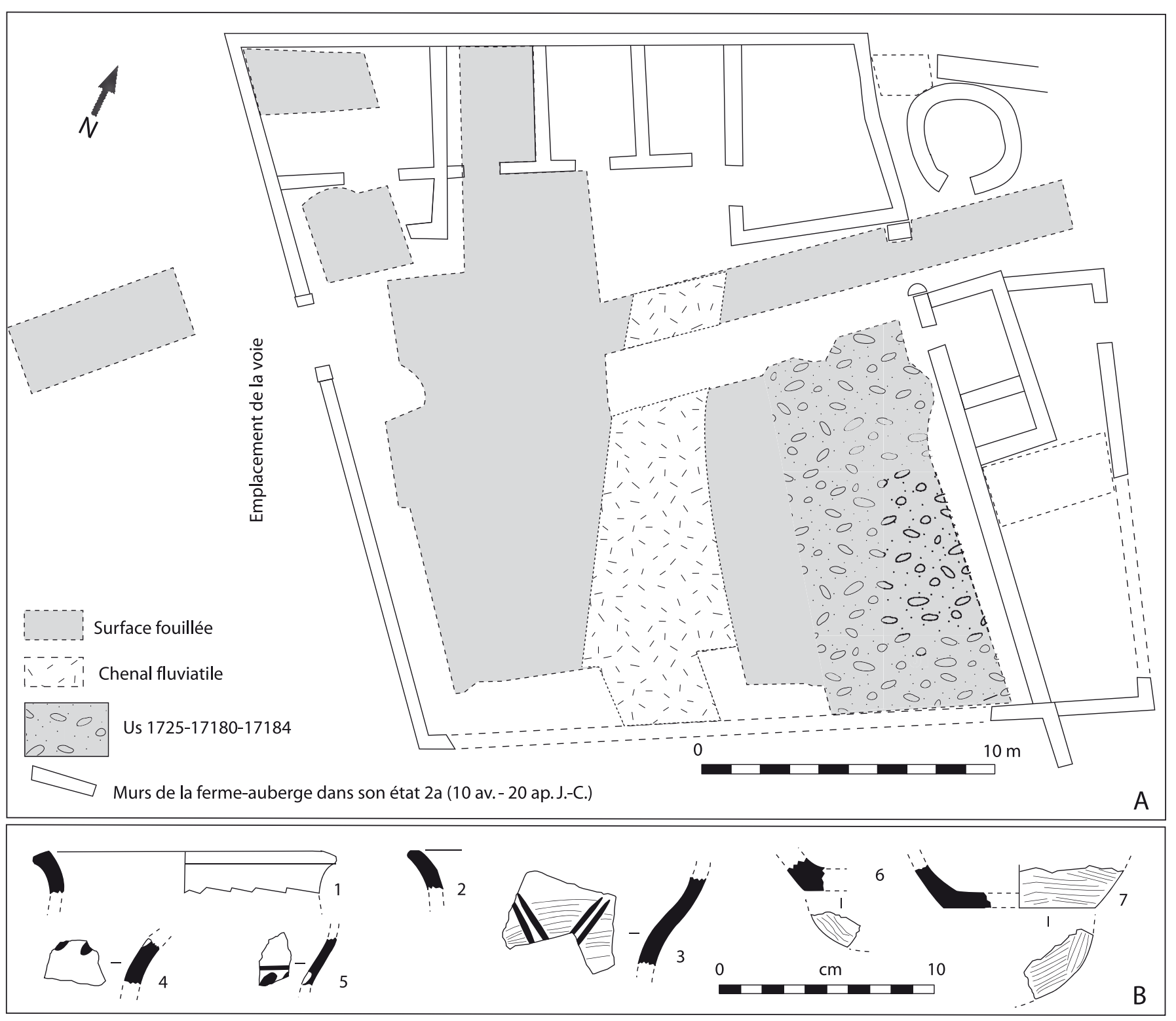

Fig. 10. A. Localisation, dans la partie fouillée, de la portion d'aménagement Us 17125-17180-17184 antérieur à la nécropole. B. Céramique non tournée incluse dans l'aménagement Us 17125-17180-17184.

du sondage IV (Fiches, Gutherz, Roux 1979, p. 36-38 et fig. 15) et des couches 8 et 10 de la pièce 3 (Fiches 1983, p. 82-83 et fig. $2, n^{\circ} 14$ à 71). Mais elle n’est pas différente non plus de celle des couches d'habitat immédiatement postérieures, comme par exemple celle de la couche 3 du sondage IV, datée de la deuxième moitié du III s. av. J.-C. (Fiches, Gutherz, Roux 1979, p. 39-41, et fig. 17), ni d'ailleurs de celle des tombes de la nécropole qui couvre les trois derniers quarts du $\mathrm{III}^{\mathrm{e}} \mathrm{s}$. et les environs de 200 av. J.-C. On soulignera aussi que le peignage couvrant à la fois la panse des urnes et le plan de pose des fonds est une technique qui, dans la région, ne concerne que les $\mathrm{IV}^{\mathrm{e}}, \mathrm{III}^{\mathrm{e}}$ et première moitié du II ${ }^{\mathrm{e}} \mathrm{s}$. av. J.-C. On la retrouve, par exemple, à Roque de Viou dans la seconde moitié du IV ${ }^{\mathrm{e}}$ s. av. J.-C. (Garmy 1974, fig. 35 et 47) et à Nages dans la première moitié du III ${ }^{\mathrm{e}} \mathrm{s}$. av. J.-C. (Py 1978, p. 183, fig. $87 \mathrm{n}^{\circ} 15$, p. 187, fig. 89 $\mathrm{n}^{\circ} 2$, et p. 188); elle se poursuit ensuite, comme à Lattes à la fin du III' s. av. J.-C. ou sur l'oppidum d'Ambrussum du milieu du $\mathrm{III}^{\mathrm{e}} \mathrm{s}$. av. J.-C. à la première moitié du siècle suivant (Py 1990b, p. 91, fig. 2-18, n 1 ; Fiches, Gutherz, Roux 1979, p. 38, fig. $15 \mathrm{n}^{\circ} 49$, p. 43 , fig. 19 $\mathrm{n}^{\circ} 9$, et p. 46, fig. $22 \mathrm{n}^{\circ} 37$ ). En définitive, compte-tenu de la présence de la nécropole au-dessus de ce niveau dès le milieu du $\mathrm{III}^{\mathrm{e}} \mathrm{s}$. av. J.-C., cet aménagement peut être daté dans les cent ans qui précèdent et sans doute 
plutôt du début du III' ${ }^{\mathrm{s}}$. av. J.-C. puisque ce mobilier n'est guère différent de celui que renferment les tombes. Il doit donc précéder de peu l'établissement du cimetière et peut être contemporain de la création de l'oppidum fortifié sur la hauteur du Devès.

Cet aménagement (Us 17125-17180-17184) ${ }^{7}$ repose sur un autre niveau d'alluvions limoneuses (US 17152), sondé sur $25 \mathrm{~cm}$ d'épaisseur et stérile en documents $\operatorname{archéologiques}^{8}$ (fig. 9).

\subsection{Après la nécropole}

Le sol de la nécropole est recouvert par un niveau horizontal bien marqué partout par de très nombreuses petites coquilles d'escargots, de couleur blanche, entières. Celles-ci traduisent l'existence d'un couvert végétal d'herbes non piétinées, un terrain alors ni cultivé ni fréquenté par l'homme (US 17023d).

Cette terrasse est ensuite à nouveau surmontée par des limons sur une vingtaine de centimètres d'épaisseur (US 17011 et $17023 \mathrm{c})^{9}$, qui traduisent de fréquents débordements du fleuve. Ceux-ci entraînent l'abandon de ce lieu. C'est durant cette phase de crues successives, datée du milieu du $\mathrm{II}^{\mathrm{e}} \mathrm{s}$. au début du $\mathrm{I}^{\mathrm{er}} \mathrm{s}$. av. J.-C., que se place le creusement d'un chenal fluviatile de 7 à $8 \mathrm{~m}$ de large et à fond presque plat, d'orientation NO-SE, parallèle au fleuve. Cette direction semble indiquer une formation par le ruisseau des Combes. Ce chenal traverse tout le secteur funéraire fouillé. Son fond a atteint et creusé le niveau de la nécropole sur une bande de 3 à $5 \mathrm{~m}$ de large, et a pu ainsi détruire d'éventuelles tombes sur son tracé.

Cette période d'instabilité hydrologique sera suivie par plusieurs autres (phases $3 \mathrm{~b}$ et 5 de J.-F. Berger) à partir du milieu du I ${ }^{\text {er }}$ s. av. J.-C., qui seront la cause d'exhaussements successifs des structures de l'auberge par apports successifs de remblais à partir du dernier tiers du Irr s. av. J.-C. (phases 4 et 6 de J.-F. Berger) (fig. 9, n 4 à 6). Grâce à ces atterrissements, les fondations des murs gallo-romains n'ont pas atteint le niveau de la nécropole.

Dans la partie supérieure de la couche Us 17023 et dans la couche US 17009 qui la surmonte, au sein d'alluvions limoneuses, sous la base de la première couche de remblais d'aménagement de l'auberge, prennent place

7 Phase 2 de J.-F. Berger.

8 Phase 1 de J.-F. Berger.

9 Phase 3 de J.-F. Berger. deux petits « dépôts » datables dans les trois premiers quarts du I ${ }^{\text {er }}$ s. av. J.-C., en deux endroits différents, à $15 \mathrm{~m}$ de distance l'un de l'autre, dans un contexte mal connu mais antérieur à l'aménagement de la station routière : les dépôts D1 et D2.

\section{Dépôt D1 (Us 17002)}

Le dépôt D1 regroupe plusieurs éléments, tous à la même profondeur et sur une petite surface de 50 à $70 \mathrm{~cm}$ d'axes : un morceau de tôle de bronze repliée, peut-être morceau de récipient, trois tessons de vases campaniens A tardifs dont un bord de patère Lamb. A6, deux tessons de deux vases à pâte claire récente, deux esquilles d'amphore italique, quatre tessons de deux vases non tournés, dont trois fragments d'une panse peignée d'urne, quelques pierres calcaires centimétriques non brûlées et des os d'animaux, non brûlés également, sans aucune connexion apparente ou organisation. Ces derniers, étudiés par A. Gardeisen, se rapportent, pour l'essentiel (21 restes identifiés sur 22), à deux ovinscaprins nouveau-nés ou très jeunes. Les squelettes ne sont pas complets; les portions retrouvées correspondent aux crâne, côtes, vertèbres, métatarse, radius et calcanéum, ainsi que deux coxaux de taille différente. À un autre animal du même âge, un porc très jeune ou nouveau-né, appartient un fragment de coxal. Enfin figure une esquille indéterminée, de plus grand format, ne correspondant ni à un ovin-caprin ni à un porcin, mais à un animal de plus grande taille. Aucune trace de découpe ou de préparation n'a été décelée sur ces restes.

Le dépôt inclut aussi quatre petits morceaux d'os incinérés, 1 fragment de diaphyse et 3 d'os plat, de couleur gris bleu à blanc crayeux. On ne peut dire s'il s'agit d'os humain ou animal, mais le traitement fait penser à la première éventualité.

La céramique indique une datation dans la première moitié ou le milieu du $\mathrm{I}^{\mathrm{er}} \mathrm{s}$. av. J.-C. L'espace restreint dans lequel tous ces éléments sont dispersés sans aucun ordre ne montre pas de limites aménagées. Le fait qu'il ne soit environné que par de très rares objets archéologiques sur tous les côtés reconnus, à l'est, au sud et à l'ouest, incite à voir là un dépôt voulu et organisé, ou au moins les restes d'un tel dépôt ; mais l'interprétation de cet ensemble, est sujette à caution. Si les os incinérés sont bien humains, nous serions en présence d'une sépulture ou des restes d'une sépulture; dans ce cas, le mode de dépôt serait original pour cette période, car en Languedoc oriental, pour le Ir s. av. J.-C., on n'a jusqu'ici signalé que des tombes en loculus, en fosse peu profonde, en jarre ou en coffre (Bel et al., 2008, passim). 
Si les os incinérés ne sont pas humains, on pourrait avoir affaire à un « dépôt d'offrandes » plutôt qu'à une accumulation de déchets, sans que la finalité ne puisse cependant être précisée.

\section{Dépôt D2 (Us 17048)}

Les éléments composant le dépôt D2 sont placés en position horizontale sur un sol matérialisé (Us 17023b). Il s'agit de plusieurs pièces crâniennes humaines non brûlées, groupées mais hors de toute connexion anatomique. Aux côtés de ces vestiges se trouvaient deux os d'animaux, de rares petites pierres calcaires (jusqu'à $7 \mathrm{~cm}$ d'arête) et des tessons de panse d'amphore italique et de dolium. Juste au-dessus, sont dispersés de petits charbons de bois (jusqu'à $5 \mathrm{~mm}$ ), mais avec une densité plus importante qu'ailleurs sur le sol 17023b. La présence d'amphore italique signale la deuxième moité du $\mathrm{II}^{\mathrm{e}} \mathrm{s}$. av. J.-C. ou la première moitié du siècle suivant.

Les os humains appartiennent à un même individu, un adulte gracile, de sexe non déterminable :

- la moitié postérieure du temporal droit, avec mastoïde et conduit auditif externe ; à l'intérieur, le massif pétreux est cassé transversalement ;

- la partie postérieure du pariétal droit et la partie droite de l'occipital, avec suture lambdoïde presque complètement synostosée en face endocrânienne, et en cours de synostose en face exocrânienne ;

- un fragment de la partie postérieure du pariétal gauche avec portion de la suture lambdoïde et de la ligne courbe semi-circulaire inférieure ;

- un fragment de pariétal gauche ;

- plusieurs fragments de la partie arrière des pariétaux ;

- une troisième molaire supérieure gauche à l'apex fermé et à la couronne assez usée.

Aucun autre vestige de ce sujet n'a été découvert. Il n'y a pas de trace d'un quelconque creusement de fosse dans laquelle auraient été placés ces vestiges et aucun indice d'aménagement de structure n'est observable dans les limites de la zone fouillée. L'origine de cette petite accumulation d'os reste problématique. Par leur position stratigraphique et leur datation, elle est étrangère à la nécropole.

Au Irr s. av. J.-C., le rituel funéraire «normal » pour les adultes met en œuvre l'incinération. Des os d'adultes épars et rares, presque toujours crâniens, sont parfois signalés dans des sites d'habitat de l'Âge du Fer du Midi méditerranéen, y compris à la fin de cette période, dans des contextes le plus souvent détritiques domestiques courants, et généralement on ignore tout de leur provenance (Dedet, Schwaller 1989, p. 147-149). Cependant l'exposition de crânes au public est bien attestée aussi, comme le montrent les exemplaires encloués à l'entrée du rempart de l'oppidum de la Cloche (Bouches du Rhône) au I ${ }^{\text {er }}$ s. av. J.-C. (Chabot 1983, p. 50-51) ou, tout près d'Ambrussum, les ensembles d'amas d'os de crânes d'adultes robustes, associés à des armes du $\mathrm{IIII}^{\mathrm{e}} \mathrm{s}$. av. J.-C., mis au jour dans l'habitat du Cailar (Gard), probables vestiges de trophées (Roure 2007; Girard, Roure 2009). Ce type de dépôt pourrait expliquer la présence, en position secondaire, de ces fragments crâniens d'adultes en ce lieu d'Ambrussum.

\section{La répartition des vestiges de la nécropole}

La nécropole est installée sur une surface plane, très légèrement inclinée du nord vers le sud. Vers l'angle nord-ouest de la fouille, au point le plus haut, son altitude est de 11,90 m tandis qu'à l'opposé, vers l'angle sud-est, son point le plus bas est à $11,40 \mathrm{~m}$, soit $50 \mathrm{~cm}$ de différence sur une distance de $34 \mathrm{~m}$, et une pente moyenne de l'ordre d'un centimètre et demi par mètre. Cette inclinaison est tout à fait régulière, sans aucun à-coup.

Ce niveau constitue le sol de la nécropole, bien marqué par divers éléments (fig. 11 et 12). Ce sont d'abord les structures des sépultures, 23 au total sur l'ensemble de la surface fouillée : sommet du creusement ou ouverture des loculus ; base des dépôts d'objets effectués aux abords immédiats de ces fosses et des dispositifs de recouvrement de ces ensembles. C'est aussi, au même niveau, la base d'une aire de crémation des cadavres (bûcher B1), et peut-être celle d'une seconde fouillée entre 1981 et 1985 (Structure ST 1). Ce sont encore des pierres et des petits tessons de vases ou autres objets éparpillés un peu partout, liés au fonctionnement et à la fréquentation de la nécropole et, sans doute pour partie, à l'érosion des structures funéraires.

La mise en évidence, par la fouille, du sol de la nécropole permet de penser que les infrastructures enterrées de ces tombes sont entièrement conservées ; et dans plusieurs cas, les superstructures sont partiellement conservées.

Deux événements oblitèrent cependant une partie de la surface fouillée (fig. 8).

Le sol de la nécropole est traversé, au beau milieu du secteur fouillé, par un chenal fluviatile de 4 à $5 \mathrm{~m}$ 


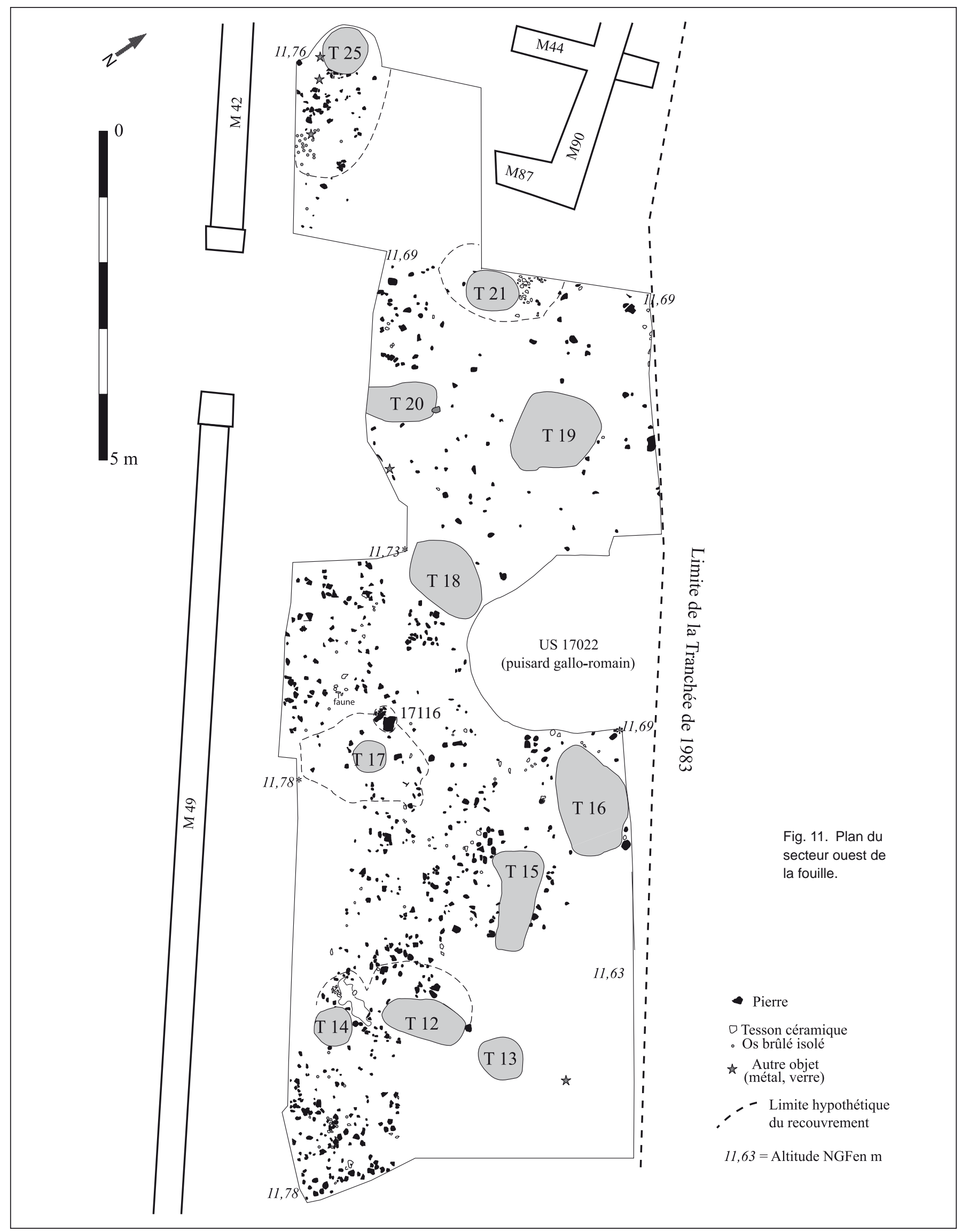


de largeur, orienté NO-SE parallèlement au lit du fleuve. Ce chenal est rapporté à la phase de dérèglement hydrologique du II e s. av. J.-C. ; il n'existait pas lors du fonctionnement du cimetière et a donc pu faire disparaître d'éventuelles sépultures.

D'autre part une grande fosse creusée dans la partie ouest de la cour de l'auberge de l'îlot 1 à l'époque gallo-romaine a pu avoir la même conséquence. Dans la partie centrale du secteur fouillé, l'ensemble des niveaux 17023, 17024, comme les niveaux de remblais d'aménagement de la maison sus-jacents, sont traversés par une fosse de 2,8 à $3 \mathrm{~m}$ de diamètre à l'ouverture, aux parois très abruptes (US 17022), qui entame également la terrasse sous-jacente 17051. Cette fosse est comblée par des pierres calcaires mesurant jusqu'à $30 \mathrm{~cm}$ d'arête, entre lesquelles se sont infiltrés de la terre, quelques os d'animaux et des tessons d'époque gallo-romaine. Il s'agit vraisemblablement d'un puisard destiné à assainir la cour de l'habitation gallo-romaine.

Les structures funéraires se répartissent sur l'ensemble de la surface fouillée, l'aire de crémation B1 dans l'angle sud-est et les sépultures dans tous les secteurs conservés du niveau funéraire.

\section{La méthode d'étude : de la fouille à la publication}

Pour ce qui concerne l'espace exploré entre 1999 et 2003, les divers niveaux de remblais d'aménagement de l'habitation de l'îlot 1 surmontant le niveau funéraire ont été décapés mécaniquement, sur une épaisseur de 1,1 à $1,2 \mathrm{~m}$. La profondeur de la nécropole par rapport au sol actuel, 2,9 à 3,3 m, la difficulté d'accès pour le tractopelle, le stockage temporaire des terres, car il convenait de remblayer après la fouille pour ne pas mettre en péril les structures gallo-romaines, ont obligé à effectuer les travaux de terrain en cinq campagnes annuelles de trois semaines à un mois. L'ensemble du secteur n'a donc pas pu être observé d'un seul tenant.

Afin de ne pas endommager la partie supérieure de la terrasse alluviale sur et dans laquelle prennent place les structures de la nécropole, ce décapage préliminaire a été arrêté avant la base de la couche de remblai la plus ancienne, datée vers 30 av. J.-C. Celle-ci, de même que la surface supérieure de la terrasse de la nécropole et le sol de la nécropole, ont fait l'objet d'une fouille manuelle avec outillage léger, truelles et brosses. Le dégagement des structures et superstructures funéraires, dispositifs de recouvrement et loculus des sépultures, ainsi que de l'aire de crémation B1, a été conduit avec de petites truelles, de petites spatules et des outils de chirurgie dentaire.

Pour les superstructures, tous les objets ont été laissés en place, dessinés au $1 / 10^{\mathrm{e}}$, photographiés, puis numérotés et prélevés un à un. Dans les loculus, comme il s'agit de dépôts secondaires d'incinération, avec dépôt « en vrac» de fragments osseux et de mobiliers prélevés sur un bûcher, il n'a pas paru nécessaire de coter chaque pièce. Leur ramassage a été fait en suivant la stratigraphie ou par décapages théoriques de 2 à $6 \mathrm{~cm}$ d'épaisseur. Les morceaux osseux les plus gros ont été conditionnés à part afin de pouvoir permettre leur remontage en cas de fractionnement ultérieur. Les structures funéraires, loculus, dispositifs de recouvrement, pierres, ont fait l'objet de relevés en plan et en coupe au $1 / 10^{\mathrm{e}}$. Tous les sédiments emplissant les loculus ou constituant les dispositifs de recouvrement ont été systématiquement collectés et ont fait l'objet, ultérieurement, d'un tamisage à l'eau aux mailles de $4 \mathrm{~mm}$, $2 \mathrm{~mm}$ et $0,5 \mathrm{~mm}$. La fouille de l'aire de crémation B1 a été effectuée par carrés de $20 \mathrm{~cm}$ de côté et le matériel a été prélevé selon ce même découpage, de même que la totalité du sédiment qui a également fait l'objet d'un tamisage à l'eau aux mailles de $4 \mathrm{~mm}, 2 \mathrm{~mm}$ et $0,5 \mathrm{~mm}$. Cette procédure a rendu possible d'apprécier la répartition de tous les vestiges archéologiques : celle des restes osseux humains et des différentes régions anatomiques, celle des objets personnels des défunts, des tessons de vases et des os animaux. Cela permet de mieux cerner le procédé de crémation et la place qu'occupe le reste du matériel, en dehors des os humains, dans le déroulement de la cérémonie de la crémation. Une couverture photo de l'ensemble, sol, tombes, aire de crémation, a été réalisée en noir et en couleur.

La fouille des loculus et l'étude archéo-anthropologique des restes osseux brûlés - tri, identification, détermination par région anatomique et étude pondérale - ont été menées selon le protocole établi dans H. Duday (Duday et al. 2000). Les valeurs de référence sont celles de B. Hermann (1976) et J.I. Mackinley (1993 ; 1994) pour le poids moyen d'un squelette brûlé, de Lowrance et Latimer (dans Krogman 1978) pour la représentation pondérale relative des différentes régions anatomiques du squelette adulte et de E. Bonucci et G. Grazziani pour l'évaluation de la température de crémation (Bonucci, Grazziani 1975).

L'étude pondérale a également revêtu un autre aspect : la comparaison du poids moyen des fragments osseux entre tombes et bûcher B1, mais aussi, pour les 


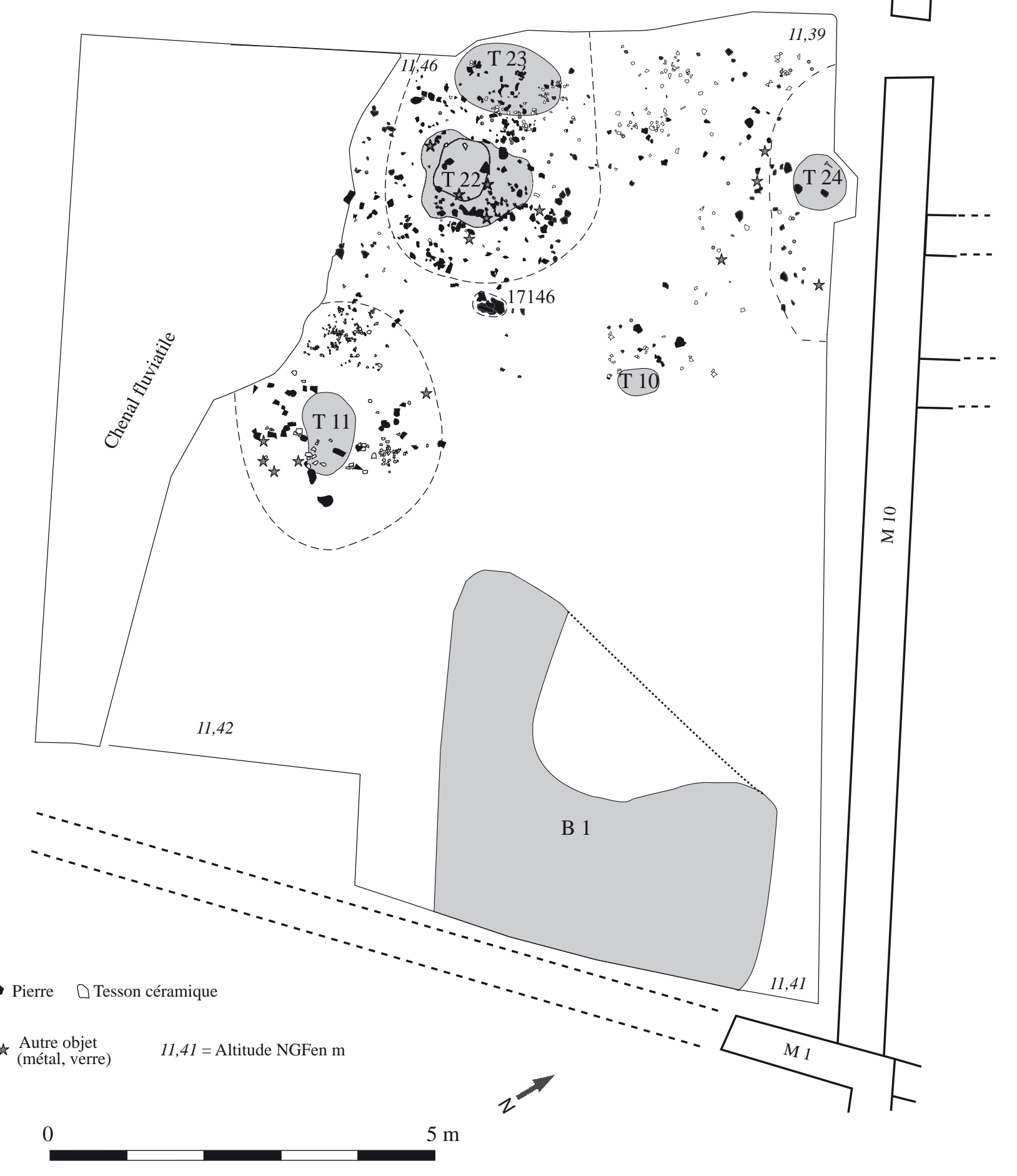

Fig. 12. Plan du secteur est de la fouille. 
premières, entre loculus et dispositif de recouvrement, ainsi qu'entre les deux catégories de tombes distinguées. Pour cela seules ont été dénombrées les pièces osseuses « déterminées » au niveau des grandes régions du squelette, tête, tronc et membres. En effet, les fragments « indéterminés », très nombreux du fait de leur taille le plus souvent extrêmement réduite découlant de la maille de tamisage utilisée de $0,5 \mathrm{~mm}$, ne pouvaient qu'amoindrir les éventuelles différences, et ils n'ont donc pas été comptés en nombre. D'autre part, les membres supérieurs et inférieurs n'ont pu être que rarement différenciés, car la fragmentation très importante des restes osseux n'a pas permis, le plus souvent, de faire la distinction entre ces deux régions anatomiques. On a donc dû se contenter de considérer la catégorie globale des restes des membres.

L'estimation de l'âge au décès est fondée sur le stade de maturation des pièces du squelette, dents et os, et, pour les adultes sur les processus de dégénérescence osseuse. Pour les enfants jusque vers 14 ans c'est le développement de la dentition qui constitue le critère le plus important, éruption et minéralisation des différentes dents, dents déciduales et dents définitives. On a utilisé ici les schémas fournis par D.H. Ubelaker (1978) et ceux de C.F.A. Moorrees, E.A. Fanning et E.E. Hunt (1963a ; 1963b), qui tiennent compte de la variabilité individuelle. Pour les enfants les plus jeunes, fœtus et nouveau-nés, outre le degré de calcification des germes dentaires, les os permettent l'estimation de la stature du corps. À l'aide des dimensions prises sur la plupart des os mesurables, on peut calculer la taille de chaque individu et, à partir des équations établies par I. GY. Fazekas et F. Kósa, l'âge au décès exprimé en mois lunaires de vingt-huit jours pour la période de vie intra-utérine et la naissance (Fazekas, Kósa 1978). Mais ceux-ci ne prennent en compte que des mesures globales, le plus souvent la longueur totale de l'os et dans certains cas une largeur, qui ne peuvent pas être effectuées lorsque les os sont incomplets. Pour tenter néanmoins d'estimer la stature d'un sujet à partir de pièces incomplètes ou endommagées, $H$. Duday et
A.-M. Tillier ont proposé, lors de l'étude des sujets de Sallèles d'Aude, un système beaucoup plus détaillé de mesures (Duday, Laubenheimer, Tillier 1995). Pour les enfants plus âgés, en plus de la dentition, on fait également entrer en ligne de compte les critères d'ossification des os, l'apparition des points d'ossification épiphysaires et complémentaires et la soudure de ces points à la diaphyse ou au corps de l'os (Ferembach, Schwidetzky, Stloukal 1979). L'appréciation de l'âge au décès des adultes repose sur l'absence de surfaces métaphysaires, le degré de synostose des sutures crâniennes et l'épaisseur de la corticale des os longs. La diagnose sexuelle n'a jamais été possible sur les restes osseux incinérés de cette nécropole.

Dans les dénombrements de restes humains, la notation des dents définitives est faite comme suit :

$\mathrm{I}=$ incisive $; \mathrm{C}=$ canine $; \mathrm{P}=$ prémolaire ; $\mathrm{M}=$ molaire ; en exposant ${ }^{123}=$ première, deuxième, troisième supérieures; en indice ${ }_{1,2,3},=$ première, deuxième, troisième inférieures $; \mathrm{C}^{\mathrm{I}}$ ou $\mathrm{C}_{\mathrm{I}}$ pour la canine supérieure ou inférieure $; \mathrm{d}=$ droite $; \mathrm{g}=$ gauche.

Dans la description des objets, et en particulier du matériel céramique, nous utilisons diverses classifications. Pour les céramiques à vernis noir de l'atelier de Rosas, nous suivons la classification de N. Lamboglia (1952) adaptée aux productions de cet atelier par E. Sanmartí (1978) et donnons les équivalences que A.-M. Puig i Griessenberger a récemment établies (Puig 2006). Pour les céramiques non tournées, attiques, de l'atelier des petites estampilles, les productions à pâte claire massaliète et grises peintes et les amphores massaliètes nous adoptons le classement des formes mis au point pour le site de Lattes, Dicocer ${ }^{2}$ (Py, Adroher Auroux, Sanchez 2001).

L'étude du matériel métallique a été effectuée après des campagnes de radiographie, stabilisation et restauration menées à bien par le Laboratoire de conservation, restauration et recherches du Centre Archéologique du Var à Draguignan (J. Rebière et J. Françoise). 



\section{Chapitre 2}

\section{Tombes, structures annexes et sol de la nécropole (fouilles 1999 - 2003)}

$\mathrm{C}$ e chapitre rassemble, de manière analytique, les données récoltées dans les seize tombes découvertes lors des recherches conduites entre 1999 et 2003, l'examen des deux structures annexes, ainsi que celui des vestiges livrés par le sol de la nécropole.

Toutes les tombes appartiennent à la catégorie des «dépôts secondaires de crémation », selon la terminologie préconisée dans Blaizot dir. 2009, p. 175. Pour chacune, seront successivement examinés l'état des structures, les restes osseux du défunt, la morphologie et le remplissage du loculus, le dispositif de recouvrement, ainsi que le mobilier et les restes osseux animaux que ces structures ont livrés.

Également fouillé dans ce secteur de la nécropole durant ces campagne de recherches, le bûcher funéraire B1, qui nous renseigne sur les modalités de l'étape de la crémation, peut-être en rapport direct avec ces sépultures elles-mêmes, fera l'objet du chapitre suivant.

\section{La tombe T10}

\section{1. État et composantes}

La tombe T10 accueille les restes d'un adulte de sexe non déterminé. Le mobilier associé ne permet pas de préciser ce dernier. Entièrement fouillée, cette sépulture comprend un loculus et les traces d'une structure de recouvrement (fig. 13).

\subsection{Le défunt}

Le défunt est représenté par 190,3 g d'os incinérés. La morphologie des os, en particulier l'épaisseur de la voûte crânienne, ainsi que la fermeture des apex des dents montrent qu'il s'agit d'un adulte. La quasi-totalité des restes provient du loculus (US 17112-17169). Ceux-ci y sont dispersés, hors de tout contenant.

La couleur blanc crayeux révèle une température de crémation supérieure à $650^{\circ}$ selon le barème de E. Bonnucci et G. Grazziani (1975), et les morceaux de diaphyses sont très souvent fissurés en ondes concentriques, indice d'une incinération d'os frais. Le poids d'os déposés ne représente que $8,6 \%$ du poids moyen d'un squelette d'adulte brûlé, 1627,1 g selon McKinley (1993). Les taux d'identification sont de $83 \%$ du poids total des fragments. L'essentiel est constitué par les membres, $88,7 \%$ du poids identifié (poids théorique $62,6 \%$ ). Crâne et tronc sont, par contre, extrêmement sous-représentés, respectivement $6,9 \%$ et $4,4 \%$, au lieu des 20,4 et $17 \%$ attendus (fig. 13, A et B).

Le poids moyen des fragments déterminés, toutes régions anatomiques confondues, est de $0,15 \mathrm{~g}(0,13 \mathrm{~g}$ pour la tête, $0,10 \mathrm{~g}$ pour le tronc et $0,16 \mathrm{~g}$ pour les membres).

\subsection{Le loculus}

Les limites du loculus (US 17112-17169) se discernent mal de l'encaissant. Le plan est grossièrement ovalaire, d'environ $50 \mathrm{~cm}$ sur l'axe NE-SO, pour environ $30 \mathrm{~cm}$ sur l'axe NO-SE. La profondeur n'excède pas $7 \mathrm{~cm}$. Le comblement est formé d'une terre alluviale semblable à celle de la terrasse environnante. Il s'en distingue cependant par des passées cendreuses, des mouchetures de petits morceaux de charbons de bois, de nombreux fragments d'os humains incinérés et 16 petits tessons de vases appartenant probablement à 15 récipients (fig. 13, C).

\section{Mobilier du loculus}

Ce matériel consiste en tessons isolés d'environ 15 récipients céramiques :

-1 tesson de vase à vernis noir de l'atelier de Rosas, de forme non déterminable ; 


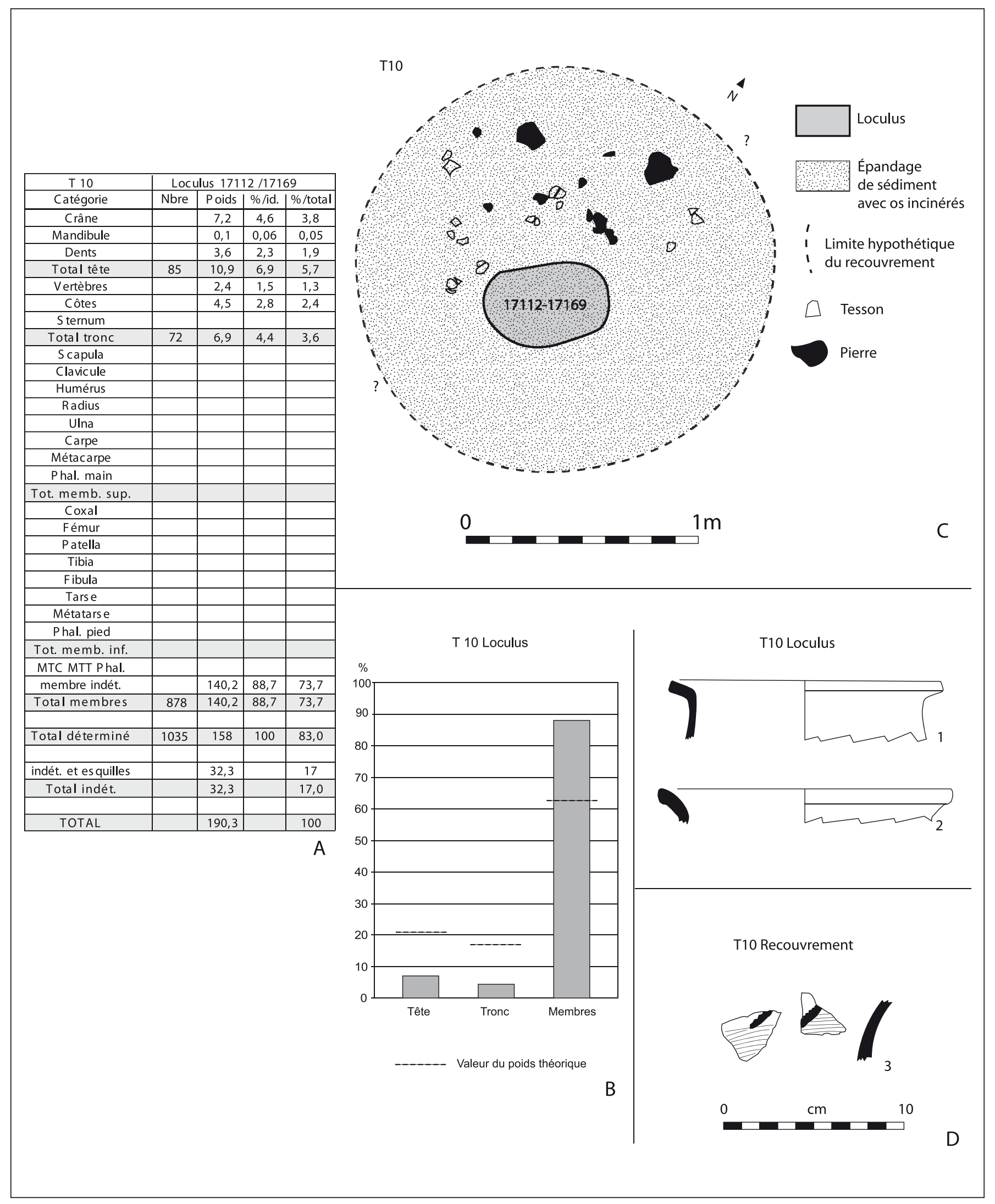

Fig. 13. Tombe T10. A : tableau de détermination des os humains (poids en grammes; calcul des \% sur la masse).

$B$ : répartition du poids des os par grandes régions anatomiques (\% par rapport au total déterminé). C : plan de la tombe. D : mobilier (1-3 : céramique non tournée). 
- 1 tesson d'urne non tournée de forme probable CNT-LOR U5d : col tronconique rentrant, bord déversé formant méplat vers l'intérieur, lèvre aplatie (fig. 13, $\left.\mathrm{n}^{\circ} 1\right)$;

- 2 tessons de bord d'une autre urne non tournée de forme probable CNT-LOR U5d : bord déversé à lèvre aplatie (fig. 13, $\mathrm{n}^{\circ} 2$ ) ;

- 12 tessons ou esquilles de panses de plusieurs vases non tournés (12 exemplaires ?), urnes et coupes (non dessinés).

Os d'animaux (détermination A. Gardeisen) :

- 5 fragments d'extrémité distale de membre antérieur d'un capriné jeune, non brûlée, pouvant provenir d'une portion d'animal incomplètement prélevée (extrémité distale des phalanges I et II, juvénile ; extrémité proximale des phalanges II (non soudée) et III (axiale et abaxiale) ; corps de scaphoïde, juvénile) ;

-1 fragment d'apophyse articulaire de vertèbre cervicale de capriné ;

-1 fragment de côte (cf. bœuf) ;

- Indéterminés : 17 esquilles brûlées et 11 esquilles non brûlées ;

- Malacofaune : gastéropodes blancs de petite taille.

\subsection{La structure de recouvrement}

Les vestiges de la superstructure qui recouvrait ce loculus sont marqués par plusieurs indices. Une portion d'urne non tournée cassée sur place et quelques petites pierres calcaires reposent à plat sur le sol de la nécropole entourant le loculus à l'ouest et au nord. Quelques très rares fragments d'os humains incinérés et quelques charbons de bois sont dispersés dans les deux ou trois centimètres de terre alluviale surmontant le comblement du loculus et le sol aux environs immédiats, et recouvrant les pierres et les tessons. La limite de cette structure est imprécise, mais les vestiges qui attestent ce recouvrement sont présents jusqu'à un mètre de distance $\mathrm{du}$ loculus, ce qui lui confère un diamètre de l'ordre de $2 \mathrm{~m}$ (fig. 13, C).

\section{Mobilier de la structure de recouvrement}

- portion de la panse d'une urne non tournée du type ovoïde (23 tessons non jointifs, représentant environ $10 \%$ du récipient); peignage horizontal ; sur l'épaule, décor de grandes impressions au peigne, obliques (fig. 13, $\mathrm{n}^{\circ} 3$ ) ;

-1 tesson de col d'urne non tournée, qui pourrait appartenir à l'exemplaire précédent.

\section{La tombe T11}

\section{1. État et composantes de la tombe}

La tombe 11 abrite un seul défunt incinéré, un adulte de sexe non déterminable, mais la composition du mobilier (voir infra) pourrait cependant signaler une femme.

Cette sépulture a pu être intégralement fouillée ; elle comprend un loculus et une structure de recouvrement s'étendant largement tout autour (fig. 14 à 17).

\subsection{Le défunt}

Le défunt est représenté par 284,2 g d'os brûlés. D'après la morphologie des os et la fermeture de l'apex des deux racines de dents conservées, il s'agit d'un adulte. Un fragment crânien dont la suture n'est pas synostosée, sur aucune des deux faces, semble indiquer un adulte jeune. Le sexe anthropologique ne peut pas être précisé.

Les pièces osseuses sont réparties dans le loculus $(183,7 \mathrm{~g})$ et dans les vestiges du dispositif de recouvrement (100,5 g), et les deux lots ne montrent ni doublets et ni pièces morphologiquement incompatibles.

Dans les deux cas, les restes osseux présentent le même aspect: ils sont de taille très réduite ; les morceaux de diaphyses sont très souvent fissurés en ondes concentriques, indice d'une incinération d'os frais ; tous ont une couleur blanc crayeux qui révèle une température de crémation supérieure à $650^{\circ}$ selon le barème de E. Bonnucci et G. Grazziani (1975).

Dans le loculus, les os sont dispersés, hors de tout contenant, et si aucune disposition particulière des fragments n'a été perçue, ils sont cependant plus abondants dans la moitié supérieure du comblement (décapage 1), que dans la moitié inférieure (décapage 2), respectivement $65 \%$ et $35 \%$ de la masse du lot. Ils sont également éparpillés dans le dispositif de recouvrement.

Le loculus ayant été découvert complet, on peut considérer que l'on a retrouvé la quasi-totalité du lot qui y a été déposé. Il n'en va pas de même pour les os de la superstructure qui, elle, n'est que partiellement conservée. Le poids d'os déposés dans le loculus ne représente guère que $11,3 \%$ du poids moyen d'un squelette d'adulte brûlé, 1627,1 g selon McKinley (1993) et la part découverte dans le recouvrement n'en constitue que 6,2\%. 


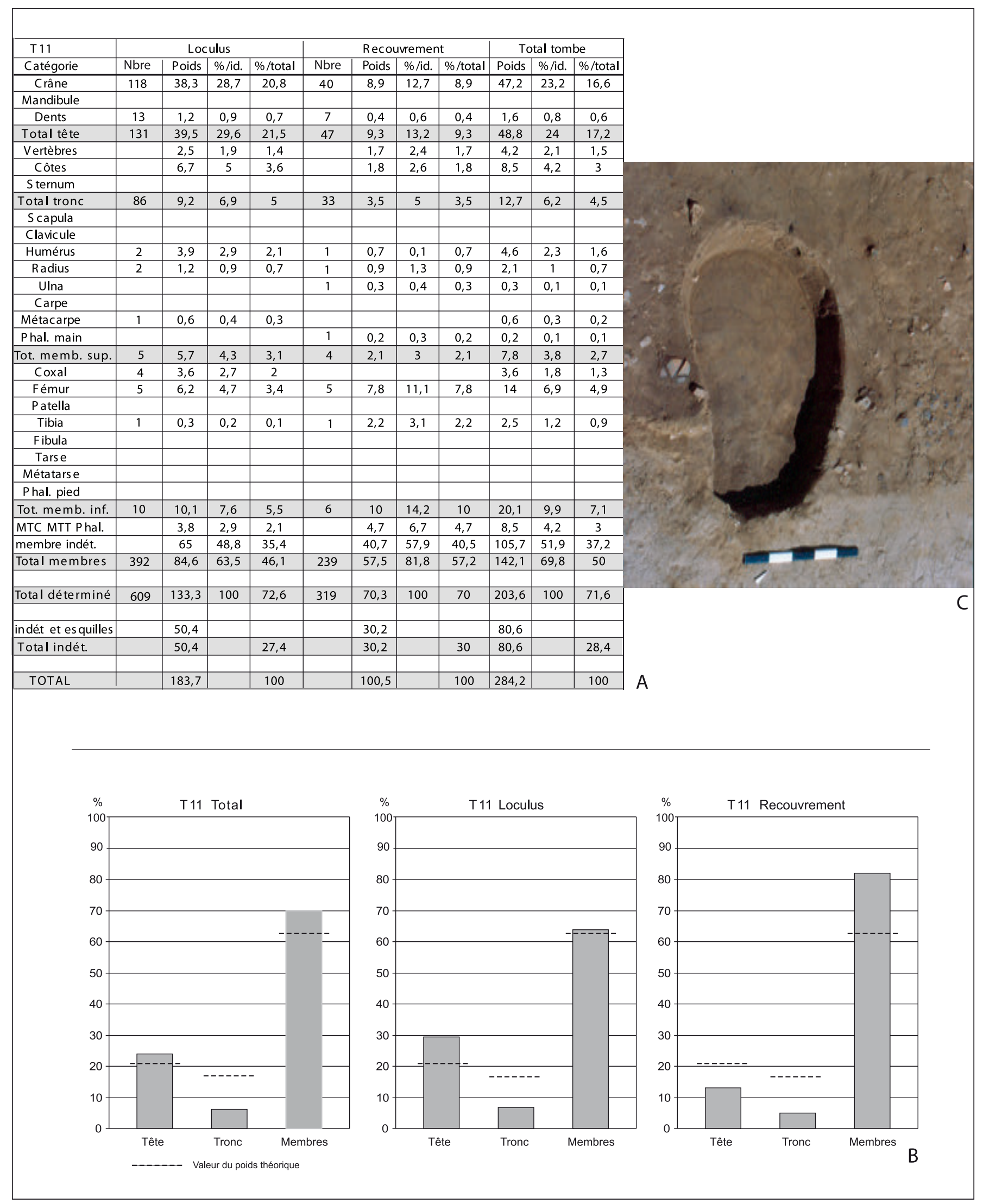

Fig. 14. Tombe T11. A : tableau de détermination des os humains (poids en grammes; calcul des \% sur la masse).

$\mathrm{B}$ : répartition du poids des os par grandes régions anatomiques (\% par rapport au total déterminé). C : vue du loculus en fin de fouille. 


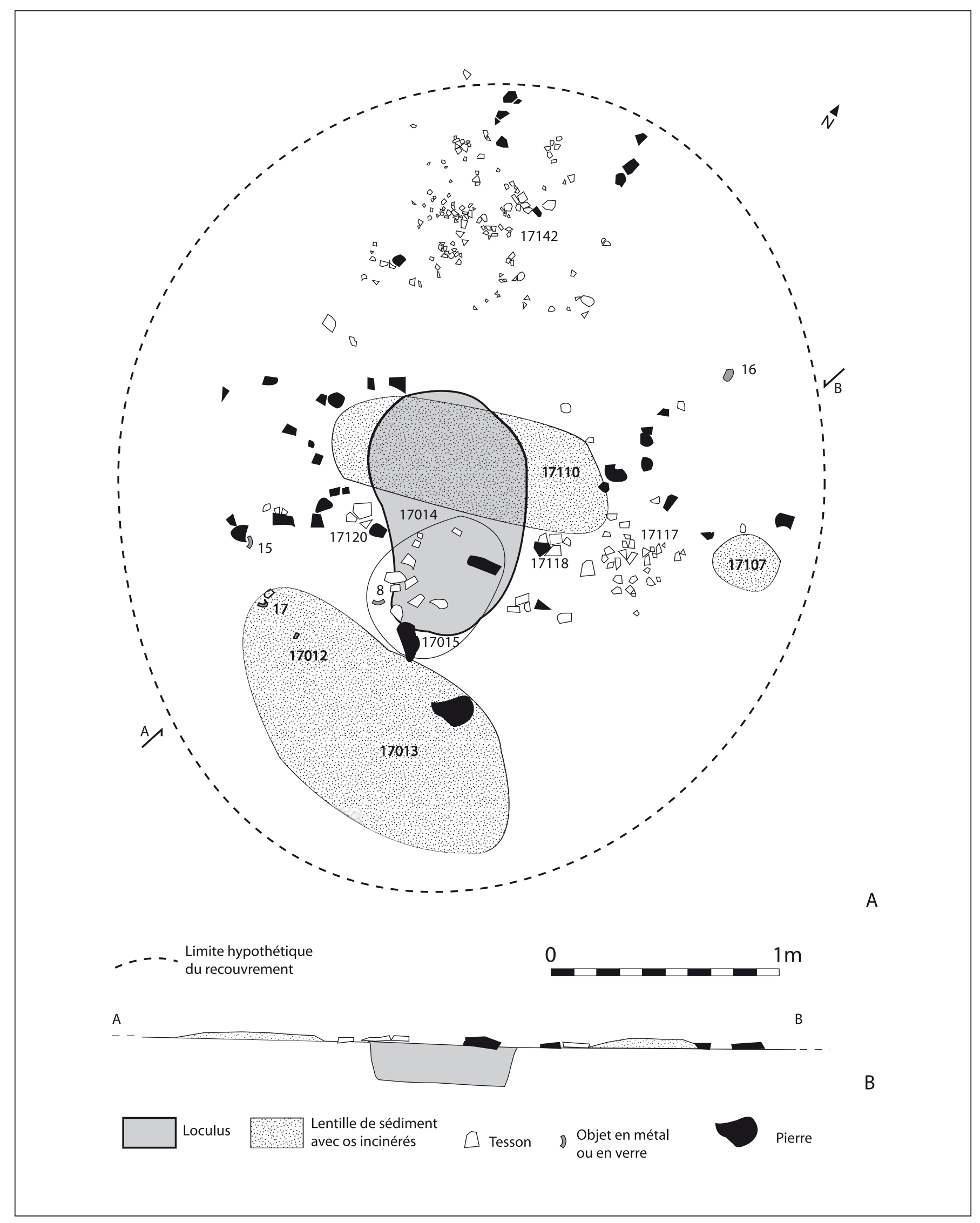

Fig. 15. Tombe T11. Plan de la tombe. 
Les taux d'identification sont de 72,6\% du poids total des fragments pour le loculus et $70 \%$ pour la superstructure. Dans le loculus, avec 29,6\% du poids identifié, le crâne est sur-représenté (poids théorique : 20,4 \%). Cela se fait au détriment du tronc, 6,9\% au lieu des $17 \%$ attendus, car le taux des membres, $63,5 \%$, est conforme à la valeur théorique $(62,6 \%)$. Ces proportions diffèrent dans le lot provenant de la superstructure: le crâne est ici sous-représenté, 13,2\% des fragments identifiés, au bénéfice des membres, très largement sur-représentés $(81,8 \%)$, tandis que le tronc, avec $5 \%$, est toujours aussi peu présent (fig. 14, A et B).

Le poids moyen des fragments déterminés, toutes régions anatomiques confondues, est le même pour le loculus et le dispositif de recouvrement et s'élève à $0,22 \mathrm{~g}$ (provenant du loculus : 0,30 g pour la tête, $0,11 \mathrm{~g}$ pour le tronc et $0,22 \mathrm{~g}$ pour les membres ; provenant du recouvrement : $0,20 \mathrm{~g}$ pour la tête, $0,11 \mathrm{~g}$ pour le tronc et $0,24 \mathrm{~g}$ pour les membres). Pour les 7 fragments identifiés comme provenant des membres supérieurs, le poids moyen est de $1,12 \mathrm{~g}$; pour les 16 fragments identifiés comme provenant des membres inférieurs, il est de $1,18 \mathrm{~g}$.

\subsection{Le loculus}

Le loculus (US 17014) a un plan grossièrement ovalaire, de 1,1 $\mathrm{m}$ et $0,7 \mathrm{~m}$ d'axes (fig. 14, $\mathrm{C}$ et 15). Il est profond de $15 \mathrm{~cm}$; ses parois sont obliques, très abruptes, et son fond est plat. Son remplissage est formé d'une terre gris sombre, charbonneuse, dont la couleur tranche très nettement avec celle de l'encaissant. Outre les os humains, il renferme, dispersés en son sein, des morceaux d'objets incomplets, et exceptionnellement une pièce complète.

\section{Mobilier du loculus}

Objets personnels de parure et d'habillement :

- une fibule en bronze (fig. 16, $\mathrm{n}^{\circ} 1$ ), de type 8 ou 9 de C. Tendille, représentée par plusieurs morceaux : moitié de ressort bilatéral à six spires et corde externe (long. cons. : $13 \mathrm{~mm}$; diam. spire : $8 \mathrm{~mm}$ ), un petit morceau d'arc filiforme et plusieurs petits fragments déformés par le feu, non localisables ;

- une moitié de maillon de chaînette en bronze (fig. 16, $\mathrm{n}^{\circ} 2$ ); section circulaire ; diam. : $10 \mathrm{~mm}$. Cet objet a également brûlé.

Pièce métallique de fonction non déterminée:

- Pince en fer (fig. 16, $\mathrm{n}^{\circ}$ 7), formée d'une seule pièce repliée sur elle-même: d'un côté plaque sub-rectangulaire de profil incurvé, de l'autre, tige de section aplatie allant en s'amincissant depuis la plaque qu'elle prolonge ; cette tige forme une boucle en correspondance avec une moitié de la plaque; long.: $77 \mathrm{~mm}$; larg. plaque : $17 \mathrm{~mm}$; ép. plaque : 1,5 à $3 \mathrm{~mm}$; ép. tige : $3 \mathrm{~mm}$.

Vaisselle céramique

Le matériel céramique comprend une portion de vase et des tessons isolés d'environ 14 autres récipients :

- portion de la partie supérieure d'une urne non tournée de CNT-LOR U5d, variante d (13 tessons) : col tronconique rentrant, bord déversé formant méplat vers l'intérieur, lèvre aplatie, panse ovoïde peignée verticalement, épaule décorée d'un rang horizontal de petites impressions; diam. ouv. : $155 \mathrm{~mm}$; diam. max. : $180 \mathrm{~mm}$. Quatre autres tessons de ce vase proviennent des épandages recouvrant le loculus (US 17015 et 17110) et un autre, d'un des amas déposés sur le paléosol (US 17012-17013). Au total, ces 18 morceaux forment moins de $10 \%$ du vase (fig. 16, $\mathrm{n}^{\circ} 3$ );

-4 tessons d'urne non tournée de forme probable CNT-LOR U5d: panse ovoïde peignée verticalement (fig. 16, $\left.\mathrm{n}^{\circ} 4\right)$;

-1 tesson d'urne non tournée de forme probable CNTLOR U5d : bord déversé, lèvre aplatie (fig. 16, $\mathrm{n}^{\circ}$ 5) ;

-1 tesson de bord de vase non tourné (fig. 16, $\mathrm{n}^{\circ} 6$ ) ;

- 11 petits tessons de panses appartenant à autant d'urnes non tournées (non dessinés).

Os d'animaux (détermination A. Gardeisen) :

- 2 fragments de porcs adultes (première phalange soudée de doigt latéral et extrémité distale d'humérus droit) ;

- 1 fragment d'extrémité distale de première phalange (cf. lapin) ;

- mandibule d'insectivore (cf. musaraigne);

- Indéterminés : 22 esquilles non brûlées.

\subsection{La structure de recouvrement}

De la structure de recouvrement subsistent deux sortes de vestiges (fig. 15) :

- un épandage d'objets posés horizontalement sur une partie du remplissage du loculus et débordant au sud-ouest sur le paléosol (US 17015), des portions de quatre vases écrasés en surface du paléosol de la nécropole, en périphérie du loculus (US 17117, 17118, 17120 et 17142), et quelques objets dispersés, aux alentours immédiats, également sur le paléosol (US 17104) ;

- des lentilles de terre limoneuse d'extension plus ou moins importante, de $6 \mathrm{~cm}$ d'épaisseur maximum, 
incluant du matériel, formant des restes d'une accumulation de matériaux qui devaient recouvrir le loculus et ses abords à la manière d'un petit tumulus très peu élevé (US 17012, 17013, 17107 et 17110).

Les limites de ce recouvrement ne sont pas connues, mais les restes conservés, lentilles et portions de vases, lui donnent au moins 3,3 $\mathrm{m}$ de diamètre ou de côté.

\section{Mobilier de la structure de recouvrement}

\section{L'épandage US 17015}

Sur la partie sud-ouest du comblement du loculus, débordant sur le paléosol, prend place une épandage d'objets disposés à plat, relativement groupés. Outre deux petites pierres plates calcaires $(130 \mathrm{~mm}$ sur $30 \mathrm{~mm}$ et $150 \mathrm{~mm}$ sur $8 \mathrm{~mm}$ ), non brûlées, figurent les pièces suivantes :

-3 morceaux d'un bracelet en bronze, soit $25 \%$ environ (fig. 16, $\mathrm{n}^{\circ} 8$ ); section en « $\mathrm{D} »$; pas de décor visible ; diam. int. : environ $60 \mathrm{~mm}$; haut. : $5 \mathrm{~mm}$; ép. : $3 \mathrm{~mm}$;

-3 tessons de l'urne non tournée $n^{\circ} 3$ dont la majeure partie des morceaux prend place dans le remplissage du loculus ;

-1 bord d'amphore massaliète de type A-MAS bd 9 (fig. 16, $\mathrm{n}^{\circ}$ 9) ;

- 1 petit tesson de bord de coupe à pâte claire massaliète (non dessiné) ;

- 2 tessons d'une grande urne non tournée de forme probable CNT-LOR U5d ; panse ovoïde peignée horizontalement, épaule décorée d'impressions de peigne disposées en deux lignes brisées (fig. 16, $\mathrm{n}^{\circ} 10$ ) ;

-6 tessons de panses de 6 vases non tournés (non dessinés) ;

- 1 morceau d'extrémité arrière de chenet modelé en terre cuite (fig. 16, $\left.\mathrm{n}^{\circ} 11\right)$.

Les portions de vases écrasés :

- Jouxtant le bord occidental du loculus (US 17120), 4 tessons jointifs de la panse arrondie convexe d'une grande jatte non tournée, soit moins de $5 \%$ du vase (non dessiné) ;

- À $10 \mathrm{~cm} \mathrm{du} \mathrm{bord} \mathrm{oriental} \mathrm{du} \mathrm{loculus} \mathrm{(US} \mathrm{17118),}$ 6 tessons jointifs d'une grande coupe non tournée de forme CNT-LOR C2d, représentant environ $15 \%$ du vase ; panse arrondie convexe ; bord rentrant à lèvre aplatie ; sous le bord, arrachement d'une anse horizontale en boudin ; diam. max. : $265 \mathrm{~mm}$ (fig. 16, $\mathrm{n}^{\circ} 12$ ) ;

- Immédiatement à la suite de la précédente vers l'est (US 17117), 49 petits tessons, souvent jointifs, d'une urne non tournée de forme probable CNT-LOR U5d : départ de col tronconique rentrant, panse ovoïde à peignage horizontal, épaule décorée de longues impressions de peigne disposées en une ligne brisée; diam. max. : $240 \mathrm{~mm} .11$ autres petits tessons de ce vase prennent place à $1 \mathrm{~m}$ de là, dans la partie sud du recouvrement (17117). Au total ce sont $25 \%$ environ de cette urne qui sont représentés (fig. 16, $\mathrm{n}^{\circ} 13$ ) ;

- A $30 \mathrm{~cm} \mathrm{du}$ bord septentrional du loculus (US 17142), 158 tessons, très souvent de très petite taille, parfois jointifs, d'une urne non tournée de forme CNT-LOR U5d, variante $\mathrm{d}$ : col tronconique rentrant, bord déversé avec méplat vers l'intérieur, lèvre aplatie, panse ovoïde peignée horizontalement, épaule décorée d'impressions au peigne disposées en deux lignes brisées, sur fond de peignage horizontal, fond plat avec, incisé sur la partie conservée, un trait large et peu profond, probable élément de croix ; diam. ouv. : $150 \mathrm{~mm}$; diam. max. : $175 \mathrm{~mm}$; haut. estimée : $210 \mathrm{~mm}$; environ $50 \%$ du vase est représenté (fig. 16, $\mathrm{n}^{\circ} 14$ ).

Les lentilles de terre:

Ces lentilles de limon semblable à celui qui recouvre la nécropole enferment quelques petits charbons de bois, des tessons et pierres calcaires centimétriques éclatées au feu, ainsi que de nombreux petits fragments d'os humains incinérés dispersés, 100,5 g au total. La lentille la plus vaste au sud (US 17012-17013) a livré $88 \mathrm{~g}$ de ces os ; au nord, celle qui couvre partiellement le loculus (US 17110), en contenait 8,5 g; celle de l'est (US 17107), seulement 3,2 g.

Lentille US 17107 :

-2 petits tessons d'amphore massaliète (non dessinés) ;

- portion de panse peignée et de col d'une urne non tournée, 13 tessons, soit moins de $10 \%$ du vase (non dessinés) ;

- 4 petits tessons informes d'une urne ou d'une coupe non tournée, soit moins de $5 \%$ du vase (non dessinés) ;

- 9 petits tessons informes de 9 vases, urnes ou coupes (non dessinés).

Lentille US 17110 :

-2 tessons de l'urne non tournée $n^{\circ} 3$ dont la majeure partie des morceaux prend place dans le remplissage du loculus ;

- 3 tessons de l'urne non tournée $n^{\circ} 13$ dont la majeure partie est écrasée sur le paléosol au nord-est (US 17117) ;

- 1 petit tesson de panse de vase en campanienne A ancienne (non dessiné) ;

- 1 tesson de panse d'urne ou d'œnochoé à pâte claire massaliète (non dessiné) ;

- 1 tesson d'urne non tournée de forme probable CNT-LOR U5d : bord évasé avec méplat vers l'intérieur, lèvre épaissie (fig. 16, $\mathrm{n}^{\circ} 15$ ). 


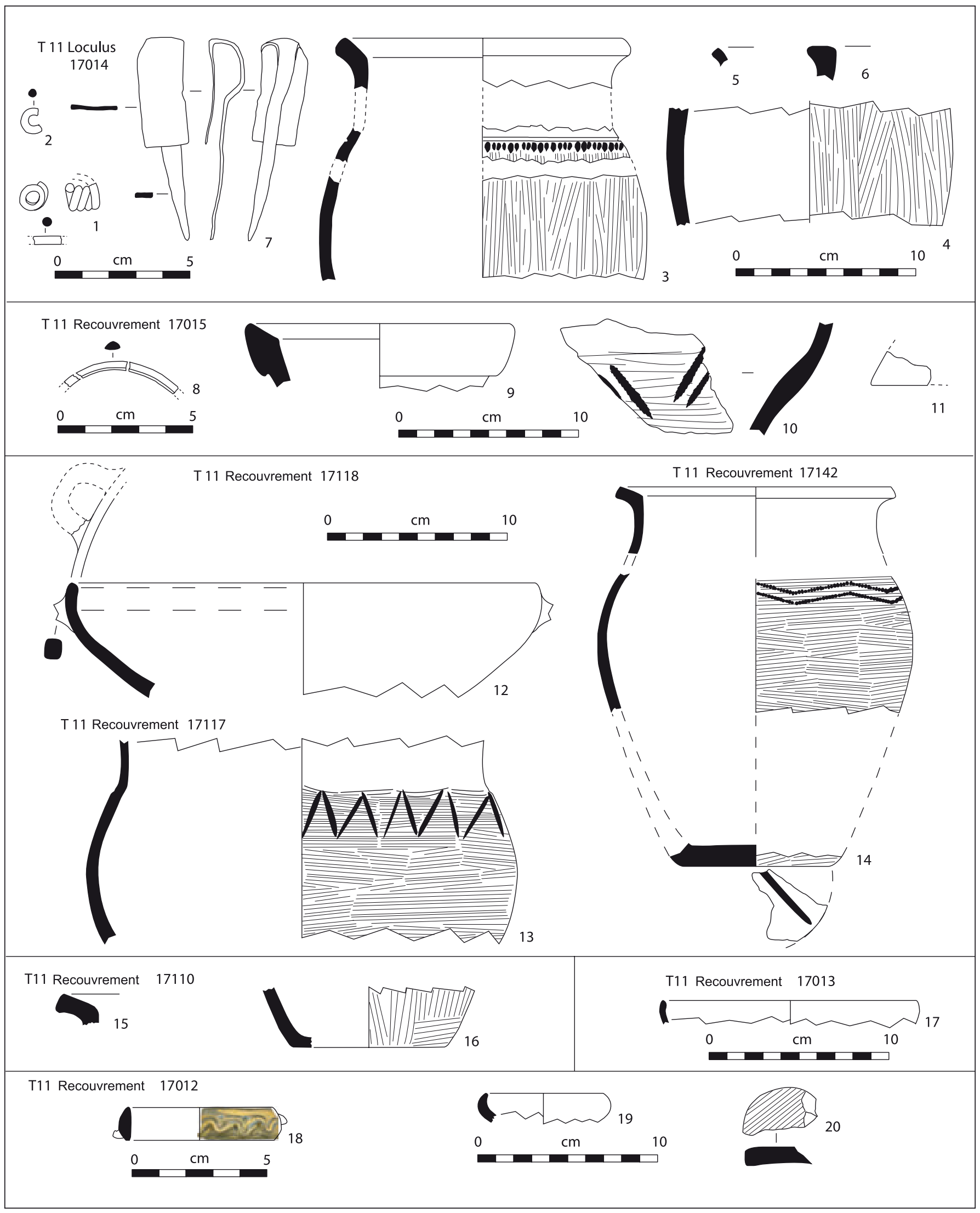

Fig. 16. Tombe T11. Mobilier (1, 2 et 8 : bronze ; 3-6, 10, 12-16 et 20 : céramique non tournée ; $7:$ fer ; 9 : amphore massaliète ; 11 : chenet modelé en terre cuite ; $18:$ verre ; 17 et 19 : céramique à vernis noir). 


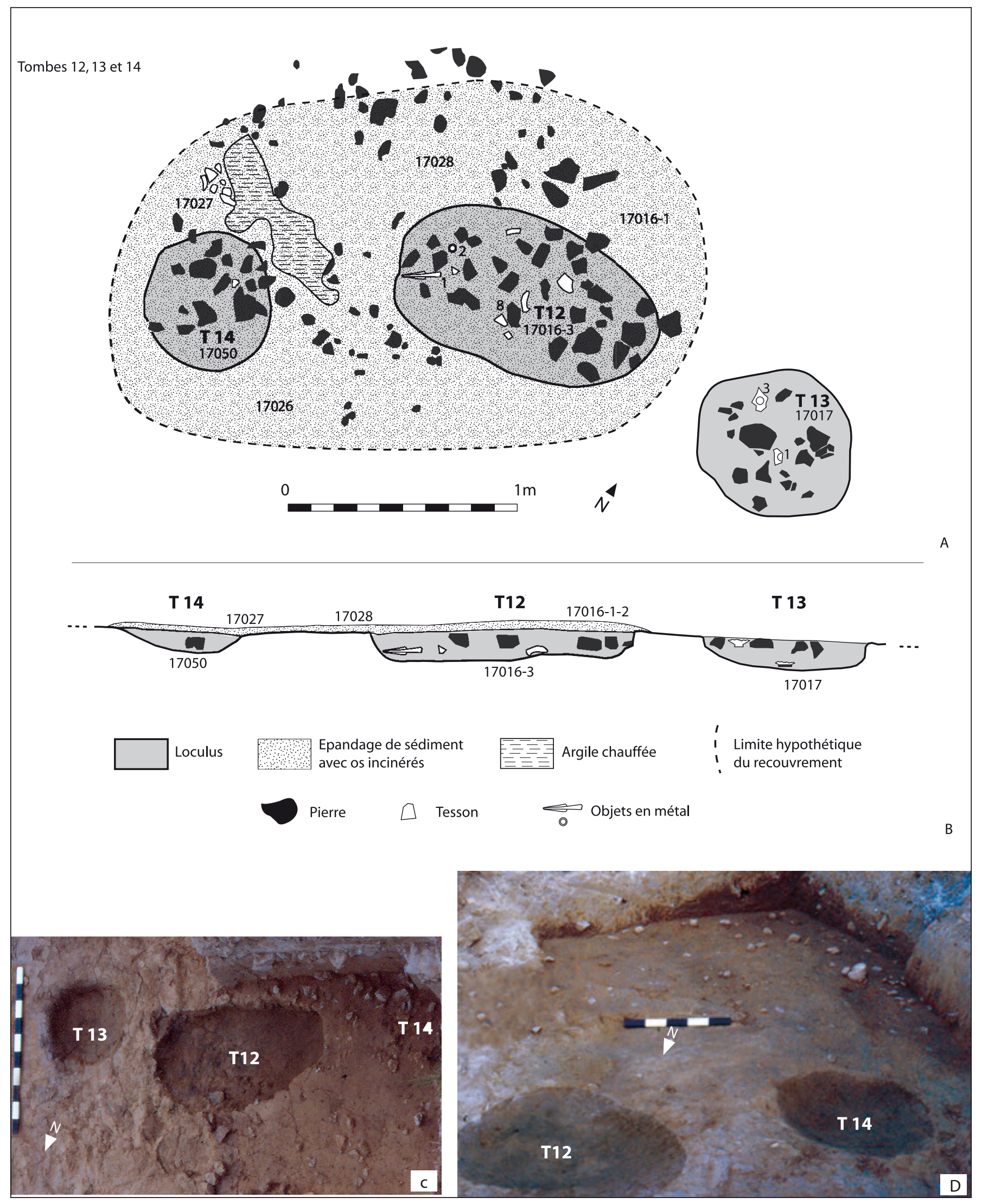

Fig. 17. Tombes T12, T13 et T14. A : plan. B : coupe. C : vue prise du nord, loculus des tombes 12 et 13 en fin de fouille ; comblement du loculus de la tombe 14. D : vue prise du nord, loculus des tombes 12 et 14 en fin de fouille. 
- 1 tesson d'urne non tournée : partie inférieure de panse peignée verticalement et obliquement, fond plat (fig. 16, $\left.\mathrm{n}^{\circ} 16\right)$;

- 38 petits tessons de panses peignées et de cols de plusieurs urnes non tournées (non dessinés).

Lentille US 17012-17013 :

- 1 morceau de bracelet en pâte de verre incolore ; orné d'une onde en fort relief et de filets rapportés en verre jaune sur la tige et l'onde; section en « $\mathrm{D}$ » (groupe 4, forme 9 de Haevernick 1960) ; diam. int. : $55 \mathrm{~mm}$; haut. : $12 \mathrm{~mm}$; ép. : 4 à $6 \mathrm{~mm}$ (fig. 16, $\left.\mathrm{n}^{\circ} 18\right)$;

- 1 tesson de l'urne non tournée $n^{\circ} 3$ dont la majeure partie des morceaux prend place dans le remplissage du loculus ;

- 1 tesson de bord de coupelle à vernis noir de l'atelier de Rosas, de forme Lamb. 27 (= Puig 11.b) ; diam. ouv. : $130 \mathrm{~mm}$ (fig. 16, $\mathrm{n}^{\circ}$ 17). Il porte la trace d'un feu secondaire ;

- 1 tesson de bord de coupelle à vernis noir de l'atelier de Rosas, de forme Lamb. 24-25 (= Puig 2.a) ; diam. ouv. : $65 \mathrm{~mm}$ (fig. 16, $\left.\mathrm{n}^{\circ} 19\right)$. Ce tesson porte également la trace d'un feu secondaire ;

- 1 tesson de vase à vernis noir de l'atelier de Rosas, de forme indéterminée (non dessiné) ;

- 7 petits tessons de panses de 7 vases non tournés (non dessinés) ;

- Moitié de rondelle découpée dans un tesson de panse peignée d'urne non tournée; diam. : $45 \mathrm{~mm}$; ép. $9 \mathrm{~mm}$ (fig. 16, $\mathrm{n}^{\circ}$ 20) ;

- Petit morceau de base de chenet modelé en terre cuite (non dessiné) ;

- Plusieurs fragments de bronze en partie fondus (non dessinés).

Os d'animaux (détermination A. Gardeisen) :

- 12 fragments de caprinés (1 extrémité distale d'humérus gauche adulte, 1 extrémité distale de métapode adulte, 1 fragment dentaire adulte, 1 sésamoïde, 1 fragment de calcanéum droit, 1 bord latéral de diaphyse de fémur, 1 incisive très usée, 1 bord latéral de diaphyse d'os long (cf. radius), 1 extrémité distale de corps de côte (cf. capriné), 1 fragment sous-articulaire de corps de côte juvénile (cf. capriné), 1 fragment de neurocrâne (cf. capriné), 1 fragment sous-articulaire de corps de côte juvénile (porc ou capriné ?) ;

- 1 fragment de porc juvénile (extrémité proximale non soudée de deuxième phalange) ;

-1 fragment de corps de côte d'un animal de grande taille (cf. bœuf) ;

-1 fragment de canidé (diaphyse d'ulna) ;

- 1 fragment d'extrémité proximale de fibula d'oiseau (cf. galliforme) ;
- Indéterminés : 54 esquilles non brûlées, 6 esquilles brûlées blanches et 5 esquilles brûlées bleu-noir.

\section{La tombe $\mathrm{T} 12$}

\section{1. État et composantes de la tombe}

La tombe 12 est celle d'un adulte, âgé probablement de plus de trente ans. Le sexe n'est pas déterminable, mais le mobilier laisse apparaitre une connotation masculine. Cette sépulture comprend un loculus et une structure de surface qui recouvre aussi la tombe 14 , dont le loculus est tout proche, à seulement $0,5 \mathrm{~m}$ de celui de la tombe 12 . L'ensemble a pu être entièrement fouillé (fig. 17).

\subsection{Le défunt}

Le défunt est représenté par, au moins, $742 \mathrm{~g}$ d'os brûlés (fig. 18, A). Il s'agit là du lot recueilli dans le loculus (US 17016-2 et 17016-3) ; mais ce n'est sans doute pas la totalité des restes de ce défunt déposés dans cette sépulture, car le recouvrement commun aux tombes 12 et 14 a aussi livré 561,4 g d'os incinérés qu'il est impossible de répartir entre les deux adultes de ces deux sépultures.

La morphologie des os et la fermeture des apex des dents, y compris sur une troisième molaire, indiquent un adulte. Ce pourrait être un adulte âgé de plus de trente ans, mais pas un vieillard, car, si les sutures sont encore libres sur la face exocrânienne, elles sont en cours de synostose sur l'endocrâne. Le sexe anthropologique ne peut pas être précisé.

Le poids d'os déposés dans le loculus représente 45,6\% du poids moyen d'un squelette d'adulte brûlé (1627,1 g selon McKinley 1993). Les taux d'identification sont de $89,2 \%$ du poids total des fragments. La sur-représentation des membres est importante, 74,5\% du poids identifié pour un poids théorique de $62,6 \%$; cela se fait au détriment du crâne, $16,6 \%$ du poids identifié au lieu des $20,4 \%$ attendus, et surtout du tronc, nettement sous-représenté, 8,9\% (poids théorique : $17 \%$ ) (fig. 18, B). La couleur blanc crayeux révèle une température de crémation supérieure à $650^{\circ}$ selon le barème de E. Bonnucci et G. Grazziani (1975), et les morceaux de diaphyses sont très souvent fissurés en ondes concentriques, indice d'une incinération d'os frais. 


\begin{tabular}{|c|c|c|c|c|c|c|c|c|c|c|}
\hline \multirow{2}{*}{$\begin{array}{l}\text { T } 12 \\
\text { Catégorie }\end{array}$} & \multicolumn{3}{|c|}{ Loculus $17016-2$} & \multicolumn{3}{|c|}{ Loculus $17016-3$} & \multicolumn{4}{|c|}{ Total loculus } \\
\hline & P oids & $\% /$ id. & $\% /$ total & Poids & $\% /$ id. & $\% /$ total & Nbre & P oids & $\% /$ id. & \%/total \\
\hline Crâne & 4,8 & 28,9 & 21,3 & 94,2 & 14,6 & 13,1 & 254 & 99,1 & 15 & 13,3 \\
\hline Mandibule & & & & 3,9 & 0,6 & 0,5 & 5 & 3,9 & 0,6 & 0,5 \\
\hline Dents & 0,2 & 1,2 & 0,8 & 8,3 & 1,3 & 1,2 & 75 & 8,5 & 1,3 & 1,1 \\
\hline Total tête & 5 & 30,1 & 22,2 & 106,4 & 16,5 & 14,8 & 334 & 111,3 & 16,8 & 14,9 \\
\hline Vertèbres & 0,3 & 1,8 & 1,3 & 35,6 & 5,5 & 4,9 & & 36 & 5,4 & 4,8 \\
\hline Côtes & 0,5 & 3 & 2,2 & 22,3 & 3,5 & 3,1 & & 22,8 & 3,4 & 3,1 \\
\hline \multicolumn{11}{|l|}{ S ternum } \\
\hline Total tronc & 0,8 & 4,8 & 3,6 & 58 & 9 & 8,1 & 467 & 58,8 & 8,9 & 7,9 \\
\hline Scapula & & & & 1,4 & 0,2 & 0,2 & 9 & 1,4 & 0,2 & 0,2 \\
\hline \multicolumn{11}{|l|}{ Clavicule } \\
\hline Humérus & 0,6 & 3,6 & 2,7 & 6,1 & 0,9 & 0,8 & 6 & 6,7 & 1 & 0,9 \\
\hline Radius & & & & 19,3 & 3 & 2,7 & 16 & 19,3 & 2,9 & 2,6 \\
\hline Ulna & & & & 9,9 & 1,5 & 1,4 & 5 & 9,9 & 1,5 & 1,3 \\
\hline Carpe & & & & 0,6 & 0,1 & 0,1 & 3 & 0,6 & 0,1 & 0,1 \\
\hline \multicolumn{11}{|l|}{ Métacarpe } \\
\hline \multicolumn{11}{|l|}{ Phal. main } \\
\hline Tot. memb. sup. & 0,6 & & & 37,3 & 5,8 & 5,2 & 39 & 37,9 & 5,7 & 5,1 \\
\hline Coxal & & & & 3,5 & 0,5 & 0,5 & 4 & 3,5 & 0,5 & 0,5 \\
\hline Fémur & & & & 7,8 & 1,2 & 1,1 & 4 & 7,8 & 1,2 & 1,1 \\
\hline \multicolumn{11}{|l|}{ Patella } \\
\hline Tibia & 2,3 & 13,6 & 10,2 & 27,8 & 4,3 & 3,9 & 20 & 30 & 4,5 & 4 \\
\hline Fibula & & & & 1,2 & 0,2 & 0,2 & 2 & 1,2 & 0,2 & 0,2 \\
\hline Tarse & & & & 12,9 & 2 & 1,8 & 5 & 12,9 & 1,9 & 1,7 \\
\hline \multicolumn{11}{|l|}{ Métatarse } \\
\hline Phal. pied & & & & 0,8 & 0,1 & 0,1 & 2 & 0,8 & 0,1 & 0,1 \\
\hline Tot. memb. inf. & 2,3 & & & 54,1 & 8,4 & 7,5 & 37 & 56,3 & 8,5 & 7,6 \\
\hline MTC MTT P hal. & 1,6 & 9,6 & 7,1 & 27,5 & 4,3 & 3,8 & & 29,2 & 4,4 & 3,9 \\
\hline membre indét. & 6,3 & 38 & 28 & 362 & 56,1 & 50,3 & & 368,3 & 55,6 & 49,6 \\
\hline Total membres & 10,8 & 65 & 48 & 480,9 & 74,5 & 66,8 & 2244 & 491,7 & 74,3 & 66,3 \\
\hline Total déterminé & 16,6 & 100 & 73,8 & 645,3 & 100 & 89,7 & 3045 & 661,9 & 100 & 89,2 \\
\hline indét. et es quilles & 5,9 & & & 74,3 & & & & 80,1 & & 10,8 \\
\hline Total indét. & 5,9 & & 26,2 & 74,3 & & 10,3 & & 80,1 & & 10,8 \\
\hline TOTAL & 22,5 & & 100 & 719,5 & & 100 & & 742 & & 100 \\
\hline
\end{tabular}
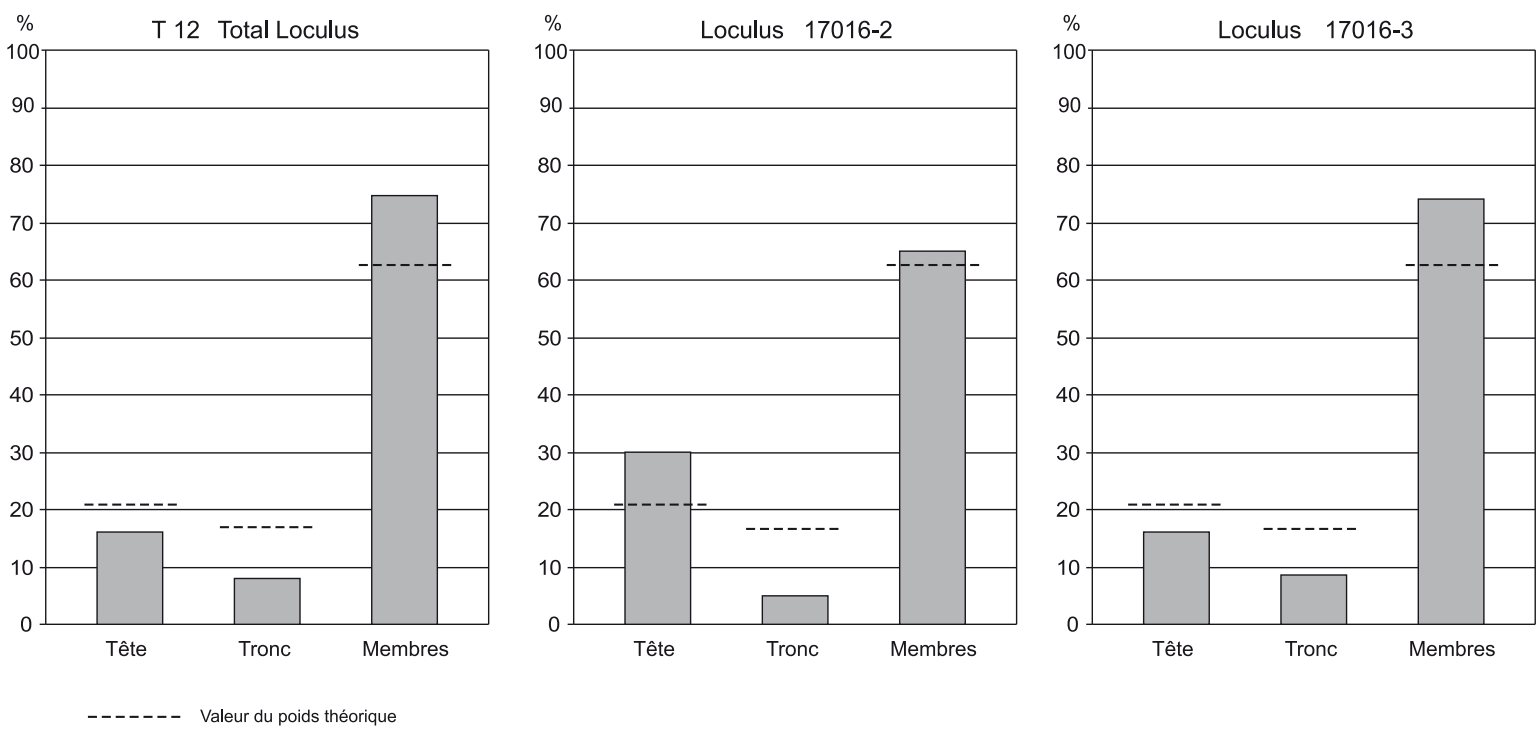

Fig. 18. Tombe T12. A : tableau de détermination des os humains (poids en grammes ; calcul des $\%$ sur la masse). B : répartition du poids des os par grandes régions anatomiques (\% par rapport au total déterminé). 
Les os ont été placés, dans le loculus, hors de tout contenant, mais selon deux procédés. La grande majorité, 719,5 g soit $97 \%$, parfois de grande taille et souvent amalgamés entre eux, provient d'un amoncellement de magma cendreux et charbonneux, gris foncé à noirâtre, occupant la partie centrale de la fosse (US 17016-3). Les autres vestiges, plus fragmentés et moins nombreux $(22,5 \mathrm{~g})$, sont mélangés à la terre du comblement, en sa partie supérieure (US 17016-2). Aucune incompatibilité n'existe entre les deux lots qui, par ailleurs, proviennent des mêmes régions du corps.

Le poids moyen des fragments déterminés, toutes régions anatomiques confondues, est de $0,22 \mathrm{~g}(0,33 \mathrm{~g}$ pour la tête, $0,16 \mathrm{~g}$ pour le tronc et $0,22 \mathrm{~g}$ pour les membres). Pour les 39 fragments identifiés comme provenant des membres supérieurs, le poids moyen est de $0,97 \mathrm{~g}$; pour les 37 fragments identifiés comme provenant des membres inférieurs, il est de $1,52 \mathrm{~g}$.

\subsection{Le loculus}

Le loculus (US 17016-2 et 3) a un plan ovalaire très allongé orienté SO - NE, de 1,30 m sur 0,65 m d'axes. Sa profondeur maximum est de $0,15 \mathrm{~m}$ vers le centre. Ses parois sont abruptes, proches de la verticale, et son fond est à peu près plat. La partie supérieure du remplissage du loculus (US 17016-2) est formée d'une terre grise très sombre incluant de nombreux petits fragments de charbons de bois ainsi que des morceaux d'os humains incinérés. En son sommet se trouvent une trentaine de petites pierres calcaires non roulées, de 4 à $18 \mathrm{~cm}$ d'arête, deux morceaux jointifs d'une table de meule en basalte de 7 à $8 \mathrm{~cm}$ d'arête, et un tesson de dolium, de même calibre. Deux de ces pierres ont éclaté, mais leurs morceaux ont été retrouvés dans le loculus. La partie médiane et la base du remplissage (US 17016-3) est formé de cendres blanchâtres enfermant des amas de magma d'os incinérés.

Le mobilier est dispersé dans la partie basse du remplissage au sein des amas de cendres: une pointe de lance, deux éléments de suspension d'épée, un maillon de chaînette et trois morceaux d'objets non déterminés, trente-six tessons se rapportant à une ou deux amphores massaliètes et seize pièces de vaisselle. Certains de ces objets montrent des traces d'un feu secondaire. On soulignera que des morceaux de la même coupe à vernis noir (fig. 19, $\mathrm{n}^{\circ} 8$ ) se rencontrent dans ce loculus et dans la structure de recouvrement, et que des tessons de la même coupe claire massaliète (fig. 19, $\mathrm{n}^{\circ}$ 13) prennent place dans ce loculus, dans la structure de recouvrement, mais aussi dans le loculus de la tombe 13 .

\section{Mobilier du loculus}

Objets personnels, armement et fourniment :

- Pointe de lance en fer presque complète (il manque les deux extrémités) ${ }^{\mathbf{1 0}}$; lame triangulaire à carène très basse et tranchants rectilignes, nervure axiale très saillante de section losangique et longue douille conique avec nervure de l'empennage se prolongeant sur presque toute sa longueur tout en s'affaiblissant progressivement. Long. tot. cons. : $171 \mathrm{~mm}$; long. tot. restituée: $180 \mathrm{~mm}$; long. lame restituée : $115 \mathrm{~mm}$; long. partie pénétrante : $110 \mathrm{~mm}$; larg. lame : 32,9 mm ; long. douille restituée : $65 \mathrm{~mm}$; diam. douille : $21,7 \mathrm{~mm}$; part de la lame: $67 \%$; effilement de la lame : $27 \%$; portion pénétrante de la lame : $96 \%$. Cet objet n'a pas subi de déformation (fig. 19, $\mathrm{n}^{\circ} 1$ et fig. 115).

- Deux éléments de la ceinture de suspension d'un fourreau d'épée :

- anneau circulaire en fer (fig. 19, $\mathrm{n}^{\circ} 2$ ), de section circulaire ; diam. : $34 \mathrm{~mm}$; haut. : 4,5 à $5,5 \mathrm{~mm}$;

- agrafe de ceinture, en fer (fig. 19, $\mathrm{n}^{\circ} 3$ et fig. 115); boucle rectangulaire; corps cordiforme; crochet terminé par un bouton relevé, en calotte sphérique ; long. : $48 \mathrm{~mm}$; larg. : $20 \mathrm{~mm}$;

- Morceau d'un maillon de chaînette en bronze (fig. 19, $\mathrm{n}^{\circ} 4$ ) ; section ovalaire ; diam. : $10 \mathrm{~mm}$. Cet objet a subi l'action d'un feu secondaire.

Objets métalliques indéterminés :

- Morceau d'un anneau de serrage en bronze (fig. 19, $\mathrm{n}^{\circ} 5$ ) ; section en lunule ; diam. int. : $60 \mathrm{~mm}$. ; objet indéterminé. Cet objet a subi l'action d'un feu secondaire ;

- Petit morceau de tôle de bronze coulée (fig. 19, $\mathrm{n}^{\circ} 6$ ), déformé par l'action d'un feu secondaire ; ép. : $1 \mathrm{~mm}$; objet indéterminé ;

- Segment de tige en fer (fig. 19, $\mathrm{n}^{\circ}$ 7), rectiligne, de section circulaire ; diam. : 6 à $8 \mathrm{~mm}$; long. cons. : $20 \mathrm{~mm}$.

\section{Matériel céramique}

Le mobilier céramique comprend un vase déposé sans doute complet dans le loculus, un autre, sans doute complet, dont les morceaux ont été répartis dans le loculus et le recouvrement de cette tombe ainsi que dans le loculus de la tombe 13 :

- 1 coupe à vernis noir de l'atelier de Rosas, de forme Lamb. 28a-b (= forme Puig 13.a), presque complète (fig. 19, $\mathrm{n}^{\circ} 8$ ); diam. max. : $105 \mathrm{~mm}$; haut. : $42 \mathrm{~mm}$;

10 La terminologie utilisée ici, les mesures et les rapports pris en compte sont ceux qui ont été mis au point dans Dedet, Marchand, à paraître). 


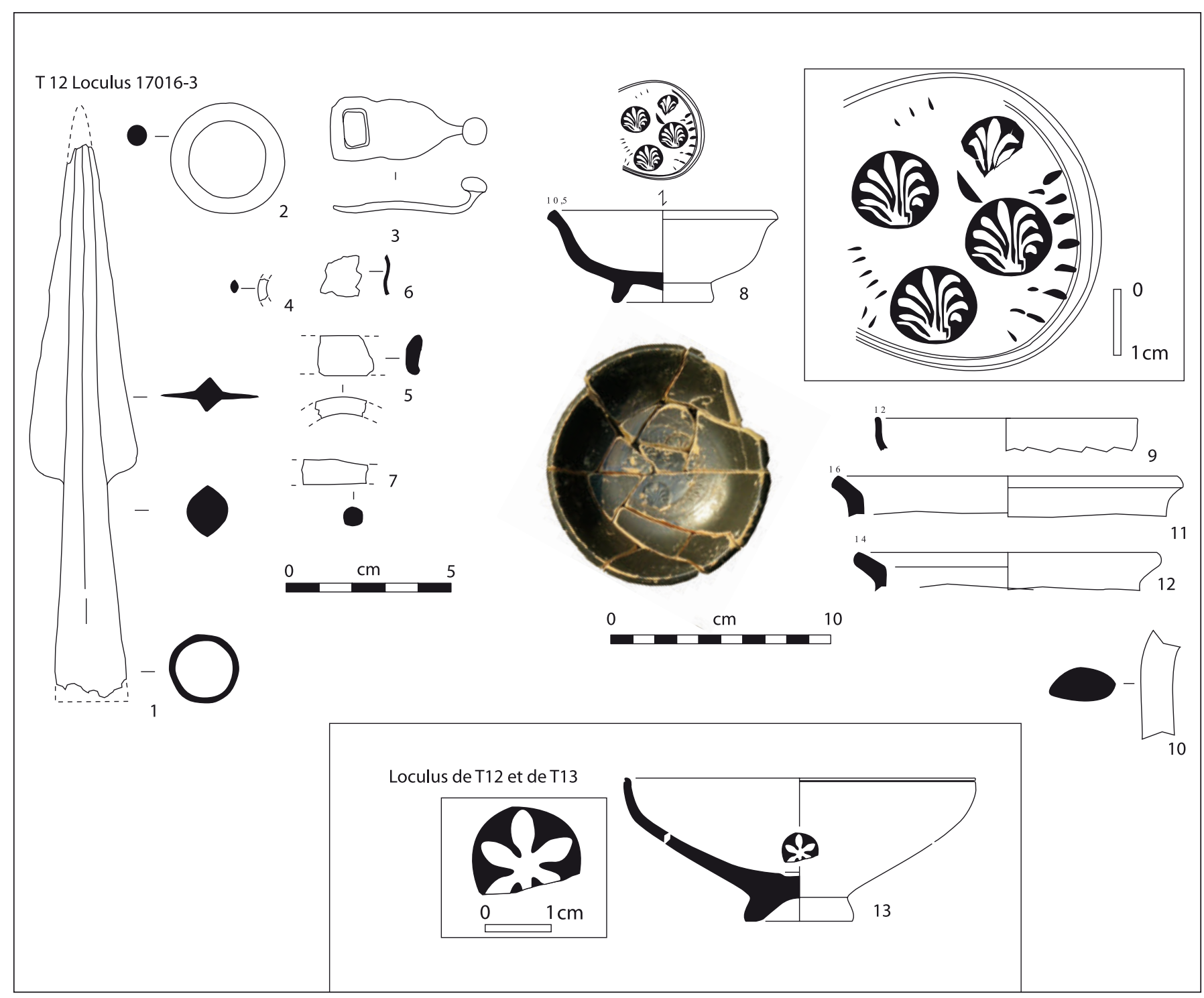

Fig. 19. Tombes T12 et T13. Mobilier (1-3 et $7:$ fer ; 4-6 : bronze ; $8:$ céramique à vernis noir ; $9:$ céramique grise peinte ; $10:$ amphore massaliète ; 11 et 12 : céramique non tournée ; 13 : céramique à pâte claire).

diam. base : $45 \mathrm{~mm}$; sur le fond, quatre palmettes parallèles entourées d'un cercle de guillochis. La grande majorité des tessons de ce vase sont dans le loculus, mais deux autres morceaux proviennent de la couverture de la tombe (US 17028) ;

-10 tessons d'un bol à pâte claire massaliète de forme CL-MAS 321 proche de la forme Lamb. 27a-b ; panse arrondie; bord légèrement rentrant, souligné par une rainure horizontale à l'extérieur; lèvre arrondie et amincie; pâte de couleur rosée ; au centre du fond, rosette à six pétales en relief dans un cartouche circulaire de $16 \mathrm{~mm}$ de diamètre, décor bien attesté sur cette forme de coupe à Olbia (Bats 1988, p. 179); surfaces couvertes d'une peinture brun rouge dont ne subsistent que quelques plages adhérant mal à l'épiderme à l'extérieur ; diam. ouv. : 160 mm. Deux tessons de ce vase proviennent du loculus et trois autres de la couverture (US 17028), d'autres morceaux du bord et toute la partie inférieure de ce vase figurent dans le loculus de la tombe 13 (fig. 19, $\mathrm{n}^{\circ} 13$ );

-1 tesson de bord de coupe grise peinte de forme GR-PEINTE 4 (Py et al. 2001, p. 1121); panse légèrement ondulée; bord légèrement dégagé et lèvre arrondie ; diam. ouv. : $120 \mathrm{~mm}$ (fig. 19, ${ }^{\circ}$ 9) ;

-1 éclat de vase à pâte claire massaliète (non dessiné) ;

-2 petits tessons jointifs d'une panse d'amphore massaliète et un morceau d'anse de petite taille (fig. 19, $\mathrm{n}^{\circ} 10$ ), appartenant peut-être au même exemplaire ; le morceau d'anse porte la trace d'un feu secondaire ; 
- 14 petits tessons, appartenant probablement à 7 urnes non tournées :

- 3 tessons d'une grande urne de forme probable CNT-LOR U5d : bord déversé, lèvre aplatie ; panse peignée ; diam. ouv. $160 \mathrm{~m}$ (fig. 19, $\mathrm{n}^{\circ} 11$ ) ;

- 1 bord et 1 tesson d'urne non tournée de forme probable CNT-LOR U5d : col tronconique rentrant, bord déversé avec méplat vers l'intérieur, lèvre arrondie; diam. ouv. $140 \mathrm{~mm}$ (fig. 19, $\mathrm{n}^{\circ}$ 12) ;

- 2 tessons jointifs d'un col d'urne, avec une très nette différence de couleur de part et d'autre de la cassure montrant l'effet d'un feu secondaire (non dessiné) ;

- 2 tessons d'un autre col d'urne (non dessiné) ;

- 5 tessons de 3 panses peignées d'urnes (non dessiné) ;

-1 tesson de dolium indigène portant un cordon horizontal lisse et deux éclats (non dessiné).

Os d'animaux (détermination A. Gardeisen)

Le lot comprend les vestiges de deux dépôts différenciés et bien caractérisés ainsi que des restes isolés :

- 66 restes fragmentés et carbonisés d'un crâne de porcelet d'environ 3 mois (4 fragments du neurocrâne, 9 des deux mandibules, 31 de dents lactéales isolées et des esquilles osseuses présentant le même stade de carbonisation) ;

- 27 fragments du gril costal d'un capriné juvénile, carbonisés à blanc, provenant de la même série des cinq premières côtes (au moins), droites ;

-2 fragments de caprinés (de racine de dent jugale et de coxal) ;

- esquille d'os compact épais présentant des négatifs d'enlèvements corticaux d'un animal de grande taille ;

- 391 esquilles brûlées à des divers degrés, de la couleur noire à la couleur blanche, qui proviennent potentiellement en partie des restes déterminés comme dépôts initiaux (crâne de porcelet et gril costal de capriné) mais aussi de divers os longs appartenant à des animaux matures ;

- Indéterminés : 4 esquilles non brûlées.

\section{La tombe T13}

\section{1. État et composantes de la tombe}

La tombe T13 abrite un seul défunt incinéré, un jeune enfant, âgé de trois à cinq ans. La quasi totalité de son matériel provient du loculus, qui a été entièrement fouillé. La structure de recouvrement a presque entièrement disparu. Les rares vestiges découverts reposent sur le paléosol, immédiatement au N-NE, montrant que la partie supérieure du loculus n'a pas été tronquée (fig. 17, A, B et C).

\subsection{Le défunt}

Ce jeune enfant est représenté par 71,5 g d'os brûlés. Ces derniers proviennent presque tous $(69,8 \mathrm{~g})$ du loculus (US 17017); les rares esquilles issues des restes de la superstructure ont un poids négligeable $(1,7 \mathrm{~g})$. La détermination de l'âge, entre trois et cinq ans, repose sur un faisceau d'éléments dont la précision est variable : aucun fragment de calotte crânienne n'est épais ; les morceaux de diaphyses offrent un aspect général très gracile; une seconde phalange du pied montre une surface métaphysaire, de même que deux autres morceaux d'extrémités proximales de phalanges de pied ou de main; de nombreux germes de dents définitives indiquent un âge de 4 ans plus ou moins douze mois, en particulier les germes de $\mathrm{M}^{1}, \mathrm{C}^{\prime} \mathrm{d}, \mathrm{C}, \mathrm{g}$ et les fragments de germes de trois molaires et de deux incisives.

Les pièces osseuses sont très fragmentées. L'incinération a affecté des os frais, comme le montrent les fissurations en ondes concentriques des diaphyses. Presque tous les restes ont une couleur blanc crayeux, indiquant une température de crémation de l'ordre de $650^{\circ}$ selon le barème de E. Bonnucci et G. Grazziani (Bonucci, Grazziani 1975).

Toutes les parties du squelette ont été concernées par le prélèvement sur le bûcher (fig. 20, A). L'indice pondéral crânien s'établit à 50,4\%, celui du tronc à 5,2 \% et celui des membres à 44,4\%; mais un tiers des fragments n'a pu être déterminé (fig. 20, B). La prééminence du crâne, très nettement en dessus de la valeur théorique de $20,4 \%$ pour les adultes selon Lowrance et Latimer (dans Krogman 1978), tient sans doute au fait que la tête est en proportion plus grosse chez les jeunes enfants (Trotter, Hixon 1974, cité dans Lenorzer 2009, p. 88).

Les restes osseux sont dispersés dans l'ensemble du comblement du loculus, hors de tout contenant, et aucune disposition particulière n'a été perçue. En particulier, aucune différence importante de répartition des pièces osseuses n'apparaît entre les cinq décapages effectués.

Le poids moyen des fragments déterminés, toutes régions anatomiques confondues, est de $0,09 \mathrm{~g}(0,12 \mathrm{~g}$ pour la tête, $0,06 \mathrm{~g}$ pour le tronc et $0,08 \mathrm{~g}$ pour les membres). 


\subsection{Le loculus}

Le loculus (US 17018) a un plan grossièrement ovalaire et mesure $75 \mathrm{~cm}$ sur son grand axe E-O et $65 \mathrm{~cm}$ sur son petit axe N-S. Sa profondeur maximale est de $15 \mathrm{~cm}$ vers le centre. Ses parois sont obliques, plus abruptes vers l'Est et le Sud, et son fond est légèrement arrondi (fig. 17, A, B et C).

Le remplissage (US 17017) est formé d'une terre gris sombre gluante, très charbonneuse, dont la couleur tranche très nettement avec celle de l'encaissant.

Il a été fouillé en cinq décapages théoriques de $3 \mathrm{~cm}$ d'épaisseur. Dans toute son épaisseur il renferme de très nombreux petits fragments de charbons de bois et de très nombreux morceaux d'os humains incinérés. Au sommet du remplissage se trouve la partie inférieure d'un bol à pâte claire massaliète qui a subi l'action du feu (fig. 19, $\mathrm{n}^{\circ} 13$ ) et dont des tessons de la partie supérieure gisent également dans le loculus et dans la structure de recouvrement de la tombe T12. Vingt-quatre pierres calcaires non roulées, de 2 à $12 \mathrm{~cm}$ d'arête, prennent place dans la moitié supérieure du remplissage (décapages 1 à 3). Certaines ont subi l'action du feu. Dispersés dans le reste du comblement figurent six petits tessons non tournés se rapportant à autant de récipients, et un fragment de bord de la coupe claire massaliète déjà mentionnée (fig. 19, $\mathrm{n}^{\circ} 13$ ), montrant nettement les traces d'un feu secondaire. Sur le fond du loculus git un fond de coupelle à vernis noir (fig. 20, $\mathrm{C}, \mathrm{n}^{\circ} 1$ ).

\section{Mobilier du loculus}

Le matériel du loculus comprend les tessons de deux coupes dont d'autres morceaux ont été découverts dans le recouvrement de la tombe ou dans la tombe T12, ainsi que des tessons isolés de six autres récipients :

- 1 tesson de bord, portant des traces de feu secondaire, et plusieurs morceaux du fond de la coupe à pâte claire massaliète CL-MAS 321 dont plusieurs tessons ont été déposés dans le loculus et le recouvrement de la tombe T12 (fig. 19, ${ }^{\circ} 13$ );

- 1 tesson de fond de bol CAMP-A 27a-b, en campanienne A ancienne, portant en son centre, dans un cartouche circulaire de $12 \mathrm{~mm}$ de diamètre, une rosette à six pétales en forme de larmes au dessin très fin, dont seul le contour est en relief ; diam. fond : $60 \mathrm{~mm}$ (fig. 20, $\mathrm{C}, \mathrm{n}^{\circ} 1$ ). Il a subi l'action d'un feu secondaire. Trois autres morceaux du même vase, dont deux se raccordent à ce fond, se trouvaient sur le sol, à proximité de ce loculus, à la base du dispositif de recouvrement de la tombe (voir infra) ;
- 1 tesson d'urne non tournée de forme probable CNT-LOR U5d : bord déversé à lèvre arrondie ; diam. ouv. : $150 \mathrm{~mm}$ (fig. 20, $\mathrm{C}, \mathrm{n}^{\circ} 2$ ) ;

- 1 tesson d'urne non tournée : bord déversé à lèvre arrondie (fig. 20, C, $\mathrm{n}^{\circ} 3$ ) ;

-3 tessons de panses de trois autres urnes non tournées (non dessinés) ;

- 1 tesson de couvercle non tourné de forme CNTLOR V2a : bord dans la continuité de la paroi rectiligne, lèvre aplatie (fig. 20, $\mathrm{C}, \mathrm{n}^{\circ} 4$ ) ;

Os d'animaux (détermination A. Gardeisen) :

- 1 fragment de dent jugale de capriné, brûlée ;

-1 esquille d'os long d'animal de petite taille, brûlée ;

- Microfaune : 1 fragment de côte ;

- Malacofaune : petit lot d'escargots.

- Poisson (détermination G. Piquès) : 2 vertèbres de corb (cf. Sciaena umbra Linné, 1758), 2/3e caudale et $7^{\mathrm{e}}$ caudale d'un même individu; la dernière marque de croissance situe la saison de mort du poisson vers le début de l'automne.

\subsection{La structure de recouvrement}

Quelques rares os incinérés et trois morceaux de la panse du vase à vernis noir, dont le fond a été placé dans le loculus (fig. 20, $\mathrm{C}, \mathrm{n}^{\circ} 1$ ), sont dispersés sur le sol au nord-est du loculus de la tombe T13, à environ $1 \mathrm{~m}$ de ce dernier. Ces tessons ont fortement brûlé et ont éclaté à la chaleur. Ce matériel paraît provenir du démantèlement d'un amoncellement de terre (US 17007) recouvrant ce loculus.

\section{La tombe T14}

\section{1. État et composantes de la tombe}

La tombe T14 a accueilli un adulte de sexe non déterminé, plus jeune et gracile que celui de la tombe T12 voisine à laquelle l'associe la même structure de recouvrement. La différence des poids moyens des fragments osseux déterminés du lot provenant de ce loculus avec celui de la tombe T12 montre qu'il s'agit bien de deux incinérations distinctes et donc de deux sujets différents. Là aussi, d'après le mobilier déposé, il s'agirait d'un homme. 


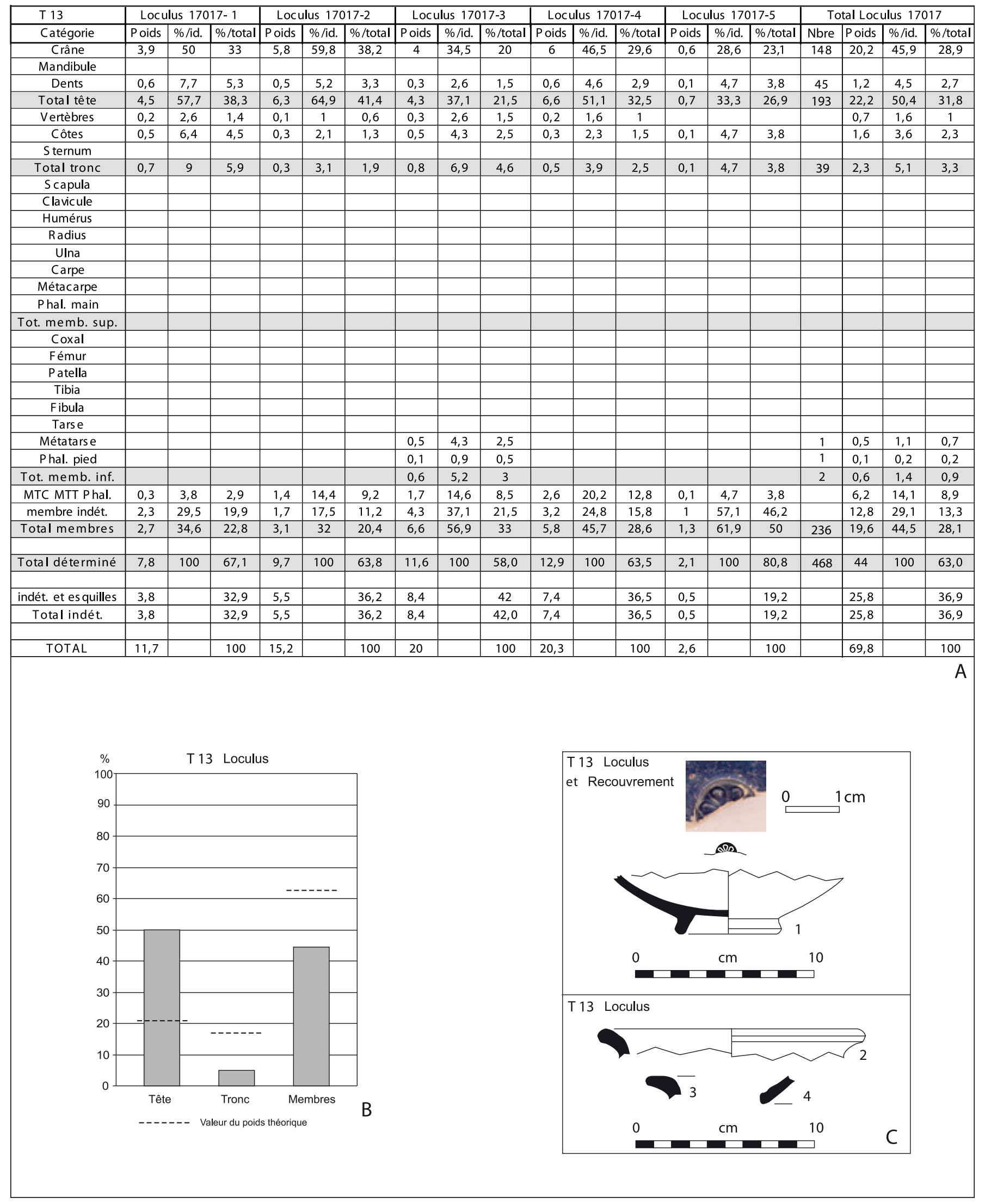

Fig. 20. Tombe T13. A : tableau de détermination des os humains (poids en grammes; calcul des \% sur la masse). B : répartition du poids des os par grandes régions anatomiques (\% par rapport au total déterminé). C : mobilier (1: céramique à vernis noir ; 2-4: céramique non tournée). 


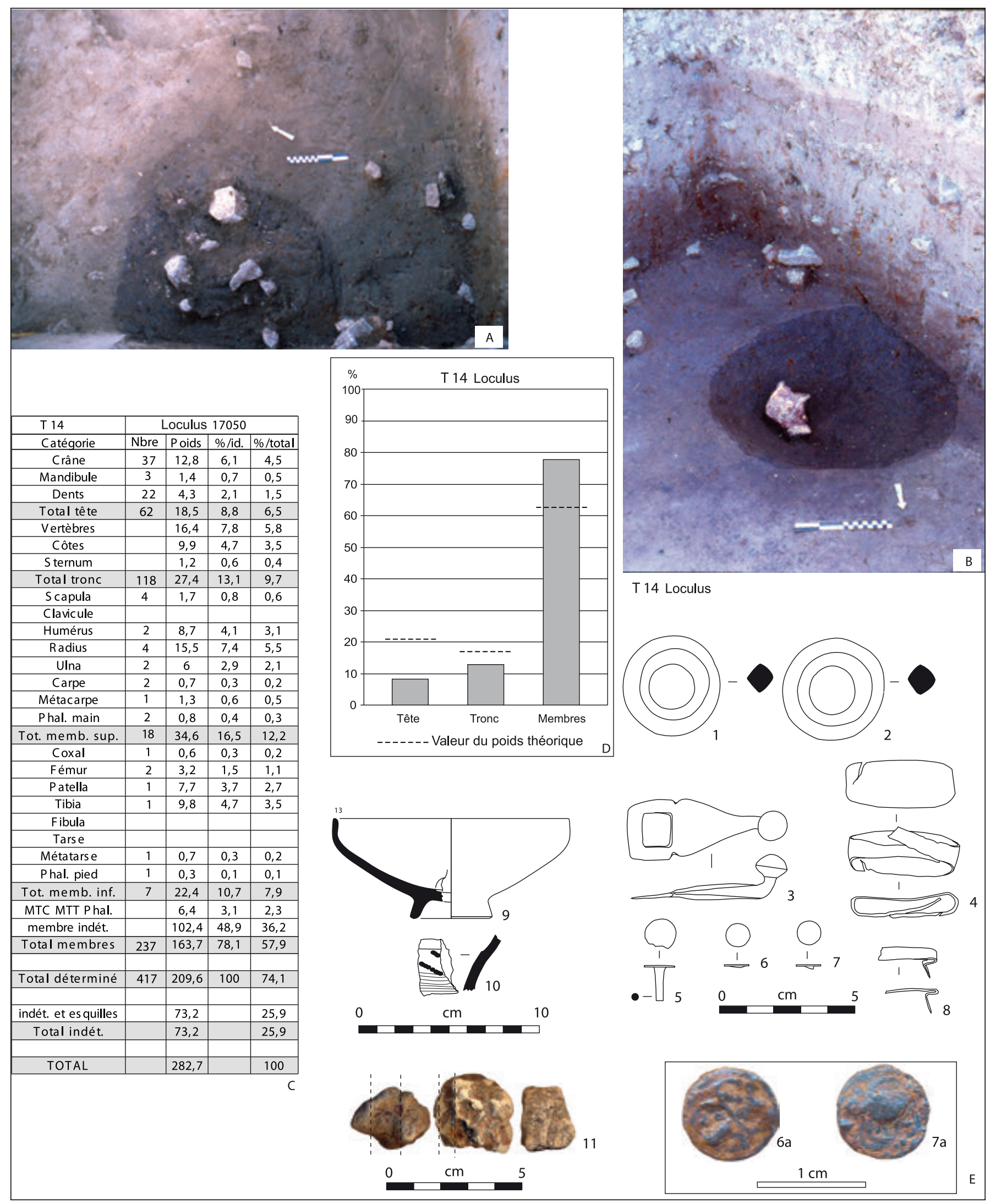

Fig. 21. Tombe T14. A : comblement du loculus vu du sud-ouest. B : loculus en fin de fouille vu du nord. C : tableau de détermination des os humains (poids en grammes ; calcul des \% sur la masse). D : répartition du poids des os par grandes régions anatomiques (\% par rapport au total déterminé). $\mathrm{E}$ : mobilier (1-8: fer ; 9 : céramique à pâte claire massaliète ; 10 : céramique non tournée $; 11$ : morceaux de torchis). 
Cette sépulture est complète, à l'exception de la portion sud-ouest de la structure de recouvrement surmontée par les murs de l'habitat gallo-romain qui ont limité la fouille dans cette direction (fig. 17, A, B, C et D, et fig. 21, A et B).

\subsection{Le défunt}

Ce sont 282,8 g d'os brûlés qui proviennent du loculus de la tombe T14 (US 17050) (fig. 21, C). D'après la morphologie des os, et en particulier la synostose des extrémités aux corps diaphysaires et celle du listel sur les corps vertébraux, de même que la fermeture des apex des dents, on a affaire à un adulte. Aucun fragment crânien ne montre de suture synostosée ; il pourrait donc s'agir d'un adulte jeune. Par ailleurs, le sexe anthropologique ne peut être précisé.

Le poids d'os contenus dans ce loculus représente $17,4 \%$ du poids moyen d'un squelette d'adulte brûlé (1627,1 g selon McKinley 1993), mais il ne s'agit sans doute pas de la totalité des restes déposés dans cette sépulture, car une partie, au moins, des os livrés par le recouvrement commun aux loculus des tombes T12 et T14 a toutes chances d'appartenir à ce défunt.

C'est $74,1 \%$ du poids total des fragments de ce lot qui a pu être identifié. La sur-représentation des membres est importante, $78,1 \%$ du poids identifié pour un poids théorique de $62,6 \%$; cela se fait surtout au détriment du crâne, très peu représenté ici, $8,8 \%$ du poids identifié au lieu des $20,4 \%$ attendus, tandis que le tronc, $13,1 \%$ du poids identifié, est nettement moins sous-représenté que d'habitude (poids théorique : $17 \%$ ) (fig. 21, D). La couleur blanc crayeux révèle une température de crémation supérieure à $650^{\circ}$ selon le barème de $\mathrm{E}$. Bonnucci et G. Grazziani (1975) et les morceaux de diaphyses sont très souvent fissurés en ondes concentriques, indice d'une incinération d'os frais.

Les os ont été placés dans le loculus hors de tout contenant, irrégulièrement répartis dans l'ensemble du comblement avec des concentrations notables autour des pierres.

Le poids moyen des fragments déterminés, toutes régions anatomiques confondues, est de $0,50 \mathrm{~g}(0,25 \mathrm{~g}$ pour la tête, $0,23 \mathrm{~g}$ pour le tronc et $0,69 \mathrm{~g}$ pour les membres). Pour les 18 fragments identifiés comme provenant des membres supérieurs, le poids moyen est de $1,92 \mathrm{~g}$; pour les 7 fragments identifiés comme provenant des membres inférieurs, il est de 3,20 g.

\subsection{Le loculus}

Le loculus (US 17050) est une cuvette de plan circulaire, de 55 à $60 \mathrm{~cm}$ de diamètre à l'ouverture, aux parois asymétriques, abruptes dans la moitié orientale, en pente douce dans la moitié occidentale et à fond arrondi. Sa profondeur maximale est de $12 \mathrm{~cm}$ (fig. 17, A, B, C et D, et fig. 21, A et B). Le remplissage est composé d'un sédiment limoneux gris très foncé, incluant des charbons de bois épars, en général inférieurs à $0,5 \mathrm{~cm}$ et exceptionnellement plus gros jusqu'à $1 \mathrm{~cm}$, des morceaux de parois en torchis, ayant plus ou moins subi l'action du feu, pouvant atteindre $5 \mathrm{~cm}$ de côté, montrant, pour certains, des empreintes de branches et de brindilles (fig. 21, $\mathrm{C}, \mathrm{n}^{\circ} 11$ ). De nombreuses pierres calcaires non roulées, parfois éclatées au feu, n'excédant pas $10 \mathrm{~cm}$ d'arête mais le plus souvent plus petites, sont présentes de la partie supérieure du comblement jusqu'au fond, surtout au centre de la structure. De même que les restes osseux, le mobilier, plusieurs éléments de la ceinture de suspension et de la poignée d'une épée, sept tessons d'une coupe et quatre tessons de quatre autres vases, ainsi que les restes de torchis se répartissent dans toute l'épaisseur du remplissage du loculus.

\section{Mobilier du loculus}

Objets personnels : armement et fourniment

- Rivet en fer (fig. 21, E, $n^{\circ}$ 5), de garniture de poignée d'une épée ; tête discoïde plate ; tige creuse, dont il manque l'une des extrémités, sans doute pourvue d'une autre tête discoïde ; long. cons. : $14,5 \mathrm{~mm}$; diam. tête : $11,5 \mathrm{~mm}$; diam. tige : $3 \mathrm{~mm}$;

- Deux petits clous en fer (fig. 21, E, nº 6,6a, 7 et 7a), probable décoration de fourreau ou de poignée d'épée ; tête discoïde plate et décorée ; sur les deux, arrachement de la tige ; diam. : 8,8 mm ;

- Morceau de ruban en fer replié deux fois ; long. cons. : $21 \mathrm{~mm}$; larg. : $5 \mathrm{~mm}$; ép. :1,7 mm (fig. 21, E, $\mathrm{n}^{\circ} 8$ ) ;

- Quatre éléments de la ceinture de suspension d'un fourreau d'épée :

- deux gros anneaux circulaires en fer (fig. 21, E, $\mathrm{n}^{\circ} 1$ et 2), de section losangique ; diam. respectivement : $37 \mathrm{~mm}$ et 37 à $39 \mathrm{~mm}$; haut. respectivement : 10 à $11 \mathrm{~mm}$ et 10 à $12 \mathrm{~mm}$;

- agrafe de ceinture, en fer (fig. 21, E, n ${ }^{\circ} 3$ et fig. 115); boucle rectangulaire; corps cordiforme; crochet terminé par un bouton relevé, conique ; long. : $59 \mathrm{~mm}$; larg. : $23 \mathrm{~mm}$;

- passant de courroie en fer (fig. 21, E, n 4) ; formé d'une fine plaque ovale, prolongée aux deux extrémités par deux pattes très amincies, repliées sur un côté de la plaque; long. : $41 \mathrm{~mm}$; larg. : $17 \mathrm{~mm}$. 
Matériel céramique

Vase réparti dans les tombes T12 et T14:

- 7 tessons d'une coupe à pâte claire massaliète de forme CL-MAS 321, presque complète ; pâte grise et couverte gris noir, savonneuse ; le fond porte le cartouche circulaire d'une rosette ; diam. max. : $132 \mathrm{~mm}$; haut. : $56 \mathrm{~mm}$; dix autres tessons de ce vase figurent dans la superstructure de recouvrement commune aux loculus des tombes T12 et T14, au nord (us 17027) et au sud-est du loculus (us 17026) ; l'ensemble de ces fragments représente 80 à $90 \%$ du récipient, et sans doute celui-ci était-il complet lors du bris dans et sur la tombe elle-même (fig. 21, E, nº 9).

Tessons de vases isolés :

- 1 tesson d'urne non tournée de forme probable CNT-LOR U5d ; départ du col lissé, épaule décorée d'un rang d'impressions obliques au peigne, panse peignée horizontalement (fig. 21, E, $\mathrm{n}^{\circ} 10$ ) ;

-1 petit tesson de panse peignée de grande urne non tournée (non dessiné) ;

-2 petits tessons de deux grands vases non tournés (non dessinés).

Os d'animaux (détermination A. Gardeisen) :

- 2 fragments de caprinés, non brûlés (talus gauche presque entier (longueur externe : $27,9 \mathrm{~mm}$; épaisseur externe : 15,4 mm); 1 malléole gauche);

- 4 fragments carbonisés d'une vertèbre cervicale de capriné ;

- 1 corps d'incisive supérieure de porc, non brûlé ;

- Indéterminés : 3 esquilles brûlées noires et 3 esquilles brûlées blanches.

\section{La structure de recouvrement des tombes T12 et T14}

La structure surmontant les loculus des deux tombes T12 et T14 (US 17016, 17016-1, 17026, 17027 et 17028) est composée du même sédiment d'alluvions limoneuses brunâtres qui recouvre l'ensemble du sol de la nécropole. Elle n'est perceptible que grâce à l'abondant matériel qu'elle contient, dessinant une aire sans doute ovale, orientée NE-SO, mais dont les deux extrémités ne sont pas connues, à cause de la limite de fouille au sud-ouest et par manque ou destruction au nord-est. Cette structure recouvre les deux loculus et déborde largement tout autour, sauf au nord-est. Sa largeur est d'environ $2 \mathrm{~m}$, mais les limites bien évidemment restent floues, tandis que sa longueur excède cette dimension ; son épaisseur maximum est de $5 \mathrm{~cm}$ (fig. 17, A et B).

A la base de cette structure, de nombreuses petites pierres calcaires non roulées, provenant de la colline du Dévès, sont éparpillées sur le dessus du comblement des loculus et sur le sol de la nécropole environnant. Aucune ne dépasse $10 \mathrm{~cm}$ d'arête et certaines ont éclaté au feu. Un long amas compact de morceaux d'argile cuite provenant de la paroi d'un four à galette, borde le loculus de la tombe T14 au nord. Plusieurs morceaux, d'une épaisseur de $15 \mathrm{~mm}$, présentent deux surfaces planes ; pour d'autres, d'épaisseur semblable, une surface plane lisse, correspondant à l'extérieur du four, est opposée à une surface gravée de sillons en tous sens (fig. 22, C, $\mathrm{n}^{\circ} 14$ ). Cette portion de four n'a pas été chauffée à cet emplacement car des morceaux rubéfiés jouxtent des secteurs à peine chauffés (fig. 17, A).

Dans toute l'épaisseur du recouvrement prennent place quelques petits charbons de bois mais aussi de très nombreux fragments osseux humains incinérés, épars, pour un poids total de 561,3 g. De nombreux objets mobiliers proviennent des parties surmontant directement les loculus ou leurs abords les plus immédiats, et certains d'entre eux montrent clairement les liens entre le dispositif de recouvrement et les deux loculus :

- au-dessus ou immédiatement au nord-ouest du loculus de la tombe T12: plusieurs tessons appartenant aux coupes à vernis noir et claire massaliète (fig. 19, $\mathrm{n}^{\circ} 8$ et 13) dont la majeure partie prend place dans le loculus de la tombe T12 (voir supra) ; 44 tessons paraissant appartenir à autant de vases non tournés ;

- immédiatement au nord-ouest du loculus de la tombe T12: un morceau de bracelet (fig. 22, C, $\mathrm{n}^{\circ} 8$ ), deux clous d'umbo de bouclier (fig. 22, C, $\mathrm{n}^{\circ} 5$ et 6 ) et un passant de ceinture (fig. 22, $\mathrm{C}, \mathrm{n}^{\circ} 2$ ) ;

- au-dessus du loculus de la tombe T14 : huit tessons appartenant à la coupelle claire massaliète CL-MAS 321 dont des morceaux se trouvent également dans le loculus de la tombe T14 (voir supra) (fig. 21, C, $\mathrm{n}^{\circ} 9$ ) ; un tesson d'amphore massaliète ;

- au-dessus du loculus de la tombe T14 et immédiatement au nord-ouest, dix-sept tessons de la partie supérieure d'une urne non tournée, soit entre 30 et $40 \%$ du vase (fig. 22, C, $\mathrm{n}^{\circ} 10$ ), répartis en deux amas, un fond appartenant, semble-t-il, à une autre urne non tournée et trois morceaux, soit $80 \%$, d'un couvercle non tourné miniature (fig. 22, C, $\mathrm{n}^{\circ} 12$ );

- au nord-ouest du loculus de la tombe T14, un morceau de fibule en fer (fig. 22, C, $\mathrm{n}^{\circ}$ 9) ;

- au sud-est de ce loculus; un gros anneau en fer de ceinture de suspension d'épée (fig. 22, C, $\mathrm{n}^{\circ} 1$ ), 


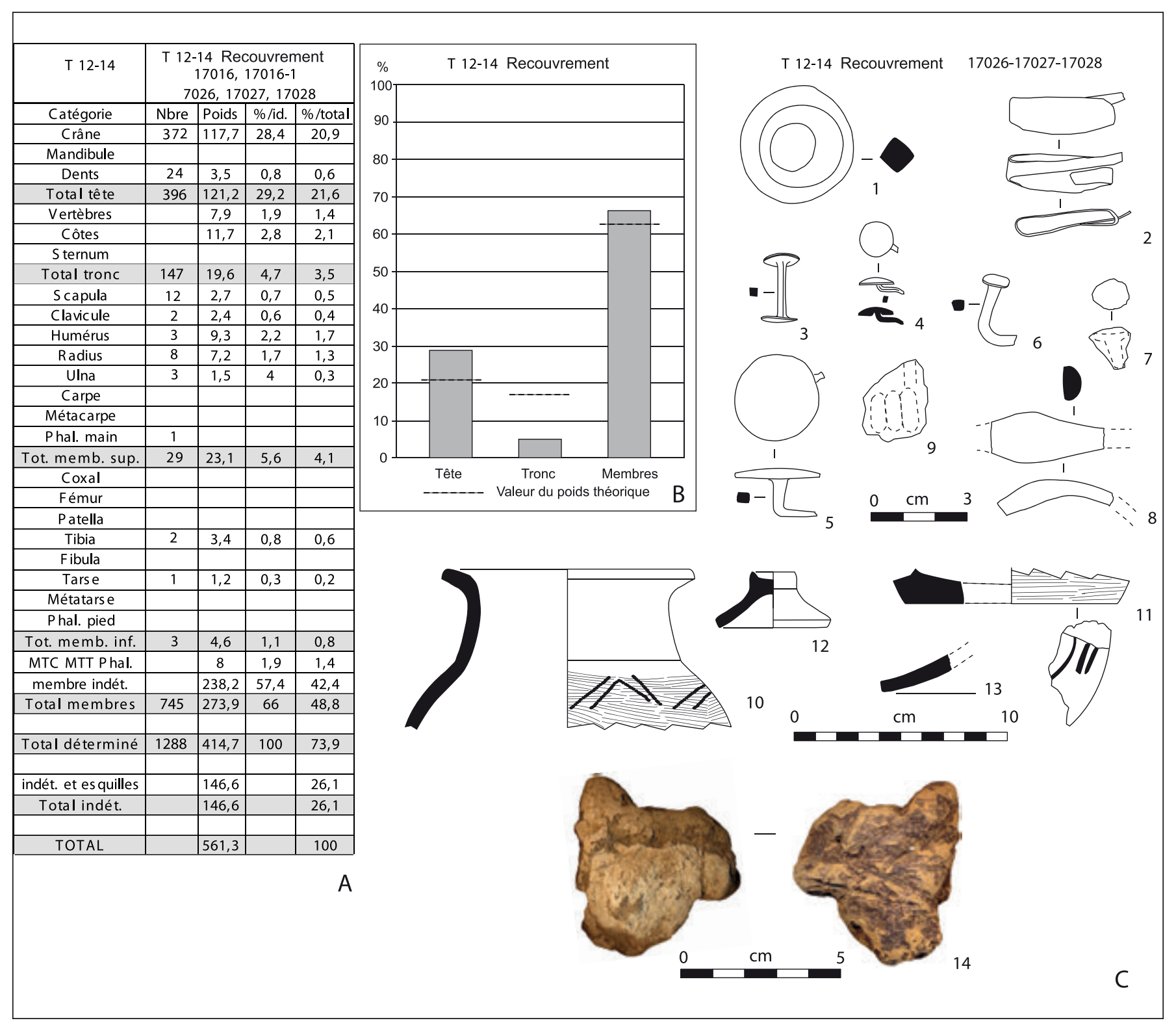

Fig. 22. Recouvrement des tombes 12 et 14. A : tableau de détermination des os humains (poids en grammes; calcul des \% sur la masse). $\mathrm{B}$ : répartition du poids des os par grandes régions anatomiques (\% par rapport au total déterminé).

C : mobilier (1-7 et 9 : fer ; 8 : bronze ; 10-13 : céramique non tournée ; 14 : élément de structure en argile cuite).

identique à ceux de ce loculus, deux clous de garniture de poignée d'épée (fig. $22, \mathrm{C}, \mathrm{n}^{\circ} 3$ et 4 ) et un possible rivet d'umbo (fig. 22, $\mathrm{C}, \mathrm{n}^{\circ}$ 7) ;

- dispersés de part et d'autre du loculus de la tombe T14, à l'ouest et à l'est, vingt-quatre petits tessons non tournés, appartenant vraisemblablement à autant de vases.

\section{Restes osseux humains}

Les restes humains incinérés, au total $561,3 \mathrm{~g}$, se rapportent à de l'adulte, d'après la morphologie des os, les apex des dents fermés, et les sutures synostosées sur la face endocrânienne, non sysnostosées ou en cours de synostose sur la face exocrânienne. Le sexe biologique ne peut être précisé (fig. 22, A).

Les fragments osseux sont plus abondants au-dessus et autour du loculus de la tombe T14 qu'au-dessus et autour de celui de la tombe T12, et un segment de radius situé à proximité du loculus T14 recolle avec un morceau du même os découvert dans ce loculus lui-même. Cependant, il n'existe pas de solution de continuité permettant de séparer deux ensembles pouvant correspondre sûrement à chacun de ces deux sujets. Les dimensions maxima des fragments sont inférieures à 
celles des morceaux déposés dans les loculus, mais cela se note pour toutes les autres tombes de ce secteur de la nécropole. En revanche, l'aspect de ces restes ne diffère pas de ceux des loculus : même couleur et mêmes fissurations en ondes concentriques révélant également une incinération d'os frais à une température semblable. Par ailleurs, le poids moyen des fragments déterminés, toutes régions anatomiques confondues, est de $0,32 \mathrm{~g}$ $(0,31 \mathrm{~g}$ pour la tête, $0,13 \mathrm{~g}$ pour le tronc et $0,37 \mathrm{~g}$ pour les membres). Pour les 29 fragments identifiés comme provenant des membres supérieurs, le poids moyen est de $0,80 \mathrm{~g}$; pour les 3 fragments identifiés comme provenant des membres inférieurs, il est de 1,50 g. Ces valeurs sont tout à fait semblables aux homologues calculées pour les deux loculus. De cette répartition et de cette similitude, on déduira donc que ces os peuvent provenir des deux adultes déposés dans ces deux loculus, sans qu'il soit possible de faire la part de chacun d'eux.

Les taux d'identification sont de 73,9\% du poids total des fragments. Crâne et membres sont sur-représentés : $29,2 \%$ du poids identifié pour le premier (pour un poids théorique de 20,4\%) et 68,5\% pour les seconds (au lieu des $62,6 \%$ attendus) ; avec $4,7 \%$, le tronc est très nettement sous-représenté (poids théorique : $17 \%$ ) (fig. 22, B).

\section{Mobilier de la structure de recouvrement commune aux tombes T12 et T14}

Objets personnels : armement et fourniment

- Un rivet en fer de garniture de poignée d'épée : deux têtes discoïdes très légèrement bombées, non décorées ; tige de section quadrangulaire ; long. : 21,5 mm ; diam. têtes : 11 à $11,5 \mathrm{~mm}$; côté tige : 2,5 à $3 \mathrm{~mm}$ (fig. 22, $\mathrm{C}, \mathrm{n}^{\circ} 3$ ) ;

- Un rivet en fer à tête discoïde légèrement bombée et non décorée ; tige de section quadrangulaire recourbée et cassée ; diam. tête : $11 \mathrm{~mm}$ (fig. 22, C, $\mathrm{n}^{\circ} 4$ ). Il pourrait s'agir d'un rivet de décoration de poignée d'épée ou de fourreau ;

- Un grand rivet de fixation d'ailettes d'umbo de bouclier (fig. 22, C, $\mathrm{n}^{\circ}$ 5), en fer ; tête discoïde légèrement bombée, non décorée (diam. : $27 \mathrm{~mm}$ ); tige de section quadrangulaire, repliée à angle droit, déterminant une épaisseur de $10 \mathrm{~mm}$ pour la planche du bouclier ;

- Un petit rivet en fer (fig. 22, C, $\mathrm{n}^{\circ} 6$ ); petite tête discoïde légèrement bombée, non décorée (diam. : $8 \mathrm{~mm}$ ); tige de section quadrangulaire, repliée à angle droit, déterminant une épaisseur de $15 \mathrm{~mm}$ pour l'objet fixé par ce rivet. Il pourrait également s'agir de la fixation d'un umbo de bouclier ;

- Un rivet en fer (fig. 22, C, $\mathrm{n}^{\circ}$ 7), fragmentaire ; cet objet est très corrodé et n'a pas fait l'objet d'une restauration ; il pourrait s'agir d'un élément de fixation d'umbo de bouclier à tête discoïde ;

- Un gros anneau circulaire en fer (fig. 22, C, $\mathrm{n}^{\circ} 1$ ) faisant partie d'une ceinture de suspension d'un fourreau d'épée ; section losangique ; diam. : 35 à $37 \mathrm{~mm}$; haut. : 11 à $14 \mathrm{~mm}$. Cet élément est semblable à ses homologues du loculus 14 ; il s'agit vraisemblablement de la même suspension ;

- Un passant de courroie en fer (fig. 22, C, $\mathrm{n}^{\circ} 2$ ); formé d'une fine plaque ovale, prolongée aux deux extrémités par deux pattes très amincies, repliées sur un côté de la plaque; long. : 33,5 mm; larg. : $12 \mathrm{~mm}$. Ce passant est de mêmes forme et conception que celui du loculus $14\left(n^{\circ} 4\right)$; quoiqu'un peu plus petit, il doit faire partie de la même ceinture.

Objets personnels : parure et habillement

- Un morceau de grand bracelet en bronze (fig. 22, $\mathrm{C}, \mathrm{n}^{\circ} 8$ ), portant une nodosité ovale ; section en « $\mathrm{D}$ »; haut. : 9 à $16 \mathrm{~mm}$. Cet objet est déformé par l'action d'un feu secondaire; le diamètre semble cependant compris entre 65 et $75 \mathrm{~mm}$;

- Un morceau de ressort de grande fibule en fer (fig. 22, C, nº 9) (très corrodé et non restauré).

Matériel céramique :

- Des tessons des trois coupes complètes partagées avec les tombes voisines : coupes à vernis-noir et claire massaliète fig. $19, \mathrm{n}^{\circ} 8$ et $\mathrm{n}^{\circ} 13$ du loculus 12 , et coupe claire massaliète fig. $21, \mathrm{C}, \mathrm{n}^{\circ} 9$ du loculus 14 ;

- Un couvercle non tourné miniature, presque complet, de forme CNT-LOR V2a (environ $80 \%$ du vase sont présents) : bord dans la continuité de la paroi rectiligne, lèvre aplatie, petit fond annulaire; surfaces brutes ; diam. max. : $55 \mathrm{~mm}$; haut. : $26 \mathrm{~mm}$ (fig. 22, $\left.\mathrm{C}, \mathrm{n}^{\circ} 12\right)$;

- 1 tesson d'urne non tournée du type à panse ovoïde ; base de la panse peignée horizontalement, fond plat avec, à l'extérieur, plusieurs traits incisés larges et peu profonds ; diam. fond: $100 \mathrm{~mm}$ (fig. 22, C, $\mathrm{n}^{\circ} 11$ ) ;

- Portion de la partie supérieure d'une urne non tournée de forme CNT-LOR U5d, variante d, 30 tessons soit environ $40 \%$ du vase : col tronconique rentrant, bord déversé, lèvre aplatie, panse ovoïde à peignage horizontal ; épaule décorée d'impressions au peigne disposées en deux lignes brisées, sur fond de peignage horizontal ; diam. ouv. : $120 \mathrm{~mm}$ (fig. 22, C, $\mathrm{n}^{\circ} 10$ ).

- Tessons de vases isolés :

- 1 tesson de couvercle non tourné de forme CNTLOR V2b : bord dans la continuité de la paroi concave, lèvre aplatie (fig. 22, C, $\mathrm{n}^{\circ} 13$ ) ;

- 4 fragments de bords appartenant à trois urnes non tournées (non dessinés) ; 
- 65 tessons de panses non tournées, correspondant semble-t-il à autant de vases (non dessinés) ;

- 1 fragment d'épaule d'amphore massaliète, avec arrachement d'anse (non dessiné).

Os d'animaux (détermination A. Gardeisen) :

- 3 fragments crâniens de porc juvénile, carbonisés à blanc, se rapportant probablement au crâne du porcelet du loculus de la tombe 12 ;

- 2 fragments de plats de côtes d'un capriné, pouvant également provenir du gril costal identifié dans le loculus de la tombe 12 ;

-2 fragments d'un équidé adulte mâle (1 dent jugale supérieure non brûlée de taille gracile ne présentant pas de pli caballin ; la couronne est cassée mais ce fait peut résulter de l'action du feu (ou de la chaleur), même si l'émail n'en porte pas de trace ; 1 racine de canine en partie chauffée, ayant pu se casser sous l'effet de la chaleur.) ;

- 2 fragments de porcs (fragment d'émail dentaire, cf. molaire ; fragment de coxal gauche (acétabulum), brûlé, blanc sur le bord ventral et noir sur le bord dorsal);

-2 esquilles crâniennes brûlées d'un animal de petite taille ;

- 3 fragments de diaphyses d'os longs d'un animal de petite taille ;

- fragment de diaphyse d'os long d'un animal de grande taille, brûlée, noire ;

- Indéterminés : 33 esquilles brûlées ; 6 esquilles non brûlées ;

- Malacofaune : fragment de bord de coquillage.

\section{La tombe T15}

\section{1. État et composantes de la tombe}

La tombe T15 a accueilli un adulte de sexe non déterminé. Elle comprend un loculus, qui a pu être entièrement fouillé, mais aucune trace d'un éventuel recouvrement n'a été décelée. Ce loculus n'a cependant pas été arasé car le sol de la nécropole est bien marqué à ses environs immédiats (fig. 23, A et B).

\subsection{Le défunt}

$\mathrm{Au}$ défunt se rapportent 101,8 g d'os brûlés, provenant tous du loculus (US 17033). La détermination de l'âge adulte repose sur la morphologie des os et la fermeture des apex des dents. Les sutures sont libres sur la face exocrânienne et en cours de synostose sur l'endocrâne. Il s'agit donc d'un adulte peut-être âgé de plus de trente ans, mais pas un vieillard. Le sexe anthropologique ne peut pas être précisé (fig. 23, C).

Le poids d'os représente $16 \%$ du poids moyen d'un squelette d'adulte brûlé (1627,1 g selon McKinley 1993). Les taux d'identification sont de $58 \%$ du poids total des fragments. La sur-représentation des membres est importante, $83,7 \%$ du poids identifié pour un poids théorique de $62,6 \%$; cela se fait au détriment du crâne, $14,6 \%$ du poids identifié au lieu des $20,4 \%$ attendus, et surtout du tronc, très nettement sous-représenté, $1,7 \%$ (poids théorique : $17 \%$ ) (fig. 23, D). La couleur blanc crayeux est l'indice d'une température de crémation supérieure à $650^{\circ}$ selon le barème de E. Bonnucci et G. Grazziani (1975) et la fissuration en ondes concentriques des morceaux de diaphyses marque une incinération d'os frais. Les restes osseux ont été déposés dispersés dans le loculus, hors de tout contenant.

Le poids moyen des fragments déterminés, toutes régions anatomiques confondues, est de $0,33 \mathrm{~g}(0,30 \mathrm{~g}$ pour la tête, $0,10 \mathrm{~g}$ pour le tronc et $0,36 \mathrm{~g}$ pour les membres). Pour les 3 fragments identifiés comme provenant des membres inférieurs, il est de $1,54 \mathrm{~g}$.

\subsection{Le loculus}

Le loculus est une grande cuvette de plan ovalaire, de $1,5 \mathrm{~m}$ de long sur $0,5 \mathrm{~m}$ de large, mais très peu profonde, 2 à $3 \mathrm{~cm}$ seulement (US 17033). Elle est remplie d'un sédiment limoneux gris jaunâtre contenant, éparpillés sur toute sa surface, des nodules d'argile chauffée, quelques rares petits morceaux de charbons de bois, des os humains incinérés très fragmentés et un mobilier peu abondant, avec notamment au sud, plusieurs éléments d'objets en bronze et en fer (fig. 23, A et B).

\section{Mobilier du loculus}

Objets personnels: parure et habillement :

- Plusieurs fragments d'une grande fibule en bronze et corail (fig. 23, E, $\mathrm{n}^{\circ} 1$ ) : moitié de ressort bilatéral à six ou huit spires et corde externe ; morceau d'arc filiforme ; morceaux du porte-ardillon ; cabochon en corail appartenant à la décoration du pied, de forme ovale, percé au centre d'un trou de rivet, orné de trois demicercles concentriques en creux opposés; larg. rest. au ressort : env. $35 \mathrm{~mm}$; axes du cabochon : 8 à $10 \mathrm{~mm}$. La couleur blanchâtre du corail montre une exposition 
au feu. Il s'agit d'une fibule du type à pied replié vers l'arc et terminé par un petit disque sur lequel devait être riveté le cabochon (type $11 \mathrm{de} \mathrm{C}$. Tendille).

- Quatre segments d'un ruban en bronze, de section lenticulaire, déformé par le feu; larg. : 9 à $12 \mathrm{~mm}$; ép. : $4 \mathrm{~mm}$; il s'agit peut-être d'un bracelet (fig. 23, E, $\left.\mathrm{n}^{\circ} 2\right)$.

Tessons de vases isolés :

-1 petit tesson de vase à vernis noir de l'atelier de Rosas, de forme non déterminable ;

- 3 tessons de grande urne non tournée de forme probable CNT-LOR U5d, ne représentant qu'une très petite partie du récipient : col tronconique rentrant à surface lissée, panse ovoïde peignée horizontalement ; épaule décorée d'impressions de coups de peigne obliques; diam. max. estimé : env. 220 mm (fig. 23, E, n 3);

-1 tesson de fond plat de grande urne non tournée (fig. 23, E, $\mathrm{n}^{\circ} 4$ ), peut-être même exemplaire que le précédent ;

- 1 bord déversé d'urne non tournée (fig. 23, E, $\mathrm{n}^{\circ}$ 5);

- 1 bord déversé à lèvre aplatie d'urne non tournée de forme probable CNT-LOR U5d (fig. 23, E, $\mathrm{n}^{\circ}$ 6) ;

-22 tessons informes non tournés, correspondant vraisemblablement à autant de vases (non dessinés).

Os d'animaux (détermination A. Gardeisen) :

- Caprinés : 3 fragments de vertèbre thoracique et 1 fragment d'émail dentaire ;

- Indéterminés : 1 esquille brûlée, noire, et 5 esquilles non brûlées ;

- Microfaune : 1 vertèbre (cf. reptile); 1 fragment de phalange ou de vertèbre caudale brûlée.

\section{La tombe T16}

\section{1. État et composantes de la tombe}

C'est la tombe d'un adulte de sexe non déterminé. Elle se compose d'un loculus, entièrement fouillé, et de quelques restes, très localisés, du dispositif de recouvrement (fig. 24, A, B et C).

\subsection{Le défunt}

Ce défunt est attesté par 155,6 g d'os brûlés, éparpillés dans le loculus (US 17030-2), hors de tout contenant.
La détermination de l'âge adulte repose sur la morphologie des os et la fermeture des apex des dents. Le sexe anthropologique ne peut pas être précisé (fig. 24, D).

Les os sont très fragmentés, et peu d'éléments sont identifiables, 48,8 \% seulement du poids total. Le crâne et plus encore le tronc sont sous-représentés : respectivement $13,6 \%$ et $3 \%$ du poids total déterminé contre $20,4 \%$ et $17 \%$ en théorie. Avec $83,4 \%$ (pour $62,6 \%$ attendus) les membres sont largement prédominants (fig. 24, E).

L'incinération a affecté des os frais, comme le montrent les fissurations en ondes concentriques des diaphyses. Presque tous les restes ont une couleur blanc crayeux, traduisant une température de crémation de l'ordre de $650^{\circ}$ selon le barème de $\mathrm{E}$. Bonnucci et G. Grazziani (Bonucci, Grazziani 1975).

Le poids moyen des fragments déterminés, toutes régions anatomiques confondues, est de $0,36 \mathrm{~g}(0,30 \mathrm{~g}$ pour la tête, $0,22 \mathrm{~g}$ pour le tronc et $0,40 \mathrm{~g}$ pour les membres). Pour le seul fragment identifié comme provenant d'un membre supérieur, le poids est de 1,61 g et pour le seul fragment identifié comme provenant d'un membre inférieur, il est de $2,07 \mathrm{~g}$.

\subsection{Le loculus}

Le loculus (US 17030-2) est une cuvette de plan ovalaire, large mais peu profonde, mesurant $1,7 \mathrm{~m}$ de long sur $1 \mathrm{~m}$ de large et $4 \mathrm{~cm}$ de profondeur maximum. Son fond est irrégulier. Le comblement est constitué par un sédiment alluvial de couleur gris jaunâtre. Il inclut quelques pierres calcaires non roulées, n'excédant pas $10 \mathrm{~cm}$ d'arête et montrant parfois des traces de feu. En revanche, il est dépourvu de nodules d'argile cuite ou chauffée, ce qui le distingue nettement du remplissage de la tombe précédente. La densité des os humains incinérés diminue du centre vers la périphérie, tandis que, dans la même direction, augmente la fragmentation des restes. Les rares charbons de bois, toujours de petites dimensions, inférieurs à $5 \mathrm{~mm}$, montrent une répartition semblable. Le mobilier se compose de 43 tessons appartenant à 39 récipients différents, non tournés à une exception près. Aucun objet métallique ne figure dans le dépôt (fig. 24, A, B et C).

\section{Mobilier du loculus}

Tessons de vases isolés :

- 1 tesson de panse de coupe claire massaliète, à pâte de couleur grise, de forme non déterminable (non dessiné) ; 


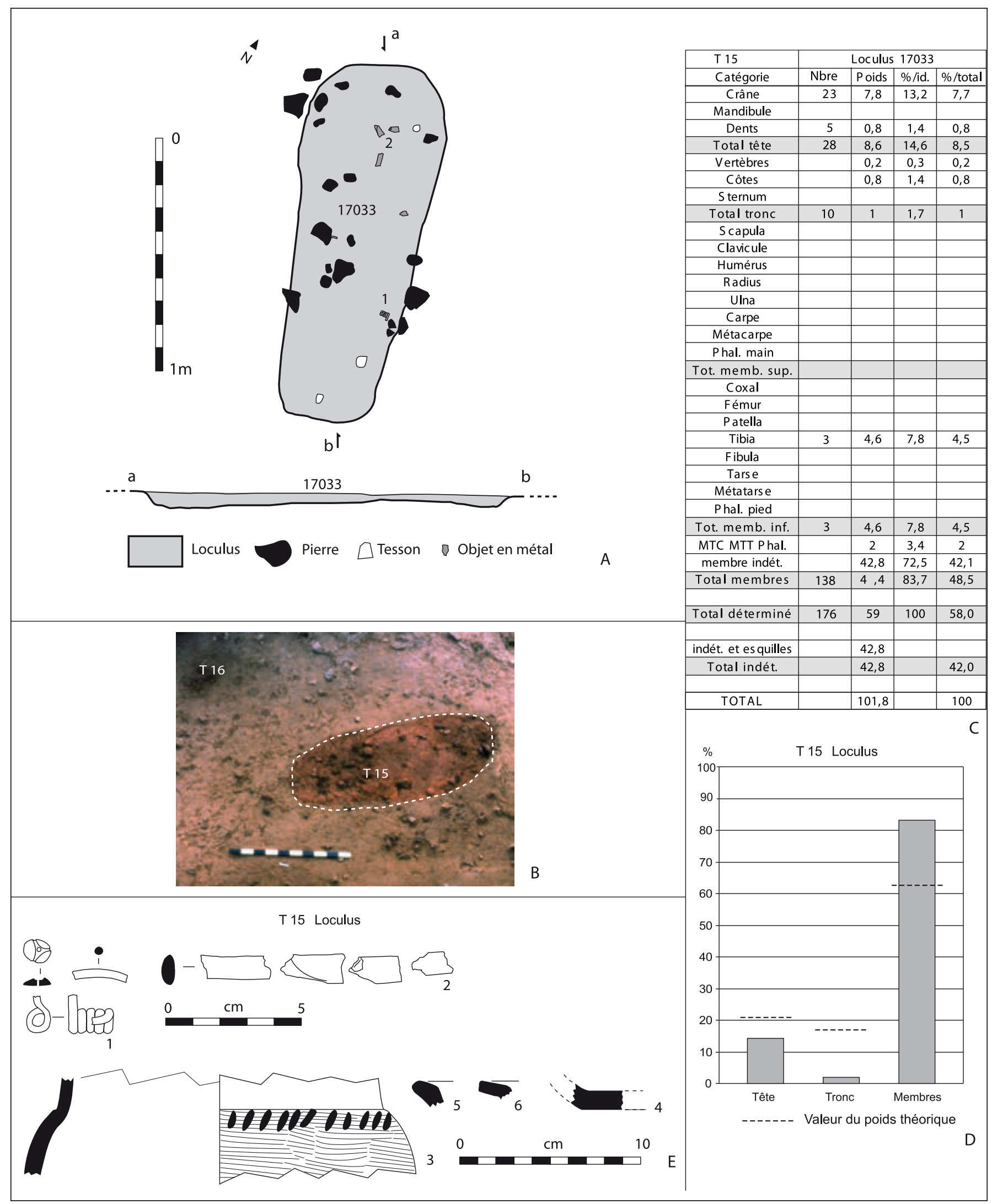

Fig. 23. Tombe T15. A : plan et coupe. B : loculus vu du sud-ouest. C : tableau de détermination des os humains (poids en grammes ; calcul des \% sur la masse). $\mathrm{D}$ : répartition du poids des os par grandes régions anatomiques (\% par rapport au total déterminé).

$\mathrm{E}:$ mobilier ( 1 : fibule en bronze et corail ; 2 : bronze ; 3-6 : céramique non tournée). 


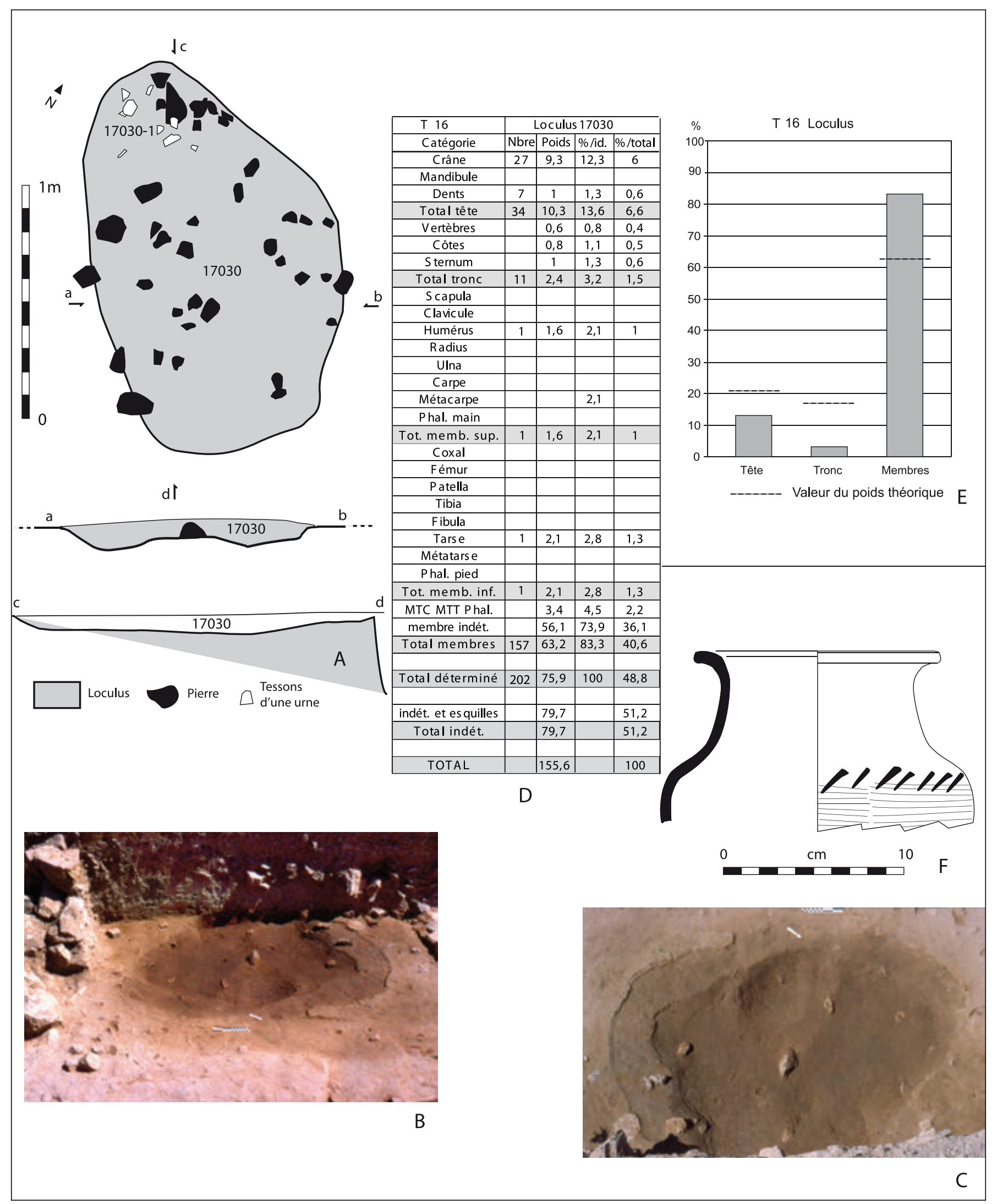

Fig. 24. Tombe T16. A : plan et coupes. B : remplissage du loculus, vu du sud-ouest. C : loculus en fin de fouille, vu du sud-ouest. D : tableau de détermination des os humains (poids en grammes; calcul des \% sur la masse). E : répartition du poids des os par grandes régions anatomiques (\% par rapport au total déterminé). F : mobilier (céramique non tournée). 
- 5 tessons de la panse d'une urne non tournée (non dessinés) ;

- 1 tesson de l'épaule d'une urne non tournée (non dessiné) ;

- 36 tessons informes de céramique non tournée provenant, semble-t-il, d'autant de vases (non dessinés).

Os d'animaux (détermination A. Gardeisen) :

- 1 fragment dorsal de diaphyse de métatarse de capriné (cf. mouton) ;

-1 fragment de plat de côte d'un animal de petite taille ;

- Indéterminés : 11 esquilles brûlées, noires, et 12 esquilles non brûlées ;

- Malacofaune : 1 fragment de coquille de moule.

\subsection{Le dispositif de recouvrement}

La seule trace conservée de la structure de recouvrement de la tombe consiste dans la présence d'une quinzaine de tessons d'une urne non tournée gisant à plat sur la surface supérieure du comblement du loculus, près de son extrémité ouest (fig. 24, A, 17030-1).

\section{Mobilier du dispositif de recouvrement}

Matériel céramique :

- Portion de la partie supérieure d'une urne non tournée de forme CNT-LOR U5d, variante d, 15 tessons représentant environ $10 \%$ du récipient: col tronconique rentrant à surface lissée, bord déversé avec méplat vers l'intérieur, panse ovoïde peignée horizontalement, épaule décorée d'une rangée de coups incisés obliques ; diam. max. : $170 \mathrm{~mm}$ (fig. 24, F).

\section{La tombe T17}

\section{1. État et composantes de la tombe}

La tombe T17 abrite un seul défunt incinéré, un adulte de sexe non déterminable. Entièrement fouillée, elle se compose d'un loculus (US 17053), d'un dispositif enterré annexe (US 17115), et d'une structure de recouvrement s'étendant largement tout autour (US 17029) (fig. 25, A, B et C).

\subsection{Le défunt}

Le défunt, un adulte, est représenté par 413,4 g d'os brûlés. L'estimation de l'âge repose sur divers indices, la morphologie des os, le listel soudé sur les corps vertébraux, la fermeture de l'apex des racines de dents conservées et notamment d'une troisième molaire inférieure. Le sexe anthropologique ne peut pas être précisé (fig. 26, A).

Le loculus a livré $153.4 \mathrm{~g}$ d'os et la structure de recouvrement, $260 \mathrm{~g}$, et les deux lots sont tout à fait compatibles. Dans les deux cas, les restes osseux ont une couleur blanc crayeux qui révèle une température de crémation supérieure à $650^{\circ}$ selon le barème de E. Bonnucci et G. Grazziani (1975) et les morceaux de diaphyses sont très souvent fissurés en ondes concentriques, indice d'une incinération d'os frais. Qu'il s'agisse du loculus ou de la superstructure, les restes osseux sont dispersés, hors de tout contenant, et aucune disposition particulière des fragments n'a été perçue. Toutefois, ceux-ci sont très rares dans la partie inférieure du remplissage du loculus $(4,2 \mathrm{~g}$ dans les trois décapages du fond, décapages 3 à 5) et deviennent de plus en plus abondants vers le haut (20,1 g à mi-hauteur, dans le décapage 2, et 128,8 g en haut, dans le décapage 1).

Le poids d'os déposés dans le loculus représente 9,4\% du poids moyen d'un squelette d'adulte brûlé, $1627,1 \mathrm{~g}$ selon McKinley (1993) et celui des os contenus dans le recouvrement, $16 \%$, soit au total, $25,4 \%$. Les taux d'identification des pièces sont comparables pour le loculus et la superstructure, respectivement 73,3 et $75,7 \%$ du poids total des fragments. Dans le loculus, le tronc est sous-représenté : $10,8 \%$ du poids identifié (poids théorique : $17 \%$ ); il en va de même, ce qui est plus rare, et avec un déficit plus important, du crâne : $8,7 \%$, au lieu des 20,4\% attendus ; avec $80,5 \%$, les membres, évidemment, dépassent la valeur théorique $(62,6 \%)$. A l'intérieur du loculus, la ventilation de ces proportions par décapage n'est pas significative car les effectifs sont trop inégaux. Le lot du recouvrement montre, pour sa part, une répartition quelque peu différente : avec $21 \%$ du poids d'os identifiés, le crâne est normalement représenté, avec $3,2 \%$, le tronc est fortement sous-représenté, et ce déficit est compensé par les membres $(75,8 \%)$ (fig. 26, B).

Le poids moyen des fragments déterminés, toutes régions anatomiques confondues, est semblable dans le loculus et dans le dispositif de recouvrement et s'élève à $0,31 \mathrm{~g}$ pour le premier et $0,33 \mathrm{~g}$ pour le second (provenant du loculus : $0,24 \mathrm{~g}$ pour la tête, $0,17 \mathrm{~g}$ pour le tronc et $0,36 \mathrm{~g}$ pour les membres; provenant du recouvrement : $0,26 \mathrm{~g}$ pour la tête, $0,27 \mathrm{~g}$ pour le tronc et $0,37 \mathrm{~g}$ pour les membres). Pour les 6 fragments identifiés comme provenant des membres supérieurs, le poids moyen est de 
$0,11 \mathrm{~g}$; pour le seul fragment identifié comme provenant d'un membre inférieur, il est de 2,80 g.

\subsection{Le loculus}

Le loculus (US 17053) présente, à l'ouverture, un plan circulaire de $50 \mathrm{~cm}$ de diamètre. C'est une cuvette profonde de $12 \mathrm{~cm}$ au maximum au centre, à fond arrondi et à la paroi abrupte marquée par un net ressaut à mi-hauteur au nord (fig. 25, A et B).

Le remplissage comprend deux strates. Au fond prend place une couche de sédiment gris sombre dont le sommet se trouve au niveau du ressaut de la paroi nord du loculus (décapages 17053-3 à 5). Ce sédiment enrobe trois pierres verticales qui affleurent le sommet de ce niveau. Il inclut de rares petits morceaux de charbons de bois et de très rares fragments osseux humains incinérés.

La strate supérieure est formée d'un sédiment noir incluant de petits morceaux de charbons de bois (décapages 17053-1 et 2). Plusieurs pierres calcaires centimétriques, éclatées au feu, reposent à sa base, sur le sommet du niveau précédent (décapages 17053-2). Trois pierres calcaires de 3 à $5 \mathrm{~cm}$ d'arête, montrant des traces de passage au feu, et plusieurs éclats prennent place dans la partie supérieure de cette couche (décapage 17053-1).

Les morceaux d'os humains brûlés, souvent de grandes dimensions, éparpillés, abondent dans ce niveau. Ils sont toutefois beaucoup moins nombreux dans le décapage inférieur 17053-2 (20,1 g) que dans le décapage supérieur 17053-1 (128,8 g). C'est dans ce dernier que figurent les seuls objets mobiliers retrouvés dans le loculus et qui portent des traces de passage sur le bûcher, morceaux d'un anneau en bronze (fig. 25, D, $n^{\circ} 1$ ) et d'une lamelle en fer (fig. 25, D, $n^{\circ} 2$ ).

\section{Mobilier du loculus}

Objets métalliques indéterminés :

- Deux morceaux d'un anneau en bronze; section en $\mathrm{D}$; diam. ext. : $22 \mathrm{~mm}$; haut. : $3 \mathrm{~mm}$ (fig. 25, $\mathrm{D}$, $\left.\mathrm{n}^{\circ} 1\right)$;

- Quatre morceaux de lamelle de fer recourbée ; ép. : $1 \mathrm{~mm}$; il s'agit peut-être d'une bague de serrage d'emmanchement (fig. 25, D, $\mathrm{n}^{\circ} 2$ ).

Os d'animaux (détermination A. Gardeisen) :

- Indéterminés : 5 esquilles carbonisées, de couleur blanc-bleu ;

- Malacofaune : petit lot d'escargots terrestres.

\subsection{Le dispositif enterré annexe (US 17115 et 17116)}

Le dispositif annexe US 17115 et 17116 se trouve à $20 \mathrm{~cm} \mathrm{du}$ bord nord du loculus US 17053. Il se compose d'une fosse profonde (US 17115) dont les limites ne peuvent être appréciées, approximativement, que par les grosses pierres de calcaire local (US 17116) qu'elle renferme, car le sédiment de son comblement est exactement le même que celui des environs, des alluvions limoneuses gris jaunâtre (fig. 25, A et C).

Ces pierres présentent une disposition particulière. L'élément principal est constitué par deux blocs parallélépipédiques allongés, superposés verticalement dans la moitié orientale du dispositif. La pierre du fond (US 17116-2) mesure $24 \mathrm{~cm}$ de long sur $12 \mathrm{~cm}$ de large. Elle est surmontée par un bloc plus important (US 17116-1), de $48 \mathrm{~cm}$ de long, $25 \mathrm{~cm}$ de large et $16 \mathrm{~cm}$ d'épaisseur. Ce dernier élément a une forme régulière mais seule la surface plane de son sommet semble avoir été aménagée. Il émerge de $8 \mathrm{~cm}$ au-dessus du sol de la nécropole. Ces deux blocs forment une sorte de pilier vertical de $73 \mathrm{~cm}$ de hauteur, presque entièrement enterré. Ce dispositif est calé, à l'ouest, par six blocs décimétriques, irréguliers et bruts, en position verticale, à l'exception de ceux qui sont placés en haut du comblement, en position horizontale. L'ensemble de ces pierres implique le creusement d'une fosse de plan ovalaire, d'au moins 60 et $40 \mathrm{~cm}$ d'axes à l'ouverture et d'une profondeur minimum de $65 \mathrm{~cm}$, avec paroi verticale dans sa moitié est et oblique très prononcée dans sa moitié ouest. A part quelques très rares menus charbons de bois dans la partie supérieure du comblement, le sédiment enrobant ces pierres ne renferme aucun document, os ou objet. Il en va de même dans le niveau situé audessous de cet amas de blocs.

\subsection{La structure de recouvrement (US 17029)}

La structure de recouvrement (US 17029) est constituée par une nappe d'alluvions limoneuses de couleur gris clair jaunâtre, de plan ovale, de $2 \mathrm{~m}$ sur l'axe SO-NE et $1,5 \mathrm{~m}$ sur l'axe $\mathrm{SE}-\mathrm{NO}$, d'une épaisseur de $6 \mathrm{~cm}$ maximum, incluant de très nombreux os humains incinérés (fig. 25, A). Ce sédiment ne se différencie de celui qui surmonte l'ensemble du sol de la nécropole que par la présence de ces morceaux d'os, éparpillés dans toute son épaisseur. Localement ceux-ci sont plus abondants, notamment dans deux secteurs au nord et à l'ouest du loculus. Cet épandage contient également 29 tessons épars, appartenant à autant de vases différents. 


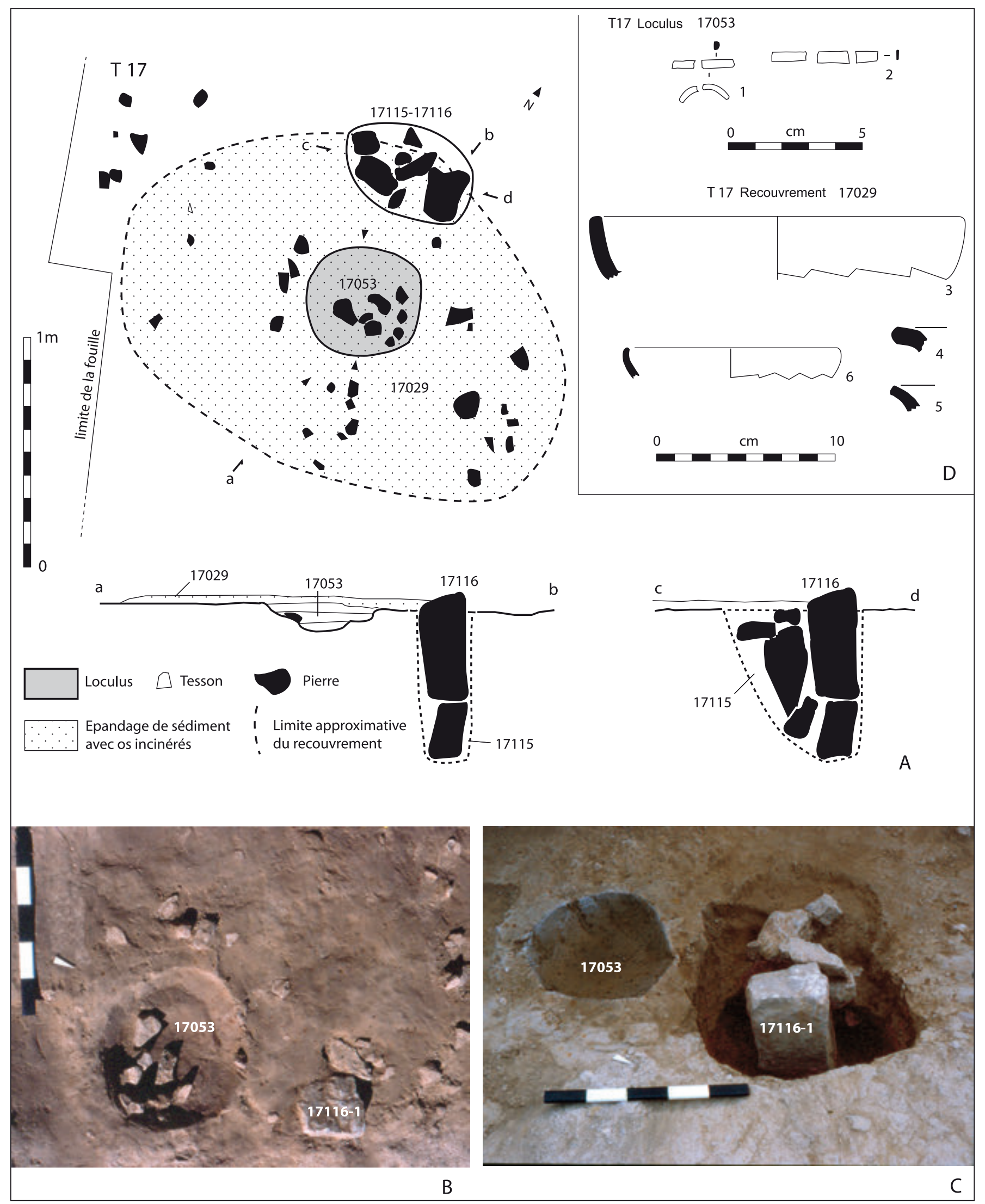

Fig. 25. Tombe T17. A : plan et coupes. B : loculus fouillé et structure annexe, vus du sud-ouest. C : loculus et structure annexe en fin de fouille, vus du sud-ouest. $D$ : mobilier ( 1 : bronze $; 2:$ fer ; 3-5: céramique non tournée ; $6:$ céramique à vernis noir). 
CHAPITRE 2 - TOMBES, STRUCTURES ANNEXES ET SOL DE LA NÉCROPOLE

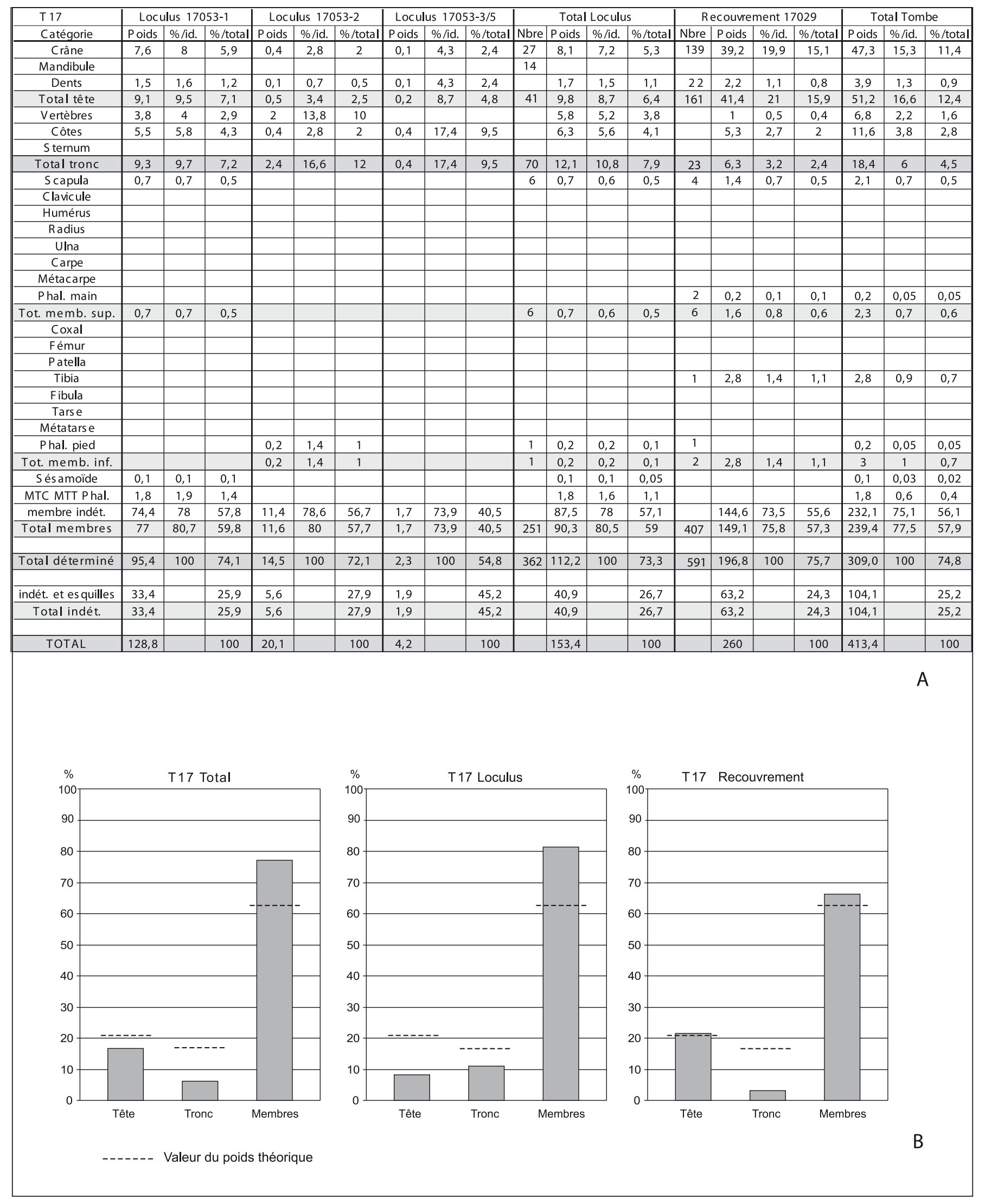

Fig. 26. Tombe T17. A : tableau de détermination des os humains (poids en grammes; calcul des \% sur la masse).

$\mathrm{B}$ : répartition du poids des os par grandes régions anatomiques (\% par rapport au total déterminé). 
Il recouvre le comblement du loculus US 17053 et déborde largement tout autour; il s'étend aussi sur le dessus des pierres de la fosse annexe US 17115, mais laisse apparaître, du moins lors de la fouille, le sommet de la grande pierre verticale de cette fosse (US 17116-1).

\section{Mobilier de la structure de recouvrement}

Tessons de vases isolés :

- 1 tesson de bord de bol à vernis noir de l'atelier de Rosas, de forme Lamb. 27 (= forme Puig 11.a); diam. ouv. : $120 \mathrm{~mm}$ (fig. 25, $\mathrm{D}, \mathrm{n}^{\circ} 6$ ) ;

- 3 petits tessons de panse d'un autre récipient à vernis noir de l'atelier de Rosas, de forme non déterminable (non dessiné) ;

- 1 tesson de panse de vase fermé, urne ou œnochoé, à pâte claire massaliète (non dessiné) ;

- 1 tesson d'urne non tournée : bord déversé à lèvre arrondie (fig. 25, $\mathrm{D}, \mathrm{n}^{\circ} 4$ ) ;

- 1 tesson d'urne non tournée : bord déversé à lèvre aplatie (fig. 25, D, $\mathrm{n}^{\circ}$ 5) ;

- 1 tesson de coupe non tournée CNT-LOR C1 : panse arrondie-convexe, bord divergent à lèvre arrondie ; diam. max. : env. 210 mm (fig. 25, $\mathrm{D}, \mathrm{n}^{\circ}$ 3) ;

-23 tessons de vases non tournés, urnes à panse peignée et coupes, appartenant probablement à autant de vases.

Os d'animaux (détermination A. Gardeisen) :

- caprinés : 1 molaire; 1 fragment de diaphyse de métapode carbonisé, noir ;

- 1 fragment indéterminé d'épiphyse d'os long d'animal de petit taille ;

- Indéterminés : 5 esquilles brûlées, noires, 7 esquilles carbonisées de couleur blanc-bleu et 14 esquilles non brûlées ;

- Malacofaune :1 fragment de coquillage marin.

\section{La tombe T18}

\section{1. État et composantes de la tombe}

La tombe T18 abrite les restes d'un grand enfant, adolescent ou adulte, de sexe indéterminé. Elle se compose d'un loculus (US 17035), entièrement fouillé, mais aucune trace d'une éventuelle structure de recouvrement n'a été observée; cependant, la partie supérieure du loculus n'a pas été tronquée car le paléosol est conservé aux abords immédiats (fig. 27, A).

\subsection{Le défunt}

Du défunt, proviennent $121 \mathrm{~g}$ d'os brûlés, éparpillés dans le loculus, hors de tout contenant (fig. 27, B). Son âge ne peut être précisé ; il s'agit d'un grand enfant ou d'un individu de taille adulte, mais pas un jeune enfant ; le sexe anthropologique n'est pas non plus appréciable ; toutefois, parmi les rares pièces l'accompagnant, la présence d'éléments d'armes et de fourniment plaide en faveur d'un individu masculin.

Ces restes sont très fragmentés, et peu d'éléments sont identifiables (56,5\% seulement du poids total d'os). Le crâne est absent, le tronc représente $1,8 \%$ du poids total d'os déterminés et les membres 98,2 \% (fig. 27, C).

L'incinération a affecté des os frais comme l'indiquent les fissurations en ondes concentriques des diaphyses. Presque tous les fragments osseux sont de couleur blanc crayeux, traduisant une crémation vers $650^{\circ}$ selon le barème de E. Bonnucci et G. Grazziani, mais quelques-uns néanmoins montrent une couleur noire attestant une température plus basse par endroits (Bonucci, Grazziani 1975).

Le poids moyen des fragments déterminés, toutes régions anatomiques confondues, est de $0,39 \mathrm{~g}(0,17 \mathrm{~g}$ pour le tronc et $0,40 \mathrm{~g}$ pour les membres). Pour les 5 fragments identifiés comme provenant des membres supérieurs, le poids moyen est de $1,26 \mathrm{~g}$; pour les 3 fragments identifiés comme provenant des membres inférieurs, il est de 2,53 g.

\subsection{Le loculus}

Une cuvette de plan ovalaire, large et peu profonde, constitue le loculus (US 17035). Elle mesure 1,4 m de long sur $0,9 \mathrm{~m}$ de large et 2 à $3 \mathrm{~cm}$ de profondeur (fig. 27, A). Elle est remplie d'un sédiment limoneux gris foncé à noirâtre. Celui-ci contient, dispersées, quelques pierres calcaires non roulées, ne dépassant pas $7 \mathrm{~cm}$ de côté, certaines présentant des éclatements thermiques. Les os humains incinérés, quelques rares petits morceaux de charbons de bois et un mobilier peu abondant sont dispersés dans l'ensemble de ce remplissage.

\section{Mobilier du loculus}

Objets personnels : armement et fourniment

- Un rivet de fixation d'ailette d'umbo de bouclier, en fer; tête discoïde, légèrement creusée dans sa partie 


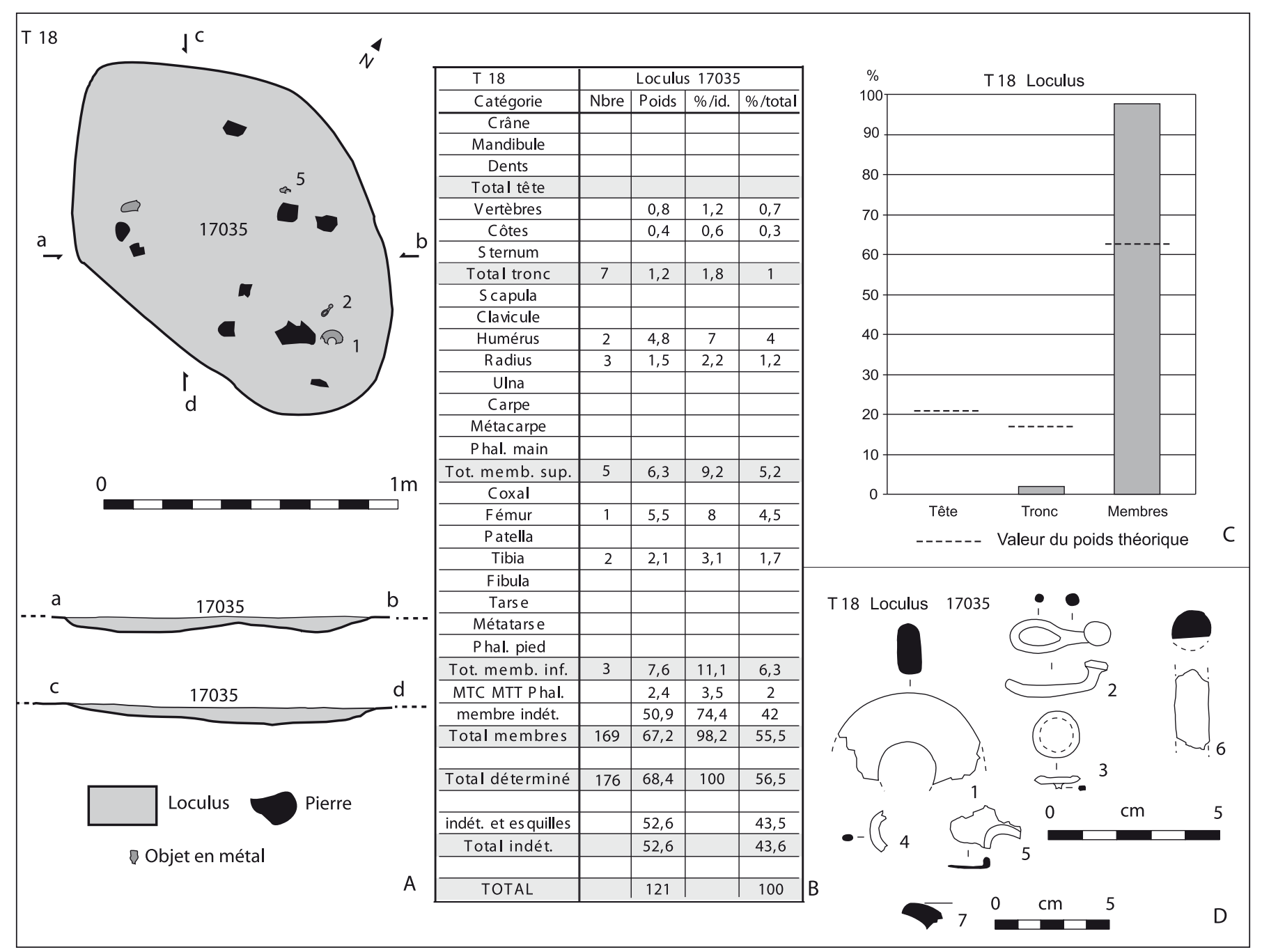

Fig. 27. Tombe T18. A : plan et coupes. B : tableau de détermination des os humains (poids en grammes ; calcul des \% sur la masse). $\mathrm{C}$ : répartition du poids des os par grandes régions anatomiques (\% par rapport au total déterminé).

D : mobilier ( 1,3 et $6:$ fer ; 2,4 et $5:$ bronze ; $7:$ céramique non tournée).

centrale ; départ de la tige de fixation, de section quadrangulaire, très fine (l'extrémité manque); diam. : $13 \mathrm{~mm}$ (fig. 27, $\mathrm{C}, \mathrm{n}^{\circ}$ 3).

- Deux éléments de la ceinture de suspension d'un fourreau d'épée :

- Anneau circulaire plat, en fer (fig. 27, C, $\mathrm{n}^{\circ} 1$ ), fragmentaire; section rectangulaire; diam. : $45 \mathrm{~mm}$; haut. : $8 \mathrm{~mm}$. Cet objet est passé sur le bûcher ;

- Agrafe de ceinture en bronze; boucle ovalaire; crochet relevé à angle droit, terminé par un bouton circulaire ; long. : $30 \mathrm{~mm}$; larg. : $11 \mathrm{~mm}$. Cet objet est passé sur le bûcher (fig. 27, C, n 2).

- Moitié de maillon de chaînette en bronze, de section lenticulaire ; diam. : 12 mm (fig. 27, C, n 4).

Objets métalliques non déterminés :

- Morceau de plaque en bronze présentant un orifice circulaire bordé d'un bourrelet (long. cons. : $20 \mathrm{~mm}$ ) et deux autres fragments en bronze, tous partiellement fondus ; objet non déterminé (fig. 27, $\mathrm{C}, \mathrm{n}^{\circ} 5$ ) ;

- Segment de tige en fer; section probablement circulaire; long. cons. : $23 \mathrm{~mm}$; diam. env. $12 \mathrm{~mm}$ (fig. 27, $\mathrm{C}, \mathrm{n}^{\circ}$ 6).

Tessons de vases isolés :

-2 petits tessons d'une urne non tournée: bord déversé à lèvre aplatie ; diam. ouv. : 140 mm (fig. 27, $\left.\mathrm{C}, \mathrm{n}^{\circ} 7\right)$;

- 21 petits tessons de panses d'urnes non tournées, appartenant semble-t-il, à 20 exemplaires différents (non dessinés).

Os d'animaux (détermination A. Gardeisen) :

- Capriné : 1 fragment de molaire supérieure ;

- Indéterminés : 4 esquilles brûlées, noires ;

- Microfaune : 2 fragments. 


\section{La tombe T19}

\section{1. État et composantes de la tombe}

La tombe T19 abrite un seul sujet incinéré, un adulte. Le sexe ne peut être déterminé, mais, d'après la symbolique du mobilier, la nature et l'abondance des objets de parure, il semble cependant s'agir d'une femme. La sépulture comprend un loculus qui a pu être entièrement fouillé mais aucune trace d'une éventuelle structure de recouvrement n'a été décelée (fig. 28, A, B et C).

\subsection{Le défunt}

Le défunt est représenté par 437,7 g d'os brûlés. D'après la fermeture des apex des dents, la morphologie des os, et en particulier la soudure du listel sur le corps vertébral, on a affaire à un adulte. Il pourrait en fait s'agir d'un adulte de plus de trente ans, car les sutures, souvent colmatées en face endocrânienne, sont toujours libres en face exocrânienne. Le sexe anthropologique ne peut pas être précisé (fig. 28, D).

Le poids d'os déposés représente $27 \%$ du poids moyen d'un squelette d'adulte brûlé, $1627,1 \mathrm{~g}$ selon McKinley (1993). Le taux d'identification des fragments est de 68,5\% du poids total. Avec $21,1 \%$ du poids identifié, la représentation du crâne est conforme au poids théorique $(20,4 \%)$. Celle du tronc est faible, $8,7 \%$ (poids théorique: $17 \%$ ), tandis que les membres sont sur-représentés, 70,2\% du poids identifié au lieu des 62,6\% attendus (fig. 28, E). La couleur blanc crayeux révèle une température de crémation supérieure à $650^{\circ}$ selon le barème de E. Bonnucci et G. Grazziani (1975), et les morceaux de diaphyses sont très souvent fissurés en ondes concentriques, indice d'une incinération d'os frais.

Les os ont été placés dans le loculus, hors de tout contenant. Ils sont dispersés, mais leur densité est cependant plus forte dans la partie centrale de la structure.

Le poids moyen des fragments déterminés, toutes régions anatomiques confondues, est de $0,32 \mathrm{~g}(0,27 \mathrm{~g}$ pour la tête, $0,30 \mathrm{~g}$ pour le tronc et $0,34 \mathrm{~g}$ pour les membres). Pour les 25 fragments identifiés comme provenant des membres supérieurs, le poids moyen est de $1,34 \mathrm{~g}$; pour les 8 fragments identifiés comme provenant des membres inférieurs, il est de $1,39 \mathrm{~g}$.

\subsection{Le loculus}

Le loculus est une large cuvette, de plan ovalaire, de $1,45 \mathrm{~m}$ et 1,25 $\mathrm{m}$ sur ses axes. Sa profondeur est faible en regard de son ouverture, $13 \mathrm{~cm}$ au maximum, et son fond est irrégulier (fig. 28, A, B et C). Le comblement est un sédiment limoneux gris foncé à noirâtre. Cette couleur n'est cependant pas homogène, la partie centrale étant plus sombre que la périphérie. Ce sédiment renferme, dispersées, quelques rares pierres calcaires non roulées, ne dépassant pas $10 \mathrm{~cm}$ de côté, certaines présentant des éclatements dus au feu. On y trouve également de petits nodules d'argile plus ou moins cuite, ainsi que, surtout dans la partie centrale, de petits charbons de bois (moins de $5 \mathrm{~mm}$ ). Le matériel céramique est rare, en tout 46 petits tessons épars, se rapportant à autant de vases différents ; en revanche le mobilier de bronze, également dispersé en plan et en hauteur, est abondant. Nombre de fragments de bronze présentent un début de fusion.

\section{Mobilier du loculus}

Objets de parure et d'habillement :

- Un pendant d'oreille en argent, en forme de croissant renflé en sa partie centrale et s'amincissant vers les deux extrémités pointues qui se chevauchent légèrement ; diam. : 12,8 à 13,3 mm (fig. 29, n $^{\circ} 1$ ) ;

- Une perle en pâte de verre bleue, en cours de fusion; diam. : 11 à $12 \mathrm{~mm}$; ép. : env. $7 \mathrm{~mm}$ (fig. 29, $\left.\mathrm{n}^{\circ} 2\right)$;

- Un bracelet ou un anneau de cheville en bronze moulé, ouvert, formé d'une succession d'oves pleins et peu proéminents, reliés l'un à l'autre par une moulure, chacune des deux extrémités étant constituée par un de ces oves. Cet objet a été tordu et cassé en plusieurs morceaux, ce qui ne permet pas de calculer précisément le diamètre et donc, de savoir s'il été porté au bras ou à la cheville. Long. déroulée : $155 \mathrm{~mm}$; haut de la tige : $18 \mathrm{~mm}$. (fig. 29, $\mathrm{n}^{\circ} 3$ );

- Fragments d'une fibule : morceau de ressort en bronze, de 3 spires conservées (diam. : $9 \mathrm{~mm}$ ) ; quatre petits éléments de corail : trois triangulaires ou trapézoïdaux, moulurés et perforés d'un petit trou de fixation ; un en arc de cercle, orné sur une face de petits godrons. Malgré le caractère très incomplet de cet objet, on peut y reconnaître une fibule en bronze, à ressort bilatéral relativement long, pourvue d'un pied replié vers l'arc et terminé par un disque supportant la décoration de corail, triangles et losanges rayonnants et arc périphérique (type $11 \mathrm{de}$ C. Tendille). Les éléments de corail ont subi l'action du feu et sont de couleur grise (fig. 29, ${ }^{\circ} 4$ ) ;

- Nombreux éléments d'une ceinture en bronze, dite "féminine" de type méridional, comprenant une chaîne 


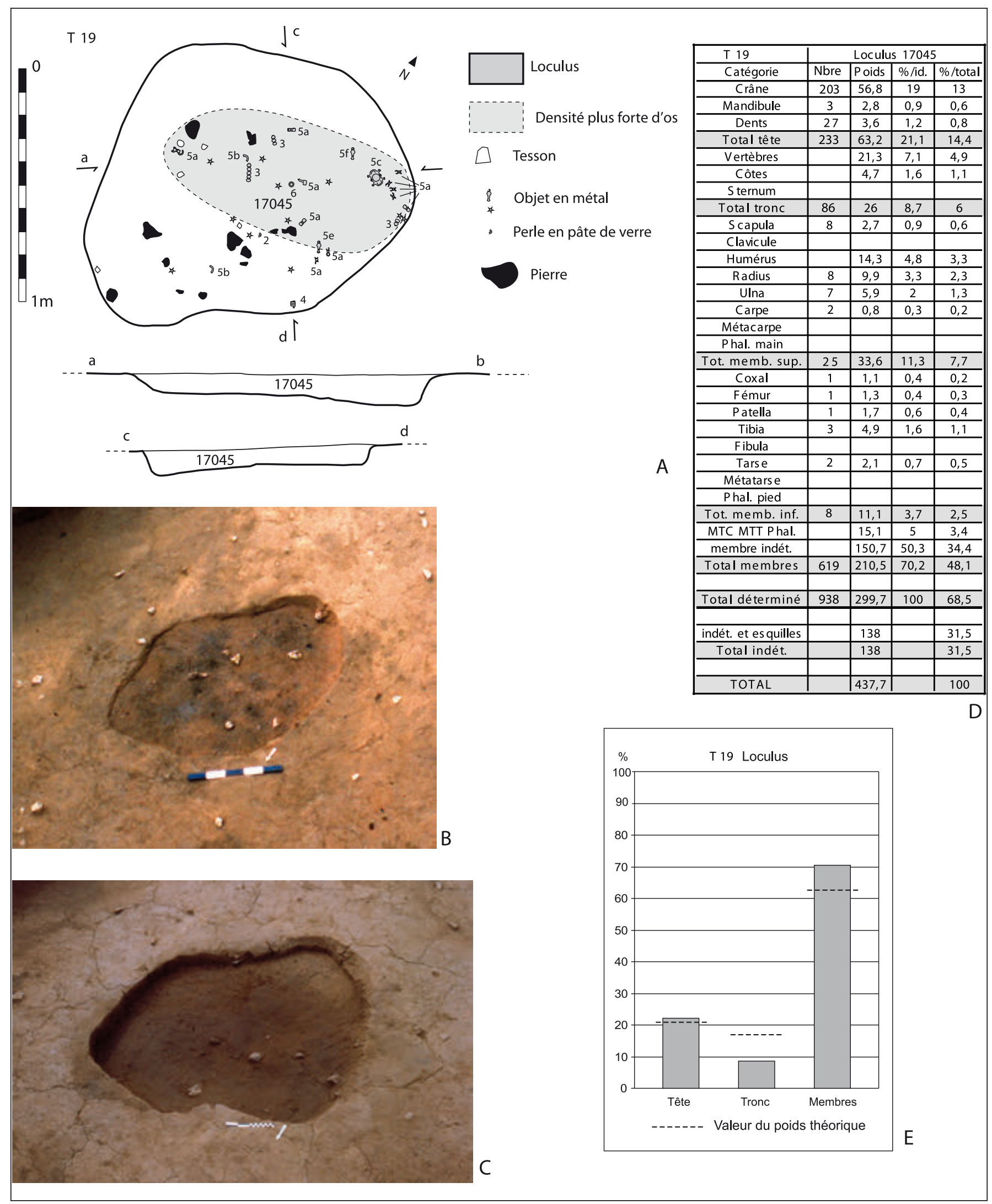

Fig. 28. Tombe T19. A : plan et coupes. B : remplissage du loculus en cours de fouille, vu du nord. C : loculus en fin de fouille, vu du nord. $\mathrm{D}$ : tableau de détermination des os humains (poids en grammes; calcul des $\%$ sur la masse). E : répartition du poids des os par grandes régions anatomiques (\% par rapport au total déterminé). 


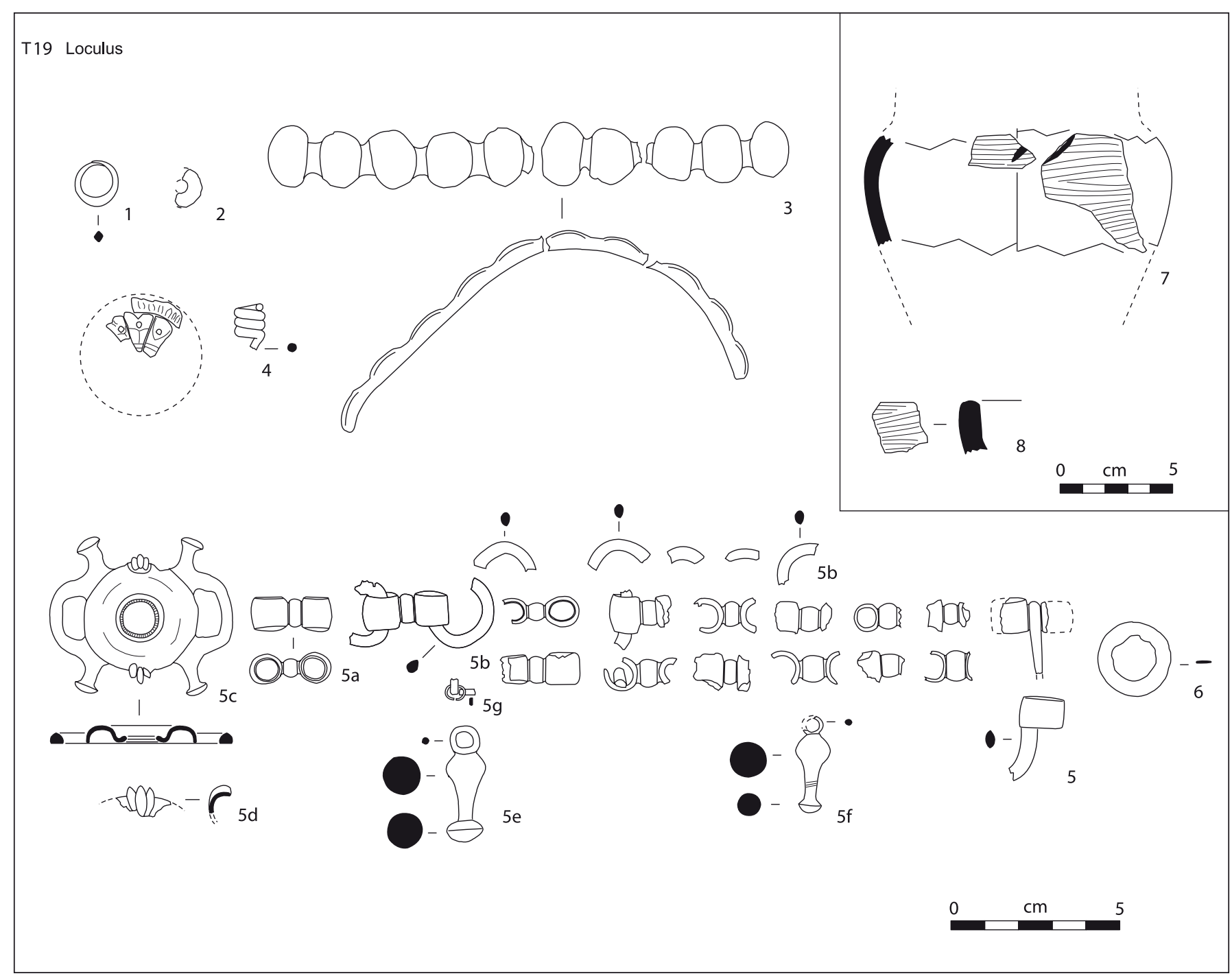

Fig. 29. Tombe T19. Mobilier ( $1:$ argent ; $2:$ verre ; 4 : fibule en bronze et corail ; 3,5 et $6:$ bronze ; 7 et $8:$ céramique non tournée).

composite à laquelle s'accrochent des pendentifs et des agrafes, soit les éléments suivants (fig. 29, $\mathrm{n}^{\circ} 5$ et fig. 115) :

- 10 à 12 maillons doubles, complets ou fragmentaires ; les deux anneaux, en ruban plat, sont reliés par une courte tige à moulure simple; Long. des exemplaires complets : 24 à $25 \mathrm{~mm}$; larg. maillons : 9 à $10 \mathrm{~mm}$; larg. moulures : 7 à 8 mm (fig. 29, n $\left.{ }^{\circ} 5 \mathrm{a}\right)$;

- 4 ou 5 anneaux simples, fragmentaires, de section lenticulaire, reliant les maillons doubles entre eux ; diam. : $10 \mathrm{~mm}$; haut. : $3 \mathrm{~mm}$ (fig. 29, $\mathrm{n}^{\circ}$ 5b) ;

- une agrafe circulaire ajourée, formée d'un anneau de section en « $\mathrm{U} »$, portant deux appendices ajourés diamétralement opposés, terminés chacun par deux boutons en calotte sphérique; entre les appendices, prend place une triple moulure sur le bord de l'anneau ; Long. : $55 \mathrm{~mm}$; haut. $\max$. : $47 \mathrm{~mm}$ (fig. 29, $\mathrm{n}^{\circ} 5 \mathrm{c}$ );
- morceau d'une seconde agrafe du même type que la précédente ; il n'en reste que la mouluration ornant le bord de l' anneau entre les appendices (fig. 29, $\mathrm{n}^{\circ} 5 \mathrm{~d}$ ) ;

- 2 pendentifs coniques, renflés, munis d'un anneau de suspension, terminés par un bouton en calotte sphérique ; Long. : respectivement 34 et $28 \mathrm{~mm}$ (fig. 29, $\mathrm{n}^{\circ} 5 \mathrm{e}$ et $\left.5 \mathrm{f}\right)$.

- un morceau de chaînette ; petits maillons ouverts, formés d'un petit ruban plat, recourbé, aux extrémités jointives ; diam. : $6 \mathrm{~mm}$ (fig. 29, $\mathrm{n}^{\circ} 5 \mathrm{~g}$ ).

Certains éléments de cette parure ont subi un début de fusion.

- Un anneau en bronze, très plat, aux bords amincis presque affûté à l'extérieur; deux irrégularités sur le pourtour intérieur peuvent correspondre à des traces d'usure ; diam. : $21 \mathrm{~mm}$; larg. : $4 \mathrm{~mm}$; ép. : 1,5 mm (fig. 29, $n^{\circ} 6$ ). Cet objet peut appartenir à la ceinture $n^{\circ} 1$. 


\section{Matériel céramique}

Portions de vases :

- Petite portion d'une urne non tournée de forme probable CNT-LOR U5d, 8 tessons représentant moins de $5 \%$ du récipient : panse ovoïde peignée horizontalement, épaule décorée de grandes impressions obliques au peigne, (fig. 29, $\mathrm{n}^{\circ} 7$ );

- Petite portion d'une jatte non tournée de forme CNT-LOR J1a, 17 tessons représentant moins de $5 \%$ du récipient : panse à profil légèrement arrondie, peignée à l'extérieur, bord évasé à lèvre arrondie (fig. 29, $n^{\circ} 8$ ).

Tessons de vases isolés :

- 1 petit fragment informe de vase à vernis noir de l'atelier de Rosas ;

-1 petit tesson de panse d'amphore à pâte jaune (ibérique?);

-20 petits tessons informes et esquilles de vases non tournés, indéterminés, appartenant semble-t-il, à autant de récipients.

Os d'animaux (détermination A. Gardeisen) :

- Capriné : 1 fragment crânial d'axis, brûlé ;

- 3 fragments de côtes et 1 fragment crânien, brûlés à blanc, d'animaux de petite taille ;

- 1 fragment de diaphyse d'os long d'animal de grande taille ;

- Indéterminés : 1 esquille non brûlée, 1 esquille brûlée à blanc et 23 esquilles brûlées, noires.

\section{La tombe T20}

\section{1. État et composantes de la tombe}

La connaissance de cette tombe, qui se rapporte à un individu adulte de sexe non déterminable, est probablement très lacunaire. Seule a été fouillée une portion d'une grande lentille d'alluvions enrobant du matériel (US 17046), située en limite du secteur accessible de la nécropole. Cette structure peut donc se prolonger vers le sud. Sa partie fouillée repose directement sur le paléosol de la nécropole et aucun loculus n'a été repéré au-dessous. Il est possible que cet épandage constitue une tombe à part entière, mais, vu la morphologie des autres sépultures fouillées alentours, il pourrait plutôt s'agir d'une structure de recouvrement d'une tombe dont le loculus se situerait plus au sud, hors du secteur fouillé (fig. 30, A et B).

\subsection{Le défunt}

Cet épandage (US 17046) a livré 23,1 g d'os humains brûlés, dispersés (fig. 30, C). Ils appartiennent à un adulte : un fragment de voûte crânienne présente une suture libre en face exocrânienne et en cours de synostose en face endocrânienne. Le sexe n'est pas précisable.

Les os sont très fragmentés et peu d'éléments sont identifiables (56,3\% seulement du poids total d'os). Le crâne représente $16,1 \%$ du poids total d'os déterminés, le tronc $0,8 \%$ et les membres $83,1 \%$ (fig. 30, D).

L'incinération a affecté des os frais, comme le montrent les fissurations en ondes concentriques des diaphyses. Presque tous les restes ont une couleur blanc crayeux, traduisant une température de crémation de l'ordre de $650^{\circ}$ selon le barème de $\mathrm{E}$. Bonnucci et G. Grazziani (Bonucci, Grazziani 1975).

Le poids moyen des fragments déterminés, toutes régions anatomiques confondues, est de $0,13 \mathrm{~g}(0,11 \mathrm{~g}$ pour la tête, $0,03 \mathrm{~g}$ pour le tronc et $0,14 \mathrm{~g}$ pour les membres).

\subsection{L'aire d'épandage}

Le matériel recueilli se répartit sur une aire d'au moins $1,1 \mathrm{~m}$ de long (mais une prolongation au sud hors du secteur fouillé ne peut être écartée) sur 0,6 m de large, à la surface du paléosol de la nécropole. Cette aire est composée d'alluvions limoneuses brunâtres semblables à celles qui recouvrent le sol, et ne s'en différencie que par la présence de petits fragments d'os humains brûlés, quelques petites pierres calcaires non roulées ayant éclaté au feu (aucune ne dépasse $10 \mathrm{~cm}$ d'arête), de rares petits charbons de bois épars, ainsi que quelques tessons de vases non tournés.

\section{Mobilier de l'aire d'épandage}

- Portion de la partie inférieure d'un grand couvercle non tourné de forme probable CNT-LOR V2a, 2 tessons représentant environ $20 \%$ du vase ; paroi, semble-t-il, rectiligne, pied annulaire, fond percé d'un large trou après cuisson ; diam. pied : $70 \mathrm{~mm}$ (fig. 30, $\mathrm{E}, \mathrm{n}^{\circ} 1$ ) ;

-9 petits tessons de céramiques non tournées appartenant, semble-t-il, à autant de récipients.

Os d'animaux (détermination A. Gardeisen) :

-1 fragment de racine de molaire (cf. bœuf) ;

- Indéterminés : 2 esquilles brûlées, noires. 


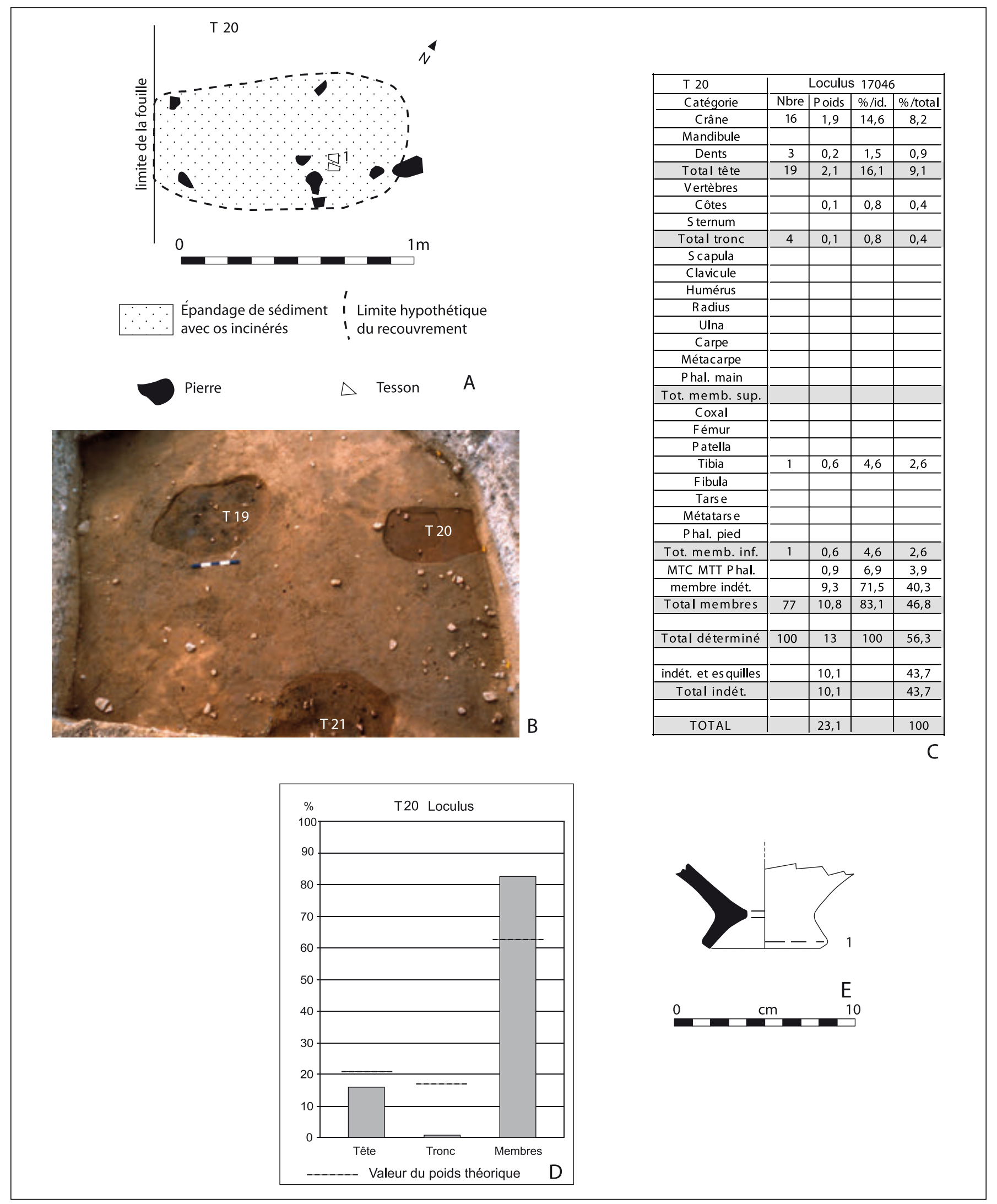

Fig. 30. Tombe T20. A : plan. B : vue des loculus des tombes 19, 20 et 21 prise du nord. C : tableau de détermination des os humains (poids en grammes ; calcul des \% sur la masse). D : répartition du poids des os par grandes régions anatomiques (\% par rapport au total déterminé).

E : mobilier (céramique non tournée). 


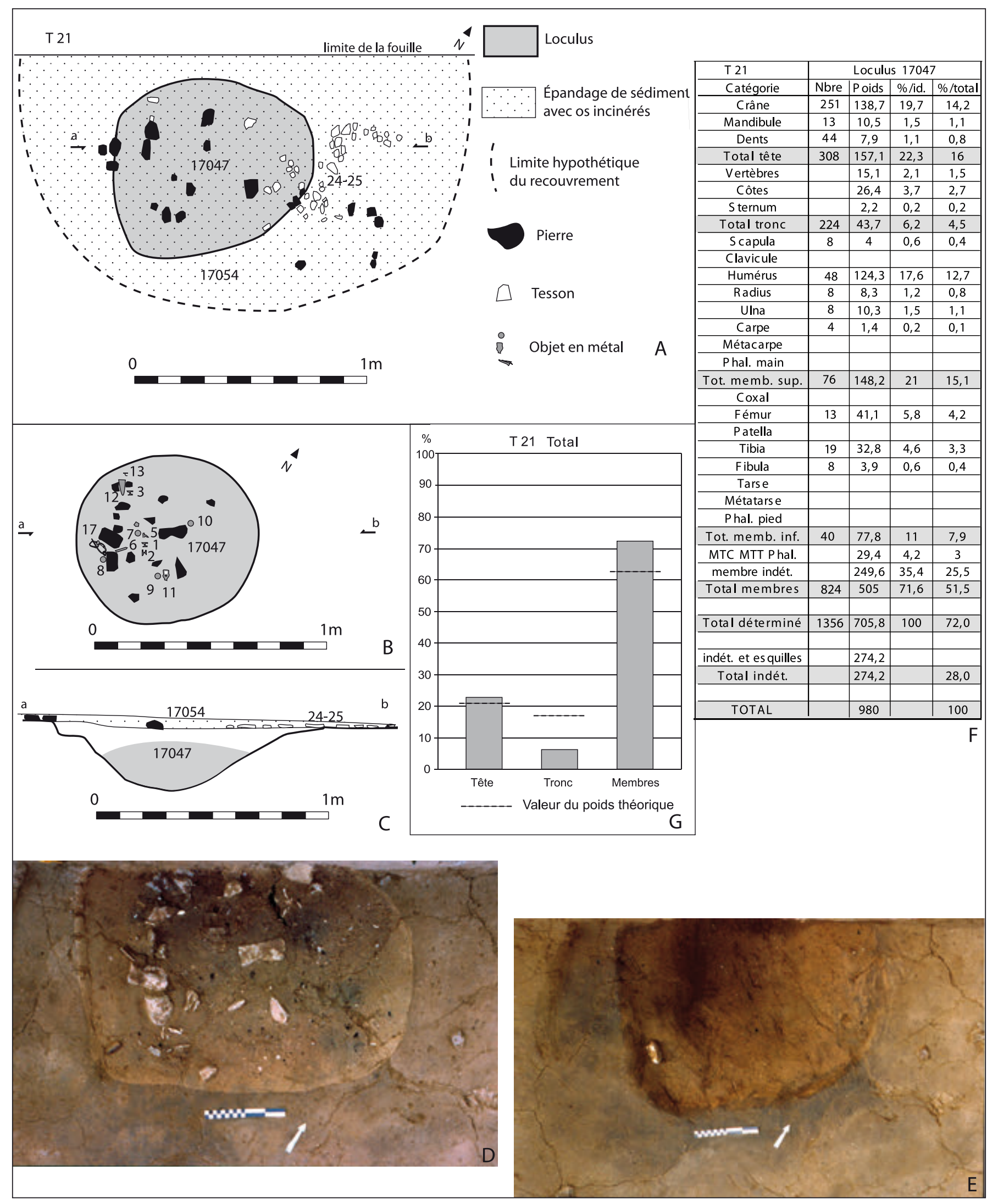

Fig. 31. Tombe 21. A : plan au niveau de la structure de recouvrement. B : plan du remplissage du loculus. C : coupe. D : remplissage du loculus en cours de fouille, vu du sud-est. $\mathrm{E}$ : loculus en fin de fouille, vu du sud-est. F : tableau de détermination des os humains (poids en grammes ; calcul des \% sur la masse). G : répartition du poids des os par grandes régions anatomiques (\% par rapport au total déterminé). 


\section{La tombe $\mathrm{T} 21$}

\section{1. État et composantes de la tombe}

La tombe T21 accueille un seul sujet incinéré, un adulte de sexe non déterminable ; le mobilier (voir infra) paraît cependant symboliser un homme. La sépulture comprend un loculus et une structure de recouvrement débordant largement tout autour, mais seule la moitié méridionale de cette dernière a pu être entièrement fouillée (fig. 31, A à E).

\subsection{Le défunt}

Le défunt est représenté par $980 \mathrm{~g}$ d'os brûlés (fig. 31, F). La morphologie des os, et en particulier les soudures des extrémités aux corps diaphysaires, ainsi que la fermeture des apex des dents montrent qu'il s'agit d'un adulte. Il pourrait cependant s'agir d'un adulte jeune car la face endocrânienne montre seulement un début de synostose des sutures, tandis que celles-ci sont encore libres sur l'exocrâne. Le sexe anthropologique ne peut pas être précisé. La couleur blanc crayeux révèle une température de crémation supérieure à $650^{\circ}$ selon le barème de E. Bonnucci et G. Grazziani (1975), et les morceaux de diaphyses sont très souvent fissurés en ondes concentriques, indice d'une incinération d'os frais.

Ces os ont été placés dans le loculus, hors de tout contenant, mais le mode de dépôt traduit deux gestes successifs. Dans la partie inférieure et centrale du loculus, a été déposé un magma cendreux et charbonneux, gris foncé à noirâtre, gluant, contenant de très nombreux morceaux d'os, souvent amalgamés entre eux, parfois de grande taille, certains segments de diaphyses atteignant quatre centimètres de long. Dans la partie périphérique du comblement, de couleur grisâtre à marron, les restes osseux, moins nombreux et plus fragmentés, sont dispersés. Aucune incompatibilité n'existe entre les deux lots qui, par ailleurs, proviennent des mêmes régions du corps. La partie fouillée du recouvrement n'a pas livré d'os humains ; on ne peut affirmer toutefois que la totalité des restes osseux ait été déposée dans le loculus, car on ignore si la moitié non fouillée du recouvrement est à l'image de la partie sud.

Le poids d'os déposés dans le loculus représente $60 \%$ du poids moyen d'un squelette d'adulte brûlé, 1627,1 g selon McKinley (1993). Les taux d'identification sont de $72 \%$ du poids total des fragments. La sur-représentation des membres est importante, 71,6\% du poids identifié pour un poids théorique de $62,6 \%$; le crâne est très légèrement sur-représenté, $22,3 \%$ au lieu des $20,4 \%$ attendus ; la représentation du tronc reste très faible, 6,2 \% (poids théorique : $17 \%$ ) (fig. 31, G).

Le poids moyen des fragments déterminés, toutes régions anatomiques confondues, est de $0,52 \mathrm{~g}(0,51 \mathrm{~g}$ pour la tête, $0,20 \mathrm{~g}$ pour le tronc et $0,61 \mathrm{~g}$ pour les membres). Le poids moyen est de $1,95 \mathrm{~g}$ pour les 76 fragments identifiés comme provenant des membres supérieurs et pour les 40 fragments identifiés comme provenant des membres inférieurs.

\subsection{Le loculus}

Le loculus (US 17047) est une cuvette de plan ovale de 70 à $90 \mathrm{~cm}$ d'axes à l'ouverture, à fond arrondi et aux parois abruptes, profonde de $31 \mathrm{~cm}$ (fig. 31, A à E). Le remplissage est composé d'un sédiment limoneux gris foncé à noirâtre, gluant, vers le centre et vers le fond, grisâtre à marron vers la périphérie. Il inclut, épars dans sa zone centrale comme dans sa périphérie, des nodules d'argile chauffée, des charbons de bois, en général inférieurs à $0,5 \mathrm{~cm}$, de rares pierres calcaires non roulées, n'excédant pas $10 \mathrm{~cm}$ d'arête, mais le plus souvent plus petites, certaines ayant éclaté au feu, des os humains brûlés, et des objets dispersés dans toute l'épaisseur du remplissage: trois tessons seulement de deux récipients, mais un abondant mobilier métallique se rapportant à une épée $\left(\mathrm{n}^{\circ} 1\right.$ à 5$)$, son fourreau $\left(\mathrm{n}^{\circ} 6\right)$ et sa suspension ( $\mathrm{n}^{\circ} 7$ à 11$)$, une lance $\left(\mathrm{n}^{\circ} 12\right)$, un bouclier $\left(\mathrm{n}^{\circ} 13\right.$ à $16)$, à $l^{\prime}$ habillement $\left(n^{\circ} 17\right)$ et à trois objets non déterminés ( $\mathrm{n}^{\circ} 18$ à 23 ). Certains des objets en bronze sont en fusion.

\section{Mobilier du loculus}

Objets personnels : armement et fourniment

- Cinq rivets en fer (fig. 32, $\mathrm{n}^{\circ} 1$ à 5), pourvus d'une tête discoïde à chacune des deux extrémités, permettant la fixation des éléments de garniture de la poignée d'une épée ; l'un d'eux ( $\left.\mathrm{n}^{\circ} 5\right)$ est cassé au niveau du départ d'une tête. Les têtes ont un même diamètre de chaque côté, mais, selon l'extrémité, elles n'ont cependant pas la même forme : légèrement bombées d'un côté ; de l'autre légèrement concaves (fig. 32, $\mathrm{n}^{\circ} 1$ - 3 et sans doute 5) ou avec un petit bourrelet périphérique $\left(\mathrm{n}^{\circ} 4\right)$; les tiges ont une section ronde ; long. $\mathrm{n}^{\circ} 1$ à $4: 20 \mathrm{~mm} ; 20 \mathrm{~mm} ; 18 \mathrm{~mm}$; $24 \mathrm{~mm}$; long. cons. $\mathrm{n}^{\circ} 5: 18 \mathrm{~mm}$; diam. têtes : $11 \mathrm{~mm}$;

- Six morceaux de bord en gouttière de la plaque avers d'un fourreau d'épée, en tôle de fer (fig. 32, 


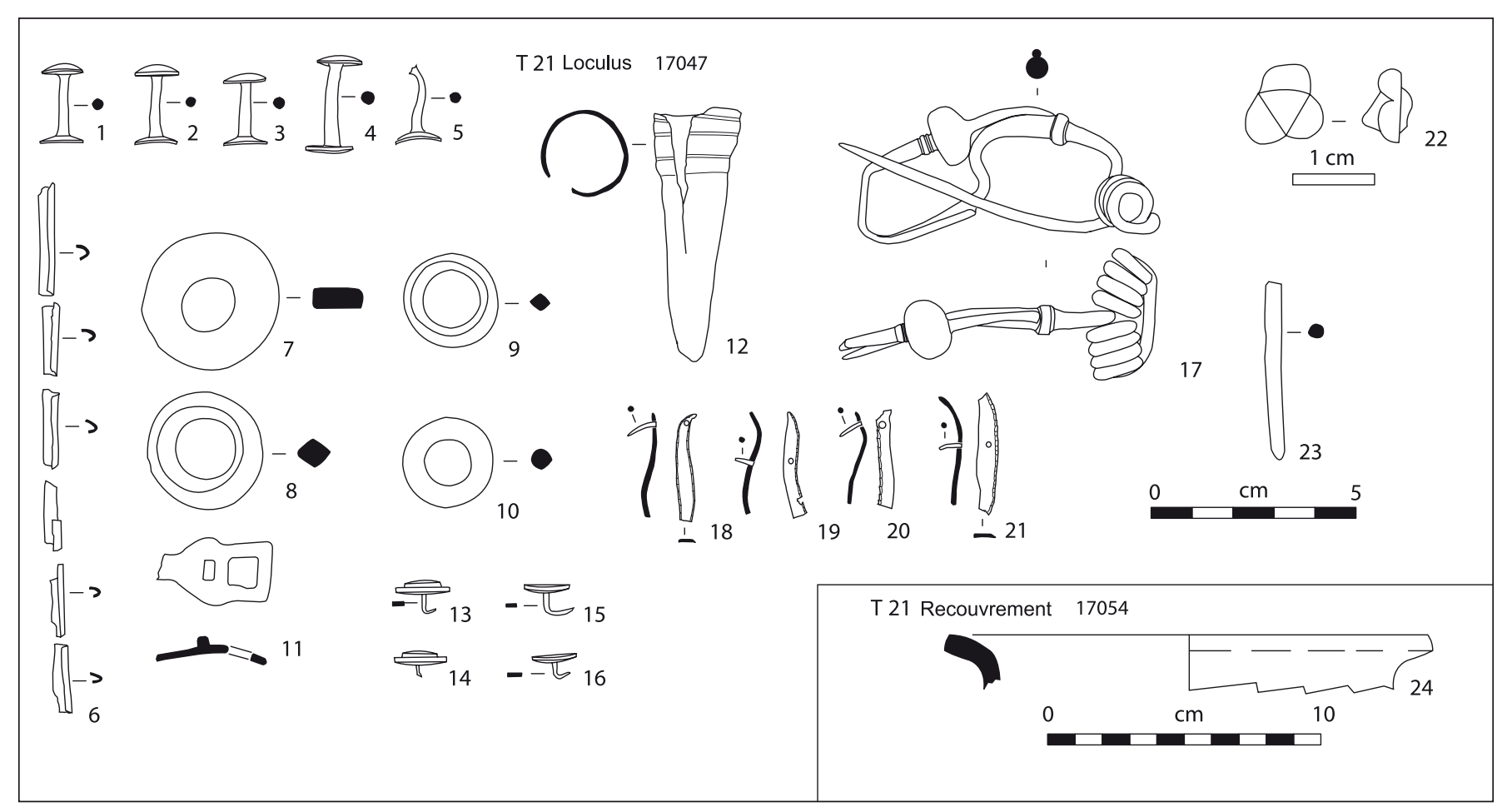

Fig. 32. Tombe T21. Mobilier (1-9 et 12-21 et $23:$ fer ; 10, 11 et $22:$ bronze ; 24 : céramique non tournée).

$\left.\mathrm{n}^{\circ} 6\right)$; long. cons. : $27 \mathrm{~mm} ; 16,5 \mathrm{~mm} ; 18 \mathrm{~mm} ; 16 \mathrm{~mm}$; $16 \mathrm{~mm}$; ép. tôle : $0,7 \mathrm{~mm}$;

- Quatre anneaux (fig. 32, n ${ }^{\circ} 7$ à 10), dissemblables, en fer ou en bronze, et une agrafe en bronze $\left(n^{\circ} 11\right)$, se rapportant à la lanière de cuir permettant la suspension d'un fourreau d'épée :

- Anneau circulaire plat, en fer (fig. 32, $\mathrm{n}^{\circ}$ 7), section rectangulaire; légèrement bombé sur une face; diam. : $35 \mathrm{~mm}$; haut. : 4,5 à $8 \mathrm{~mm}$;

- Anneau circulaire, en fer (fig. 32, $\mathrm{n}^{\circ}$ 8), section losangique ; diam. : $29 \mathrm{~mm}$; haut. : $7 \mathrm{~mm}$;

- Anneau circulaire, en fer (fig. 32, $\mathrm{n}^{\circ}$ 9), section losangique ; diam. : 23 à $24 \mathrm{~mm}$; haut. : $5 \mathrm{~mm}$;

- Anneau circulaire, en bronze (fig. 32, $\mathrm{n}^{\circ}$ 10), section circulaire ; diam. : 22,5 mm ; haut. : $5 \mathrm{~mm}$;

- Agrafe de ceinture, en bronze (fig. 32, $\mathrm{n}^{\circ} 11$ ); boucle rectangulaire ; corps cordiforme ; crochet manquant ; long. cons. : $27 \mathrm{~mm}$; larg. : $16 \mathrm{~mm}$.

- Talon de lance en fer $\left(\mathrm{n}^{\circ} 12\right)$, formé d'une simple douille conique, courte, large et à pointe mousse, élaborée à partir d'une feuille de tôle enroulée dont les bords sont bien visibles; trois moulures vers le bord; pas de trou de fixation apparent; diam. ouv. : 21 à 21,5 mm; long. : $62 \mathrm{~mm}$; ép. $1 \mathrm{~mm}$.

- Quatre rivets de fixation d'ailettes d'un umbo de bouclier, en fer (fig. 32, $\mathrm{n}^{\circ} 13$ à 16) :

- deux exemplaires à tête discoïde (fig. 32, $\mathrm{n}^{\circ} 13$ et 14), dont la partie centrale est légèrement bombée ; diam. : $13 \mathrm{~mm}$; tige de section quadrangulaire très fine, incomplète pour le $\mathrm{n}^{\circ} 14$, repliée à angle droit pour le $\mathrm{n}^{\circ} 13$ et déterminant une épaisseur de $4 \mathrm{~mm}$ pour la planche du bouclier ;

- deux exemplaires à tête discoïde (fig. 32, $\mathrm{n}^{\circ} 15$ et 16), dont la partie centrale est légèrement concave ; diam. : $11 \mathrm{~mm}$; tige de section quadrangulaire très fine, repliée à angle droit et déterminant une épaisseur de $4 \mathrm{~mm}$ et de $3 \mathrm{~mm}$ pour la planche du bouclier.

Objet personnel : parure et habillement

- Fibule en fer (fig. 32, $\mathrm{n}^{\circ} 17$ et fig. 115), complète ; ressort à deux fois quatre spires et corde externe ; arc en tige légèrement épaissie au centre, de section circulaire et de forme outrepassée ; grand pied recourbé formant deux angles arrondis et venant se fixer au sommet de l'arc par deux petites griffes; près de l'arc, ce pied est orné d'une grosse perle en bulbe d'oignon, confectionnée dans la masse du métal, précédée de stries transversales ; long porte-ardillon; long. : $77 \mathrm{~mm}$; larg. au ressort : $36 \mathrm{~mm}$; type 13b de R. Gebhard (1991).

Objets métalliques non déterminés :

- Quatre lamelles en fer (fig. 32, $\mathrm{n}^{\circ} 18$ à 21), en ruban légèrement sinueux et ondulé, pointu à une extrémité, coupé en biais à l'autre ; les bords sont chanfreinés et décorés de légères indentations ; chaque lamelle possède au moins un fin rivet rectiligne et très pointu ; long. 
lamelle : 25 à $29 \mathrm{~mm}$; larg. max. : $5 \mathrm{~mm}$; ép. : $1 \mathrm{~mm}$; long. max. rivet: $6 \mathrm{~mm}$. Ces lamelles devaient être clouées sur un support; il peut s'agir d'éléments de décoration d'une poignée d'épée, d'un fourreau ou d'un coffret ;

- Tête de clou (?) en bronze ; sur une face, une pointe centrale pyramidale à base triangulaire équilatérale et trois renflements périphériques en croissant; face opposée irrégulière ; $9 \mathrm{~mm}$ d'axes et $7 \mathrm{~mm}$ d'épaisseur maximum (fig. 32, $\mathrm{n}^{\circ} 22$ ) ;

- Segment de tige en fer (fig. 32, $\mathrm{n}^{\circ} 23$ ) ; long. cons. : $44 \mathrm{~mm}$; diam. : $4 \mathrm{~mm}$ (objet non restauré);

-3 petits fragments de tôle de bronze, recourbée ; ép. : $1 \mathrm{~mm}$; objet indéterminé (non dessiné) ;

-5 petits fragments et gouttes de bronze en fusion (non dessiné).

Matériel céramique : tessons de vases isolés

-2 tessons de la panse peignée d'une grande urne non tournée (non dessiné) ;

- 1 tesson de panse d'urne ou d'œnochoé à pâte claire massaliète (non dessiné).

Os d'animaux (détermination A. Gardeisen) :

- 24 fragments d'un métacarpien droit d'équidé, incomplet, se rapportant à l'extrémité proximale, à la diaphyse et à l'extrémité distale (DT proximal : 44,5 mm ; DAP proximal : 29,8 mm). Cet os est brûlé de façon irrégulière, certaines zones étant carbonisées alors que d'autres ne montrent que des effets de la chaleur. Il semblerait qu'il ait été brûlé et en partie cassé sur le feu, à la suite de quoi seuls quelques fragments ont été pris, intentionnellement ou non, pour être déposés dans le loculus. Il paraît en effet peu probable que l'os ait été placé complet dans la tombe : les conditions taphonomiques n'expliqueraient pas la quasi -absence de la diaphyse qui par nature, est une portion extrêmement résistante chez cette espèce ;

- Indéterminés : 23 esquilles non brûlées.

\subsection{La structure de recouvrement}

La partie fouillée de la superstructure US 17054 comprend deux sortes de vestiges. Quelques rares pierres et tessons sont éparpillés, à plat, sur le dessus du comblement du loculus ou sur le paléosol de la nécropole jusqu'à environ $0,5 \mathrm{~m}$ du bord du loculus. Une portion très fragmentée de la partie supérieure d'une urne non tournée est écrasée sur le dessus de la partie orientale du remplissage du loculus et sur le paléosol (fig. 32, $\mathrm{n}^{\circ} 24$ ). L'ensemble est recouvert, sur une épaisseur de 3 à $5 \mathrm{~cm}$ par un épandage d'alluvions limoneuses brunâtres, enfermant de très rares petits fragments d'os humains brûlés. Ce recouvrement déborde de 20 à $50 \mathrm{~cm}$ le loculus, et dans le secteur fouillé mesure $2 \mathrm{~m}$ de diamètre (fig. 31, A).

\section{Mobilier de la structure de recouvrement}

Matériel céramique :

- Portion de la partie supérieure d'une urne non tournée de forme probable CNT-LOR U5d, 120 petits tessons représentant environ $15 \%$ du récipient : bord déversé à lèvre aplatie, col tronconique rentrant lissé, panse ovoïde peignée ; diam. ouv. : $180 \mathrm{~mm}$ (fig. 32, $\mathrm{n}^{\circ} 24$ ) ;

-2 tessons de panse de deux autres vases non tournés (non dessiné).

\section{La tombe $T 22$}

\section{1. État et composantes de la tombe}

La tombe T22 appartient à un jeune enfant, âgé entre deux et quatre ans. Elle comprend un loculus (US 17138) et une structure de surface (US 17136) qui recouvre aussi la tombe 23 toute proche, dont le loculus n'est qu'à $0,4 \mathrm{~m}$ de celui de la tombe 22 . L'ensemble a été entièrement fouillé (fig. 33, 34 et 35, A et B).

\subsection{Le défunt}

Le défunt est représenté par $88,9 \mathrm{~g}$ d'os brûlés (fig. 35, C). L'essentiel (87,4 g) provient du loculus (US 17138); quelques esquilles compatibles avec ce lot, d'un poids de $1,5 \mathrm{~g}$, figurent aussi dans la structure de recouvrement (US 17136). La morphologie des os, particulièrement ceux du crâne, et surtout la dentition permettent de fixer l'âge au décès entre deux et quatre ans : 8 racines et 28 fragments de couronnes de dents déciduales, germes ou fragments de germes de dents définitives dont $\mathrm{I}^{1} \mathrm{~d}$, $\mathrm{I}^{1} \mathrm{~g}, \mathrm{I}_{2} \mathrm{~d}$ ou g, $\mathrm{C}^{\mathrm{I}} \mathrm{d}$ ou g, $\mathrm{C}_{\mathrm{I}} \mathrm{d}$ ou g, et $\mathrm{M}_{1} \mathrm{~g}$. La couleur blanc crayeux révèle une température de crémation supérieure à $650^{\circ}$ selon le barème de $\mathrm{E}$. Bonnucci et G. Grazziani (1975), et les morceaux de diaphyses sont très souvent fissurés en ondes concentriques, indice d'une incinération d'os frais.

Les taux d'identification sont de $85,3 \%$ du poids total des fragments. La sur-représentation de la tête est très importante, $64,5 \%$ du poids d'os identifiés, mais 


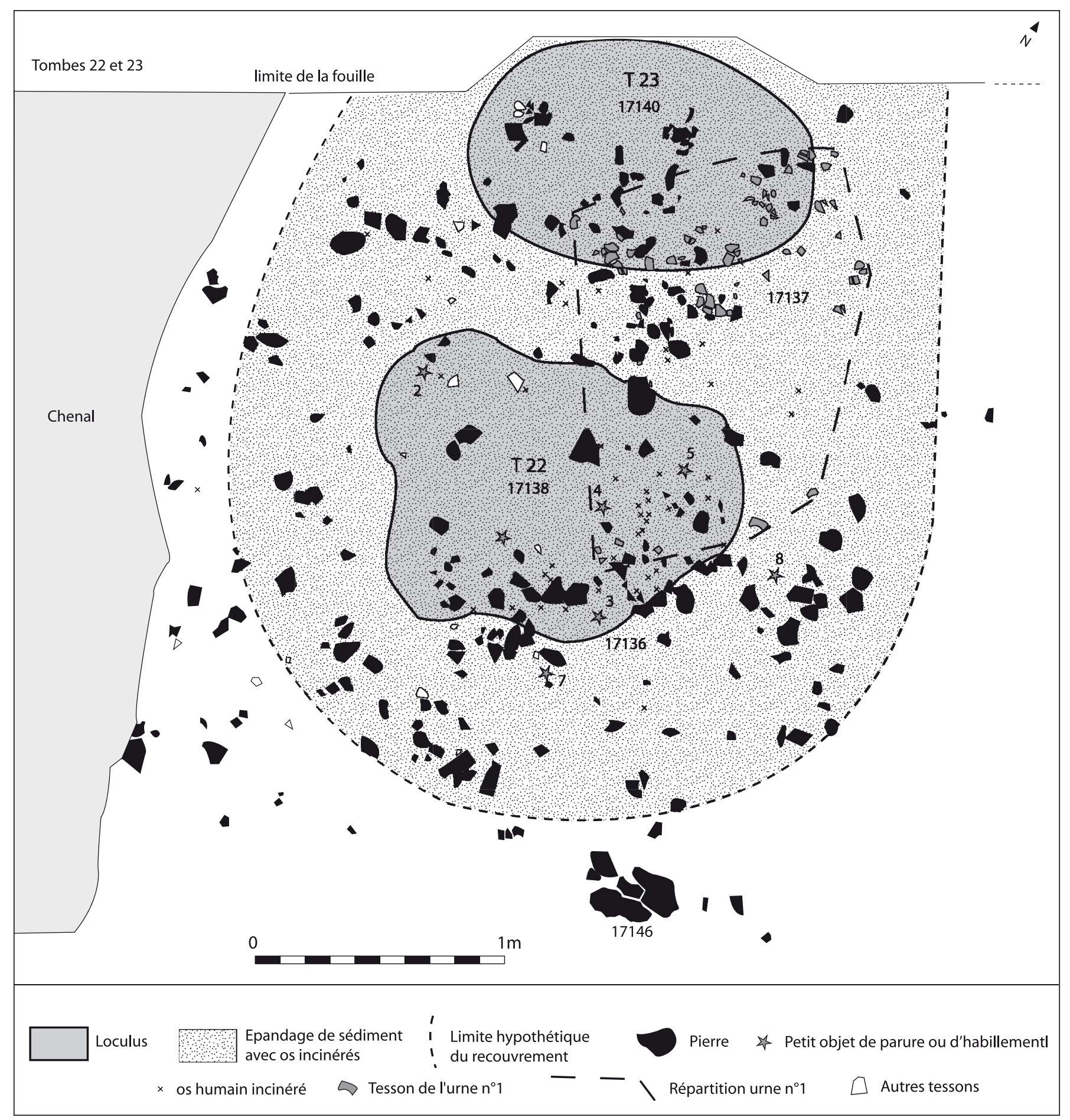

Fig. 33. Recouvrement des tombes T22 et T23 et structure annexe 17146. Plan.

c'est là un fait courant dans les tombes de jeunes enfants (fig. 35, C) (voir supra, tombe 13).

Dans le loculus, les os ont été déposés hors de tout contenant, plus nombreux dans la partie inférieure du comblement (US 17138-2) que dans sa partie supérieure (US 17138-1). Dans la partie inférieure, ont été versées des poignées de résidus du bûcher, non triés : les fragments osseux, de taille souvent supérieure à ceux du haut du loculus, sont agglutinés au sein de plusieurs lentilles cendreuses et charbonneuses. Dans la partie supérieure, les restes du défunt sont éparpillés dans la terre alluviale ayant servi au remplissage de la fosse. Dans la structure de recouvrement, les quelques restes osseux sont dispersés. 


\subsection{Le loculus}

Le loculus (US 17138) est une large cuvette, de plan grossièrement ovalaire, mesurant à l'ouverture $1,5 \mathrm{~m}$ sur l'axe SO-NE et 1,1 m sur l'axe NO-SE. Sa profondeur maximum atteint $36 \mathrm{~cm}$, mais son fond est irrégulier. En effet, son creusement montre deux tranches : une partie supérieure (US 17138-1) large, sur $14 \mathrm{~cm}$ de profondeur, aux parois très peu inclinées ; une partie inférieure (US 17138-2) de moindre extension, de 0,8 m d'axe NS et $0,65 \mathrm{~m}$ d'axe $\mathrm{EO}$, mais de $22 \mathrm{~cm}$ de profondeur, aux parois abruptes (fig. 33, $\mathbf{3 4}$ et 35, A et B).

Le comblement de la partie supérieure US 17138-1 est composé d'une terre alluviale jaunâtre, par endroits gris sombre, mouchetée de petits charbons de bois millimétriques ou plus rarement centimétriques, épars et, d'une manière générale, ne présentant pas une forte densité. Il comprend des pierres décimétriques, essentiellement réparties, mais de manière discontinue, au-dessus de la partie la plus profonde de la fosse et vers le centre. Ce sont des éléments calcaires non roulés, provenant de la colline du Dévès. Quelques-uns portent des traces nettes de rubéfaction, mais, pour la plupart, il est impossible de savoir si les éclatements sont dus au feu. Sont inclus dans cette partie du comblement, de manière très dispersée, de rares fragments osseux humains incinérés, le plus souvent de très petites dimensions, et de petites perles très fines en pâte de verre bleue.

Le comblement de la partie inférieure US 17138-2 est de couleur plus sombre. C'est toujours une terre limoneuse alluviale, mais le mélange de terre charbonneuse est plus important. Les charbons de bois y sont plus gros et moins rares. Par endroits, on rencontre des poches grises et noirâtres avec morceaux osseux incinérés plus gros mélangés à des charbons et des cendres. De petites perles très fines en pâte de verre bleue, semblables à celles de l'US 17138-1, sont également dispersées dans ce comblement.

De nombreux petits tessons de céramiques non tournées, ainsi que quelques rares tessons de dolium et d'amphore massaliète sont également éparpillés dans le comblement, souvent plaqués contre la paroi de la fosse et en position verticale. Ce loculus est relativement profond et son creusement a atteint et dépassé le niveau d'aménagement caractérisé par des pierres et des galets (us 17125-17180-17184), antérieur à la nécropole et repéré aux alentours immédiats de cette tombe (voir supra chap. 1). La présence de ces tessons de vases dans ce loculus pourrait donc être accidentelle et provenir de cette couche, remaniée lors de l'aménagement du loculus : l'abondance de ces éléments, le fait que chacun, ou presque, relève d'un vase différent et le caractère hétérogène de cet assemblage plaident en faveur de cette hypothèse.

\section{Mobilier du loculus}

Objets de parure :

- Nombreux éléments d'un collier, comprenant :

- Un anneau en bronze, incomplet et brisé en deux morceaux ; section lenticulaire ; diam. ext. : $26 \mathrm{~mm}$; cet objet a subi l'action du feu (fig. 35, E, $\mathrm{n}^{\circ} 1$ );

- 56 petites perles en pâte de verre; parmi elles, 55 de couleur bleue et 1 de couleur jaune ; section arrondie, fine et irrégulière; diam. ext. : de 5 à $6 \mathrm{~mm}$ pour 55 d'entre-elles, et $7 \mathrm{~mm}$ pour une seule. Beaucoup de ces perles sont plus ou moins déformées par le feu (fig. 35, $\left.\mathrm{E}, \mathrm{n}^{\circ} 2\right)$;

- Une moitié de perle moyenne, en pâte de verre bleue ; section en D ; diam. ext. : 1 mm (fig. 35, E, $\mathrm{n}^{\circ} 3$ ) ;

- Une grosse perle, en pâte de verre bleue, complètement déformée par le feu ; diam. ext. : env. 1,5 mm (fig. 35, E, $\mathrm{n}^{\circ} 4$ ).

Objet métallique indéterminé :

- Un petit fragment de tôle de bronze découpée; long. cons. : $8 \mathrm{~mm}$; ép. : 0,5 mm (fig. 35, E, $\mathrm{n}^{\circ} 5$ ).

Tessons contenus dans le remplissage, dont la présence est peut-être involontaire :

-5 tessons de bords déversés de cinq urnes non tournées, de forme probable CNT-LOR U5d (fig. 35, E, n ${ }^{\circ} 6$ à 10) ;

- 10 tessons d'épaules de quatre urnes non tournées de forme probable CNT-LOR U5d (il peut s'agir des mêmes exemplaires que les précédents) : trois épaules décorées de grandes impressions au peigne disposées en une ou deux lignes brisées (fig. 35, E, n ${ }^{\circ} 11$ à 13) ; une autre ornée d'impressions au peigne horizontal (fig. 35, E, $\mathrm{n}^{\circ} 14$ ) ; épaules et panses sont peignées horizontalement ;

-76 petits tessons et quelques esquilles de panses de vases non tournés appartenant, semble-t-il, à autant d'urnes et coupes (non dessinés) ;

- 6 fragments de panses de dolia non tournés (non dessinés) ;

- 6 fragments de panses d'amphores massaliètes (non dessinés) ;

- 1 petit tesson de bord de kylix à pâte claire massaliète de forme CL-MAS 433 (fig. 35, E, $\mathrm{n}^{\circ} 15$ ) ;

- 1 morceau de couvercle circulaire, taillé dans un tesson de panse de grand vase non tourné, dépourvu de peignage ; diam. : $85 \mathrm{~mm}$ (fig. 35, $\mathrm{E}, \mathrm{n}^{\circ} 16$ ). 
Os d'animaux (détermination A. Gardeisen) :

- 4 fragments de frontal d'un porc juvénile, brûlés à blanc ;

- Indéterminés : 49 esquilles à différents degrés de combustion (couleurs bleu, blanc, noir);

- Microfaune : 1 os long de batracien.

\section{La tombe $\mathrm{T} 23$}

\section{1. État et composantes de la tombe}

La tombe T23 a accueilli un adulte de sexe non déterminé, mais d'après le mobilier associé, il s'agirait d'une femme. Elle comprend un loculus (US 17140) et une structure de surface (US 17136) qui recouvre aussi la tombe 22. Cette sépulture est complète, à l'exception de la partie septentrionale du recouvrement qui s'étend en dehors de l'emprise de la fouille (fig. 33, 34, et 36, A).

\subsection{Le défunt}

Le défunt est représenté par 352,3 g d'os brûlés, qui proviennent du loculus (US 17140) (fig. 36, B). D'après la morphologie des os, et en particulier la synostose des extrémités aux corps diaphysaires et la fermeture de l'apex sur la racine dentaire, on a affaire à un adulte. Les sutures sont synostosées en face endocrânienne et en cours de synostose en face exocrânienne. Par ailleurs, le sexe anthropologique ne peut être précisé. La crémation a été faite à une température supérieure à $650^{\circ}$ comme le révèle la couleur blanc crayeux des fragments (selon le barème de E. Bonnucci et G. Grazziani ; 1975). Et ce sont bien des os frais qui ont été brûlés car les morceaux de diaphyses sont très souvent fissurés en ondes concentriques. Les os ont été placés dans le loculus, hors de tout contenant, irrégulièrement répartis dans le comblement.

Sur l'ensemble du lot, 79,6\% du poids total des fragments ont pu être identifiés. La représentation des membres, $65,2 \%$ du poids des fragments reconnus, est presque conforme au poids théorique $(62,6 \%)$. Avec $33,3 \%$ du poids des fragments identifiés, celle du crâne est anormalement forte (poids théorique : 20,4\%). Le tronc est, pour sa part extrêmement sous-représenté : $1,5 \%$ au lieu des $17 \%$ attendus. Le poids d'os représente $21,7 \%$ du poids moyen d'un squelette d'adulte brûlé (1627,1 g selon McKinley 1993), et comme la structure de recouvrement n'a livré que très peu d'os
(7,1 g qui se répartissent entre les défunts des tombes 22 et 23), on a, là, la quasi-totalité des restes de ce défunt déposés dans la sépulture (fig. 36, C).

Le poids moyen des fragments déterminés, toutes régions anatomiques confondues, est de $0,26 \mathrm{~g}(0,26 \mathrm{~g}$ pour la tete, $0,10 \mathrm{~g}$ pour le tronc et $0,27 \mathrm{~g}$ pour les membres).

\subsection{Le loculus}

Le loculus (US 17140) est une cuvette de plan ovalaire, mesurant $1,4 \mathrm{~m}$ sur son grand axe ouest-est, et $0,8 \mathrm{~m}$ sur le petit axe nord-sud, peu profonde, $8 \mathrm{~cm}$ au maximum. Le fond est à peu près plat et les parois d'inclinaison très variable, par endroits verticales (fig. 33, 34 et 36, A). Son remplissage comprend deux couches.

À la base (US 17145) prend place une terre limoneuse alluviale de couleur gris moyen, mêlée de cendres et de charbons de bois millimétriques dispersés. Cette couche renferme de nombreux fragments osseux humains incinérés, parfois de dimensions importantes, épars sur l'ensemble de la surface, et quelques petits tessons de vases non tournés.

Sur le sommet de cette strate reposent deux concentrations de pierres calcaires issues de la colline du Dévès, l'une à l'ouest, l'autre au centre du loculus, chacune constituée d'un seul lit d'éléments (US 17144) (fig. 36, A). Ces pierres portent des traces de feu et certaines ont éclaté à la chaleur mais les morceaux sont restés jointifs en place. Une terre semblable à celle de l'US 17145 lie entre eux ces éléments. La concentration centrale, mais aussi le dessus de l'US 17145 plus à l'est, sont partiellement recouverts par de gros morceaux de charbons de bois décimétriques provenant de morceaux de bûches en place. Sous ces bûches, le contact avec la couche US 17145 et avec la terre liant les pierres de l'US 17144 est fortement rougi. Ce sont des morceaux de bûches incandescents qui ont été placés dans le comblement de la fosse, ce qui a occasionné la fragmentation des pierres, dont les morceaux se sont maintenus en place, et la rubéfaction de l'interface. Le sédiment de l'US 17144 enrobe de nombreux morceaux d'os humains incinérés et quelques tessons non tournés de petite taille. Une fusaïole se trouve entre les deux concentrations pierreuses (fig. 34 et $\mathbf{3 6}, \mathrm{n}^{\circ}$ 5). Sur ou entre les pierres de la concentration occidentale, prennent place quatre morceaux de bracelets en bronze se rapportant à deux ou trois exemplaires (fig. 34 et $\mathbf{3 6}, \mathrm{n}^{\circ} 1$ à 3 ). L'un de ces morceaux a subi un début de fusion. Sur le dessus de la concentration centrale de pierres, parmi les bûches 


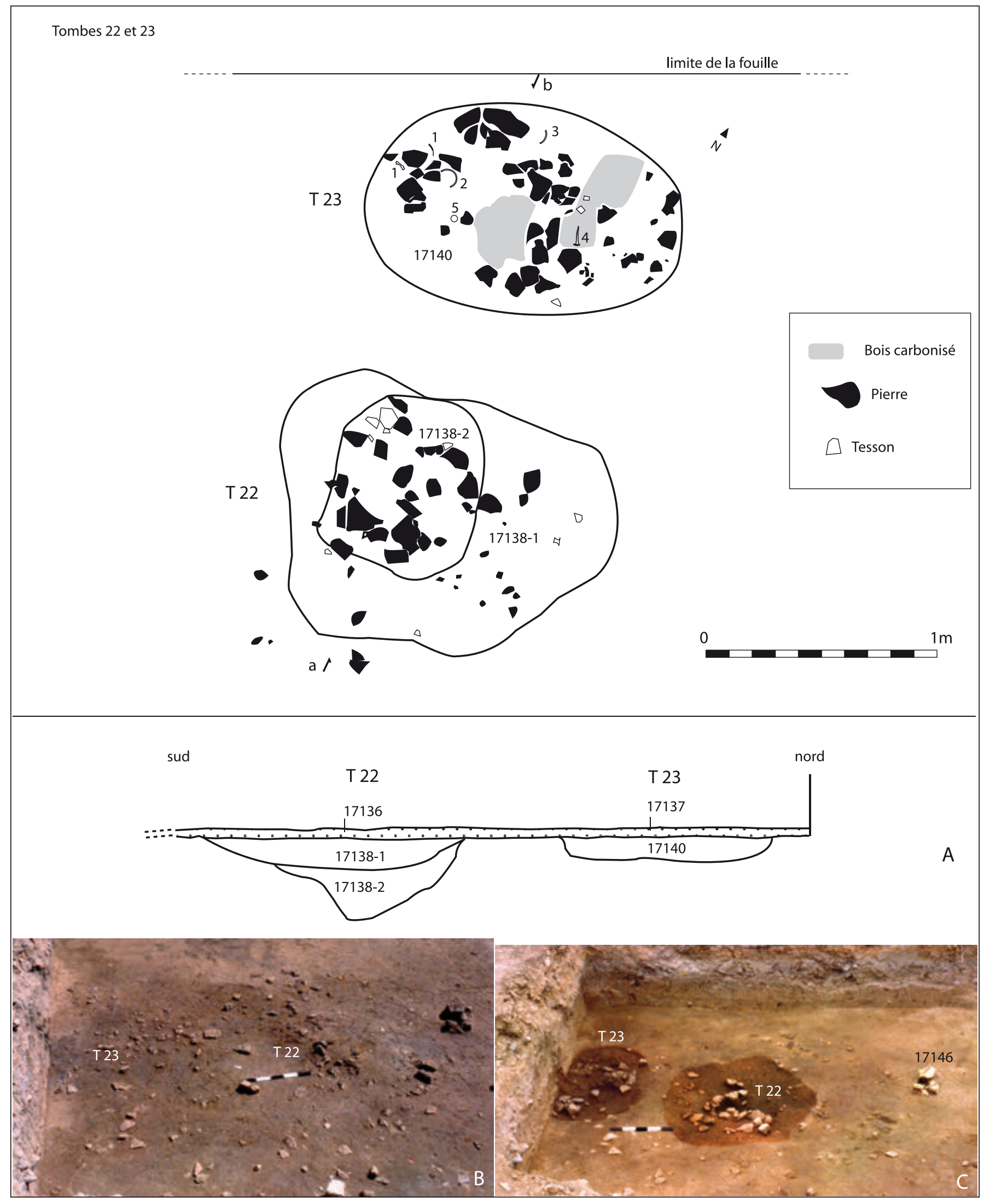

Fig. 34. Tombes 22 et 23. A : plan et coupes. B : structure de recouvrement en cours de fouille, vue du sud-ouest. C : loculus des tombes 22 et 23 en cours de fouille, vus sud-ouest). 


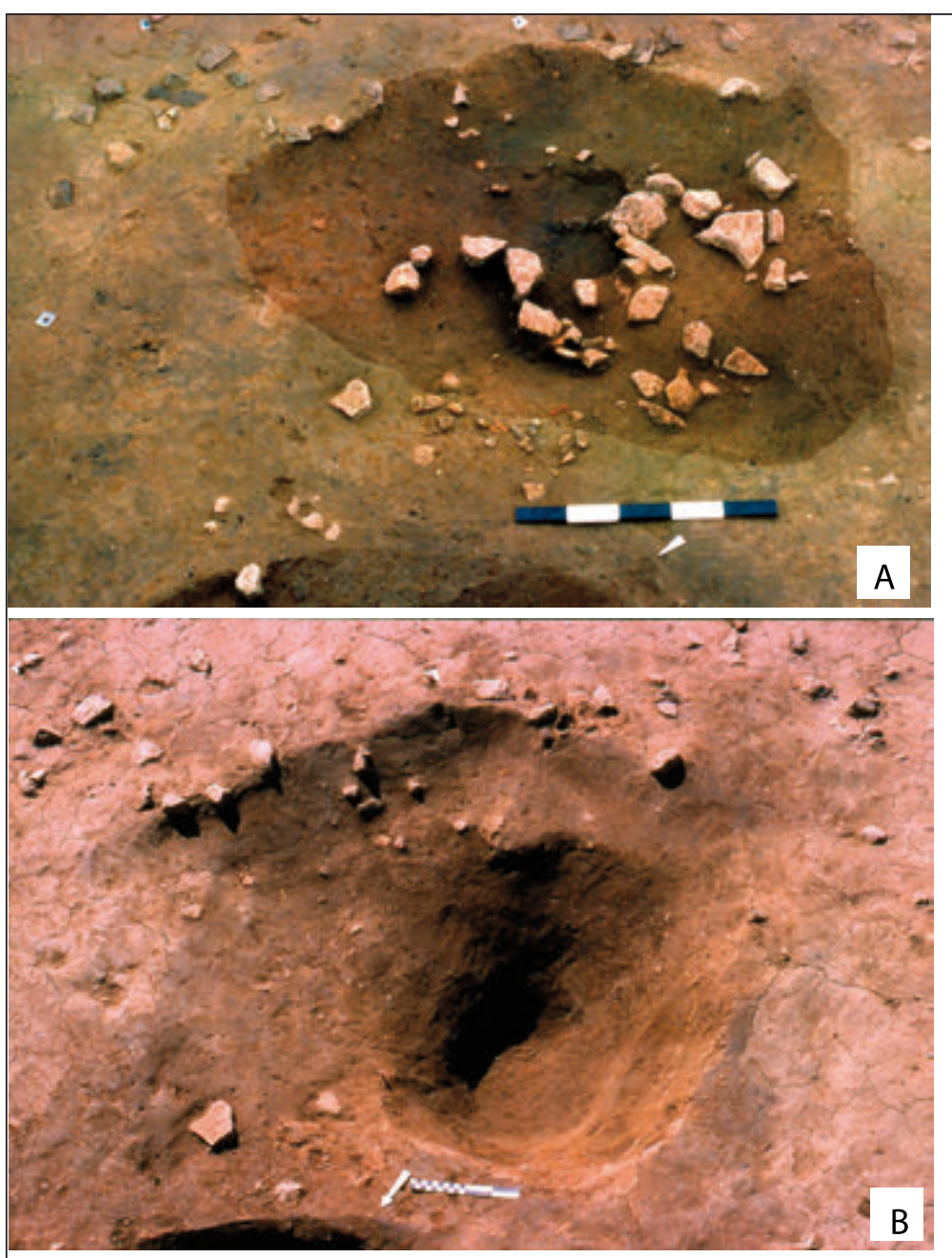

T 22

\begin{tabular}{|c|c|c|c|}
\hline T 22 & \multicolumn{3}{|c|}{ Loculus 17138} \\
\hline Catégorie & Poids & $\%$ /id. & $\% /$ total \\
\hline Crâne & 44,9 & 60,2 & 51,4 \\
\hline Mandibule & & & \\
\hline Dents & 3,2 & 4,3 & 3,7 \\
\hline Total tête & 48,1 & 64,5 & 55 \\
\hline Vertèbres & 1 & 1,3 & 1,1 \\
\hline Côtes & 3,2 & 4,3 & 3,7 \\
\hline Sternum & & & \\
\hline Total tronc & 4,2 & 5,6 & 4,8 \\
\hline Scapula & & & \\
\hline Clavicule & & & \\
\hline Humérus & & & \\
\hline Radius & & & \\
\hline Ulna & & & \\
\hline Carpe & & & \\
\hline Métacarpe & & & \\
\hline Phal. main & 0,4 & 0,5 & 0,5 \\
\hline Tot. memb. sup. & 0,4 & 0,5 & 0,5 \\
\hline Coxal & & & \\
\hline Fémur & & & \\
\hline Patella & & & \\
\hline Tibia & & & \\
\hline Fibula & & & \\
\hline Tarse & & & \\
\hline Métatarse & & & \\
\hline P hal. pied & & & \\
\hline Tot. memb. inf. & & & \\
\hline MTC MTT P hal. & & & \\
\hline membre indét. & 21,9 & 29,4 & 25,1 \\
\hline Total membres & 22,3 & 29,9 & 25,5 \\
\hline & & & \\
\hline Total déterminé & 74,6 & 100 & 85,3 \\
\hline indét. et es quilles & 12,8 & & 14,6 \\
\hline Total indét. & 12,8 & & 14,6 \\
\hline & & & \\
\hline TOTAL & 87,4 & & 100 \\
\hline & & & C \\
\hline & & \\
\hline
\end{tabular}

T 22 Loculus

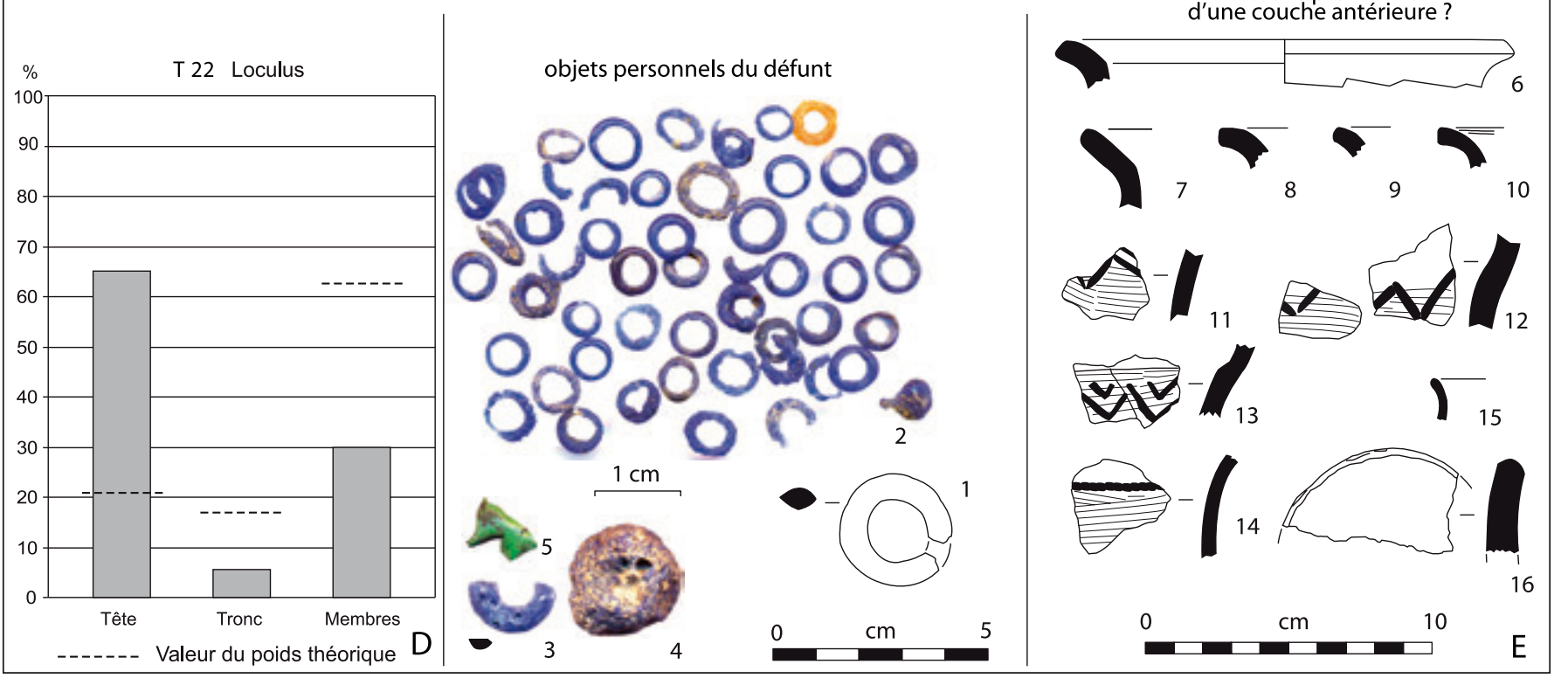

Fig. 35. Tombe T22. A : sommet du remplissage du loculus, vue prise du nord-ouest. B : loculus en fin de fouille, vue prise du nord-ouest. C : tableau de détermination des os humains (poids en grammes; calcul des \% sur la masse). D : répartition du poids des os par grandes régions anatomiques (\% par rapport au total déterminé). $E$ : mobilier (1 et $5:$ bronze ; 2-4 : verre ; $6-14$ et 16 : céramique non tournée ; 15 : céramique à pâte claire massaliète). 
carbonisées, figure aussi un gros clou en fer (fig. 34 et 36, $\mathrm{n}^{\circ} 4$ ). Vers la périphérie sud et est du loculus, le sédiment est moins sombre, et les charbons et les os incinérés sont plus rares.

\section{Mobilier du loculus}

Objets personnels, parure :

- 2 morceaux jointifs d'un bracelet en bronze (fig. 36, $\mathrm{n}^{\circ} 1$ ), incomplet; section lenticulaire; pas de décor ; diam. int. : $70 \mathrm{~mm}$; haut. de la tige : $6 \mathrm{~mm}$. Un des deux morceaux est en fusion, tandis que l'autre ne porte pas trace d'un feu secondaire : le bracelet a donc été cassé avant d'être placé sur le bûcher ;

- Moitié d'un second bracelet en bronze (fig. 36, $\mathrm{n}^{\circ} 2$ ), incomplet; section lenticulaire; pas de décor; diam. int. : $63 \mathrm{~mm}$; haut. de la tige : 6 à $7,5 \mathrm{~mm}$;

- Segment de bracelet en bronze (fig. 36, $\mathrm{n}^{\circ} 3$ ) ; section lenticulaire ; pas de décor ; diam. int. : env. $70 \mathrm{~mm}$; haut. de la tige : $7 \mathrm{~mm}$. Ce morceau peut appartenir au bracelet précédent ou à un troisième exemplaire.

Objet personnel, ustensile :

-1 grosse fusaïole en terre cuite (fig. 36, $\mathrm{n}^{\circ} 5$ ); biconique à carène très adoucie ; diam. : $37 \mathrm{~mm}$; haut. : $24 \mathrm{~mm}$.

Objet métallique d'usage non déterminé :

-1 grand clou en fer (fig. 36, $\mathrm{n}^{\circ} 4$ ) ; tête discoïde, légèrement bombée; tige de section quadrangulaire; diam. tête : $21 \mathrm{~mm}$; long. : $69 \mathrm{~mm}$.

Matériel céramique : tessons de vases isolés :

- 1 tesson d'urne non tournée de forme probable CNT-LOR U5d : bord déversé à lèvre arrondie ; diam. ouv. : $150 \mathrm{~mm}$ (fig. $\mathbf{3 6}, \mathrm{n}^{\circ}$ 6) ;

- 3 tessons de col et bord déversé d'urne non tournée de forme probable CNT-LOR U5d : col tronconique rentrant à surface lissée, bord déversé à lèvre aplatie ; diam. ouv. : $160 \mathrm{~mm}$ (fig. 36, $\mathrm{n}^{\circ} 7$ ) ;

-1 tesson de bord couvercle non tourné de forme probable CNT-LOR V2b, bord dans la continuité d'une paroi, semble-t-il, concave, lèvre aplatie ; diam. ouv. : env. $180 \mathrm{~mm}$ (fig. 36, $\mathrm{n}^{\circ} 8$ ) ;

-1 tesson de grande coupe non tournée de forme CNT-LOR C1; panse arrondie convexe, embouchure évasée avec bord à lèvre aplatie et élargie; diam. ouv. : 250 à 300 mm (fig. 36, n 9) ;

-25 petits tessons et quelques esquilles de panses se rapportant, semble-t-il, à autant de vases non tournés, urnes et coupes (non dessinés) ;

-1 petit fragment d'amphore massaliète (non dessiné).
Os d'animaux (détermination A. Gardeisen) :

- 11 fragments d'un crâne de porc juvénile, carbonisé à blanc (fragments crâniens et des mandibules, bourgeons dentaires et 58 esquilles);

-1 troisième prémolaire inférieure de chien, non brûlée ;

- Indéterminés : 10 esquilles brûlées, couleur noire, qui se différencient nettement du lot des esquilles attribuées à la fragmentation du crâne de porcelet.

\section{La structure de recouvrement des tombes $\mathbf{T} 22$ et $\mathbf{T} 23$}

\subsection{La structure}

Une même structure de surface recouvre les loculus des tombes T22 et T23, et déborde largement tout autour sur le sol de la nécropole, formant une aire probablement ovalaire, de $3 \mathrm{~m}$ sur l'axe ouest-est, et de plus de $3 \mathrm{~m}$ sur l'axe nord-sud, l'extension vers le nord ne pouvant être appréciée du fait de la limite de la fouille (fig. 33 et $\mathbf{3 7}$, B). Elle est matérialisée par différents éléments qui en marquent la base :

- de nombreuses pierres centimétriques, jusqu'à $15 \mathrm{~cm}$ d'arête, reposant sur le dessus du comblement des deux loculus et sur le sol environnant, sur l'ensemble de cette aire ;

- une urne non tournée incomplète, écrasée (fig. 37, $\mathrm{A}, \mathrm{n}^{\circ} 1$ ), dont l'aire de répartition des morceaux recouvre partiellement les deux loculus 22 et 23 , et le sol de la nécropole entre ces deux structures (fig. 33, US 17137);

- sur le sol de la nécropole, entre les deux loculus, 29 petits morceaux et esquilles d'os humains incinérés ;

- trois perles (fig. 37, A, $\mathrm{n}^{\circ} 3$ à 5), et un tesson de vase non tourné (fig. 37, A, n ${ }^{\circ}$ 6), sur le dessus du comblement du loculus de la tombe 22 ;

- à proximité immédiate de ce loculus, sur le sol de la nécropole, deux autres petits objets d'habillement ou de parure, une perle (fig. 37, $\mathrm{A}, \mathrm{n}^{\circ}$ 7) et un élément de ceinture (fig. 37, A, $\mathrm{n}^{\circ} 2$ ).

Par ailleurs, la terre alluviale qui surmonte le loculus de la tombe T22 et le sol environnant sur deux ou trois centimètres d'épaisseur se différencie du limon recouvrant le sol de la nécropole environnant; en effet, elle est mouchetée de petits fragments de charbons de bois. 


\subsection{Restes osseux humains}

Les fragments osseux incinérés, pour un poids de $7,1 \mathrm{~g}$, se rapportent à un enfant et à un sujet de taille adulte; ils sont donc compatibles avec les défunts des loculus des tombes 22 et 23 . Ce sont, notamment, 8 petits morceaux crâniens, dont un de taille adulte et cinq d'enfant et 7 fragments de membres dont trois de taille adulte, et en particulier un métatarsien, et deux d'enfant.

\subsection{Mobilier}

\section{Objets personnels, parure et habillement}

- Morceau de maillon double en bronze, appartenant à une chaîne-ceinture «féminine » de type méridional ; les deux anneaux sont reliés par une moulure simple; long. cons. $12 \mathrm{~mm}$ (fig. 37, $\mathrm{A}, \mathrm{n}^{\circ} 2$ ) ;

- Deux petites perles en pâte de verre bleue (fig. 37, $\mathrm{A}, \mathrm{n}^{\circ} 3$ et 4$)$; section arrondie, fine et irrégulière ; diam. ext. : 5,5 mm (fig. 37, A, $\mathrm{n}^{\circ}$ 3) et 4,5 mm (fig. 37, A, $\left.\mathrm{n}^{\circ} 4\right)$. Ces perles sont semblables à celles découvertes dans le loculus de la tombe 22 ;

- Grosse perle annulaire double, en pâte de verre bleu, ornée d'un filet ondulant jaune opaque, déformée par le feu; deux sections en D; dim. actuelle de l'objet déformé : 20 et $14 \mathrm{~mm}$ d'axes ; 16 à $17 \mathrm{~mm}$ de haut (fig. 37, $\mathrm{A}, \mathrm{n}^{\circ} 5$ ) ;

- Morceau de perle en pâte de verre bleu opaque, déformée par le feu ; diam. : $10 \mathrm{~mm}$ (fig. 37, A, n 7).

\section{Matériel céramique}

Portion de vase :

- Portion d'une urne non tournée de forme CNT-LOR U5d, variante d, 107 tessons, souvent de très petite taille, représentant environ $50 \%$ du récipient : col cylindrique avec, à sa partie supérieure, cassure ancienne horizontale retaillée pour former une lèvre oblique, panse ovoïde à peignage horizontal, épaule décorée d'impressions au peigne disposées selon une ligne brisée ; sur la partie conservée du fond, trait incisé large et peu profond, probable croix ; diam. max. rest. : $180 \mathrm{~mm}$; haut. rest. : $230 \mathrm{~mm}$ (fig. 37, A, nº 1).

Tessons de vases isolés :

-2 tessons de vases à vernis noir de l'atelier de Rosas, de forme non déterminable, dont un morceau de fond porteur d'une estampille très endommagée, sans doute palmette, à la lecture très hypothétique (fig. $\mathbf{3 7}, \mathrm{n}^{\circ} 8$ ) ;

-1 tesson d'un grand vase non tourné fermé ; bord rentrant ; diam. max. est. : $360 \mathrm{~mm}$ (fig. 37, $\mathrm{A}, \mathrm{n}^{\circ}$ 6) ;
- 4 petits tessons informes de quatre vases non tournés (non dessinés).

\subsection{Le dispositif annexe (US 17146)}

À proximité immédiate de la structure de recouvrement, à une douzaine de $\mathrm{cm}$ seulement de sa bordure sud-orientale, est à moitié enterré un dispositif de pierres calcaires locales, brutes et non brûlées (US 17146). Il se compose d'une fosse profonde, dont les limites, non perceptibles, ne peuvent être déduites que par les pierres verticales qu'elle renferme, et d'un amoncellement de pierres à la surface du sol de la nécropole (US 17135) (fig. 37, B à E).

Un bloc de forme trapézoïdale (haut : $32 \mathrm{~cm}$; large 12 à $20 \mathrm{~cm}$; épais : $6 \mathrm{~cm}$ ) est enfoui verticalement dans le sédiment sous-jacent $\left(\mathrm{n}^{\circ} 1\right)$. Sa base se trouve à $40 \mathrm{~cm}$ sous le sol de la nécropole et son sommet à $8 \mathrm{~cm}$. Cette pierre est directement surmontée par un second bloc, de forme triangulaire (haut : $30 \mathrm{~cm}$; large : $25 \mathrm{~cm}$ au sommet; épais : 7 à $10 \mathrm{~cm})\left(\mathrm{n}^{\circ} 2\right)$. Ce dernier, enfoncé de $7 \mathrm{~cm}$ dans le sol, émerge de $23 \mathrm{~cm}$ au-dessus de lui, selon une orientation est-ouest. Contre lui, du côté nord, est adossé un petit amas de quatre pierres calcaires non brûlées décimétriques ( $\mathrm{a}, \mathrm{b}, \mathrm{c}$ et $\mathrm{d}$ ), posées sur le sol de la nécropole (US 17135).

Le sédiment entourant la base du bloc 2 et le bloc 1 ne se différencie pas de celui des environs, et il est stérile en documents archéologiques. La fouille en profondeur autour de ces blocs n'a pas permis de repérer les limites de la fosse dans laquelle ces éléments ont dû être placés. La présence des pierres $a, b, c$ et d regroupées autour du bloc 2 et reposant sur la surface 17135 semblent assurer un lien chronologique de contemporanéité entre le sol de la nécropole et ce dispositif semi-enterré, dont la signification reste cependant énigmatique.

\section{La tombe $\mathbf{T} 24$}

\section{1. État et composantes de la tombe}

La tombe T24 abrite un seul défunt incinéré, un grand enfant entre 12 et 15 ans, de sexe non déterminable, mais la présence d'une perle dans le mobilier (voir infra) pourrait indiquer un sujet féminin. Elle comprend un loculus (US 17173) et une structure de 


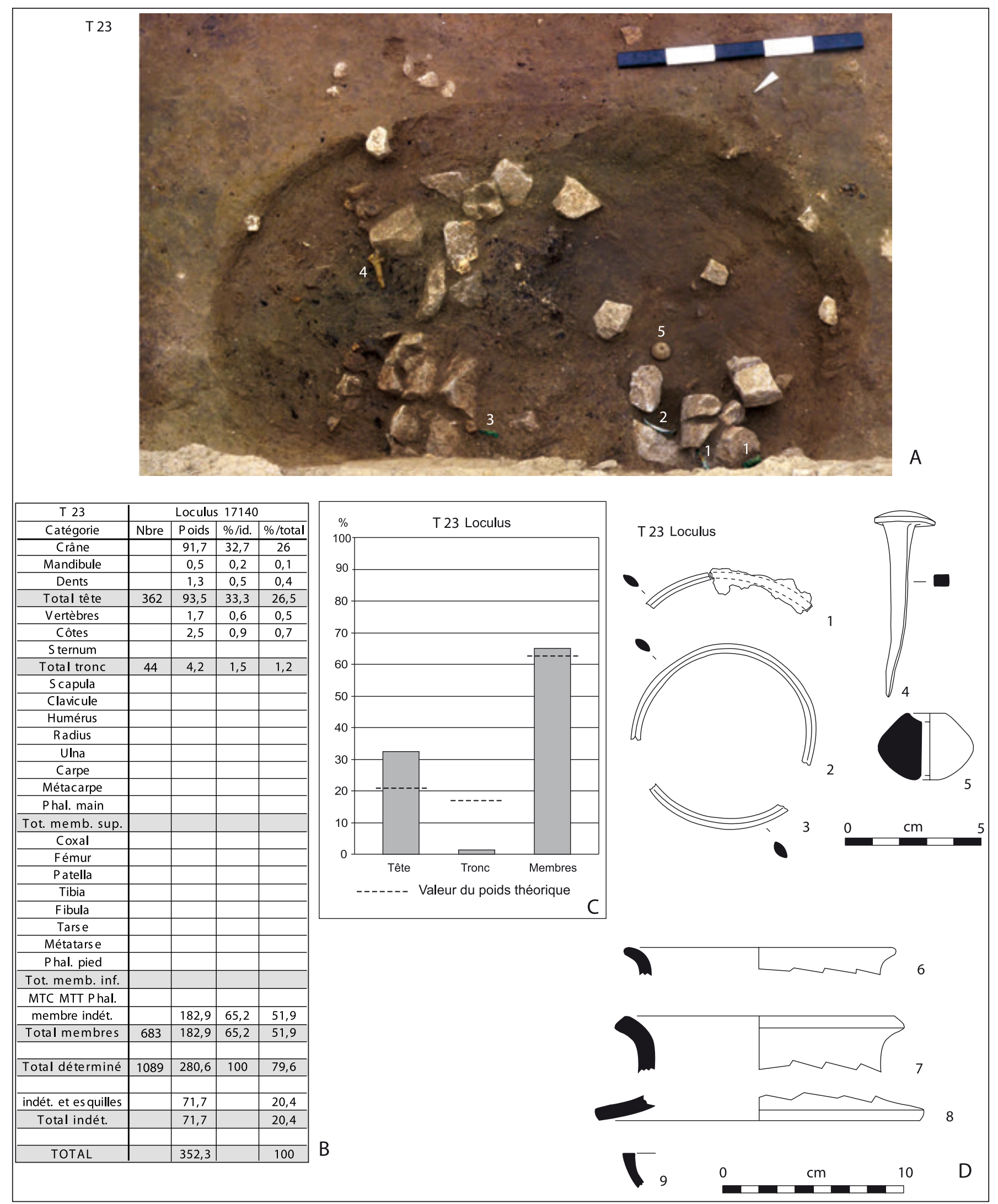

Fig. 36. Tombe T23. A : remplissage du loculus, vue prise du nord-ouest (1-3: bracelets ; 4 : clou ; 5 fusaïole) ;

B : tableau de détermination des os humains (poids en grammes; calcul des $\%$ sur la masse). C : répartition du poids des os par grandes régions anatomiques (\% par rapport au total déterminé). D : mobilier (1-3: bronze ; $4:$ fer ; 5 : terre cuite modelée ; 6-9 céramique non tournée). 


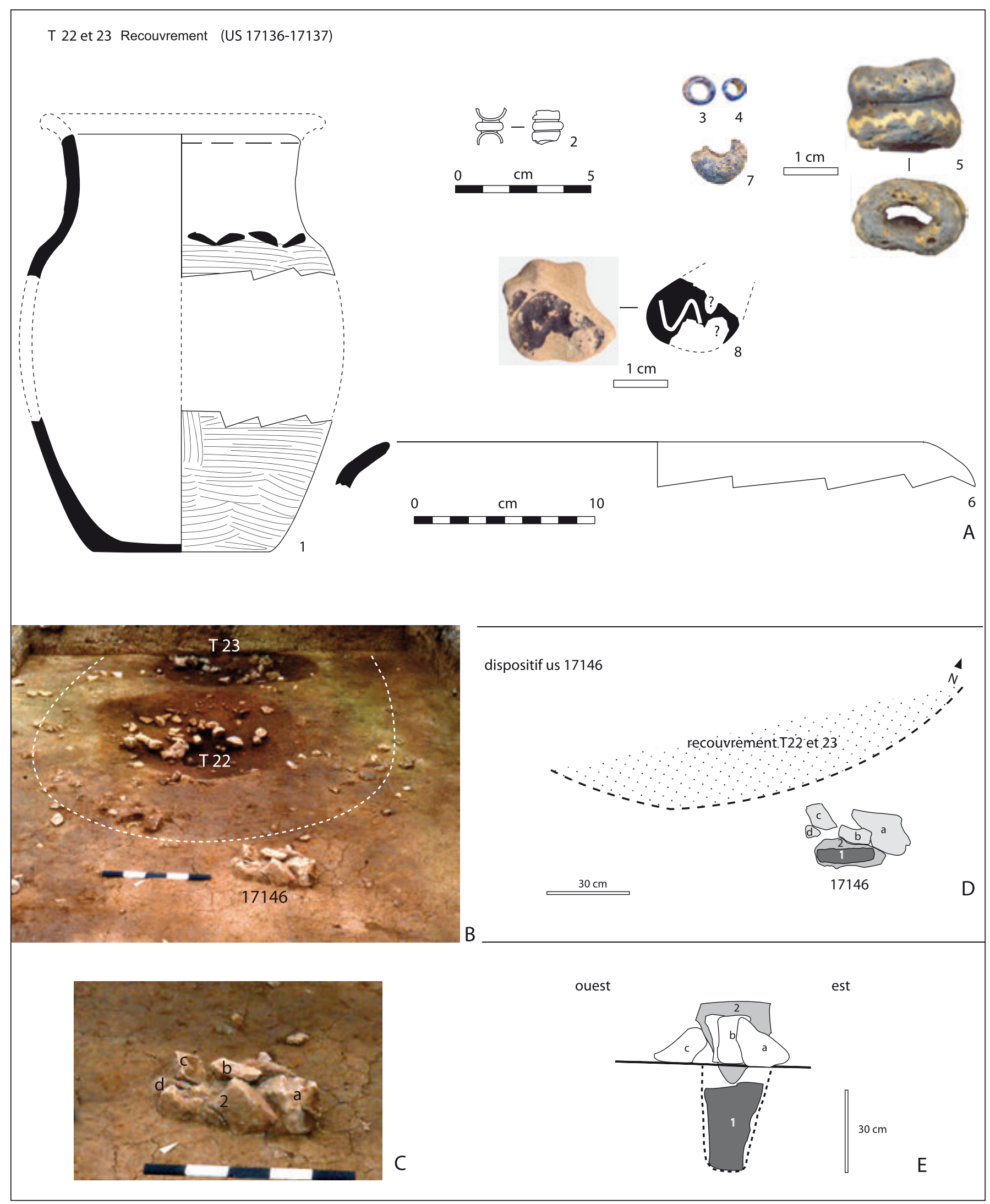

Fig. 37. Recouvrement des tombes T22 et T23. A : mobilier (1 et $6:$ céramique non tournée ; $2:$ bronze ; $3-5$ et $7:$ verre ; $8:$ céramique à vernis noir). $B$ : vue des tombes T22 et T23 et du dispositif annexe 17146, prise du sud-est (en tiretés blancs, la limte approximative de la structure de recouvrement. C : vue du dispositif annexe 17146, prise du sud-est. D et E : plan et coupe du dispositif annexe 17146. 
recouvrement (US 17166) s'étendant largement tout autour, mais seule la moitié orientale de cette dernière a pu être entièrement fouillée, la présence de murs du bâtiment gallo-romain donnant, vers l'est, une limite aux recherches (fig. 38).

\subsection{Le défunt}

Le défunt est représenté par 327,1 g d'os brûlés (fig. 39, A). L'estimation de l'âge au décès, vers 12-15 ans, repose sur plusieurs indices, outre le caractère gracile des pièces osseuses: plusieurs fragments de diaphyses montrent une surface métaphysaire; un fragment d'épiphyse distale d'ulna et trois extrémités proximales de phalanges ne sont pas soudées; si les racines des incisives et des premières molaires sont complètement formées, avec des apex fermés, il n'en va pas de même des premières prémolaires et des deuxièmes molaires dont les racines ne sont formées qu'à $80 \%$. Le sexe anthropologique ne peut pas être précisé.

La couleur blanc crayeux révèle une température de crémation supérieure à $650^{\circ}$ selon le barème de E. Bonnucci et G. Grazziani (1975), et les morceaux de diaphyses sont très souvent fissurés en ondes concentriques, indice d'une incinération d'os frais.

Le loculus a livré 319,6 g d'os incinérés, et la partie fouillée de la structure de recouvrement seulement $7,5 \mathrm{~g}$. On ne peut affirmer toutefois que la quasi totalité des restes osseux ait été déposée dans le loculus, car on ignore si la moitié non fouillée du recouvrement est à l'image de la partie occidentale.

Le poids d'os déposés dans le loculus représente 19,6\% du poids moyen d'un squelette d'adulte brûlé, $1627,1 \mathrm{~g}$ selon McKinley (1993). Les taux d'identification sont de $91,4 \%$ du poids total des fragments pour le loculus. Le crâne, surtout, mais aussi dans une moindre mesure, les membres sont sur-représentés, avec, respectivement, 27,6 et 66,4\% du poids identifié (pour des poids théoriques de 20,4 et $62,6 \%$ ), tandis que la représentation du tronc est très faible, $6 \%$ (poids théorique : $17 \%$ ) (fig. 39, B).

Les os ont été placés dans le loculus hors de tout contenant, mais le mode de dépôt traduit deux gestes successifs. Dans la partie inférieure du loculus (US 17174), un magma très dense de cendres gris blanchâtre incluant des charbons de bois et de très nombreux morceaux d'os, souvent amalgamés entre eux, de grosses dimensions, traduit un prélèvement en bloc, sur le bûcher, de matières brûlantes (fig. 39, A). Dans la partie supérieure (US 17173), les restes osseux, de taille plus réduite, sont éparpillés dans un sédiment limoneux versé au-dessus de ce magma, qui s'est coloré en rouge lie de vin, sans doute par suite de la chaleur. Les deux lots diffèrent en volume, 90,4 g pour la partie supérieure et 229,2 g pour l'amas de la partie inférieure, mais aucune incompatibilité n'existe entre eux, et, par ailleurs, les restes les composant proviennent des mêmes régions du corps.

Toutes régions anatomiques confondues, le poids moyen des fragments déterminés provenant du loculus est semblable à celui des os du dispositif de recouvrement et s'élève à $0,17 \mathrm{~g}$ pour le premier et $0,18 \mathrm{~g}$ pour le second (provenant du loculus : $0,18 \mathrm{~g}$ pour la tête, $0,11 \mathrm{~g}$ pour le tronc et $0,18 \mathrm{~g}$ pour les membres ; provenant du recouvrement : $0,15 \mathrm{~g}$ pour la tête, $0,10 \mathrm{~g}$ pour le tronc et $0,20 \mathrm{~g}$ pour les membres). Le poids moyen des 8 fragments identifiés comme provenant des membres inférieurs est de $1,38 \mathrm{~g}$.

\subsection{Le loculus}

Le loculus (US 17173-17174) est une cuvette conique, de $70 \mathrm{~cm}$ de diamètre à l'ouverture, profonde de $30 \mathrm{~cm}$ au maximum, aux parois inclinées à $45^{\circ}$ (fig. 38 et 40, A).

Son comblement comprend deux parties. La partie inférieure (US 17174), épaisse de $20 \mathrm{~cm}$ au maximum, est composée d'un magma cendreux riche en os humains incinérés et en charbons de bois. Au milieu de ce comblement, prennent place cinq pierres calcaires provenant de la colline du Dévès et dépourvues de traces d'éclatement au feu. Ces éléments mesurent jusqu'à $10 \mathrm{~cm}$ d'arête. Les pierres situées sur les bords de la fosse épousent le pendage très oblique de ceux-ci ; les autres sont horizontales. Sous ces pierres, vers le centre, gisent, sans ordre et selon des pendages variés, cinq morceaux d'une urne non tournée incomplète (fig. 40, B, n ${ }^{\circ} 1,1 \mathrm{~b}$ et 1c), certains jointifs. Le fond du comblement se compose du même magma cendreux et osseux, mais il est dépourvu de pierres. Une couche de terre limoneuse de couleur rouge lie de vin forme la partie supérieure du remplissage (US 17173). Elle est mouchetée de petits charbons de bois millimétriques ou plus rarement centimétriques, épars, et inclut des morceaux d'os humains incinérés de petite taille, relativement abondants. Elle enrobe cinq pierres décimétriques calcaires provenant de la colline du Dévès, qui ne portent pas de trace de rubéfaction, et contient deux tessons de deux urnes non tournées (fig. 40, B, n 2). 


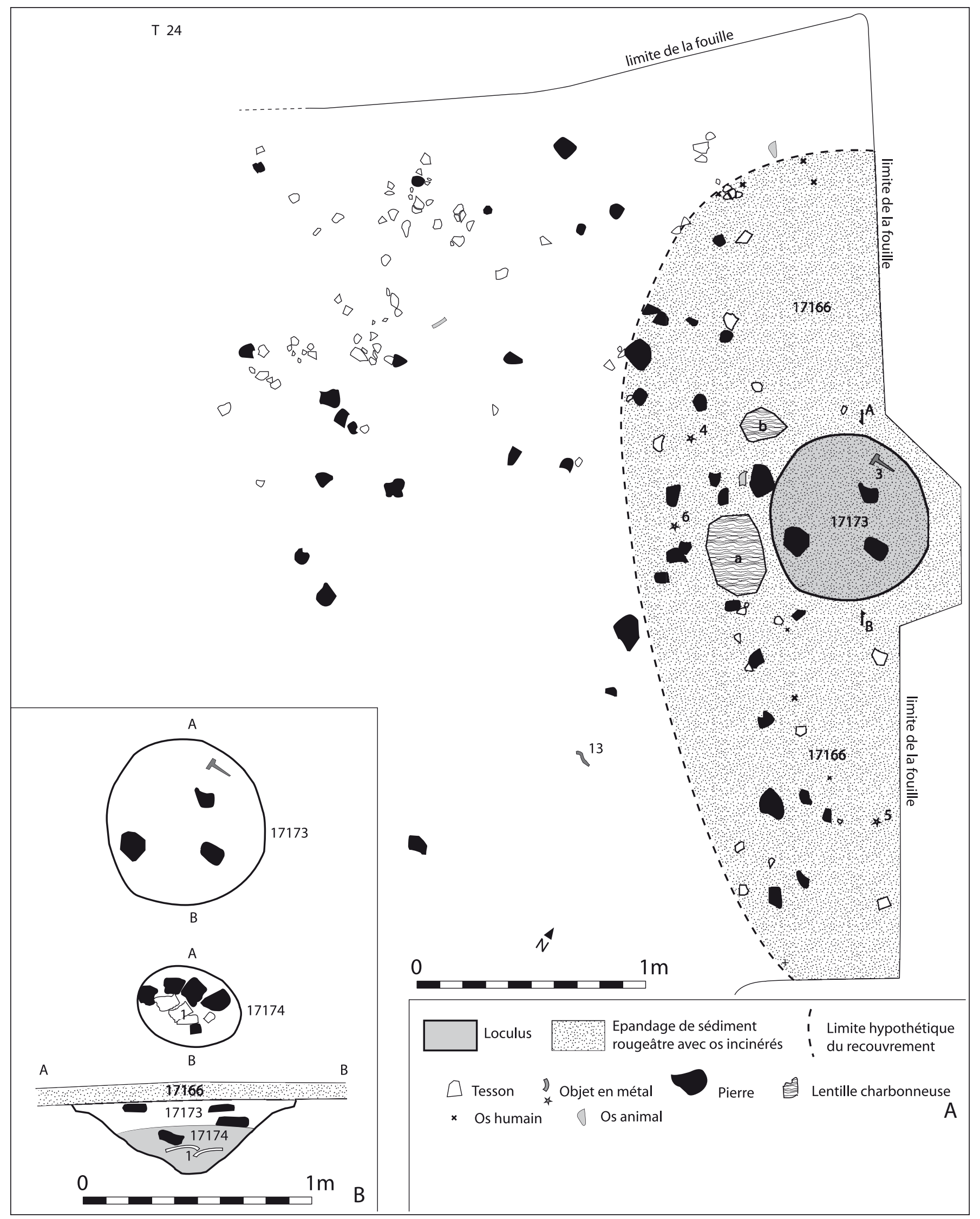

Fig. 38. Tombes T24. A : plan de la structure de recouvrement et du loculus. B : plan du loculus à deux niveaux du remplissage, et coupe. 


\begin{tabular}{|c|c|c|c|c|c|c|c|c|c|c|c|c|c|c|c|c|c|}
\hline \multirow{2}{*}{$\begin{array}{c}\text { T } 24 \\
\text { Catégorie }\end{array}$} & \multicolumn{3}{|c|}{ Loculus 17173} & \multicolumn{3}{|c|}{ Loculus 17174} & \multicolumn{4}{|c|}{ Total loculus } & \multicolumn{4}{|c|}{ Recouvrement } & \multicolumn{3}{|c|}{ Total tombe } \\
\hline & Poids & $\% /$ id. & $\% /$ total & P oids & $\% /$ id. & $\% /$ total & Nbre & Poids & $\% /$ id. & $\% /$ total & Nbre & Poids & $\% /$ id. & $\% /$ total & \begin{tabular}{|l|} 
Poids \\
\end{tabular} & $\% /$ id. & $\% /$ total \\
\hline Crâne & 17,5 & 21,9 & 19,4 & 57 & 26,9 & 24,9 & 400 & 74,5 & 25,5 & 23,3 & 5 & 0,8 & 14,8 & 10,7 & 75,3 & 25,3 & 23 \\
\hline Mandibule & & & & 0,6 & 0,3 & 0,3 & 1 & 0,6 & 0,2 & 0,2 & & & & & 0,6 & 0,2 & 0,2 \\
\hline Dents & 1,8 & 2,3 & 2 & 3,7 & 1,7 & 1,6 & 49 & 5,5 & 1,9 & 1,7 & 1 & 0,1 & 1,6 & 1,3 & 5,6 & 1,9 & 1,7 \\
\hline Total tête & 19,3 & 24,2 & 21,3 & 61,3 & 28,9 & 26,8 & 450 & 80,6 & 27,6 & 25,2 & 6 & 0,9 & 16,7 & 12 & 81,5 & 27,4 & 24,9 \\
\hline Vertèbres & 2,9 & 3,6 & 3,2 & 0,9 & 0,4 & 0,4 & & 3,8 & 1,3 & 1,2 & & 0,1 & 1,6 & 1,3 & 3,9 & 1,3 & 1,2 \\
\hline Côtes & 2,6 & 3,3 & 2,9 & 11,1 & 5,2 & 4,8 & & 13,7 & 4,7 & 4,3 & & 0,1 & 1,6 & 1,3 & 13,8 & 4,6 & 4,2 \\
\hline \multicolumn{18}{|l|}{ S ternum } \\
\hline Total tronc & 5,5 & 6,9 & 6,1 & 12 & 5,7 & 5,2 & 161 & 17,5 & 6 & 5,5 & 2 & 0,2 & 3,2 & 2,7 & 17,7 & 6 & 5,4 \\
\hline Scapula & & & & 0,3 & 0,1 & 0,1 & 1 & 0,3 & 0,1 & 0,1 & & & & & 0,3 & 0,1 & 0,1 \\
\hline \multicolumn{18}{|l|}{ Clavicule } \\
\hline \multicolumn{18}{|l|}{ Humérus } \\
\hline \multicolumn{18}{|l|}{ Radius } \\
\hline \multicolumn{18}{|l|}{ Ulna } \\
\hline \multicolumn{18}{|l|}{ Carpe } \\
\hline \multicolumn{18}{|l|}{ Métacarpe } \\
\hline \multicolumn{18}{|l|}{$\mathrm{Phal}$ main } \\
\hline Tot. memb. sup. & & & & 0,3 & 0,1 & 0,1 & 1 & 0,3 & 0,1 & 0,1 & & & & & 0,3 & 0,1 & 0,1 \\
\hline Coxal & & & & 4,7 & 2,2 & 2,1 & 3 & 4,7 & 1,6 & 1,5 & & & & & 4,7 & 1,6 & 1,4 \\
\hline Fémur & & & & 1,5 & 0,7 & 0,7 & 1 & 1,5 & 0,5 & 0,5 & & & & & 1,5 & 0,5 & 0,5 \\
\hline \multicolumn{18}{|l|}{ Patella } \\
\hline Tibia & & & & 1,8 & 0,8 & 0,8 & 2 & 1,8 & 0,6 & 0,6 & & & & & 1,8 & 0,6 & 0,6 \\
\hline \multicolumn{18}{|l|}{ Fibula } \\
\hline Tarse & & & & 3 & 1,4 & 1,3 & 2 & 3 & 1 & 0,9 & & & & & 3 & 1 & 0,9 \\
\hline \multicolumn{18}{|l|}{ Métatarse } \\
\hline \multicolumn{18}{|l|}{ Phal. pied } \\
\hline Tot. memb. inf. & & & & 11 & 5,2 & 4,8 & 8 & 11 & 3,8 & 3,4 & & & & & 11 & 3,7 & 3,4 \\
\hline MTC MTT P hal. & 0,3 & 0,4 & 0,3 & 7,7 & 3,6 & 3,4 & & 7,7 & 2,6 & 2,4 & & & & & 7,7 & 2,6 & 2,4 \\
\hline membre indét. & & & & 119,9 & 56,5 & 52,3 & & 174,7 & 59,9 & 54,7 & & 4,3 & 79,6 & 57,3 & 179 & 60,2 & 54,8 \\
\hline Total membres & 55,1 & 69 & 61 & 138,9 & 65,5 & 60,6 & 1062 & 194 & 66,4 & 60,7 & 22 & 4,3 & 79,6 & 57,3 & 198,3 & 66,7 & 60,6 \\
\hline Total déterminé & 79,9 & 100 & 88,4 & 212,2 & 100 & 92,6 & 1673 & 292,1 & 100 & 91,4 & 30 & 5,4 & 100 & 72 & 297,5 & 100 & 90,9 \\
\hline indét. et es quilles & 10,5 & & & 17 & & & & 27,5 & & & & 2,1 & & & 29,6 & & 9,1 \\
\hline Total indét. & 10,5 & & 11,6 & 17 & & 7,4 & & 27,5 & & 8,6 & & 2,1 & & 28 & 29,6 & & 9,1 \\
\hline TOTAL & 90,4 & & 100 & 229,2 & & 100 & & 319,6 & & 100 & & 7,5 & & 100 & 327,1 & & 100 \\
\hline
\end{tabular}
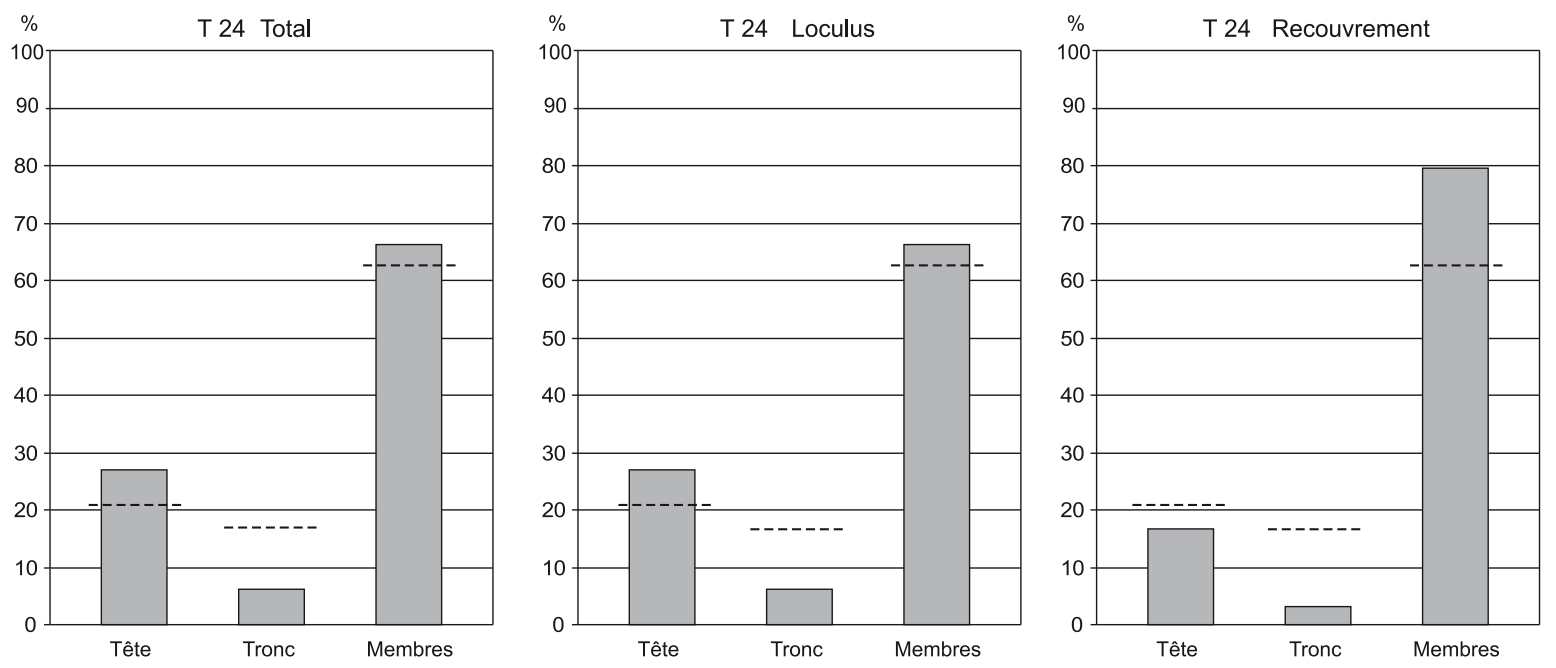

------ Valeur du poids théorique

Fig. 39. Tombe T24. A : tableau de détermination des os humains (poids en grammes; calcul des \% sur la masse). $\mathrm{B}$ : répartition du poids des os par grandes régions anatomiques (\% par rapport au total déterminé). 


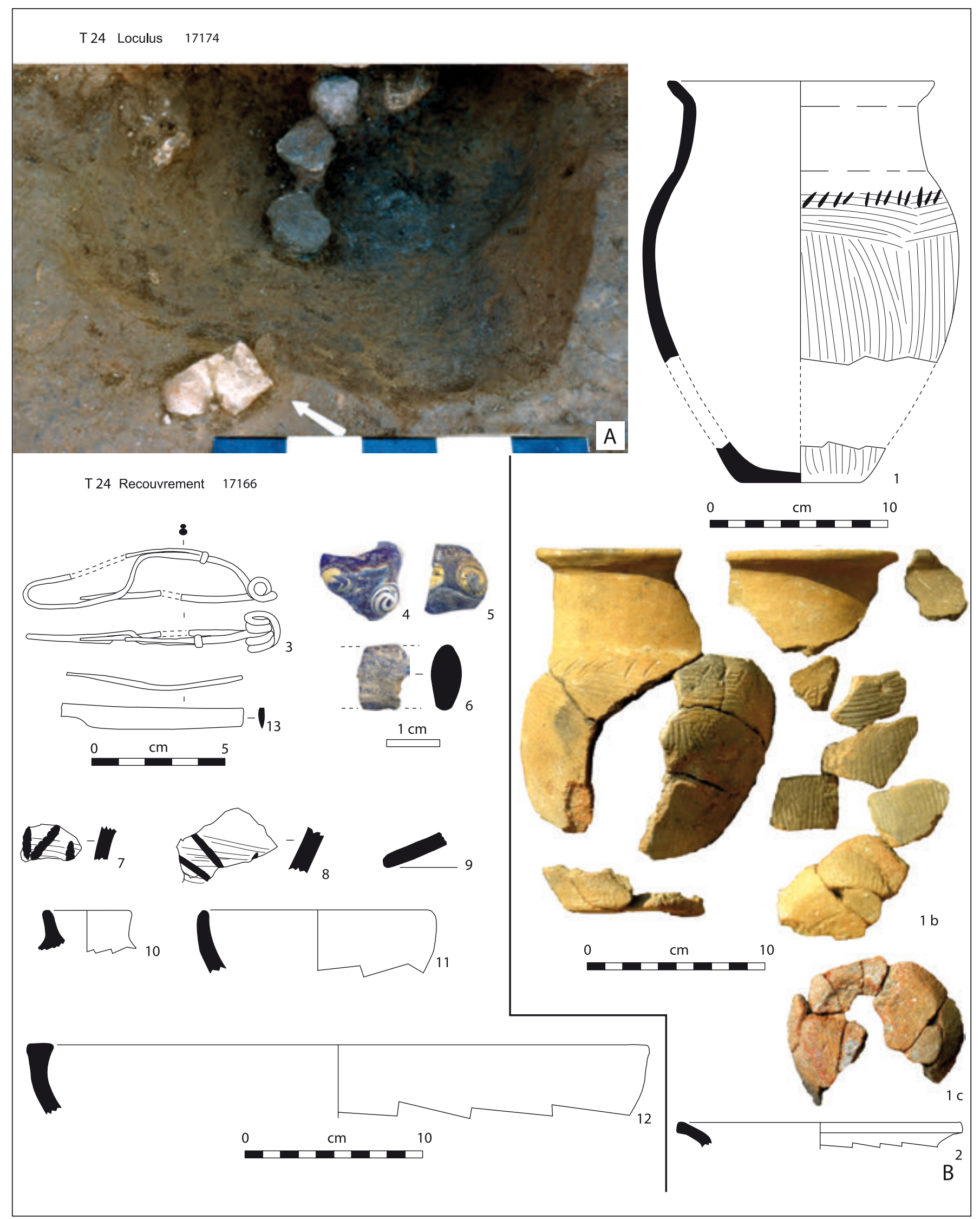

Fig. 40. Tombe T24. A : loculus en cours de fouille, vue prise du sud-ouest. B : mobilier (1, 2 et 7-12: céramique non tournée ; 3 et $13:$ fer ; 4-6 : verre). 


\section{Mobilier du loculus}

Matériel céramique : une portion de vase et tessons isolés de deux vases :

- Portion d'une urne non tournée de forme CNTLOR U5d, variante d, 28 tessons, la plupart jointifs, représentant environ $50 \%$ du vase : col tronconique rentrant à surface polie, bord évasé à lèvre arrondie, panse ovoïde à peignage horizontal sur l'épaule et vertical ailleurs, épaule décorée d'un rang horizontal de petites impressions fusiformes obliques, fond plat avec stries de peignage par endroit ; diam. max. : $178 \mathrm{~mm}$; haut. estimée : $225 \mathrm{~mm}$ (fig. 40, B, $\mathrm{n}^{\circ} 1,1 \mathrm{~b}$ et 1c). Les traces d'un coup porté sur le fond du vase depuis l'extérieur a provoqué un large éclatement circulaire et une perforation. Ce choc semble avoir causé le bris du récipient (fig. 40, $\left.\mathrm{B}, \mathrm{n}^{\circ} 1 \mathrm{c}\right)$;

- 1 tesson d'urne non tournée de forme probable CNT-LOR U5d : bord évasé à lèvre arrondie ; diam. ouv. : $160 \mathrm{~mm}$ (fig. 40, $\mathrm{B}, \mathrm{n}^{\circ} 2$ ) ;

-1 tesson de panse de vase non tourné, à surface extérieure lissée (non dessiné).

Os d'animaux (détermination A. Gardeisen) :

- 5 fragments et 14 esquilles de neurocrâne de capriné adulte, brûlés de couleur bleue ;

- Indéterminé : 1 fragment d'os crânien non brûlé ;

- Malacofaune : 1 fragment de coquillage.

\subsection{La structure de recouvrement}

Le loculus et le paléosol environnant sont surmontés, sur un à deux centimètres d'épaisseur, par une fine couche de limon de couleur rouge lie de vin (fig. 38). Dans la partie qui a pu être fouillée, ce recouvrement s'étend sur une aire allongée nord - sud, d'environ $4 \mathrm{~m}$, débordant d'environ 1,2 $\mathrm{m}$ au nord du loculus et $1,8 \mathrm{~m}$ au sud. Sa largeur reste inconnue, du fait de la limite de la fouille vers l'est ; cependant, à l'ouest, cette superstructure ne déborde le loculus que de $0,5 \mathrm{~m}$.

Cette aire inclut des nodules d'argile plus sombres, de nombreux petits charbons de bois épars, quelques pierres plates calcaires centimétriques, de rares petits fragments d'os humains incinérés, surtout au-dessus du loculus et à ses abords immédiats, 40 tessons de vases non tournés en position horizontale, appartenant à 38 récipients, et quatre petits objets de parure ou d'habillement. Deux petits amas de charbons de bois, d'un centimètre d'épaisseur, prennent place en bordure occidentale du loculus.

\section{Mobilier de la structure de recouvrement}

Objets de parure et d'habillement :

- Au-dessus du loculus, fibule en fer (fig. 40, B, $\mathrm{n}^{\circ} 3$ et fig. 115), presque complète (il manque la partie médiane du pied); ressort bilatéral à quatre spires et corde extérieure ; arc en tige mince de section circulaire ; long pied recourbé et fixé au sommet de l'arc par deux petites griffes enveloppantes ; long. : $95 \mathrm{~mm}$; larg. au ressort : $16 \mathrm{~mm}$; la lacune au niveau du pied ne permet pas de savoir si celui-ci était orné d'un nodule ; type 13 c ou 14 de R. Gebhard (1991);

- À $45 \mathrm{~cm}$ à l'ouest du loculus, un morceau d'une grosse perle cylindrique en pâte de verre bleu, à trois rangs de protubérances ornées d'un filet blanc ou jaune en spirale (type IV-1-1 de Zepezauer 1989, p. 113-114); diam. : $17 \mathrm{~mm}$; haut. : $16 \mathrm{~mm}$ (fig. 40, $\mathrm{B}, \mathrm{n}^{\circ} 4$ ). Cette perle a subi l'action d'un feu secondaire ;

- À $1 \mathrm{~m}$ au sud-est du loculus, un morceau d'une seconde grosse perle cylindrique en pâte de verre bleu, à protubérances ornées d'un filet jaune en spirale (type IV-1-1 de Zepezauer 1989, p. 113-114); haut. : $13 \mathrm{~mm}$ (fig. 40, B, n ${ }^{\circ}$ 5). Cet objet a aussi subi l'action d'un feu secondaire ;

- À $45 \mathrm{~cm}$ au sud-ouest du loculus, un petit morceau d'une troisième grosse perle en pâte de verre bleu foncé uni, cylindrique et de section ovale; diam. : $32 \mathrm{~mm}$; haut. : $12 \mathrm{~mm}$ (fig. 40, B, ${ }^{\circ}$ 6). Cet objet a également subi l'action d'un feu secondaire.

Objet métallique indéterminé :

- À proximité immédiate du recouvrement, au sud, un morceau de lamelle en fer légèrement recourbée ; long. cons. : $67 \mathrm{~mm}$; haut. : $8 \mathrm{~mm}$; ép. : 2 à $3 \mathrm{~mm}$ (fig. $40, \mathrm{~B}, \mathrm{n}^{\circ} 13$ ).

Tessons de vases isolés :

- 2 tessons d'épaule de deux urnes non tournées, décorés d'un rang horizontal d'impressions disposées en ligne brisée (fig. 40, B, $\mathrm{n}^{\circ} 7$ et 8 ) ;

- 1 tesson de grand couvercle non tourné de forme CNT-LOR V2a : bord à lèvre arrondie, dans la continuité de la paroi rectiligne (fig. 40, $\mathrm{B}, \mathrm{n}^{\circ} 9$ ) ;

- 1 pied annulaire de couvercle non tourné ; diam. pied : $50 \mathrm{~mm}$ (fig. 40, $\left.\mathrm{B}, \mathrm{n}^{\circ} 10\right)$;

-1 tesson de petite coupe non tournée de forme CNTLOR C1 : panse arrondie convexe, embouchure évasée, bord à lèvre arrondie ; diam. max. : 135 mm (fig. 40, B, $\left.\mathrm{n}^{\circ} 11\right)$;

- 3 tessons d'une grande jatte non tournée de forme CNT-LOR J1e, variante 1: panse arrondie convexe, embouchure évasée, bord à lèvre élargie avec aplatissement horizontal ; diam. ouv. : $350 \mathrm{~mm}$ (fig. 40, B, $\mathrm{n}^{\circ} 12$ ) ; 
- 31 tessons de panses appartenant à autant de vases non tournés (non dessinés) ;

-1 tesson de panse de petit dolium (non dessiné).

Os d'animaux (détermination A. Gardeisen) :

- 4 fragments de caprinés (1 deuxième molaire supérieure gauche adulte, 1 extrémité distale de phalange I, 1 fragment de diaphyse distale de tibia, 1 fragment de diaphyse (tubérosité deltoïdienne) d'humérus) ;

-1 couronne de troisième incisive supérieure gauche de porc jeune adulte ;

-1 fragment de vertèbre d'animal de petite taille ;

- Indéterminés : 8 esquilles.

L'ensemble est très altéré, jaune, poreux, et très friable : il s'agit probablement des effets de la chaleur, sans carbonisation directe au feu.

\section{La tombe $T 25$}

\section{1. État et composantes de la tombe}

La tombe T25 abrite un seul défunt incinéré, un adulte de sexe non déterminable, mais la composition du mobilier (voir infra) paraît correspondre à un homme. Elle comprend un loculus (US 17182) et une structure de recouvrement (US 17116-17118) s'étendant largement tout autour ; cette dernière n'a pu être cependant entièrement fouillée car elle est surmontée par des murs du bâtiment gallo-romain et sa partie nord et ouest nous échappe (fig. 41).

\subsection{Le défunt}

Le défunt est représenté par 786,2 g d'os brûlés (fig. 42, A). La morphologie des os, la fermeture de l'apex des quatre racines de dents conservées, le listel soudé sur les corps vertébraux montrent qu'il s'agit d'un adulte. Le sexe anthropologique ne peut pas être précisé.

Les restes osseux ont une couleur blanc crayeux qui révèle une température de crémation supérieure à $650^{\circ}$ selon le barème de E. Bonnucci et G. Grazziani (1975) et les morceaux de diaphyses sont très souvent fissurés en ondes concentriques, indice d'une incinération d'os frais.

Le loculus a livré $765,9 \mathrm{~g}$ d'os et la partie fouillée du recouvrement $20,3 \mathrm{~g}$ et les deux lots sont tout à fait compatibles. Dans les deux cas, les restes osseux sont dispersés hors de tout contenant, et aucune disposition particulière des fragments n'a été perçue. Cependant, dans le loculus, ceux-ci sont souvent de grandes dimensions, à la différence de ceux du recouvrement, toujours très petits.

Le poids d'os déposés dans le loculus représente $48,3 \%$ du poids moyen d'un squelette d'adulte brûlé, $1627,1 \mathrm{~g}$ selon McKinley (1993). Les taux d'identification sont de $89,6 \%$ du poids total des fragments pour le loculus et $91,6 \%$ pour la superstructure. Dans le loculus, la représentation du crâne est presque normale, $19,2 \%$ du poids identifié ; celle du tronc est très faible, $6,9 \%$ (poids théorique : $17 \%$ ) et celle des membres, en revanche, plus élevée que la valeur théorique, 73,3\% au lieu des 62,6\% attendus (fig. 42, B).

Le poids moyen des fragments déterminés, toutes régions anatomiques confondues, est semblable dans le loculus et dans le dispositif de recouvrement et s'élève à $0,33 \mathrm{~g}$ pour le premier et $0,34 \mathrm{~g}$ pour le second (provenant du loculus : 0,34 g pour la tête, $0,19 \mathrm{~g}$ pour le tronc et $0,36 \mathrm{~g}$ pour les membres; provenant du recouvrement : $0,30 \mathrm{~g}$ pour la tête, $0,10 \mathrm{~g}$ pour le tronc et $0,35 \mathrm{~g}$ pour les membres). Pour les 31 fragments identifiés comme provenant des membres supérieurs, le poids moyen est de $0,82 \mathrm{~g}$; pour les 12 fragments identifiés comme provenant des membres inférieurs, il est de $3,09 \mathrm{~g}$.

\subsection{Le loculus}

Le loculus (US 17182) présente, à l'ouverture, un plan arrondi de 65 à $70 \mathrm{~cm}$ de diamètre. Sa profondeur maximum est de $32 \mathrm{~cm}$ (fig. 41). Le creusement comprend deux parties : la partie supérieure (US 17182-1) forme un ressaut de 5 à $10 \mathrm{~cm}$ de large, à environ $5 \mathrm{~cm}$ de profondeur ; la partie inférieure de la fosse, de 43 à $50 \mathrm{~cm}$ de diamètre à ce niveau, a des parois très abruptes et un fond arrondi. La partie supérieure est remplie d'une terre alluviale rougeâtre sombre, qui inclut des morceaux de bûches centimétriques, jusqu'à $3 \mathrm{~cm}$, étouffés par l'enfouissement, et de nombreux gros morceaux d'os humains incinérés. Dans la partie médiane du remplissage (US 17182-2), le sédiment devient gris et noir, charbonneux et cendreux, et comporte quelques petites pierres calcaires de la colline éclatées au feu. Il inclut également de très nombreux fragments osseux incinérés, certains de grandes dimensions, quelques petits tessons de céramiques non tournées ou à vernis noir, le mobilier métallique et les perles en pâte de verre. Un morceau d'épiphyse est collé à l'applique $\mathrm{n}^{\circ} 4$ par l'oxyde. Le fond du loculus (US 17182-3) est occupé par une terre cendreuse de couleur gris blanchâtre, où les fragments osseux sont moins nombreux. 


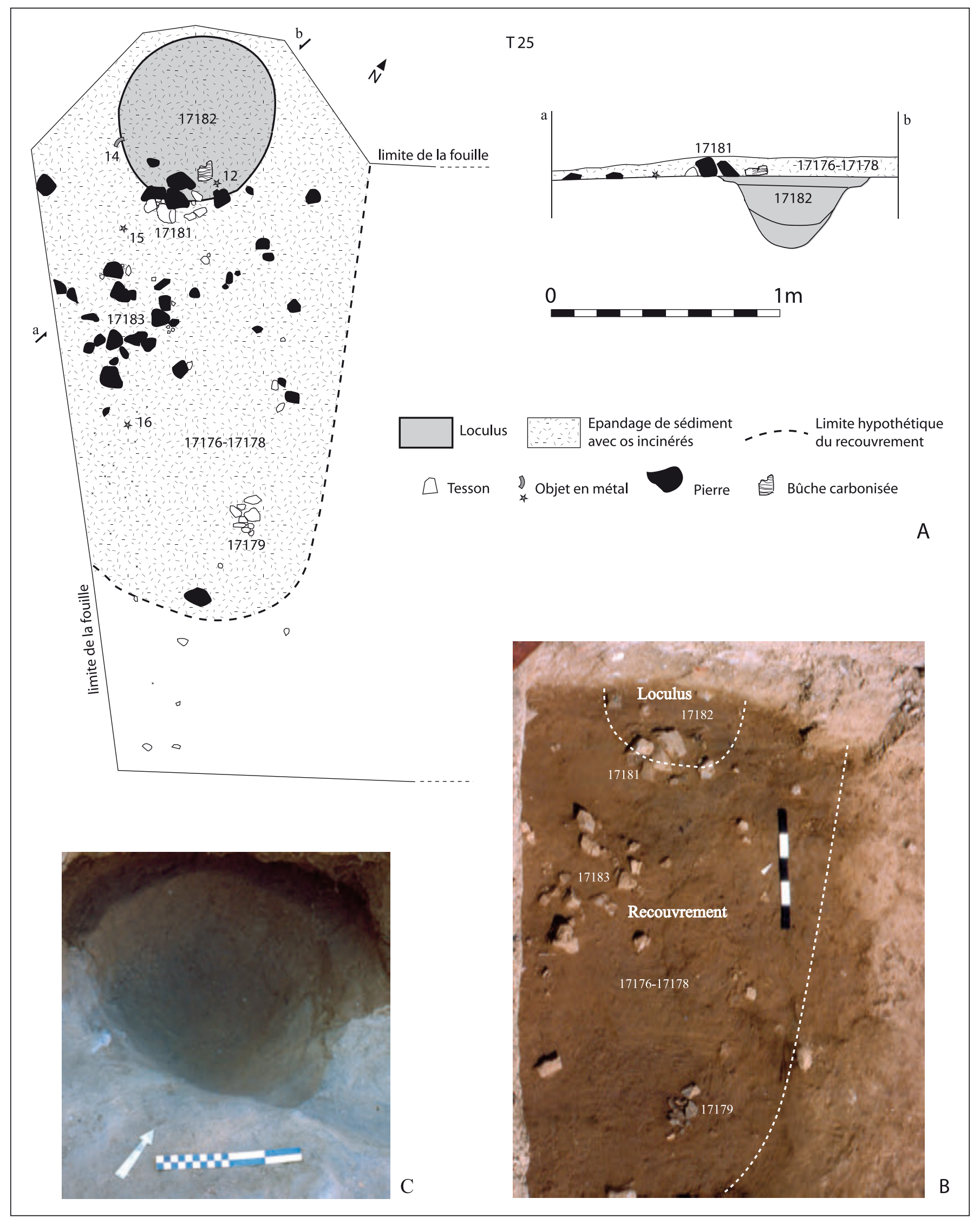

Fig. 41. Tombe T25. A : plan et coupe. B : structure de recouvrement et loculus vus du sud-est. C : loculus en fin de fouille, vu du sud-est. 
CHAPITRE 2 - TOMBES, STRUCTURES ANNEXES ET SOL DE LA NÉCROPOLE

\begin{tabular}{|c|c|c|c|c|c|c|c|c|c|c|c|}
\hline \multirow{2}{*}{$\begin{array}{c}\text { T } 25 \\
\text { Catégorie }\end{array}$} & \multicolumn{4}{|c|}{ Loculus } & \multicolumn{4}{|c|}{ Recouvrement } & \multicolumn{3}{|c|}{ Total tombe } \\
\hline & Nbre & Poids & \%/id. & $\% /$ total & Nbre & Poids & \%/id. & $\% /$ total & P oids & $\% /$ id. & $\% /$ total \\
\hline Crâne & 410 & 123,9 & 18 & 16,2 & 10 & 3,5 & 18,8 & 17,2 & 127,4 & 18,1 & 16,2 \\
\hline Mandibule & 3 & 4,6 & 0,7 & 0,6 & & & & & 4,6 & 0,7 & 0,6 \\
\hline Dents & 21 & 3,6 & 0,5 & 0,5 & 2 & 0,5 & 2,7 & 2,5 & 4,1 & 0,6 & 0,5 \\
\hline Total tête & 434 & 132,1 & 19,2 & 17,2 & 12 & 4 & 21,5 & 19,7 & 136,1 & 19,3 & 17,3 \\
\hline Vertèbres & & 28,4 & 4,1 & 3,7 & & 0,1 & & & 28,5 & 4 & 3,6 \\
\hline Côtes & & 22,4 & 3,3 & 2,9 & & & & & 22,4 & 3,2 & 2,8 \\
\hline \multicolumn{12}{|l|}{ S ternum } \\
\hline Total tronc & 274 & 50,8 & 7,4 & 6,6 & 1 & 0,1 & 0,5 & 0,5 & 50,9 & 7,2 & 6,5 \\
\hline S capula & 12 & 1,3 & 0,2 & 0,2 & & & & & 1,3 & 0,2 & 0,2 \\
\hline \multicolumn{12}{|l|}{ Clavicule } \\
\hline Humérus & 3 & 9,6 & 1,4 & 1,3 & & & & & 9,6 & 1,4 & 1,2 \\
\hline Radius & 1 & 7,5 & 1,1 & 1 & & & & & 7,5 & 1,1 & 1 \\
\hline Ulna & 1 & 1,1 & 0,2 & 0,1 & & & & & 1,1 & 0,2 & 0,1 \\
\hline Carpe & 4 & 2,9 & 0,4 & 0,4 & & & & & 2,9 & 0,4 & 0,4 \\
\hline \multicolumn{12}{|l|}{ Métacarpe } \\
\hline Phal. main & 10 & 3 & 0,4 & 0,4 & & & & & 3 & 0,4 & 0,4 \\
\hline Tot. memb. sup. & 31 & 25,4 & 3,7 & 3,3 & & & & & 25,4 & 3,6 & 3,2 \\
\hline \multicolumn{12}{|l|}{ Coxal } \\
\hline Fémur & 4 & 15,4 & 2,2 & 2 & & & & & 15,4 & 2,2 & 2 \\
\hline Patella & 1 & 2 & 0,3 & 0,3 & & & & & 2 & 0,3 & 0,3 \\
\hline Tibia & 2 & 16,3 & 2,4 & 2,1 & & & & & 16,3 & 2,3 & 2,1 \\
\hline \multicolumn{12}{|l|}{ Fibula } \\
\hline Tarse & 1 & 0,3 & 0,04 & 0,04 & & & & & 0,3 & 0,04 & 0,04 \\
\hline Métatarse & 1 & 2,3 & 0,3 & 0,3 & & & & & 2,3 & 0,3 & 0,3 \\
\hline Phal. pied & 3 & 0,8 & 0,2 & 0,1 & & & & & 0,8 & 0,1 & 0,1 \\
\hline Tot. memb. inf. & 12 & 37,1 & 5,4 & 4,8 & & & & & 37,1 & 5,3 & 4,7 \\
\hline MTC MTT P hal. & & 20,6 & 3 & 2,7 & & & & & 20,6 & 2,9 & 2,6 \\
\hline membre indét. & & 420,5 & 61,3 & 54,9 & & 14,5 & 78 & 71,4 & 435 & 61,7 & 55,3 \\
\hline Total membres & 1391 & 503,6 & 73,4 & 65,8 & 41 & 14,5 & 78 & 71,4 & 518,1 & 73,5 & 65,9 \\
\hline Total déterminé & 2093 & 686,5 & 100 & 89,6 & 54 & 18,6 & 100 & 91,6 & 705,1 & 100 & 89,7 \\
\hline indét. et es quilles & & 79,4 & & & & 1,7 & & & 81,1 & & 10,3 \\
\hline Total indét. & & 79,4 & & 10,4 & & 1,7 & & 8,4 & 81,1 & & 10,3 \\
\hline TOTAL & & 765,9 & & 100 & & 20,3 & & 100 & 786,2 & & 100 \\
\hline
\end{tabular}

A
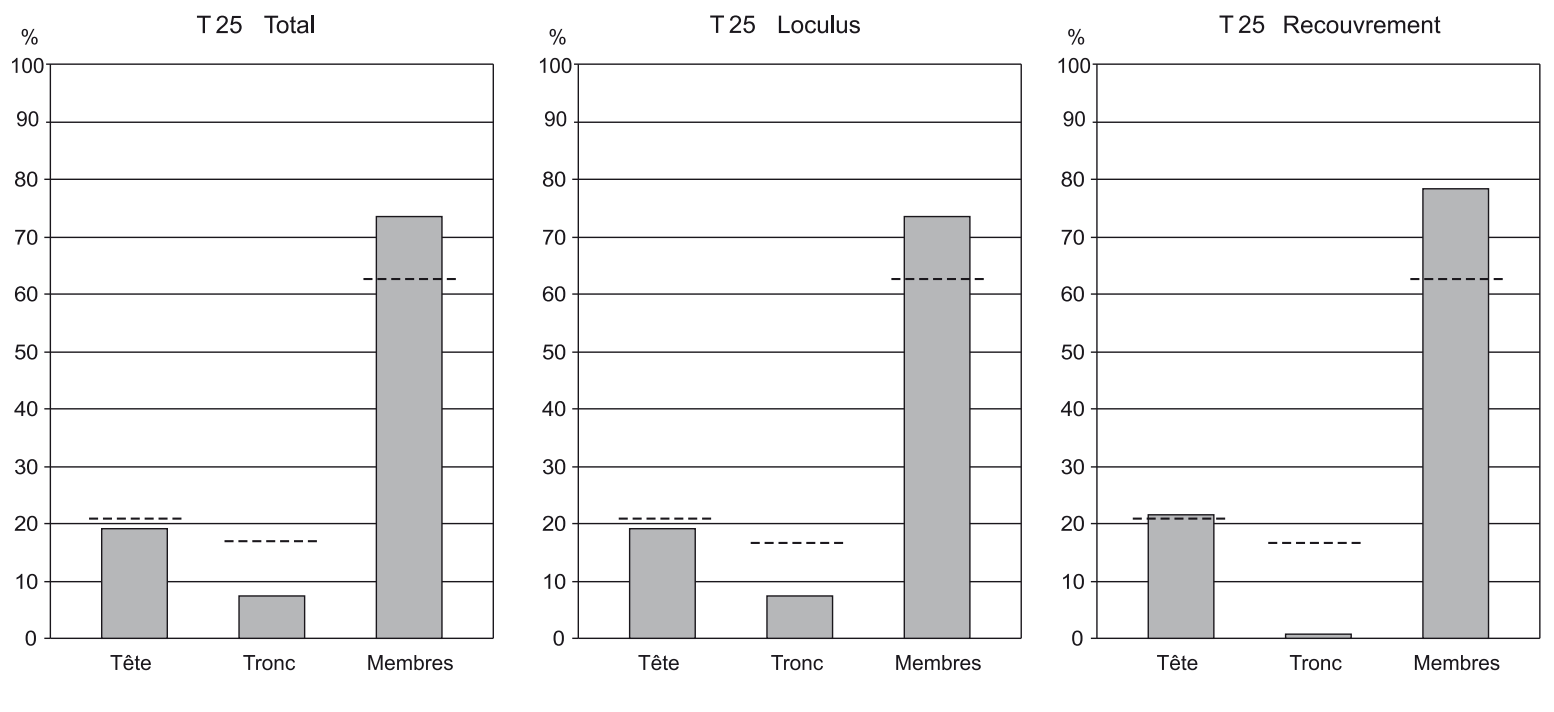

Valeur du poids théorique

Fig. 42. Tombe 2T5. A : tableau de détermination des os humains (poids en grammes; calcul des \% sur la masse). B : répartition du poids des os par grandes régions anatomiques (\% par rapport au total déterminé). 


\section{Mobilier du loculus}

Objets personnels, armement et fourniment :

- Petit rivet de fixation d'ailettes d'umbo de bouclier, en fer ; tête discoïde, non décorée (diam. : 12 à 14 mm); tige de section quadrangulaire, repliée à angle droit, déterminant une épaisseur de $8,5 \mathrm{~mm}$ pour la planche du bouclier (fig. 43, $\mathrm{n}^{\circ} 1$ );

- Petit rivet de fixation d'ailettes d'umbo de bouclier, en fer, semblable au précédent (diam. : 13 à $14 \mathrm{~mm}$ ); l'extrémité de la tige manque (fig. $\mathbf{4 3}, \mathrm{n}^{\circ} 2$ );

- Petit fragment de bord de fourreau d'épée, en fer ; gouttière avec bord de plaque; long. cons. : $13 \mathrm{~mm}$ (fig. $43, n^{\circ} 3$ ).

Objets métalliques divers :

- Applique tronconique en fer à bélière dont l'extrémité est cassée; diam. : $50 \mathrm{~mm}$; il s'agit peut-être d'une applique de ceinture ou de harnachement (fig. 43, $\left.\mathrm{n}^{\circ} 4\right)$;

- Maillon de chaînette en fer, de forme ovale, ouvert, en ruban aplati ; axes : $9 \mathrm{~mm}$ sur $11 \mathrm{~mm}$; haut. : $4 \mathrm{~mm}$; ép. moyenne : $1,5 \mathrm{~mm}$ (fig. $43, \mathrm{n}^{\circ} 5$ ) ;

- Deux fragments d'une petite tige en fer recourbée, de section quadrangulaire; long. cons. : 17 et $14 \mathrm{~mm}$; ép. moyenne : $2 \mathrm{~mm}$ (fig. $43, \mathrm{n}^{\circ} 6$ ) ;

- Fragment d'un ruban plat, en fer recourbé ; long. cons. : $12 \mathrm{~mm}$; larg. moyenne : $4 \mathrm{~mm}$; ép. : $1 \mathrm{~mm}$ (fig. 43, $\mathrm{n}^{\circ} 7$ );

- Trois fragments d'un anneau en bronze incomplet ; section lenticulaire; diam. : $19 \mathrm{~mm}$. Cet objet a subi l'action du feu (fig. 43, $\mathrm{n}^{\circ} 8$ ).

Objets personnels, parure et habillement :

- Perle en pâte de verre bleu sombre, à section en « $\mathrm{D}$ », irrégulière ; diam. : $11 \mathrm{~mm}$; haut. : 3 à $5 \mathrm{~mm}$ (fig. 43, $\mathrm{n}^{\circ}$ 9) ;

- Perle en pâte de verre bleu sombre, en cours de fusion; probablement semblable à la précédente ; diam. : 10 à $11 \mathrm{~mm}$; haut. : $5 \mathrm{~mm}$ (fig. 43, $\mathrm{n}^{\circ} 10$ ).

Matériel céramique, portions de deux vases et tessons de vases isolés :

- Portion d'une coupe-kylix de l'atelier de Rosas, de forme Lamb. 42B (= forme Puig 33), 20 tessons représentant environ $25 \%$ du vase ; diam. ouv. : $130 \mathrm{~mm}$ (fig. 43, $\mathrm{n}^{\circ} 11$ ) ;

- Portion (6 tessons) de l'épaule d'une urne non tournée (fig. 43, $\mathrm{n}^{\circ}$ 12) dont la majorité des tessons se trouve à la base du recouvrement, à l'extérieur et tout près du loculus, (US 17181) (voir infra);

- 1 tesson de panse de bol de l'atelier de Rosas, de forme Lamb. 27 (= forme Puig 11).
- 2 tessons jointifs de la panse d'une autre urne non tournée (fig. $\mathbf{4 3}, \mathrm{n}^{\circ}$ 14) dont la majorité des tessons est également répartie à l'extérieur du loculus, à la base du recouvrement (US 17179) (voir infra). L'un porte la trace d'un feu secondaire, l'autre non et la différence est très notable au niveau du raccord entre les deux tessons ;

- 8 petits tessons de panses de vases non tournés semblant appartenir à autant d'exemplaires (non dessinés).

Os d'animaux (détermination A. Gardeisen) :

- 2 fragments de capriné brûlés, noirs (neurocrâne et diaphyse de métacarpien) ;

- 1 fragment de bourgeon dentaire de porc ;

- 1 fragment de bord caudal de scapula d'animal de petite taille ;

- Indéterminé : 1 esquille non brûlée.

\subsection{La structure de recouvrement}

Dans sa partie fouillée, la superstructure de la tombe T25 comprend deux sortes d'éléments. Un certain nombre de vestiges, os, mobilier ou pierres, sont posés sur le dessus du comblement du loculus ou sur le paléosol de la nécropole, soit dispersés, soit rassemblés en trois petits groupements (US 17181, 17183 et 17179) (fig. 41, A et B). L'ensemble est recouvert par un épandage de sédiment de couleur légèrement plus sombre que sur le reste du secteur fouillé (US 1717617177-17178). Épaisse au maximum de $10 \mathrm{~cm}$, cette superstructure s'étend vers le sud jusqu'à environ $2 \mathrm{~m}$ du bord du loculus, mais seulement $30 \mathrm{~cm}$ environ à l'est, ces limites restant toutefois imprécises.

\section{Groupement US 17181}

Ce groupement US 17177-17181 repose en partie sur le sol de la nécropole et en partie sur le dessus du comblement du loculus. Très serré, il se compose de trois pierres, d'une portion d'une urne non tournée écrasée sur place (fig. $\mathbf{4 3}, \mathrm{n}^{\circ}$ 12) et de deux grands morceaux de diaphyses humaines incinérées. Les pierres, du calcaire de la colline du Dévès, mesurent 12 à $14 \mathrm{~cm}$ d'arête et portent quelques traces d'éclatement au feu. Elles sont disposées selon des pendages obliques. Les tessons sont coincés entre les pierres ou appuyées contre elles. A proximité immédiate au nord, prennent place une quatrième pierre, un morceau de bûche long d'environ $10 \mathrm{~cm}$ ), qui s'est consumé sur place, et un talon de lance (fig. 43, $\mathrm{n}^{\circ} 13$ ). 


\section{Matériel du groupement US 17181}

Objet personnel, armement :

- Petit talon de lance en fer: douille conique courte, large et à pointe arrondie, formée d'un cornet simple ; chevauchement des deux extrémités de la feuille visible près du bord ; pas de trou de fixation perceptible ; long. : $69 \mathrm{~mm}$; diam. base : $20 \mathrm{~mm}$ (fig. 43, $\mathrm{n}^{\circ} 13$ ).

Matériel céramique :

- Portion (25 tessons) d'une urne non tournée de forme CNT-LOR U5d, variante $\mathrm{d}$ : col tronconique rentrant, bord déversé à lèvre arrondie et méplat vers l'intérieur, panse ovoïde peignée horizontalement, épaule décorée d'un rang horizontal de légères impressions en demicercle, fond plat; diam. max. : $170 \mathrm{~mm}$. Des tessons de cette urne proviennent aussi du loculus US 17181 et du groupement US 17183 au total c'est donc environ $15 \%$ du vase qui est représenté (fig. $\mathbf{4 3}, \mathrm{n}^{\circ} 12$ ).

\section{Groupement US 17183}

Il s'agit d'une concentration assez lâche de pierres plates calcaires, de 7 à $8 \mathrm{~cm}$ d'arête, posées à plat sur le sol mais sans ordre. Ces pierres, qui proviennent également de la colline du Dévès, ne portent pas de traces d'éclatement au feu. Elles sont associées à dix petits tessons de poteries isolés :

- 1 tesson d'amphore massaliète (non dessiné) ;

-1 tesson du bord de l'urne non tournée $\mathrm{n}^{\circ} 12$;

- 1 tesson d'épaule décorée appartenant probablement à l'urne $\mathrm{n}^{\circ} 14$ du groupement US 17179 ;

- 7 petits tessons de panses appartenant, au moins, à trois vases non tournés (non dessinés).

\section{Groupement US 17179}

Écrasée dans un très léger creux du sol $(1$ à $2 \mathrm{~cm}$ de profondeur), une portion de la partie inférieure d'une grande urne non tournée de forme CNT-LOR U5d, 11 tessons représentant environ $15 \%$ du vase : panse ovoïde à peignage horizontal, épaule décorée d'impressions fusiformes obliques, fond plat ; diam. max. : $220 \mathrm{~mm}$ (fig. 43, $\mathrm{n}^{\circ}$ 14).

\section{Mobilier dispersé sur le sol}

Objets personnels, parure et habillement :

- Sur le bord même du loculus, un fragment de bracelet en bronze (fig. 43, $\mathrm{n}^{\circ} 15$ ); section en « $\mathrm{D} » ;$ pas de décor visible; diam. int. : $68 \mathrm{~mm}$; haut. : $8 \mathrm{~mm}$;

- À $20 \mathrm{~cm}$ du loculus, tout près de l'amas 17181 , petite fibule en fer à pied discoïde sur lequel est fixé un élément de corail (type 11 de $\mathrm{C}$. Tendille), presque complète (seul manque l'ardillon) (fig. 43, $\mathrm{n}^{\circ} 16$ et fig. 115); ressort bilatéral à six spires enroulées sur un axe en fer, non débordant ; corde externe ; arc en anse de panier, de section arrondie, légèrement épaissi dans sa partie centrale ; pied recourbé vers l'arc, dont la terminaison s'élargit en une flèche ; sur cette dernière est fixée une large plaque arrondie sur laquelle est riveté un cabochon ovale en corail, au moyen d'un rivet central ; autour de ce rivet, le cabochon est orné de trois séries opposées de demi-cercles concentriques ; long. : $38 \mathrm{~mm}$; larg. au ressort : $19 \mathrm{~mm}$; diam. du support du cabochon : $12 \mathrm{~mm}$; axes du cabochon : 8 à $12 \mathrm{~mm}$. La couleur blanchâtre du corail résulte d'une exposition au feu.

Objets personnels, armement :

- Â $1 \mathrm{~m}$ au sud du loculus, rivet (fig. $\mathbf{4 3}, \mathrm{n}^{\circ} 17$ ), en fer; tête discoïde, non décorée (diam. : $12 \mathrm{~mm}$ ); tige de section quadrangulaire, cassée à son extrémité, non repliée dans sa partie conservée (long. cons. de la tige : $12 \mathrm{~mm})$. Ce rivet a pu servir pour la fixation d'une ailette d'umbo de bouclier ou celle de la garniture de la poignée d'une épée.

Épandage US 17176-17177-17178 :

L'épandage US 17176-17177-17178 est moucheté de petits fragments de charbons de bois millimétriques, plus denses que sur le reste du sol de la nécropole. Il inclut de très petits fragments osseux humains incinérés très dispersés, pour un poids total, dans la partie fouillée, de $20,3 \mathrm{~g}$. Il contient aussi quatre petits tessons de panse de quatre vases non tournés (non dessinés) et quelques fragments d'os animaux.

Os d'animaux (détermination A. Gardeisen) :

- 1 fragment de diaphyse distale de métatarsien de capriné adulte, montrant des stries et impacts transverses ou obliques de découpe bouchère sur le bord latéral ;

-1 fragment de corps de côte et 1 fragment de vertèbre thoracique d'animal de petite taille.

\section{Le niveau de sol de la nécropole}

Outre l'ouverture des loculus et la base des dispositifs de recouvrement des sépultures, la surface du sol de circulation de la nécropole est bien marquée, partout, par la présence d'objets, principalement des tessons de poteries et de petites pierres calcaires non roulées, issues de la colline du Dévès. Ces objets ne montrent aucune 


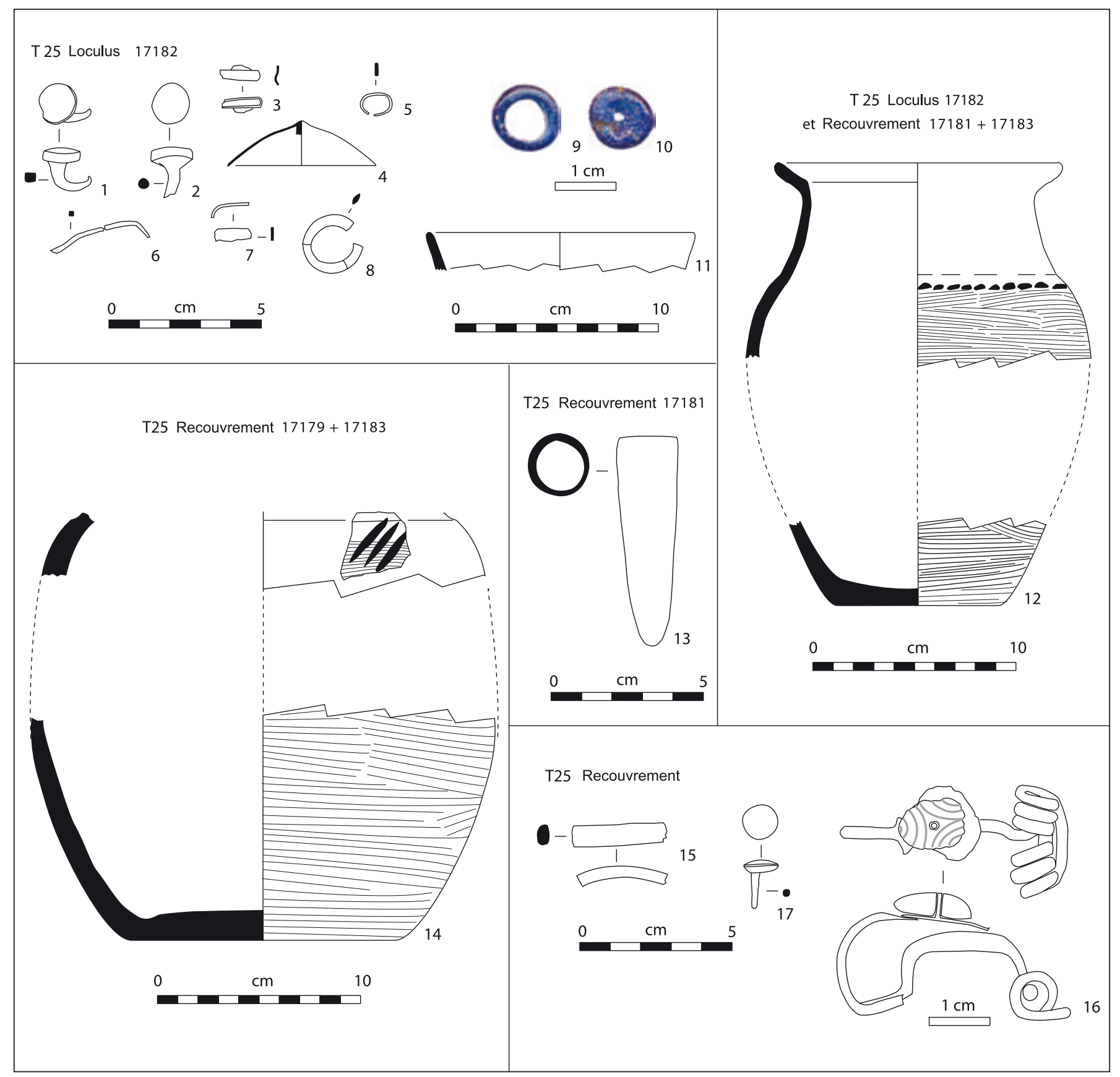

Fig. 43. Tombe 25. Mobilier (1-7, 13 et $17:$ fer ; 8 et $15:$ bronze ; 9 et $10:$ verre ; $11:$ céramique à vernis noir ; 12 et 14 : céramique non tournée ; 16 : fer et corail).

concentration ni agencement particulier. Au contraire, ils sont dispersés et éparpillés dans les espaces entre les tombes. Tous, tessons et pierres, sont de petites dimensions. Quelques rares fragments d'os humains incinérés sont également disséminés sur ce niveau. À l'évidence ces éléments proviennent de l'érosion des structures de recouvrement des tombes. Dans l'inventaire, on suivra un ordre par secteur topographique.

\subsection{Abords de la tombe T25 (US 17176)}

Objets mobiliers :

- céramique à vernis noir : 1 bord de bolsal attique de forme AT-VN 532-561; 11 petits tessons informes de vases de l'atelier de Rosas (non dessiné) ;

- amphore massaliète : 3 petits tessons de panse (non dessiné) ; 
- céramique non tournée : 71 morceaux de panses de plusieurs urnes et coupes (non dessiné).

Os d'animaux (détermination A. Gardeisen) :

-1 fragment de vertèbre cervicale (cf. boeuf).

\subsection{Abords de la tombe T17 (US17102 et 17111)}

Os humains incinérés :

- membres : 3 fragments de diaphyses $(7,1 \mathrm{~g})$.

Objets mobiliers :

- céramique non tournée :

- fragments de cols tronconiques rentrants et bords déversés de 6 urnes (fig. 44, $\mathrm{n}^{\circ} 1$ et 2); 1 fragment d'épaule décoré d'impressions au peigne (fig. 44, $\mathrm{n}^{\circ} 4$ ) ; 34 morceaux de panses peignées de plusieurs urnes; 1 fond plat d'urne à plan de pose peigné, comme la panse (fig. 44, $\mathrm{n}^{\circ} 5$ ); tous ces tessons semblent se rapporter à des urnes de forme CNT-LOR U5d ;

- 1 tesson de jatte non tournée de forme CNT-LOR $\mathrm{J} 1 \mathrm{e}$, variante 1 : panse arrondie convexe, embouchure évasée, bord à lèvre élargie avec aplatissement horizontal ; diam. ouv. : $270 \mathrm{~mm}$ (fig. 44, $\mathrm{n}^{\circ} 3$ );

- 44 tessons d'urnes ou de coupes.

- dolium indigène : 5 tessons ;

- amphore massaliète : 1 morceau de panse ;

- chenet modelé en terre cuite : 1 fragment de corps (fig. 44, $\mathrm{n}^{\circ} 6$ ).

Os d'animaux (détermination A. Gardeisen) :

-2 fragments de diaphyse de métatarse de capriné (cf. mouton).

\subsection{Entre les tombes $\mathrm{T} 15, \mathrm{~T} 16, \mathrm{~T} 17$ et $\mathrm{T} 18$ (US 17024 et 17034)}

Os humains incinérés :

- crâne : 1 fragment $(0,1 \mathrm{~g})$;

- membres : 21 fragments de diaphyses $(8,1 \mathrm{~g})$;

- indéterminé : 1 fragment $(0,1 \mathrm{~g})$.

Objets mobiliers :

- céramique non tournée :

- 10 fragments de cols et bords déversés, 31 morceaux de panses peignées et 1 fond plat se rapportant à au moins 5 urnes de forme probable CNT-LOR U5d (fig. 44, $\mathrm{n}^{\circ} 7$ et 8 );

- 2 tessons de 2 grandes coupes de forme CNTLOR C2: panse arrondie convexe, embouchure rétrécie, bord convergent à lèvre aplatie ou arrondie (fig. 44, $\mathrm{n}^{\circ} 9$ et 10); 1 fond annulaire de grande coupe (non dessiné).

- céramique à vernis noir : 2 fragments informes de vases de l'atelier de Rosas; 1 bord de coupe Lamb. 27 en campanienne A ou vernis noir de Rosas.

Os d'animaux (détermination A. Gardeisen) :

-1 corps de talus droit de capriné, très altéré (juvénile?).

\subsection{Abords de la tombe T12 (17024)}

Os humains incinérés :

- crâne : 13 fragments $(2,2 \mathrm{~g})$;

- tronc : 3 fragments de côtes et 1 de vertèbre $(0,3 \mathrm{~g})$;

- membres : 82 fragments de diaphyses $(8,8 \mathrm{~g})$.

Os d'animaux (détermination A. Gardeisen) :

- 1 fragment d'extrémité proximale d'os long de bœuf (cf. humérus), altéré ;

-1 fragment de diaphyse de métacarpe de capriné, altéré ;

- Indéterminé : 1 esquille.

\subsection{Au sud des tombes T12, T13 et T14 (US 17103 et 17105)}

Os humains incinérés :

- crâne : 1 fragment $(0,2 \mathrm{~g})$;

- membres : 21 fragments de diaphyses (5,6 g).

Objets mobiliers :

- céramique non tournée :

- 3 cols et bords, 5 morceaux de panses peignées et 1 fond plat d'urne de forme probable CNT-LOR U5d (fig. 44, $\mathrm{n}^{\circ} 11$ à 13);

- 1 tesson de coupe de forme CNT-LOR C1 : panse arrondie convexe, embouchure évasée, bord à lèvre aplatie (fig. 44, $\mathrm{n}^{\circ}$ 14) ;

- 1 tesson de grande coupe de forme CNT-LOR $\mathrm{C} 2$ : panse arrondie convexe, embouchure rétrécie, bord convergent à lèvre amincie (fig. 44, $\mathrm{n}^{\circ} 15$ ).

- céramique à pâte claire massaliète : 1 fond annulaire de coupe à bande peinte ocre rouge (fig. 44, $\mathrm{n}^{\circ} 16$ ) ;

- amphore massaliète : 1 petit morceau de panse ;

- chenet modelé en terre cuite : 1 morceau d'extrémité arrière (fig. 44, $\mathrm{n}^{\circ}$ 17).

Os d'animaux (détermination A. Gardeisen) :

-1 fragment d'extrémité articulaire de scapula de bœuf ; 


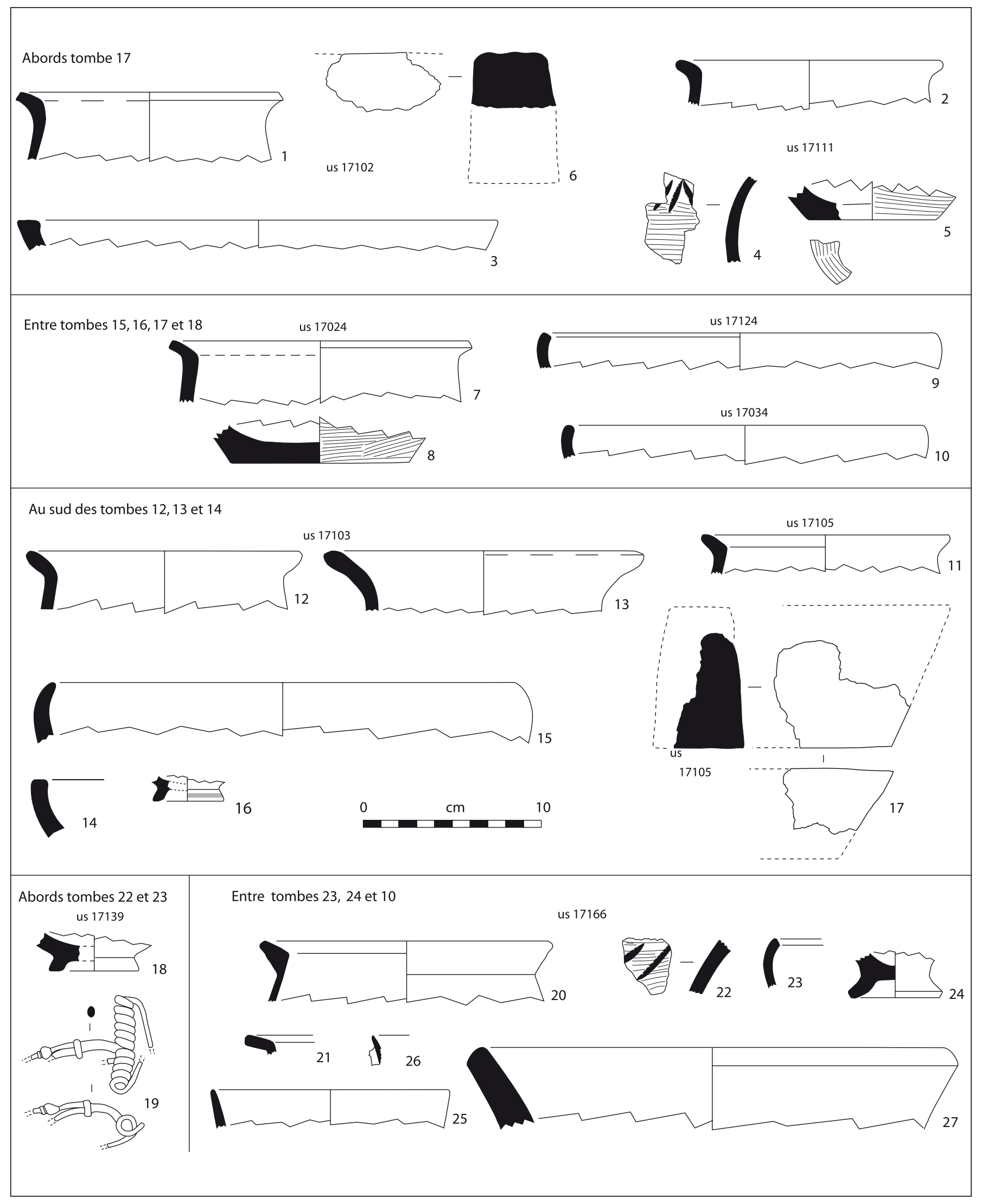

Fig. 44. Sol. Mobilier (1-5, 7-15, 20-24: céramique non tournée ; 6 et $17:$ chenets modelés en terre cuite ; 16 et 26 : céramique à pâte calire massaliète ; 18 et 25 : céramique à vernis noir ; $27:$ mortier massaliète ; $19:$ fer). 
-1 fragment de bord de corps de côte (cf. bœuf) ;

-2 fragments de vertèbre (cf. mammifère de petite taille) ;

- Indéterminés : 5 esquilles.

\subsection{Abords des tombes $\mathrm{T} 22$ et $\mathrm{T} 23$ (US 17135, 17139 et 17141)}

Os humains incinérés :

- crâne : 5 fragments $(0,7 \mathrm{~g})$;

- membres : 4 fragments de diaphyses $(0,5 \mathrm{~g})$.

Objets mobiliers :

- Petite fibule en fer, incomplète (il manque la partie antérieure du pied et le porte-ardillon) (fig. 44, $\mathrm{n}^{\circ} 19$ et fig. 115); long ressort bilatéral à onze spires et corde externe ; arc en tige mince de section lenticulaire, légèrement épaissi vers le centre; grand pied recourbé dont il ne reste que l'extrémité, fixée au sommet de l'arc par deux petites griffes enveloppantes ; près de l'arc, le pied est décoré d'un petit nodule en bulbe d'oignon précédé d'une mouluration; long. cons. : $46 \mathrm{~mm}$; larg. au ressort : $37 \mathrm{~mm}$; Type 23 de R. Gebhard (1991) ;

- céramique non tournée : 25 tessons d'urnes ou de coupes ;

- céramique à vernis noir : 1 fond de coupelle à vernis noir de l'atelier de Rosas, peut-être de forme Lamb. 24-25 (= forme Puig 1 ou 2); diam. base: $50 \mathrm{~mm}$ (fig. 44, $\left.\mathrm{n}^{\circ} 18\right)$;

- amphore massaliète : 1 petit morceau de panse.

Os d'animaux (détermination A. Gardeisen) :

-1 troisième molaire presque entière de porc adulte jeune, d'environ deux ans (début d'usure) ;

- 1 fragment de molaire de porc adulte, usée ;

- 1 troisième molaire inférieure droite de capriné, très usée (DMD : 23,1 $\mathrm{mm}$; DVL : 9,0 mm).

\subsection{Entre les tombes T23, T24 et T10 (US 17166)}

Os humains incinérés :

- crâne : 7 fragments $(1,2 \mathrm{~g})$;

- tronc : 2 fragments de côtes $(0,5 \mathrm{~g})$;

- membres : 10 fragments de diaphyses $(2,1 \mathrm{~g})$;

- indéterminé : 1 fragment $(0,1 \mathrm{~g})$.

Objets mobiliers :

- céramique non tournée ;

- 2 cols et bords et 1 fragment d'épaule d'urnes de forme probable CNT-LOR U5d; l'épaulement est décoré d'impressions au peigne sur le peignage de la paroi (fig. 44, $\mathrm{n}^{\circ} 20$ à 22) ;

- 1 tesson de coupe de forme CNT-LOR C2 : panse arrondie convexe, embouchure rétrécie, bord convergent à lèvre amincie (fig. 44, n 23) ;

- 1 fond annulaire de couvercle (fig. 44, $\mathrm{n}^{\circ} 24$ );

- 58 tessons d'urnes ou de coupes.

- céramique à vernis noir de l'atelier de Rosas : 4 tessons d'un bol de forme Lamb. 31 (= forme Puig 33) et 8 tessons informes (fig. 44, $\mathrm{n}^{\circ} 25$ ) ;

- céramique à pâte claire massaliète : 1 bord de coupe CL-MAS 433, avec départ d'anse horizontale (fig. 44, $\left.\mathrm{n}^{\circ} 26\right)$;

- mortier massaliète : 1 bord (fig. 44, $\mathrm{n}^{\circ} 27$ ).

Os d'animaux (détermination A. Gardeisen) :

- porc: 1 fragment de diaphyse distale d'humérus droit (adulte), 1 corps de première incisive inférieure gauche, 1 fragment de racine d'incisive supérieure ;

- capriné : 1 fragment de diaphyse de radius ;

- bœuf: 1 fragment d'extrémité proximale de métatarse ;

- Indéterminés : 8 esquilles ;

- Malacofaune : fragment de coquillage.

\subsection{Abords de la tombe T11 (US 17104)}

Objets mobiliers :

- parure :

- 1 petite perle en pâte de verre bleue, à section en « $\mathrm{D}$ » (diamètre 5 à $6 \mathrm{~mm}$ ) (fig. 45, $\left.\mathrm{n}^{\circ} 1\right)$;

- un morceau d'un bracelet en bronze, à $60 \mathrm{~cm}$ au sud-ouest du loculus; peut-être ouvert, car le ruban s'amincit vers une des extrémités ; section en « $\mathrm{D}$ »; pas de décor visible ; haut. : 6 à $9 \mathrm{~mm}$; ép. : $5 \mathrm{~mm}$; diam. int. : environ $55 \mathrm{~mm}$ (fig. $45, \mathrm{n}^{\circ} 3$ ).

- habillement :

- 1 arc de fibule en bronze, à sommet élargi en forme de losange, de section plate (long. cons. : $47 \mathrm{~mm}$; largeur : $23 \mathrm{~mm}$ ) ; cet objet est déformé par l'action d'un feu secondaire (fig. 45, $\left.\mathrm{n}^{\circ} 4\right)$;

- 1 passant en fer ; formé d'une plaque fine, grossièrement ovale, prolongée aux deux extrémités par deux pattes repliées, de section quadrangulaire ; long. : $27 \mathrm{~mm}$; larg. : $11 \mathrm{~mm}$; à $1 \mathrm{~m}$ au nord du loculus, (fig. 45, $\mathrm{n}^{\circ} 2$ ).

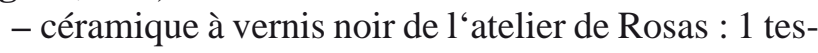
son de bord de bol de forme Lamb. 27 (= Puig 11.b) (fig. $\mathbf{4 5}, \mathrm{n}^{\circ} 5$ ) et 1 petit tesson informe ;

- céramique de la Côte catalane : 1 anse et carène de gobelet de forme COT-CAT Gb0 (fig. 45, ${ }^{\circ}$ 6) ; 


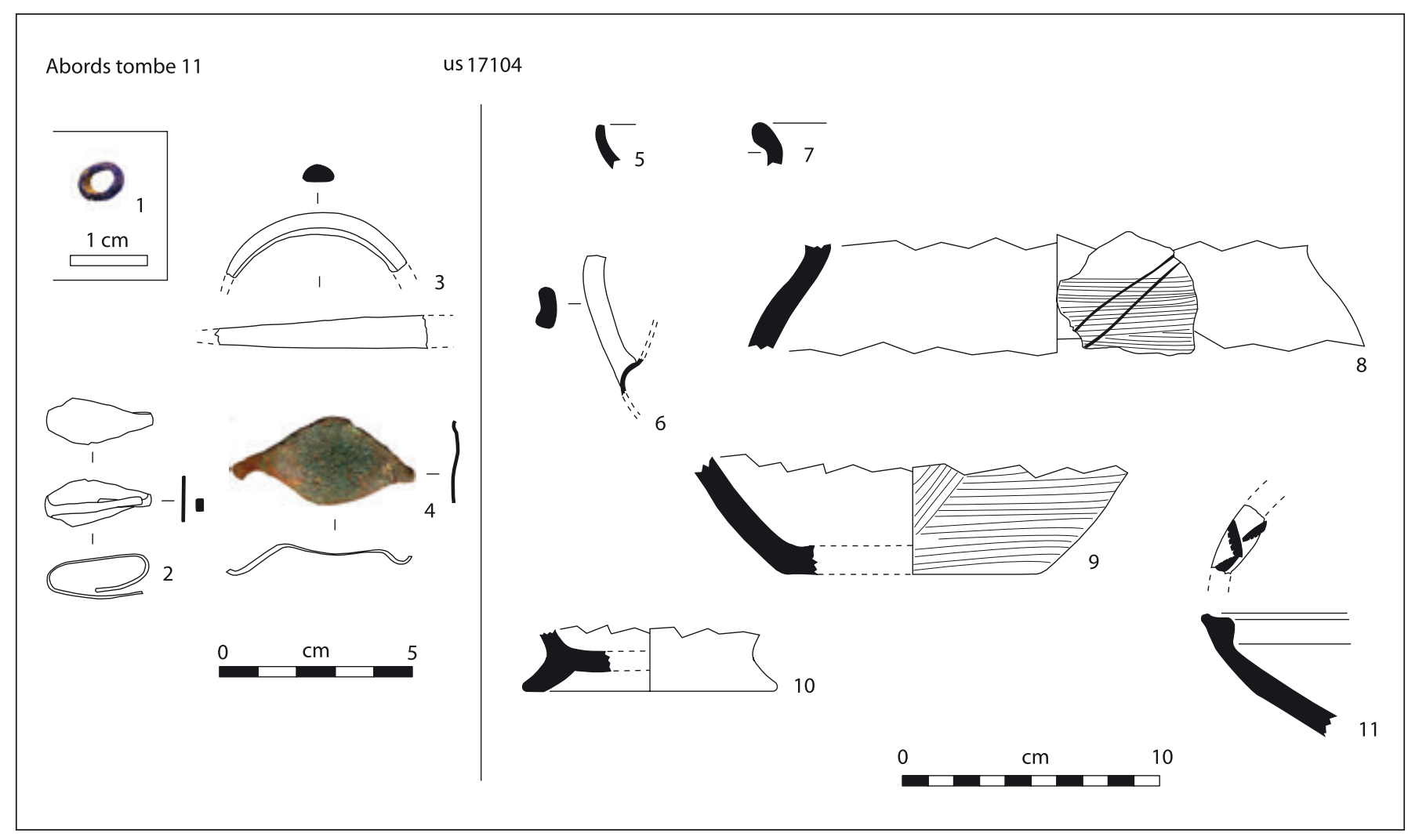

Fig. 45. Sol. Mobilier ( $1:$ verre $; 2:$ fer $; 3$ et $4:$ bronze $; 5:$ céramique à vernis noir $; 6:$ céramique de la Côte catalane ; 7-11 : céramique non tournée) .

- céramique non tournée :

- 1 bord déversé, une partie supérieure de panse peignée avec décor de deux lignes incisées largement, peut-être double ligne brisée, 16 morceaux de panses peignées et 1 fond plat d'urnes de forme probable CNTLOR U5d (fig. 45, nº 7 à 9);

- 1 fond annulaire de coupe (fig. 45, $\mathrm{n}^{\circ} 10$ ) ; 1 bord de jatte portant des impressions au peigne disposées en dents de loup, et localement épaissi (fig. 45, $\mathrm{n}^{\circ} 11$ ) ; 7 tessons d'urnes ou de coupes ;

- dolium indigène : 1 tesson.

Os d'animaux (détermination A. Gardeisen) :

- 1 fragment de dent jugale inférieure d'équidé ;

- 1 troisième phalange d'équidé aux bords émoussés (mesures de la facette articulaire DT max. : 45,0 mm ; DAP max. : 22,0 mm) ;

- 1 fragment de diaphyse distale de fémur (bord caudal) d'un herbivore de grande taille, peut-être un équidé (sous réserve);

-1 fragment de canine de porc femelle adulte ;

- capriné : 1 deuxième prémolaire inférieure gauche, 1 quatrième prémolaire inférieure droite, 1 deuxième molaire inférieure droite peu usée (jeune adulte) ;

- 1 fragment d'os crânien de grand herbivore ;
- Indéterminés : 9 esquilles de diaphyses d'os longs divers.

\subsection{Quel statut pour ces vestiges du sol de circulation?}

La présence de ces restes divers et dispersés sur l'aire de circulation entourant bûcher et tombes, avant que les limons d'inondation du Vidourle ne scellent l'ensemble, peut avoir deux origines.

L'érosion des structures de recouvrement des tombes, qui, peu épaisses semble-t-il, contiennent des éléments semblables, en est responsable pour les restes osseux humains incinérés, les rares objets de parure et d'habillement, et, sans doute, pour une part au moins des autres objets. Mais la fréquentation et l'activité des vivants durant la période d'utilisation du lieu à des fins funéraires a dû aussi générer divers déchets, périssables ou non, dont peuvent témoigner certains objets, en particulier des tessons de vases, et les os d'animaux, ou du moins une part d'entre eux. Ce dernier aspect a été évoqué pour la nécropole de la Porta Nocera à Pompéi (Lepetz, Van Andringa 2008, p. 121-122). 




\section{Chapitre 3}

\section{L'aire de crémation B1 (fouilles 1999 - 2003)}

$\mathrm{L}$ 'angle sud-est du terrain exploré sous l'emplacement de la cour gallo-romaine a livré une aire de crémation (fig. 8). Celle-ci n'a pas pu être entièrement fouillée car sa partie méridionale s'engage sous le mur sud de la cour, interdisant la recherche dans cette direction. Cependant, les variations de la densité des vestiges, notamment osseux, mesurée par petits carrés de $20 \mathrm{~cm}$ de côté, indiquent que le centre de ce bûcher a été reconnu, et la diminution régulière du nombre des restes vers le sud permet d'apprécier l'extension de cette structure dans cette direction et donc sa surface totale probable.

En plan, cette aire forme un demi-ove de 4,15 m sur son petit axe SO-NE et de $6 \mathrm{~m}$ estimés sur son grand axe NO-SE. Sur ce dernier, elle n'a pu être fouillée que sur $4,7 \mathrm{~m}$ de long. La superficie totale peut être estimée à $18 \mathrm{~m}^{2}$ environ.

La surface reconnue est de $14,5 \mathrm{~m}^{2}$. Cependant, dans sa partie nord, une zone de $3,5 \mathrm{~m}^{2}$ a manifestement disparu. Ce sont donc, en tout, $11 \mathrm{~m}^{2}$ qui ont été fouillés et cette surface englobe toute la partie centrale de ce bûcher et ses limites ouest, nord-ouest et est.

Cette fouille n'a pas pu être effectuée d'un seul tenant, du fait des contraintes liées à la présence des structures d'époque gallo-romaine sus-jacentes et à la profondeur des vestiges de la nécropole, mais au cours de trois campagnes successives: d'abord la partie nord, en 2001, une berne de $2 \mathrm{~m}$ de large le long du mur méridional de la ferme-auberge ayant été réservée lors du décapage mécanique préalable ; puis la partie méridionale jusqu'à la verticale de la fondation de ce mur, les deux années suivantes.

Ce bûcher est installé sur le sol antique de la nécropole qui n'a pas été excavé pour l'occasion. Globalement, il comprend un socle aménagé (US $17121+17122+$ $17123+17134+17172$ ) que surmonte une couche de fonctionnement qui déborde quelque peu tout autour (US $17109+17113+17114+17130+17132+17164$ ) (fig. $9, \mathrm{n}^{\circ} 2$; fig. 46 et 47 ).

\section{Le socle de l'aire de crémation B1}

\subsection{Description}

Le socle de l'aire de crémation B1 (US 17121 + 17122 $+17123+17134+17172$ ) repose sur le niveau alluvial horizontal du Vidourle (US 17126), dépourvu de toute pierre, pierraille et mobilier, mais tacheté de quelques petits charbons de bois millimétriques. De plan ovale, il mesure $4,15 \mathrm{~m}$ au maximum sur son axe est-ouest. Son grand axe nord-sud peut être estimé à 6 m (fig. 47).

Haute de 10 à $12 \mathrm{~cm}$ au maximum, cette structure est constituée d'une couche de sédiment limoneux brun clair, semblable aux alluvions environnantes (fig. 9, $\mathrm{n}^{\circ} 2$ ). Elle s'en distingue cependant très nettement par la présence de divers éléments : de très nombreuses petites pierres et pierrailles calcaires, généralement centimétriques, mais souvent décimétriques, disposées plus ou moins densément, des tessons céramiques, des déchets culinaires, des vestiges de structures d'habitations, de petits nodules calcaires jaunes ou gris, partiellement décomposés, des nodules d'argile indurés ainsi que de petits fragments de charbons de bois, millimétriques, peu abondants et dispersés. Les pierres, jamais roulées, proviennent de la colline du Dévès, assise de l'habitat protohistorique tout proche. Entre elles prennent place des tessons verticaux ou obliques, parfois de dimensions importantes, poteries culinaires mais aussi amphores et dolia, et différents vestiges d'habitat, comme de rares morceaux de chenets d'argile, de soles de foyers détruits, ainsi que des ossements d'animaux non brûlés. Tous ces éléments sont dépourvus de traces de feu, à l'exception cependant de ceux qui se trouvaient au contact de la couche susjacente et qui ont été noircis, ou rougis par le foyer dans la partie centrale de cette structure. La surface de cette structure est plus importante que celle de la couche de fonctionnement du bûcher. Elle correspond au niveau d'aménagement de l'aire de crémation.

Une dépression large mais très peu profonde est aménagée au sein du socle, en position centrale de 


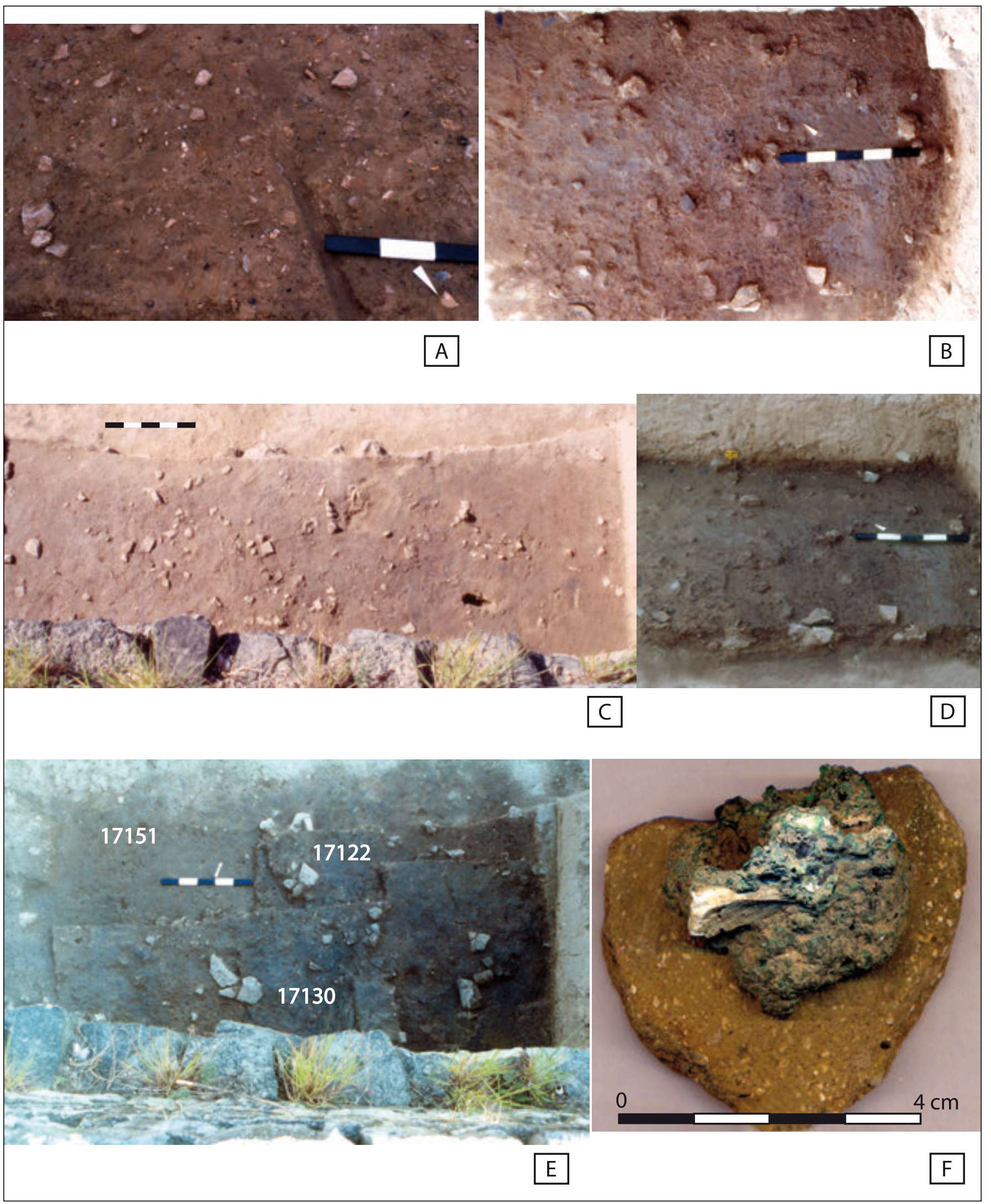

Fig. 46. Aire de crémation B1. A, B et C : couche de fonctionnement (us 17113-17130) ; D : socle (us 17122) ; E : couche de fonctionnement (us 17130), socle us (17122) et terrasse alluviale (us 17151) ; F : couche de fonctionnement, tesson de céramique non tournée, objet en bronze fondu et os brûlés, amalgamés par la chaleur. 


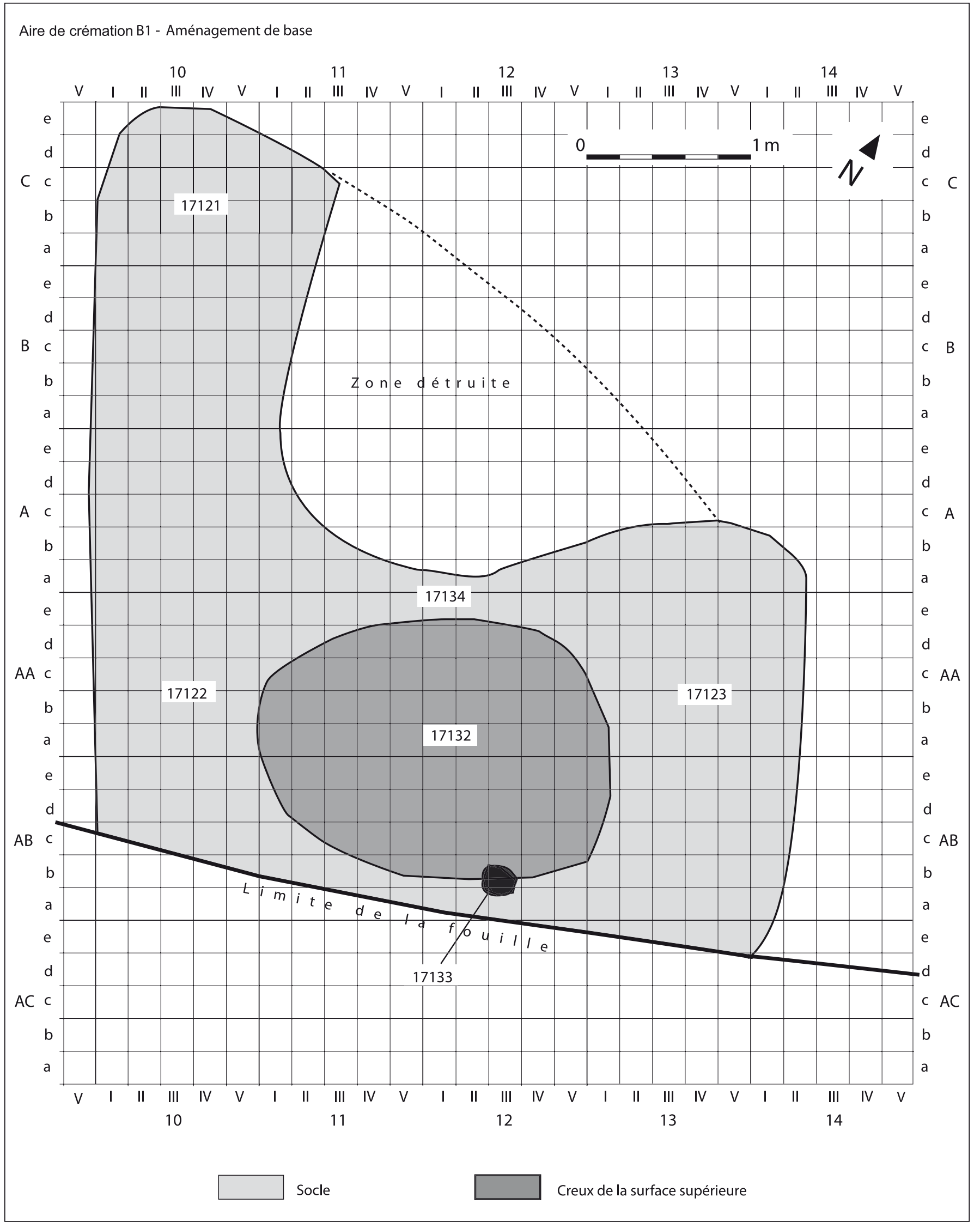

Fig. 47. Aire de crémation B1. Plan de l'aménagement de base. 
l'axe ouest-est, dans la partie méridionale fouillée (US 17132). Elle présente un plan ovale et mesure 2,1 m sur son grand axe ouest-est et 1,5 $\mathrm{m}$ sur le petit axe nordsud. Sa profondeur n'excède pas $10 \mathrm{~cm}$ vers le centre (fig. 9, $\mathrm{n}^{\circ} 2$ et fig. 47).

Le socle en lui-même n'a pas livré d'os humains incinérés. Ces derniers sont seulement présents au contact avec la couche de crémation ; ils sont à rattacher en fait à cette couche de fonctionnement.

De même qu'il ne contenait pas d'os humains incinérés, de même le socle ne renfermait-il aucun objet d'équipement personnel des défunts, comme des pièces de parure ou d'habillement, des éléments d'armement et de fourniment ou des fusaïoles. Ce qu'il inclut évoque bien plutôt les rejets des activités domestiques. Sans doute, le matériau qui le constitue provient-il des couches de sédimentation de l'habitat installé sur la colline même du Dévès, comme l'indique l'origine des éléments pierreux inclus.

\subsection{Mobilier du socle (US $17121+17122+$ $17123+17134+17172)$}

\section{A) Céramique non tournée}

Le socle renfermait 598 morceaux de céramique non tournée, sans compter de nombreuses esquilles millimétriques. Ceux-ci appartiennent pratiquement à autant d'urnes, de couvercles, de coupes, de jattes ou de dolia.

Urnes :

La plupart des morceaux identifiables se rapportent à des urnes de forme CNT-LOR U5d, et notamment la variante $\mathrm{d}$ : col tronconique rentrant ou plus rarement cylindrique, à surface lissée, bord déversé avec souvent la présence d'un méplat vers l'intérieur, panse ovoïde à peignage horizontal ou entrecroisé et fond plat ou, parfois, très légèrement creux; l'épaule peut être décorée d'impressions du peigne disposées en oblique, soit dans la même direction, soit de direction alternée pour former une ligne brisée simple ou double (fig. 48, n 1 à 10, 21 à 26 et 28 à 31 ). Ces vases ont des dimensions moyennes ou grandes : le diamètre à l'ouverture s'échelonne de 110 à $170 \mathrm{~mm}$; le diamètre maximum est compris entre $150 \mathrm{~mm}$ (fig. 48, $\mathrm{n}^{\circ} 1$ et 21) et $240 \mathrm{~mm}$ (fig. 48, $\mathrm{n}^{\circ} 28$ ). D' autres bords (fig. 48, $\mathrm{n}^{\circ} 12$ à 20) ou fonds (fig. 48, $\mathrm{n}^{\circ} 33$ et 34 ) pourraient relever de cette forme mais l'état de fragmentation ne permet pas de l'assurer.

Autres formes : un fond creux (fig. 48, $\mathrm{n}^{\circ} 32$ ); un fragment de fond plat portant un large trait incisé avant cuisson (fig. 48, $\mathrm{n}^{\circ} 35$ ) ; un morceau d'anse verticale de cruche, en boudin épais (fig. $48, \mathrm{n}^{\circ} 27$ ).

Couvercles :

Les couvercles ont une vasque, soit le plus souvent, légèrement concave, de forme CNT-LOR V2b (fig. 49, $\mathrm{n}^{\circ} 1$ à $5,7,8$ et 11), soit rectiligne, de forme CNT-LOR V2a (fig. 49, $\mathrm{n}^{\circ}$ 6, 9 et 10). Les lèvres sont le plus souvent arrondies ou aplaties, plus rarement amincies. Les 11 exemplaires attestés peuvent être classés en deux groupes selon la taille: une série grande, avec un diamètre de $270 \mathrm{~mm}$ (fig. 49, $\mathrm{n}^{\circ} 2$ ), de $240 \mathrm{~mm}$ (fig. 49, $\mathrm{n}^{\circ} 1$ et 4) ou de $200 \mathrm{~mm}$ (fig. 49, $\left.\mathrm{n}^{\circ} 10\right)$; et une série petite, avec un diamètre de $130 \mathrm{~mm}$ (fig. 49, $\mathrm{n}^{\circ}$ 5), de $135 \mathrm{~mm}$ (fig. 49, $\mathrm{n}^{\circ}$ 9) ou de $140 \mathrm{~mm}$ (fig. 49, $\mathrm{n}^{\circ} 3$ ).

\section{Coupes :}

Les coupes ont toutes une panse arrondie convexe. La forme et l'orientation du bord permettent de distinguer :

-8 exemplaires de forme CNT-LOR C2 : embouchure rétrécie, bord convergent à lèvre arrondie ou plus rarement aplatie ou épaissie (fig. 49, nº 12 à 19). Figurent sous cette forme surtout des spécimens de grande dimension (diam. max. : 200 à $250 \mathrm{~mm}$ ), mais aussi une coupelle (diam. max. : $65 \mathrm{~mm}$ ) ;

- 10 exemplaires de forme CNT-LOR C1 : embouchure évasée, bord divergent à lèvre arrondie ou aplatie ou plus rarement épaissie en marli ; diam. max. : 200 à 240 mm (fig. 49, n 20 à 29).

Le fond de ces coupes peut être annulaire (fig. 49, $\mathrm{n}^{\circ}$ 30) ou plat (fig. 49, $\mathrm{n}^{\circ} 31$ et 32).

Jattes :

- 1 partie supérieure d'une grande jatte non tournée de forme CNT-LOR J1e, variante 3: panse arrondie convexe, embouchure évasée, bord à lèvre élargie avec aplatissement incliné vers l'intérieur; diam. max. : $420 \mathrm{~mm}$ (fig. 49, $\mathrm{n}^{\circ} 33$ );

-2 bords de 2 jattes non tournées de forme CNT-LOR $\mathrm{J} 1 \mathrm{~b}$ : panse tronconique ou très légèrement arrondie, bord évasé à lèvre aplatie ou arrondie et décorée sur le dessus de coups imprimés (fig. 49, nº 34 et 35).

Dolium :

- 41 tessons de panses peignées.

\section{B) Céramiques tournées}

Céramique à vernis noir :

- Atelier des Petites Estampilles : 4 tessons, dont un bord convergent de bol de moyenne taille PET-EST 2783, variante 3 ; diam. bord : $140 \mathrm{~mm}$ (fig. 50, $\mathrm{n}^{\circ}$ 2). 


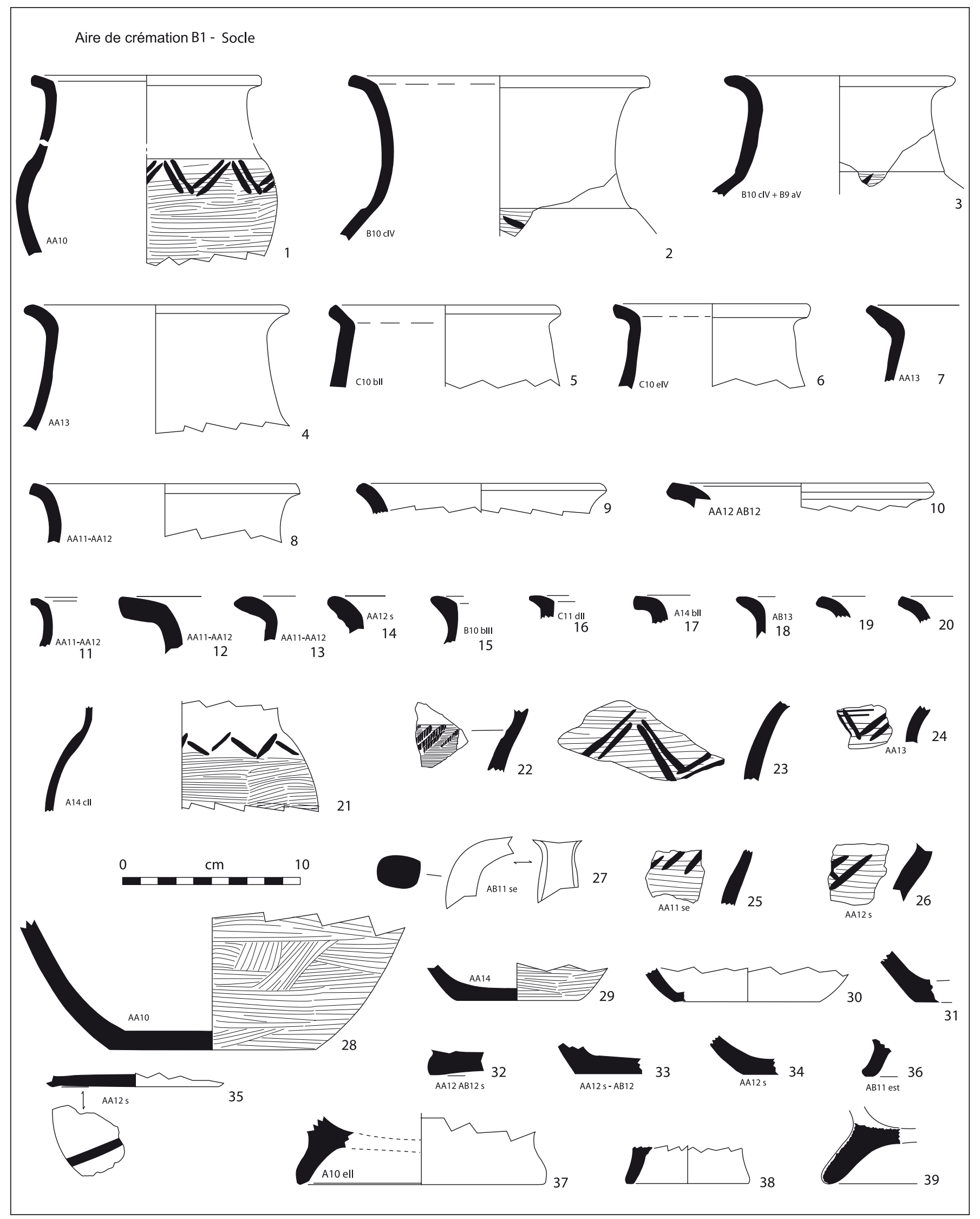

Fig. 48. Aire de crémation B1, socle (us 17121 + 17122 + 17123 + 17134 + 17172). Mobilier (céramique non tournée). 


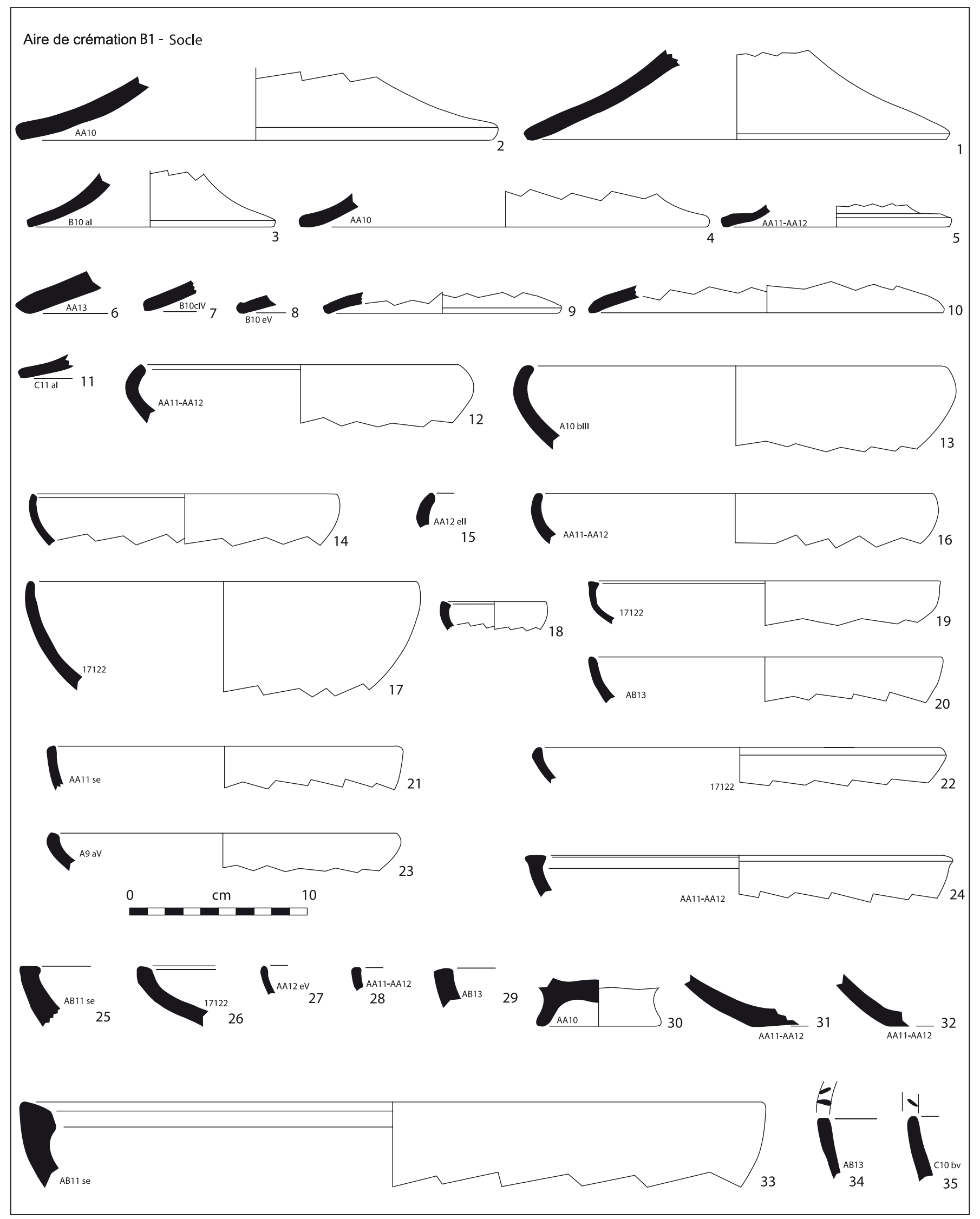

Fig. 49. Aire de crémation B1, socle (us $17121+17122+17123+17134$ + 17172). Mobilier (céramique non tournée). 


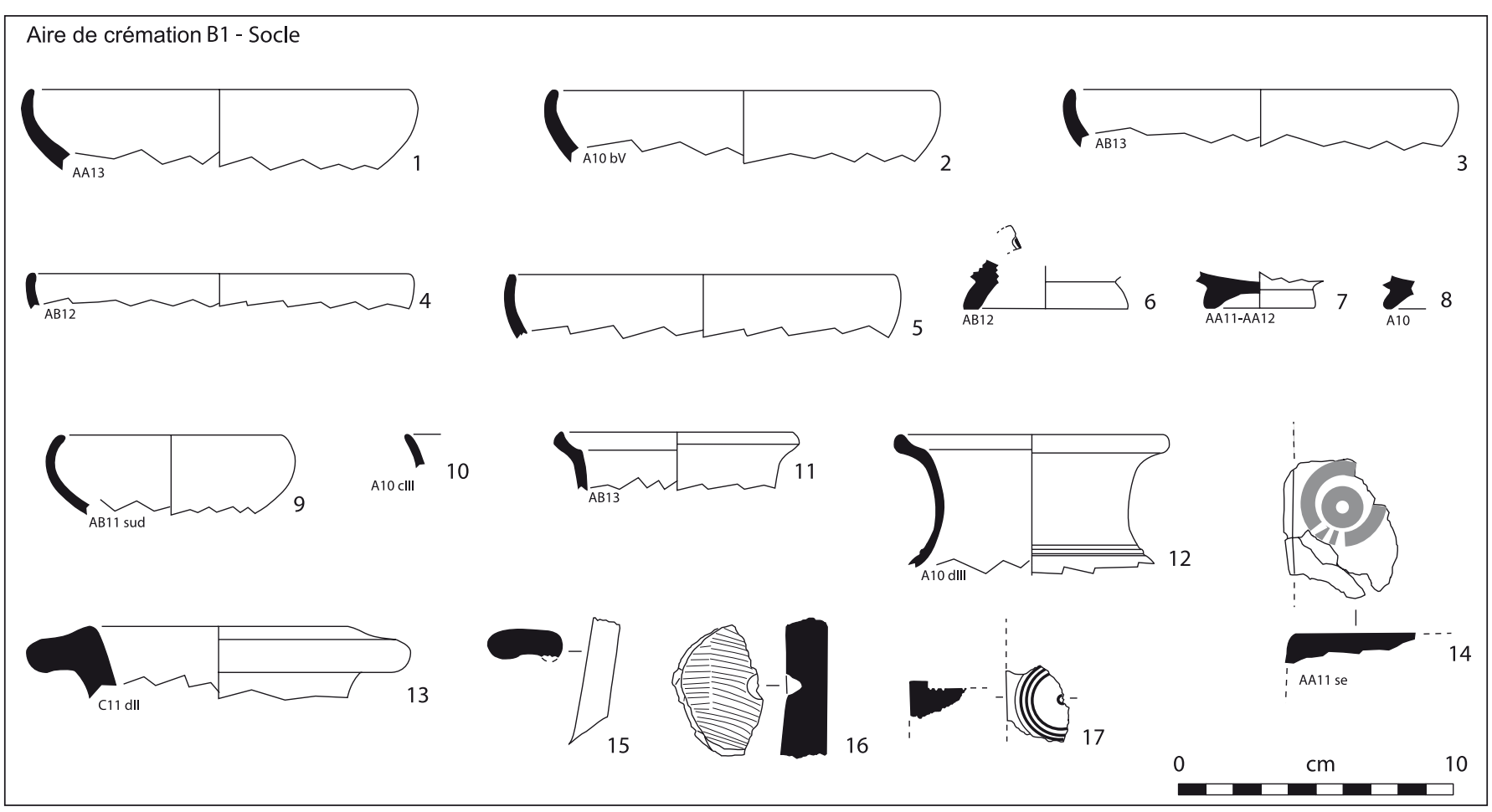

Fig. 50. Aire de crémation B1, socle (us $17121+17122+17123+17134+17172)$. Mobilier (1-6 : céramique à vernis noir ; 7 et $8:$ céramique grise peinte massaliète ; 9-12 et 15 : céramique à pâte claire massaliète ; 13 : amphore grecque ? 14 : chenet modelé en terre cuite ; 16 : céramique non tournée $17:$ terre cuite).

- Atelier de Rosas : 4 bords de bols Lamb. 27 (forme Puig 11.b) (fig. 50, $\mathrm{n}^{\circ} 3$ à 5), diam. ouv. : 130 mm ( $\left.{ }^{\circ} 4\right)$ et $140 \mathrm{~mm}\left(\mathrm{n}^{\circ} 3\right.$ et 5$) ; 1$ bord de bol Lamb. 27 (forme Puig 11.c) (fig. 50, $\mathrm{n}^{\circ} 1$ ), diam. ouv. : $140 \mathrm{~mm} ; 2$ bords, 4 tessons de panse et 2 fonds de bols Lamb. 27 (forme Puig 11) dont 1 fond (diam.: $60 \mathrm{~mm}$ ) avec bordure d'estampille visible (fig. 50, $\mathrm{n}^{\circ}$ 6) ; 13 tessons informes, généralement de petite taille appartenant à autant de vases ;

- Atelier de Rosas ou Campanienne A: 3 tessons informes.

Céramique grise peinte massaliète :

-5 fragments dont deux fonds et un morceau de panse de coupes GR-PEINTE 2-4 (fig. 50, $\mathrm{n}^{\circ} 7$ et 8).

Céramique à pâte claire massaliète :

- 22 fragments dont un bord de coupe CL-MAS 236 (fig. 50, n ${ }^{\circ}$ 9), un bord de kylix CL-MAS 433 (fig. 50 $\left.\mathrm{n}^{\circ} 10\right)$ et deux cols et une anse verticale bifide de cruches CL-MAS 525 (fig. 50, $\mathrm{n}^{\circ} 11,12$ et 15).

Amphore :

-Amphore grecque ?: 1 bord (fig. 50, $\mathrm{n}^{\circ}$ 13) et 1 fragment d'anse en boudin, à pâte jaune.

-Amphore massaliète : 23 fragments dont 1 anse.
Divers :

-4 rondelles taillées dans des morceaux de panses de dolia, dont une percée en son centre et une autre avec percement incomplet en son centre (fig. 50, $\mathrm{n}^{\circ} 16$ ); diam. : $36 \mathrm{~mm} ; 47 \mathrm{~mm} ; 48$ à $54 \mathrm{~mm} ; 50 \mathrm{~mm}$;

- Chenet modelé en terre cuite : deux morceaux de corps de chenet dont un décoré de cercles concentriques estampés (fig. 50, $\mathrm{n}^{\circ} \mathbf{1 4}$ );

- Morceau de plaque en terre cuite portant, sur la face conservée, trois cercles concentriques estampés et un petit cercle central, le tout dans un cartouche circulaire (diam. max. cons. : $22 \mathrm{~mm}$ ) (fig. 50, $\mathrm{n}^{\circ}$ 17).

\section{Le niveau de fonctionnement de l'aire de crémation B1}

\subsection{Description}

La couche de fonctionnement du bûcher B1 est composée d'un sédiment cendreux. À la base, la partie centrale est formée d'une strate de couleur rouge sombre-lie de vin (17130) (fig. 51). Elle remplit la légère dépression qui creuse le socle vers le centre (17132). Dans cette zone, son épaisseur n'excède pas 
$10 \mathrm{~cm}$. En périphérie de celle-ci, cette couche n'a plus qu'un ou deux centimètres d'épaisseur. Elle contient de petits morceaux d'os humains incinérés, sans aucune connexion anatomique, des tessons de céramiques et des objets ou morceaux d'objets métalliques ou en verre en partie fondus, pièces de parure ou d'habillement, armes et fourniment, ustensiles. Elle est surmontée par une couche de couleur noir à gris, charbonneuse et cendreuse (17109-17113-17114) qui déborde largement tout autour de la couche rougeâtre pour recouvrir, en périphérie, directement le socle. Cette couche, épaisse de $10 \mathrm{~cm}$ dans la partie centrale, s'amincit vers la périphérie. Elle renferme le même type de matériel que la couche 17130, mais en plus grande quantité dans sa partie centrale. Sont également présentes des petites pierres calcaires centimétriques provenant de la colline du Dévès, qui ont fortement chauffé, comme le montrent les éclats thermiques et les traces nombreuses de rubéfaction. Cette couche inclut aussi des lentilles de cendres blanchâtres pouvant atteindre $10 \mathrm{~cm}$ de diamètre, et même exceptionnellement $20 \mathrm{~cm}$, dans lesquelles les morceaux d'os sont plus abondants et de dimensions plus importantes qu'ailleurs, mais toujours sans connexions anatomiques. En revanche, les fragments de charbons de bois sont rares et de très petite taille.

L'existence d'une zone centrale rougie est un fait souvent constaté à la base de certains bûchers. Les analyses et les expérimentations ont montré que cette rubéfaction intervient en atmosphère oxydante au début de la crémation, avant que les braises ne tombent et ne colmatent les espaces vides (Lambot 1994 ; Blaizot dir. 2009, p. 105107). Dans le cas présent, la légère dépression centrale du socle a constitué un tel espace sous le bûcher, dont les éléments devaient prendre appui aux alentours, sur la surface du socle. Elle a dû permettre, lors de la première crémation, la circulation de l'air par la base et donc un bon tirage.

Par ailleurs, la grande rareté des restes de charbon de bois est également en adéquation avec la constatation de la quasi-absence de tout reste de combustible après la crémation du bûcher expérimental d'Acy-Romance (Lambot 1994, p. 256 et 259, fig. 11).

Un trou de poteau ovale de 15 à $22 \mathrm{~cm}$ d'axes et $18 \mathrm{~cm}$ de profondeur (17133) est creusé jusqu'à la base du socle, à travers les trois couches 17130, 17132 et 17134 , en bordure sud-est de la zone de couleur rougeâtre. Il ne contient qu'une petite pierre calcaire verticale, enrobée par le comblement de terre alluviale jaune. Il pourrait s'agir d'un creusement destiné à implanter un dispositif d'ancrage ou de décoration du bûcher. Cependant, rien ne subsiste du poteau lui-même, indice que sa partie inférieure, enterrée dans le socle, n'a pas brûlé.

Selon l'étude anthracologique menée par C. CenzonSalvayre et A. Durand (infra, annexe 1), le bois utilisé pour ces crémations provient en quasi-totalité de chênes, essentiellement, à $80 \%$ environ, Chêne caducifolié cf. pubescent (Quercus FC cf. pubescens) et pour environ 20 \% Chêne kermès ou vert (Quercus ilex-Q. coccifera). Comme le soulignent les auteurs de ce travail, il s'agit là d'un excellent combustible, que l'on trouve alors en abondance dans la végétation de garrigue toute proche de la nécropole. En revanche, les espèces poussant sur les rives du Vidourle, pourtant aussi proches, ne sont pas sollicitées.

\subsection{Matériel du niveau de fonctionnement de l'aire de crémation B1 : la couche rouge US 17132}

\subsubsection{Les restes osseux humains}

Ce petit secteur de l'aire de crémation a livré 457,6 g d'os humains incinérés, essentiellement répartis dans la partie centrale de la légère dépression, avec un petit débordement vers l'est (fig. 52 et 53). Sur un total de 356,4 g d'os déterminés avec plus ou moins de précision, $63,4 \mathrm{~g}$ relèvent du crâne, soit 17,8\%,19,4 g du tronc, soit 5,4\%, et 273,6 g des membres, soit 76,8\%. Quatre sujets, au moins, sont attestés d'après le stade de maturation des os ou le développement de la denture.

La plupart des éléments permettant une appréciation de l'âge indiquent un stade de maturation adulte, ou bien une taille adulte.

\section{A) Éléments se rapportant à de l'adulte :}

- un rocher gauche (AB11 eIV);

- un corps vertébral avec listel soudé (AB12 dIV) ;

- un cotyle de coxal (AA12 bII) ;

- une extrémité distale de métacarpien ou de métatar$\operatorname{sien}(\mathrm{AA} 12 \mathrm{bI})$.

\section{B) Éléments signalant de l'adulte ou de l'adolescent :}

-8 racines dentaires à l'apex colmaté (AA11 aV; AA12 aI, aII, bI et bIV) ;

- une apophyse orbitaire de malaire gauche (AB12 dIV) ;

- des morceaux de crâne épais (AA11 aV ; AB11 eII) ;

- des morceaux de massif pétreux (AB11 eII) ;

- un scaphoïde gauche (AA12 aI) ;

- une tête et un col de talus droit (AA12 aII). 


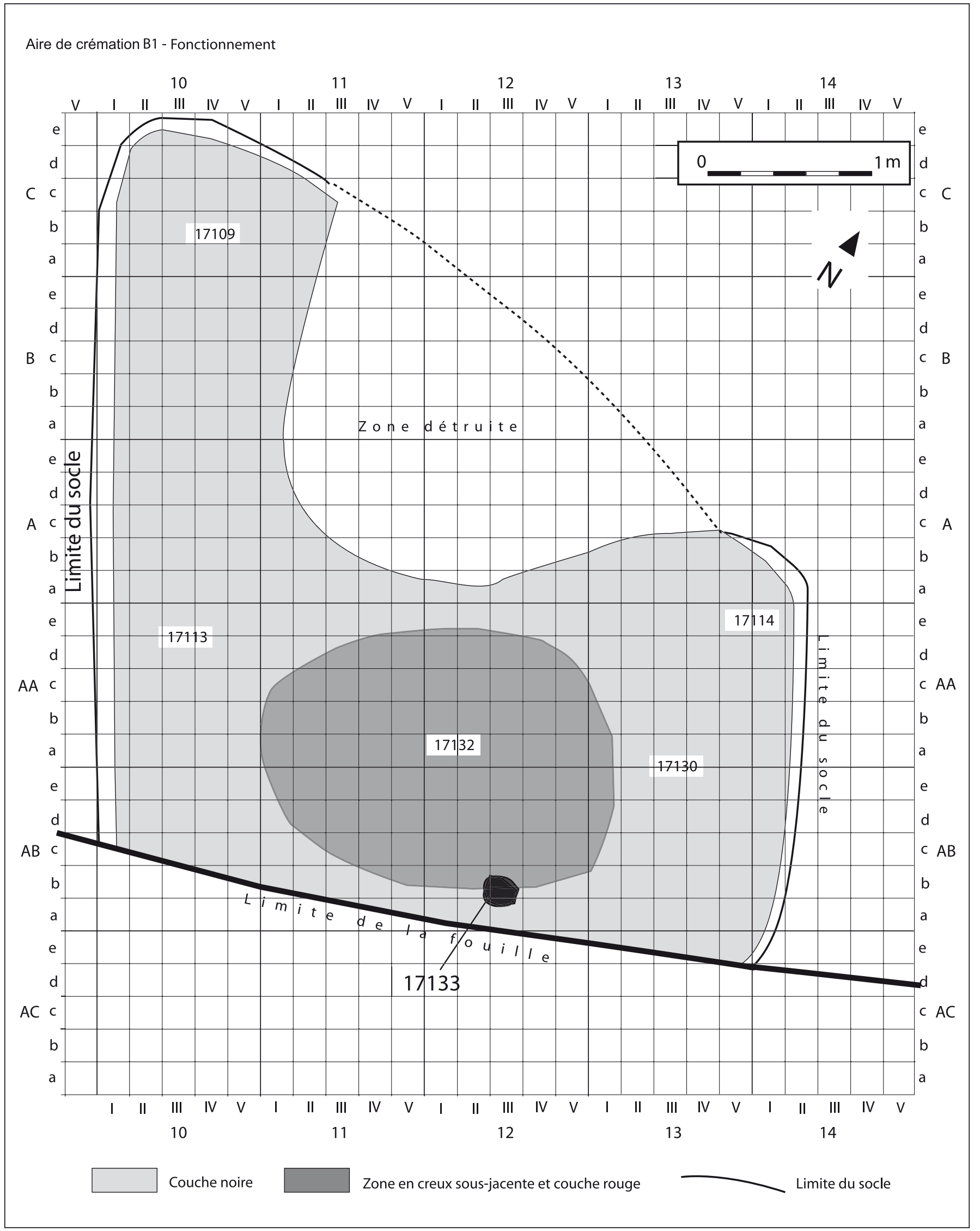

Fig. 51. Aire de crémation. Plan du niveau de fonctionnement. 


\begin{tabular}{|c|c|c|c|c|c|c|c|c|c|}
\hline \multirow{2}{*}{$\begin{array}{l}\text { Couche rouge } \\
\text { us } 17132\end{array}$} & \multirow{2}{*}{$\begin{array}{c}\text { Poids total } \\
\text { en } \mathrm{g}\end{array}$} & \multicolumn{2}{|c|}{ OS DÉTERMINÉS } & \multicolumn{2}{|c|}{ CRÂNE } & \multicolumn{2}{|c|}{ TRONC } & \multicolumn{2}{|c|}{ MEMBRES } \\
\hline & & Poids & $\% /$ total & Poids & $\% /$ déter. & Poids & $\% /$ déter. & Poids & $\% /$ déter. \\
\hline \multicolumn{10}{|l|}{ CARRÉ AA11 } \\
\hline a I & 1,1 & 0,6 & $54,5 \%$ & 0,1 & $16,6 \%$ & 0,1 & $16,6 \%$ & 0,4 & 66,6 \\
\hline a II & 1,2 & 1 & $83,3 \%$ & 0,1 & $10 \%$ & 0,1 & $10 \%$ & 0,8 & $80 \%$ \\
\hline a III & 1,2 & 0,7 & $58,3 \%$ & 0,5 & $71,4 \%$ & & & 0,2 & $28,6 \%$ \\
\hline a IV & 10,4 & 7,2 & $69,2 \%$ & 1,8 & $25 \%$ & 0,3 & $4,2 \%$ & 5,1 & $70,8 \%$ \\
\hline a V & 26.6 & 20 & $75,2 \%$ & 5.4 & $27 \%$ & 0,7 & $3,5 \%$ & 13,9 & $69,5 \%$ \\
\hline b I & 0,3 & 0,2 & $66,6 \%$ & & & & & 0,2 & $100 \%$ \\
\hline b II & 3,3 & 2,1 & $63,6 \%$ & 0,6 & $28,6 \%$ & 0,4 & $19 \%$ & 1,1 & $52,4 \%$ \\
\hline b III & 16,3 & 12,8 & $78,5 \%$ & 1,3 & $10,2 \%$ & 1,1 & $8,6 \%$ & 10,4 & $81,2 \%$ \\
\hline b IV & 13,7 & 11,2 & $81,8 \%$ & 0,4 & $3,6 \%$ & 0,2 & $1,8 \%$ & 10,6 & $94,6 \%$ \\
\hline b V & 13,7 & 8,9 & $65 \%$ & 1,4 & $15,7 \%$ & 1,2 & $13,5 \%$ & 6,3 & $70,8 \%$ \\
\hline $\mathrm{cI}$ & 0,9 & 0,5 & $55,6 \%$ & 0,5 & $100 \%$ & & & & \\
\hline c III & 1,1 & 0,3 & $27,3 \%$ & & & & & 0,3 & $100 \%$ \\
\hline $\mathrm{dV}$ & 0,3 & 0,3 & $100 \%$ & 0,1 & $33,3 \%$ & & & 0,2 & $66,6 \%$ \\
\hline CARRÉ AA12 & & & & & & & & & \\
\hline a I & 50 & 37,9 & $75,8 \%$ & 4,4 & $11,6 \%$ & 2,2 & $5,8 \%$ & 31,3 & $82,6 \%$ \\
\hline a II & 25,1 & 21,3 & $84,7 \%$ & 2 & $9,4 \%$ & 0,2 & $0,9 \%$ & 19,1 & $89,7 \%$ \\
\hline a III & 7,6 & 5,9 & $77,6 \%$ & 1,1 & $18,6 \%$ & 0,2 & $3,4 \%$ & 4,6 & $78 \%$ \\
\hline a IV & 0,7 & 0,3 & $42,9 \%$ & 0,1 & $33,3 \%$ & 0,1 & $33,3 \%$ & 0,1 & $33,3 \%$ \\
\hline $\mathrm{aV}$ & 0,6 & 0,5 & $83,3 \%$ & & & & & 0,5 & $100 \%$ \\
\hline b I & 52,5 & 32,9 & $62,7 \%$ & 5,8 & $17,6 \%$ & 0,9 & $2,7 \%$ & 26,2 & $79,6 \%$ \\
\hline b II & 25,2 & 20,8 & $82,5 \%$ & 4,3 & $20,7 \%$ & 2,5 & $12 \%$ & 14 & $67,3 \%$ \\
\hline b III & 16,1 & 12,1 & $75,2 \%$ & 4,6 & $38 \%$ & 0,2 & $1,7 \%$ & 7,3 & $60,3 \%$ \\
\hline b IV & 2,7 & 1,9 & $70,4 \%$ & 0,2 & $10,5 \%$ & 0,1 & $5,3 \%$ & 1,6 & $84,2 \%$ \\
\hline b V & 1 & 1 & $100 \%$ & 0,5 & $50 \%$ & & & 0,5 & $50 \%$ \\
\hline CARRÉ AB11 & & & & & & & & & \\
\hline a V & 1 & 1 & $100 \%$ & 1 & $100 \%$ & & & & \\
\hline b IV & 0,1 & & & & & & & & \\
\hline b V & 15,9 & 15,9 & $100 \%$ & & & 0,8 & $5 \%$ & 15,1 & $95 \%$ \\
\hline $\mathrm{cl}$ & 0,5 & 0,5 & $100 \%$ & & & & & 0,5 & $100 \%$ \\
\hline c II & 1,5 & 1,2 & $80 \%$ & 0,1 & $8,3 \%$ & & & 1,1 & $91,7 \%$ \\
\hline c IIII & 1,9 & 1,8 & $94,7 \%$ & & & 0,1 & $5,6 \%$ & 1,7 & $94,4 \%$ \\
\hline cIV & 0,6 & 0,5 & $83,3 \%$ & & & & & 0,5 & $100 \%$ \\
\hline d II & 0,3 & 0,3 & $100 \%$ & & & & & 0,3 & $100 \%$ \\
\hline d III & 6,9 & 6,3 & $91,3 \%$ & 3,4 & $54 \%$ & 0,4 & $6,3 \%$ & 2,5 & $39,7 \%$ \\
\hline dIV & 14,1 & 13,1 & $92,9 \%$ & 3,2 & $24,4 \%$ & 0,1 & $0,8 \%$ & 9,8 & $74,8 \%$ \\
\hline $\mathrm{dV}$ & 1,4 & 1,2 & $85,7 \%$ & 0,1 & $8,3 \%$ & 0,2 & $16,6 \%$ & 0,9 & $75 \%$ \\
\hline e II & 4,4 & 3,4 & $77,3 \%$ & 2,1 & $61,7 \%$ & 0,4 & $11,8 \%$ & 0,9 & $26,5 \%$ \\
\hline e III & 1,2 & 1,2 & $100 \%$ & & & & & 1,2 & $100 \%$ \\
\hline e IV & 18,8 & 15,3 & $81,4 \%$ & 4,8 & $31,4 \%$ & 2,2 & $14,4 \%$ & 8,5 & $55,6 \%$ \\
\hline $\mathrm{eV}$ & 29,3 & 26 & 88,7 & 1,5 & $5,8 \%$ & 0,3 & $1,2 \%$ & 24,2 & $93 \%$ \\
\hline CARRÉ AB12 & & & & & & & & & \\
\hline b I & 0,2 & & & & & & & & \\
\hline b II & 0,4 & 0,1 & $25 \%$ & & & & & 0,1 & $100 \%$ \\
\hline b IV & 1,4 & 1,3 & $92,9 \%$ & 0,4 & $30,7 \%$ & & & 0,9 & $69,3 \%$ \\
\hline $\mathbf{b} \mathbf{V}$ & 1 & 0,7 & $70 \%$ & & & & & 0,7 & $100 \%$ \\
\hline $\mathrm{cl}$ & 2,6 & 2,1 & $80,8 \%$ & & & 1 & $47,6 \%$ & 1,1 & $52,3 \%$ \\
\hline c II & 0,3 & 0,3 & $100 \%$ & & & 0,2 & $66,6 \%$ & 0,1 & $33,3 \%$ \\
\hline$c$ IIII & 0,5 & 0,5 & $100 \%$ & & & & & 0,5 & $100 \%$ \\
\hline c IV & 15,4 & 10,1 & $65,6 \%$ & 4 & $39,6 \%$ & 0,2 & $2 \%$ & 5,9 & $58,4 \%$ \\
\hline $\mathrm{cV}$ & 0,4 & 0,2 & $50 \%$ & & & 0,1 & $50 \%$ & 0,1 & $50 \%$ \\
\hline d I & 1,6 & 0,8 & $50 \%$ & & & 0,1 & $12,5 \%$ & 0,7 & $87,5 \%$ \\
\hline d II & 1,4 & 0,9 & $64,3 \%$ & 0,1 & $11,1 \%$ & & & 0,8 & $88,9 \%$ \\
\hline d III & 0,3 & 0,2 & $66,6 \%$ & & & 0,1 & $50 \%$ & 0,1 & $50 \%$ \\
\hline dIV & 5,7 & 4,7 & $82,5 \%$ & 1,1 & $23,4 \%$ & 0,1 & $2,1 \%$ & 3,5 & $74,5 \%$ \\
\hline$d V$ & 13,6 & 8,6 & $63,2 \%$ & 3,9 & $45,3 \%$ & 0,5 & $5,8 \%$ & 4,2 & $48,8 \%$ \\
\hline e I & 7,5 & 4,1 & $54,7 \%$ & 1 & $24,4 \%$ & 0,1 & $2,4 \%$ & 3 & $73,2 \%$ \\
\hline e III & 0,1 & 0,1 & $100 \%$ & 0,1 & $100 \%$ & & & & \\
\hline e IIII & 4,1 & 3,1 & $75,6 \%$ & 0,2 & $6,5 \%$ & 0,5 & $16,1 \%$ & 2,4 & $77,4 \%$ \\
\hline e IV & 1,3 & 0,7 & $5,4 \%$ & 0,4 & $57,1 \%$ & 0,1 & $14,3 \%$ & 0,2 & $28,6 \%$ \\
\hline e V & 1,1 & 0,9 & $81,8 \%$ & 0,4 & $44,4 \%$ & 0,1 & $11,1 \%$ & 0,4 & $44,4 \%$ \\
\hline CARRÉ AB 13 & & & & & & & & & \\
\hline b I & 0,3 & 0,3 & $100 \%$ & & & & & 0,3 & $100 \%$ \\
\hline b III & & & & & & & & & \\
\hline cIV & 7,2 & 7,2 & $100 \%$ & & & 0,7 & $9,7 \%$ & 6,5 & $90,3 \%$ \\
\hline$d \mathrm{I}$ & 0,2 & & & & & & & & \\
\hline d IV & 0,2 & & & & & & & & \\
\hline e I & 17,3 & 17,2 & $99,4 \%$ & 0,4 & $2,3 \%$ & 0,6 & $3,5 \%$ & 16,2 & $94,2 \%$ \\
\hline e II & 0,1 & 0,1 & $100 \%$ & & & & & 0,1 & $100 \%$ \\
\hline e IIII & 2,9 & 2,9 & $100 \%$ & & & & & 2,9 & $100 \%$ \\
\hline e IV & 1 & 1 & $100 \%$ & & & & & 1 & $100 \%$ \\
\hline TOTAL & 457,6 & 356,4 & $77,8 \%$ & 63,4 & $17,8 \%$ & 19,4 & $5,4 \%$ & 273,6 & $76,8 \%$ \\
\hline
\end{tabular}

Fig. 52. Aire de crémation. Niveau de fonctionnement, couche rouge (us 17132). Tableau de détermination des os humains (poids en grammes). 


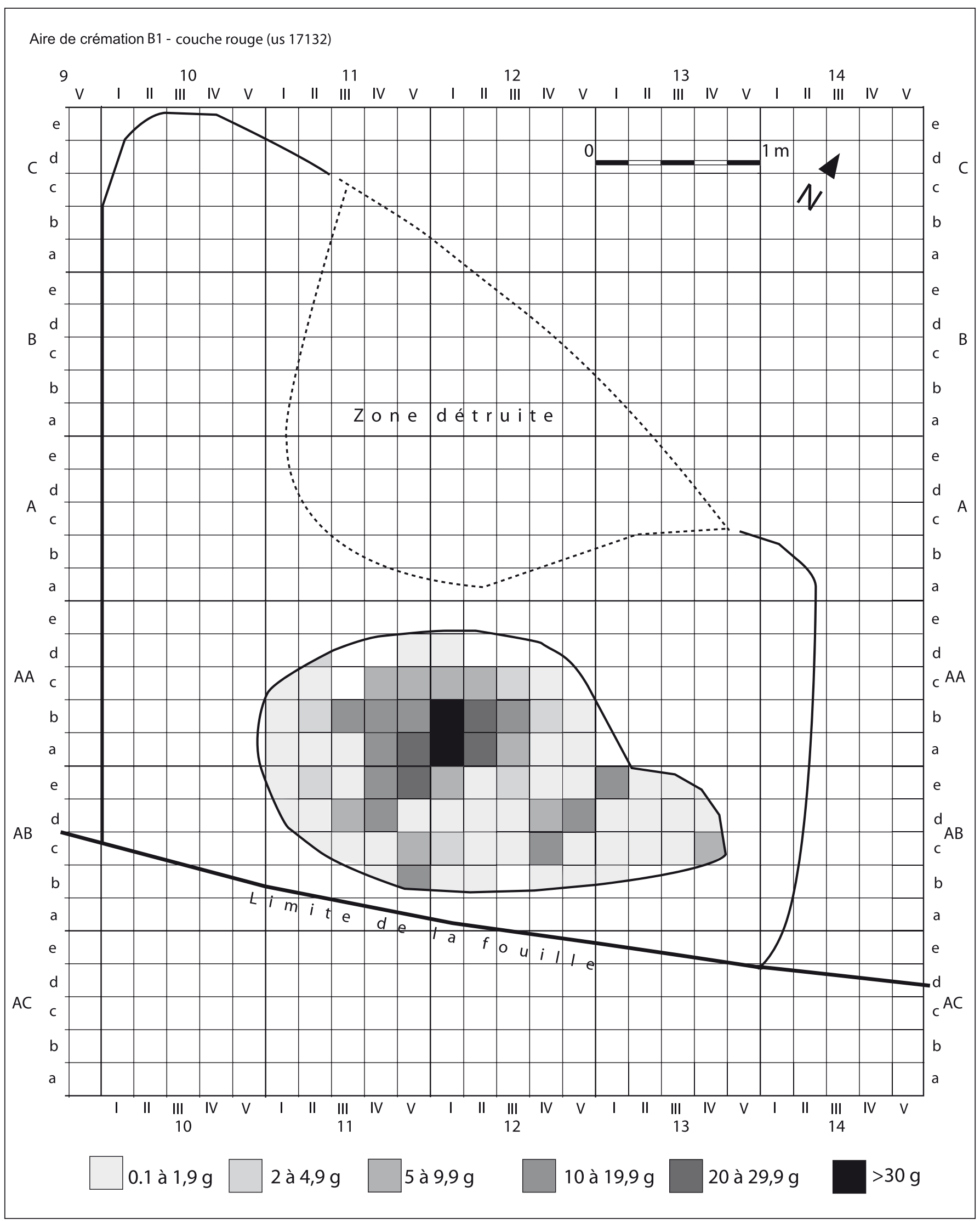

Fig. 53. Bûcher B1. Niveau de fonctionnement, couche rouge (us 17132). Répartition spatiale des os humains en fonction du poids, par carré de $20 \mathrm{~cm}$ de côté. 


\section{C) Enfin plusieurs fragments osseux ou dentaires se rapportent à des sujets beaucoup plus jeunes :}

- phase de gestation (fœetus ou périnatal) : la partie postéro-latérale d'un corps de vertèbre non déterminable (AA12 bI) ; la seule mesure possible, bien qu'approchée, est la hauteur du corps : $4 \mathrm{~mm}$ (c'est la mesure Cv3 préconisée par Duday, Laubenheimer, Tillier 1995, p. 68) ; une moitié distale de métacarpien ou de métatarsien, dont la taille est moitié plus petite que celle d'un enfant à terme (AA11 cIII); un petit morceau de voute crânienne (AA12 bI) ;

- jeune enfant de 4 à 6 ans : deux germes d'incisives définitives (mais pas les premières incisives supérieures) (AA12 aI, AA12 aIII), dont les couronnes sont complètement formées (stade Crc de Moorrees, Fanning et Hunt 1963b).

Dans cette partie de l'ustrinum, apparaissent donc les restes d'au moins un adulte, d'un sujet en phase de gestation et d'un jeune enfant entre quatre et six ans.

Le poids moyen des 1452 pièces déterminées dans cette couche du bûcher est de $0,25 \mathrm{~g}$, toutes pièces anatomiques confondues, $0,23 \mathrm{~g}$ pour le crâne (273 fragments), $0,13 \mathrm{~g}$ pour le tronc (152 fragments) et $0,27 \mathrm{~g}$ pour les membres (1027 fragments) (fig. 65).

\subsubsection{Les objets}

\section{A) Céramique non tournée}

La couche rouge 17132 de l'ustrinum a livré 116 morceaux de vases non tournés ainsi que de nombreuses esquilles millimétriques.

Urnes :

- Plusieurs morceaux d'urnes de forme CNT-LOR U5d à panse ovoïde peignée, fond plat et col haut lissé :

- 1 col tronconique rentrant à bord déversé, lèvre amincie et méplat vers l'intérieur ; diam. ouv. : $110 \mathrm{~mm}$ (fig. 54, $\mathrm{n}^{\circ} 1$ );

- 3 bords déversés, à lèvre amincie ou aplatie (fig. 54, $\mathrm{n}^{\circ} 2$ et 3 ) ;

- 1 épaule de panse décorée d'impressions du peigne disposées en oblique dans la même direction, sur peignage horizontal (fig. 54, $\mathrm{n}^{\circ} 4$ ) ;

- 4 fonds plats, avec bas de panse peignée (fig. 54, $\mathrm{n}^{\circ} 5$ à 7 ); trois d'entre eux ont un plan de pose peigné et l'un porte un large trait incisé avant cuisson, sans doute une branche de croix (fig. 54, $\mathrm{n}^{\circ}$ 5) ;

Couvercles :

- 1 couvercle de forme CNT-LOR V2b : bord aplati, dans la continuité de la paroi concave (diam. ouv.: $320 \mathrm{~mm}$ ) (fig. 54, $\mathrm{n}^{\circ} 13$ );
- 1 couvercle de forme CNT-LOR V2a : bord aminci, dans la continuité de la paroi rectiligne (diam. ouv. : $240 \mathrm{~mm}$ ) (fig. 54, $\mathrm{n}^{\circ}$ 14) ;

- 1 bord aplati de couvercle de forme CNT-LOR V2a ou V2b (fig. 54, n 12).

Coupes :

- 2 tessons de 2 coupes de forme CNT-LOR C2: panse arrondie convexe, embouchure rétrécie, bord convergent à lèvre aplatie (fig. 54, $\mathrm{n}^{\circ} 9$ et 10$)$;

- 1 tesson de coupe de forme CNT-LOR C1 : panse arrondie convexe, embouchure évasée, bord divergent à lèvre épaissie en marli oblique vers l'intérieur (fig. 54, $\left.\mathrm{n}^{\circ} 11\right)$;

- 1 fond creux ; diam. : 120 mm (fig. 54, $\mathrm{n}^{\circ}$ 8).

Jatte :

- 1 partie supérieure de grande jatte de forme proche de CNT-LOR J1f : panse évasée avec légère inflexion près du bord formant une carène, bord avec aplatissement incliné vers l'intérieur et décoré d'impressions au peigne disposées en dents de loup ; la surface extérieure est peignée ; diam ouv. : $240 \mathrm{~mm}$ (fig. 54, $\mathrm{n}^{\circ}$ 15).

Urnes ou coupes :

-2 fonds annulaires de coupes ou d'urnes (fig. 54, $\mathrm{n}^{\circ} 17$ et 18$)$.

Dolium :

-1 tesson de panse peignée.

\section{B) Céramiques tournées}

Céramique à vernis noir :

- Atelier de Rosas : 3 tessons de bord de 3 bols Lamb. 27 (=forme Puig 11.b), diam. ouv. : 140 à $150 \mathrm{~mm}$ (fig. 54, nº 21 à 23) ;

- Atelier de Rosas ou campanienne A : 1 petit tesson informe.

Céramique à pâte claire massaliète :

-3 tessons de deux cruches : 2 fragments d'une anse et $1 \mathrm{col}$ (fig. $54, \mathrm{n}^{\circ} 19$ et 20 ).

Amphore massaliète :

-4 fragments de panse.

\section{C) Armement et fourniment}

- Morceau de plaque avers de fourreau d'épée, en tôle de fer (fig. 54, $\mathrm{n}^{\circ}$ 26); bord en gouttière ; long. cons. : $22 \mathrm{~mm}$; larg. cons. : $16 \mathrm{~mm}$; ép. : 1,5 mm. 


\section{D) Parure et habillement}

- Anneau circulaire en fer, large, très plat; petite perforation centrale; diam. : 38 à $39 \mathrm{~mm}$; diam. perforation: $6 \mathrm{~mm}$; ép. 1 à $3 \mathrm{~mm}$ (fig. 54, $\mathrm{n}^{\circ} 27$ ). Cet objet est à rapprocher des sept anneaux de la tombe 7 , de mêmes morphologie et dimensions, mais en bronze ; sans doute se rapporte-t-il aussi à une pièce d'habillement, par exemple fixée sur une ceinture ;

- Morceau de maillon double, en bronze, appartenant à une chaîne-ceinture de type méridional ; les deux anneaux, en ruban plat, sont reliés par une courte tige moulurée; Long. cons. : $12 \mathrm{~mm}$; larg. maillons : $8 \mathrm{~mm}$ (fig. 54, $\mathrm{n}^{\circ} 28$ );

- Grosse perle cylindrique en pâte de verre bleu, à trois rangs de protubérances ornées d'un filet blanc ou jaune en spirale (type IV-1-1 de Zepezauer 1989, p. 113114); fortement déformée par le feu; diam.: env. $24 \mathrm{~mm}$; haut. : env. $16 \mathrm{~mm}$ (fig. 54, $\mathrm{n}^{\circ} 31$ );

- Perle moyenne en pâte de verre bleu uniforme (fig. 54, $\mathrm{n}^{\circ} 32$ ); section en « $\mathrm{D} »$; diam. : $10 \mathrm{~mm}$; haut. : 4 à $5 \mathrm{~mm}$;

- 14 petites perles en pâte de verre de couleur bleu clair (fig. 54, no 33 à 46) ; section arrondie, fine et irrégulière ; plusieurs sont déformées par la chaleur ; diam. : 4 à $6 \mathrm{~mm}$;

- Petite perle en os (fig. 54, $n^{\circ}$ 47) ; section en « $\mathrm{D} »$, très fine ; hauteur irrégulière ; diam. : 4,9 mm ; haut. : 1,3 à $2,3 \mathrm{~mm}$.

\section{E) Ustensiles}

- Rondelle taillée dans un morceau de panse peignée d'urne non tournée ; diam. : 33 à 37 mm (fig. 54, n 24).

- Petite fusaïole modelée en terre cuite (fig. 54, $\left.\mathrm{n}^{\circ} 25\right)$, biconique ; diam. : $22 \mathrm{~mm}$; haut. : $16 \mathrm{~mm}$.

\section{F) Objet indéterminé}

- Morceau de tige en fer (fig. 54, $\mathrm{n}^{\circ}$ 30), rectiligne et amincie vers une extrémité (non restauré); section arrondie (diam. max. : $4 \mathrm{~mm}$ ) ; long. cons. : $16 \mathrm{~mm}$.

\subsection{Matériel du niveau de fonctionnement de l'aire de crémation $B 1$ : la couche noire}

\subsubsection{Les restes osseux humains}

La couche de fonctionnement de l'aire de crémation B1 (us17109-17113-17114-17130-17164), de couleur noire, qui surmonte et déborde largement le comblement rougeâtre de la dépression (us 17132), a livré 6401,5 g d'os humains incinérés (fig. 55 à 64). En tout 4792,5 g d'os sont déterminés avec plus ou moins de précision, dont 995,8 g pour le crâne, soit $20,8 \%, 188,4$ g pour le tronc, soit $3,9 \%$, et $3608,3 \mathrm{~g}$ pour les membres, soit $75,3 \%$. La densité maximum d'os se place au centre de la structure (fig. 66).

La majorité des pièces autorisant une appréciation de l'âge se rapportent à un stade de maturation adulte ou de taille adulte. Par ailleurs, quelques os ou dents marquent la présence de sujets plus jeunes, adolescent, jeune enfant, fœtus ou périnatal et peut-être grand enfant.

\section{A) Éléments se rapportant à de l'adulte}

- Crâne :

- deux morceaux de voute crânienne avec segments de sutures synostosées sur les deux faces (AA13 eI et AA10 bIV) ;

- 33 morceaux de voute crânienne avec segments de sutures synostosées en face endocrânienne et en cours de synostose en face exocrânienne (AA10 aIV, AA11 aIII, AA11 a IV, AA11 bV, AA12 aII, AA12 aV, AA12 bI, AA12 bIII, AA12 cI, AA12 dV, AA13 eV, AA13 tous carrés, AB11 bIV, AB11 cIV, AB12 bI, AB12 bIV, AB12 cI, AB12 cIV, AB12 dV, AB12 eV, AB13 aII, AB13 aIII, AB13 bII, AB13 bIII, AB13 dII, C11 cII) ;

- un morceau de partie supérieure de malaire gauche avec suture fronto-zygomatique (AB11 bV);

- un morceau d'apophyse orbitaire externe droite (AA11 cII) ;

- mandibules : deux portions de deux mandibules, dans le secteur de la crête geni (AA13 dIII-dIV, AB13 aIV) ; deux condyles gauches (AA11 dV, AB13 cIII) et un condyle droit (AA11 cIV); une apophyse coronoïde droite (AB13 bI) et une gauche (AA12 bIII) ; un bord postérieur de branche montante (AA13 dIII-dIV) ;

- racines de deux $\mathrm{M}^{3}$ ou $\mathrm{M}_{3}$, aux apex fermés (AA11 aII et AA13 cII) ;

- Rachis :

- 15 morceaux de corps vertébraux au listel soudé (AA11 bII, AA11 bIV, AA11 cII, AA11 dII, AA12 bII, AA12 cIII, AB12 bIII, AB12 bV, AB12 dII, AB12 dIII, $\mathrm{AB} 12$ dV, AB12 eIII, AB13 aI, AB13 eI, AB13 cI).

\section{B) Éléments signalant une taille adulte}

- Crâne :

- 6 morceaux de voute crânienne avec segments de sutures libres (A11 bII, AA11 cV, AA11 dIII, AA12 dV, AB12 cIII, AB13 bIII) ;

- 46 extrémités de racines de dents à l'apex fermé : B10 eIV, B11 cI, AA11 aIII, AA11 aIV (2 ex.), AA11 


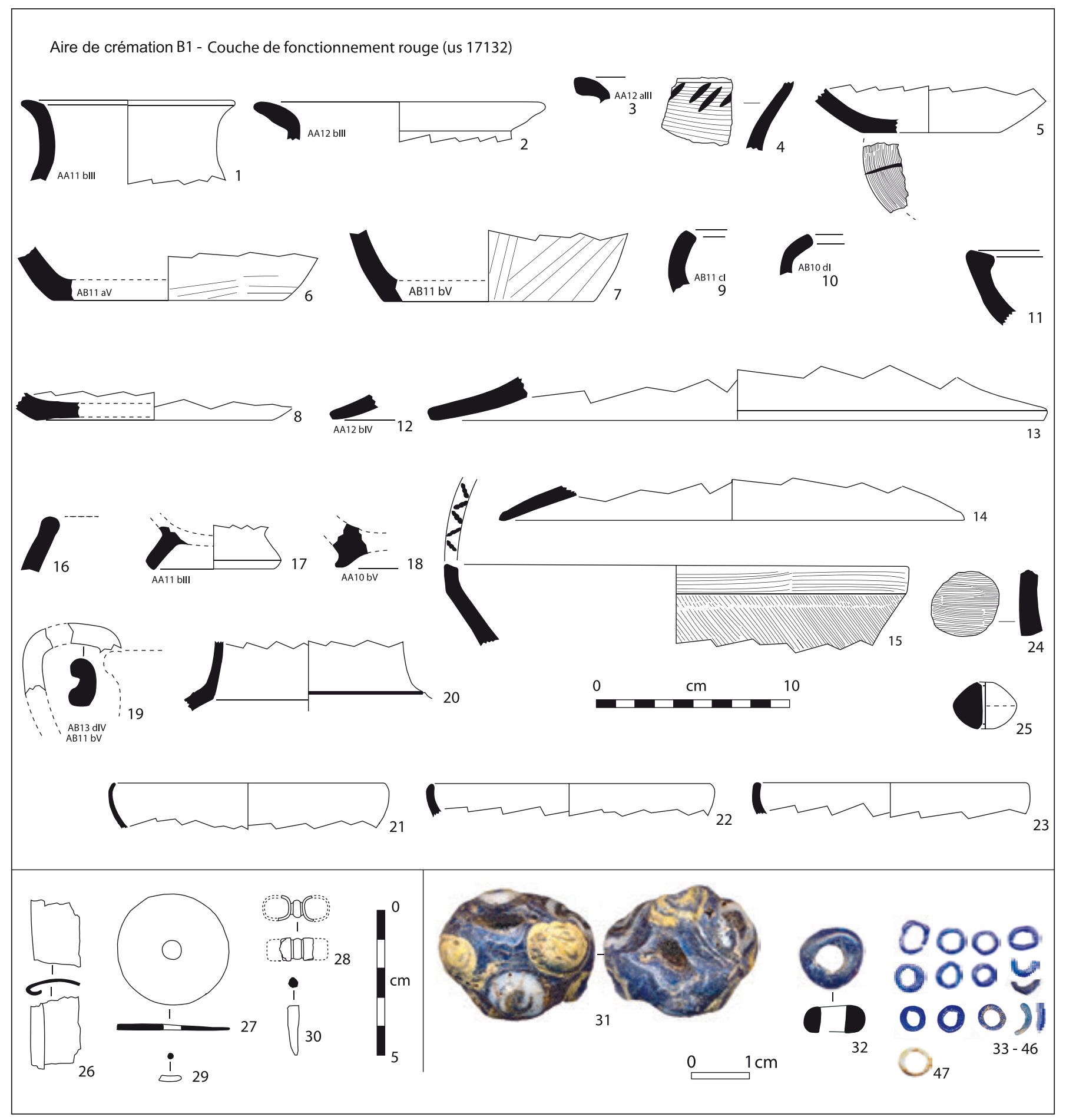

Fig. 54. Bûcher B1. Niveau de fonctionnement, couche rouge (us 17132). Mobilier (1-18 et $24:$ céramique non tournée ; 19 et 20 : céramique à pâte claire massaliète ; 21-23: céramique à vernis noir ; 25 : terre cuite modelée . 26, 27 et $30:$ fer ; 28 et 29 : bronze ; 31-46: verre ; 47: os).

bV, AA11 cV (une M sup.), AA11 dV (une I²), AA12 aI, AA12 aV, AA12 bIII (une I'), AA12 cI (4 ex.), AA12 CIII, AA12 dI (2ex.), AA12 dIII (une M), AA12 eII, AA13 dIII-dIV, AA13 eI (2ex.), AA13 tous carrés, AB10 bIII, AB11 cII, AB11 dII, AB11 eIV, AB11 eV, AB12 bI (2 ex.), AB12bV, AB12 cII, AB12 cV, AB12 dI (2ex.),
AB12 dV (2ex.), AB12 eI (2ex.), AB13 bV, AB13 cI, AB13 cII, AB13 dI, AB13 eI, AB13 eIII;

- Rachis :

- deux morceaux d'atlas semblables (apophyse transverse et arc antérieur) (AA12 aV, AB12 cV) ; un morceau d'axis avec apophyse odontoïde soudée (B10 dV). 
- Membre supérieur :

- un bord axillaire de scapula (AA11 cIII), deux morceaux de diaphyses d'humérus (AA12 dI, AA11 dII) ; trois épiphyses proximales de radius (AA11 cIII, AB13 dIII-dIV, AB13 eIII) ; trois morceaux de diaphyses de radius (AA11 dII, AA11 eI, AA11 eV); deux scaphoïdes gauches dont un gracile (AA12 dI, AB13 dII) ; un scaphoïde droit gracile (AA11 dV); un fragment de scaphoïde (AB13 eI) ; un cuboïde gauche (AA11 eV) ; un lunatum droit (AA11 ev) et un fragment d'un autre lunatum (corne postérieure) (AB13 eII); un hamatum gauche (apophyse unciforme) (AB11 dII) ; une extrémité proximale de phalange II à $\mathrm{V}$ de la main $(\mathrm{AA} 11 \mathrm{eV})$.

- Membre inférieur :

- coxal: un morceau avec crête iliaque soudée (AA12 cIII) ; un morceau avec fond de grande échancrure sciatique, mais l'état de conservation ne permet pas de diagnose sexuelle (AA12 bIII) ;

- un fragment de diaphyse de fémur et un fragment d'épiphyse distale de fémur (AB13 cIII, AA13 dIII-dIV) ;

- un fragment de diaphyse de tibia (AA11 dII) ; une phalange moyenne II à V de pied (AA11 dV); extrémité proximale de deux phalanges proximales ou moyennes de pied (AA11 eV, AB11 dII).

- Membre supérieur ou inférieur :

- 4 morceaux d'extrémité distale de métacarpiens ou de métatarsiens II à V (AA12 cI, AA12 dIII, AA13 dIIIdIV, AA13 tous carrés) ;

- 14 morceaux d'extrémité proximale de phalange II à $\mathrm{V}$ des mains ou des pieds $(\mathrm{A} 10 \mathrm{aV}, \mathrm{AA} 11 \mathrm{aIV}, \mathrm{AA} 11$ cI, AA11 cV, AA11 dIV, AA11 dV, AA12 cV, AA12 dV, AA 13 tous carrés, $\mathrm{AB} 11 \mathrm{cV}, \mathrm{AB} 11 \mathrm{dV}, \mathrm{AB} 12 \mathrm{eIV}, \mathrm{AB} 13$ aIII, AB13 bII).

\section{C) Éléments se rapportant à l'adolescence (15-20 ans)}

- une épiphyse distale de fémur non soudée à la diaphyse (AA11 dIV) ;

- une épiphyse proximale de phalange du pied, très récemment soudée, où apparaît encore le cartilage de conjugaison $(\mathrm{AB} 11 \mathrm{dV})$.

\section{D) Éléments se rapportant à la jeune enfance (2-6 ans)}

- Crâne :

- 5 morceaux de voute crânienne (AB13 dI, AB13 dIV) et un fragment d'apophyse zygomatique (AB13 dI) ;

- un germe d'incisive définitive $\left(\mathrm{I}^{2}, \mathrm{I}_{1}\right.$ ou $\left.\mathrm{I}_{2}\right)(\mathrm{AC} 13$ eIV) à la couronne complètement formée, environ 4-6 ans (stade Crc de Moorrees, Fanning et Hunt 1963b) ;
- un germe de canine définitive (AA10 aV) à la couronne complètement formée (environ 2-5 ans) ;

- un germe de première molaire inférieure droite définitive (AA11 aII) à la couronne complètement formée, environ 2-4 ans (selon Ubelaker 1978) ;

- un fragment de première ou deuxième molaire inférieure droite ou gauche définitive (AB12 bIV), environ 2-4 ans si $\mathrm{M}^{1}$ ou 4-6 ans si $\mathrm{M}^{2}$;

- Squelette post-céphalique :

- une moitié distale de phalange proximale ou moyenne de main ou de pied (AA12 cI) ;

- un segment de corps costal (de jeune enfant?) (AA11 cV).

\section{E) Fæetus ou périnatal}

- un germe de première ou deuxième molaire déciduale (AA12 aV) où seule existe la couronne, soit un âge fotal (stade Cco de Moorrees, Fanning et Hunt 1963b) ;

- un corps de vertèbre lombaire (AA11 cIII), d'un fœetus de 5 à 7 mois lunaires in utero ; les mesures préconisées par H. Duday, F. Laubenheimer et A.-M. Tillier (1995, p. 68) sont: $\mathrm{Cv} 1=4,4 \mathrm{~mm}, \mathrm{Cv} 2=6,9 \mathrm{~mm}$ et $\mathrm{Cv} 3$ $=3,1 \mathrm{~mm}$, soit, pour toutes les trois, la moitié des valeurs mesurées sur les corps vertébraux de lombaires des nouveau-nés à terme de Sallèles-d'Aude, par exemple le sujet 7 (9,5 à 10 mois lunaires) ou les sujets 8, 9 et 13 (10 mois lunaires), (Duday, Laubenheimer, Tillier 1995, p. 130-132, tab. XLII, XLIV et XLVI) ;

- un processus transverse d'arc neural $(\mathrm{AB} 11 \mathrm{cV})$; aucune mesure n'est possible, mais la taille de cet élément est plus réduite que pour un nouveau-né à terme ;

- un métacarpien (AB11 eIII), âge fœtal ou périnatal.

\section{F) Jeune enfant ou grand enfant}

Un fragment de germe de deuxième ou troisième molaire supérieure ou inférieure définitive, à la couronne complètement formée (AA13 dIII-dIV); s'il s'agit d'une deuxième molaire, cet élément indique un âge vers 4-9 ans et il est compatible avec les autres restes dentaires de jeune enfant ; si l'on a affaire à une troisième molaire, celle-ci indiquerait un âge supérieur, vers 11-14 ans, soit la présence d'un grand enfant.

Le poids moyen des 16888 fragments déterminés dans cette couche noire du bûcher est de $0,27 \mathrm{~g}$, toutes pièces anatomiques confondues. Il est de $0,23 \mathrm{~g}$ pour le crâne (3455 fragments), 0,14 g pour le tronc (1310 fragments) et $0,29 \mathrm{~g}$ pour les membres (12123 fragments) (fig. 65). 


\begin{tabular}{|c|c|c|c|c|c|c|c|c|c|}
\hline \multirow{2}{*}{$\begin{array}{c}\text { couche noire } \\
\text { CARRÉ C10 }\end{array}$} & \multirow{2}{*}{$\begin{array}{l}\text { Poids total } \\
\text { en g }\end{array}$} & \multicolumn{2}{|c|}{ OS DÉTERMINÉS } & \multicolumn{2}{|c|}{ CRÂNE } & \multicolumn{2}{|c|}{ TRONC } & \multicolumn{2}{|c|}{ MEMBRES } \\
\hline & & Poids & $\% /$ total & Poids & $\% /$ déter. & Poids & $\% /$ déter. & Poids & $\% /$ déter. \\
\hline a I & 3,4 & 2,9 & $85,3 \%$ & 0,4 & $13,8 \%$ & & & 2,5 & $86,2 \%$ \\
\hline a II & 3,6 & 3,2 & $88,9 \%$ & 0,2 & $6,2 \%$ & & & 3 & $93,8 \%$ \\
\hline a III & 8,6 & 6,5 & $75,6 \%$ & 0,8 & $12,3 \%$ & 0,1 & $1,5 \%$ & 5,6 & $86,2 \%$ \\
\hline a IV & 13,2 & 10,5 & $79,5 \%$ & 0,4 & $3,8 \%$ & & & 10,1 & $96,2 \%$ \\
\hline $\mathrm{aV}$ & 15,5 & 13,8 & $89 \%$ & 0,2 & $1,4 \%$ & 1,1 & $8 \%$ & 12,5 & $90,6 \%$ \\
\hline $\mathrm{bl}$ & 0,1 & 0 & & & & & & & \\
\hline $\mathrm{b} \|$ & 1,2 & 1,1 & $91,7 \%$ & 0,5 & $45,45 \%$ & & & 0,6 & $54,5 \%$ \\
\hline b III & 1,6 & 0,9 & $56,3 \%$ & & & & & 0,9 & $56,3 \%$ \\
\hline b IV & 2,9 & 2,4 & $82,8 \%$ & 0,3 & $12,5 \%$ & 0,1 & $4,2 \%$ & 2 & $83,3 \%$ \\
\hline $\mathrm{bV}$ & 6,7 & 6 & $89,6 \%$ & 0,3 & $5 \%$ & & & 5,7 & $95 \%$ \\
\hline $\mathrm{cl}$ & 0,1 & 0 & & & & & & & \\
\hline c II & 1,3 & 1,2 & $92,3 \%$ & 1,1 & $91,7 \%$ & 0,1 & $8,3 \%$ & & \\
\hline c III & 5,1 & 3,2 & $62,7 \%$ & 0,2 & $6,3 \%$ & & & 3 & $93,7 \%$ \\
\hline c IV & 5,3 & 3,5 & $66 \%$ & 0,4 & $11,4 \%$ & 0,2 & $5,7 \%$ & 2,9 & $82,9 \%$ \\
\hline $\mathrm{cV}$ & 8,7 & 7,3 & $83,9 \%$ & 0,9 & $12,3 \%$ & & & 6,4 & $87,7 \%$ \\
\hline \multicolumn{10}{|l|}{ d I } \\
\hline \multicolumn{10}{|l|}{$\mathrm{d} \mathrm{II}$} \\
\hline d III & 1,6 & 1,3 & $81,3 \%$ & & & & & 1,3 & $100 \%$ \\
\hline $\mathrm{d}$ IV & 4,1 & 2,5 & $61 \%$ & 0,2 & $8 \%$ & & & 2,3 & $92 \%$ \\
\hline $\mathrm{dV}$ & 4,1 & 2,4 & $58,5 \%$ & 0,2 & $8,3 \%$ & & & 2,2 & $91,7 \%$ \\
\hline $\mathrm{el}$ & 0,1 & 0 & & & & & & & \\
\hline e II & 1,7 & 1,5 & $88,2 \%$ & & & & & 1,5 & 100 \\
\hline e III & 1,5 & 1 & $66,6 \%$ & 0,2 & $20 \%$ & & & 0,8 & $80 \%$ \\
\hline e IV & 3,5 & 2,8 & $80 \%$ & 1,3 & $46,4 \%$ & & & 1,5 & $53,6 \%$ \\
\hline $\mathrm{e} \mathrm{V}$ & 2,6 & 2 & $76,9 \%$ & 0,2 & $10 \%$ & & & 1,8 & $90 \%$ \\
\hline TOTAL & 97,4 & 76,5 & & 7,8 & & 1,6 & & 67,1 & \\
\hline couche noire & Poids total & \multicolumn{2}{|c|}{ OS DÉTERMINÉS } & \multicolumn{2}{|c|}{ CRÂNE } & \multicolumn{2}{|c|}{ TRONC } & \multicolumn{2}{|c|}{ MEMBRES } \\
\hline CARRÉ C11 & en $\mathbf{g}$ & Poids & $\% /$ total & Poids & $\% /$ déter. & Poids & $\% /$ déter. & Poids & $\% /$ déter. \\
\hline a I & 5,9 & 4,4 & $74,6 \%$ & 0,6 & $13,6 \%$ & & & 3,8 & $86,4 \%$ \\
\hline \multicolumn{10}{|l|}{ a II } \\
\hline \multicolumn{10}{|l|}{ a III } \\
\hline \multicolumn{10}{|l|}{ a IV } \\
\hline \multicolumn{10}{|l|}{$\mathrm{aV}$} \\
\hline $\mathrm{bl}$ & 10,5 & 6,9 & $65,7 \%$ & 2,1 & $30,4 \%$ & 0,5 & $7,2 \%$ & 4,3 & $62,3 \%$ \\
\hline $\mathrm{b} \|$ & & & & & & & & & \\
\hline b III & & & & & & & & & \\
\hline $\mathrm{b}$ IV & & & & & & & & & \\
\hline $\mathrm{b} V$ & & & & & & & & & \\
\hline $\mathrm{cl}$ & 16,5 & 13,3 & $80,6 \%$ & 2,1 & $15,8 \%$ & & & 11,2 & $84,2 \%$ \\
\hline c II & 5,1 & 3,9 & $76,5 \%$ & 0,7 & $17,9 \%$ & 0,1 & $2,6 \%$ & 3,1 & $79,5 \%$ \\
\hline $\mathrm{c}$ III & & & & & & & & & \\
\hline $\mathrm{c}$ IV & & & & & & & & & \\
\hline $\mathrm{cV}$ & & & & & & & & & \\
\hline $\mathrm{d} I$ & 8,4 & 6,5 & $77,4 \%$ & 0,2 & $3,1 \%$ & & & 6,3 & $96,9 \%$ \\
\hline d II & 1 & 0,7 & $70 \%$ & 0,1 & $14,3 \%$ & & & 0,6 & $85,7 \%$ \\
\hline$d \mathrm{dII}$ & & & & & & & & & \\
\hline $\mathrm{d} \mathrm{IV}$ & & & & & & & & & \\
\hline $\mathrm{dV}$ & & & & & & & & & \\
\hline $\mathrm{el}$ & & & & & & & & & \\
\hline e II & 1,6 & 1 & $62,5 \%$ & & & & & 1 & $100 \%$ \\
\hline e III & & & & & & & & & \\
\hline e IV & & & & & & & & & \\
\hline $\mathrm{e} V$ & & & & & & & & & \\
\hline TOTAL & 49 & 36,7 & & 5,8 & & 0,6 & & 30,3 & \\
\hline
\end{tabular}

Fig. 55. Aire de crémation B1. Niveau de fonctionnement, couche noire (us17109-17113-17114-17130-17164), carrés C10 et C11. Tableau de détermination des os humains (poids en grammes). 


\begin{tabular}{|c|c|c|c|c|c|c|c|c|c|}
\hline \multirow{2}{*}{\begin{tabular}{|c|} 
Couche noire \\
CARRÉ B10
\end{tabular}} & \multirow{2}{*}{$\begin{array}{l}\text { Poids total } \\
\text { en g }\end{array}$} & \multicolumn{2}{|c|}{ OS DÉTERMINÉS } & \multicolumn{2}{|c|}{ CRÂNE } & \multicolumn{2}{|c|}{ TRONC } & \multicolumn{2}{|c|}{ MEMBRES } \\
\hline & & Poids & $\% /$ total & Poids & $\% /$ déter. & Poids & $\% /$ déter. & Poids & $\% /$ déter. \\
\hline a I & 0,4 & 0,1 & $25 \%$ & & & & & 0,1 & $100 \%$ \\
\hline a II & 0,9 & 0,5 & $55,6 \%$ & & & & & 0,5 & $100 \%$ \\
\hline a III & 1,2 & 0,9 & $75 \%$ & 0,1 & $11,1 \%$ & & & 0,8 & $88,9 \%$ \\
\hline a IV & 0,7 & 0,3 & $42,9 \%$ & 0,3 & $100 \%$ & & & & \\
\hline $\mathrm{aV}$ & 3,5 & 1,8 & $51,4 \%$ & 0,1 & $5,6 \%$ & & & 1,7 & $94,4 \%$ \\
\hline $\mathrm{bl}$ & 0,4 & 0,1 & $25 \%$ & 0,1 & $100 \%$ & & & & \\
\hline $\mathrm{b} \|$ & 2,4 & 2 & $83,3 \%$ & 0,6 & $30 \%$ & & & 1,4 & $70 \%$ \\
\hline b III & 0,7 & 0,6 & $85,7 \%$ & & & & & 0,6 & $100 \%$ \\
\hline b IV & 0,9 & 0,6 & $66,7 \%$ & & & & & 0,6 & $100 \%$ \\
\hline $\mathrm{b} \vee$ & 0,3 & 0,2 & $66,6 \%$ & & & & & 0,2 & $100 \%$ \\
\hline $\mathrm{cl}$ & 0,8 & 0,4 & $50 \%$ & & & & & 0,4 & $100 \%$ \\
\hline c II & 3,2 & 3 & $93,8 \%$ & 0,4 & $13,3 \%$ & & & 2,6 & $86,7 \%$ \\
\hline$\overline{c ~ I I I}$ & 1 & 0,6 & $60 \%$ & & & & & 0,6 & $100 \%$ \\
\hline c IV & 10,2 & 9,5 & $93,1 \%$ & 0,6 & $6,3 \%$ & 0,2 & $2,1 \%$ & 8,7 & $91,6 \%$ \\
\hline$c V$ & 11,7 & 7,3 & $62,4 \%$ & 1,4 & $19,2 \%$ & 0,1 & $1,4 \%$ & 5,8 & $79,4 \%$ \\
\hline d I & 0,7 & 0,4 & $57,1 \%$ & & & & & 0,4 & $100 \%$ \\
\hline d II & 1,5 & 1,4 & $93,3 \%$ & 0,1 & $7,1 \%$ & & & 1,3 & $92,9 \%$ \\
\hline d III & 5,8 & 4,6 & & 0,4 & $8,7 \%$ & & & 4,2 & $91,3 \%$ \\
\hline$d$ IV & 21,6 & 16,8 & $77,8 \%$ & 0,2 & $1,2 \%$ & & & 16,6 & $98,8 \%$ \\
\hline$d V$ & 17,8 & 13,8 & $80,7 \%$ & 0,7 & $5,1 \%$ & 0,6 & $4,3 \%$ & 12,5 & $90,6 \%$ \\
\hline el & 0,7 & 0,6 & $85,7 \%$ & & & & & 0,6 & $100 \%$ \\
\hline e II & 2,6 & 2,3 & $88,5 \%$ & 0,6 & $26,1 \%$ & & & 1,7 & $73,9 \%$ \\
\hline e III & 13 & 9,5 & $73,1 \%$ & 0,4 & $4,2 \%$ & 0,1 & $1,1 \%$ & 9 & $94,7 \%$ \\
\hline e IV & 9,5 & 6,9 & $72,6 \%$ & 0,4 & $5,8 \%$ & 0,3 & $4,3 \%$ & 6,2 & $89,9 \%$ \\
\hline $\mathrm{e} \mathrm{V}$ & 6,3 & 5,8 & $92,1 \%$ & 2,2 & $37,9 \%$ & & & 3,6 & $62,1 \%$ \\
\hline TOTAL & 117,2 & 90 & & 8,6 & & 1,3 & & 80,1 & \\
\hline couche noire & Poids total & \multicolumn{2}{|c|}{ OS DÉTERMINÉS } & \multicolumn{2}{|c|}{ CRÂNE } & \multicolumn{2}{|c|}{ TRONC } & \multicolumn{2}{|c|}{ MEMBRES } \\
\hline CARRÉ B11 & en $\mathrm{g}$ & Poids & $\% /$ total & Poids & $\% /$ déter. & Poids & $\% /$ déter. & Poids & $\% /$ déter. \\
\hline \multicolumn{10}{|l|}{ a I } \\
\hline \multicolumn{10}{|l|}{ a II } \\
\hline \multicolumn{10}{|l|}{ a III } \\
\hline \multicolumn{10}{|l|}{ a IV } \\
\hline \multicolumn{10}{|l|}{$\mathrm{aV}$} \\
\hline \multicolumn{10}{|l|}{$\mathrm{bl}$} \\
\hline $\mathrm{b} \|$ & & & & & & & & & \\
\hline b III & & & & & & & & & \\
\hline b IV & & & & & & & & & \\
\hline $\mathrm{bV}$ & & & & & & & & & \\
\hline $\mathrm{cl}$ & 1,6 & 1,3 & $81,3 \%$ & 0,3 & $23,1 \%$ & & & 1 & $76,9 \%$ \\
\hline c II & & & & & & & & & \\
\hline c III & & & & & & & & & \\
\hline c IV & & & & & & & & & \\
\hline $\mathrm{c} V$ & & & & & & & & & \\
\hline d I & 5,8 & 5,4 & $93,1 \%$ & 0,6 & $11,1 \%$ & & & 4,8 & $88,8 \%$ \\
\hline $\mathrm{d} \| \mathrm{I}$ & & & & & & & & & \\
\hline $\mathrm{d} \mathrm{IIII}$ & & & & & & & & & \\
\hline$d \mathrm{IV}$ & & & & & & & & & \\
\hline $\mathrm{dV}$ & & & & & & & & & \\
\hline el & 2 & 1,6 & $80 \%$ & 0,2 & $12,5 \%$ & & & 1,4 & $87,5 \%$ \\
\hline e II & & & & & & & & & \\
\hline e IIII & & & & & & & & & \\
\hline e IV & & & & & & & & & \\
\hline $\mathrm{e} \mathrm{V}$ & & & & & & & & & \\
\hline TOTAL & 9,4 & 8,3 & & 1,1 & & & & 7,2 & \\
\hline
\end{tabular}

Fig. 56. Aire de crémation B1. Niveau de fonctionnement, couche noire (us17109-17113-17114-17130-17164), carrés B10 et B11. Tableau de détermination des os humains (poids en grammes). 


\begin{tabular}{|c|c|c|c|c|c|c|c|c|c|}
\hline \multirow{2}{*}{\begin{tabular}{|c|} 
couche noire \\
CARRÉ A10 \\
\end{tabular}} & \multirow{2}{*}{$\begin{array}{c}\text { Poids total } \\
\text { en g }\end{array}$} & \multicolumn{2}{|c|}{ OS DÉTERMINÉS } & \multicolumn{2}{|c|}{ CRÂNE } & \multicolumn{2}{|c|}{ TRONC } & \multicolumn{2}{|c|}{ MEMBRES } \\
\hline & & Poids & $\% /$ total & Poids & $\% /$ déter. & Poids & $\% /$ déter. & Poids & $\% /$ déter. \\
\hline a I & 2,8 & 1,3 & $46,4 \%$ & & & & & 1,3 & $100 \%$ \\
\hline a II & 0,7 & 0,4 & $57,1 \%$ & & & & & 0,4 & $100 \%$ \\
\hline a III & 5 & 3,1 & $62 \%$ & 0,3 & $9,7 \%$ & & & 2,8 & $90,3 \%$ \\
\hline a IV & 5,8 & 4,6 & $79,3 \%$ & 1,1 & $23,9 \%$ & & & 3,5 & $76,1 \%$ \\
\hline $\mathrm{aV}$ & 4,4 & 4,4 & $100 \%$ & 0,5 & $11,4 \%$ & 0,2 & $4,5 \%$ & 3,7 & $84,1 \%$ \\
\hline \multicolumn{10}{|l|}{$\mathrm{bl}$} \\
\hline \multicolumn{10}{|l|}{$\mathrm{b} \|$} \\
\hline b III & 6,7 & 3,9 & $58,2 \%$ & & & & & 3,9 & $100 \%$ \\
\hline b IV & 3,1 & 2,3 & $74,2 \%$ & 0,2 & $8,7 \%$ & & & 2,1 & $91,3 \%$ \\
\hline $\mathrm{bV}$ & 0,1 & 0,1 & $100 \%$ & & & & & 0,1 & $100 \%$ \\
\hline \multicolumn{10}{|l|}{$\mathrm{cl}$} \\
\hline \multicolumn{10}{|l|}{ c II } \\
\hline c III & 0,8 & 0,8 & $100 \%$ & & & & & 0,8 & $100 \%$ \\
\hline \multicolumn{10}{|l|}{ c IV } \\
\hline \multicolumn{10}{|l|}{$\mathrm{c} V$} \\
\hline $\mathrm{dl}$ & 0,1 & 0 & & & & & & & \\
\hline d II & 0,3 & 0,3 & $100 \%$ & 0,1 & $33,3 \%$ & 0,1 & $33,3 \%$ & 0,1 & $33,3 \%$ \\
\hline \multicolumn{10}{|l|}{$\mathrm{d} \mathrm{III}$} \\
\hline$d$ IV & 4 & 0 & & & & & & & \\
\hline \multicolumn{10}{|l|}{$d V$} \\
\hline $\mathrm{el}$ & 0,1 & 0,1 & $100 \%$ & & & & & 0,1 & $100 \%$ \\
\hline e II & 1,8 & 1,3 & $72,2 \%$ & & & & & 1,3 & $100 \%$ \\
\hline e III & 0,4 & 0 & & & & & & & \\
\hline \multicolumn{10}{|l|}{ e IV } \\
\hline $\mathrm{eV}$ & & & & & & & & & \\
\hline al à eV & 0,9 & 0,9 & $100 \%$ & & & & & 0,9 & $100 \%$ \\
\hline TOTAL & 37,2 & 23,5 & & 2,2 & & 0,3 & & 21 & \\
\hline couche noire & Poids total & OS DI & MINÉS & & & & & & RES \\
\hline CARRÉ A11 & en $\mathrm{g}$ & Poids & $\% /$ total & Poids & $\% /$ déter. & Poids & $\% /$ déter. & Poids & $\% /$ déter. \\
\hline a I & 12,3 & 9,3 & $75,6 \%$ & 0,3 & $3,2 \%$ & 0,2 & $2,2 \%$ & 8,8 & $94,6 \%$ \\
\hline a II & 8,1 & 5,3 & $65,4 \%$ & 0,1 & $1,9 \%$ & 0,2 & $3,8 \%$ & 5 & $94,3 \%$ \\
\hline a III & 17,4 & 10,1 & $58 \%$ & 3,3 & $32,7 \%$ & & & 6,8 & $67,3 \%$ \\
\hline a IV & 0,5 & 0,4 & $80 \%$ & 0,1 & $25 \%$ & & & 0,3 & $75 \%$ \\
\hline $\mathrm{aV}$ & 2,4 & 1,2 & $50 \%$ & 0,2 & $16,7 \%$ & & & 1 & $83,3 \%$ \\
\hline $\mathrm{bl}$ & 0,8 & 0,3 & $37,5 \%$ & & & & & 0,3 & $100 \%$ \\
\hline $\mathrm{b} \|$ & 17 & 11 & $64,7 \%$ & 0,5 & $4,5 \%$ & 0,2 & $1,8 \%$ & 10,3 & $93,6 \%$ \\
\hline b III & & & & & & & & & \\
\hline b IV & & & & & & & & & \\
\hline $\mathrm{bV}$ & & & & & & & & & \\
\hline $\mathrm{cl}$ & & & & & & & & & \\
\hline$c \|$ & & & & & & & & & \\
\hline c III & & & & & & & & & \\
\hline $\mathrm{cIV}$ & & & & & & & & & \\
\hline $\mathrm{c} \mathrm{V}$ & & & & & & & & & \\
\hline$d \mathrm{I}$ & & & & & & & & & \\
\hline d II & & & & & & & & & \\
\hline $\mathrm{d} \mathrm{III}$ & & & & & & & & & \\
\hline d IV & & & & & & & & & \\
\hline$d V$ & & & & & & & & & \\
\hline $\mathrm{el}$ & & & & & & & & & \\
\hline e II & & & & & & & & & \\
\hline e III & & & & & & & & & \\
\hline e IV & & & & & & & & & \\
\hline $\mathrm{e} \mathrm{V}$ & & & & & & & & & \\
\hline al à eV & 2,7 & 2,3 & $85,20 \%$ & 0,3 & $13 \%$ & & & 2 & $87 \%$ \\
\hline TOTAL & 61,2 & 39,9 & & 4,8 & & 0,6 & & 34,5 & \\
\hline
\end{tabular}

Fig. 57. Aire de crémation B1. Niveau de fonctionnement, couche noire (us17109-17113-17114-17130-17164), carrés A10 et A11. Tableau de détermination des os humains (poids en grammes). 


\begin{tabular}{|c|c|c|c|c|c|c|c|c|c|}
\hline \multirow{2}{*}{$\begin{array}{c}\text { couche noire } \\
\text { CARRÉ A12 }\end{array}$} & \multirow{2}{*}{$\begin{array}{c}\text { Poids total } \\
\text { en g }\end{array}$} & \multicolumn{2}{|c|}{ OS DÉTERMINÉS } & \multicolumn{2}{|c|}{ CRÂNE } & \multicolumn{2}{|c|}{ TRONC } & \multicolumn{2}{|c|}{ MEMBRES } \\
\hline & & Poids & $\% /$ total & Poids & $\% /$ déter. & Poids & $\% /$ déter. & Poids & $\% /$ déter. \\
\hline a I & 4,8 & 2,2 & $45,8 \%$ & 1,6 & $72,7 \%$ & & & 0,6 & $27,3 \%$ \\
\hline a II & 4,3 & 2,9 & $67,4 \%$ & 0,1 & $3,4 \%$ & & & 2,8 & $96,6 \%$ \\
\hline \multicolumn{10}{|l|}{ a III } \\
\hline \multicolumn{10}{|l|}{ a IV } \\
\hline $\mathrm{aV}$ & 4,2 & 3,1 & $73,8 \%$ & 0,9 & $29 \%$ & 0,3 & $9,7 \%$ & 1,9 & $61,3 \%$ \\
\hline \multicolumn{10}{|l|}{ b l } \\
\hline \multicolumn{10}{|l|}{ b II } \\
\hline \multicolumn{10}{|l|}{$\mathrm{b} \mathrm{III}$} \\
\hline \multicolumn{10}{|l|}{ b IV } \\
\hline \multicolumn{10}{|l|}{$\mathrm{bV}$} \\
\hline \multicolumn{10}{|l|}{$\mathrm{cl}$} \\
\hline \multicolumn{10}{|l|}{ c II } \\
\hline \multicolumn{10}{|l|}{ c III } \\
\hline c IV & & & & & & & & & \\
\hline $\mathrm{cV}$ & & & & & & & & & \\
\hline $\mathrm{d} I$ & & & & & & & & & \\
\hline d II & & & & & & & & & \\
\hline $\mathrm{d}$ III & & & & & & & & & \\
\hline d IV & & & & & & & & & \\
\hline$d V$ & & & & & & & & & \\
\hline e I & & & & & & & & & \\
\hline e II & & & & & & & & & \\
\hline e III & & & & & & & & & \\
\hline e IV & & & & & & & & & \\
\hline e V & & & & & & & & & \\
\hline TOTAL & 13,3 & 8,2 & & 2,6 & & 0,3 & & 5,3 & \\
\hline couche noire & Poids total & OS D & MINÉS & & & & & & RES \\
\hline CARRÉ A13 & en g & Poids & $\% /$ total & Poids & $\% /$ déter. & Poids & $\% /$ déter. & Poids & $\% /$ déter. \\
\hline a l & 4,2 & 1,8 & $42,9 \%$ & 0,8 & $44,4 \%$ & 0,2 & $11,1 \%$ & 0,8 & $44,4 \%$ \\
\hline a II & 8 & 4,6 & $61,3 \%$ & 1,9 & $38,8 \%$ & 0,3 & $6,1 \%$ & 2,7 & $55,1 \%$ \\
\hline a III & 13,9 & 10,6 & $76,3 \%$ & 3,7 & $34,9 \%$ & 0,6 & $5,7 \%$ & 6,3 & $59,4 \%$ \\
\hline a IV & 12,1 & 9,1 & $75,2 \%$ & 4,7 & $51,6 \%$ & 0,1 & $1,1 \%$ & 4,3 & $47,3 \%$ \\
\hline $\mathrm{aV}$ & 5,9 & 3 & $50,8 \%$ & 0,6 & $20 \%$ & 0,2 & $6,7 \%$ & 2,2 & $73,3 \%$ \\
\hline $\mathrm{bl}$ & 4,8 & 2,6 & $54,2 \%$ & 0,6 & $23,1 \%$ & 0,4 & $15,4 \%$ & 1,6 & $61,5 \%$ \\
\hline b II & 7,4 & 4,9 & $66,2 \%$ & 3,4 & $69,4 \%$ & & & 1,5 & $30,6 \%$ \\
\hline b III & 9,8 & 5,6 & $57,1 \%$ & 2,4 & $42,9 \%$ & 0,3 & $5,4 \%$ & 2,9 & $51,8 \%$ \\
\hline b IV & 11,3 & 9 & $79,6 \%$ & 2,8 & $31,1 \%$ & 0,3 & $3,3 \%$ & 5,9 & $65,6 \%$ \\
\hline b V & 4,8 & 3,1 & $64,6 \%$ & 1 & $32,3 \%$ & 0,1 & $3,2 \%$ & 2 & $64,5 \%$ \\
\hline $\mathrm{cl}$ & & & & & & & & & \\
\hline$c$ II & & & & & & & & & \\
\hline$c \mathrm{CII}$ & & & & & & & & & \\
\hline c IV & & & & & & & & & \\
\hline$c \mathrm{~V}$ & & & & & & & & & \\
\hline d I & & & & & & & & & \\
\hline d II & & & & & & & & & \\
\hline d III & & & & & & & & & \\
\hline d IV & & & & & & & & & \\
\hline$d V$ & & & & & & & & & \\
\hline el & & & & & & & & & \\
\hline e II & & & & & & & & & \\
\hline e III & & & & & & & & & \\
\hline e IV & & & & & & & & & \\
\hline $\mathrm{eV}$ & & & & & & & & & \\
\hline al à eV & 1,3 & 1,1 & $84,6 \%$ & 0,6 & $54,5 \%$ & 0,3 & $27,3 \%$ & 0,2 & $18,2 \%$ \\
\hline TOTAL & 83,5 & 55,7 & & 22,5 & & 2,8 & & 30,4 & \\
\hline
\end{tabular}

Fig. 58. Aire de crémation B1. Niveau de fonctionnement, couche noire (us17109-17113-17114-17130-17164), carrés A12 et A13. Tableau de détermination des os humains (poids en grammes). 


\begin{tabular}{|c|c|c|c|c|c|c|c|c|c|}
\hline \multirow{2}{*}{\begin{tabular}{|c|} 
couche noire \\
CARRÉ A14
\end{tabular}} & \multirow{2}{*}{$\begin{array}{c}\text { Poids total } \\
\text { en g }\end{array}$} & \multicolumn{2}{|c|}{ OS DÉTERMINÉS } & \multicolumn{2}{|c|}{ CRÂNE } & \multicolumn{2}{|c|}{ TRONC } & \multicolumn{2}{|c|}{ MEMBRES } \\
\hline & & Poids & $\% /$ total & Poids & $\% /$ déter. & Poids & $\% /$ déter. & Poids & $\% /$ déter. \\
\hline al & 3,8 & 3,3 & $86,8 \%$ & 1,6 & $48,5 \%$ & & & 1,7 & $51,5 \%$ \\
\hline a \| & 0,2 & 0 & & & & & & & \\
\hline \multicolumn{10}{|l|}{ a III } \\
\hline \multicolumn{10}{|l|}{ a IV } \\
\hline \multicolumn{10}{|l|}{$\mathrm{aV}$} \\
\hline $\mathrm{bl}$ & 1,1 & 1 & $90,9 \%$ & 0,4 & $40 \%$ & & & 0,6 & $60 \%$ \\
\hline $\mathrm{b} \|$ & 1,4 & 1,1 & $78,6 \%$ & 0,1 & $9,1 \%$ & & & 1 & $90,9 \%$ \\
\hline \multicolumn{10}{|l|}{$\mathrm{b} \| \mathrm{II}$} \\
\hline \multicolumn{10}{|l|}{ b IV } \\
\hline \multicolumn{10}{|l|}{$\mathrm{bV}$} \\
\hline \multicolumn{10}{|l|}{$\mathrm{cl}$} \\
\hline \multicolumn{10}{|l|}{ c II } \\
\hline \multicolumn{10}{|l|}{$c \mid \|$} \\
\hline \multicolumn{10}{|l|}{ c IV } \\
\hline$c \vee$ & & & & & & & & & \\
\hline d I & & & & & & & & & \\
\hline $\mathrm{d} \| \mathrm{I}$ & & & & & & & & & \\
\hline $\mathrm{d} \mid \mathrm{II}$ & & & & & & & & & \\
\hline d IV & & & & & & & & & \\
\hline $\mathrm{dV}$ & & & & & & & & & \\
\hline el & & & & & & & & & \\
\hline e $\|$ & & & & & & & & & \\
\hline e III & & & & & & & & & \\
\hline e IV & & & & & & & & & \\
\hline e V & & & & & & & & & \\
\hline TOTAL & 6,5 & 5,4 & & 2,1 & & & & 3,3 & \\
\hline couche noire & Poids total & OS D & RMINÉS & & & & & & RES \\
\hline CARRÉ AA10 & en $\mathbf{g}$ & Poids & $\% /$ total & Poids & $\% /$ déter. & Poids & $\% /$ déter. & Poids & $\% /$ déter. \\
\hline a I & & & & & & & & & \\
\hline a II & 0,8 & 0,5 & $62, \%$ & & & & & 0,5 & $100 \%$ \\
\hline a III & 1,7 & 1,4 & $82,4 \%$ & & & & & 1,4 & $100 \%$ \\
\hline a IV & 2,4 & 2,4 & $100 \%$ & & & & & 2,4 & $100 \%$ \\
\hline $\mathrm{aV}$ & 20,3 & 17,5 & $86,2 \%$ & 9,2 & $52,6 \%$ & 0,4 & $2,3 \%$ & 7,9 & $45,1 \%$ \\
\hline bl & & & & & & & & & \\
\hline b II & 1,8 & 1,8 & $100 \%$ & & & & & 1,8 & $100 \%$ \\
\hline $\mathrm{b} \| \mathrm{I}$ & 3,7 & 3,1 & $83,8 \%$ & 0,2 & $6,5 \%$ & & & 2,9 & $93,5 \%$ \\
\hline b IV & 12,8 & 11,1 & $86,7 \%$ & 2 & $18 \%$ & 0,1 & $0,9 \%$ & 9 & $81,1 \%$ \\
\hline$b V$ & 25,8 & 18,8 & $72,9 \%$ & 6,5 & $34,6 \%$ & 0,7 & $3,7 \%$ & 11,6 & $61,7 \%$ \\
\hline $\mathrm{Cl}$ & & & & & & & & & \\
\hline$c \|$ & 0,9 & 0,8 & $88,9 \%$ & 0,3 & $37,5 \%$ & & & 0,5 & $62,5 \%$ \\
\hline$c \mid \|$ & 6,2 & 5,5 & $88,7 \%$ & 0,2 & $3,6 \%$ & 0,1 & $1,8 \%$ & 5,2 & $94,5 \%$ \\
\hline c IV & 8,2 & 7,5 & $91,5 \%$ & 1,2 & $16 \%$ & & & 6,3 & $84 \%$ \\
\hline$c V$ & 31,5 & 26,9 & $85,4 \%$ & 6,3 & $23,4 \%$ & 1,4 & $5,2 \%$ & 19,2 & $71,4 \%$ \\
\hline d I & 0,4 & 0,1 & $25 \%$ & 0,1 & $100 \%$ & & & & \\
\hline$d \|$ & 0,6 & 0,5 & $83,3 \%$ & 0,3 & $60 \%$ & & & 0,2 & $40 \%$ \\
\hline d III & 6,3 & 5,2 & $82,5 \%$ & 0,4 & $7,7 \%$ & & & 4,8 & $92,3 \%$ \\
\hline d IV & 6,1 & 4,7 & $77 \%$ & 0,9 & $19,1 \%$ & 0,1 & $2,1 \%$ & 3,7 & $78,7 \%$ \\
\hline$d V$ & 21,5 & 17,6 & $81,9 \%$ & 5,1 & $29 \%$ & 0,3 & $1,7 \%$ & 12,2 & $69,3 \%$ \\
\hline $\mathrm{el}$ & 0,4 & 0,3 & $75 \%$ & & & & & 0,3 & $100 \%$ \\
\hline e II & 2,4 & 1,6 & $66,7 \%$ & 0,2 & $12,5 \%$ & 0,1 & $6,2 \%$ & 1,3 & $81,3 \%$ \\
\hline e III & 2,9 & 2,3 & $79,3 \%$ & 0,8 & $34,8 \%$ & & & 1,5 & $65,2 \%$ \\
\hline e IV & 18,1 & 15,4 & $85,1 \%$ & 1,7 & $11 \%$ & 0,3 & $1,9 \%$ & 13,4 & $87 \%$ \\
\hline $\mathrm{eV}$ & 22,7 & 15,5 & $68,3 \%$ & 1 & $6,4 \%$ & 0,4 & $2,6 \%$ & 14,1 & $91 \%$ \\
\hline al à eV & 9,4 & 6,7 & $71,3 \%$ & 0,1 & $1,5 \%$ & 0,4 & $6 \%$ & 6,2 & $92,5 \%$ \\
\hline TOTAL & 206,9 & 167,2 & & 36,5 & & 4,3 & & 126,4 & \\
\hline
\end{tabular}

Fig. 59. Aire de crémation B1. Niveau de fonctionnement, couche noire (us17109-17113-17114-17130-17164), carrés A14 et AA10. Tableau de détermination des os humains (poids en grammes). 


\begin{tabular}{|c|c|c|c|c|c|c|c|c|c|}
\hline \multirow{2}{*}{$\begin{array}{l}\text { couche noire } \\
\text { CARRÉ AA11 }\end{array}$} & \multirow{2}{*}{$\begin{array}{c}\text { Poids total } \\
\text { en g }\end{array}$} & \multicolumn{2}{|c|}{ OS DÉTERMINÉS } & \multicolumn{2}{|c|}{ CRÂNE } & \multicolumn{2}{|c|}{ TRONC } & \multicolumn{2}{|c|}{ MEMBRES } \\
\hline & & Poids & $\% /$ total & Poids & $\% /$ déter. & Poids & $\% /$ déter. & Poids & $\% /$ déter. \\
\hline a I & 16,1 & 13,8 & $85,7 \%$ & 3,7 & $26,8 \%$ & 0,2 & $1,4 \%$ & 9,9 & $71,7 \%$ \\
\hline a II & 32 & 22,2 & $69,4 \%$ & 9,1 & $41,0 \%$ & 0,5 & $2,3 \%$ & 12,6 & $56,8 \%$ \\
\hline a III & 53,3 & 38,5 & $72,2 \%$ & 11 & $28,5 \%$ & 2,1 & $5,5 \%$ & 25,4 & $66,0 \%$ \\
\hline a IV & 38 & 27,7 & $72,9 \%$ & 9,4 & $33,9 \%$ & 1,1 & $4 \%$ & 17,2 & $62,1 \%$ \\
\hline $\mathrm{aV}$ & 55,9 & 44,8 & $80,1 \%$ & 7,6 & $17,0 \%$ & 1,1 & $2,4 \%$ & 36,1 & $80,6 \%$ \\
\hline $\mathrm{b} \mathrm{I}$ & 27,3 & 23,6 & $86,4 \%$ & 2,7 & $11,4 \%$ & 1,5 & $6,4 \%$ & 19,4 & $82,2 \%$ \\
\hline b II & 45,4 & 27,7 & $61 \%$ & 3,3 & $11,9 \%$ & 1,9 & $6,9 \%$ & 22,5 & $81,2 \%$ \\
\hline b III & 74,8 & 59,6 & $79,7 \%$ & 15,7 & $26,3 \%$ & 3 & $5 \%$ & 40,9 & $68,6 \%$ \\
\hline b IV & 57,7 & 44,8 & $77,6 \%$ & 14,1 & $31,5 \%$ & 3,9 & $8,7 \%$ & 26,8 & $59,8 \%$ \\
\hline $\mathrm{bV}$ & 92,2 & 73,5 & $79,7 \%$ & 11,2 & $15,2 \%$ & 4,6 & $6,3 \%$ & 57,7 & $78,5 \%$ \\
\hline $\mathrm{cl}$ & 36,6 & 27,2 & $74,3 \%$ & 3,7 & $13,6 \%$ & 2,2 & $8,1 \%$ & 21,3 & $78,3 \%$ \\
\hline c II & 37,5 & 28 & $74,7 \%$ & 3,5 & $12,5 \%$ & 1,7 & $6,1 \%$ & 22,8 & $81,4 \%$ \\
\hline c III & 61,2 & 48,5 & $79,2 \%$ & 7,2 & $14,8 \%$ & 1,9 & $3,9 \%$ & 39,4 & $81,2 \%$ \\
\hline c IV & 100,1 & 65,5 & $65,4 \%$ & 9,1 & $13,9 \%$ & 2,3 & $3,5 \%$ & 54,1 & $82,6 \%$ \\
\hline$c V$ & 121,8 & 89,5 & $73,5 \%$ & 21,3 & $23,8 \%$ & 4,9 & $5,5 \%$ & 63,3 & $70,7 \%$ \\
\hline d I & 34 & 24,3 & $71,5 \%$ & 2,5 & $10,3 \%$ & 0,4 & $1,6 \%$ & 21,4 & $88,1 \%$ \\
\hline$d$ II & 40,2 & 30,1 & $74,9 \%$ & 1,6 & $5,3 \%$ & 1,5 & $5 \%$ & 27 & $89,7 \%$ \\
\hline $\mathrm{d} \mathrm{III}$ & 101,9 & 73,7 & $72,3 \%$ & 3,9 & $5,3 \%$ & 4,9 & $6,6 \%$ & 64,9 & $88,1 \%$ \\
\hline d IV & 128,1 & 95,6 & $74,6 \%$ & 8,3 & $8,6 \%$ & 3,8 & $4 \%$ & 83,5 & $87,3 \%$ \\
\hline$d V$ & 161,2 & 118,9 & $73,8 \%$ & 12,3 & $10,3 \%$ & 4,9 & $4,1 \%$ & 101,7 & $85,5 \%$ \\
\hline e I & 21,2 & 15,6 & $73,6 \%$ & 1,2 & $7,7 \%$ & 0,5 & $3,2 \%$ & 13,9 & $89,1 \%$ \\
\hline e II & 39 & 25,9 & $66,4 \%$ & 2,7 & $10,4 \%$ & 1,6 & $6,2 \%$ & 21,6 & $83,4 \%$ \\
\hline e III & 45,6 & 35 & $76,8 \%$ & 3,6 & $10,3 \%$ & 2,2 & $6,3 \%$ & 29,2 & $83,4 \%$ \\
\hline e IV & 66,4 & 46,5 & $70 \%$ & 6,8 & $14,6 \%$ & 1,1 & $2,4 \%$ & 38,6 & $83,0 \%$ \\
\hline $\mathrm{e} \mathrm{V}$ & 63,8 & 40 & $62,8 \%$ & 2,2 & $5,5 \%$ & 3,2 & $8 \%$ & 34,6 & $86,5 \%$ \\
\hline al à eV & 21,4 & 19,9 & $93 \%$ & 4 & $20,1 \%$ & 0,8 & $4 \%$ & 15,1 & $75,9 \%$ \\
\hline TOTAL & 1572,7 & 1160,4 & & 181,7 & & 57,8 & & 920,9 & \\
\hline
\end{tabular}

\begin{tabular}{|c|c|c|c|c|c|c|c|c|c|}
\hline \multirow{2}{*}{$\begin{array}{l}\text { couche noire } \\
\text { CARRÉ AA12 }\end{array}$} & \multirow{2}{*}{$\begin{array}{l}\text { Poids total } \\
\text { en g }\end{array}$} & \multicolumn{2}{|c|}{ OS DÉTERMINÉS } & \multicolumn{2}{|c|}{ CRÂNE } & \multicolumn{2}{|c|}{ TRONC } & \multicolumn{2}{|c|}{ MEMBRES } \\
\hline & & Poids & $\% /$ total & Poids & $\% /$ déter. & Poids & $\% /$ déter. & Poids & $\% /$ déter. \\
\hline a I & 62,4 & 52 & $83,3 \%$ & 16,8 & $32,3 \%$ & 0,8 & $1,5 \%$ & 34,4 & $66,2 \%$ \\
\hline a II & 50,1 & 37,3 & $74,4 \%$ & 6,8 & $18,2 \%$ & 0,6 & $1,6 \%$ & 29,9 & $80,2 \%$ \\
\hline \multicolumn{10}{|l|}{ a III } \\
\hline a IV & 55,3 & 35,6 & $64,4 \%$ & 11,2 & $31,5 \%$ & 0,3 & $0,8 \%$ & 24,1 & $67,7 \%$ \\
\hline $\mathrm{aV}$ & 49,5 & 36,3 & $73,3 \%$ & 7,9 & $21,8 \%$ & 1,4 & $3,8 \%$ & 27 & $74,4 \%$ \\
\hline $\mathrm{bl}$ & 49,2 & 44,3 & $90 \%$ & 13,9 & $31,4 \%$ & 0,2 & $0,4 \%$ & 30,2 & $68,2 \%$ \\
\hline b II & 38,1 & 24,7 & $64,8 \%$ & 3,6 & $14,6 \%$ & 0,5 & $2 \%$ & 20,6 & $83,4 \%$ \\
\hline b III & 159,9 & 124,5 & $77,9 \%$ & 19,4 & $15,6 \%$ & 2,3 & $1,8 \%$ & 102,8 & $80,6 \%$ \\
\hline b IV & 45,8 & 34,1 & $74,5 \%$ & 5,8 & $17 \%$ & 1,7 & $5 \%$ & 26,6 & $78 \%$ \\
\hline $\mathrm{bV}$ & 41,9 & 29,1 & $69,5 \%$ & 8,1 & $27,8 \%$ & 0,4 & $1,4 \%$ & 20,6 & $70,8 \%$ \\
\hline $\mathrm{cl}$ & 125,2 & 92,8 & $74,1 \%$ & 17,9 & $19,3 \%$ & 4,7 & $5,1 \%$ & 70,2 & $75,6 \%$ \\
\hline c II & 81,9 & 55,3 & $67,5 \%$ & 13,3 & $24 \%$ & 3,3 & $6 \%$ & 38,7 & $70 \%$ \\
\hline c III & 77,5 & 46,3 & $59,7 \%$ & 8,4 & $18,1 \%$ & 2,2 & $4,8 \%$ & 35,7 & $77,1 \%$ \\
\hline c IV & 68,3 & 41,9 & $61,3 \%$ & 7,4 & $17,7 \%$ & 2,1 & $5 \%$ & 32,4 & $77,3 \%$ \\
\hline$c V$ & 41,1 & 29,7 & $72,3 \%$ & 5,6 & $18,9 \%$ & 2,3 & $7,7 \%$ & 21,8 & $73,4 \%$ \\
\hline d I & 96,9 & 61,7 & $63,7 \%$ & 5,5 & $8,9 \%$ & 5,9 & $9,6 \%$ & 50,3 & $81,5 \%$ \\
\hline d II & 82 & 55,3 & $67,4 \%$ & 14,4 & $26 \%$ & 4,7 & $8,5 \%$ & 36,2 & $65,5 \%$ \\
\hline d III & 59,9 & 36,9 & $61,6 \%$ & 6,9 & $18,7 \%$ & 0,9 & $2,4 \%$ & 29,1 & $78,9 \%$ \\
\hline d IV & 34,3 & 22,1 & $64,4 \%$ & 5,6 & $25,3 \%$ & 1 & $4,5 \%$ & 15,5 & $70,1 \%$ \\
\hline$d V$ & 48,2 & 34,1 & $70,7 \%$ & 5,9 & $17,3 \%$ & 1,2 & $3,6 \%$ & 27 & $79,2 \%$ \\
\hline e I & 26,4 & 15,8 & $59,8 \%$ & 1,5 & $9,5 \%$ & 0,7 & $4,4 \%$ & 13,6 & $86,1 \%$ \\
\hline e II & 35,8 & 21,8 & $60,9 \%$ & 1,9 & $8,7 \%$ & 0,2 & $0,9 \%$ & 19,7 & $90,4 \%$ \\
\hline e III & 31,8 & 22 & $69,2 \%$ & 9,7 & $44,1 \%$ & 0,3 & $1,4 \%$ & 12 & $54,5 \%$ \\
\hline e IV & 3,9 & 1,7 & $43,6 \%$ & 0,4 & $23,5 \%$ & & & 1,3 & $76,5 \%$ \\
\hline $\mathrm{eV}$ & 3,5 & 2,1 & $60 \%$ & 0,6 & $28,6 \%$ & 0,1 & $4,8 \%$ & 1,4 & $66,7 \%$ \\
\hline al à eV & 28,8 & 18,3 & $63,5 \%$ & 4,5 & $24,6 \%$ & 1,3 & $7,1 \%$ & 12,5 & $68,3 \%$ \\
\hline TOTAL & 1397,7 & 975,7 & & 203 & & 39,1 & & 733,6 & \\
\hline
\end{tabular}

Fig. 60. Aire de crémation B1. Niveau de fonctionnement, couche noire (us17109-17113-17114-17130-17164), carrés AA11 et AA12. Tableau de détermination des os humains (poids en grammes). 


\begin{tabular}{|c|c|c|c|c|c|c|c|c|c|}
\hline \multirow{2}{*}{$\begin{array}{l}\text { couche noire } \\
\text { CARRÉ AA13 }\end{array}$} & \multirow{2}{*}{$\begin{array}{c}\text { Poids total } \\
\text { en g }\end{array}$} & \multicolumn{2}{|c|}{ OS DÉTERMINÉS } & \multicolumn{2}{|c|}{ CRÂNE } & \multicolumn{2}{|c|}{ TRONC } & \multicolumn{2}{|c|}{ MEMBRES } \\
\hline & & Poids & $\% /$ total & Poids & $\% /$ déter. & Poids & $\% /$ déter. & Poids & $\% /$ déter. \\
\hline a I & 16,2 & 14,1 & $87 \%$ & 3,8 & $26,9 \%$ & 0,9 & $6,4 \%$ & 9,4 & $66,7 \%$ \\
\hline a II & 30,8 & 26,9 & $87,3 \%$ & 5,8 & $21,6 \%$ & 1,1 & $4,1 \%$ & 20 & $74,3 \%$ \\
\hline a III & 18,5 & 16,9 & $91,4 \%$ & 6,9 & $40,8 \%$ & 0,9 & $5,3 \%$ & 9,1 & $53,8 \%$ \\
\hline a IV & 9 & 8,4 & $93,3 \%$ & 3,7 & $44 \%$ & 0,2 & $2,4 \%$ & 4,5 & $53,6 \%$ \\
\hline $\mathrm{aV}$ & 6,5 & 6,2 & $95,4 \%$ & 2,3 & $37,1 \%$ & 1 & $16,1 \%$ & 2,9 & $46,8 \%$ \\
\hline $\mathrm{bl}$ & 8,2 & 6 & $73,2 \%$ & 2,4 & $40 \%$ & 0,2 & $3,3 \%$ & 3,4 & $56,7 \%$ \\
\hline $\mathrm{b \|}$ & 25,5 & 20,4 & $80 \%$ & 8,1 & $39,7 \%$ & 0,9 & $4,4 \%$ & 11,4 & $55,9 \%$ \\
\hline b III & 21,2 & 18,7 & $88,2 \%$ & 6,6 & $35,3 \%$ & 0,4 & $2,1 \%$ & 11,7 & $62,6 \%$ \\
\hline $\mathrm{b}$ IV & 7,2 & 6,5 & $90,3 \%$ & 4 & $61,5 \%$ & 0,2 & $3,1 \%$ & 2,3 & $35,4 \%$ \\
\hline $\mathrm{bV}$ & 4,4 & 3,8 & $86,4 \%$ & 2,4 & $63,2 \%$ & 0,1 & $2,6 \%$ & 1,3 & $34,2 \%$ \\
\hline $\mathrm{cl}$ & 44 & 34,9 & $79,3 \%$ & 11,4 & $32,7 \%$ & 2,1 & $6 \%$ & 21,4 & $61,3 \%$ \\
\hline$c \|$ & 40,9 & 26,4 & $64,5 \%$ & 9,1 & $34,5 \%$ & 0,3 & $1,1 \%$ & 17 & $64,4 \%$ \\
\hline$c|l|$ & 1,6 & 1,6 & $100 \%$ & 1 & $62,5 \%$ & & & 0,6 & $37,5 \%$ \\
\hline c IV & 4 & 3,5 & $87,5 \%$ & 1,7 & $48,6 \%$ & 0,1 & $2,8 \%$ & 1,7 & $48,6 \%$ \\
\hline $\mathrm{cV}$ & 6,2 & 5,6 & $90,3 \%$ & 3,9 & $69,6 \%$ & 0,3 & $5,4 \%$ & 1,4 & $25 \%$ \\
\hline d I & 54,9 & 41,8 & $76,1 \%$ & 8,6 & $20,6 \%$ & 1,8 & $4,3 \%$ & 31,4 & $75,1 \%$ \\
\hline d II & 36 & 24,3 & $67,5 \%$ & 11,2 & $46,1 \%$ & 0,8 & $3,3 \%$ & 12,3 & $50,6 \%$ \\
\hline$d$ III -d IV -d V & 88,7 & 67,2 & $75,8 \%$ & 33,1 & $49,3 \%$ & 4,1 & $6,1 \%$ & 30 & $44,6 \%$ \\
\hline el & 15 & 8,5 & $56,6 \%$ & 4,2 & $49,4 \%$ & & & 4,3 & $50,6 \%$ \\
\hline e $\|$ & 33,3 & 22,7 & $68,2 \%$ & 8,1 & $35,7 \%$ & 0,4 & $1,8 \%$ & 14,2 & $62,6 \%$ \\
\hline e III & 1,2 & 0,4 & $33,3 \%$ & & & & & 0,4 & $100 \%$ \\
\hline \multicolumn{10}{|l|}{ e IV } \\
\hline $\mathrm{e} \mathrm{V}$ & 1,2 & 0,5 & $41,7 \%$ & 0,5 & $100 \%$ & & & & \\
\hline TOTAL & 474,5 & 365,3 & & 138,8 & & 15,8 & & 210,7 & \\
\hline couche noire & Poids total & \multicolumn{2}{|c|}{ OS DÉTERMINÉS } & \multicolumn{2}{|c|}{ CRÂNE } & \multicolumn{2}{|c|}{ TRONC } & \multicolumn{2}{|c|}{ MEMBRES } \\
\hline CARRÉ AA14 & en g & Poids & $\% /$ total & Poids & $\% /$ déter. & Poids & $\% /$ déter. & Poids & $\% /$ déter. \\
\hline a I & 0,6 & 0,5 & $83,3 \%$ & 0,1 & $20 \%$ & 0,2 & $40 \%$ & 0,2 & $40 \%$ \\
\hline \multicolumn{10}{|l|}{ a $\|$} \\
\hline \multicolumn{10}{|l|}{ a III } \\
\hline \multicolumn{10}{|l|}{ a IV } \\
\hline \multicolumn{10}{|l|}{$\mathrm{aV}$} \\
\hline $\mathrm{bl}$ & 1,5 & 1,4 & $93,3 \%$ & & & & & 1,4 & $100 \%$ \\
\hline $\mathrm{b} \|$ & 1,1 & 1 & $90,9 \%$ & 0,1 & $10 \%$ & 0,1 & $10 \%$ & 0,8 & $80 \%$ \\
\hline \multicolumn{10}{|l|}{ b III } \\
\hline \multicolumn{10}{|l|}{$\mathrm{b}$ IV } \\
\hline $\mathrm{bV}$ & & & & & & & & & \\
\hline $\mathrm{cl}$ & 0,6 & 0,6 & $100 \%$ & 0,5 & $83,3 \%$ & & & 0,1 & $16,7 \%$ \\
\hline$c \|$ & & & & & & & & & \\
\hline $\mathrm{c} I \| \mathrm{I}$ & & & & & & & & & \\
\hline c IV & & & & & & & & & \\
\hline $\mathrm{cV}$ & & & & & & & & & \\
\hline d I & & & & & & & & & \\
\hline$d \|$ & & & & & & & & & \\
\hline d III & & & & & & & & & \\
\hline d IV & & & & & & & & & \\
\hline $\mathrm{dV}$ & & & & & & & & & \\
\hline $\mathrm{el}$ & 3,5 & 3,5 & $100 \%$ & 0,7 & $20 \%$ & & & 2,8 & $80 \%$ \\
\hline e $\|$ & & & & & & & & & \\
\hline e III & & & & & & & & & \\
\hline e IV & & & & & & & & & \\
\hline e V & & & & & & & & & \\
\hline TOTAL & 7,3 & 7 & & 1,4 & & 0,3 & & 5,3 & \\
\hline
\end{tabular}

Fig. 61. Aire de crémation B1. Niveau de fonctionnement, couche noire (us17109-17113-17114-17130-17164), carrés AA13 et AA14. Tableau de détermination des os humains (poids en grammes). 


\begin{tabular}{|c|c|c|c|c|c|c|c|c|c|}
\hline \multirow{2}{*}{$\begin{array}{l}\text { couche noire } \\
\text { CARRÉ AB10 }\end{array}$} & \multirow{2}{*}{$\begin{array}{c}\text { Poids total } \\
\text { en g }\end{array}$} & \multicolumn{2}{|c|}{ OS DÉTERMINÉS } & \multicolumn{2}{|c|}{ CRÂNE } & \multicolumn{2}{|c|}{ TRONC } & \multicolumn{2}{|c|}{ MEMBRES } \\
\hline & & Poids & $\% /$ total & Poids & $\% /$ déter. & Poids & $\% /$ déter. & Poids & $\% /$ déter. \\
\hline \multicolumn{10}{|l|}{ a I } \\
\hline \multicolumn{10}{|l|}{ a II } \\
\hline \multicolumn{10}{|l|}{ a III } \\
\hline \multicolumn{10}{|l|}{ a IV } \\
\hline \multicolumn{10}{|l|}{$\mathrm{aV}$} \\
\hline \multicolumn{10}{|l|}{$\mathrm{bl}$} \\
\hline \multicolumn{10}{|l|}{ b II } \\
\hline \multicolumn{10}{|l|}{ b III } \\
\hline \multicolumn{10}{|l|}{ b IV } \\
\hline \multicolumn{10}{|l|}{ b V } \\
\hline \multicolumn{10}{|l|}{$\mathrm{cl}$} \\
\hline \multicolumn{10}{|l|}{$\mathrm{c} \|$} \\
\hline $\mathrm{c}$ III & 0,3 & 0 & & & & & & & \\
\hline c IV & 1,1 & 0,5 & $45,5 \%$ & & & & & 0,5 & $100 \%$ \\
\hline $\mathrm{cV}$ & 6,2 & 6,2 & $100 \%$ & 0,3 & $4,8 \%$ & 0 & & 5,9 & $95,2 \%$ \\
\hline $\mathrm{d} I$ & 0,9 & 0,4 & $44,4 \%$ & & & 0,1 & $25 \%$ & 0,3 & $75 \%$ \\
\hline \multicolumn{10}{|l|}{ d II } \\
\hline $\mathrm{d}$ III & 0,7 & 0,6 & $85,7 \%$ & 0,1 & $16,7 \%$ & & & 0,5 & $83,3 \%$ \\
\hline $\mathrm{d}$ IV & 2,8 & 2,7 & $96,4 \%$ & & & 0,1 & $3,7 \%$ & 2,6 & $96,3 \%$ \\
\hline $\mathrm{dV}$ & 8,9 & 7,7 & $86,5 \%$ & 1 & $13 \%$ & 0,1 & $1,3 \%$ & 6,6 & $85,7 \%$ \\
\hline \multicolumn{10}{|l|}{$\mathrm{el}$} \\
\hline e II & 7 & 7 & $100 \%$ & & & & & 7 & $100 \%$ \\
\hline e III & 3,3 & 3,1 & $93,9 \%$ & 0,1 & $3,2 \%$ & 0,1 & $3,2 \%$ & 2,9 & $93,5 \%$ \\
\hline e IV & 5,7 & 4,7 & $82,5 \%$ & & & & & 4,7 & $100 \%$ \\
\hline $\mathrm{e} \mathrm{V}$ & 11,5 & 10,2 & $88,7 \%$ & 1,9 & $18,6 \%$ & 0,1 & $1 \%$ & 8,2 & $80,4 \%$ \\
\hline TOTAL & 48,4 & 43,1 & & 3,4 & & 0,5 & & 39,2 & \\
\hline
\end{tabular}

\begin{tabular}{|c|c|c|c|c|c|c|c|c|c|}
\hline \multirow{2}{*}{$\begin{array}{l}\text { couche noire } \\
\text { CARRÉ AB11 }\end{array}$} & \multirow{2}{*}{$\begin{array}{l}\text { Poids total } \\
\text { en g }\end{array}$} & \multicolumn{2}{|c|}{ OS DÉTERMINÉS } & \multicolumn{2}{|c|}{ CRÂNE } & \multicolumn{2}{|c|}{ TRONC } & \multicolumn{2}{|c|}{ MEMBRES } \\
\hline & & Poids & $\% /$ total & Poids & $\% /$ déter. & Poids & $\% /$ déter. & Poids & $\% /$ déter. \\
\hline \multicolumn{10}{|l|}{ a I } \\
\hline \multicolumn{10}{|l|}{ a II } \\
\hline \multicolumn{10}{|l|}{ a III } \\
\hline \multicolumn{10}{|l|}{ a IV } \\
\hline \multicolumn{10}{|l|}{ a V } \\
\hline $\mathrm{bl}$ & 4,3 & 3,2 & $74,4 \%$ & & & & & 3,2 & $100 \%$ \\
\hline $\mathrm{b} \|$ & 4,8 & 4,8 & $100 \%$ & 0,3 & $6,2 \%$ & 0,2 & $4,2 \%$ & 4,3 & $89,6 \%$ \\
\hline $\mathrm{b}$ |II & 22,5 & 20,3 & $90,2 \%$ & 0,7 & $3,4 \%$ & & & 19,6 & $96,6 \%$ \\
\hline $\mathrm{b}$ IV & 28 & 21,4 & $76,4 \%$ & 3,2 & $15 \%$ & & & 18,2 & $85 \%$ \\
\hline $\mathrm{b} \mathrm{V}$ & 59,9 & 50,1 & $87,1 \%$ & 12,4 & $24,7 \%$ & 0,7 & $1,4 \%$ & 37 & $73,9 \%$ \\
\hline $\mathrm{cl}$ & 9,5 & 9,3 & $97,9 \%$ & 0,8 & $8,6 \%$ & & & 8,5 & $91,4 \%$ \\
\hline $\mathrm{c} \mathrm{II}$ & 11,7 & 9,2 & $78,6 \%$ & 1,1 & $12 \%$ & & & 8,1 & $88 \%$ \\
\hline $\mathrm{c}$ III & 18,7 & 14,4 & $77 \%$ & 1,8 & $12,5 \%$ & 0,1 & $0,7 \%$ & 12,5 & $86,8 \%$ \\
\hline $\mathrm{c}$ IV & 25,8 & 19,9 & $77,1 \%$ & 1,9 & $9,5 \%$ & 0,3 & $1,5 \%$ & 17,7 & $88,9 \%$ \\
\hline$c V$ & 39,1 & 35,2 & $90 \%$ & 6,6 & $18,7 \%$ & 0,3 & $0,9 \%$ & 28,3 & $80,4 \%$ \\
\hline $\mathrm{d}$ l & 15,1 & 12,8 & $84,8 \%$ & 3,1 & $24,2 \%$ & & & 9,7 & $75,8 \%$ \\
\hline $\mathrm{d} \| \mathrm{I}$ & 18 & 13,9 & $77,2 \%$ & 2 & $14,4 \%$ & 2,5 & $18 \%$ & 9,4 & $67,6 \%$ \\
\hline d III & 34,9 & 27,1 & $77,7 \%$ & 3,5 & $12,9 \%$ & & & 23,6 & $85,5 \%$ \\
\hline$d$ IV & 45,2 & 35,1 & $77,7 \%$ & 2,3 & $6,5 \%$ & 0,8 & $2,3 \%$ & 32 & $91,2 \%$ \\
\hline $\mathrm{dV}$ & 43,4 & 29,6 & $68,2 \%$ & 2,9 & $9,8 \%$ & 0,2 & $0,7 \%$ & 26,5 & $89,5 \%$ \\
\hline $\mathrm{el}$ & 18,5 & 14,7 & $79,5 \%$ & 5,6 & $38,1 \%$ & 0,3 & $2 \%$ & 8,8 & $59,9 \%$ \\
\hline e II & 21,4 & 17,5 & $81,8 \%$ & 1,7 & $9,7 \%$ & 0,4 & $2,3 \%$ & 15,4 & $88 \%$ \\
\hline e III & 30,9 & 22,1 & $71,5 \%$ & 3,7 & $16,7 \%$ & & & 18,4 & $83,3 \%$ \\
\hline e IV & 38,2 & 28,2 & $74,3 \%$ & 3,2 & $11,3 \%$ & 0,2 & $0,7 \%$ & 24,8 & $87,3 \%$ \\
\hline $\mathrm{e} \mathrm{V}$ & 59,8 & 43,2 & $72,2 \%$ & 8,6 & $19,9 \%$ & 0,1 & $0,2 \%$ & 34,5 & $79,9 \%$ \\
\hline al à eV & 1 & 1 & & & & & & 1 & $100 \%$ \\
\hline TOTAL & 550,7 & 433 & & 65,4 & & 6,1 & & 361,5 & \\
\hline
\end{tabular}

Fig. 62. Aire de crémation B1. Niveau de fonctionnement, couche noire (us17109-17113-17114-17130-17164), carrés AB10 et AB11. Tableau de détermination des os humains (poids en grammes). 


\begin{tabular}{|c|c|c|c|c|c|c|c|c|c|}
\hline \multirow{2}{*}{$\begin{array}{l}\text { couche noire } \\
\text { CARRÉ AB12 }\end{array}$} & \multirow{2}{*}{$\begin{array}{c}\text { Poids total } \\
\text { en g }\end{array}$} & \multicolumn{2}{|c|}{ OS DÉTERMINÉS } & \multicolumn{2}{|c|}{ CRÂNE } & \multicolumn{2}{|c|}{ TRONC } & \multicolumn{2}{|c|}{ MEMBRES } \\
\hline & & Poids & $\% /$ total & Poids & $\% /$ déter. & Poids & $\% /$ déter. & Poids & $\% /$ déter. \\
\hline \multicolumn{10}{|l|}{ a I } \\
\hline \multicolumn{10}{|l|}{ a II } \\
\hline a III & 5 & 3,3 & $66 \%$ & 2,4 & $72,7 \%$ & & & 0,9 & $27,3 \%$ \\
\hline a IV & 3,8 & 2,2 & $57,9 \%$ & 0,7 & $31,8 \%$ & 0,2 & $9,1 \%$ & 1,3 & $59,1 \%$ \\
\hline $\mathrm{aV}$ & 6,6 & 4,3 & $65,2 \%$ & 0,5 & $11,6 \%$ & & & 3,8 & $88,4 \%$ \\
\hline $\mathrm{bl}$ & 36,2 & 25,4 & $70,2 \%$ & 6,8 & $26,8 \%$ & 0,2 & $0,8 \%$ & 18,4 & $72,4 \%$ \\
\hline b II & 38,9 & 31 & $79,7 \%$ & 5,5 & $17,7 \%$ & 1,2 & $3,9 \%$ & 24,3 & $78,4 \%$ \\
\hline b III & 54 & 39,9 & $73,9 \%$ & 6,9 & $17,3 \%$ & 0,8 & $2 \%$ & 32,2 & $80,7 \%$ \\
\hline $\mathrm{b}$ IV & 33,8 & 23,6 & $69,8 \%$ & 4,9 & $20,8 \%$ & 2,1 & $8,9 \%$ & 16,6 & $70,3 \%$ \\
\hline $\mathrm{bV}$ & 20,7 & 12,6 & $60,9 \%$ & 4,1 & $32,5 \%$ & 0,5 & $4 \%$ & 8 & $63,5 \%$ \\
\hline $\mathrm{cl}$ & 49,1 & 34,2 & $69,7 \%$ & 6,3 & $18,4 \%$ & 1,5 & $4,4 \%$ & 26,4 & $77,2 \%$ \\
\hline c II & 26,5 & 20,7 & $78,1 \%$ & 3,8 & $18,3 \%$ & 2 & $9,7 \%$ & 14,9 & $72 \%$ \\
\hline c III & 66,7 & 49,4 & $74,1 \%$ & 12,3 & $24,9 \%$ & 0,5 & $1 \%$ & 36,6 & $74,1 \%$ \\
\hline c IV & 47 & 36,3 & $77,2 \%$ & 11,7 & $32,2 \%$ & 2 & $5,5 \%$ & 22,6 & $62,3 \%$ \\
\hline$c V$ & 29,1 & 20,8 & $71,5 \%$ & 4,1 & $19,7 \%$ & 0,6 & $2,9 \%$ & 16,1 & $77,4 \%$ \\
\hline $\mathrm{d} I$ & 76,5 & 61,6 & $80,5 \%$ & 12,9 & $20,9 \%$ & 3,9 & $6,3 \%$ & 44,8 & $72,7 \%$ \\
\hline d II & 57,4 & 44,3 & $77,2 \%$ & 9 & $20,3 \%$ & 5,2 & $11,7 \%$ & 30,1 & $67,9 \%$ \\
\hline d III & 82,6 & 66,3 & $80,3 \%$ & 12,4 & $18,7 \%$ & 3,6 & $5,4 \%$ & 50,3 & $75,9 \%$ \\
\hline d IV & 54 & 43,2 & $80 \%$ & 8,6 & $19,9 \%$ & 1 & $2,3 \%$ & 33,6 & $77,8 \%$ \\
\hline$d V$ & 48,8 & 39,1 & $80,1 \%$ & 10,2 & $26,1 \%$ & 0,3 & $0,8 \%$ & 28,6 & $73,1 \%$ \\
\hline $\mathrm{el}$ & 59,6 & 41,4 & $69,5 \%$ & 4,4 & $10,6 \%$ & 0,5 & $1,2 \%$ & 36,5 & $88,2 \%$ \\
\hline e II & 72,3 & 53,8 & $74,4 \%$ & 7,2 & $13,5 \%$ & 2,3 & $4,3 \%$ & 44,3 & $82,3 \%$ \\
\hline e III & 66,2 & 46 & $69,5 \%$ & 7,2 & $15,6 \%$ & 3,7 & $8 \%$ & 35,1 & $76,3 \%$ \\
\hline e IV & 72,5 & 54,9 & $75,7 \%$ & 7,7 & $14 \%$ & 3,4 & $6,2 \%$ & 43,8 & $79,8 \%$ \\
\hline $\mathrm{eV}$ & 40,6 & 30,2 & $74,4 \%$ & 13,1 & $43,4 \%$ & 1,6 & $5,3 \%$ & 15,5 & $51,3 \%$ \\
\hline indét & 0,9 & 0,9 & $100 \%$ & & & & & 0,9 & $100 \%$ \\
\hline TOTAL & 1048,8 & 785,4 & & 162,7 & & 37,1 & & 585,6 & \\
\hline \multirow{2}{*}{$\begin{array}{l}\text { couche noire } \\
\text { CARRÉ AB13 }\end{array}$} & Poids total & \multicolumn{2}{|c|}{ OS DÉTERMINÉS } & \multicolumn{2}{|c|}{ CRÂNE } & \multicolumn{2}{|c|}{ TRONC } & \multicolumn{2}{|c|}{ MEMBRES } \\
\hline & en g & Poids & $\% /$ total & Poids & $\% /$ déter. & Poids & $\% /$ déter. & Poids & $\% /$ déter. \\
\hline a I & 15,4 & 14,2 & $92,2 \%$ & 4,3 & $30,3 \%$ & 0,6 & $4,2 \%$ & 9,3 & $65,5 \%$ \\
\hline a II & 13,4 & 11,7 & $87,3 \%$ & 6,4 & $54,7 \%$ & 0,1 & $0,9 \%$ & 5,2 & $44,4 \%$ \\
\hline a III & 9,6 & 8,9 & $92,7 \%$ & 2,4 & $27 \%$ & 0,1 & $1,1 \%$ & 6,4 & $71,9 \%$ \\
\hline a IV & 9,4 & 7,4 & $78,7 \%$ & 1,4 & $18,9 \%$ & 0,5 & $6,8 \%$ & 5,5 & $74,3 \%$ \\
\hline $\mathrm{aV}$ & 3,1 & 3,1 & $100 \%$ & 0,4 & $12,9 \%$ & & & 2,7 & $87,1 \%$ \\
\hline $\mathrm{bl}$ & 23,3 & 19,2 & $82,4 \%$ & 5,3 & $27,6 \%$ & 0,9 & $4,7 \%$ & 13 & $67,7 \%$ \\
\hline b II & 36,6 & 25,5 & $69,7 \%$ & 5,7 & $22,4 \%$ & 1,1 & $4,3 \%$ & 18,7 & $73,3 \%$ \\
\hline $\mathrm{b}$ III & 19,8 & 18,9 & $95,5 \%$ & 6,2 & $32,8 \%$ & 0,6 & $3,2 \%$ & 12,1 & $64 \%$ \\
\hline b IV & 9,8 & 8,2 & $83,7 \%$ & 0,5 & $6,1 \%$ & 0,4 & $4,9 \%$ & 7,3 & $89 \%$ \\
\hline $\mathrm{b} V$ & 6,3 & 5,3 & $84,1 \%$ & 0,3 & $5,7 \%$ & & & 5 & $94,3 \%$ \\
\hline $\mathrm{cl}$ & 35,5 & 28,7 & $80,8 \%$ & 9,8 & $34,1 \%$ & 1,8 & $6,3 \%$ & 17,1 & $59,6 \%$ \\
\hline$c$ II & 21 & 18,7 & $89 \%$ & 3,5 & $18,7 \%$ & 1,4 & $7,5 \%$ & 13,8 & $73,8 \%$ \\
\hline$c \mid I I$ & 22,1 & 19,1 & $86,4 \%$ & 4,4 & $23 \%$ & 0,5 & $2,6 \%$ & 14,2 & $74,3 \%$ \\
\hline$c$ IV & 9,3 & 8,5 & $91,4 \%$ & 2,8 & $32,9 \%$ & 0,1 & $1,2 \%$ & 5,6 & $65,9 \%$ \\
\hline$c \mathrm{~V}$ & 7,8 & 6,5 & $83,3 \%$ & 0,9 & $13,8 \%$ & 0,2 & $3,1 \%$ & 5,4 & $83,1 \%$ \\
\hline $\mathrm{d}$ I & 26,7 & 24,5 & $91,8 \%$ & 11,8 & $48,2 \%$ & 1,9 & $7,7 \%$ & 10,8 & $44,1 \%$ \\
\hline d II & 21,5 & 19,4 & $90,2 \%$ & 9,4 & $48,4 \%$ & 0,5 & $2,6 \%$ & 9,5 & $49 \%$ \\
\hline d III & 20,9 & 18,8 & $90 \%$ & 6,6 & $35,1 \%$ & 0,8 & $4,3 \%$ & 11,4 & $60,6 \%$ \\
\hline d IV & 11,3 & 9,4 & $83,2 \%$ & 3,7 & $39,4 \%$ & 0,4 & $4,2 \%$ & 5,3 & $56,4 \%$ \\
\hline$d V$ & 7,2 & 5,3 & $73,6 \%$ & 1,2 & $22,6 \%$ & 0,1 & $1,9 \%$ & 4 & $75,5 \%$ \\
\hline $\mathrm{el}$ & 27 & 23,2 & $85,9 \%$ & 6,4 & $27,6 \%$ & 2,7 & $11,6 \%$ & 14,1 & $60,8 \%$ \\
\hline e II & 19,5 & 17,5 & $91,1 \%$ & 4 & $22,9 \%$ & 0,9 & $5,1 \%$ & 12,6 & $72 \%$ \\
\hline e III & 22,8 & 19,4 & $85,1 \%$ & 7,9 & $40,7 \%$ & 0,2 & $1 \%$ & 11,3 & $58,2 \%$ \\
\hline e IV & 12,1 & 10,1 & $83,5 \%$ & 5 & $49,5 \%$ & 0,8 & $8 \%$ & 4,3 & $42,6 \%$ \\
\hline $\mathrm{eV}$ & 5,7 & 5 & $87,7 \%$ & 1,5 & $30 \%$ & & & 3,5 & $70 \%$ \\
\hline TOTAL & 417,1 & 356,5 & & 111,8 & & 16,6 & & 228,1 & \\
\hline
\end{tabular}

Fig. 63. Aire de crémation B1. Niveau de fonctionnement, couche noire (us17109-17113-17114-17130-17164), carrés AB12 et AB13. Tableau de détermination des os humains (poids en grammes). 


\begin{tabular}{|c|c|c|c|c|c|c|c|c|c|}
\hline \multirow{2}{*}{$\begin{array}{l}\text { couche noire } \\
\text { CARRÉ AB14 }\end{array}$} & \multirow{2}{*}{$\begin{array}{l}\text { Poids total } \\
\text { en g }\end{array}$} & \multicolumn{2}{|c|}{ OS DÉTERMINÉS } & \multicolumn{2}{|c|}{ CRÂAE } & \multicolumn{2}{|c|}{ TRONC } & \multicolumn{2}{|c|}{ MEMBRES } \\
\hline & & Poids & $\% /$ total & Poids & $\% /$ déter. & Poids & $\% /$ déter. & Poids & $\% /$ déter. \\
\hline $\mathrm{a} \mid$ & 9,7 & 9 & $92,8 \%$ & 1,6 & $17,8 \%$ & 0,2 & $2,2 \%$ & 7,2 & $80 \%$ \\
\hline \multicolumn{10}{|l|}{ a II } \\
\hline \multirow{2}{*}{\multicolumn{10}{|c|}{$\begin{array}{l}\text { a III } \\
\text { a IV }\end{array}$}} \\
\hline & & & & & & & & & \\
\hline \multicolumn{10}{|l|}{$\mathrm{aV}$} \\
\hline $\mathrm{b}$ I & 3,6 & 2,8 & $77,8 \%$ & 0,9 & $32,1 \%$ & 0,1 & $3,6 \%$ & 1,8 & $64,3 \%$ \\
\hline \multicolumn{10}{|l|}{ b II } \\
\hline \multicolumn{10}{|l|}{ b III } \\
\hline \multirow{2}{*}{\multicolumn{10}{|c|}{$\frac{b I V}{b V}$}} \\
\hline & & & & & & & & & \\
\hline \multicolumn{10}{|l|}{$\mathrm{cl}$} \\
\hline \multicolumn{10}{|l|}{ c II } \\
\hline \multirow{2}{*}{\multicolumn{10}{|c|}{$\frac{c \text { III }}{c \text { IV }}$}} \\
\hline & & & & & & & & & \\
\hline \multicolumn{10}{|l|}{$\mathrm{c} \mathrm{V}$} \\
\hline d I & 3,6 & 3,3 & $91,7 \%$ & 1,6 & $48,5 \%$ & 0,1 & $3 \%$ & 1,6 & $48,5 \%$ \\
\hline \multicolumn{10}{|l|}{$d$ II } \\
\hline \multicolumn{10}{|l|}{ d III } \\
\hline \multirow{2}{*}{\multicolumn{10}{|c|}{$\frac{d I V}{d V}$}} \\
\hline & & & & & & & & & \\
\hline el & 0,8 & 0,8 & $100 \%$ & & & & & 0,8 & $100 \%$ \\
\hline \multicolumn{10}{|l|}{ e II } \\
\hline \multicolumn{10}{|l|}{ e IIII } \\
\hline \multirow{2}{*}{\multicolumn{10}{|c|}{$\frac{\text { e IV }}{\text { eV }}$}} \\
\hline $\mathrm{e} \mathrm{V}$ & & & & & & & & & \\
\hline TOTAL & 17,8 & 15,9 & & 4,1 & & 0,4 & & 11,4 & \\
\hline
\end{tabular}

\begin{tabular}{|c|c|c|c|c|c|c|c|c|c|}
\hline \multirow{2}{*}{\begin{tabular}{|l|} 
couche noire \\
CARRÉ AC13
\end{tabular}} & \multirow{2}{*}{$\begin{array}{l}\text { Poids total } \\
\text { en g }\end{array}$} & \multicolumn{2}{|c|}{ OS DÉTERMINÉS } & \multicolumn{2}{|c|}{ CRÂNE } & \multicolumn{2}{|c|}{ TRONC } & \multicolumn{2}{|c|}{ MEMBRES } \\
\hline & & Poids & $\% /$ total & Poids & $\% /$ déter. & Poids & $\% /$ déter. & Poids & $\% /$ déter \\
\hline \multicolumn{10}{|l|}{ a I } \\
\hline \multicolumn{10}{|l|}{ a II } \\
\hline \multicolumn{10}{|l|}{$d V$} \\
\hline $\mathrm{el}$ & 6,8 & 6,6 & $97,1 \%$ & 0,5 & $7,6 \%$ & 0,1 & $1,5 \%$ & 6 & $90,9 \%$ \\
\hline e II & 3,4 & 3,4 & $100 \%$ & 1,1 & $32,4 \%$ & & & 2,3 & $67,6 \%$ \\
\hline e III & 1,2 & 1,1 & $91,7 \%$ & 0,1 & $9,1 \%$ & & & 1 & $90,9 \%$ \\
\hline e IV & 1,9 & 1,4 & $73,7 \%$ & 0,1 & $7,1 \%$ & & & 1,3 & $92,9 \%$ \\
\hline $\mathrm{eV}$ & 5,7 & 5,6 & $98,2 \%$ & 4,3 & $76,8 \%$ & & & 1,3 & $23,2 \%$ \\
\hline TOTAL & 19 & 18,1 & & 6,1 & & 0,1 & & 11,9 & \\
\hline
\end{tabular}

\begin{tabular}{|c|c|c|c|c|c|c|c|c|c|}
\hline \multirow{2}{*}{$\begin{array}{l}\text { couche noire } \\
\text { CARRÉ AC14 }\end{array}$} & \multirow{2}{*}{$\begin{array}{c}\text { Poids total } \\
\text { en g }\end{array}$} & \multicolumn{2}{|c|}{ OS DÉTERMINÉS } & \multicolumn{2}{|c|}{ CRÂNE } & \multicolumn{2}{|c|}{ TRONC } & \multicolumn{2}{|c|}{ MEMBRES } \\
\hline & & Poids & $\% /$ total & Poids & $\% /$ déter. & Poids & $\%$ / déter. & Poids & $\% /$ déter. \\
\hline \begin{tabular}{|c|}
$\mathrm{a} I$ \\
\end{tabular} & & & & & & & & & \\
\hline a II & & & & & & & & & \\
\hline$d V$ & & & & & & & & & \\
\hline e I & 2,4 & 2 & $83,3 \%$ & 0,4 & $20 \%$ & 0,1 & $5 \%$ & 1,5 & $75 \%$ \\
\hline e II & & & & & & & & & \\
\hline e III & & & & & & & & & \\
\hline e IV & & & & & & & & & \\
\hline $\mathrm{eV}$ & & & & & & & & & \\
\hline TOTAL & 2,4 & 2 & & 0,4 & & 0,1 & & 1,5 & \\
\hline
\end{tabular}

Fig. 64. Aire de crémation B1. Niveau de fonctionnement, couche noire (us17109-17113-17114-17130-17164), carrés AB14, AC13 et AC 14. Tableau de détermination des os humains (poids en grammes).

\begin{tabular}{|c|c|c|c|c|c|c|c|c|c|c|c|c|}
\hline & \multicolumn{3}{|c|}{ CRÂNE } & \multicolumn{3}{|c|}{ TRONC } & \multicolumn{3}{|c|}{ MEMBRES } & \multicolumn{3}{|c|}{ TOUTES PARTIES CONFONDUES } \\
\hline & Nbre frag. & Poids total & Poids moyen & Nbre frag. & Poids total & Poids moyen & Nbre frag. & Poids total & Poids moyen & Nbre frag. & Poids total & Poids moyen \\
\hline $\begin{array}{c}\text { Bûcher B1 } \\
\text { couche rouge }\end{array}$ & 273 & $63,4 \mathrm{~g}$ & $0,23 \mathrm{~g}$ & 152 & $19,4 \mathrm{~g}$ & $0,13 \mathrm{~g}$ & 1027 & $273,6 \mathrm{~g}$ & $0,27 \mathrm{~g}$ & 1452 & $356,4 \mathrm{~g}$ & $0,25 \mathrm{~g}$ \\
\hline $\begin{array}{l}\text { Bûcher B1 } \\
\text { couche noire }\end{array}$ & 3455 & $995,8 \mathrm{~g}$ & $0,29 \mathrm{~g}$ & 1310 & $188,4 \mathrm{~g}$ & $0,14 \mathrm{~g}$ & 12123 & $3608,3 \mathrm{~g}$ & $0,30 \mathrm{~g}$ & 16888 & $4792,5 \mathrm{~g}$ & $0,28 \mathrm{~g}$ \\
\hline $\begin{array}{r}\text { Bûcher B1 } \\
\text { (ensemble) }\end{array}$ & 3728 & $1059,2 \mathrm{~g}$ & $0,28 \mathrm{~g}$ & 1462 & $207,8 \mathrm{~g}$ & $0,14 \mathrm{~g}$ & 13150 & $3881,9 \mathrm{~g}$ & $0,30 \mathrm{~g}$ & 18340 & $5148,9 \mathrm{~g}$ & $0,28 \mathrm{~g}$ \\
\hline $\begin{array}{l}\text { Tombes } \\
10 \text { à } 25 \\
\text { (ensemble) }\end{array}$ & 3344 & 836,5 & $0,28 \mathrm{~g}$ & 1879 & $293,3 \mathrm{~g}$ & $0,16 \mathrm{~g}$ & 16036 & $4505,8 \mathrm{~g}$ & $0,28 \mathrm{~g}$ & 21259 & $5635,6 \mathrm{~g}$ & $0,27 \mathrm{~g}$ \\
\hline
\end{tabular}

Fig. 65. Comparaison du poids moyen des fragments d'os humains déterminés par grandes régions anatomiques entre l'aire de crémation B1 et l'ensemble des tombes 10 à 25. 


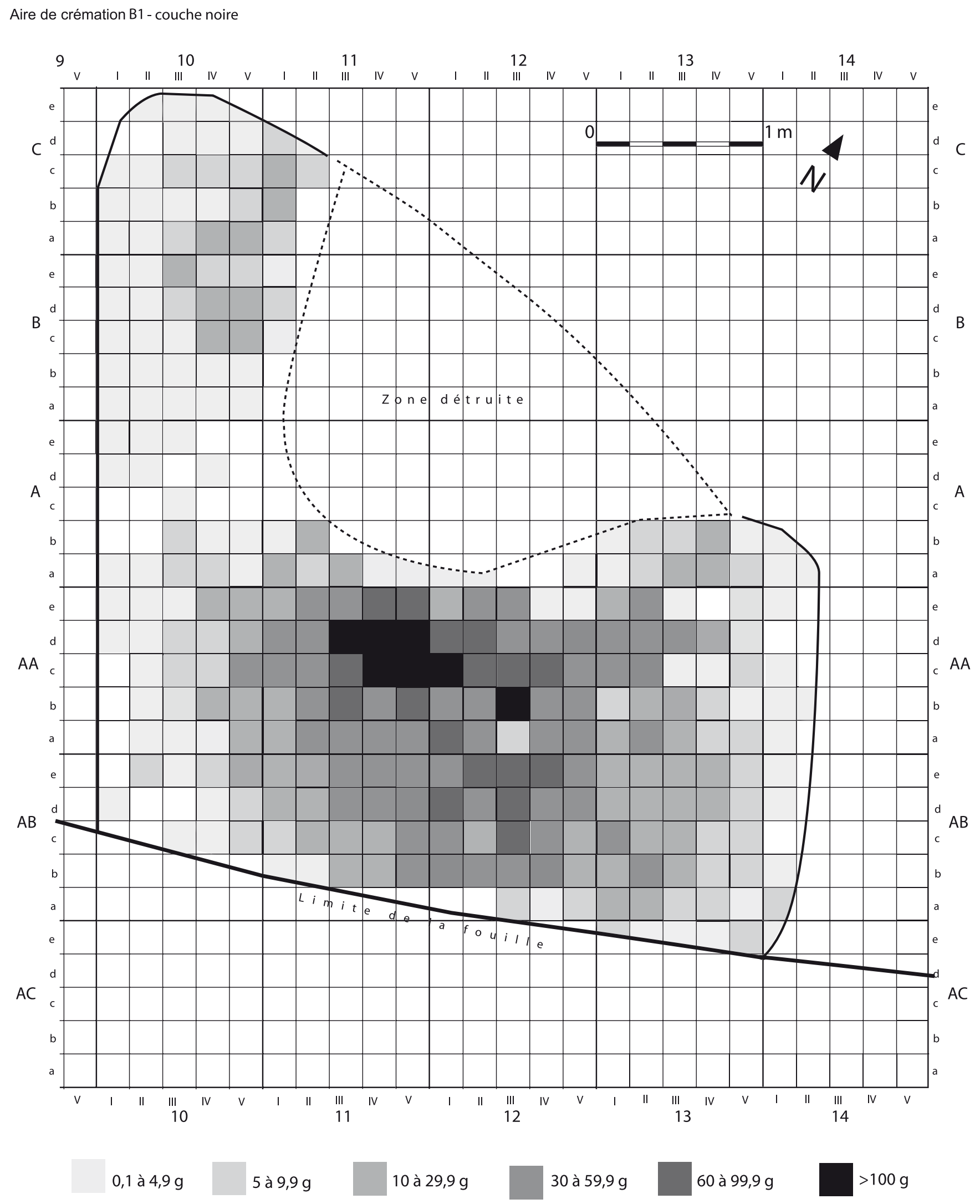

Fig. 66. Aire de crémation B1. Niveau de fonctionnement, couche noire (us17109-17113-17114-17130-17164). Répartition spatiale des os humains en fonction du poids, par carré de $20 \mathrm{~cm}$ de côté. 


\subsubsection{Les objets}

\section{A) Céramique non tournée}

Le niveau de fonctionnement du bûcher B1 (us1710917113-17114-17130-17164) a livré 690 morceaux de vases non tournés, de taille souvent plus importante que ceux du socle, ainsi que de nombreuses esquilles millimétriques. Parfois, ces tessons se rapportent aux mêmes récipients. Sauf le cas exceptionnel des morceaux d'une coupe à vernis noir (vase $n^{\circ} 1$ ) presque complète brûlée, ces tessons ne portent généralement pas de trace de feu secondaire.

Urnes :

La plupart des morceaux identifiables se rapportent à des urnes de forme CNT-LOR U5d, à col tronconique rentrant ou plus rarement cylindrique, à surface lissée, bord déversé à lèvre arrondie ou aplatie, panse ovoïde, le plus souvent peignée horizontalement, et fond plat ou, parfois, légèrement creux ; l'épaule peut être décorée d'impressions du peigne disposées en oblique, soit dans la même direction, soit de direction alternée pour former une ligne brisée simple ou double. Ces vases ont des dimensions moyennes : les diamètres à l'ouverture s'échelonnent de 80 à 150 mm (fig. 67, nº 1 à 22). Le plan de pose d'un fond plat est peigné et porte de larges traits incisés avant cuisson, sans doute en croix (fig. 67, $\left.\mathrm{n}^{\circ} 21\right)$.

Des morceaux d'une urne à panse globuleuse non peignée et épaule décorée d'une double ligne brisée largement incisée (fig. 67, $\mathrm{n}^{\circ} 23$ ) et un fond annulaire bas (fig. 67, $\mathrm{n}^{\circ} 24$ ) appartiennent à d'autres formes qu'on ne peut préciser.

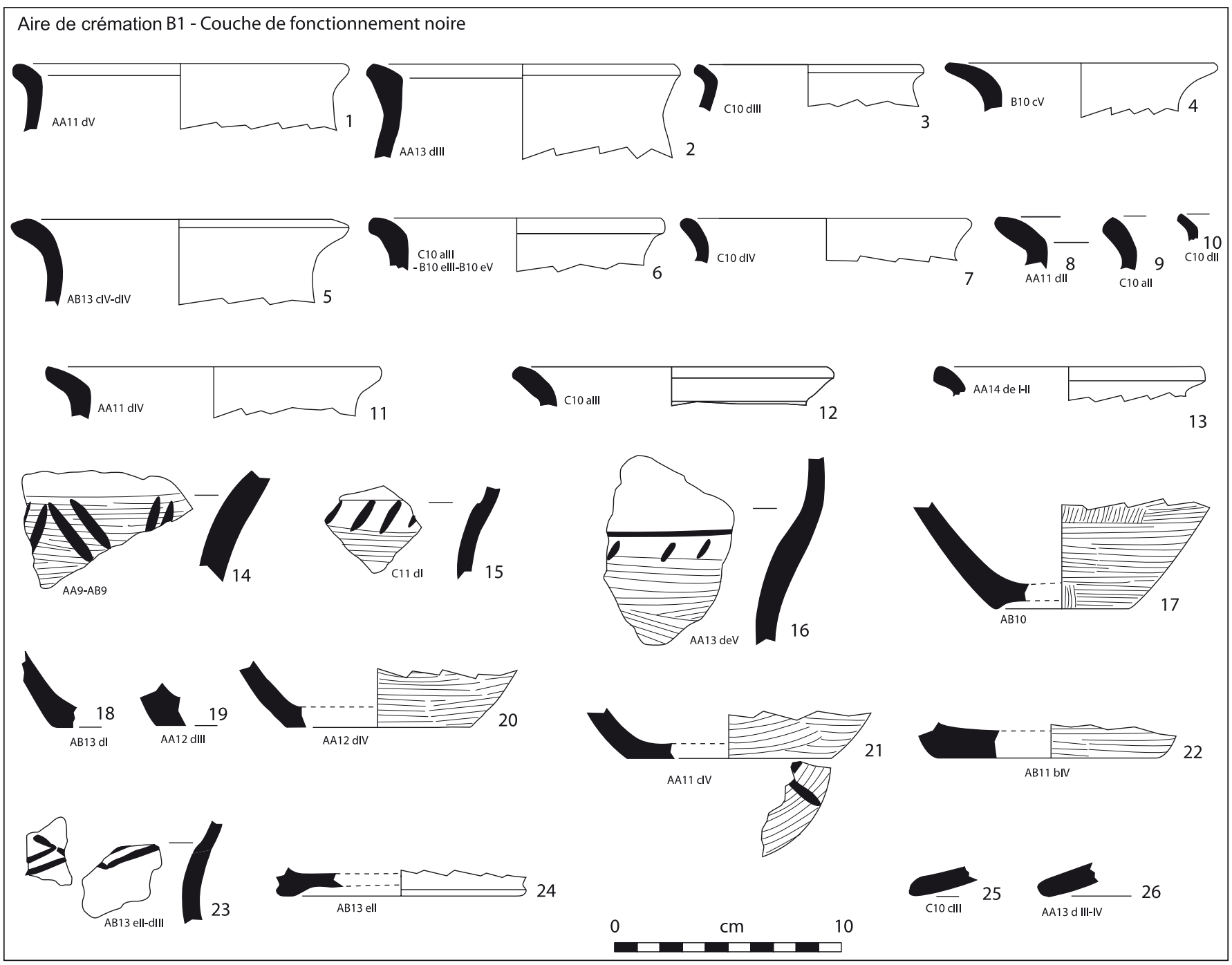

Fig. 67. Aire de crémation B1. Niveau de fonctionnement, couche noire (us17109-17113-17114-17130-17164). Mobilier (1-26 : céramique non tournée). 
Couvercles :

- 2 bords de couvercles de forme CNT-LOR V2a ou V2b, à lèvre arrondie ou aplatie (fig. 67, $\mathrm{n}^{\circ} 25$ et 26).

Coupes :

- 4 tessons de 4 coupes de forme CNT-LOR C2 : panse arrondie convexe, embouchure rétrécie, bord convergent à lèvre arrondie ou plus rarement aplatie ; diam. max. : 130 à 290 mm (fig. 68, $n^{\circ} 1$ à 4);

- 4 tessons de 4 coupes de forme CNT-LOR C4 : panse carénée, embouchure rétrécie, bord convergent à lèvre aplatie (fig. 68, $\mathrm{n}^{\circ} 5,7$ à 9) ;

- 5 tessons de 5 coupes de forme CNT-LOR C1 : panse arrondie-convexe, embouchure évasée, bord à lèvre arrondie ou aplatie; diam. max. : 110 à $220 \mathrm{~mm}$ (fig. 68, $\mathrm{n}^{\circ} 10$ à 14) ;

- 1 tesson de coupe de forme CNT-LOR C1d : panse arrondie-convexe, embouchure évasée, bord à lèvre aplatie, et une anse horizontale sous le bord à la manière des coupes tournées (fig. $68, \mathrm{n}^{\circ} 15$ ).

Jatte :

- 1 partie supérieure de grande jatte de forme proche de CNT-LOR J1e, variante 1 : panse arrondie, à bord légèrement élargi avec aplatissement horizontal ; diam. max. : 340 mm (fig. 68, $\mathrm{n}^{\circ} 16$ ).

Urnes ou coupes :

- 4 fonds annulaires de coupes ou d'urnes (fig. 68, $\mathrm{n}^{\circ} 17$ à 20).

Dolium :

- 12 tessons de panses; une rondelle taillée dans un morceau de panse ; diam. : $60 \mathrm{~mm}$.

\section{B) Céramiques tournées}

Attique à vernis noir :

-1 petit tesson informe.

Céramique à vernis noir de l'atelier de Rosas :

- 43 tessons d'un bol Lamb. 27 (= forme Puig 11.b), diam. ouv. : $120 \mathrm{~mm}$, diam. base : $55 \mathrm{~mm}$ (fig. 68, $\mathrm{n}^{\circ} 27$ ) ; ce vase est incomplet (environ $80 \%$ présent) et les tessons sont éparpillés sur $4 \mathrm{~m}^{2}$ dans la partie est du bûcher (fig. 78, vase 1); tous les tessons de ce vase portent les traces homogènes d'un feu secondaire ;

- au moins 12 tessons d'un autre bol Lamb. 27 (= forme Puig 11.b), diam. ouv. : $140 \mathrm{~mm}$ (fig. 68, $\mathrm{n}^{\circ} 28$ ) ; ce vase est très incomplet (environ $25 \%$ présent) et les tessons, ne portant pas de trace de feu, sont groupés, toujours dans la partie orientale du bûcher (fig. 78, vase 2) ;
- 2 tessons de bord d'un troisième bol Lamb. 27 (= forme Puig 11.b), diam. ouv. : $140 \mathrm{~mm}$ (fig. 68, $\mathrm{n}^{\circ} 29$ ) ;

- 22 tessons, de petite taille généralement, dont 8 bords et des morceaux de panses de plusieurs bols Lamb. 27 (= forme Puig 11).

Campanienne A :

- 1 bord de coupe Lamb. A 31a, décoré d'une rainure sous le bord à l'extérieur et d'un filet horizontal peint sous la lèvre à l'intérieur (fig. 68, n 30 ).

Atelier de Rosas ou Campanienne A :

-6 petits tessons informes.

Céramique grise peinte massaliète :

- un fragment informe.

Céramique à pâte claire massaliète :

- cruches : 2 bords, 2 fonds, 1 anse et 46 fragments de panses, appartenant à au moins 4 exemplaires (fig. 68, $\mathrm{n}^{\circ} 21$ à 25$)$;

- coupes : un bord de coupe CL-MAS 237 (fig. 68, $\left.\mathrm{n}^{\circ} 26\right)$;

- informes : deux fragments.

Amphore massaliète :

- 19 fragments dont 1 anse.

\section{C) Armement et fourniment}

- Extrémités distales d'une épée et de son fourreau en fer, fondus, presque à l'état de scorie (fig. 69, $\mathrm{n}^{\circ} 1$ ); on discerne, en coupe, la plaque avers du fourreau, aux bords en gouttière (larg. : $29 \mathrm{~mm}$; ép. : $1 \mathrm{~mm}$ ), et la lame (ép. : $4 \mathrm{~mm}$ ) ; l'élargissement de l'extrémité, vaguement arrondie, évoque la bouterolle ; long. cons. : $51 \mathrm{~mm}$;

- Clou en fer, de poignée d'épée ou de fourreau (fig. 69, $\mathrm{n}^{\circ} 2$ ) ; tête ronde, bombée ; tige de section en mince ruban ; diam. tête : $9 \mathrm{~mm}$; long. : $11 \mathrm{~mm}$;

- Trois rivets en fer de garniture de poignée d'épée, dont il manque une extrémité (fig. 69, n 3 à 5) (non restaurés) ; tête discoïde, légèrement bombée ; tige de section quadrangulaire; diam. tête : respectivement $12 \mathrm{~mm}, 11 \mathrm{~mm}$ et $11 \mathrm{~mm}$; long. cons. : respectivement $26 \mathrm{~mm}, 25 \mathrm{~mm}$ et $26 \mathrm{~mm}$. Des rivets semblables figurent dans le recouvrement commun des tombes 12 et 14 et dans la tombe 21 ;

- Petit morceau de bord en gouttière de plaque avers de fourreau d'épée, en tôle de fer (fig. 69, $n^{\circ} 6$ ) ; long. cons. : $13 \mathrm{~mm}$; ép. : $1 \mathrm{~mm}$. Des bords de gouttière semblable figurent dans la tombe 21 .

- Passant en fer de ceinture de fixation de fourreau d'épée (fig. 69, $\mathrm{n}^{\circ}$ 8) ; face formée d'une plaque 


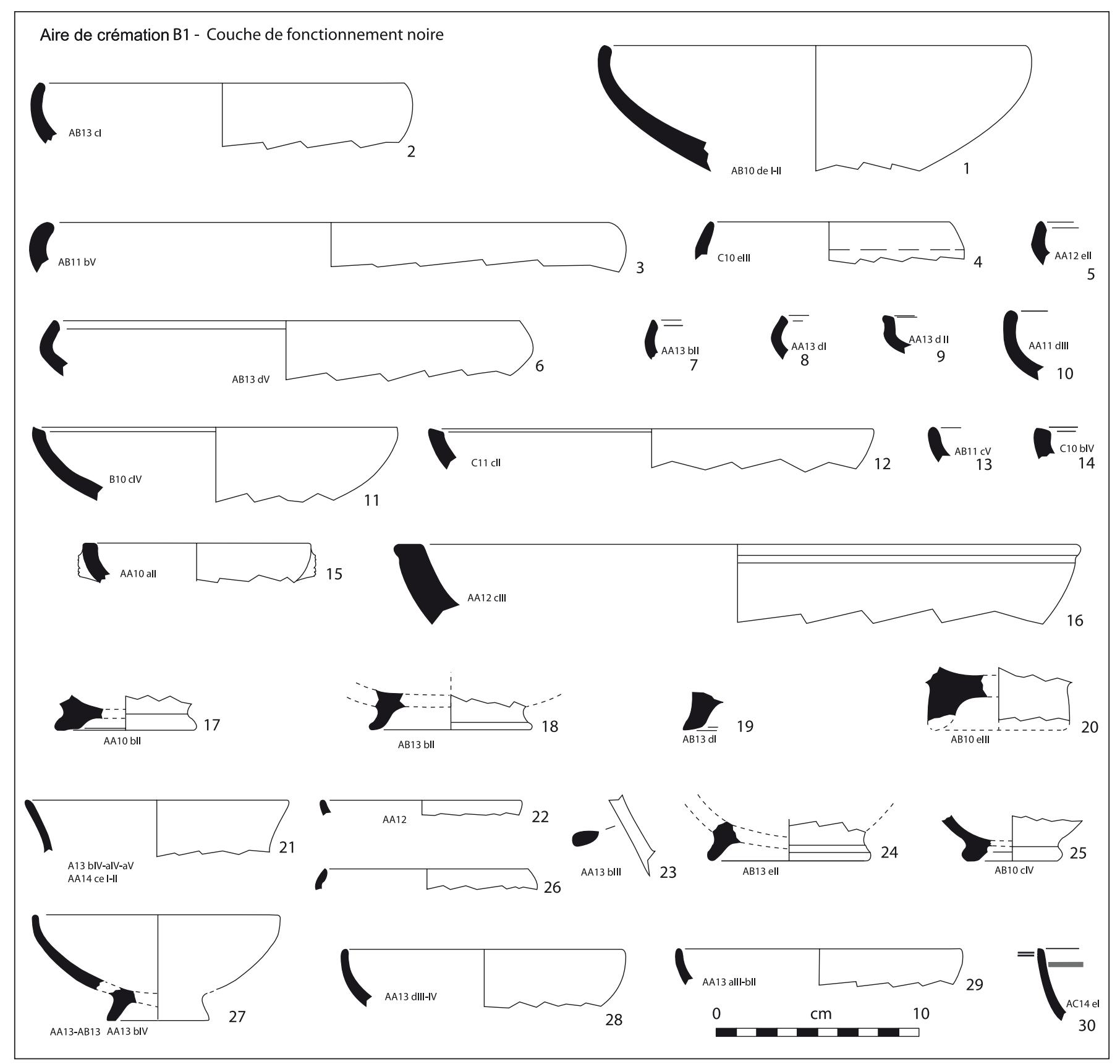

Fig. 68. Aire de crémation B1. Niveau de fonctionnement, couche noire (us17109-17113-17114-17130-17164). Mobilier (1-20 : céramique non tournée ; 21-26 : céramique à pâte claire massaliète ; 27-30 : céramique à vernis noir).

fine, grossièrement losangique, prolongée aux deux extrémités par deux longues pattes repliées, de section quadrangulaire, débordant la longueur du passant luimême ; long. passant : $33 \mathrm{~mm}$; long. hors tout : $39 \mathrm{~mm}$; larg. : $11 \mathrm{~mm}$; ép. : 1,5 à $2 \mathrm{~mm}$. Les dimensions de cet objet donnent une indication sur les mesures maxima de la section de la ceinture : $30 \mathrm{~mm}$ sur $8 \mathrm{~mm}$.

- Petit morceau d'orle de bouclier, en fer (fig. 69, $\mathrm{n}^{\circ} 7$ ) ; long. cons. : $15 \mathrm{~mm}$; ép. : $1 \mathrm{~mm}$.

\section{D) Parure et habillement}

- Moitié d'anneau circulaire en bronze, à tige mince de section lenticulaire aplatie (fig. 69, $\mathrm{n}^{\circ} 9$ ); diam. : $26 \mathrm{~mm}$; section tige : $3,5 \times 5,5 \mathrm{~mm}$;

- Trois morceaux d'une grosse fibule en bronze (fig. 69, $\mathrm{n}^{\circ} 10$ ) : arc en anse de panier, à sommet élargi en forme d'ovale, de section rectangulaire, ne montrant pas de trace de fixation d'un éventuel prolongement du 
pied ; long porte-ardillon avec départ du pied recourbé ; cinq spires d'un gros ressort conservées; la tête et une extrémité du ressort présentent un début de fusion ; long. rest. : $70 \mathrm{~mm}$ environ.

Il manque la majeure partie du pied, mais cinq éléments de corail destinés à orner un disque et qui ont également subi l'action du feu vu leur couleur blanchâtre ou gris, ont été trouvés à proximité immédiate et font sans doute partie de cette fibule : un élément en arc de cercle orné sur une face d'impressions ovalaires (diam. : $35 \mathrm{~mm}$; larg. : 3,5 mm); quatre éléments triangulaires, dont deux cassés près de la pointe dirigée vers le centre du disque, perforés d'un petit trou de fixation, renflés au centre et relevés aux angles en portions de boules proéminentes (haut. : 9 et 10,2 $\mathrm{mm}$; base : 5,5 à $6,2 \mathrm{~mm}$ ) (fig. 69, $\mathrm{n}^{\circ} 11$ ). On a donc sans doute affaire à une fibule du type à pied discoïde orné d'éléments de corail assemblés, triangles et losanges rayonnants et bandeau périphérique, et à ressort bilatéral relativement long (type 11 de Tendille 1978).

- Élément de corail triangulaire pour disque de fibule (fig. 69, $\mathrm{n}^{\circ} 12$ ); sa facture diffère quelque peu de celle

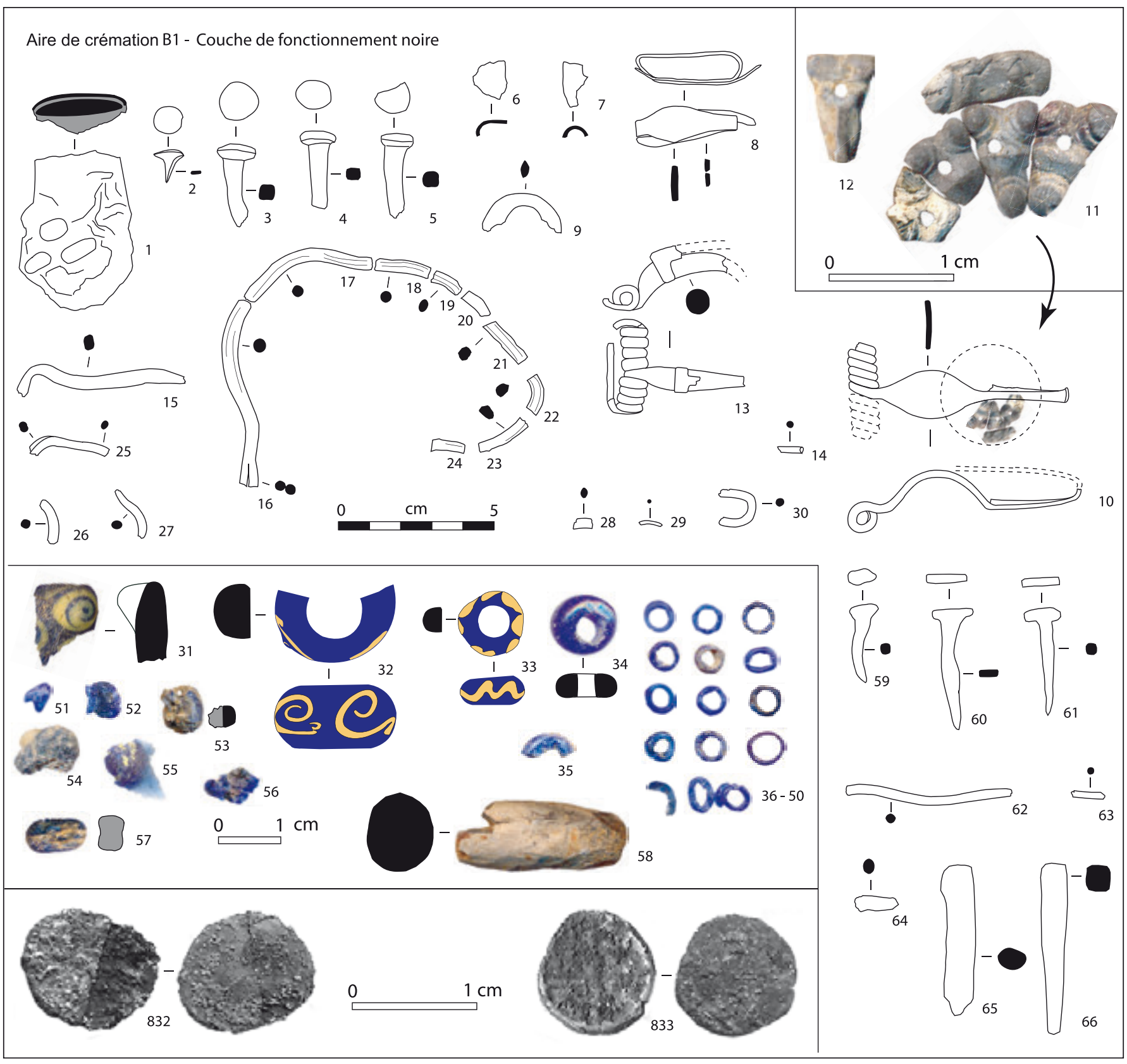

Fig. 69. Bûcher B1. Niveau de fonctionnement, couche noire (us17109-17113-17114-17130-17164). Mobilier (1-8, 13, 30, $60,61,65$ et 66 : fer ; 9, 10,14-29, 59 et 62-64 : bronze ; 11 et 12 : corail ; 31-57 : verre ; 58 : bois ; 832 et 833 : oboles de Marseille en argent). 
des éléments précédents, ce qui signale une autre fibule, sans doute du même type, à pied discoïde : bandeau bordant la base, cercle saillant autour de la perforation médiane et arête médiane vers la pointe (haut. : $9 \mathrm{~mm}$; base : $5 \mathrm{~mm}$ ) ;

- Fibule en fer (fig. 69, $\mathrm{n}^{\circ} 13$ ), dont il manque le pied et l'ardillon; ressort bilatéral à huit spires et corde externe; arc en anse de panier, de section arrondie, légèrement épaissi dans sa partie centrale muni d'une bague d'attache d'un pied probablement recourbé ; long. cons. : $45 \mathrm{~mm}$; larg. au ressort : $32 \mathrm{~mm}$;

- Morceau de tige en bronze, rectiligne, de section circulaire (diam. tige : $2, \mathrm{~mm}$ ); long. cons. $8 \mathrm{~mm}$. Il s'agit peut-être d'un ardillon de fibule (fig. 69, n 14) ;

- Segment de tige mince en bronze, de section quadrangulaire. Cet objet est très déformé par le feu, tordu et vrillé ; long. cons. développée : $6 \mathrm{~mm}$; section tige : $4 \mathrm{~mm}$ sur $5 \mathrm{~mm}$ (fig. $\left.69, \mathrm{n}^{\circ} 15\right)$;

- Neuf morceaux de tige en bronze paraissant se rapporter à un même torque : tige de section circulaire (diam. : $4 \mathrm{~mm}$ ) striée longitudinalement et non ébarbée ; à l'une des extrémités d'un de ces morceaux, la tige se dédouble en deux branches plus fines (diam. : $3 \mathrm{~mm}$ ) qui devaient former un anneau pour assurer la fermeture. Ces fragments sont tordus, vrillés et ont subi l'action du feu, de sorte que le diamètre de l'objet ne peut être calculé ; long. cons. développées : respectivement $62 \mathrm{~mm}$, $52 \mathrm{~mm}, 19 \mathrm{~mm}, 11 \mathrm{~mm}$ et $10 \mathrm{~mm}$ (fig. 69, $\mathrm{n}^{\circ} 16$ à 24);

- Morceau d'un possible second torque en bronze, à tige plus mince que celle de l'exemplaire précédent, de section ovale (ép. tige : 2 à $3 \mathrm{~mm}$ ); à l'une des extrémités, la tige se dédouble. Cet élément est tordu et a subi l'action du feu, de sorte que le diamètre ne peut être calculé ; long. cons. développée : $26 \mathrm{~mm}$ (fig. $69, \mathrm{n}^{\circ} 25$ ) ;

- Fragment de petit anneau circulaire en bronze, à tige mince de section circulaire ; diam. : $25 \mathrm{~mm}$; diam. tige : $3 \mathrm{~mm}$. Cet objet s'est tordu sous l'effet du feu (fig. 69, $\mathrm{n}^{\circ} 26$ ) ;

- Fragment de petit anneau circulaire en bronze, à tige mince de section lenticulaire ; diam. : $25 \mathrm{~mm}$. Cet objet a subi l'action du feu (fig. 69, $\mathrm{n}^{\circ} 27$ );

- Petit fragment d'anneau en bronze, de section ovale; long. cons. corde : $6 \mathrm{~mm}$; haut. $3 \mathrm{~mm}$ (fig. 69, $\left.\mathrm{n}^{\circ} 28\right)$;

- Petit fragment d'anneau en bronze, de section circulaire (fig. 69, $\mathrm{n}^{\circ} 29$ ), très fin (section : $1,5 \mathrm{~mm}$ ); long. cons. corde : $8 \mathrm{~mm}$;

- Morceau de maillon de chaînette, en fer, de forme ovale et de section circulaire (diam. : $3 \mathrm{~mm}$; petit axe : $12 \mathrm{~mm}$ ) (fig. 69, $\mathrm{n}^{\circ} 30$ ).

- Fragment de grosse perle cylindrique en pâte de verre bleu, à plusieurs rangs de protubérances ornées d'un filet blanc ou jaune opaque en spirale (type IV-1-1 de Zepezauer 1989, p. 113-114); section en « $\mathrm{D} »$; diam. : env. $14 \mathrm{~mm}$ (fig. 69, $\mathrm{n}^{\circ} 31$ );

- Moitié de grosse perle annulaire en pâte de verre bleu, ornée d'un rang de spirales se terminant vers l'extérieur, formées d'un filet jaune opaque (type I-1 de Zepezauer 1989, p. 110) ; forme ronde, section en « $\mathrm{D}$ »; diam. : $20 \mathrm{~mm}$; haut. : $10 \mathrm{~mm}$; ép. : 5 à $6 \mathrm{~mm}$ (fig. 69, $\mathrm{n}^{\circ} 32$ ) ;

- Perle moyenne en pâte de verre bleu opaque, décorée d'un filet jaune opaque en ligne ondée ; forme ronde ; section en « $\mathrm{D}$ »; diam. : 10 à $11 \mathrm{~mm}$; haut. : 3 à $5 \mathrm{~mm}$; ép. : 2 à $3 \mathrm{~mm}$ (fig. 69, $\left.\mathrm{n}^{\circ} 33\right)$;

- Perle moyenne en pâte de verre bleu uniforme (fig. 69, $\left.\mathrm{n}^{\circ} 34\right)$; section en « $\mathrm{D}$ »; diam. : 9 à $10 \mathrm{~mm}$; haut. : 4 à $5 \mathrm{~mm}$;

- Moitié de perle moyenne en pâte de verre bleue (fig. 69, $\mathrm{n}^{\circ} 35$ ), partiellement fondue ; section en « $\mathrm{D} »$; diam. : $10 \mathrm{~mm}$;

- 16 petites perles en pâte de verre, de couleur bleu clair à outremer (fig. 69, $\mathrm{n}^{\circ} 36$ à 50); section arrondie, fine et irrégulière; plusieurs sont déformées par la chaleur et trois d'entre elles sont collées par un début de fusion ; diam. : 4 à $6 \mathrm{~mm}$;

- Trois autres perles semblables, en partie fondues et agglomérées par la fusion (fig. 69, $\mathrm{n}^{\circ}$ 52) ;

-6 petits fragments informes de pâte de verre bleue fondue, appartenant à des perles (fig. 69, n 51 et 53 à 57).

\section{E) Monnaies}

- Deux oboles de Marseille, en argent, altérées par le feu, du type OBM-11 (Py 2006, p. 47-54) ; D/ Tête juvénile à gauche sans favoris ; R/ Roue à quatre rayons, légende MA dans deux cantons ; métrologie :

- fig. 69, $\mathrm{n}^{\circ} 832: 0,40 \mathrm{~g}$; module : 9-10 mm; épaisseur : $1 \mathrm{~mm}$; orientation ?

- fig. 69, $\mathrm{n}^{\circ} 833: 0,50 \mathrm{~g}$; module : 9-10 mm; épaisseur : $1 \mathrm{~mm}$; orientation ?

\section{F) Ustensiles}

- Morceau de petit manche en bois fossilisé (fig. 69, $\left.\mathrm{n}^{\circ} 58\right)$; taillé au couteau ; extrémité conservée amincie en pointe mousse ; section grossièrement arrondie ; long. cons. : $28 \mathrm{~mm}$; diam. max. : 11 à $12 \mathrm{~mm}$.

\section{G) Petits objets divers}

- Clou de décoration en bronze (fig. 69, $\mathrm{n}^{\circ} 59$ ) ; tête légèrement bombée; tige tordue, de section sub-quadrangulaire; long. : $25 \mathrm{~mm}$.

- Clavette en fer (fig. 69, $\mathrm{n}^{\circ}$ 60) ; section quadrangulaire ; long. : $39 \mathrm{~mm}$. 
- Clavette en fer (fig. 69, $\mathrm{n}^{\circ}$ 61) (non restaurée) ; section quadrangulaire ; long. : $34 \mathrm{~mm}$;

- Morceau de tige en bronze, cassée aux deux extrémités, tordue et vrillée (fig. 69, $\mathrm{n}^{\circ}$ 62) ; section circulaire (diam. tige : $3 \mathrm{~mm}$ ) ; long. cons. développée : $54 \mathrm{~mm}$;

- Morceau de tige en bronze (fig. 69, $\mathrm{n}^{\circ}$ 63), légèrement courbée, de section circulaire (diam. tige: $2,7 \mathrm{~mm}$ ) ; long. cons. $11 \mathrm{~mm}$;

- Morceau de tige en bronze (fig. 63, $\mathrm{n}^{\circ}$ 64), rectiligne, de section ovale ( $3 \mathrm{~mm}$ sur $4 \mathrm{~mm}$ ); long. cons. $13 \mathrm{~mm}$; cet objet a subi l'action du feu ;

- Morceau de tige en fer (fig. 69, $\mathrm{n}^{\circ} 65$ ), rectiligne (non restauré) ; long. cons. : $51 \mathrm{~mm}$;

- Morceau de tige en fer (fig. 69, $\mathrm{n}^{\circ}$ 66), rectiligne et amincie vers une extrémité (non restauré), de section quadrangulaire (8 $\mathrm{mm}$ de côté au maximum); long. cons. : $55 \mathrm{~mm}$;

- Tête de clou en fer, non restaurée (non dessiné) ;

- Trois petites scories de fer ; dim. max. : respectivement, $12 \mathrm{~mm}, 12 \mathrm{~mm}$ et $21 \mathrm{~mm}$;

-14 petits fragments d'objets en bronze fondus, non déterminables; dim. max. : $6 \mathrm{~mm}$ à $13 \mathrm{~mm}$ (non dessinés) ;

- Un petit fragment d'objet en fer, très corrodé, non déterminable ; dim. max. : 19 mm (non dessiné).

\subsection{Synthèse des données sur le fonctionnement de l'aire de crémation $B 1$}

Le matériel issu des deux couches de fonctionnement du bûcher distinguées lors de la fouille, le comblement de la dépression centrale à matrice rougeâtre et le sédiment noirâtre recouvrant la dépression et le socle, ne diffère pas par la nature des éléments. C'est seulement la quantité de ceux-ci qui varie de l'une à l'autre ; les deux inventaires distincts de la documentation établis cidessus ( $\S 2.2$. et $\S 2.3$.) le montrent bien. Séparés par la fouille, ces deux ensembles de documents doivent donc être réunis in fine pour analyser les caractéristiques de l'utilisation de ce lieu.

\subsubsection{La composition du lot osseux et le nombre d'individus incinérés}

\section{La fragmentation des os :}

Au total, la masse d'os humains incinérés recueillie dans les deux couches de la partie fouillée du bûcher, s'élève à $6859,1 \mathrm{~g}$, le tamisage ayant été effectué, rappelons-le, à la maille $0,5 \mathrm{~mm}$. Ces restes osseux sont très fragmentés. Les 18340 pièces «déterminées », ou du moins réparties selon les trois grandes régions anatomiques, le crâne, le tronc et les membres, ont un poids moyen de $0,28 \mathrm{~g}$. Cette masse moyenne varie de $0,23 \mathrm{~g}$ pour le crâne (3728 fragments) à $0,14 \mathrm{~g}$ pour le tronc (1462 fragments) et $0,30 \mathrm{~g}$ pour les membres (13153 fragments). On notera à ce propos qu'il n'y a pas de différence significative de ces poids moyens des fragments osseux entre la couche de fonctionnement noire $(0,28 \mathrm{~g}$ pour le crâne, $0,14 \mathrm{~g}$ pour le tronc, $0,30 \mathrm{~g}$ pour les membres et $0,28 \mathrm{~g}$ pour l'ensemble) et la dépression centrale rouge $(0,23 \mathrm{~g}$ pour le crâne, $0,14 \mathrm{~g}$ pour le tronc, $0,27 \mathrm{~g}$ pour les membres et $0,25 \mathrm{~g}$ pour l'ensemble) (fig. 65). De surcroît, ces valeurs sont très proches de celles qui sont calculées globalement pour l'ensemble des tombes 10 à 25 qui ont fait l'objet du même tamisage que le bûcher B $1: 0,28 \mathrm{~g}$ pour le crâne (3344 fragments), $0,16 \mathrm{~g}$ pour le tronc (1879 fragments), $0,28 \mathrm{~g}$ pour les membres (16036 fragments) et $0,27 \mathrm{~g}$ pour l'ensemble (21259 fragments déterminés) (fig. 65). Même si aucun recollage n'assure que le matériel des tombes provient précisément de ce bûcher B1, néanmoins la similitude est très nette, s'agissant en outre des mêmes classes d'âge de défunts attestés.

La faiblesse de ces valeurs pondérales moyennes se retrouve également dans les vestiges osseux animaux découverts dans le même niveau de fonctionnement de cette aire de crémation B1. Dans son étude, A. Gardeisen indique un poids moyen de $0,36 \mathrm{~g}$ pour les os de faune déterminés (voir infra, Annexe 2, § 2.1.). La fragmentation de ces restes résulte très probablement d'une utilisation répétée de cette structure, avec, probablement, étalement des restes de l'incinération antérieure lors d'une nouvelle crémation. La comparaison avec les structures de crémation d'Ensérune et de Mourrel-Ferrat, contemporaines de celle d'Ambrussum, n'a pas été possible par manque de pareilles données chiffrées sur ces deux sites.

\section{La représentation des diverses régions du squelette :}

Sur l'ensemble du lot osseux provenant du bûcher, les trois quarts, 5148,9 g soit $75 \%$, ont pu être répartis entre les trois grandes régions squelettiques, crâne, tronc et membres. Avec 1059,2 g les restes crâniens et dentaires comptent pour $20,6 \%$ du total déterminé. Le tronc, avec $207,8 \mathrm{~g}$, n'en forme que $4 \%$, tandis que les membres, qui totalisent $3881,9 \mathrm{~g}$ en constituent $75,4 \%$.

Si la représentation du crâne est tout à fait conforme au poids théorique $(20,4 \%)$, il n'en va pas de même du tronc, très sous-représenté par rapport aux $17 \%$ théoriques attendus, ni des membres, à l'inverse, attestés bien au-delà de la valeur théorique de 62,6\%. Pour rétablir 
des proportions normales, il faudrait que la grande majorité des os non déterminés se rapportassent au tronc, ce qui ne peut être exclu vu le degré de fragmentation des pièces. Mais, un semblable déficit du tronc, généralement au profit des membres, se retrouve dans les dépôts osseux des tombes fouillées à Ambrussum. Il marque aussi la plupart des sépultures à incinération secondaire de la Protohistoire du sud de la France, mais ne se retrouve pas chez d'autres populations où cette pratique funéraire est en usage. On a pu donc y voir « une particularité qui tient manifestement au processus même de l'incinération » dans cette région, à cette époque (Duday, Depierre, Janin 2000, p. 22).

\section{Le nombre d'individus incinérés :}

Les déterminations osseuses cumulées des deux couches permettent une évaluation du nombre minimum d'individus, fondée sur la présence de doublets et sur celle d'éléments autorisant une estimation de l'âge au décès. Ainsi sont attestés les restes d'au moins cinq défunts : deux adultes, un robuste et un gracile, de sexe non déterminable, un adolescent de 15 à 22 ans, également de sexe non connu, un jeune enfant de 2 à 6 ans et un fotus de 5 à 7 mois lunaires in utero, la présence de ce dernier pouvant résulter de la crémation d'une femme morte enceinte (peut-être l'adulte gracile ?).

Pour évaluer l'adéquation de ce décompte minimum des individus avec la masse totale d'os incinérés recueillis sur ce bûcher, deux paramètres doivent être pris en considération : d'une part, le poids théorique d'os brûlés d'un individu et, d'autre part, le poids moyen d'os prélevés par les survivants pour être déposés dans les sépultures, et cela, pour chaque classe d'âge concernée.

Le poids théorique d'os d'un adulte brûlé varie considérablement selon les études. Selon B. Hermann (1976), la fourchette se place entre 970 et 2630 g. Pour J.I. Mackinley (1993), elle se situe entre 1001,5 et 2422,5 g si le tamisage exclut les fragments inférieurs à $2 \mathrm{~mm}$, et entre 1227 et $3001 \mathrm{~g}$ si on prend en compte les fragments récupérés au tamis inférieur à $2 \mathrm{~mm}$. Le poids moyen varie aussi en fonction du sexe du défunt : 1700,3 g pour une femme et $1841,6 \mathrm{~g}$ pour un homme selon B. Hermann et, respectivement, $1615,7 \mathrm{~g}$ et $2285,5 \mathrm{~g}$. selon J.I. Mackinley ${ }^{11}$. Le poids théorique moyen d'os brûlés d'un enfant de quatre ans est de $636 \mathrm{~g}$ pour M.W. Warren et W.R. Maples (1997, p. 420-421), et celui d'un périnatal, de 71 à $95 \mathrm{~g}$ pour M. Trotter et B.B. Hixon (1974).

11 M.W. Warren et W.R. Maples (1997) font état de poids moyens plus élevés, $1819 \mathrm{~g}$ pour les femmes et $2903 \mathrm{~g}$ pour les hommes.
Le prélèvement osseux destiné à être placé dans la tombe varie, à Ambrussum, avec l'âge du mort: une tombe d'adulte accueille en moyenne 391,6 g d'os (calcul sur 14 sépultures d'adultes complètes); les deux jeunes enfants entre deux et six ans, tombes 13 et 22, sont représentés respectivement par 71,5 et $88,3 \mathrm{~g}$, soit une moyenne de $80,2 \mathrm{~g}$; pour sa part, la seule sépulture d'adolescent attestée (tombe 2) n'a pas été complètement fouillée.

Vu la variété des données théoriques, deux estimations doivent être considérées, avec les poids théoriques minimum et avec les poids théoriques maximum, sans chercher à distinguer les hommes des femmes, puisque d'après la connotation symbolique de plusieurs catégories d'objets, ce bûcher a concerné des adultes des deux sexes (fig. 70). La première évaluation, en additionnant poids théoriques minimum et prélèvements protohistoriques, totalise $4879 \mathrm{~g}$. La seconde, poids théoriques maximum donnés par J.I. Mackinley pour un tamisage prenant en compte les fragments inférieurs à $2 \mathrm{~mm}$, et prélèvements, s'élève à 10989 g (fig. 70).

Comparons ces deux valeurs à celle de la masse osseuse recueillie, $6859 \mathrm{~g}$, à laquelle s'ajoutent $1255 \mathrm{~g}$ pour les prélèvements supposés concernant les deux adultes, l'adolescent et le jeune enfant ${ }^{12}$ (le fœtus n'est pas ici pris en compte puisque cette classe d'âge ne bénéficie pas d'une place dans la nécropole), soit en tout 8114 g. Force est de constater que cette valeur entre dans la fourchette des valeurs théoriques, mais qu'elle est nettement plus proche de la limite supérieure. De surcroît, sans compter ce qui a pu disparaître avant que la structure ne soit enfouie sous les sédiments du Vidourle, ce n'est pas la totalité de ce bûcher qui a pu être fouillée. Toute la partie méridionale a échappé à l'investigation. Cependant, si on considère que la zone de densité maximum des restes correspond au centre du dispositif, et que la diminution vers le sud est semblable à celle que l'on constate vers le nord, on peut sans doute ajouter un ou deux individus supplémentaires au total déterminé, défunt(s) adulte(s) plutôt qu'immature(s), étant donné le type de recrutement de la nécropole (voir infra).

Le poids d'os recueillis peut donc provenir des seuls cinq sujets attestés, et si l'hypothèse d'un ou deux adultes supplémentaires doit être envisagée, il semble que l'on doive faire l'économie de celle d'un nombre plus important de crémations. Cela doit toutefois rester du domaine de la conjecture et de l'approximation vu les incertitudes concernant l'âge et le sexe des défunts,

12 Soit trois fois $391,6 \mathrm{~g}$ et $80,2 \mathrm{~g}$. 


\begin{tabular}{|c|c|c|c|c|}
\hline & INDIVIDU & POIDS THÉORIQUE EN G. & $\begin{array}{l}\text { PRÉLĖVEMENT } \\
\text { THÉORIQUE EN G. }\end{array}$ & TOTAL \\
\hline \multirow{6}{*}{ MINIMUM } & Adulte $n^{\circ} 1$ & 970 (selon Hermann 1976) & 391,6 & \\
\hline & Adulte $n^{\circ} 2$ & 970 (selon Hermann 1976) & 391,6 & \\
\hline & Adolescent $n^{\circ} 3$ & 970 (selon Hermann 1976) & 391,6 & \\
\hline & Enfant $2-6$ ans $n^{\circ} 4$ & 636 (pour 4 ans, selon Warren, Maples 1997) & 80 & \\
\hline & Fœtus & 71 (pour périnatal, selon Trotter, Hixon 1974) & non & \\
\hline & Total & 3617 & 1255 & 4872 \\
\hline \multirow{6}{*}{ MAXIMUM } & Adulte $n^{\circ} 1$ & 3001 (selon MacKınley 1993) & 391,6 & \\
\hline & Adulte $n^{\circ} 2$ & 3001 (selon MacKinley 1993) & 391,6 & \\
\hline & Adolescent $n^{\circ} 3$ & 3001 (selon MacKinley 1993) & 391,6 & \\
\hline & Enfant $2-6$ ans $n^{\circ} 4$ & 636 (pour 4 ans, selon Warren, Maples 1997) & 80 & \\
\hline & Fœtus & 95 (pour périnatal, selon Trotter, Hixon 1974) & non & \\
\hline & Total & 9734 & 1255 & 10989 \\
\hline
\end{tabular}

Fig. 70. Masse théorique d'os (en grammes) de la partie fouillée de l'aire de crémation B1 pour les cinq défunts identifiés, en fonction des estimations de Hermann 1976 et de MacKinley 1993, et du poids moyen d'os déposé dans les tombes d'Ambrussum selon l'âge au décès.

la quantité d'os prélevés par les survivants et ce que représente exactement la partie non fouillée de cette structure. En tous cas, avec une fourchette de cinq à sept individus, on a bien affaire, déjà, à un bûcher collectif.

\subsubsection{La répartition du matériel osseux}

Le prélèvement des restes osseux par carrés de vingt centimètres de côté, montre une répartition centrée. La densité est la plus forte dans sept carrés du centre, dépassant $100 \mathrm{~g}$ pour $400 \mathrm{~cm}^{2}$, le maximum étant de 161,2 g dans le carré AA11 dV. Elle décroit ensuite régulièrement vers la périphérie. La région où les densités dépassent $30 \mathrm{~g}$ pour $400 \mathrm{~cm}^{2}$, forme une aire ovale centrale, de 2,6 m sur l'axe est-ouest et 1,8 m sur l'axe nord-sud, soit une surface de $3,7 \mathrm{~m}^{2}$ (fig. 71). Cette partie centrale représente seulement environ le cinquième de la surface totale estimée de cette aire de crémation, mais elle concentre les trois quarts des restes osseux exhumés (5098 g soit $74 \%$ du total).

Aucune connexion anatomique, stricte ou lâche, n'est observable. Les fragments provenant des trois grandes parties du squelette bien identifiables, crâne, tronc, membres sont mêlés et se répartissent de la même manière, avec une densité maximum au centre du bûcher (fig. 72 à 74). Le brouillage des différentes régions anatomiques est total. Les restes qui peuvent être attribués sûrement à du jeune enfant et à du fotus sont largement éparpillés, mais gisent également dans la partie centrale (fig. 71).

\subsubsection{La composition du mobilier et sa répartition}

Plusieurs catégories fonctionnelles d'objets ont été retrouvées dans la couche de fonctionnement, restes ayant peut-être servi à l'aménagement du bûcher, objets personnels des morts et tessons de vases céramiques.

\section{A) Objets peut-être liés à l'aménagement du bûcher}

Deux clavettes et trois ou quatre clous en fer peuvent avoir servi à l'aménagement du bûcher, soit à son édification, soit à la fixation de panneaux ou d'objets le décorant. Cela reste néanmoins du domaine de l'hypothèse.

\section{B) Les objets personnels}

Parmi les pièces personnelles figurent des objets servant à la parure du corps, des accessoires d'habillement, des éléments d'armes et des ustensiles divers.

La parure est représentée par deux séries d'objets, qui tous portent des traces plus ou moins importantes du passage au feu :

- 41 perles pouvant appartenir à un seul collier, toutes en pâte de verre sauf une en os, se répartissant en trois modèles : 33 petites (dont la perle en os), de 4 à $6 \mathrm{~mm}$ de diamètre ; 4 moyennes, d'environ $10 \mathrm{~mm}$ de diamètre ; 3 grosses, d'environ $2,4 \mathrm{~mm}$ de diamètre, décorées de protubérances à ocelles ou de spirales ;

- des fragments d'un ou deux torques en bronze.

Les accessoires d'habillement, là encore en contact avec le feu, comprennent :

- au moins deux fibules, l'une en bronze et l'autre en fer, décorées d'éléments de corail ;

- un maillon double, en bronze, d'une ceinture dite «féminine »;

- au moins quatre anneaux en bronze et un en fer appartenant à une chaîne-ceinture. 


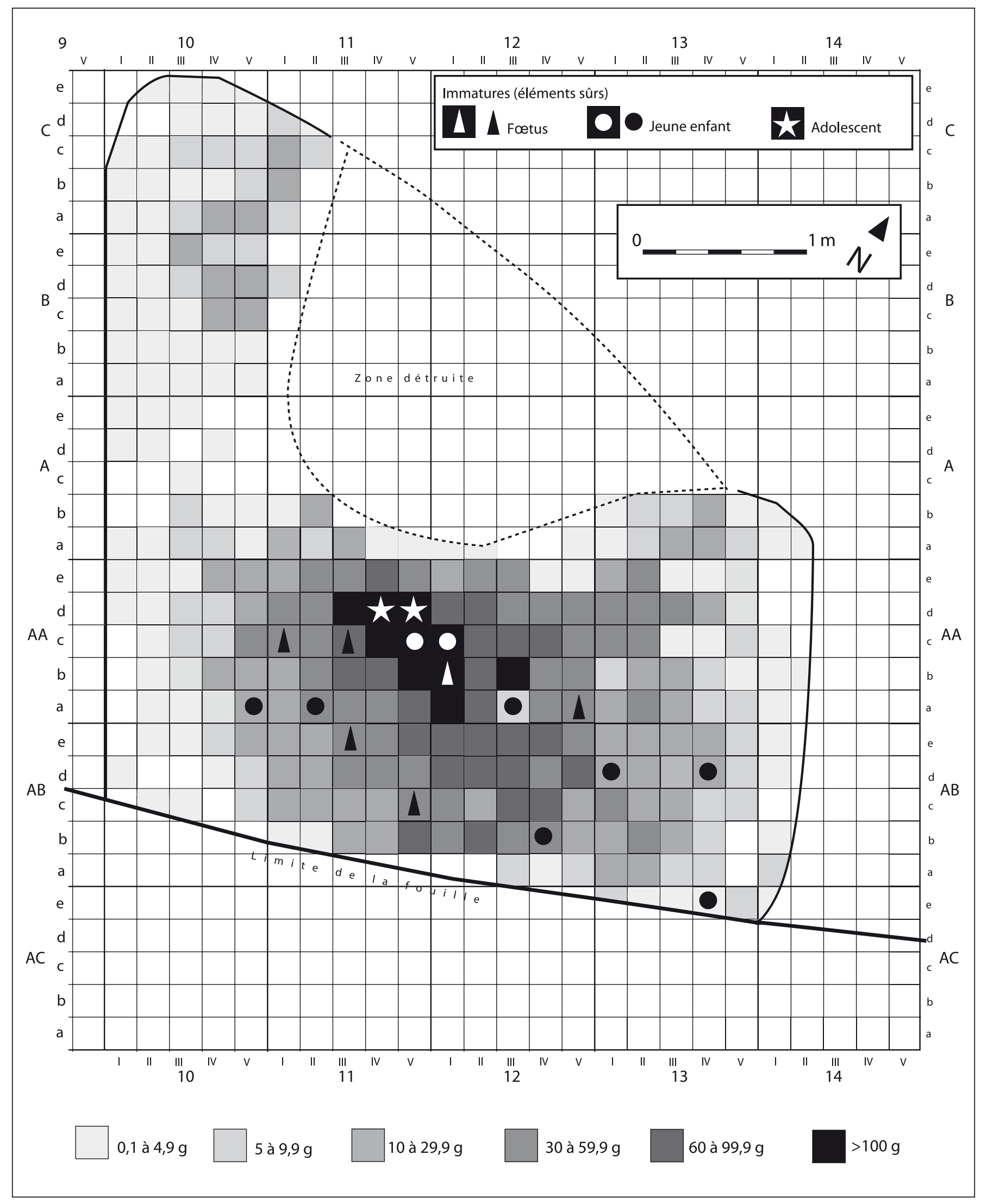

Fig. 71. Aire de crémation B1. Niveau de fonctionnement, couches rouge et noire. Répartition spatiale des os humains en fonction du poids, par carré de $20 \mathrm{~cm}$ de côté, et des restes de défunts immatures avérés. 


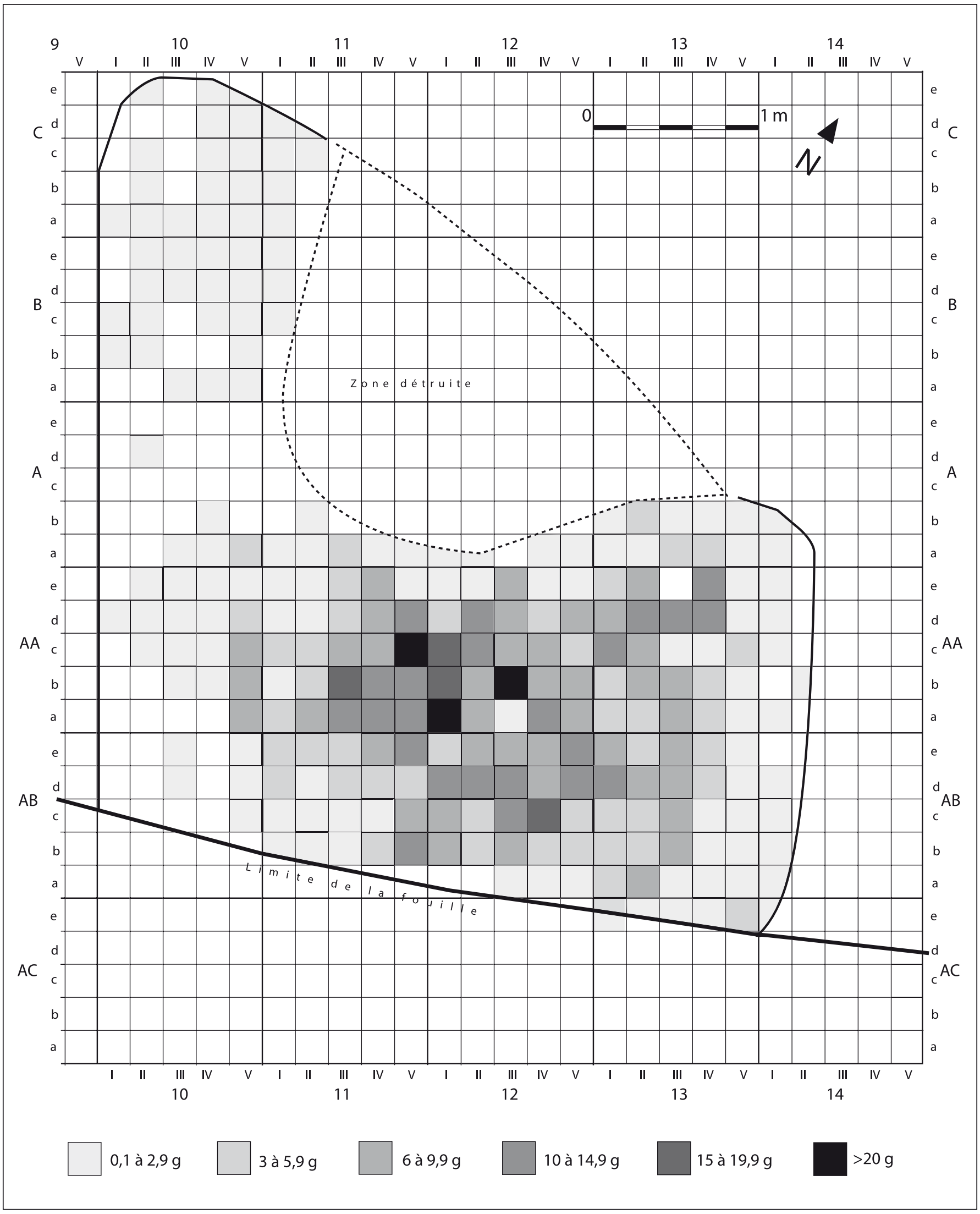

Fig. 72. Aire de crémation B1. Niveau de fonctionnement, couches rouge et noire. Répartition spatiale des os humains de la tête en fonction du poids, par carré de $20 \mathrm{~cm}$ de côté. 


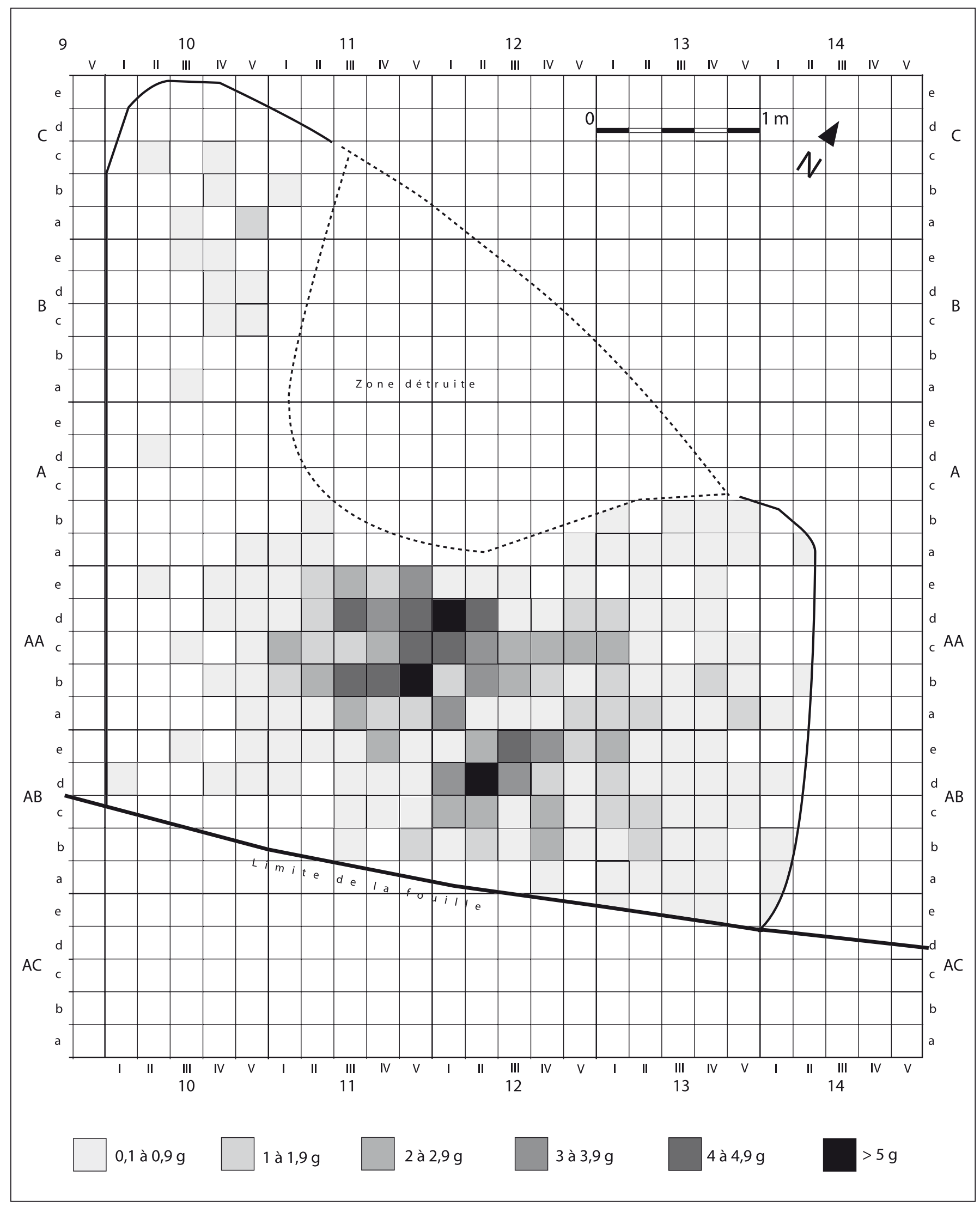

Fig. 73. Aire de crémation B1. Niveau de fonctionnement, couches rouge et noire. Répartition spatiale des os humains du tronc en fonction du poids, par carré de $20 \mathrm{~cm}$ de côté. 


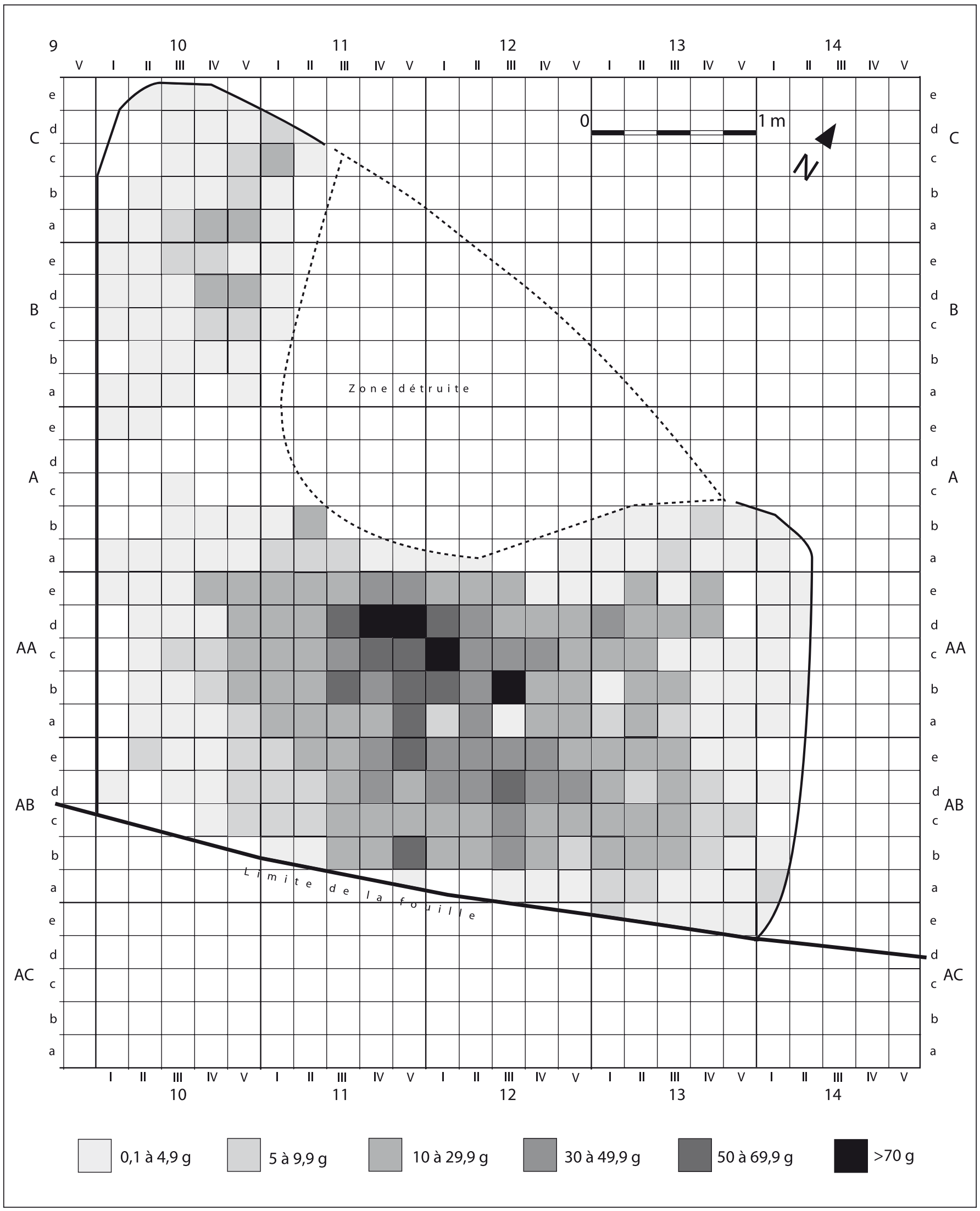

Fig. 74. Aire de crémation B1. Niveau de fonctionnement, couches rouge et noire. Répartition spatiale des os humains des membres en fonction du poids, par carré de $20 \mathrm{~cm}$ de côté. 
Toujours au rang des objets personnels, figurent :

- d'une part, une fusaïole, instrument chargé d'une connotation féminine ;

- et d'autre part, divers éléments d'armes, porteurs de la symbolique masculine : un morceau de lame d'épée dans son fourreau, trois rivets de garniture de poignée d'épée, un clou de poignée d'épée ou de fourreau, plusieurs fragments de plaque d'un fourreau, un passant de ceinture de suspension de fourreau, tous ces éléments, en fer, pouvant se rapporter à une seule arme ; un fragment d'orle en fer de bouclier.

Ces objets personnels paraissent se rapporter à un nombre restreint d'individus, deux adultes tout au plus, sans doute un homme et une femme, ainsi qu'un jeune enfant puisqu'on retrouve de semblables perles en verre dans la tombe 22 qui est celle d'un défunt âgé de deux à quatre ans. Et cela est en adéquation avec les vestiges osseux déterminés.

Ces objets montrent une dispersion plus ou moins grande sur le bûcher, semblable à celle des restes osseux. Les perles sont disséminées sur toute l'aire, avec, comme pour les restes humains une concentration dans la partie centrale (fig. 75). Les autres pièces de parure et les éléments de fibules sont, pour leur part dispersés, dans toute cette zone centrale (fig. 76). Et c'est la même répartition spatiale que montrent les morceaux d'arme et de fourniment, éléments d'épée, de fourreau, de ceinture de suspension et de bouclier (fig. 77). Manifestement cette répartition et les traces d'ustion et de fusion montrent que ces objets ont accompagné les corps sur le bûcher.

En définitive, qu'il s'agisse des os, des objets personnels ou des clous, aucun regroupement, aucun amas particulier des uns ou des autres. On a plutôt affaire, à l'évidence, à un rassemblement de l'ensemble dans la partie centrale du bûcher.

\section{C) Les restes de vases céramiques}

La céramique est représentée par 706 tessons, le plus souvent de petite taille. Les recollages sont rares. Le nombre minimum de vases fondé sur les bords s'élève à 53, mais la quantité totale de récipients concernés est impossible à évaluer.

Différentes catégories fonctionnelles sont présentes, vases à liquide et vases à solide, selon deux grandes origines, la céramique non tournée locale, la plus abondante ( $80 \%$ du nombre minimum de bords), et des productions tournées importées, plus rares (20\%). Parmi les vases à aliment solide, tous en céramique non tournée, figurent au moins 17 pots ou urnes, 7 grandes coupes et jattes et 5 couvercles pouvant être utilisés pour les uns comme pour les autres. Les vases à liquide se répartissent en, au moins, 3 cruches à pâte claire massaliète, 16 bols et coupelles à boire (dont 7 en céramique non tournée et 9 en céramique à vernis noir de l'atelier de Rosas). Cette statistique, fondée sur les bords, est sans doute bien en-dessous de la réalité, nombre de récipients n'étant attestés que par des morceaux de panse qui ne permettent guère de préciser la forme d'ensemble. Cependant, elle permet de mettre en évidence une part à peu près égale de vases à liquide que de vases à aliment solide. Par ailleurs, quelques tessons de dolium indigène et d'amphore massaliète témoignent aussi de l'existence de récipients consacrés à la réserve ou au transport. Enfin, on soulignera l'absence, dans ce lot, de tout vestige de vase à parfum comme de lampe à huile.

Si certains tessons portent d'indubitables traces d'un feu secondaire, celles-ci restent cependant rares et la plupart des morceaux de vases en sont dépourvus. La répartition de ces restes de poteries est bien différente de celle des os humains et des objets personnels des défunts. La céramique se rencontre en effet principalement en périphérie du bûcher, et la zone centrale, la plus riche en os et en pièces accompagnant les corps, apparaît beaucoup moins concernée par ce matériel (fig. 78). Presque tous ces vases n'ont pas été brisés sur le bûcher lui-même, comme le montre la rareté des connexions et des recollages. Ce sont plutôt des tessons qui ont été apportés en ce lieu, le feu une fois éteint.

La répartition des os d'animaux est également très différente de celle des os humains. Les restes de faune, quelle que soit l'espèce prise en compte, sont au contraire dispersés sur l'ensemble du bûcher (voir infra les contributions d'A. Gardeisen et de G. Piquès).

Étant donnée la variété de fonction théorique de ces récipients, conteneurs, vases à solides, vases à verser et vases à boire, la présence d'os d'animaux entrant dans l'alimentation de la population locale, il semblerait que l'on ait là les restes de repas pris par les participants aux cérémonies. On aurait ensuite volontairement brisé les vases et rejeté ensuite quelques tessons sur le bûcher, de préférence sur ses bords. De la même manière on aurait rejeté quelques os des animaux consommés à cette occasion. Peut-être convenait-il d'abandonner ainsi un témoignage de ce repas cérémoniel.

Une coupe à vernis noir provenant d'un atelier de Rosas (fig. 78, vase $n^{\circ} 1$ ) signale pour sa part un geste différent. Ses nombreux tessons, qui représentent plus de $80 \%$ du récipient ont été retrouvés, tous brûlés, dans la partie ouest du bûcher. Peut-être ce vase marque-t-il une autre intention, peut-être une libation sur le lieu de l'incinération même, lorsque le feu est encore en activité. 


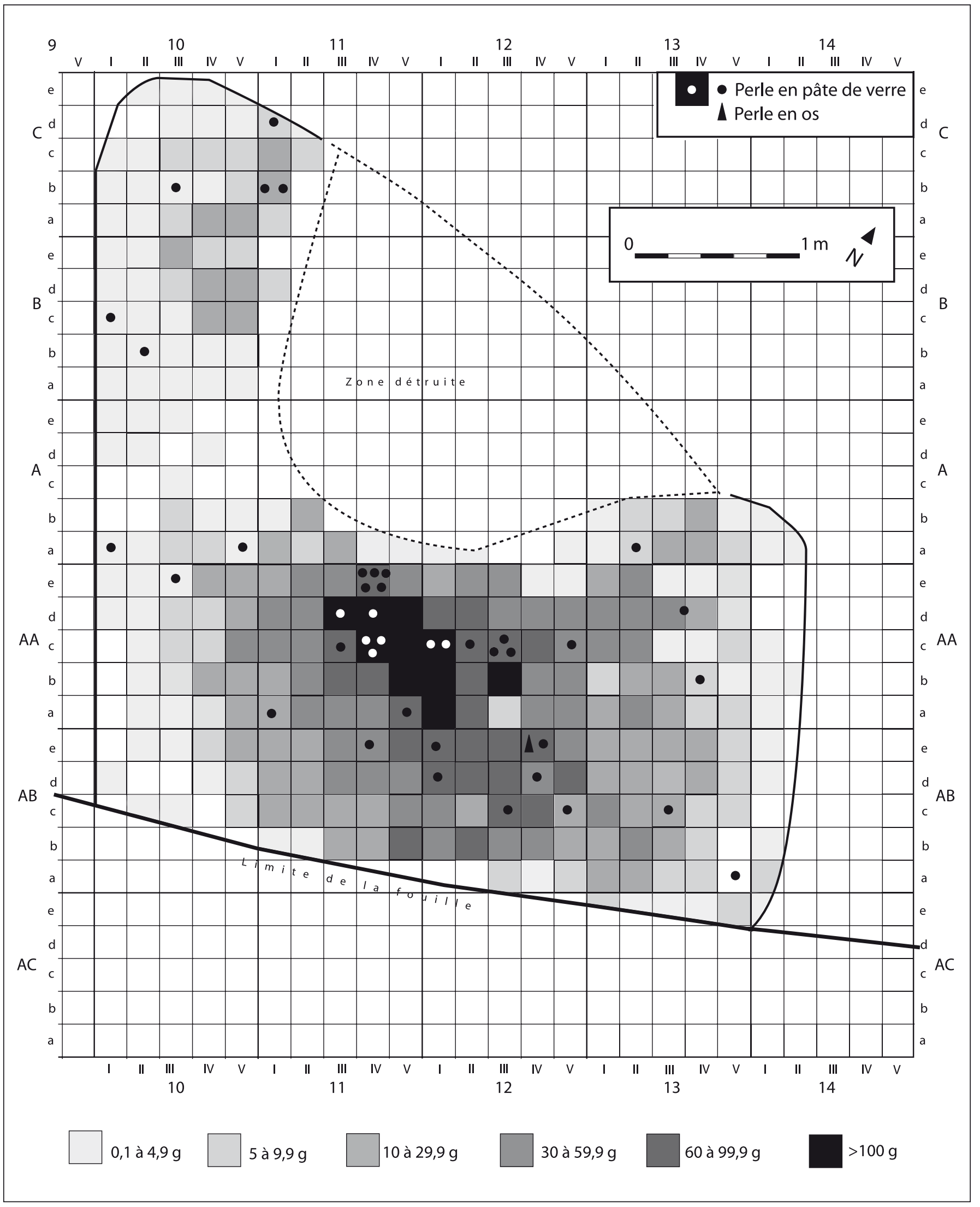

Fig. 75. Aire de crémation B1. Niveau de fonctionnement, couches rouge et noire. Répartition spatiale des perles (chaque symbole représente un exemplaire) et des os humains en fonction du poids, par carré de $20 \mathrm{~cm}$ de côté 


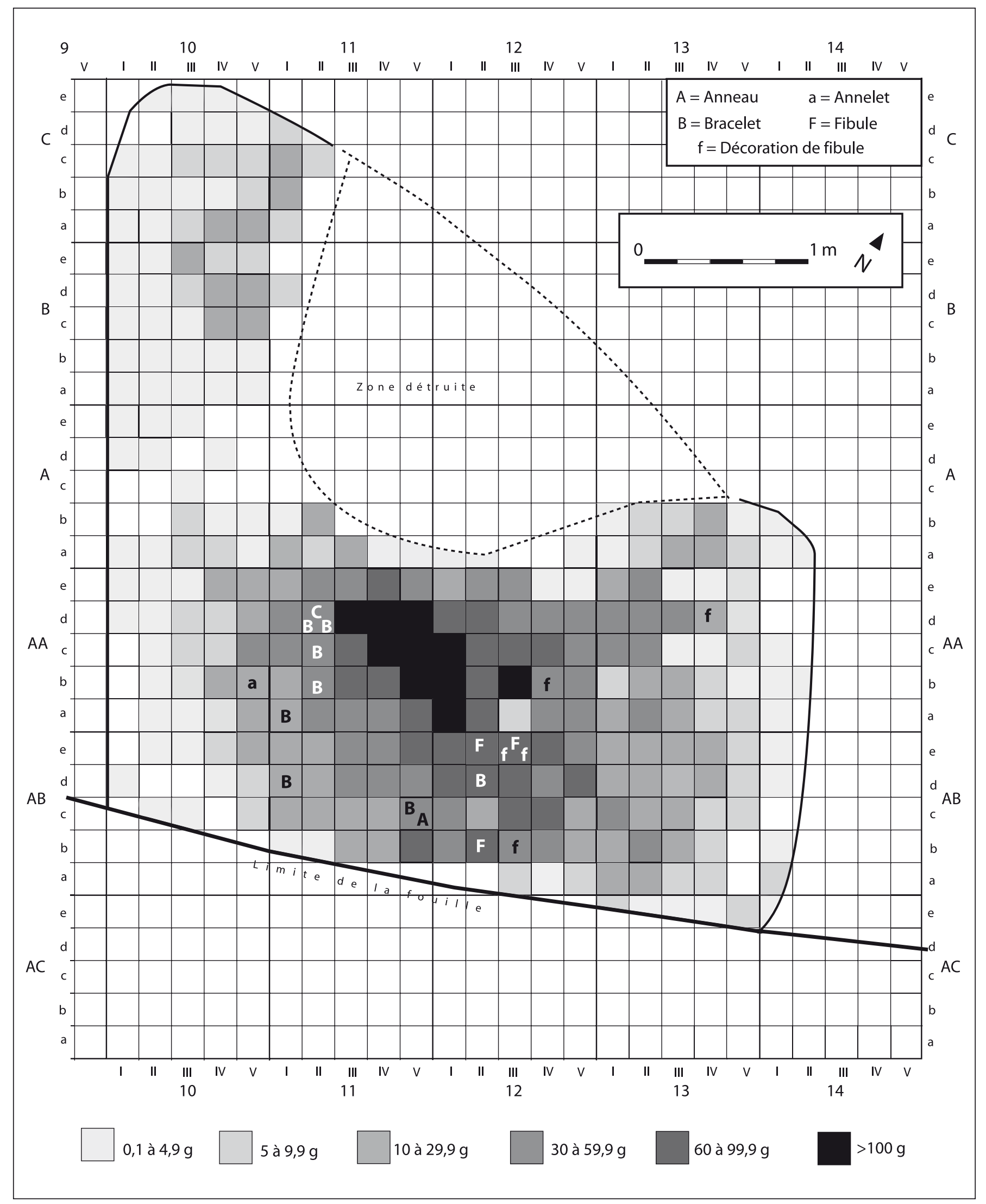

Fig. 76. Aire de crémation B1. Niveau de fonctionnement, couches rouge et noire. Répartition spatiale des anneaux, bracelets et fibules (chaque symbole représente un exemplaire) et des os humains en fonction du poids, par carré de $20 \mathrm{~cm}$ de côté. 


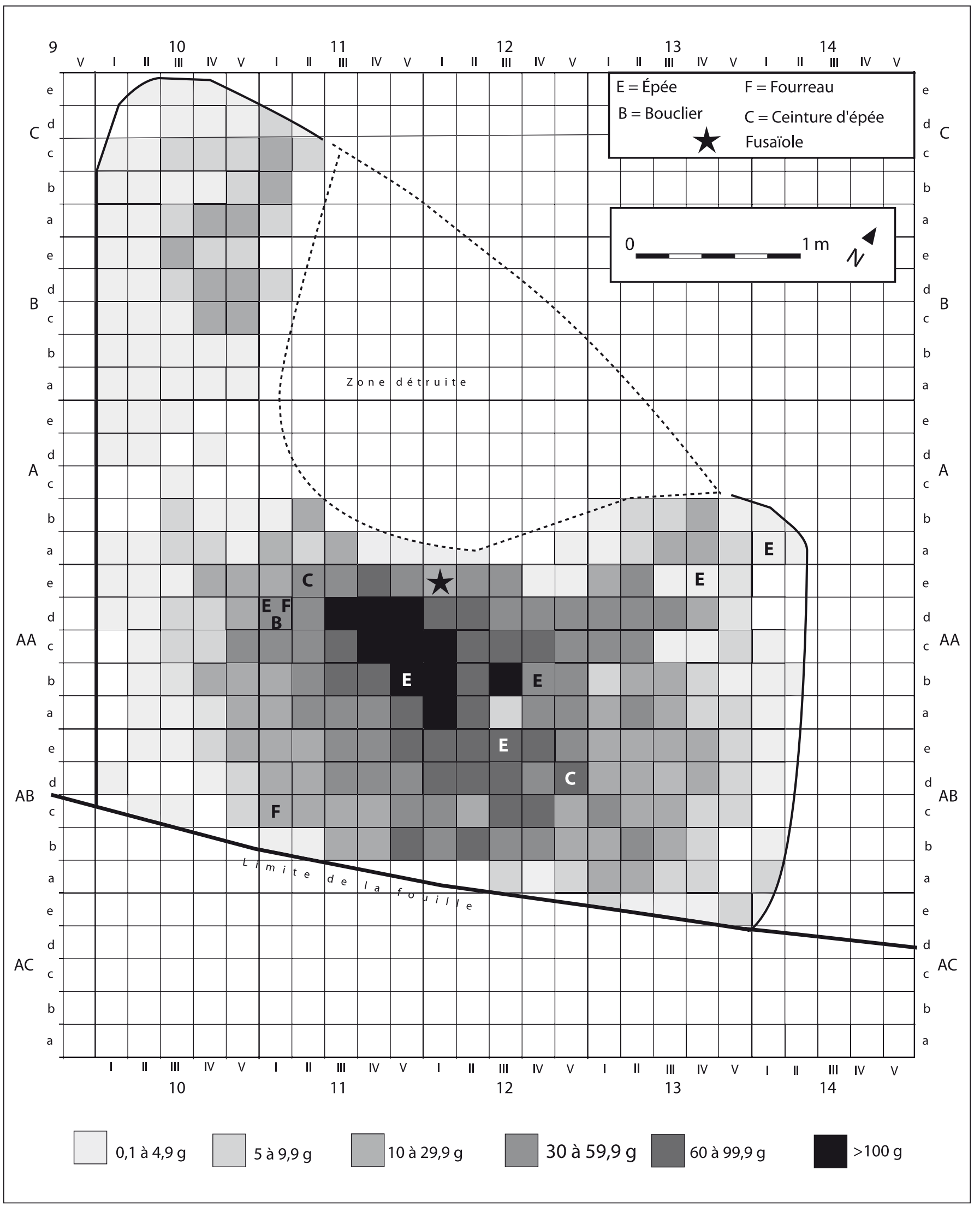

Fig. 77. Aire de crémation B1. Niveau de fonctionnement, couches rouge et noire. Répartition spatiale des éléments d'armes et de fourniment et des fusaïoles (chaque symbole représente un exemplaire) et des os humains en fonction du poids, par carré de $20 \mathrm{~cm}$ de côté. 


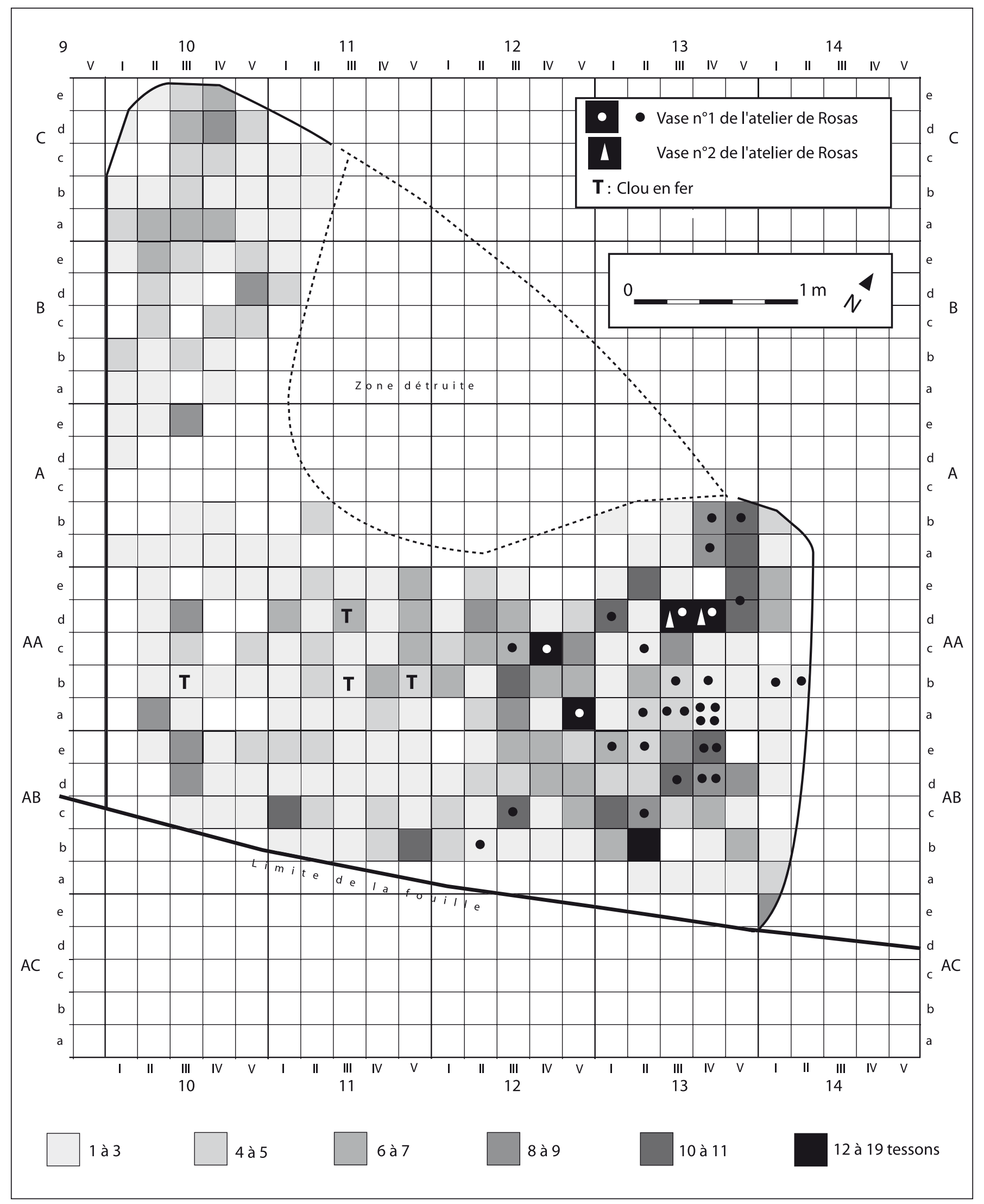

Fig. 78. Aire de crémation B1. Niveau de fonctionnement, couches rouge et noire. Répartition spatiale des tessons de vases en céramique (différences de densité par carré de $20 \mathrm{~cm}$ de côté), et spécialement de deux coupes à vernis noir et des clous en fer (chaque symbole représente un exemplaire). 


\section{Conclusion : une aire pour plusieurs crémations séparées, consécutives ou non}

En définitive, ce bûcher a été installé sur une base aménagée avec des résidus provenant de l'habitat des vivants, et cela sans doute dans un but symbolique. Il a fonctionné pour brûler cinq à sept défunts, vêtus et parés, accompagnés de leurs objets personnels adaptés à leur âge et/ou à leur appartenance sexuelle : au moins deux adultes, un homme, une femme enceinte d'environ sept mois, un adolescent et un jeune enfant entre deux et six ans. La couche de crémation subit, de la part des survivants, des prélèvements d'os humains et d'objets pour être déposés dans les tombes. Elle est aussi affectée de ratissages qui brouillent les dispositions de la ou des crémations et accumulent vers le centre de la structure la majeure partie des restes osseux humains et des objets personnels ayant accompagnés les défunts, de sorte qu'on ignore tout de la disposition et de l'orientation des corps. En fin de crémation, des tessons de vases et des os d'animaux, provenant sans doute de repas cérémoniels pris par les participants aux funérailles sont abandonnés sur cette aire de crémation.
La question de savoir si ces incinérations ont été simultanées ou successives se pose. Le contexte de la nécropole fait cependant pencher pour la seconde éventualité. En effet, les dépôts d'os et de mobilier retrouvés dans les tombes fouillées aux alentours ne présentent pour leur part aucunement le reflet d'un tel brouillage : il s'agit de tombes toujours individuelles, au mobilier cohérent, ne mélangeant pas les symboliques masculines et féminines. La seule tombe double associe un adulte et un très jeune enfant d'environ un an, occurrence souvent rencontrée dans la Protohistoire régionale (Dedet 2008, p. 157-240).

Certes, on ne peut affirmer que ces tombes soient précisément celles des morts brûlés sur ce bûcher, mais, à l'évidence, elles reflètent une pratique qui n'est pas celle de l'incinération collective de cinq à sept défunts sur un même bûcher. Il semblerait plutôt que cette aire ait servi à plusieurs crémations bien distinctes, même si le rythme de la succession de ces opérations nous échappe totalement. D'ailleurs, dans la partie rubéfiée à la base de cette aire, ne sont sûrement attestés qu'un sujet adulte, un fœtus et un jeune enfant. Une première crémation a donc pu ne concerner que ce dernier et une femme enceinte. 




\section{Chapitre 4}

\section{Les structures funéraires découvertes dans les sondages 1979-1984 à la lumière des fouilles récentes}

$\mathrm{D}$ es structures funéraires avaient déjà été découvertes dans des sondages profonds menés entre 1980 et 1984 par J.-L. Fiches, sous l'auberge de l'îlot 1 gallo-romaine et ses abords (voir supra, Introduction, § 3.). Sur un total de neuf repérées, huit avaient alors été fouillées, du moins partiellement dans le cadre très contraignant de ces sondages, mais non identifiées sur le terrain comme des vestiges funéraires, et elles ont fait l'objet d'une publication dans la monographie consacrée en 1989 aux recherches sur le quartier bas d'Ambrussum (Fiches dir. 1989, p. 29-39). Dans cet ouvrage, seuls les os humains sont étudiés structure par structure, tandis que le reste de la documentation mise au jour est examiné en bloc par catégories, et non par lieu ; de surcroît tous les vestiges céramiques ne sont pas alors pris en compte.

Bien évidemment, les travaux en extension menés entre 1999 et 2003 autorisent une meilleure vision des tombes et permettent de mieux interpréter ce qui a été mis au jour au début des années 1980 de manière parfois lacunaire. Un réexamen de ces résultats à la lumière des recherches récentes est donc nécessaire. Reprendre ces données, c'est aussi rassembler, tombe par tombe, toute la documentation disponible et la compléter, et c'est également préciser sa place chronologique. En effet ces vestiges étaient datés d'une période allant de « la fin du $\mathrm{III}^{\mathrm{e}}$ au milieu du $\mathrm{II}^{\mathrm{e}}$ s. av. J.-C. », essentiellement au vu de la céramique à vernis noir identifiée alors comme de la campanienne A (Fiches dir. 1989, p. 38).

Comme nous le verrons, l'essentiel du vernis noir que nous avons pu examiner relève en fait des productions des ateliers de Rosas et assimilés, tout comme celui des structures mises au jour dans les fouilles récentes, ce qui permet de remonter au plein $\mathrm{III}^{\mathrm{e}} \mathrm{s}$. av. J.-C. la datation avancée en 1989 pour ces premières structures découvertes. Il est vrai qu'en ce milieu des années 1980, la reconnaissance par E. Sanmartí d'une fabrication de tels vases à Rosas et dans sa région est alors toute récente et que la diffusion de ces productions n'est pas encore perçue. En revanche, pour ce qui concerne les restes osseux humains il nous a suffi de reprendre les données publiées tombe à tombe par H. Duday (dans Fiches dir., 1989, p. 30-33) ${ }^{13}$.

Le comptage des fragments d'os n'a pas été retenu ici. En effet, malgré le caractère particulièrement méticuleux de ces sondages, l'absence de tamisage lors de la fouille ne permet pas la comparaison des poids moyens des pièces récupérées entre ces deux phases des recherches ${ }^{14}$.

\section{La structure ST1 (= «Zone $01 »)$ : une portion de bûcher funéraire?}

La structure ST1 n'a pas été complètement dégagée. Elle correspond à des vestiges reconnus dans un sondage stratigraphique de $6 \mathrm{~m}$ sur $3 \mathrm{~m}$, réalisé en 1980 dans la voie Domitienne (Zone 01), entre l'auberge de l'îlot 1 et le bâtiment 40-42 (Fiches, Roux 1981, p. 19-26) (fig. 6). Ce sondage est poursuivi sur $6 \mathrm{~m}^{2}$, au-dessous du niveau de circulation le plus ancien correspondant à la création du quartier bas. Sous le radier (1057) qui constitue, sur $10 \mathrm{~cm}$ d'épaisseur, l'aménagement de la première chaussée, prennent place deux couches superposées, contenant notamment des restes humains incinérés (fig. 79, A et B) :

- couche 1058 (de - 261 à - 267): «sur $6 \mathrm{~cm}$ d'épaisseur, argile grasse, très cendreuse, notamment sur un quart de $\mathrm{m}^{2}$ dans le carré $\mathrm{J} 4$ (charbons de bois abondants) »; sa surface montre un léger pendage vers l'est ; la base est pratiquement horizontale, reposant à l'ouest (carrés J4 et J5) sur l'argile naturelle stérile, mais couvrant ailleurs la couche 1059 ;

- couche 1059 (de - 267 à - 275) : «sur 8 cm d'épaisseur, radier de cailloux à arêtes vives, reconnu sur $4 \mathrm{~m}^{2}$, dans les carrés K-L, dont on ne connaît pas l'extension

13 Dans cette publication, ces structures sont identifiées selon le numéro de la zone où elles ont été découvertes, « zones $01,10,11$, 19,31 et 36 », et « fosses A, B et C » pour trois d'entre elles. Nous leur avons donc attribué une numérotation continue, tout en signalant l'appellation primitive entre parenthèse dans les sous-titres.

14 Le poids moyen des fragments osseux recueillis dans ces sondages est de 0,52 g sur l'ensemble des tombes (valeur citée par Duday dans Fiches dir. 1989, p. 30). 
vers l'est, le nord et le sud » (Fiches, Roux 1981, p. 26, complété par des renseignements de J.-L. Fiches). La cote NGF du sol à la base du niveau funéraire est de 12,06 m.

\section{Os humains}

Le lot d'os humains incinérés recueilli compte 68 morceaux pour un poids de 71,2 g : 16 fragments $(24,5 \mathrm{~g})$ proviennent de la couche 1058 et 52 fragments $(46,7 \mathrm{~g})$ de la couche 1059. Deux éléments issus de ces deux couches ont pu être recollés. Ces restes appartiennent à, au moins, un sujet adulte (extrémité médiale de la clavicule soudée au corps) (analyse de H. Duday dans Fiches dir. 1989, p. 30-31) (fig. 79, C).

\section{Mobilier}

Le mobilier, en particulier céramique, montre également que des tessons de plusieurs vases figurent à la fois dans la couche 1058 et dans la couche 1059 .

\section{Couches 1058 et 1059 :}

- 3 tessons d'un bol à vernis noir de l'atelier de Rosas, de forme Lamb. 27 (= Puig 11.c), diam. ouv. : $150 \mathrm{~mm}$; diam. base : $50 \mathrm{~mm}$; au centre du fond, une estampille circulaire de $16 \mathrm{~mm}$ de diamètre, dont seule une moitié est conservée, avec rosette de six ou sept pétales (fig. 79, $\left.\mathrm{D}, \mathrm{n}^{\circ} 1\right)$;

-53 tessons, très souvent de très petite taille, d'une urne non tournée de forme CNT-LOR U5d, variante d ; col tronconique rentrant, bord déversé à lèvre arrondie ; panse ovoïde à peignage entrecroisé, épaule décorée d'impressions au peigne disposées en groupes d'inclinaison opposée, sur fond de peignage horizontal ; diam. ouv. : $159 \mathrm{~mm}$; diam. max. : $186 \mathrm{~mm}$ (fig. 79, D, $\mathrm{n}^{\circ} 3$ ).

-2 tessons d'un fond plat d'urne non tournée ; diam. : $95 \mathrm{~mm}$ (fig. 79, D, n 7).

\section{Couche 1058 :}

- 1 tesson d'urne non tournée : bord évasé à lèvre arrondie avec méplat vers l'intérieur; diam. ouv.: $120 \mathrm{~mm}$ (fig. 79, $\mathrm{D}, \mathrm{n}^{\circ}$ 5);

-3 tessons d'une coupelle non tournée de forme CNT-LOR C5e1 : panse arrondie-convexe, embouchure rétrécie, bord convergent à lèvre aplatie et pied annulaire bas ; facture grossière, lissage ébauché sur les surfaces, un peu moins sommaire à l'extérieur qu'à l'intérieur ; diam. ouv. : $65 \mathrm{~mm}$; diam. max. : 74,5 mm; haut.: 37 mm (fig. 79, D, n ${ }^{\circ}$ ).

Couche 1059:

- 1 grand rivet de fixation d'ailettes d'umbo de bouclier, en fer; tête discoïde plate, non décorée (diam. :
$25 \mathrm{~mm})$; tige repliée à angle droit, déterminant une épaisseur de $9 \mathrm{~mm}$ pour la planche du bouclier (fig. 79, $\mathrm{D}, \mathrm{n}^{\circ}$ 9) ;

- 1 tesson de bord de coupe à pâte claire «massaliète », de forme CL-MAS 236 ; traces de vernis ; diam. : $140 \mathrm{~mm}$ (fig. 79, $\mathrm{D}, \mathrm{n}^{\circ} 2$ ) ;

- 1 tesson de fond d'une autre coupe à pâte claire « massaliète », de forme probable CL-MAS 236 ; vernis orangé (non dessiné) ;

- 3 tessons de la partie supérieure d'une urne non tournée de forme CNT-LOR U5a2, de facture grossière : col concave, bord non replié à lèvre aplatie, panse en courbe et contre-courbe sans épaulement, haut de la panse décoré d'impressions au peigne disposées en une ligne brisée sur fond de peignage horizontal, même lissage ébauché sur toute la surface, col et panse ; diam. ouv. : $160 \mathrm{~mm}$; diam. max. : 160,5 mm (fig. 79, $\mathrm{D}, \mathrm{n}^{\circ} 4$ ) ;

- 1 tesson de bord d'une autre urne non tournée de facture grossière ; bord évasé à lèvre arrondie (fig. 79, $\left.\mathrm{D}, \mathrm{n}^{\circ} 6\right)$.

Couches 1058 ou 1059, non distinguées :

- 102 tessons, le plus souvent de petite taille, de plusieurs urnes non tournées, à panse ovoïde peignée et col lissé (non dessinés).

\section{Conclusion}

L'extension de ces deux couches qui excède $4 \mathrm{~m}^{2}$ et leur composition, avec cendres, charbons de bois et pierres, l'absence de fosse du moins dans la partie reconnue, la nature du matériel, tant osseux que mobilier et l'abondance des tessons, autant de caractères qui plaident en faveur d'une portion de bûcher funéraire du même type que celui des fouilles récentes, plutôt que des restes d'une sépulture.

\section{La tombe $\mathrm{T} 2$ (= « Zone $10 »)$}

En 1980, un sondage de $4 \mathrm{~m}^{2}$ mené jusqu'au substrat naturel dans l'angle nord-ouest de la pièce 10 de l'auberge, a permis de fouiller, sur environ $3 \mathrm{~m}^{2}$ de superficie, les vestiges d'une tombe (Fiches dir. 1989, p. 30) (fig. 6). Celle-ci comprend un loculus et une structure de recouvrement (US 10011-10012), partiellement fouillés dans le cadre du sondage ; le matériel provenant de l'un et de l'autre n'a pas été distingué (fig. 80, A).

Le loculus, engagé sous un mur plus récent à l'ouest, est de plan arrondi ou ovalaire. Son seul axe observable, nord-sud, mesure $56 \mathrm{~cm}$ et sa profondeur est de $25 \mathrm{~cm}$. Le sol (US 10012) à partir duquel la fosse est creusée est marqué, à proximité immédiate vers le sud, 


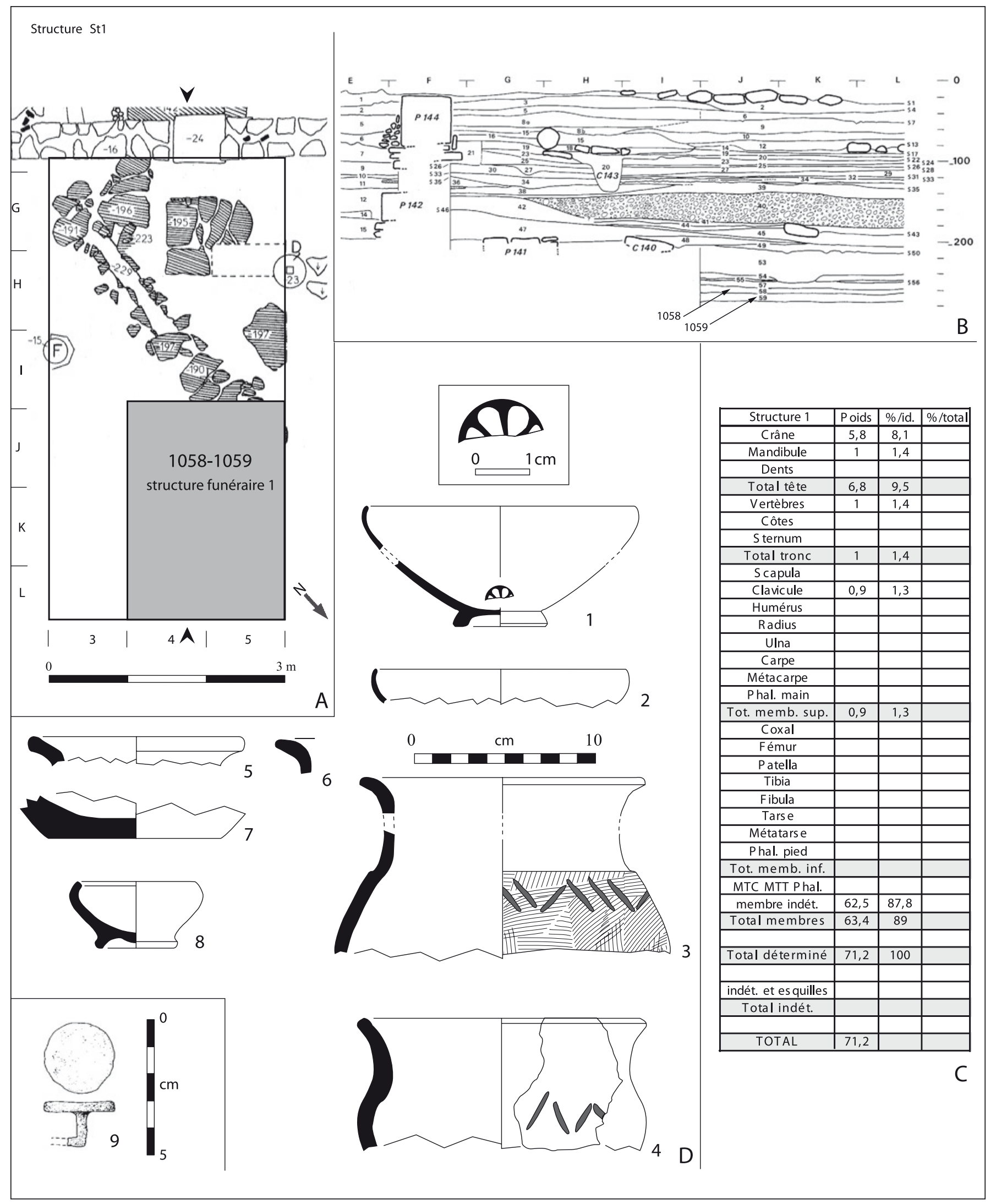

Fig. 79. Structure ST1. A : plan (d'après Fiches, Roux 1981, p. 7). B : coupe (d'après Fiches dir. 1989, p. 47). C : tableau de détermination des os humains (poids en grammes). $\mathrm{D}:$ mobilier ( $1:$ céramique à vernis noir $; 2:$ céramique à pâte claire massaliète ; $3-8:$ céramique non tournée ; $9:$ fer) ( $n^{\circ} 9$ d'après Feugère, Tendille in Fiches dir. 1989, p. 143). 
par une plaque d'argile cuite bordée d'une concentration de charbons et de cendres. Il est recouvert par une couche d'argile brune, de $4 \mathrm{~cm}$ d'épaisseur, contenant des cailloux, des nodules d'argile rouges, gris et marron, et des charbons de bois (US 10011). Cette couche s'épaissit à côté du loculus, vers l'est, jusqu'à $12 \mathrm{~cm}$. La fosse est située en bordure ouest du sondage et la fin du recouvrement n'a, semble-t-il, pas été atteinte à la limite opposée du sondage, deux mètres à l'est. La cote NGF du sol à la base du niveau funéraire est de 11,80 m.

\section{Le défunt}

Cette tombe abritait au moins un sujet immature, très probablement adolescent, de sexe indéterminé. Trois pièces du mobilier, une fusaïole et une paire de pendants d'oreille, présentent une connotation féminine tandis qu'un talon de lance signale une symbolique masculine : la dominante féminine semble indiquer une adolescente, le talon de lance pouvant avoir été ramassé involontairement sur le bûcher.

Le défunt est représenté par $68 \mathrm{~g}$ d'os incinérés, mais ce n'est là qu'une partie des os déposés puisque cette tombe n'a été qu'incomplètement dégagée (fig. 80, B). Cinq morceaux de diaphyse tibiale suggèrent une taille adulte, mais un sixième fragment appartenant à la partie proximale de la diaphyse du tibia a l'aspect du contact entre l'os et le cartilage de croissance. Ce fait indique donc qu'il s'agit d'un adolescent. Le sexe anthropologique ne peut pas être précisé (analyse de H. Duday dans Fiches dir; 1989, p. 30-31).

La couleur blanc crayeux révèle une température de crémation supérieure à $650^{\circ}$ selon le barème de E. Bonnucci et G. Grazziani (1975) et les morceaux de diaphyses sont très souvent fissurés en ondes concentriques, indice d'une incinération d'os frais. Les os ont été placés directement, hors de tout contenant, à la fois dans le loculus et dans la structure de recouvrement.

Dans le lot osseux recueilli, il apparaît que le crâne est sous-représenté, 11,6\% du poids d'os identifiés au lieu des 20,4\% attendus. Le tronc, avec $0,1 \%$, au lieu des $17 \%$ du poids théorique, est presque complètement absent. Et, évidemment, avec 88,3\%, les membres sont sur-représentés (poids théorique de 62,6\%) (fig. 80, C).

\section{Mobilier}

Objet personnel, armement :

- Talon probable de lance, à douille, court, en fer, dépourvu de trous de fixation; long. : $43 \mathrm{~mm}$; diam. ouv. : 26 mm (fig. 80, D, $\mathrm{n}^{\circ}$ 6). Des objets aussi courts sont identifiés comme talon de lance à Gournay-surAronde (par exemple Rapin, Brunaux 1988, pl. LIII, $\left.\mathrm{n}^{\circ} 1995\right)^{15}$.

Objets personnels, parure et habillement :

- Deux pendants d'oreille en bronze, semblables, en forme de croissant renflé en sa partie centrale, s'amincissant vers les deux extrémités pointues, qui sont rapprochées ; diam. : $13 \mathrm{~mm}$ (fig. 80, D, $\mathrm{n}^{\circ} 1$ et 2) ;

- Morceau de grand anneau en pâte de verre, de couleur vert d'eau transparent, lisse, sans décor ; diam. ext. : $50 \mathrm{~mm}$; diam. int. : $34 \mathrm{~mm}$; haut. : $11 \mathrm{~mm}$ (fig. 80, D, $\left.\mathrm{n}^{\circ} 3\right)$;

- Fibule en bronze dont il manque le pied, le porteardillon et l'ardillon; arc foliacé de section plate, sans trace d'une éventuelle fixation de l'extrémité du pied ; ressort bilatéral à huit spires sur un axe en fer; corde interne, enroulée autour de la tête de l'arc ; long. cons. : $55 \mathrm{~mm}$; larg. au ressort : $27 \mathrm{~mm}$. Elle a subi l'action du feu (fig. 80, D, n ${ }^{\circ} 4$ ). Les caractères morphologiques de la partie conservée semblent indiquer que l'on a peutêtre affaire à une fibule à pied discoïde (type 11 de C. Tendille 1978).

Objet personnel, ustensile :

- Fusaïole modelée en terre cuite; en forme de disque à bordure épaissie ; perforation décentrée ; diam. $31 \mathrm{~mm}$; ép. 10 à 15 mm (fig. 80, D, n 5).

Matériel céramique :

- 12 tessons d'une coupe en pâte claire massaliète de forme CL-MAS 433, incomplète ; diam. ouv. $110 \mathrm{~mm}$; haut. $48 \mathrm{~mm}$ (fig. 80, $\mathrm{D}, \mathrm{n}^{\circ} 7$ ) ;

-2 morceaux d'anse(s) d'une coupe à pâte claire massaliète (fig. 80, D, $\mathrm{n}^{\circ} 8$ et 9); appartiennent peutêtre au vase précédent ;

- Au moins 6 morceaux des parties supérieure et inférieure d'une urne non tournée de forme CNT-LOR U5d, variante d ; col tronconique rentrant, bord déversé à lèvre arrondie, panse ovoïde peignée, fond plat ; l'état de conservation ne permet pas de noter la présence d'un éventuel décor sur l'épaule ; diam ouv. : $135 \mathrm{~mm}$; diam. max. rest. : env. $165 \mathrm{~mm}$; haut. rest. : env. $190 \mathrm{~mm}$ (fig. 80, D, $\left.\mathrm{n}^{\circ} 10\right)$;

- 1 tesson de col rentrant, bord déversé d'urne non tournée, de forme probable CNT-LOR U5d ; diam. ouv. : $150 \mathrm{~mm}$ (fig. 80, D, n ${ }^{\circ} 11$ );

15 C'est également l'identification retenue par $M$. Feugère et C. Tendille dans Fiches dir. 1989, p. 36 et p. 143, fig. 97, n 18, où cet objet est, par erreur, attribué à la « Période I' (vers 100-50 av. n. è.) ». 


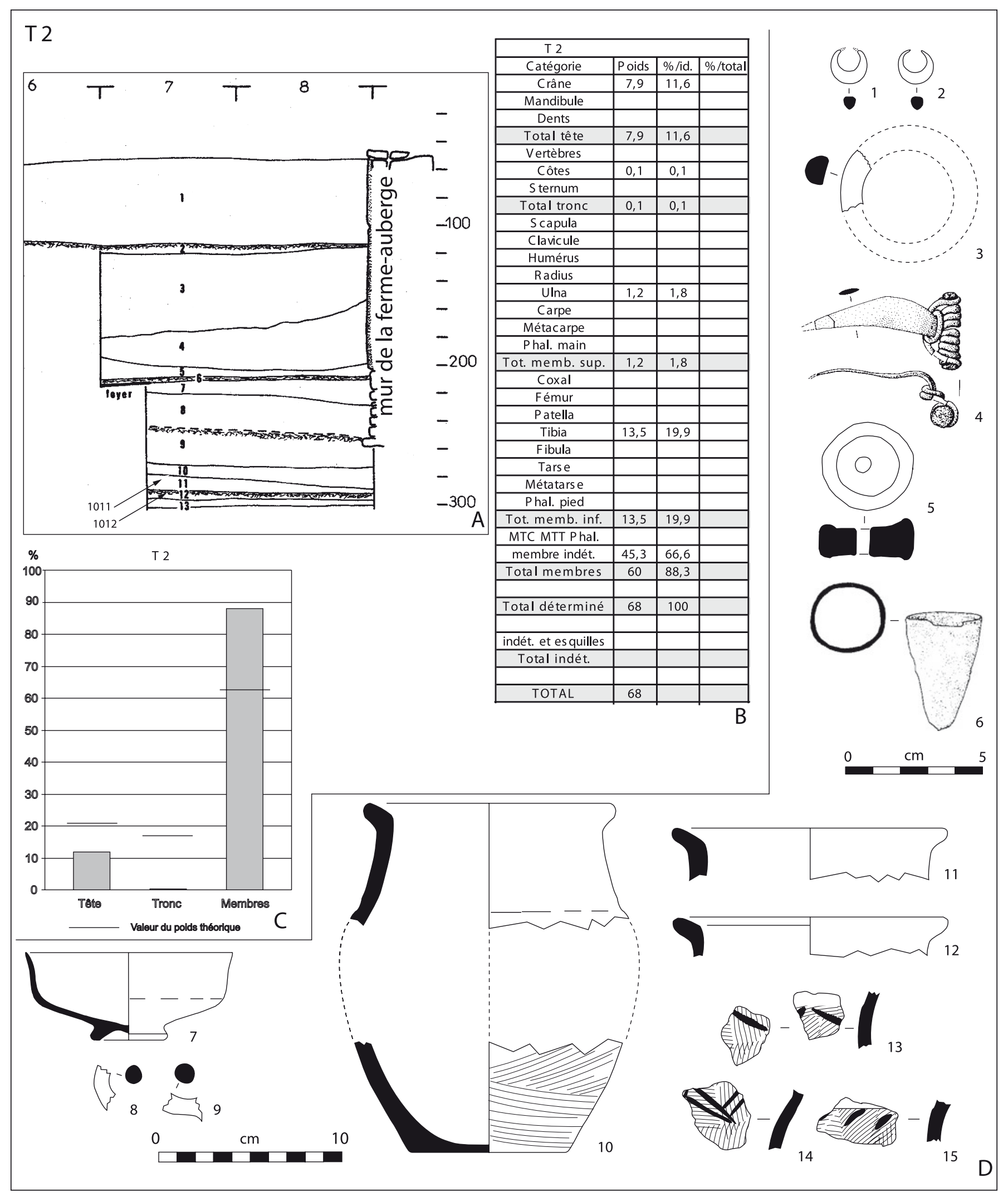

Fig. 80. Tombe T2. A : coupe (d'après Fiches dir; 1989, p. 30). B : tableau de détermination des os humains (poids en grammes). C : répartition du poids des os par grandes régions anatomiques (\% par rapport au total déterminé). D : mobilier (1, 2, et $4:$ bronze ; $3:$ verre ; $5:$ terre cuite modelée ; $6:$ fer $; 7-9:$ céramique à pâte claire massaliète ; 10-15: céramique non tournée) $\left(n^{\circ} 1,2,4\right.$ et 6 d'après Feugère, Tendille in Fiches dir. 1989, p. 36 et 143). 
- 3 tessons de bord déversé d'urne non tournée de forme probable CNT-LOR U5d ; diam. ouv. : $150 \mathrm{~mm}$ (fig. 80, D, $\mathrm{n}^{\circ} 12$ );

- 2 tessons d'épaule et de panse d'urne non tournée, peut-être la même que l'exemplaire précédent: décor, très soigné, d'impressions au peigne formant une ligne brisée ; peignage horizontal très fin sur la panse (fig. 80, $\left.\mathrm{D}, \mathrm{n}^{\circ} 13\right)$;

- 1 tesson d'épaule d'urne non tournée de forme probable CNT-LOR U5d : décor d'une double ligne brisée ; peignage horizontal sur la panse (fig. 80, $\mathrm{D}, \mathrm{n}^{\circ} 14$ ) ;

- 1 tesson d'épaule d'urne non tournée : décor peu soigné d'impressions obliques, peignage horizontal sur la panse (fig. 80, D, $\mathrm{n}^{\circ} 15$ );

- 284 tessons appartenant à plusieurs vases non tournés, urnes et coupes, représentés chacun par un petit nombre de morceaux (non dessinés).

\section{La structure funéraire ST3 (= «Zone 19 ») : une portion de dispositif de recouvrement de tombe?}

En 1981, un sondage profond, de 2,4 $\mathrm{m}$ de long sur 1,2 m de large, a été mené dans l'angle nord-ouest de la pièce 19 de la ferme-auberge, jusqu'au substrat naturel (fig. 6). Sous le niveau de fondation de cet édifice, un niveau de circulation antérieur (19013) et une couche stérile d'alluvions du Vidourle, (19014), il a permis de reconnaître, sur environ $3 \mathrm{~m}^{2}$, une couche cendreuse horizontale (19015), d'une épaisseur moyenne de $10 \mathrm{~cm}$. Celle-ci est riche en charbons de bois, surtout vers l'ouest, et elle renferme, dispersés, des os humains incinérés, 144 tessons de vases et 5 petits clous. Elle repose sur le sol naturel (19016) (fig. 81, A). La cote NGF du sol à la base du niveau funéraire est de 11,39 m. Les limites de cette couche 19015 débordent, semble-t-il de tous les côtés, le cadre de la fouille. Ces vestiges pourraient correspondre à une portion d'une structure de recouvrement d'une tombe dont le loculus se situerait à l'extérieur du sondage, à proximité immédiate.

\section{Le défunt}

Du défunt, sont attestés $63,4 \mathrm{~g}$ d'os incinérés, éparpillés au sein de la couche 19015 , hors de tout contenant. (fig. 81, B). Ils proviennent d'un sujet de taille adulte, robuste si l'on en croit un pilastre fémoral bien dégagé. Le sexe anthropologique ne peut pas être précisé (analyse de H. Duday dans Fiches dir. 1989, p. 31). Bien évidemment, ce n'est là qu'une partie des os déposés dans cette tombe.
La couleur blanc crayeux révèle une température de crémation supérieure à $650^{\circ}$ selon le barème de E. Bonnucci et G. Grazziani (1975), et les morceaux de diaphyses sont très souvent fissurés en ondes concentriques, indice d'une incinération d'os frais.

Dans ce lot, le poids des restes crâniens correspond à $20,3 \%$ du poids d'os identifiés, soit le poids théorique $(20,4 \%)$; le tronc est absent et les membres sont surreprésentés, $79,6 \%$ pour un poids théorique de $63,5 \%$ (fig. 81, C).

\section{Mobilier}

Matériel céramique

Portions de vases :

- Portion d'un petit bol à vernis noir de l'atelier de Rosas, de forme Lamb. 27 à bord parallèle (= Puig 10.b), 6 tessons non jointifs représentant moins de $10 \%$ du vase ; diam. ouv. : $120 \mathrm{~mm}$; diam. base : $35 \mathrm{~mm}$ (fig. (fig. 81, D, $\mathrm{n}^{\circ} 1$ );

- Portion (13 tessons) de la partie inférieure d'une grande urne non tournée ; panse ovoïde à peignage vertical, et horizontal à la base ; fond légèrement creux ; haut. cons. : $78 \mathrm{~mm}$; diam. fond : $95 \mathrm{~mm}$ (fig. 81, D, $\mathrm{n}^{\circ} 7$ ).

Tessons de vases isolés :

- 1 tesson d'urne non tournée de forme probable CNT-LOR U5d ; col tronconique rentrant, bord déversé ; diam. ouv. : $120 \mathrm{~mm}$ (fig. 81, $\mathrm{D}, \mathrm{n}^{\circ} 2$ ).

- 1 tesson de bord déversé d'urne non tournée ; diam. ouv. : $180 \mathrm{~mm}$ (fig. 81, $\mathrm{D}, \mathrm{n}^{\circ} 3$ ) ;

- 1 tesson de bord déversé d'urne non tournée (fig. 81, D, $\left.n^{\circ} 4\right)$;

- 1 tesson de bord déversé d'urne non tournée (fig. 81, D, $\mathrm{n}^{\circ}$ 5) ;

- 2 tessons de panse d'urne non tournée de forme probable CNT-LOR U5d: panse ovoïde à peignage horizontal et oblique ; épaule décorée d'impressions au peigne peu soignées formant une ligne brisée; diam. max. rest. : env. $200 \mathrm{~mm}$ (fig. 75, $\mathrm{D}, \mathrm{n}^{\circ}$ 6) ;

-1 tesson de fond légèrement creux d'une grande urne non tournée) ; diam. fond : $110 \mathrm{~mm}$ (fig. 81, D, $\mathrm{n}^{\circ}$ 9) ;

-1 tesson de fond annulaire d'une urne ou d'une coupe non tournée ; diam. fond : $60 \mathrm{~mm}$ (fig. 81, D, $\left.\mathrm{n}^{\circ} 10\right)$;

- 1 tesson de bord d'un grand couvercle non tourné de forme CNT-LOR V2a ou V2b, (fig. 81, D, ${ }^{\circ} 8$ ) ;

-1 anse horizontale de coupe non tournée, de section circulaire (fig. 81, D, $\mathrm{n}^{\circ} 11$ );

- 118 tessons appartenant à plusieurs vases non tournés, urnes et coupes, représentés chacun par un petit nombre de morceaux (non dessinés). 


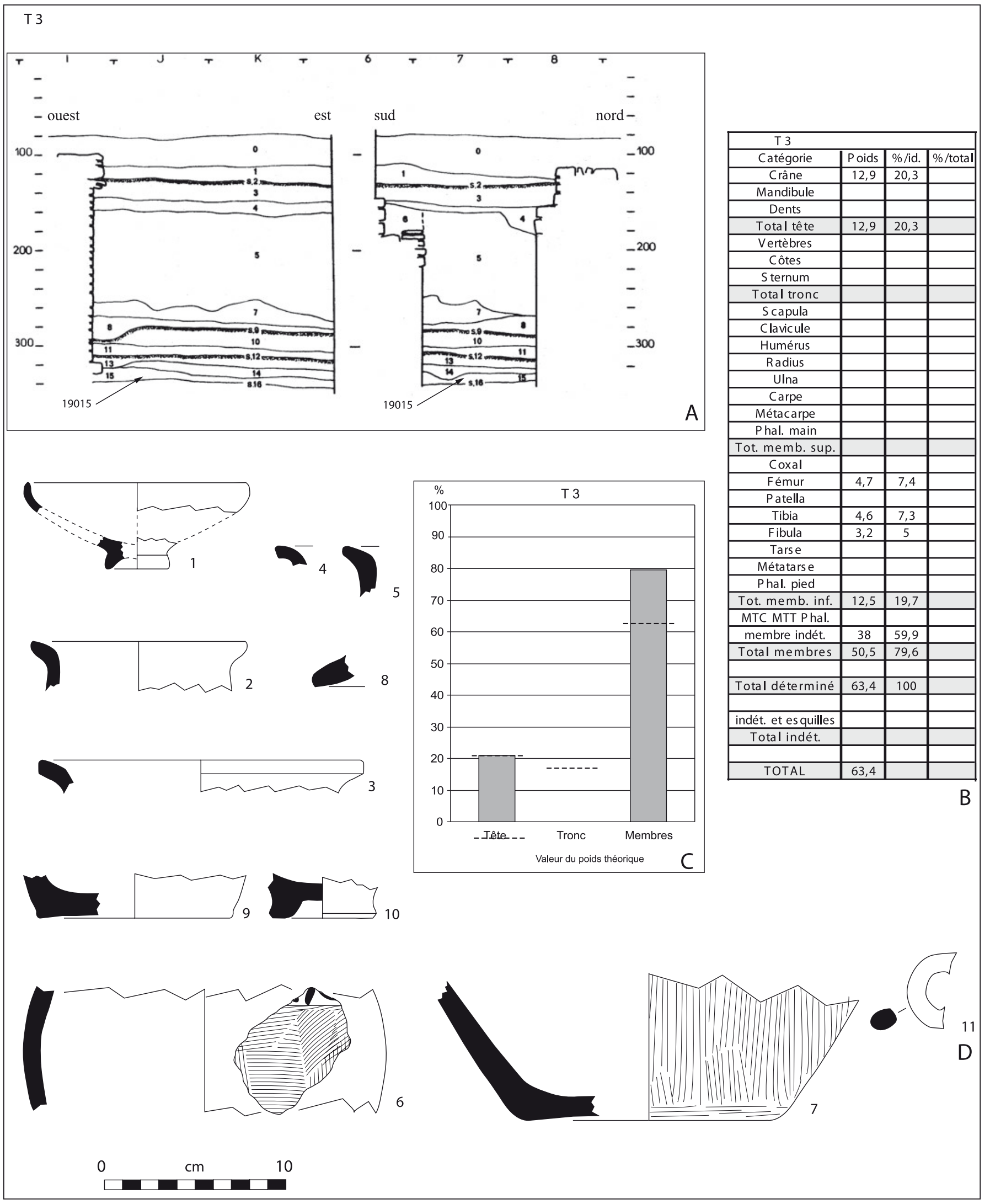

Fig. 81. Tombe T3. A : coupes (d'après Fiches, Roux 1982, p. 10). B : tableau de détermination des os humains (poids en grammes).

$C$ : répartition du poids des os par grandes régions anatomiques (\% par rapport au total déterminé). D : mobilier ( 1 : céramique à vernis noir ; 2-11 : céramique non tournée). 


\section{La tombe T4 (= « Zone $11 »)$}

En 1983, un sondage profond, de $2 \mathrm{~m}^{2}$, contre le mur nord de la salle 11, mit au jour partiellement les vestiges de la tombe 4 sous le niveau de construction des murs de l'auberge et différentes couches de remblais et d'alluvions (fig. 6). Ces restes comprennent un loculus (11026), intégralement mis au jour et une structure de recouvrement (11025) partiellement fouillée dans le cadre du sondage (Chazelles et al., 1984, p. 5 ; Fiches dir., 1989, p. 30). La cote NGF du sol à la base du niveau funéraire est de $11,43 \mathrm{~m}$.

Le loculus (11026) arrondi, mesure 50 à $57 \mathrm{~cm}$ de diamètre et $20 \mathrm{~cm}$ de profondeur. Il est creusé dans la terrasse alluviale naturelle dépourvue de tout vestige anthropique. Il renferme de nombreux os humains incinérés, dispersés, et des charbons de bois, mais il est dépourvu de tout objet mobilier. Il est recouvert, ainsi que le sol environnant à partir duquel il fut aménagé, par une couche de limon brun foncé, très argileux et compact, de $15 \mathrm{~cm}$ d'épaisseur (US 11025). Cette couche, riche également en charbons de bois, contient des os humains incinérés, dispersés, et quelques tessons de vases non tournés. Il s'agit en fait d'une portion de la structure de recouvrement de la tombe.

\section{Le défunt}

Le défunt est représenté par 299,1 g d'os incinérés (fig. 82, A). On a affaire à un adulte sans doute relativement âgé, si l'on en croit les sutures crâniennes synostosées entièrement sur la face endocrânienne, plus incomplètement sur la face exocrânienne, ainsi que des signes diffus d'atteintes dégénératives (arthrose), parfois très évoluées. C'est un sujet remarquablement robuste : reliefs crâniens puissants et moulurés, insertions musculaires sur les grands os longs des membres très fortement marquées, épiphyse distale du radius droit volumineuse. Il y a donc de fortes présomptions pour qu'il s'agisse d'un homme (analyse de H. Duday dans Fiches dir. 1989, p. 30-31).

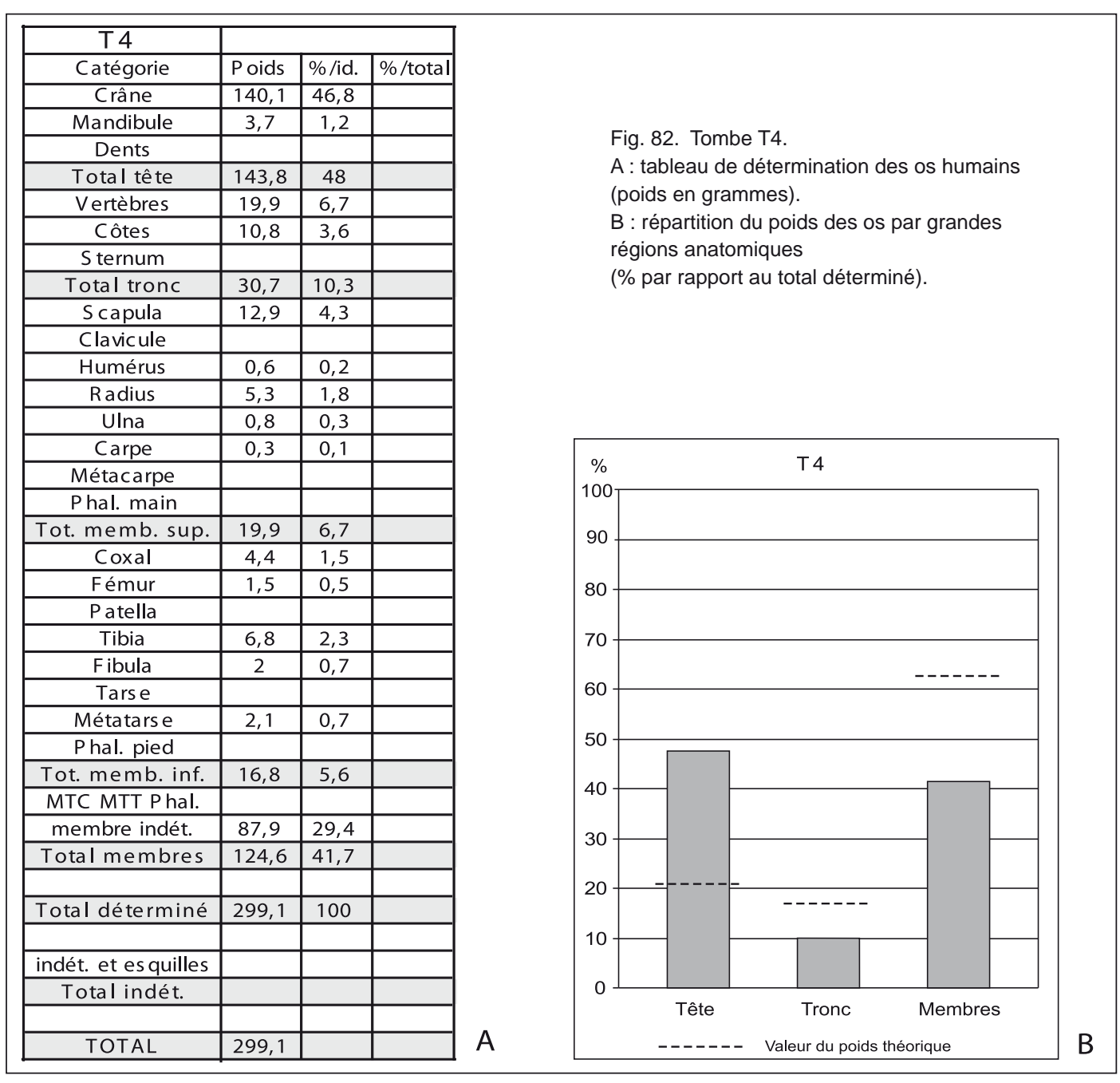


La crémation du cadavre a été irrégulière. Le crâne, dont les restes sont, pour la plupart, volumineux, et la partie supérieure du rachis sont faiblement brûlés, tandis que, pour le reste du squelette, la couleur blanc crayeux révèle une température de crémation supérieure à $650^{\circ}$ selon de barème le E. Bonnucci et G. Grazziani (1975), et les morceaux de diaphyses sont très souvent fissurés en ondes concentriques, indice d'une incinération d'os frais.

Les pièces osseuses sont réparties dans le loculus $(271,7 \mathrm{~g})$ et dans les vestiges du recouvrement $(27,4 \mathrm{~g})$, et les deux lots ne montrent ni doublets et ni pièces morphologiquement incompatibles. On notera cependant que les os du pied et du cou-de-pied proviennent tous du recouvrement. Le loculus ayant été découvert complet, on peut considérer que l'on a retrouvé la quasi-totalité du lot déposé dans ce lieu. Il n'en va pas de même pour les os de la superstructure qui, elle, n'a été que partiellement fouillée.

Le poids d'os déposés dans le loculus représente $16,7 \%$ du poids moyen d'un squelette d'adulte brûlé, 1627,1 g selon McKinley (1993) et la part découverte dans le recouvrement n'en constitue que $1,7 \%$.

Pour l'ensemble du lot découvert, le crâne est très sur-représenté : $48 \%$ du poids identifié au lieu des $20,4 \%$ attendus. Cela se fait au détriment des membres, $41,7 \%$ alors que la valeur théorique est de $62,6 \%$, tandis que le tronc montre une sous-représentation habituelle, $10,3 \%$ au lieu des $17 \%$ attendus. Cette valeur anormalement forte de l'indice pondéral crânien résulte d'une particularité du bûcher plutôt que d'un tri intentionnel : en effet, cette région a été moins brûlée que le reste du corps (fig. 82, B).

Qu'il s'agisse du loculus ou de la superstructure, les restes osseux sont dispersés hors de tout contenant.

\section{Mobilier}

Si le loculus est dépourvu de tout mobilier, la structure de recouvrement a livré un tesson de vase à pâte claire et des tessons de vases non tournés dont quatre bords et un décor (non dessinés). Les charbons de bois recueillis dans la structure de recouvrement (25 fragments) et surtout dans le loculus (312 fragments) appartiennent essentiellement à des bois de chauffe, du Chêne pubescent. Cependant, sept morceaux d'Érable champêtre, quatre morceaux de Frêne et deux de Hêtre peuvent indiquer la présence de mobilier en bois (analyse de L. Chabal dans Fiches dir. 1989, p. 33-35).

\section{La tombe T5 (= « Zone $31 »)$}

En 1983, un sondage de $2 \mathrm{~m}^{2}$ pratiqué dans la « zone 31 » de la cour de l'auberge à partir du sol correspondant à l'installation du quartier a permis de fouiller partiellement les vestiges de la tombe T5 (fig. 6). Ceux-ci comprennent un loculus funéraire (31049) creusé dans le sol naturel vierge, et une couche (31047) surmontant ces derniers et correspondant sans doute à une portion de la structure de recouvrement de la tombe (Chazelles et al. 1984, p. 5 ; Fiches dir. 1989, p. 30). La cote NGF du sol à la base du niveau funéraire est de 11,43 m (fig. 83, A).

Le loculus (31049) est creusé dans la terrasse alluviale naturelle dépourvue de tout vestige anthropique (31048). Arrondi, il mesure 50 à $60 \mathrm{~cm}$ de diamètre à l'ouverture et $15 \mathrm{~cm}$ de profondeur. Il renferme les restes osseux humains incinérés, dispersés hors de tout contenant, deux perles en corail ainsi que les tessons de trois vases incomplets. Il est recouvert, ainsi que le sol environnant, par une couche de limon brun foncé (31047), très argileux, de $20 \mathrm{~cm}$ d'épaisseur, riche en charbons de bois. Cette strate pourrait correspondre à la structure de recouvrement de la tombe. Ses limites n'ont pas été atteintes dans le cadre étroit du sondage ; seul le loculus a pu être intégralement fouillé.

\section{Le défunt}

Le défunt est représenté par 144,1 g d'os incinérés, provenant tous du loculus 31049 (fig. 83, B). L'âge au décès, compris entre huit et douze ans, peut être déduit de différents indices : une racine de dent monoradiculée dont l'apex est en voie de fermeture (probablement l'incisive permanente latérale inférieure gauche); des racines de deux dents pluriradiculées (sans doute une première et une deuxième molaires permanentes inférieures), dont les apex sont entièrement fermés pour l'une, encore béants pour l'autre ; un morceau de corps de la mandibule avec alvéole de molaire déciduale ; côte immature (tête et trois points tubérositaires non soudés) ; plusieurs épiphyses d'os longs des membres montrant la persistance du cartilage de croissance; aspect très immature de la symphyse pubienne gauche (analyse de H. Duday dans Fiches dir. 1989, p. 31).

La couleur blanc crayeux révèle une température de crémation supérieure à $650^{\circ}$ selon le barème de E. Bonnucci et G. Grazziani (1975), et les morceaux de diaphyses sont très souvent fissurés en ondes concentriques, indice d'une incinération d'os frais. Les os ont été placés dans le loculus hors de tout contenant. 


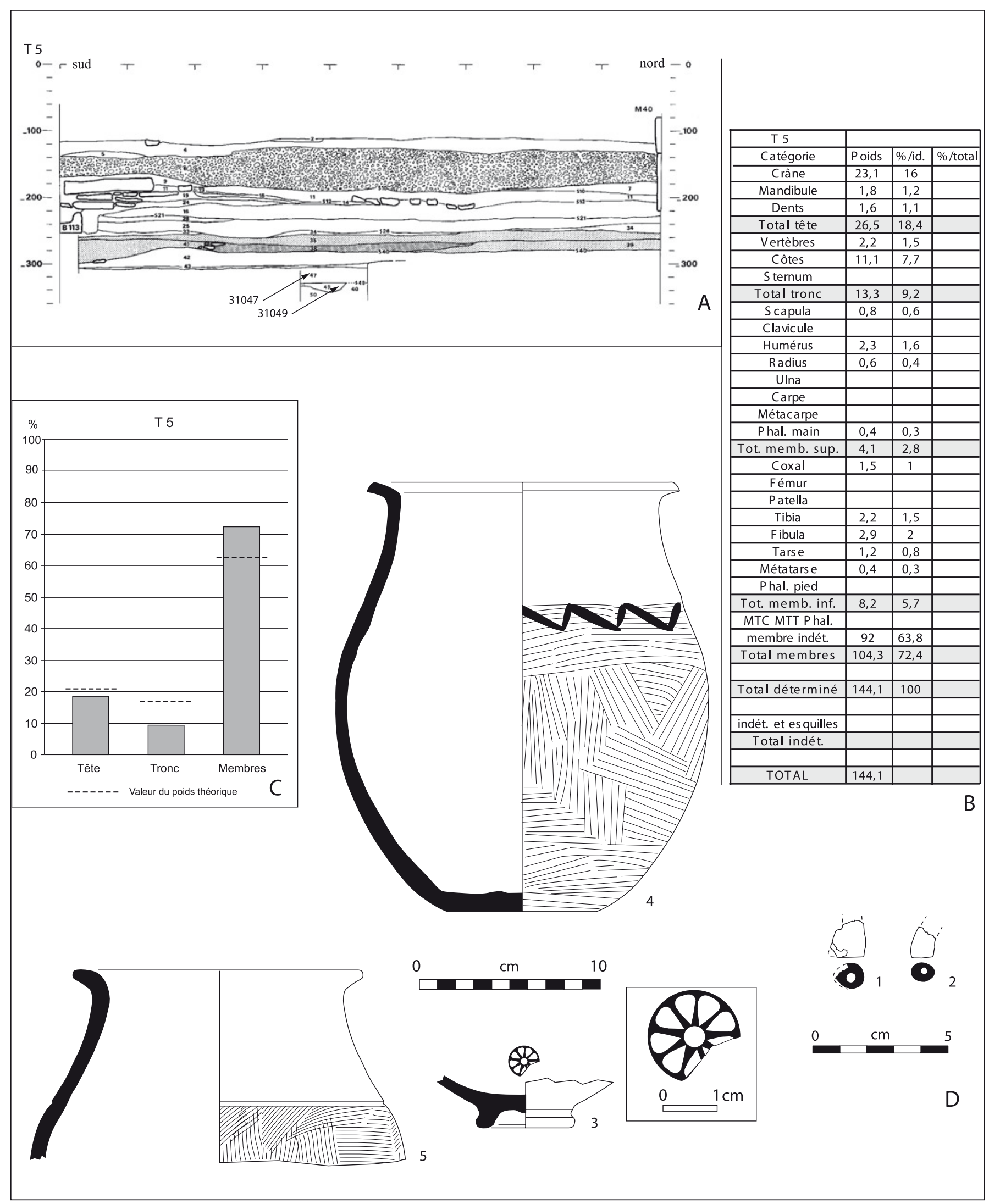

Fig. 83. Tombe T5. A : coupe (d'après Fiches dir; 1989, p. 41). B : tableau de détermination des os humains (poids en grammes). $C$ : répartition du poids des os par grandes régions anatomiques (\% par rapport au total déterminé). D : mobilier (1 et 2 : corail ; 3 : céramique à vernis noir ; 4 et 5 : céramique non tournée). 
Avec 18,4\% du poids d'os identifiés, l'indice pondéral céphalique crânien est un peu inférieur à la valeur théorique $(20,4 \%)$; le tronc est très sous-représenté, $9,2 \%$ au lieu des $17 \%$ attendus et les membres sont surreprésentés, $72,4 \%$ pour un poids théorique de $62,6 \%$ (fig. 83, C).

\section{Mobilier}

Objets personnels, parures :

- 2 perles aménagées dans des segments de branchette de corail. Le départ des ramifications a été poli. Dans les deux cas, l'une des extrémités correspond à la section sciée et polie, l'autre est une cassure. Ces deux perles ont subi l'action du feu. Dimensions : $\mathrm{n}^{\circ} 1:$ long. cons. : $14 \mathrm{~mm}$; diam. : $13 \mathrm{~mm}$; $\mathrm{n}^{\circ} 2$ : long. cons. : $12 \mathrm{~mm}$; diam. : $8 \mathrm{~mm}$ (fig. 83, $\mathrm{D}, \mathrm{n}^{\circ} 1$ et 2 ).

Matériel céramique :

- Portion d'une grande urne non tournée de forme CNT-LOR U5d, variante d, 59 tessons représentant environ $50 \%$ du récipient ; col tronconique rentrant à surface lissée, bord déversé à lèvre aplatie avec méplat vers l'intérieur, panse ovoïde peignée sub-horizontalement en haut et en bas, obliquement dans la partie centrale, épaule décorée de grandes impressions de peigne disposées en une ligne brisée, fond plat; diam. max. : $210 \mathrm{~mm}$; haut. : $238 \mathrm{~mm}$ (fig. 77, D, $\mathrm{n}^{\circ} 4$ ) ;

- 2 tessons de la partie supérieure d'une grande urne non tournée de forme CNT-LOR U5d, variante d, soit moins de $5 \%$ du vase ; col tronconique rentrant à surface lissée, bord déversé à lèvre amincie, épaule décorée d'une large ligne horizontale incisée ; panse ovoïde dont le haut est peigné verticalement ; diam. ouv. : $160 \mathrm{~mm}$ (fig. 83, $\mathrm{D}, \mathrm{n}^{\circ} 5$ ) ;

- 1 fond de bol à vernis noir de l'atelier de Rosas, de forme Lamb. 27 (= Puig 11), diam. base : $52 \mathrm{~mm}$; au centre du fond, estampille circulaire de $17 \mathrm{~mm}$ de diamètre, avec rosette à neuf pétales en forme de larmes autour d'un bouton central (rosette de série A de Puig) (fig. 83, D, $\mathrm{n}^{\circ} 3$ ).

\section{La tombe T6 (= « Zone $36 »)$}

En 1984, la poursuite d'un sondage ouvert en 1982 dans la zone 36 a permis d'atteindre, sur $6 \mathrm{~m}^{2}$, les niveaux antérieurs aux remblais de mise en place de l'auberge et correspondant à la nécropole. Il s'agit d'un loculus (36018) intégralement fouillé et, sur le sol naturel environnant, des restes d'une structure de recouvrement de la tombe (36017), reconnus sur $5 \mathrm{~m}^{2}$ (Fiches dir. 1989, p. 20, 22 et 30) (fig. 6).
Le loculus 36018 mesure $70 \mathrm{~cm}$ de diamètre à l'ouverture mais il est peu profond, $12 \mathrm{~cm}$ au maximum, creusé dans la terrasse alluviale naturelle (fig. 84, A, B et C). Il a livré, outre des restes osseux humains incinérés dispersés hors de tout contenant, une perle en verre, une rondelle en céramique et de nombreux tessons de vases incomplets. À l'est, la surface du sol naturel est marquée par des cailloux aux arêtes vives formant un empierrement (36017) parmi lequel figurent quelques os brûlés, tandis que des charbons de bois entourent le loculus sur $1 \mathrm{~m}$ environ. Le loculus, cet empierrement et la majeure partie du reste de la surface du sol fouillé dans ce sondage est recouvert, sur $5 \mathrm{~m}^{2}$, par une couche de limon argileux épaisse de 10 à $20 \mathrm{~cm}$, riche en charbons de bois (36016). Celle-ci correspond probablement à une structure de recouvrement de la tombe. Seule sa limite occidentale semble avoir été atteinte par les fouilleurs, à moins de $1 \mathrm{~m}$ du loculus.

\section{Le défunt}

Le défunt est représenté par 157,6 g d'os incinérés (fig. 84, D). C'est un adulte car le corps de la première vertèbre thoracique montre un listel soudé, mais sans doute peu âgé, tous les segments de sutures conservés étant entièrement libres sur les faces exo- et endocrânienne. Le sexe ne peut être déterminé (analyse de H. Duday dans Fiches dir. 1989, p. 31).

La crémation du cadavre a été fortement poussée. La couleur blanc crayeux révèle une température de crémation supérieure à $650^{\circ}$ selon le barème de $\mathrm{E}$. Bonnucci et G. Grazziani (1975), et les morceaux de diaphyses sont très souvent fissurés en ondes concentriques, indice d'une incinération d'os frais.

Les restes osseux sont dispersés hors de tout contenant, aussi bien dans le loculus, qui a livré l'essentiel du lot, soit 152,2 g., que dans la superstructure (5,4 g, mais cette dernière n'a pas été entièrement fouillée). Les deux lots ne montrent ni doublets et ni pièces morphologiquement incompatibles. Au contraire, deux morceaux jointifs d'une même diaphyse proviennent chacun de l'une de ces deux structures.

Le poids des os recueillis dans le loculus représente 9,4\% du poids moyen d'un squelette d'adulte brûlé, 1627,1 g selon McKinley (1993) et la part découverte dans le recouvrement n'en constitue qu'une infime part, 1,7 \%. Pour l'ensemble du lot découvert, le crâne est surreprésenté : 29,1\% du poids identifié au lieu des 20,4\% attendus. Il en va de même, dans une moindre mesure cependant, des membres, $66,6 \%$ au lieu de $62,6 \%$. 


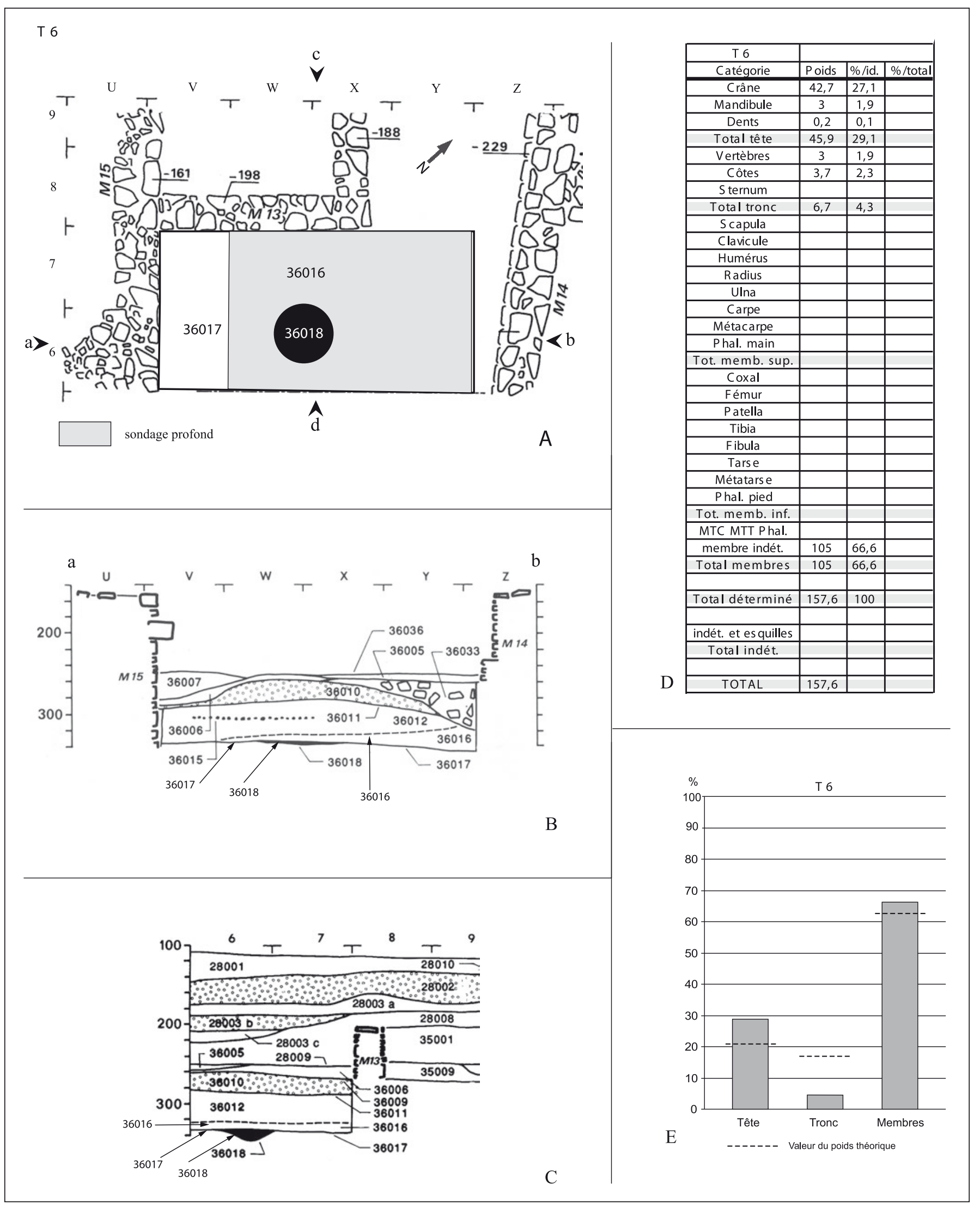

Fig. 84. Tombe 6. A, B et C : plan et coupes (d'après Fiches dir. 1989, p. 18 et 22). D : tableau de détermination des os humains (poids en grammes). $\mathrm{E}$ : répartition du poids des os par grandes régions anatomiques (\% par rapport au total déterminé). 


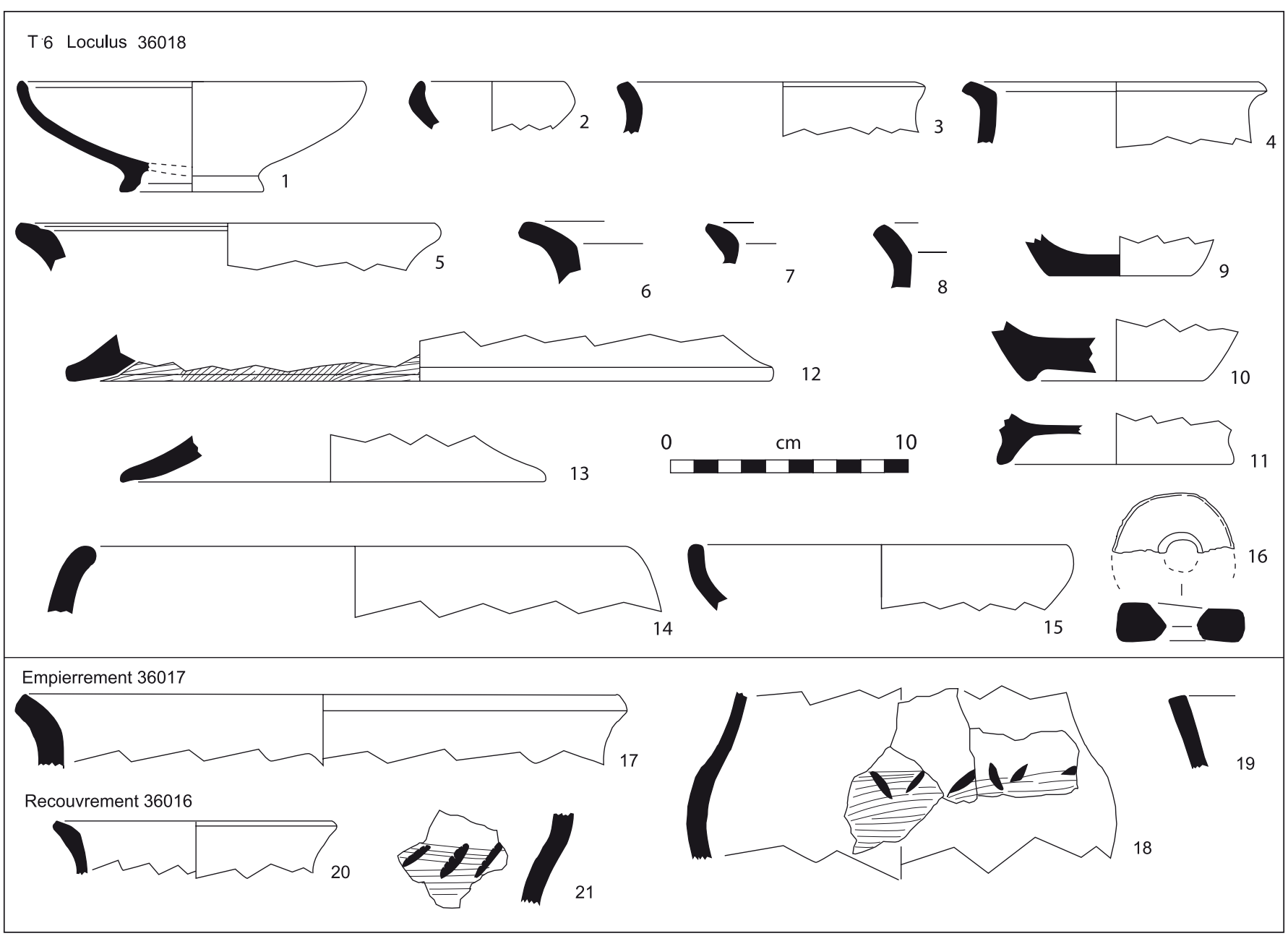

Fig. 85. Tombe T6. Mobilier (1 et $2:$ céramique à vernis noir ; 3-21 : céramique non tournée).

Le tronc pour sa part présente une très forte sousreprésentation, $4,3 \%$ pour un poids théorique de $17 \%$ (fig. 84, E).

\section{Mobilier du loculus}

Objet personnel, parure :

- Une «perle à spirale protubérante en pâte de verre » (Fiches dir. 1989, p. 36, non figuré) ; cette perle n'a pas été retrouvée ; il pourrait s'agir d'un objet comparable à une perle du loculus de la tombe 24 (fig. $40, \mathrm{~B}, \mathrm{n}^{\circ} 4$ ).

\section{Matériel céramique :}

- Portion d'un bol à vernis noir de l'atelier de Rosas, de forme Lamb. 27 (= forme Puig 11.a), 36 tessons correspondant à environ $50 \%$ du vase ; diam. ouv. : $145 \mathrm{~mm}$; diam. base : $60 \mathrm{~mm}$ (fig. $85, \mathrm{n}^{\circ} 1$ );

- 1 tesson de bord de coupelle de l'atelier de Rosas, de forme Lamb 24-25 (= forme Puig 2.a) ; diam. ouv. : $60 \mathrm{~mm}$ (fig. 85, $\mathrm{n}^{\circ} 2$ );
- 1 tesson d'urne non tournée : col tronconique rentrant et bord déversé ; diam. ouv. : $130 \mathrm{~mm}$ (fig. 85, $\left.\mathrm{n}^{\circ} 3\right)$;

- 1 tesson d'urne non tournée : col tronconique rentrant et bord déversé avec méplat vers l'intérieur ; diam. ouv. : $130 \mathrm{~mm}$ (fig. 85, $\mathrm{n}^{\circ} 4$ ) ;

- 1 tesson d'urne non tournée : bord déversé ; diam. ouv. : $180 \mathrm{~mm}$ (fig. $85, \mathrm{n}^{\circ}$ 5) ;

- 1 tesson d'urne non tournée : bord déversé avec méplat vers l'intérieur (fig. 85, $\mathrm{n}^{\circ} 6$ ) ;

- 1 tesson d'urne non tournée : bord déversé avec méplat vers l'intérieur (fig. 85, $\mathrm{n}^{\circ} 7$ ) ;

- 1 tesson d'urne non tournée: bord déversé avec méplat vers l'intérieur (fig. $\mathbf{8 5}, \mathrm{n}^{\circ} 8$ ) ;

-1 tesson d'urne non tournée: fond plat; diam. fond : $60 \mathrm{~mm}$ (fig. 85, $\mathrm{n}^{\circ}$ 9) ;

- 1 tesson d'urne non tournée : fond creux; diam. fond : $75 \mathrm{~mm}$ (fig. 85, $\left.\mathrm{n}^{\circ} 10\right)$;

- 1 tesson de fond annulaire de coupe non tournée ; diam. fond : $100 \mathrm{~mm}$ (fig. $\mathbf{8 5}, \mathrm{n}^{\circ} 11$ ). 
Fosses $A, B$ et $C$

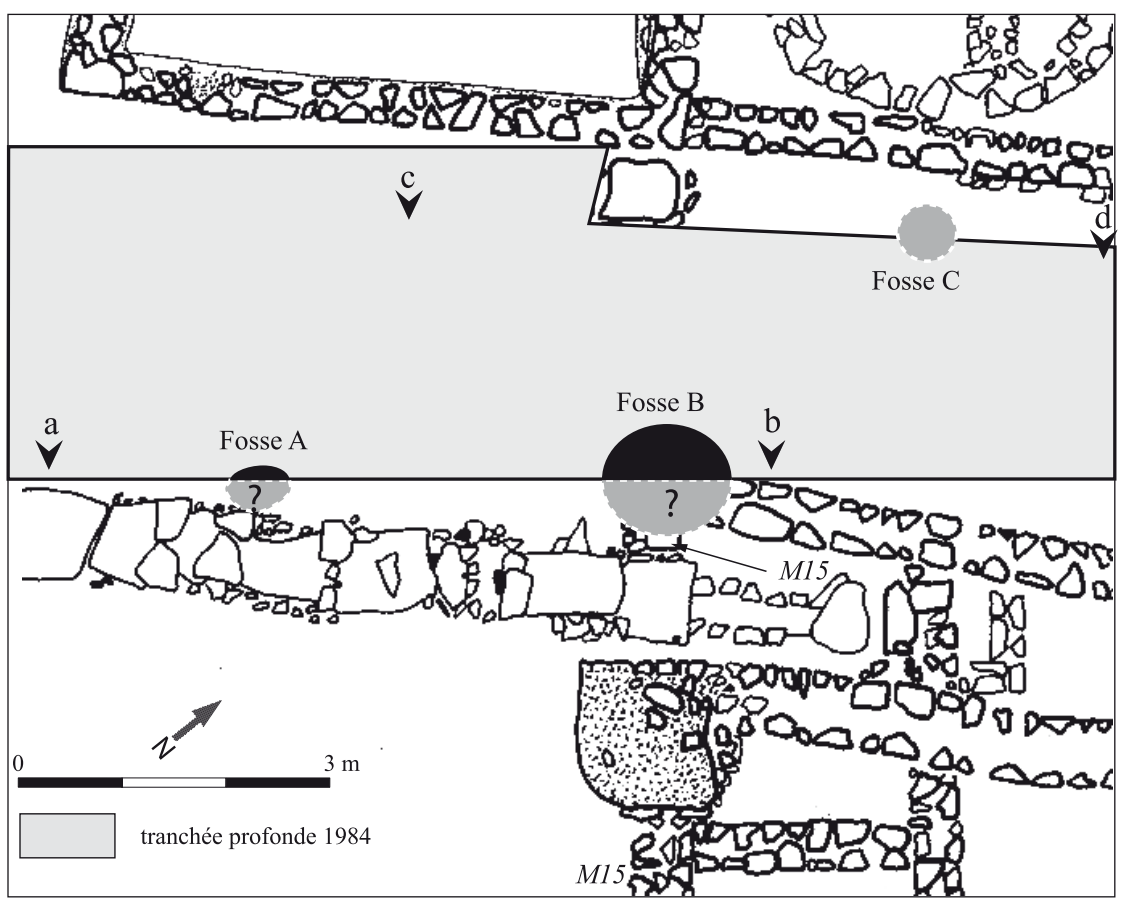

A
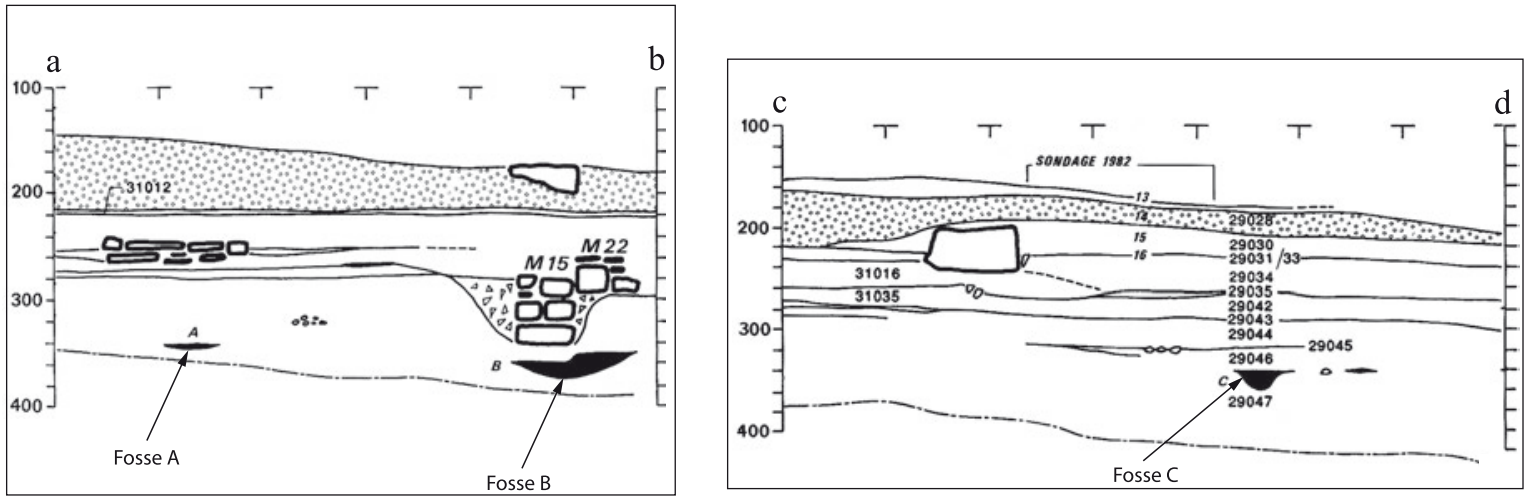

B

$\mathrm{C}$

Fig. 86. Fosses A, B et C. Plan et coupes d'après Fiches dir; 1989, p. 14, 19 et 64).

- 1 tesson de grand couvercle de forme CNT-LOR $\mathrm{V} 1 \mathrm{~b}$ : bord à facette vers l'intérieur, surface intérieure peignée ; diam. ouv. : $300 \mathrm{~mm}$ (fig. $85, \mathrm{n}^{\circ}$ 12) ;

- 1 tesson de couvercle non tourné de forme CNTLOR V2b : bord aminci ; diam. ouv. : $180 \mathrm{~mm}$ (fig. 85, $\left.\mathrm{n}^{\circ} 13\right)$;

-1 tesson d'une grande coupe non tournée de forme CNT-LOR C2: panse arrondie-convexe, embouchure rétrécie, bord rentrant à lèvre arrondie; diam. ouv. : $230 \mathrm{~mm}$ (fig. 85, $\left.\mathrm{n}^{\circ} 14\right)$;

- 1 tesson de bord d'une coupe non tournée de forme CNT-LOR C1: panse arrondie-convexe, embouchure évasée, bord divergent à lèvre arrondie; diam. ouv. : $160 \mathrm{~mm}$ (fig. 85, $\left.\mathrm{n}^{\circ} 15\right)$.

\section{Divers :}

- 1 moitié de rondelle taillée dans un tesson de panse de grande urne non tournée, percée au centre d'un trou effectué à partir des deux faces ; diam. : $51 \mathrm{~mm}$; diam. perforation : $12 \mathrm{~mm}$ (fig. 85, $\mathrm{n}^{\circ}$ 16).

Mobilier du sol empierré :

- 35 tessons de bord, col et panse d'urne non tournée de forme probable CNT-LOR U5d ; bord déversé, panse ovoïde peignée ; diam. ouv. : $250 \mathrm{~mm}$ (fig. 85, $\left.\mathrm{n}^{\circ} 17\right)$;

- 4 tessons d'urne non tournée de forme CNT-LOR U5d: col tronconique rentrant, panse ovoïde peignée horizontalement, épaule décorée d'une rangée 
d'impressions au peigne inclinées et de sens alterné (fig. 85, $\mathrm{n}^{\circ} 18$ ) ;

- 1 tesson de jatte non tournée de forme CNT-LOR J1c : panse tronconique, bord aplati lisse, avec aplatissement vers l'extérieur ; diam. ouv. : 220 mm (fig. 85, $\left.\mathrm{n}^{\circ} 19\right)$;

- 293 tessons de panses de plusieurs vases non tournés, urnes et coupes (non dessinés).

Mobilier du recouvrement :

- 1 tesson de col et bord de petite urne non tournée ; diam. ouv. : $120 \mathrm{~mm}$ (fig. 85, $\mathrm{n}^{\circ} 20$ ) ;

- 1 tesson d'épaule d'urne non tournée : panse ovoïde peignée, décor d'une rangée d'impressions au peigne inclinées et de même sens(fig. 85, $\mathrm{n}^{\circ} 21$ );

-1 petit tesson de bord d'urne non tournée (non dessiné) ;

-1 petit tesson de bord de coupe non tournée (non dessiné).

\section{La tombe T7 (= « Fosse B »)}

En 1984, une tranchée longue de près de $18 \mathrm{~m}$ a été creusée à la pelle mécanique dans la cour de l'auberge afin de lire, sur les bermes, les relations stratigraphiques existant réellement entre les couches observées jusque là dans les différents sondages de cette cour et la partie est de l'édifice (fig. 6). Sous le sol correspondant à la création de l'îlot, prennent place des colluvions et alluvions de limon (31042 et 31047). Au-dessous, une fosse ( « fosse B ») creusée à partir de la surface du sol naturel a été observée dans la berme sud de la tranchée (fig. 86, A et B). Seule la partie conservée du remplissage de cette structure a été fouillée. Elle a livré un matériel dispersé : outre des restes osseux humains incinérés, plusieurs tessons de vases en céramique et quatorze objets en bronze se rapportant probablement à une ou plusieurs ceintures. À l'évidence, il s'agit là du loculus d'une tombe, reconnue et fouillée en partie seulement.

On ne dispose pas de renseignement sur ce loculus, creusé dans la terrasse alluviale naturelle. D'après la coupe publiée (Fiches dir. 1989, p. 19, fig. 6), il a la forme d'une cuvette à fond arrondi, d'environ $115 \mathrm{~cm}$ à l'ouverture sur son axe sud/ouest-nord/est et $20 \mathrm{~cm}$ de profondeur maximum. La cote NGF du sol à la base du niveau funéraire est de $11,43 \mathrm{~m}$.

Cette portion de loculus fouillée a livré 309,5 g d'os humains incinérés, se rapportant à deux individus, un adulte de sexe non déterminé, mais dont l'équipement mobilier semble indiquer une femme, et un enfant d'environ un an (fig. 87, A).

\section{Les défunts}

L'adulte est représenté par 299,6 g d'os (analyse de H. Duday dans Fiches dir. 1989, p. 31-32). La détermination de l'âge résulte de plusieurs indices : listels vertébraux soudés, épiphyses des os longs soudées également, apex de dents permanentes fermés. Le sexe anthropologique ne peut être appréhendé. L'enfant, âgé d'environ un an, est attesté par 9,9 g d'os : des morceaux de voûte crânienne, un pédicule de vertèbre thoracique, le corps d'une vertèbre lombaire inférieure, probablement L5, et quelques épiphyses ou os courts. Bien évidemment, vu le caractère incomplet de la fouille, il ne s'agit pas là de la totalité des os déposés dans le loculus ; cependant, on soulignera la disproportion des deux lots, les os de l'enfant ne représentant que 3,2\% du poids total et $3,8 \%$ du nombre de fragments récupérés.

La crémation des cadavres a été fortement poussée. La couleur blanc crayeux révèle une température de crémation supérieure à $650^{\circ}$ selon le barème de $\mathrm{E}$. Bonnucci et G. Grazziani (1975), et les morceaux de diaphyses sont très souvent fissurés en ondes concentriques, indice d'une incinération d'os frais. Les restes osseux ont placés directement dans le loculus, hors de tout contenant.

Pour l'ensemble du lot découvert, mais il s'agit presque exclusivement de l'adulte, le crâne est sousreprésenté : $11,1 \%$ du poids identifié au lieu des $20,4 \%$ attendus. Il en va de même du tronc $7,2 \%$ pour un poids théorique de $17 \%$. Avec 81,7\% au lieu des 62,6 \% théoriques, les membres sont sur-représentés (fig. 87, B).

\section{Mobilier du loculus}

Objets personnels, parure et habillement :

Quinze pièces en bronze paraissent se rapporter à une ceinture, plutôt qu'à une suspension de fourreau dont on ne connaît aucun parallèle :

- 1 agrafe en bronze, incomplète; plaque triangulaire non ajourée, prolongée d'un côté par une tige plate, dont l'extrémité manque, et terminée de l'autre par un crochet ; la face principale de la plaque s'orne de onze doubles cercles estampés; le crochet a la forme d'une tête d'animal allongée, deux creux évoquant les yeux et dégageant une arête nasale ; long. cons. : $88 \mathrm{~mm}$; larg. max. : $31 \mathrm{~mm}$ (fig. 87, C, $\mathrm{n}^{\circ} 1$ );

-1 anneau circulaire en bronze, à tige de section en $\mathrm{D}$; une forte usure en un point du côté intérieur, de la dimension du crochet de l'agrafe précédente, semble indiquer qu'il s'agit de la boucle correspondante; diam. : $23 \mathrm{~mm}$; ép. $4 \mathrm{~mm}$. Cet objet porte des traces de passage sur le bûcher (fig. 87, C, $\mathrm{n}^{\circ} 2$ ); 


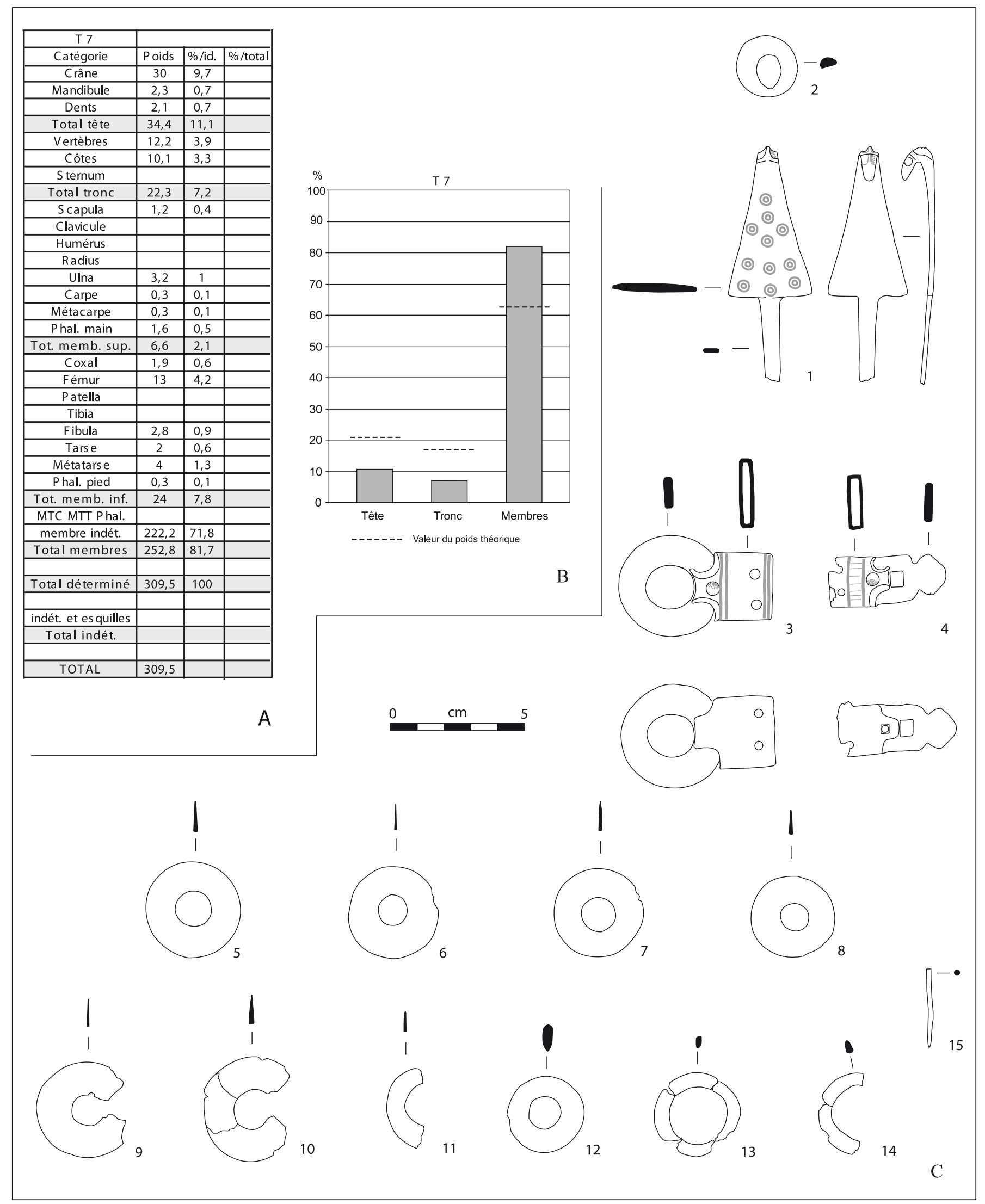

Fig. 87. Tombe T7. A : tableau de détermination des os humains (poids en grammes). B : répartition du poids des os par grandes régions anatomiques (\% par rapport au total déterminé). C : mobilier (1-15 : bronze) (1-15 d'après Feugère, Tendille dans Fiches dir. 1989, p. 36). 
- 2 extrémités de sangle en bronze, une grande et une petite, fortement apparentées par la facture et la décoration, appartenant probablement à la même ceinture :

- Grande terminaison de sangle, en bronze; talon rectangulaire creux dans lequel s'engage une sangle maintenue par deux rivets; à l'opposé de la sangle, le talon se prolonge par un appendice échancré sur lequel est riveté un anneau plat et épais ; la face principale du talon est décorée : deux lignes gravées vers la sangle, une ligne gravée vers l'anneau, échancrures et rivet en relief sur l'appendice; long. tot. : $58 \mathrm{~mm}$; larg. talon : $27 \mathrm{~mm}$; diam. anneau : $39 \mathrm{~mm}$; ép. anneau : $5 \mathrm{~mm}$; ép. logement sangle : $3 \mathrm{~mm}$ (fig. 87, C, $\mathrm{n}^{\circ} 3$ ) ;

- Petite terminaison de sangle, en bronze; talon rectangulaire creux dans lequel s'engage une sangle maintenue par deux rivets; à l'opposé de la sangle, le talon se prolonge par un appendice échancré sur lequel est rivetée une boucle rectangulaire prolongée par un appendice losangique; la face principale du talon est décorée de deux lignes gravées sur le corps et d'échancrures et rivet en relief sur l'appendice; long. tot. : $44 \mathrm{~mm}$; larg. talon : $19 \mathrm{~mm}$; ép. logement sangle: $3 \mathrm{~mm}$. Cet objet montre des traces de passage sur le bûcher, son talon étant en partie fondu (fig. 87, C, n 4).

-7 anneaux circulaires en bronze, larges, très plats, comme affûtés vers l'extérieur; petite perforation centrale ; diam. : 30 à $36 \mathrm{~mm}$; ép. 1,5 à $2 \mathrm{~mm}$. La similitude de facture de ces pièces permet de penser qu'elles font partie de la même pièce d'habillement, par exemple cousues sur une ceinture. Ces objets sont passés sur le bûcher (fig. 87, C, nº 5 à 11);

- 1 anneau circulaire en bronze, à tige large de section en lenticulaire ; diam. : $29 \mathrm{~mm}$; ép. $4 \mathrm{~mm}$. Cet objet est passé sur le bûcher (fig. 87, C, $\mathrm{n}^{\circ} 12$ );

-1 anneau circulaire en bronze, à tige mince de section lenticulaire ; diam. : $30 \mathrm{~mm}$; ép. 2,5 mm. Cet objet est passé sur le bûcher (fig. 87, C, $\mathrm{n}^{\circ} 13$ );

- 1 moitié d'anneau circulaire en bronze, à tige mince de section lenticulaire aplatie ; diam. : $32 \mathrm{~mm}$; ép. 2,5 mm (fig. 87, C, $\mathrm{n}^{\circ} 14$ ) ;

-1 morceau de tige pointue en bronze, de section ronde de $2 \mathrm{~mm}$ au maximum ; il peut s'agir d'un ardillon de fibule ou d'une extrémité d'aiguille ou d'épingle ; long. cons. : $30 \mathrm{~mm}$ (fig. 87, C, $\mathrm{n}^{\circ} 15$ ).
Matériel céramique :

Le matériel céramique découvert dans le loculus n'a pas été retrouvé. Sont seulement signalés, mais non figurés (Fiches dir. 1989, p. 19) :

-1 bord de coupe à vernis noir ${ }^{16}$ de forme Lamb A28a-b ;

-1 fond de vase à vernis noir ;

- 4 bords et 1 fond en céramique non tournée.

\section{La tombe T8 ? (= « Fosse $C »)$}

La berme septentrionale de la tranchée de 1984, qui vient d'être évoquée pour la tombe T7, a révélé, de son côté, une autre fosse ( fosse $C$ ») au même niveau que celui de cette tombe T7 (fig. $\mathbf{6}$; fig. 86, A). Creusée également à partir de la surface du sol naturel où des traces charbonneuses ont été notées (cote NGF de 11,33 m), cette fosse n'a pas été fouillée alors. Elle présente dans la coupe (Fiches dir. 1989, p. 19, fig. 6) une largeur de $32 \mathrm{~cm}$ et une profondeur maximale de $18 \mathrm{~cm}$ (fig. 86, C). Il pourrait s'agir du loculus d'une autre tombe.

\section{La structure funéraire ST9 : un foyer parafunéraire ? (= « FoyerA »)}

Enfin, dans la berme sud de cette tranchée de 1984, un foyer lenticulaire a été observé à la surface du sol naturel, à la cote 11,29 m NGF (fig. 6 ; fig. 80, A et B). D'après la coupe publiée (Fiches dir. 1989, p. 19, fig. 6) l'un de ses axes mesure environ $50 \mathrm{~cm}$. Les restes de cette structure, prélevés et tamisés à l'eau, n'ont fourni que des charbons de bois : 221 fragments de Chêne vert, 8 de Chêne pubescent et 3 indéterminables (analyse de L. Chabal dans Fiches dir. 1989, p. 34, fig. 13).

16 Ce tesson, comme le suivant est rapporté à de la «campanienne A » dans la publication de J.-L. Fiches de 1989, mais faute d'avoir pu les ré-examiner, nous ne reprendrons pas cette qualification. 


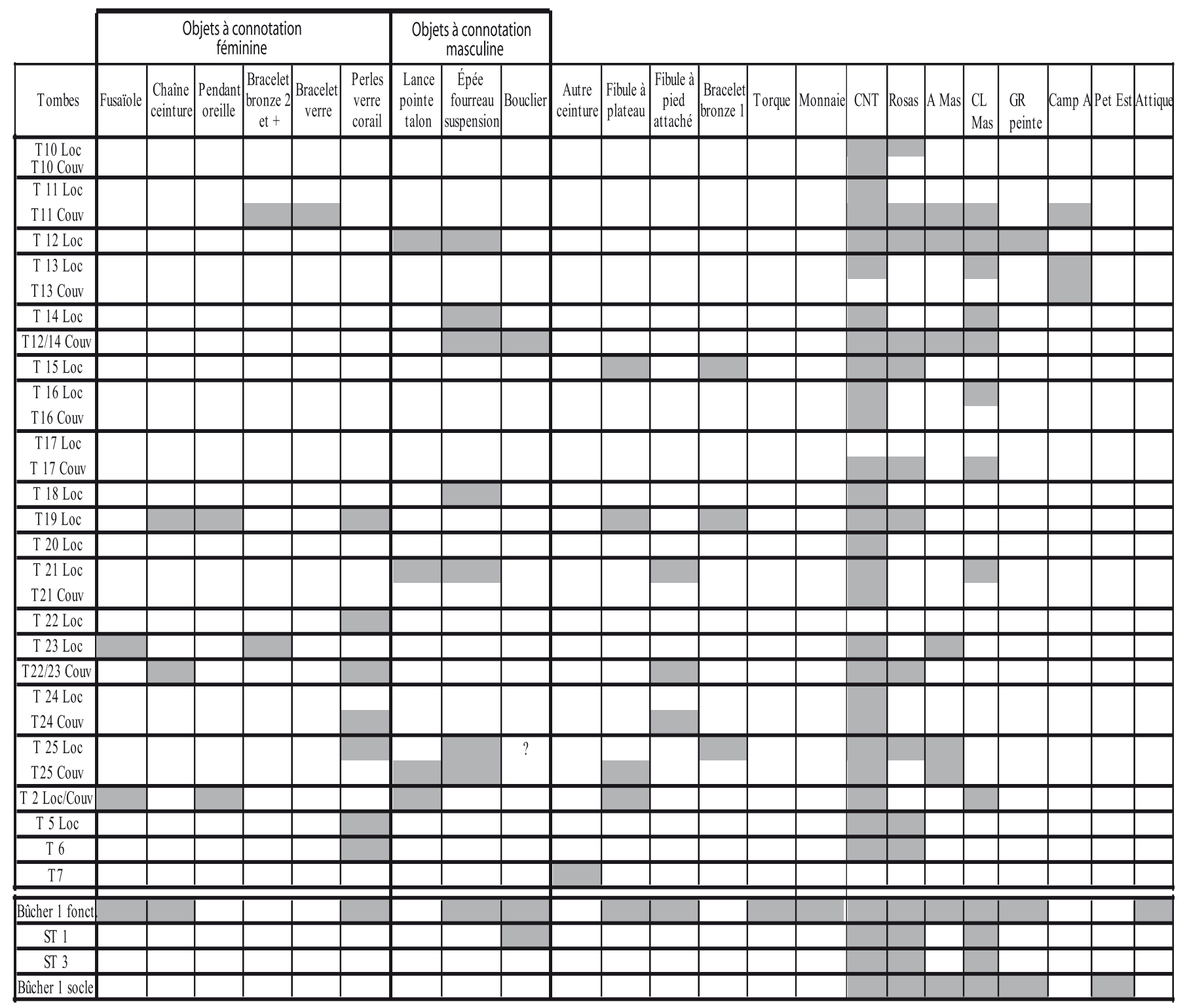

Fig. 88. Tableau synoptique des associations de mobilier déposé dans les tombes et présents dans les bûchers de crémation. 


\section{Chapitre 5}

\section{Le mobilier funéraire et son apport à la datation du quartier de la nécropole}

\begin{abstract}
près l'examen des tombes et des bûchers de crémation, et avant de synthétiser les apports 1 de cette analyse et de les replacer dans leur contexte du sud de la France, il convient de déterminer les limites chronologiques de cette portion de la nécropole d'Ambrussum et de tenter de préciser la datation de chaque structure. Pour cela, on interrogera chaque catégorie d'objets découverts, vaisselle céramique, indigène, locale ou importée, les pièces d'habillement et de parure, l'armement et le fourniment, les monnaies, les ustensiles et les pièces indéterminées.
\end{abstract}

\section{La vaisselle céramique}

Des vases, ou plutôt presque toujours des tessons, proviennent de toutes les sépultures, loculus et/ou dispositifs de recouvrement, des bûchers de crémation et du sol de la nécropole. Toutefois dans la tombe 17, seule la structure de recouvrement a fourni cette catégorie de matériel (fig. 88). Par ailleurs, on ne prendra pas en compte ici le matériel céramique découvert dans le remplissage du loculus de la tombe 22 dont la présence est peut-être involontaire, issue d'une couche antérieure.

L'essentiel du mobilier céramique est constitué de vaisselle locale, non tournée. Parmi les vases importés, sont représentées surtout les productions à pâte claire massaliète, à vernis noir des ateliers de Rosas et l'amphore massaliète, tandis que les céramiques attiques à vernis noir, grises peintes massaliètes, à vernis noir de l'atelier des petites estampilles et campaniennes «A anciennes » sont exceptionnelles. Dans l'ensemble des sépultures, les vases non tournés comptent pour $94 \%$ des restes céramiques et les vases tournés fins pour $6 \%$, se partageant à peu près équitablement entre les catégories à vernis noir et les pâtes claires. Il en va de même dans le bûcher B1, avec $94 \%$ de non tournée, $4 \%$ de vernis noir et $2 \%$ de pâte claire.

Ce matériel céramique de la sphère funéraire ne semble guère différent de celui qui a été recueilli dans les niveaux d'habitat de la fin du $\mathrm{IV}^{\mathrm{e}}$ et du $\mathrm{III}^{\mathrm{e}} \mathrm{s}$. av.
J.-C. atteints dans les sondages effectués sur l'oppidum d'Ambrussum, notamment dans le secteur IV (Fiches, Gutherz, Roux 1979; Fiches 1983). Dans ceux-ci figurent les mêmes catégories céramiques, selon des proportions semblables, entre $88 \%$ et $94 \%$ pour les vases non tournés, 2 à $5 \%$ pour les vernis noirs et 4 à $8 \%$ pour les pâtes claires ${ }^{17}$. Ce sont aussi les mêmes formes de récipients que ceux qui apparaissent dans la nécropole. Les vases utilisés à des fins funéraires paraissent donc les mêmes que ceux qui servent dans la vie quotidienne, sans préférence particulière.

\subsection{La céramique non tournée}

La céramique non tournée comprend quatre grandes séries de récipients, les urnes, les couvercles, les coupes et les jattes.

\subsubsection{Les urnes}

L'urne le plus fréquemment représentée dans la nécropole d'Ambrussum, pour ne pas dire presque exclusive, est la forme CNT-LOR U5d, et, semble-t-il, dans sa variante $\mathrm{d}$, dont les caractéristiques sont :

- un col tronconique rentrant lissé ;

- un bord nettement déversé, avec souvent un méplat bien marqué vers l'intérieur ;

- une lèvre arrondie, amincie ou aplatie ;

- une panse ovoïde, au diamètre maximum situé dans sa partie supérieure, dont la surface est toujours peignée, soit horizontalement, soit verticalement, soit encore de manière oblique entrecroisée ;

17 Les calculs ont été faits d'après les tableaux de matériel de Fiches 1983 , p. 81 à 87 , en excluant amphores et dolia et en ne prenant en compte que la vaisselle non tournée et la céramique tournée fine. On n'est pas entré dans le détail des déterminations des catégories de vernis noir, car, lors de la publication des sondages de l'habitat, à la fin des années 70 et au début des années 80, il était trop tôt pour reconnaître les productions des ateliers de Rosas qui venaient tout juste d'être identifiées et la majeure partie de ces vases était alors attribuée à de la campanienne A (voir supra, chap. 4). 


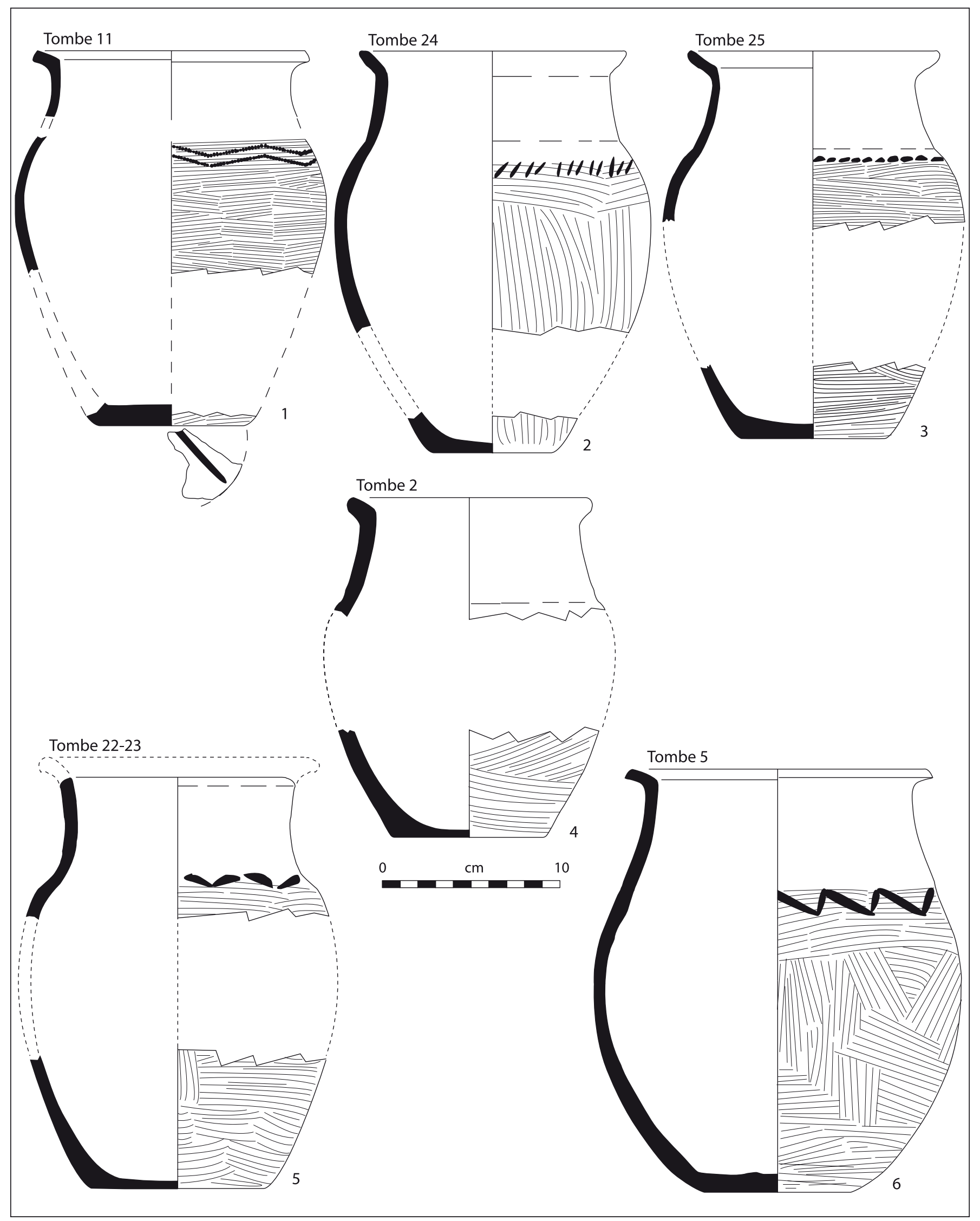

Fig. 89. Typologie des urnes non tournées du secteur fouillé de la nécropole d'Ambrussum. 


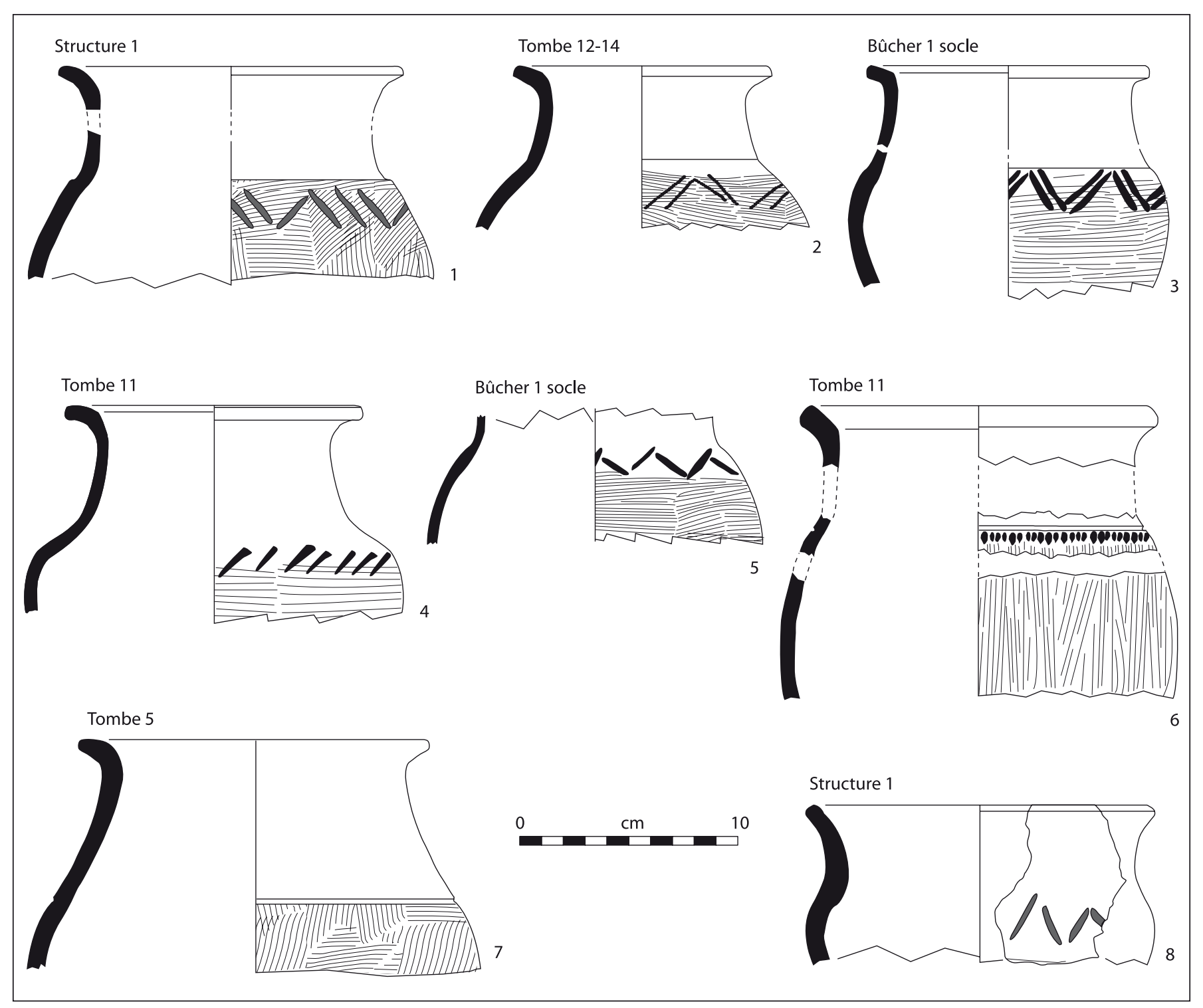

Fig. 90. Typologie des urnes non tournées du secteur fouillé de la nécropole d'Ambrussum (suite).

- une épaule plus ou moins marquée par un angle rentrant, toujours décorée d'une frise horizontale de motifs imprimés au peigne, exclusivement composée d'un alignement de dents de loup simples ou doubles, ou encore d'une file de coups imprimés obliques de même sens ou alternativement à droite et à gauche ;

- un fond plat, dont le plan de pose peut être brut de finition ou peigné.

Ce sont 14 urnes suffisamment complètes qui peuvent être classées dans CNT-LOR U5d, variante $\mathrm{d}$ : tombes T2, T5 (2 exemplaires), T11 (2 exemplaires), recouvrement T12/14, T16, T21, recouvrement T22/23, T24, T25, structure ST1, socle du bûcher B1 (2 exemplaires) (fig. 89 et $90, n^{\circ} 1$ à 7 ).
À cette forme CNT-LOR U5d se rattachent probablement aussi de nombreux éléments fragmentaires :

- des cols et/ou des bords : tombes T2 (loculus ou recouvrement: 2 exemplaires), T6 (recouvrement : 1 exemplaire), T10 (loculus : 2 exemplaires), T11 (loculus : 1 exemplaire ; recouvrement : 1 exemplaire), T12 (loculus : 2 exemplaires), T13 (loculus : 2 exemplaires), T15 (loculus: 1 exemplaire), T22 (loculus : 2 exemplaires), T24 (loculus : 1 exemplaire), structure ST3 (1 exemplaire), sol (au moins 6 exemplaires), bûcher B1 (socle : au moins 9 exemplaires; fonctionnement : au moins 6 exemplaires);

- des épaules décorées : tombes T10 (recouvrement : 1 exemplaire), T11 (recouvrement : 1 exemplaire), T14 (loculus : 1 exemplaire), T15 (loculus : 1 exemplaire), 
T19 (loculus : 1 exemplaire), T25 (loculus/recouvrement: 1 exemplaire), structure funéraire ST3 (1 exemplaire), sol (au moins 2 exemplaires), bûcher B1 (socle : au moins 2 exemplaires; fonctionnement: au moins 6 exemplaires);

- de nombreux tessons de panses peignées.

Seule une urne de la structure ST 1, au profil suffisamment conservé, relève clairement d'une autre forme : CNT-LOR U5a2, à col concave muni d'un bord non replié à lèvre aplatie, se rattachant sans épaulement, par simple courbe et contre-courbe, à une panse arrondie, décorée, en sa partie supérieure d'un alignement d'impressions en dents de loup (fig. 90, $\mathrm{n}^{\circ} 8$ ).

On notera aussi que la surface extérieure de quelques fonds plats porte parfois un ou plusieurs segments linéaires, larges et peu profonds, tracés avant cuisson dans la pâte molle : il peut s'agir de lignes croisées, mais ce n'est là qu'une possibilité vu le caractère incomplet de ces fonds.

La forme CNT-LOR U5a2, ici exceptionnelle, est relativement ancienne dans le second Âge du Fer, connue aux $\mathrm{V}^{\mathrm{e}}$ et $\mathrm{IV}^{\mathrm{e}} \mathrm{s}$. (Py, Adroher Auroux, Sanchez 2001, p. 917-918), mais elle est encore attestée dans la seconde moitié du III $\mathrm{s}$. au Marduel (Py, Lebeaupin 1989, p. 181, fig. 59, $\mathrm{n}^{\circ} 1$ et 6 ).

Les urnes de la forme très largement majoritaire CNTLOR U5d, et notamment sa variante d, sont attestées abondamment à partir de la fin du $\mathrm{IV}^{\mathrm{e}}$ et jusqu' au début du II ${ }^{\mathrm{e}}$ s. av. J.-C. dans la région du Languedoc oriental, à l'est comme à l'ouest d'Ambrussum, avec une morphologie, des proportions, une facture et une décoration comparables : par exemple, au III' s., à Nages (Py 20062007, p. 315, fig. 38, $\mathrm{n}^{\circ} 295$ ), dans la région nîmoise (Py 1990a, p. 362, doc. 62) ou encore à Lattes (Py, Adroher Auroux, Sanchez 2001, p. 920-931).

Pour sa part, le peignage, à la fois de la panse mais aussi de la face extérieure du fond des urnes, est une technique qui, dans la région, ne concerne que les $\mathrm{IV}^{\mathrm{e}}$, $\mathrm{III}^{\mathrm{e}}$ et première moitié du $\mathrm{II}^{\mathrm{e}} \mathrm{s}$. av. J.-C. On le retrouve, par exemple, à Roque de Viou dans la seconde moitié du IV e s. av. J.-C. (Garmy 1974, fig. 35 et 47), à Nages dans la première moitié du III e s. av. J.-C. (Py 1978, p. 183, fig. $87 n^{\circ} 15,187$, fig. $89 n^{\circ} 2,188$ ) ou encore à Lattes à la fin du III' ${ }^{\mathrm{e}}$ s. av. J.-C. (Py 1990b, p. 91, fig. 2-18 n 1).

\subsubsection{Les couvercles}

Rares au demeurant, les couvercles se partagent à peu près équitablement entre deux grands types de formes :
- CNT-LOR V2a, à fond annulaire bas, paroi rectiligne, bord dans la continuité de celle-ci et lèvre aplatie ou arrondie, ou encore, plus rarement, amincie : recouvrement tombes T12/14 (1 exemplaire), T13 (loculus : 1 exemplaire), T20 (loculus : 1 exemplaire), T24 (recouvrement : 1 exemplaire), bûcher B1 (socle : 3 exemplaires ; fonctionnement : 1 exemplaire) (fig. 91, $\mathrm{n}^{\circ} 1$ et 2 ) ;

- CNT-LOR V2b, à fond annulaire bas, paroi concave, bord dans la continuité de celle-ci et lèvre aplatie ou arrondie, ou encore, plus rarement, amincie : recouvrement tombes T12/14 1 exemplaire), T23 (loculus : 1 exemplaire), structure ST3 (1 exemplaire), bûcher B1 (socle : 8 exemplaires ; fonctionnement : 1 exemplaire) (fig. 91, nº 3 à 5).

En outre, la forme CNT-LOR V1b, à fond annulaire bas, paroi rectiligne, bord dans la continuité de celle-ci mais terminée par une lèvre formant un biseau ou un méplat vers l'intérieur, est représentée par un exemplaire (tombe T6).

Ces trois formes de couvercles sont très communes en Languedoc oriental à partir du $\mathrm{V}^{\mathrm{e}} \mathrm{s}$. av. J.-C. et durant tout le second Âge du Fer (Py, Adroher Auroux, Sanchez 2001, p. 954-966).

\subsubsection{Les coupes et coupelles}

Assez rares, également, les coupes se répartissent en trois grands types de formes :

- CNT-LOR C1, à panse arrondie-convexe, embouchure évasée, bord divergent à lèvre arrondie ou aplatie : tombes T6 (1 exemplaire), T17 (recouvrement : 1 exemplaire), T23 (loculus : 1 exemplaire), T24 (recouvrement : 1 exemplaire), bûcher B1 (socle : 10 exemplaires ; fonctionnement : 6 exemplaires) (fig. 91, $\mathrm{n}^{\circ} 6$ à 8);

- CNT-LOR C2, à panse arrondie-convexe, embouchure rétrécie, bord convergent à lèvre arrondie ou aplatie: tombe T6 (1 exemplaire), sol, bûcher B1 (socle : 8 exemplaires; fonctionnement : 7 exemplaires) (fig. 91, $\mathrm{n}^{\circ} 10$ et 11 );

- CNT-LOR C4, à panse carénée, embouchure rétrécie, bord convergent à lèvre aplatie : bûcher B1 (fonctionnement : 4 exemplaires) (fig. 91, $\mathrm{n}^{\circ} 13$ ) ;

Les variantes munies d'une anse CNT-LOR C1d et CNT-LOR C2d sont attestées par un spécimen chaque fois, respectivement dans le bûcher 1 (fonctionnement) et dans la tombe T11 (recouvrement) (fig. 91, $\mathrm{n}^{\circ} 9$ et 12).

Aucun de ces exemplaires ne présente de profil complet. Cependant, les morceaux de bases indiquent que ces vases sont équipés d'un fond plat ou, plus rarement, annulaire bas, mais jamais creux. 


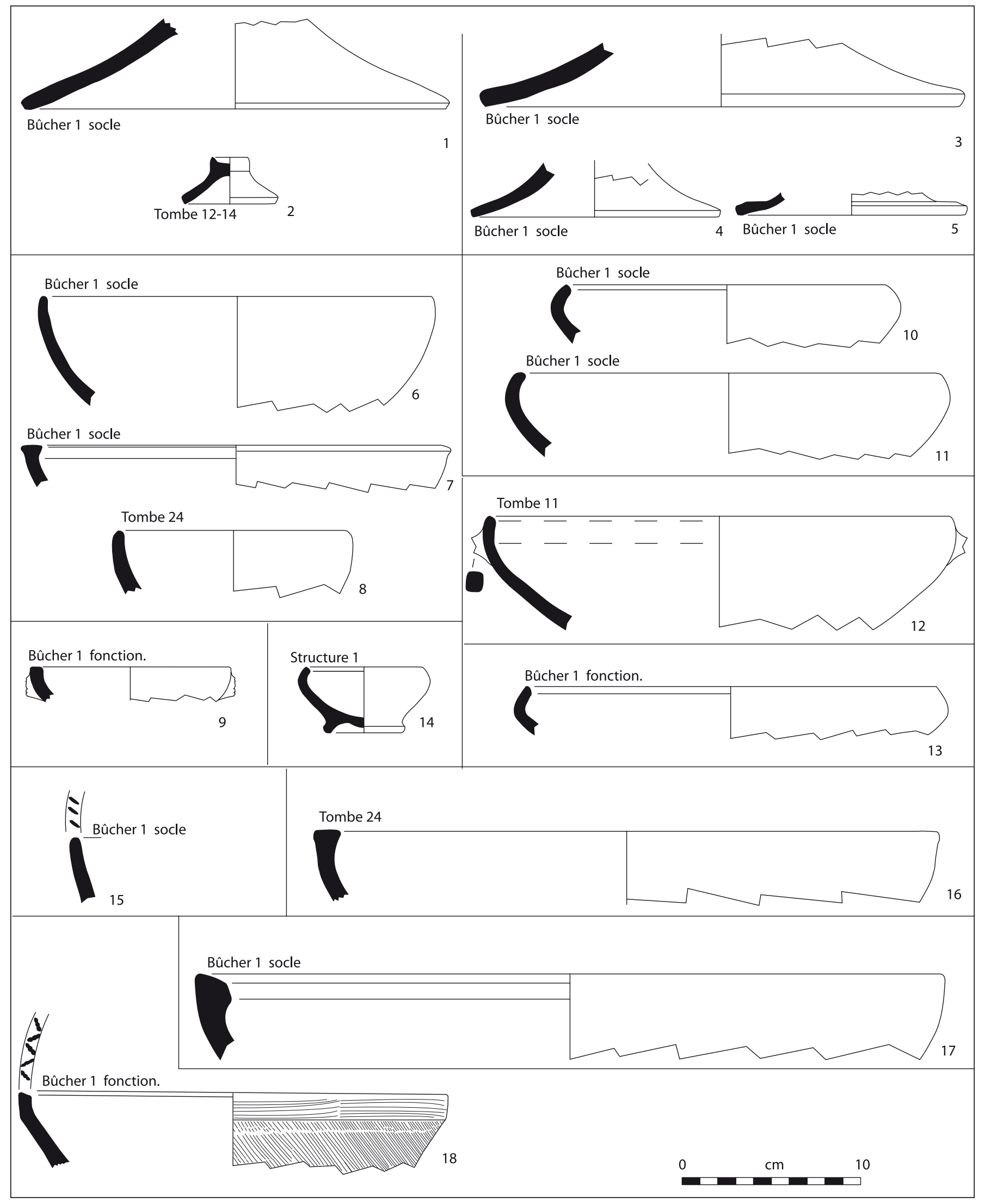

Fig. 91. Typologie des coupes-couvercle (1-5), des coupes et coupelles (6-14) et des jattes (15-18) non tournées du secteur fouillé de la nécropole d'Ambrussum. 
La catégorie de très petite taille, dite coupelle, est attestée par un spécimen de forme CNT-LOR C5e1 dans la structure ST1 (fig. 91, $\mathrm{n}^{\circ}$ 14).

Les formes de coupes CNT-LOR C1, CNT-LOR C2 et CNT-LOR C4 sont très fréquentes dans la région au milieu de l'Âge du Fer et jusqu'à la fin du $\mathrm{III}^{\mathrm{e}}$ s. av. J.-C. À partir du II s. av. J.-C. elles se raréfient peut-être en liaison avec la montée des importations de coupes à vernis noir (Py, Adroher Auroux, Sanchez 2001, p. 842, 851 et 864). La forme de coupelle CNT-LOR C5e1, attestée toujours très ponctuellement, est peut-être inspirée de la forme Puig $1 \mathrm{C}$ de l'atelier des productions à vernis noir de Rosas ou Lamb. A25 de la Campanienne A.

\subsubsection{Les jattes}

Les jattes sont présentes sous plusieurs formes et variantes, attestées chaque fois par de très rares, voire uniques exemplaires :

- CNT-LOR J1a, à panse tronconique évasée, bord à lèvre arrondie lisse : tombe 19 (loculus : 1 exemplaire) ;

- CNT-LOR J1b, à panse tronconique évasée, bord à lèvre arrondie portant des coups imprimés obliques : bûcher B1 (socle : 2 exemplaires) (fig. 91, $\mathrm{n}^{\circ} 15$ );

- CNT-LOR J1c : à panse tronconique évasée, bord à lèvre aplatie lisse, avec aplatissement vers l'extérieur : tombe T6 (1 exemplaire) ;

- CNT-LOR J1e, variante 1, à panse tronconique évasée ou arrondie, bord à lèvre élargie et aplatie, avec aplatissement horizontal: tombe T24 (recouvrement: 1 exemplaire), sol, bûcher B1 (fonctionnement : 1 exemplaire) (fig. 91, $\left.\mathrm{n}^{\circ} 16\right)$;

-CNT-LOR J1e, variante 3 , à panse tronconique évasée ou arrondie, bord à lèvre élargie et aplatie, avec aplatissement incliné vers l'intérieur : bûcher B1 (socle : 1 exemplaire) (fig. 91, $\mathrm{n}^{\circ} 17$ );

- CNT-LOR J1f, de même forme que la précédente mais avec bord à lèvre aplatie et portant des coups imprimés obliques: bûcher B1 (fonctionnement: 1 exemplaire) (fig. 91, $\left.\mathrm{n}^{\circ} 18\right)$.

Ces formes sont connues en Languedoc oriental durant le second Âge du Fer jusqu' au $\mathrm{II}^{\mathrm{e}}$ s. av. J.-C. (Py, Adroher Auroux, Sanchez 2001, p. 871-886).

\subsection{La céramique importée fine}

La vaisselle tournée fine, importée, comprent les productions «massaliètes » à pâte claire et à pâte grise peinte, les vases attiques à vernis noir, ceux, également à vernis noir des ateliers des petites estampilles, de
Rosas, et campanienne A et enfin les vases gris de la Côte catalane.

\subsubsection{La céramique à pâte claire massaliète}

La céramique à pâte claire massaliète est représentée par des vases ouverts ou fermés, dont l'état de fragmentation ne permet pas toujours de préciser la forme.

Parmi les vases ouverts, outre un pied annulaire bas de coupe indéterminée (fig. 92, $n^{\circ}$ 9), on reconnaît les formes suivantes :

- le bol CL-MAS 236, à vasque à courbure continue, bord convergent, lèvre arrondie ou amincie et pied annulaire bas : structure ST1 (1 exemplaire); bûcher B 1 (socle : 1 exemplaire) (fig. 92, $\mathrm{n}^{\circ} 1$ et 2). Cette forme apparaît au début du $\mathrm{IV}^{\mathrm{e}} \mathrm{s}$., connaît une fréquence maximum au III ${ }^{\mathrm{e}}$ s. puis disparaît au milieu du II' s. av. J.-C. (Py, Adroher Auroux, Sanchez 2001, p. 643-646) ;

- le bol CL-MAS 237, qui se distingue du précédent par un bord replié vers l'intérieur du vase : bûcher B1 (fonctionnement : 1 exemplaire) (fig. 92, $\mathrm{n}^{\circ} 3$ ). Cette forme, apparue dès la fin du $\mathrm{V}^{\mathrm{e}} \mathrm{s}$., connaît aussi un maximum de fréquence au $\mathrm{III}^{\mathrm{e}} \mathrm{s}$., mais semble disparaître un peu plus tôt que la précédente, dans le premier quart du $\mathrm{II}^{\mathrm{e}}$ s. av. J.-C. (Py, Adroher Auroux, Sanchez 2001, p. 646-649);

- le bol CL-MAS 321, à vasque à courbure continue, bord vertical ou évasé, lèvre arrondie ou amincie et pied annulaire bas : 1 exemplaire aux morceaux répartis dans les loculus des tombes $\mathrm{T} 12$ et T13, et 1 exemplaire dans le loculus de la tombe T14 (fig. 92, $\mathrm{n}^{\circ} 4$ et 5). Cette forme admet une fourchette chronologique très large avec une apparition dès le $\mathrm{V}^{\mathrm{e}} \mathrm{s}$. et une disparition dans le courant du II ${ }^{\mathrm{e}}$ s. av. J.-C. (Bats 1988, p. 175 ; Py, Adroher Auroux, Sanchez 2001, p. 654-656). Ces deux vases ont une estampille circulaire imprimée au centre du fond à l'intérieur, et, dans le cas le mieux conservé, il s'agit d'une rosette à six pétales, à l'instar des vases à vernis noir ;

- la coupe à anses CL-MAS 433, à vasque à inflexion basse, paroi légèrement concave au-dessus de la carène, bord à lèvre arrondie, anses horizontales et pied annulaire bas : tombe 2 (1 exemplaire), sol et bûcher B1 (socle : 1 exemplaire) (fig. 92, $\mathrm{n}^{\circ} 6$ à 8). La datation de cette forme, qui imite la coupe attique Lamb. A42Ba, couvre les IV $^{\text {e }}$ et III $^{e}$ s. av. J.-C. (Bats 1988, p. 177 (forme F434); Py, Adroher Auroux, Sanchez 2001, p. 696-697).

À côté de fragments de cruches ou d'œnochoés de forme indéterminée (fig. 86, $\mathrm{n}^{\circ} 12$ à 18) figure une forme identifiable : 


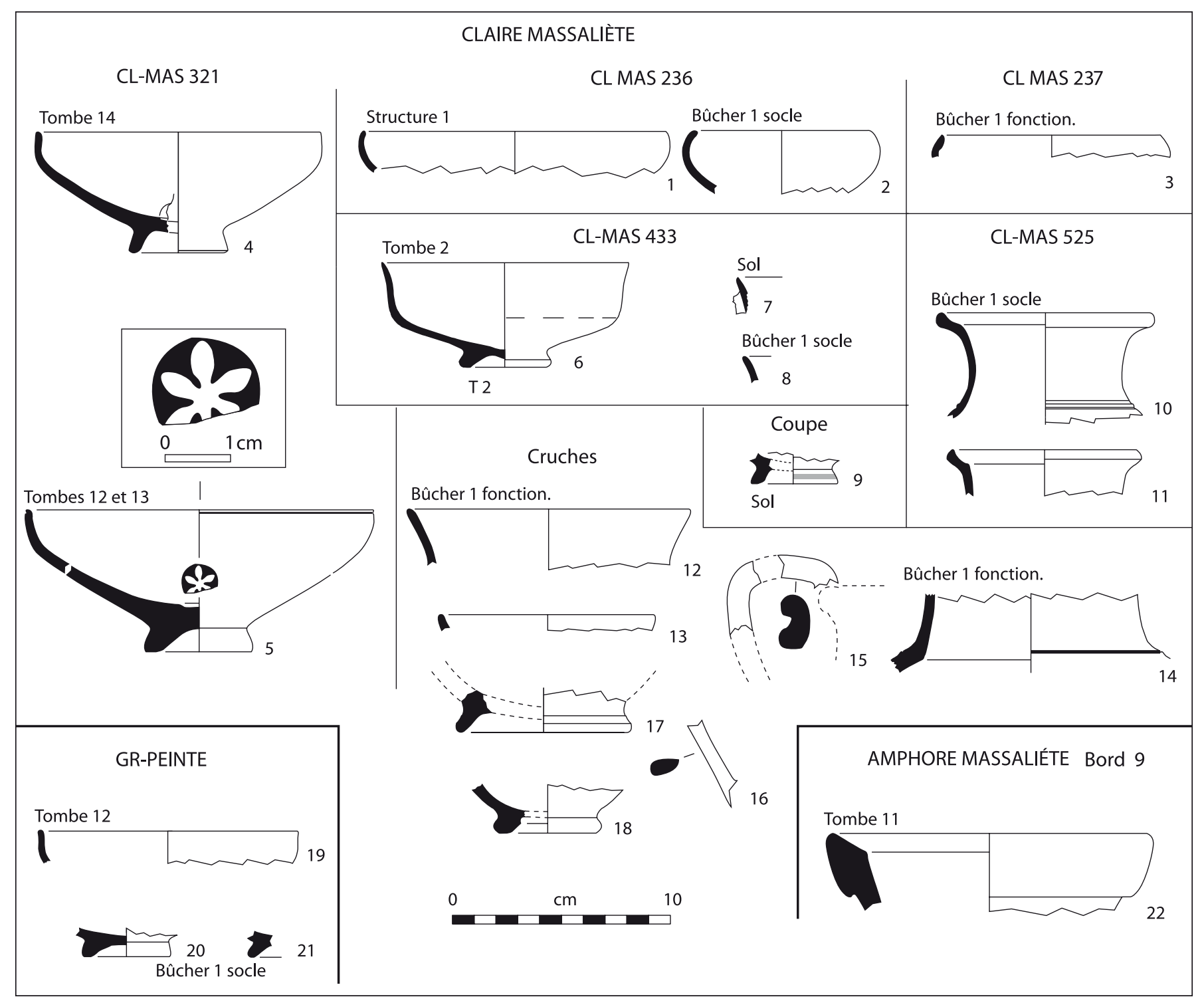

Fig. 92. Typologie de la céramique importée du secteur fouillé de la nécropole d'Ambrussum. 1-18: céramique à pâte claire massaliète ; 19 et 21 : céramique grise peinte massaliète ; $22:$ amphore massaliète.

- la cruche CL-MAS 525, à col incurvé, bord concave, panse ovoïde, anse verticale et fond annulaire bas : bûcher B 1 (socle : 2 ou 3 exemplaires) (fig. 92, $\mathrm{n}^{\circ} 10$ et 11). La chronologie de cette forme s'étend du $\mathrm{IV}^{\mathrm{e}}$ au II ${ }^{\mathrm{e}} \mathrm{s}$. av. J.-C. (Py, Adroher Auroux, Sanchez 2001, p. 721).

\subsubsection{La céramique grise peinte massaliète}

Très rare dans ce secteur de la nécropole d'Ambrussum, la céramique grise peinte massaliète n'est attestée que par des tessons de coupes de formes GR-PEINTE 2 ou 4 , à bord vertical et pied annulaire bas : tombe T12 (loculus : 1 exemplaire) et bûcher B 1 (socle : 2 à 5 exemplaires) (fig. 92, $\mathrm{n}^{\circ} 19$ à 21). Ces formes datent de la seconde moitié du IV et du III' s. av. J.-C. (Py, Adroher Auroux, Sanchez 2001, p. 1118 et 1121).

\subsubsection{La céramique attique à vernis noir}

La céramique attique à vernis noir est représentée seulement par deux fragments : un tesson informe dans le niveau de fonctionnement du bûcher B1 et par un bord de bolsal AT-VN 532-561, sur le sol de la nécropole près de la tombe T25. Cette dernière forme est bien présente dans des strates comprises entre la fin $\mathrm{du} \mathrm{V}^{\mathrm{e}}$ et le milieu du III ${ }^{e}$ s. av. J.-C. à Lattes et dans le reste du Languedoc oriental ainsi que dans la région du bas-Rhône (Py, Adroher Auroux, Sanchez 2001, p. 1161-1163). 


\subsubsection{La céramique de l'atelier des petites estampilles}

Le seul vase attribuable à l'atelier italien des petites estampilles est de forme PET-EST 2783, variante 3, un bol à vasque à profil bombé et bord convergent, de dimension moyenne (bûcher B1, socle) (fig. 93, $\mathrm{n}^{\circ} 23$ ). Il s'agit là de la forme la plus répandue dans cette catégorie de céramique à vernis noir, datable entre le dernier quart du $\mathrm{IV}^{\mathrm{e}} \mathrm{s}$. et le milieu de la seconde moitié du III ${ }^{\mathrm{e}}$ s. av. J.-C. (Py, Adroher Auroux, Sanchez 2001, p. 1161-1163).

\subsubsection{La céramique à vernis noir de l'atelier de Rosas}

Les vases de l'atelier de Rosas constituent la catégorie de céramique à vernis noir la mieux représentée dans le secteur exploré de la nécropole d'Ambrussum. Plusieurs formes sont présentes :

- la coupelle de forme Puig 2, à panse carénée près d'un bord convergent à lèvre amincie et arrondie (Puig 2006, p. 307) : tombes T11 (1 exemplaire) et T6 (1 exemplaire) (fig. 93, $\mathrm{n}^{\circ} 1$ et 2 ) ;

- la coupe de forme Puig 10b, à panse convexe continue, bord parallèle à lèvre arrondie (Puig 2006, p. 308-309): structure ST3 (1 exemplaire) (fig. 93, $\left.\mathrm{n}^{\circ} 3\right)$;

- le bol de forme Puig 11a, à panse convexe continue, peu bombée, bord divergent à lèvre arrondie (Puig 2006, p. 312-313) : tombe T6 (1 exemplaire) (fig. 93, $\left.\mathrm{n}^{\circ} 4\right)$;

- le bol de forme Puig $11 \mathrm{~b}$, à panse convexe continue, peu bombée, bord parallèle à lèvre arrondie (Puig 2006, p. 316) : tombes T11 (recouvrement, 1 exemplaire) et T17 (recouvrement, 1 exemplaire), bûcher 1 (socle : 4 exemplaires; fonctionnement : 6 exemplaires) (fig. 93, $\mathrm{n}^{\circ} 5$ à 15);

- le bol de forme Puig 11c, à panse convexe continue, peu bombée, bord convergent à lèvre arrondie (Puig 2006, p. 316) : structure ST1 (1 exemplaire estampillé d'une rosette de six ou sept pétales), bûcher 1 (socle : 1 exemplaire) (fig. 93, $\mathrm{n}^{\circ} 16$ et 17 );

- plusieurs exemplaires de bol Puig 11, dont la forme du bord ne peut être précisée, sont également présents dans la tombe T5 et le bûcher B1 (socle et fonctionnement) ;

- la coupe de forme Puig 13a, à panse à carène adoucie, partie supérieure de la panse évasée et bord déversé à lèvre à ressaut (Puig 2006, p. 324-329) : tombe T12 (1 exemplaire décoré de quatre palmettes parallèles entourées d'un cercle de guillochis) (fig. 93, n 19);

- la kylix de forme Puig 33, à panse carénée avec partie supérieure évasée et bord déversé à lèvre arrondie (Puig 2006, p. 340-341) : tombe T25 (loculus : 1 exemplaire) et sol (fig. 93, $\mathrm{n}^{\circ} 20$ et 21) ;
- un fond de coupe non classable figure dans le socle du bûcher (fig. 93, $\mathrm{n}^{\circ}$ 22) et des tessons informes dans diverses structures, tombes T10, T11, T15, T17, T19, recouvrement de T22-23, sol et bûcher 1 (socle et fonctionnement).

Toute cette production de céramique de Rosas s'inscrit entre le dernier quart du $\mathrm{IV}^{\mathrm{e}} \mathrm{s}$. et la fin du III' $\mathrm{s}$. av. J.-C. (Puig 2006, p. 466-471). À Lattes, la courbe de ces importations montre un maximum de fréquence centré autour du milieu du $\mathrm{III}^{\mathrm{e}}$ s. av. J.-C., dans les second et troisième quarts de ce siècle (Py, Adroher Auroux, Sanchez 2001, p. 1217-1218 et fig. 190).

\subsubsection{La céramique campanienne A}

En total contraste avec la céramique de l'atelier de Rosas, la campanienne A ancienne apparaît très rare ici : un tesson informe dans la tombe 11 et un fond de bol CAMP-A 27a-b, portant une rosette au dessin très fin dans la tombe 13 (fig. 93, $n^{\circ}$ 24). Cette dernière forme est importée en Gaule du Sud à partir du milieu du $\mathrm{III}^{\mathrm{e}} \mathrm{s}$. et reste la plus diffusée jusqu'au début du siècle suivant, et la finesse des pétales de la rosette est un critère d'ancienneté dans la série (Py, Adroher Auroux, Sanchez 2001, p. 453-464).

\subsubsection{Céramique à vernis noir de Rosas ou Campanienne A ancienne}

L'identification atelier de Rosas ou Campanienne A ancienne est problématique pour un bord de coupe Lamb. 27, provenant du sol, trois tessons informes issus du socle du bûcher 1 et sept autres informes de la couche de fonctionnement du même bûcher.

\subsubsection{La céramique grise de la Côte catalane}

La céramique de la Côte catalane est ici tout à fait exceptionnelle. Un seul tesson de gobelet de forme non déterminable précisément COT-CAT Gb0 est attesté : panse carénée et anse verticale, provenant du sol aux abords de la tombe T11. La datation de ces gobelets s'échelonne du $\mathrm{IV}^{\mathrm{e}} \mathrm{s}$. à la première moitié du $\mathrm{I}^{\mathrm{er}} \mathrm{s}$. av. J.-C. (Py dir. 1993, p. 395).

\subsection{Les amphores}

Le secteur exploré de la nécropole d'Ambrussum livre d'assez nombreux tessons d'amphore massaliète, et c'est là le seul type d'amphore qui y est attesté. Un bord y figure, de forme A-MAS bd9 : tombe T11 (loculus) 
(fig. 92, $\mathrm{n}^{\circ}$ 22). Pour le reste, il s'agit essentiellement de petits tessons de panses et plus rarement d'anses : tombes T11 (recouvrement: 2 tessons), T12 (loculus : 2 tessons), recouvrement T12-14 (1 tesson), T23 (1 tesson), T25 (recouvrement: 1 tesson), sol (6 tessons), bûcher B1 (socle : 23 tessons; fonctionnement : 24 tessons).

L'amphore massaliète pourvue d'un bord de type 9 caractérise la dernière phase de la production de ces récipients, comprise entre le début du $\mathrm{III}^{\mathrm{e}} \mathrm{s}$. et le milieu du $\mathrm{II}^{\mathrm{e}} \mathrm{s}$. av. J.-C., et elle est particulièrement fréquente durant la seconde moitié du $\mathrm{III}^{\mathrm{e}} \mathrm{s}$. et le premier quart du siècle suivant (Py, Adroher Auroux, Sanchez 2001, p. 191-192). On rapprochera ce fait de l'absence de découverte, dans cette partie de la nécropole du moins, de tout reste d'amphores italiques et gréco-italiques. Si l'amphore italique ne semble pas présente dans la région avant le dernier tiers du $\mathrm{II}^{\mathrm{e}}$ s. av. J.-C. (Py, Adroher Auroux, Sanchez 2001, p. 97), pour sa part, l'amphore gréco-italique arrive en nombre en Languedoc oriental dès le premier quart de ce siècle, et notamment à Lattes où elle représente déjà alors $20 \%$ des tessons d'amphore découverts sur le site (Ibid., p. 45). Une telle exclusivité de l'amphore massaliète et l'absence des productions amphoriques gréco-italiques et italiques contribuent

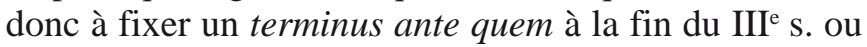
au tournant du $\mathrm{II}^{\mathrm{e}} \mathrm{s}$. av. J.-C. pour ce quartier de la nécropole d'Ambrussum.

\section{Les pièces d'habillement et de parure}

Les pièces d'habillement et/ou de parure comprennent des chaînes ceintures, des éléments métalliques de ceinture en matière périssable, des fibules, des pendants d'oreille, des torques, des bracelets et/ou anneaux de cheville et des perles entrant dans la composition de colliers ou de bracelets.

\subsection{Chaîne-ceinture en bronze dite « féminine »}

Le type de chaîne-ceinture présent dans la nécropole d'Ambrussum se compose d'une suite de maillons doubles alternant avec des anneaux auxquels sont accrochées des chaînettes terminées par des pendentifs coniques, l'ensemble se fermant au moyen d'une agrafe, le tout en bronze. De nombreux éléments, maillons doubles, anneaux, petits maillons de chaînettes, pendentifs et agrafes du loculus proviennent de la tombe 19 (fig. 94, $\mathrm{n}^{\circ} 1$ ), tandis qu'un maillon double est issu du recouvrement commun aux tombes T22 et T23, et un autre, du niveau de fonctionnement du bûcher B 1 (fig. 94, $\mathrm{n}^{\circ} 2$ et 3 ).

Ce type de chaîne-ceinture a été reconnu, parmi d'autres, comme caractéristique de la phase moyenne de la Tène et qualifiée de «féminine » par J. Déchelette (1927, p. 736-741). Ce dernier donne la photographie d'un exemplaire provenant de l'oppidum de Nages, semblable à celui de la tombe 19 (Déchelette 1927, p. 505, fig. 419). Un maillon double à moulure simple, fort proche de ceux d'Ambrussum mais abandonné en cours de fabrication, a été découvert à Lattes dans une couche de restructuration d'une maison de la deuxième moitié du III s. av. J.-C. (Tendille, Manniez 1990, p. 100-101, $\left.\mathrm{n}^{\circ} 16\right)$. Cette découverte a un double intérêt. Elle atteste une production locale de ces chaînes-ceintures, et elle date celle-ci du plein milieu du $\mathrm{III}^{\mathrm{e}} \mathrm{s}$. av. J.-C. (Feugère 1990b, p. 364).

Les fouilles du docteur Marignan faites sur l'oppidum d'Ambrussum vers 1910, ont aussi procuré une agrafe de ceinture et des maillons doubles tout à fait comparables à ceux de la tombe 19, mais évidemment, on n'en connaît pas le contexte précis ${ }^{18}$. Et de fait, des maillons doubles et des pendentifs de même forme que les exemplaires d'Ambrussum sont bien attestés dans plusieurs habitats du Languedoc central jusqu'au Var : ainsi à Lattes, des chaînons doubles dans des niveaux du dernier quart du $\mathrm{III}^{\mathrm{e}} \mathrm{s}$. (Feugère 1990a, p. 191-193, n 15 et 16) ou du milieu du II s. av. J.-C. (Py 1994b, p. 396$397, \mathrm{n}^{\circ}$ 1076), et des pendentifs dans une couche du premier quart du II $\mathrm{s}$. (Tendille, Manniez 1990, p. 101102, n 23 ; Feugère 1990a, p. 193-194, n 36), à Nages, à Mauressip, au Mont-Cavalier (Nimes), au Marduel, hors contexte ou dans des couches datées du $\mathrm{II}^{\mathrm{e}}$ ou de la première moitié du I ${ }^{\text {er }}$ s. av. J.-C., mais sur des sites toutefois déjà habités au III ${ }^{\mathrm{e}} \mathrm{s}$. av. J.-C. (Tendille 1980, p. 107-109). De tels objets sont également connus en dehors de la région, et notamment sur le Plateau suisse, et selon G. Kaenel (1990, p. 275), ils se généralisent au tout début de La Tène $\mathrm{C} 1$. Ainsi, une chaîne semblable figure dans la tombe 8 de Vevey, canton de Vaud, datée de La Tène B2/C1 (Martin-Kilcher 1981, p. 137, fig. 27, $\mathrm{n}^{\circ} 4$ ). Elle est aussi munie de pendentifs similaires à ceux qui équipent la chaîne d'Ambrussum, pendentifs que l'on retrouve encore à Ollon-La Combe Sala, dans le même canton, datés de la transition La Tène B2-C1, soit le milieu et la deuxième moitié du $\mathrm{III}^{\mathrm{e}} \mathrm{s}$. av. J.-C. (Kaenel 1990, p. 85-86 et p. 384, pl. 18, n 14).

18 Ces objets sont conservés dans la collection Grand à Gallargues, et j'en dois la connaissance à J.-L. Fiches. 


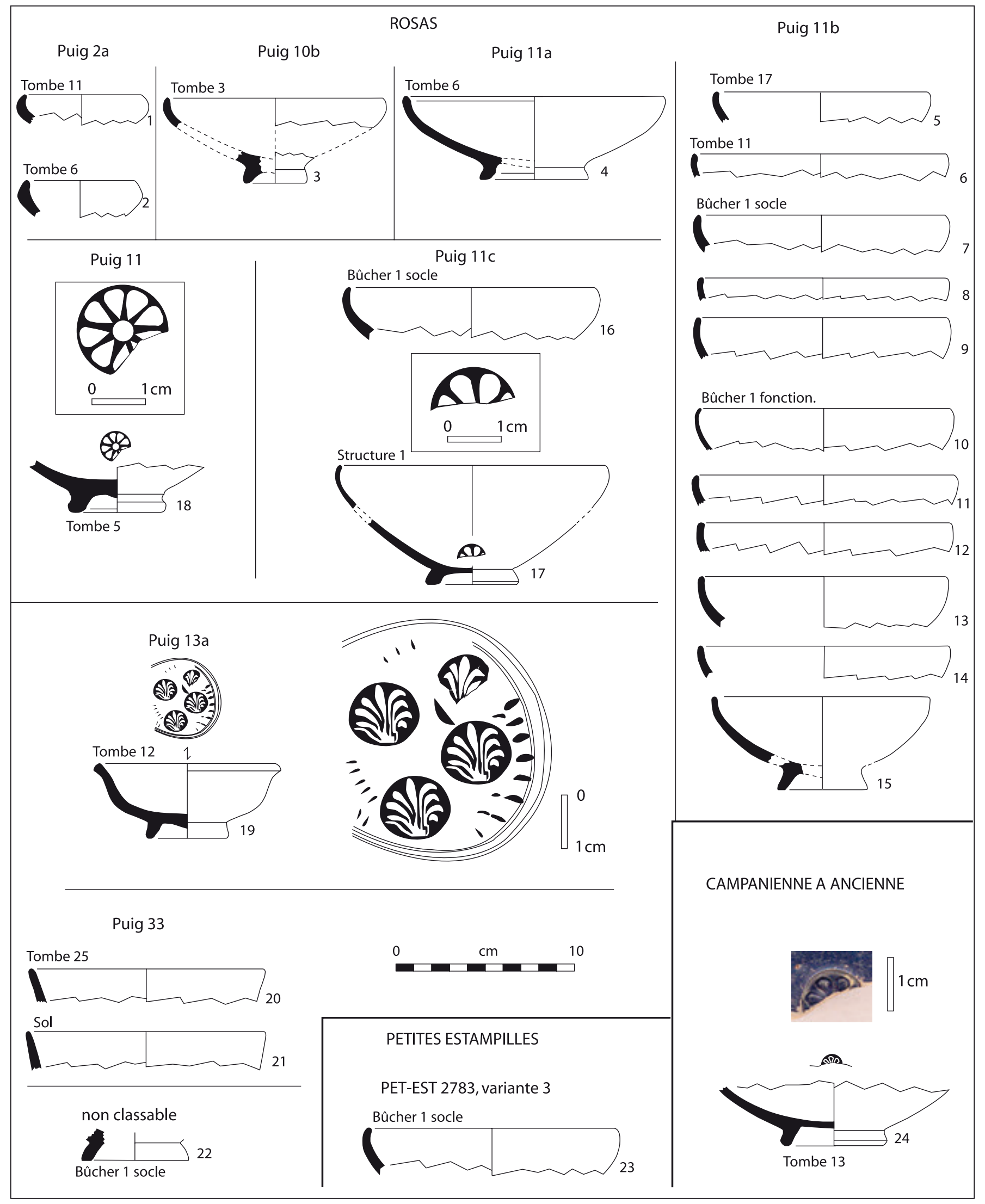

Fig. 93. Typologie de la céramique importée à vernis noir du secteur fouillé de la nécropole d'Ambrussum. 1-22 : ateliers de Rosas ; 23 : Petites Estampilles ; 24 : Campanienne A ancienne. 


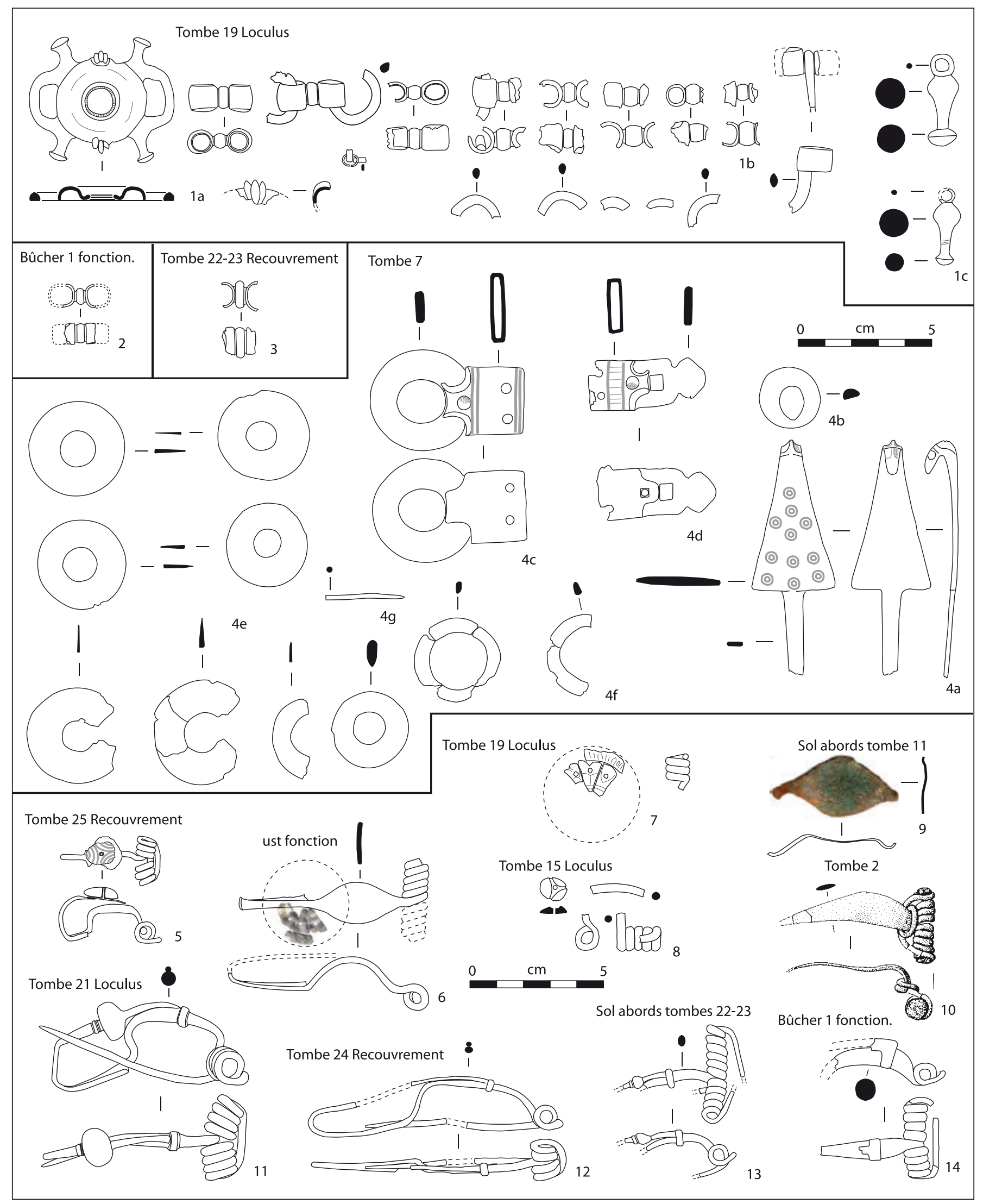

Fig. 94. Typologie des objets d'habillement du secteur fouillé de la nécropole d'Ambrussum. 1-4 : chaîne-ceinture et éléments de ceinture ; 7-14 : fibules. 


\subsection{Autre ceinture}

Dans la tombe T7 des pièces en bronze montées sur sangle, anneaux, agrafe à crochet, agrafe à anneau, appartiennent à une ceinture dont on ne connaît aucun parallèle (fig. 94, n $4 \mathrm{a}-4 \mathrm{f}$ ). Selon l'avis d'André Rapin, il ne semble pas s'agir d'une suspension de fourreau d'épée mais plutôt d'une simple ceinture (Feugère, Tendille dans Fiches dir. 1989, p. 35).

\subsection{Fibules}

Les fibules trouvées durant les fouilles de la nécropole relèvent de deux schémas différents.

Le premier schéma est celui de la fibule à pied discoïde recourbé sur l'arc et décoré d'éléments de corail rivetés, à arc de section arrondie ou aplatie et à ressort bilatéral à six ou huit larges spires avec corde extérieure ou intérieure. De tels objets figurent en fer dans le recouvrement de la tombe $\mathrm{T} 25$, et en bronze dans le niveau de fonctionnement du bûcher B1. Des exemplaires très fragmentaires en bronze sont également attestés dans les loculus des tombes T2, T15 et T19, ainsi que sur le sol aux abords de la tombe T11. Le plateau discoïdal porte soit un seul cabochon (tombes 15 et 25), soit un assemblage de plusieurs éléments triangulaires rayonnants, ceints d'une bordure circulaire (tombes T19 et bûcher B1) (fig. 94, nº 5 à 10).

Ce type de fibule est bien attesté dans le Midi méditerranéen et plusieurs exemplaires découverts dans des habitats sont bien datés par le contexte des céramiques importées : au Marduel (Saint-Bonnet-du-Gard) dans les trois derniers quarts du $\mathrm{IV}^{\mathrm{e}} \mathrm{s}$. av. J.-C. (Py, Lebeaupin 1989, p. 161, fig. 40, n 3), à La Ramasse (Clermontl'Hérault), au IV e et début du III' ${ }^{\mathrm{e}}$ s. av. J.-C. (García, 1993, p. 280, fig. 141, $\mathrm{n}^{\circ} 27$ ), dans l'île de Martigues, Bouches-du-Rhône, dans le dernier quart du $\mathrm{IV}^{\mathrm{e}} \mathrm{s}$. et durant le III' s. av. J.-C. (Rétif 2000, p. 175-177), ou encore sur l'oppidum de Nages, Gard, en sa première phase d'occupation placée dans la première moitié du III $^{\mathrm{e}}$ s. av. J.-C. (Py 1978, p. 269 et 270, fig. 128, n 1 ). À Ensérune, de tels spécimens se rencontrent dans des tombes de la première moitié du $\mathrm{III}^{\mathrm{e}} \mathrm{s}$. av. J.-C. : tombes 55 (Jannoray 1955, p. 243, fig. 32), 3-1988, 5-1988 et 6-1988 (Schwaller et al. 1995). Il s'agit du type 11 de la classification de $\mathrm{C}$. Tendille consacrée au fibules de la région nîmoise (Tendille 1978).

Cette série s'apparente aux fibules dites de Münsingen, bien connues en Gaule interne et en Suisse et datées de la seconde moitié du $\mathrm{IV}^{\mathrm{e}}$ et de la première moitié du III" s. av. J.-C. La fibule de la tombe 25 d'Ambrussum se rapproche du «type idéal » des fibules de Münsingen trouvées en Champagne défini par Charpy (1995, p. 353 et 358). Elle trouve d'autres comparaisons en Champagne (Hatt, Roualet 1977, p. 14 et 29, pl. XI, $\mathrm{n}^{\circ} 7,8$ et 11 : Tène ancienne IIIa) et sur le plateau suisse (Kaenel 1990, p. 239 : La Tène B1-B2) et notamment dans la tombe 16 de Vevey (Martin-Kilcher 1981, p. 114, fig. 9) ou dans la tombe 171 de Münsingen (Peyer 1991, p. 343 , fig. $9, \mathrm{n}^{\circ} 7$ ).

Le second schéma est celui des fibules en fer à long pied recourbé et fixé au sommet de l'arc par deux petites griffes. Il regroupe trois spécimens (fig. 94, nº 11 à 13).

Dans la tombe T21, un exemplaire avec, sur le pied, une grosse bille confectionnée dans la masse même du métal (fig. 94, $\mathrm{n}^{\circ} 11$ ), de type $13 \mathrm{~b}$ de R. Gebhard daté à La Tène C1, soit entre 275 et 200 av. J.-C. (Gebhard 1991, p. 15-16, 80-81, 95 et pl. 16, n' 203). C'est un type classique du monde celtique continental, dont l'apparition est quelque peu postérieure à la fibule à pied discoïde recourbé sur l'arc et décoré d'éléments de corail rivetés. Avec une perle plus ou moins importante, on en trouve par exemple dans le Bassin parisien dès le second quart du III $\mathrm{e}$ s. à Saint-Maur-des-Fossés, Val-de-Marne ou à Allonne, Oise, ou encore à La HauteGrève à Gouaix, Seine-et-Marne (Leconte 1990-1991, p. 74-75, fig. 24 ; Paris 1998, p. 312, fig. 34 , n 1 p. 313, fig. $35, \mathrm{n}^{\circ} 1$ et fig. $36, \mathrm{n}^{\circ} 1$; Séguier et al. 2010, p. 96 et 159, tombe 1056), en Bourgogne, dans la tombe 12 des Pâtures à Châtenay-sur-Seine ou dans la tombe 1 de l'enclos 1 de Tillies à Vix (Mordant 1977, p. 51, fig. 6, $\mathrm{n}^{\circ} 2$ et 3 ; Baray, Chaume, Millet 2007, p. 212, fig. 25, p. 213, fig. 27 et p. 218), dans le Centre à Sceaux-duGâtinais, Loiret (Augier et al. 2007, p. 126-127, fig. 8, $\mathrm{n}^{\circ} 11$ ), en Auvergne, à Clermont-Ferrand/La Grande Borne (Deberge et al. 2007, p. 188, fig. 13, $\mathrm{n}^{\circ} 65$ ) ou encore sur le Plateau suisse, comme dans les tombes 17 et 18 de Vevey, canton de Vaud, datées de La Tène B2/C1 (Martin-Kilcher 1981, p. 141, fig. 30, n 6 et 7) ou dans les tombes de Gumefens, canton de Fribourg (Schwab 1995). Dans le Midi méditerranéen de la France, ce second type est rare. Il est présent en Languedoc occidental mais de manière assez discrète: tombe 45 d'Ensérune (Feugère et al. 1994, p. 269, fig. 28, nº 9 et p. 277) ou l'habitat de la Cité à Carcassonne au $\mathrm{III}^{\mathrm{e}} \mathrm{s}$. av. J.-C. (Rancoule, Solier 1972, p. 145-146). En Languedoc oriental, il n'apparaît pas dans l'inventaire de la région nîmoise (Tendille 1978), ni dans celui de l'habitat de l'Île à Martigues, Bouches-du-Rhône (Rétif 2000), ni encore à Lattes (Raux 1994 ; Paterno 2004). Dans cette 
région, il est cependant attesté dans un des dépôts rituels du Cailar (Gard), datés du III ${ }^{\mathrm{e}}$ s. av. J.-C. (Girard, Roure 2009, p. 200 et 204, pl. 2, n ${ }^{\circ} 13$ ) et un exemplaire, en bronze, de Peyre-Haute à Guillestre dans les HautesAlpes est très proche de l'exemplaire d'Ambrussum, avec un pied pourvu d'une sphère de dimension voisine (Willaume 1991, p. 211).

Dans la tombe T24 figure un exemplaire plus allongé de forme proche mais une lacune au niveau du pied ne permet pas de savoir si celui-ci était pourvu ou non d'une perle (fig. 94, $\mathrm{n}^{\circ} 12$ ). Il s'agit du type $13 \mathrm{c}$ ou 14 de R. Gebhard, daté également à La Tène C1, soit entre 275 et 200 av. J.-C. (Gebhard 1991, p. 15-17, 95 et pl. 18). Cette fibule peut être rapprochée d'objets similaires, dont le pied, mieux conservé, est pourvu d'une nodosité, qui sont issus de la nécropole de La Haute-Grève (Gouaix, Seine-et-Marne) et qui sont placés au milieu du III s. av. J.-C. (Séguier et al. 2010, p. 100, 120 et 156157 , tombes 1029 et 1050).

Des environs du recouvrement de la tombe T22 provient une petite fibule à long ressort (fig. 94, $\mathrm{n}^{\circ} 13$ ) du type 23 de R. Gebhard, qui admet à Manching une fourchette plus large, La Tène $\mathrm{C} 1$ jusqu'à la fin de $\mathrm{La}$ Tène C2, soit entre 250 et 150 av. J.-C. (Gebhard 1991, p. 22,86 et 95 et pl. $\left.42, \mathrm{n}^{\circ} 643\right)$. Un exemplaire semblable est daté du milieu du $\mathrm{II}^{\mathrm{e}} \mathrm{s}$. av. J.-C. sur le site de Gandaillat à Clermont-Ferrand (Deberge et al. 2007, p. 189 , fig. $\left.14, \mathrm{n}^{\circ} 19\right)$. Il pourrait donc s'agir d'un des objets les plus récents de la nécropole, mais pas forcément; et outre son imprécision chronologique, on soulignera que cette fibule peut tout aussi bien provenir du recouvrement de la tombe qu'avoir été abandonnée sur le sol de la nécropole ultérieurement à l'installation de cet ensevelissement.

\subsection{Pendants d'oreille}

Les pendants d'oreille, présents dans deux tombes, en argent (tombe T19) ou en bronze (tombe T2) sont de même forme, très simple, en croissant renflé dans la partie centrale et s'amincissant vers les deux extrémités pointues qui se chevauchent légèrement (fig. 95, $\mathrm{n}^{\circ} 1$ et 2). Dans le Midi de la France, on rencontre de tels objets, en bronze ou en métal précieux, depuis le Bronze final IIIb jusqu'au début du I ${ }^{\text {er }} \mathrm{s}$. av. J.-C. sans évolution typologique (Tendille 1980, p. 99-101). C'est d'ailleurs, semble-t-il, le seul type de pendant d'oreille représenté alors, avant le dernier siècle antérieur au changement d'ère. Tout près d'Ambrussum, l'oppidum de Roque de Viou à Saint-Dionisy, Gard, en a livré un, en bronze, daté de la fin du $\mathrm{IV}^{\mathrm{e}}$ ou du début du $\mathrm{III}^{\mathrm{e}} \mathrm{s}$. par le contexte (Tendille 1980, p. 100). Un autre, également en bronze, provient de la tombe 5 de Mourrel-Ferrat (Olonzac, Hérault), datée du dernier quart du $\mathrm{IV}^{\mathrm{e}} \mathrm{s}$. av. J.-C. ou du début du siècle suivant (Janin et al. 2000, p. 224, fig. 6, $\left.n^{\circ} 54\right)$. Cet objet apparaît aussi dans plusieurs contextes funéraires d'Ampurias depuis le milieu du $\mathrm{IV}^{\mathrm{e}} \mathrm{s}$. av. J.-C. (inhumation Martí 26), à la fin du $\mathrm{IV}^{\mathrm{e}}$ et au début du III ${ }^{e}$ s.av. J.-C. (inhumation Martí 96 et 109), ainsi que dans la première moitié du $\mathrm{II}^{\mathrm{e}} \mathrm{s} . \mathrm{av}$. J.-C. (incinération Las Corts 27) (Almagro 1953, p. 61, 93, 100 et 296).

\subsection{Torques}

Le torque filiforme en bronze, à système de fermeture comportant un anneau, est représenté ici par un ou deux exemplaires dans le niveau de fonctionnement du bûcher B1 (fig. 95, $\mathrm{n}^{\circ} 3$ et 4). Bien que fréquemment figuré dans la statuaire, cet objet de parure est considéré comme très rare dans le sud de la France au second Âge du Fer (Tendille 1980, p. 100-101). Mais cela tient peutêtre à la rareté des tombes connues pour cette période. En effet, dix exemplaires à tige lisse, tous inédits, sont signalés à Ensérune (Feugère et al. 1994, p. 240). Un exemplaire proche de celui d'Ambrussum provient de l'habitat de l'île à Martigues (Bouches-du-Rhône), daté vers la première décennie du II $\mathrm{e}$ s. av. J.-C. (Rétif 2000, p. 170-171, fig. $9, \mathrm{n}^{\circ} 245$ ). De toutes manières, par son élaboration élémentaire, cet objet n'est pas ici un marqueur chronologique précis.

\subsection{Bracelets et/ou anneaux de cheville}

\section{Les bracelets sont en verre ou en bronze}

On soulignera d'abord que le bracelet en verre est exceptionnel dans les tombes d'Ambrussum. Un seul exemplaire est attesté, en verre transparent avec un décor plastique de filets jaune opaque (groupe 4, forme 9, Haevernick 1960), qui provient du recouvrement de la tombe T11 (fig. 95, $\mathrm{n}^{\circ}$ 14). Dans cette couleur, ce type de bracelet n'est attesté régionalement qu'à Ensérune (Feugère et al. 1994, p. 274, fig. 32, n 5) et n'entre pas dans le classement de R. Gebhard (1989) ni dans les compléments proposés par M. Feugère (1992). D’une manière générale, ces bracelets en verre n'apparaissent dans la région que vers le milieu du III ${ }^{\mathrm{e}} \mathrm{s}$. av. J-C. ; ils $\mathrm{y}$ sont très rares avant le dernier quart de ce siècle et ne deviennent relativement abondants qu'au siècle suivant, à Nages ou à Lattes par exemple (Feugère et al. 1994, p. 244 ; Feugère, Py 1989 ; Paterno 2004). Leur rareté 


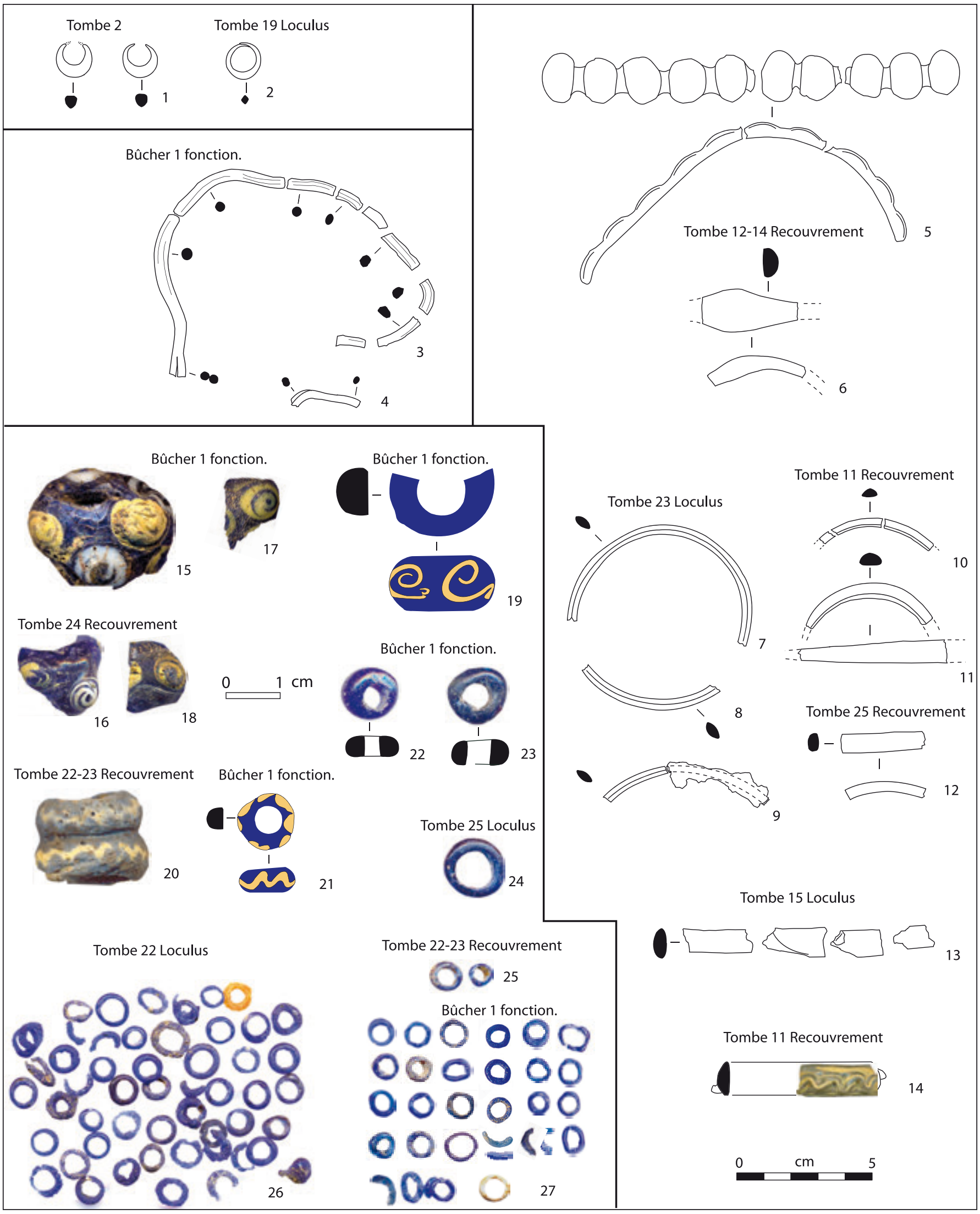

Fig. 95. Typologie des objets de parure du secteur fouillé de la nécropole d'Ambrussum. 1 et 2 : pendants d'oreille ; 3 et $4:$ torques ; 5-14 : bracelets ; $15-27$ : perles. 
dans la partie fouillée de la nécropole d'Ambrussum peut donc résulter de la datation ancienne de cette dernière.

\section{Plus nombreux, les bracelets en bronze ressortissent à plusieurs types :}

1) Le bracelet fin, à section ovale ou demi-circulaire en « $\mathrm{D}$ », sans décor visible : dans les tombes T11 (loculus et recouvrement), T15 (loculus), T23 (loculus ; deux ou trois exemplaires) et T25 (fig. 95, nº 7 à 12). L'état de fragmentation de ces pièces ne permet pas de savoir s'il s'agit d'exemplaires ouverts ou fermés, sauf peut-être pour un élément des abords de la tombe T11 car le ruban s'amincit vers une des cassures (fig. 95, $\mathrm{n}^{\circ} 11$ ). De tels bracelets en bronze sont courants en Languedoc oriental. Il s'agit du type 2 de la classification des bracelets établie par C. Tendille pour la région nîmoise, qui admet une chronologie très large, depuis le $\mathrm{VI}^{\mathrm{e}} \mathrm{s}$. jusqu'au ${ }^{\mathrm{er}} \mathrm{s}$. av. J.-C. (Tendille 1979, p. 64-67).

2) Le bracelet épais, à section ovale ou demi-circulaire en « $\mathrm{D}$ », sans décor visible : dans le loculus de la tombe 15 (fig. 95, $\mathrm{n}^{\circ}$ 13). Là encore, vu la fragmentation de l'objet, on ne sait si ce spécimen est ouvert ou fermé. C'est également un objet courant, dans sa version non décorée, au second Âge du Fer du Midi méditerranéen. Il correspond au type 6 des bracelets classés par C. Tendille (Tendille 1979, p. 72-73).

3) Le bracelet ou anneau de cheville moulé, ouvert, formé d'une succession d'oves pleins et peu proéminents, reliés l'un à l'autre par une moulure, chacune des deux extrémités étant constituée par un de ces oves : un exemplaire dans le loculus de la tombe T19 (fig. 95, $\mathrm{n}^{\circ} 5$ ). Cet objet n'est guère attesté dans le Midi de la France, si on excepte un exemplaire proche provenant du Castelet à Fontvieille, (Bouches-du-Rhône) et attribué au « second Âge du Fer » (Guillaumet, Rapin 2000, p. 80, fig. 3). Il est, en revanche, tout à fait comparable à des anneaux de cheville de la nécropole du GrandMont à Pogny, dans la Marne, datés du milieu du III' s. av. J.-C. et que l'on a rapprochés de modèles celtiques d'Europe centrale (Kruta 1985, p. 31-34 et fig. 3). La photographie de l'un des spécimens de Pogny (Charpy 1991, p. 247) montre une très grande similitude avec celui d'Ambrussum, avec des oves pleins et peu galbés. La forme de ce dernier n'est pas sans rappeler aussi celle de bracelets de Suisse occidentale, dont les oves sont cependant creux, par exemple dans la tombe 1-4 de Broc « Villa Cailler » (Fribourg), datée de La Tène B2, soit la fin du IVe et la première moitié du III ${ }^{\mathrm{e}} \mathrm{s}$. av. J.-C. (Kaenel 1990, p. 137 et 431, pl. 65, n²0), ou dans la tombe 6 de Gumefens «Pra Perrey » (Fribourg), à la transition de La Tène B2 - C1, soit le milieu du III ${ }^{\mathrm{e}}$ s. av. J.-C. (Schwab 1995, p. 246 et p. 249), ou encore en Bavière, à Traubing (Krämer 1985, p. 128 et pl. 66, n² 2).

\subsection{Perles en pâte de verre}

\section{Plusieurs catégories de perles en pâte de verre apparaissent dans les tombes d'Ambrussum}

Les grosses perles cylindriques en pâte de verre bleu, à trois rangs de protubérances ornées d'un filet blanc ou jaune opaque, en spirale (type IV-1-1 de Zepezauer 1989, p. 113-114), sont attestées dans la tombe T24 (deux exemplaires dans le recouvrement) et dans le niveau de fonctionnement du bûcher B1 (deux exemplaires) (fig. 95, $\mathrm{n}^{\circ} 15$ à 18). Tout près d'Ambrussum, l'oppidum de Nages (Gard) a livré de telles parures dans des niveaux datés de la seconde moitié du III et du début du II ${ }^{\mathrm{e}}$ s. av. J.-C. (Py 1978, p. 292-293 ; Py 20062007, p. 292, fig. $14, n^{\circ} 100$ et p. 295). En Suisse et en Allemagne du Sud ces objets apparaissent dès le second quart du $\mathrm{III}^{e} \mathrm{~s}$. (transition de La Tène B2-C1) et leur usage se poursuit jusqu'à la première moitié et le milieu du II ${ }^{\mathrm{e}}$ s. av. J.-C. (La Tène C2) (Zepezauer 1989, p. 117118). À titre d'exemples, on rapprochera les spécimens languedociens de ceux de Saint-Martin, dans le Valais, et de la tombe 1 de Chancy/Passeiry, dans le canton de Genève (Peyer 1991, p. 343, fig. 9, $\mathrm{n}^{\circ} 11$ et 12 ; Kaenel 1990 , p. 248 et p. 370 , pl. 4 , n ${ }^{\circ}$ 5), ou encore de la tombe 15 de Vevey dans le canton de Vaud, datée de la Tène B2/C2 (Martin-Kilcher 1981, p. 141, fig. 30, n 3 ).

La grosse perle annulaire en pâte de verre bleu, ornée d'un rang de spirales se terminant vers l'extérieur par une cédille et formées d'un très fin filet jaune opaque, est présente dans le niveau de fonctionnement du bûcher B1 (fig. 95, $\mathrm{n}^{\circ}$ 19). Elle relève du type I-1 de M.A. Zepezauer (1989, p. 110) et admet la même chronologie que la précédente. Avec un décor identique, et notamment la même cédille terminant la spirale, une perle semblable provient de l'habitat de la Comtasse à Bouranville, Meurthe-et-Moselle, mais hors de tout contexte daté (Thomas 1998).

La grosse perle annulaire en pâte de verre bleu, ornée d'un filet ondulant jaune opaque figure dans le recouvrement des tombes $\mathrm{T} 22$ et $\mathrm{T} 23$, et un spécimen semblable mais de module moyen provient du niveau de fonctionnement du bûcher B1 (fig. 95, $n^{\circ} 20$ et 21). Ce type de perle est attesté en Suisse occidentale à la même période : un exemplaire est associé à une grosse perle en pâte de verre bleu, à protubérances ornées d'un 
filet blanc ou jaune opaque en spirale du type IV-1-1 de Zepezauer dans la tombe 1 de Chancy/Passeiry (canton de Genève) (Kaenel 1990, p. 248 et p. 370, pl. 4, n 3 et 4). La même association se retrouve dans la tombe 35 de Steinbichel à Manching, en Bavière, datée de la seconde moitié du III ${ }^{\mathrm{e}}$ s. av. J.-C. (Krämer 1985, p. 86 et pl. 21, $\left.\mathrm{n}^{\circ} 15\right)$.

Les perles annulaires moyennes en pâte de verre bleu uni sont issues des loculus des tombes T22 et T25, du recouvrement des tombes T22 et T23 et du niveau de fonctionnement du bûcher B1 (fig. 95, nº 22 à 24). Elles sont bien connues régionalement, par exemple au Marduel dès la première moitié du $\mathrm{III}^{\mathrm{e}} \mathrm{s}$. av. J.-C. (Py, Lebeaupin 1989 , p. 168 et p. 174 , fig. $52, n^{\circ} 2$ ), ou à Nages dans la seconde moitié de ce siècle (Py 1978, p. 292 et p. 293 , fig. $\left.138, \mathrm{n}^{\circ} 28\right)$.

Les petites perles filiformes, presque toujours bleu opaque, que l'on trouve dans la tombe T22, le niveau de fonctionnement du bûcher B1 et sur le sol aux abords de la tombe T11 (fig. 95, n 25 à 27), ont leurs correspondants, dans la région, au Marduel au cours de la seconde moitié du III" s. av. J.-C. (Py, Lebeaupin 1989, p. 184 et p. 185 , fig. $62, \mathrm{n}^{\circ} 6$ et 7 ).

\section{L'armement et le fourniment}

\subsection{Pointe et talon de lance}

Une seule pointe de lance, en fer, est attestée, dans le loculus de la tombe T12 (fig. 96, $\mathrm{A}, \mathrm{n}^{\circ} 1$ ). Avec une lame triangulaire à tranchants rectilignes et carène très basse, et une longue douille, cet objet se rattache au type Ia distingué par A. Rapin à Gournay, datable des trois premiers quarts du $\mathrm{III}^{\mathrm{e}} \mathrm{s}$. av. J.-C. Il se différencie nettement des exemplaires postérieurs par la forme de sa lame et la longueur de la douille (Brunaux, Rapin 1988, p. 132-134).

Trois sépultures ont livré chacune un talon de lance en fer, le loculus de la tombe T21, le recouvrement de la tombe T25 et la tombe T2 (fig. 96, A, n 2 à 4). Dans les trois cas, il s'agit d'une douille conique courte, large et à pointe mousse, dépourvue de trou de fixation. Celle de la tombe 21 est décorée de trois moulures vers le bord. Par leurs proportions et leur mode de fixation - le cornet s'emboîtant simplement à l'extrémité de la hampe taillée en forme de cône - ces talons sont bien différents de ceux de la fin du premier Âge du Fer, comme les exemplaires de l'aven de Plérimond (Boyer, Dedet,
Marchand 2006, p. 183-186) ou ceux de la Pailletrice à Pérols, Hérault (Daveau, Dedet 2008, p. 57-58). Leurs caractères morphologiques les intègrent par contre à la série des talons à douille du second Âge du Fer, plus ou moins courts, sans variation notable durant cette période (Brunaux, Rapin 1988, p. 104-106).

\section{2. Épée, fourreau et suspension}

Une extrémité distale de lame d'épée en fer, dans son fourreau également en fer, provient du niveau de fonctionnement du bûcher B1. Mais cet objet est en grande partie fondu, presque à l'état de scorie, ce qui interdit toute notation typologique aussi bien pour l'épée que pour le fourreau. L'épée est aussi attestée par des rivets en fer, qui fixent les éléments de garniture de la poignée : un exemplaire dans le loculus de la tombe T14, cinq dans celui de la tombe T21, un dans le recouvrement des tombes T12 et T14 et un dans celui de la tombe $\mathrm{T} 25$, et trois autres enfin dans le niveau de fonctionnement du bûcher B1 (fig. 96, B, n ${ }^{\circ} 1$ à 11). C'est la découverte, dans des tombes à inhumation, de tels objets en place, par paires de part et d'autre de la soie de la poignée d'une épée qui permet cette identification, comme par exemple la sépulture 3 de La Hourgnotte à Liry, Ardennes datée du $\mathrm{III}^{\mathrm{e}}$ s. av. J.-C. (Duval 19711972, p. 60 et pl. 3, n 2 à 5). Ces rivets, longs de 18 à $24 \mathrm{~mm}$, sont pourvus d'une tête discoïde, de diamètre identique $(10$ à $11 \mathrm{~mm})$ à chacune des deux extrémités, légèrement bombée d'un côté et légèrement concave de l'autre, avec ou sans petit bourrelet périphérique, mais sans décor. Des pièces semblables, mais à têtes décorées, équipent l'épée de la tombe 163 d'Ensérune, enfouie au début du III' s. av. J.-C. (Rapin, Schwaller 1987, p. 167170 et fig. 11).

Des restes de plaque avers de fourreaux d'épée en tôle de fer, montrant le bord en gouttière, figurent dans les loculus des tombes 21 et 25 ainsi que dans le niveau de fonctionnement du bûcher B 1 (fig. 96, C, nº 1 à 4). Ces objets ne signalent cependant pas de précision chronologique à l'intérieur du second Âge du Fer.

Les éléments métalliques, en bronze ou en fer, se rapportant à des ceintures et ceinturons vraisemblablement destinés à la suspension de fourreaux d'épées, ont été trouvés dans plusieurs tombes (fig. 96, D, $\mathrm{n}^{\circ} 1$ à 17) :

- un à quatre anneaux dans les tombes T12, T14, T18 et $\mathrm{T} 21$;

- un passant en fer dans les tombes 14 (un exemplaire dans le loculus de la tombe 14 et un dans le dispositif de recouvrement commun aux tombes T12 et T14), ainsi 


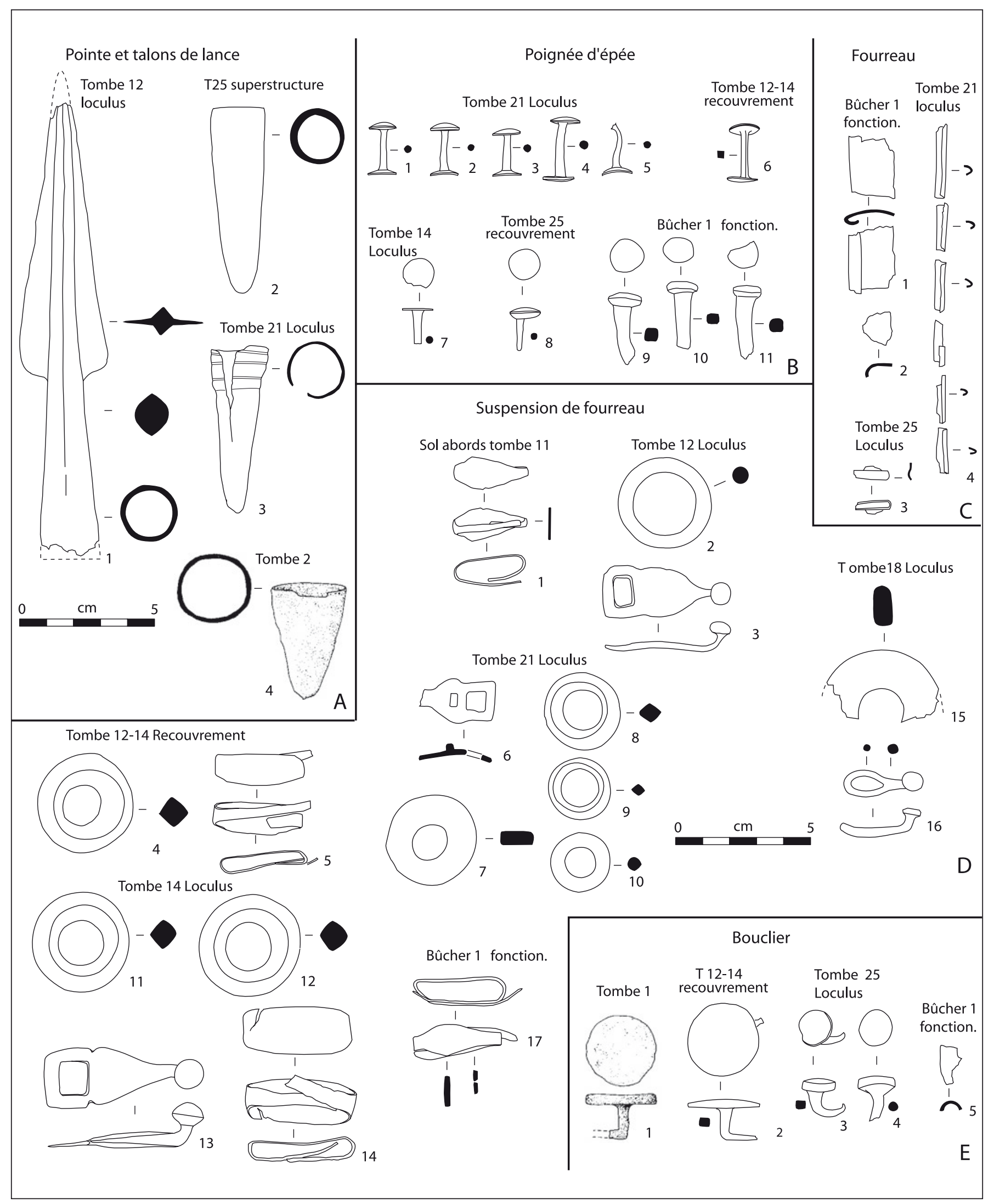

Fig. 96. Typologie des pièces d'armement et de fourniment du secteur fouillé de la nécropole d'Ambrussum. A : pointes (1) et talons (2-4) de lance.

$B$ : rivets de garniture de poignée d'épée. C : morceaux de plaques de fourreau. D : éléments de suspension de fourreau (2, 4, 7-12, 15 : anneaux ; 1,5 , 14,17 : passants ; $3,6,13,16$ : agrafes). E : rivets d'ailettes d'umbo (1-4) et fragment d'orle (5) de bouclier. 
que dans le niveau de fonctionnement du bûcher B1, et sur le sol aux abords de la tombe T11;

- une agrafe à crochet, en bronze, dans les tombes T12, T14, T18 et T21. Ces agrafes de ceinture sont de deux types : à ouverture rectangulaire séparée du crochet par un élargissement plein ou ajouré (tombes T12, T14 et T21), ou bien à anneau prolongé directement par le crochet (tombe T18).

Ces objets sous-entendent une mode de suspension à lanières de cuir, en usage $\mathrm{au} \mathrm{IV}^{\mathrm{e}} \mathrm{s}$. puis, après une interruption, à partir du dernier quart du $\mathrm{III}^{\mathrm{e}}$ av. J.-C. Les éléments de la suspension par chaîne métallique, en vogue du début à la fin du $\mathrm{III}^{\mathrm{e}} \mathrm{s}$. av. J.-C. en Gaule interne (Rapin 1990, p. 289-290 ; Lejars 1994, p. 55-62) et présente aussi, régionalement, dans les tombes d'Ensérune (Rapin, Schwaller 1987) et les dépôts rituels du Cailar (Girard, Roure 2009), manquent complètement dans ce secteur de la nécropole d'Ambrussum.

Les deux types de crochets de ceinture ici présents, sont datés, dans le domaine continental celtique du plein $\mathrm{III}^{\mathrm{e}} \mathrm{s}$. av. J.-C. à la première moitié du siècle suivant. Ceux du premier type sont semblables à un exemplaire provenant de la tombe 63 du Faubourg de Connantre à la Fère-Champenoise, Marne (Duval 1976, p. 469, fig. 10, $\mathrm{n}^{\circ} 1 \mathrm{a}$; Brunaux, Lambot 1987, p. 168, fig. 32, $\mathrm{n}^{\circ} 3$ ), et celui du second est comparable aux spécimens de la Grande-Borne à Clermont-Ferrand, Puy-de-Dôme (Deberge et al. 2007, p. 188, fig. 13, n ${ }^{\circ} 98$ et 99). L'usage de ces crochets de ceinture persiste dans la première moitié du siècle suivant (Brunaux, Lambot 1987, p. 126-129).

\subsection{Bouclier}

De boucliers sont issus deux rivets en fer d'ailettes d'umbo, repliés à angle droit, à grosse tête cylindrique plate non décorée. L'un provient de la structure ST1, l'autre du recouvrement commun aux tombes T12 et T14 (fig. 96, $\mathrm{E}, \mathrm{n}^{\circ} 1$ et 2). C'est un modèle courant durant la phase La Tène $\mathrm{C} 1$, soit les trois premiers quarts du $\mathrm{III}^{\mathrm{e}} \mathrm{s}$. av. J.-C. (Brunaux, Lambot 1987, p. 130). Le repli de ces deux rivets détermine une épaisseur de la planche du bouclier de l'ordre de $10 \mathrm{~mm}$, qui est alors la plus courante (Brunaux, Rapin 1988, p. 32). Découverts dans le loculus de la tombe T25, deux autres rivets en fer, à petite tête cylindrique plate, le mieux conservé replié à angle, semblent également provenir de la fixation des ailettes d'un umbo (fig. 96, E, n ${ }^{\circ} 3$ et 4).

Un petit segment d'orle en fer, du niveau de fonctionnement du bûcher B1, provient également, semble-t-il, d'un bouclier (fig. 96, E, n ${ }^{\circ} 3$ ).

\section{Monnaies}

Deux oboles de Marseille en argent ont été découvertes dans le niveau de fonctionnement du bûcher B1 (fig. 97, $\mathrm{n}^{\circ} 30$ et 31). Elles appartiennent au type OBM11 de $\mathrm{M}$. Py, oboles à la roue et MA avec tête à gauche sans favoris. Leur datation s'inscrit entre le début du $\mathrm{III}^{\mathrm{e}}$ et la première moitié du Ir s. av. J.-C. (Py 2006, p. 47-54).

\section{Ustensiles}

$\mathrm{Au}$ rang des ustensiles, figurent trois fusaïoles en terre cuite, dans le loculus de la tombe T23, dans la tombe T2 et dans le niveau de fonctionnement du bûcher B1 (fig. 97, n 27 à 29). Bien qu'il ne s'agisse pas là d'une catégorie d'objets autorisant une datation précise, on notera cependant que les deux spécimens biconiques (tombe T23 et bûcher B1) relèvent de la forme majoritaire au second Âge du Fer (Py 1990a, p. 453-456 ; Raux 1999, p. 480, fig. 22 et p. 482).

\section{Objets à usage indéterminé}

Plusieurs éléments métalliques pourraient appartenir à la décoration de poignées d'épée, de ceintures en cuir ou encore de coffrets en bois :

- deux petits clous en fer à tête discoïde plate et décorée, dans le loculus de la tombe T14 (fig. 97, $\mathrm{n}^{\circ} 1$ et 2) ;

- deux petits clous en fer à tête discoïde plate non décorée et deux autres à tête discoïde bombée, dans le loculus de la tombe T21 (fig. 97, $\mathrm{n}^{\circ} 3$ à 6) ;

- un petit clou en fer à tige courte dans le niveau de fonctionnement du bûcher B1 (fig. 97, $\mathrm{n}^{\circ} 7$ ) ;

- un petit clou en fer à tête discoïde plate non décorée, dans le loculus de la tombe T18 (fig. 97, $\mathrm{n}^{\circ}$ 9);

- un autre à tête discoïde légèrement bombée et non décorée, dans le recouvrement des tombes T12-T14 (fig. 97, $\mathrm{n}^{\circ} 8$ );

- dans le loculus de la tombe T21, quatre petites lamelles en fer, en ruban légèrement sinueux et ondulé, pointu à une extrémité et coupé en biais à l'autre, avec des bords chanfreinés portant de légères indentations ; chacune est pourvue d'au moins un fin rivet rectiligne et très pointu (fig. 97, $\mathrm{n}^{\circ} 10$ à 13 );

- un ruban en fer replié deux fois, dans le loculus de la tombe T14 (fig. 97, $\mathrm{n}^{\circ} 14$ ) ;

- une applique tronconique à bélière, en fer, dans le loculus de la tombe T25 (fig. 97, $\mathrm{n}^{\circ} 16$ ) ;

- une tête de clou (?) en bronze, décorée de renflements, dans le loculus de la tombe T21 (fig. 97, $\mathrm{n}^{\circ} 15$ ) ; 


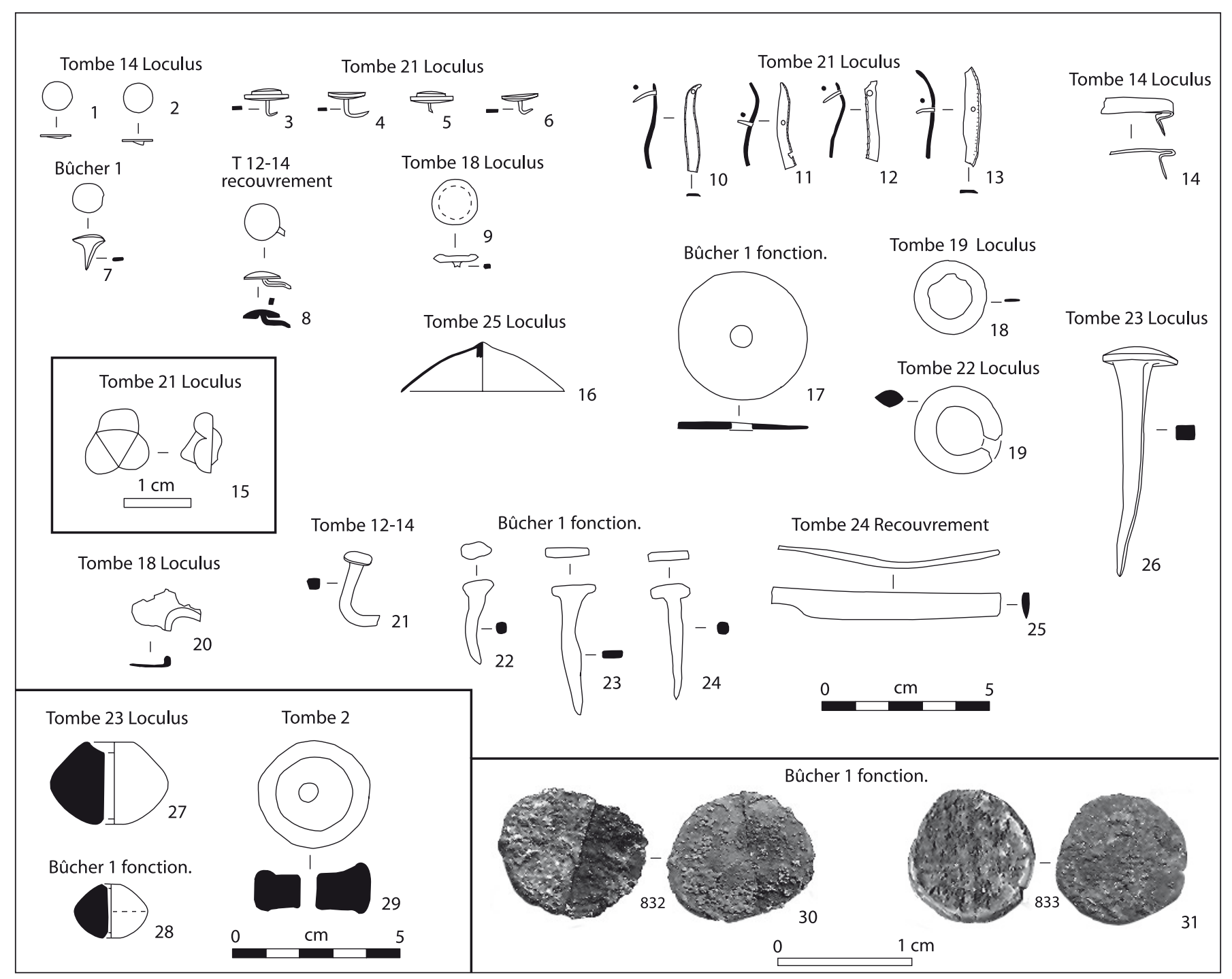

Fig. 97. Typologie des autres objets du secteur fouillé de la nécropole d'Ambrussum. 1-26 : rivets, clous, lamelles, anneaux ; 27-29 : fusaïoles ; 30 et 31 : monnaies.

- un anneau large et très plat en fer, dans le bûcher B1 (fig. 97, $\mathrm{n}^{\circ}$ 17).

Enfin, à côté des anneaux en bronze plus ou moins complets et des morceaux de tiges ou de fiches en fer, un certain nombre d'objets ont une destination encore plus problématique :

-1 grand clou en fer dans le loculus de la tombe T23 (fig. 97, $\mathrm{n}^{\circ} 26$ ) ;

- trois clavettes en fer (non restaurées) dans le niveau de fonctionnement du bûcher B1 (fig. 97, n² 22 à 24 );

- une lamelle en fer légèrement recourbée dans le recouvrement de la tombe T24 (fig. 97, $\mathrm{n}^{\circ} 25$ );

- un morceau de plaque en bronze coulée, présentant un orifice circulaire bordé d'un bourrelet, dans le loculus de la tombe 18 (fig. 97, $\mathrm{n}^{\circ} 20$ ).

\section{Datation des tombes}

Parmi les différentes catégories d'objets énumérées ci-dessus qui apportent des éléments de chronologie plus ou moins précis, on retiendra celles qui sont les mieux datées :

- Céramique non tournée : si coupes, couvercles et jattes évoquent une large période, du milieu de l'Âge du Fer à la fin du $\mathrm{II}^{\mathrm{e}} \mathrm{s}$. av. J.-C., la fourchette est plus étroite pour les urnes, qui s'inscrivent entre la fin du $\mathrm{IV}^{\mathrm{e}}$ et le début du IIe s. av. J.-C ;

- Parure en pâte de verre, les grosses perles à décor ocellé ou spiralé, entre le second quart du $\mathrm{III}^{\mathrm{e}} \mathrm{s}$. et le milieu du II ${ }^{\mathrm{e}}$ s. av. J.-C ;

- Fibules en fer : les fibules à pied discoïde recourbé sur l'arc, à plateau décoré d'appliques de corail et ressort 
bilatéral à six ou huit spires, entre environ 325 et 250 av. J.-C. ; les fibules à long pied recourbé, muni ou non d'une boule et agrafé au sommet de l'arc, et à ressort court, relevant des types $13 \mathrm{~b}$ et $13 \mathrm{c}$ ou 14 de R. Gebhard, entre environ 275 et 200 av. J.-C. ; la petite fibule de même forme mais au ressort long du type 23 de R. Gebhard, entre environ 250 et 150 av. J.-C. (objet découvert sur le sol de la nécropole) ;

- Autres parures en bronze : les chaînes-ceintures à maillons doubles en bronze, dite féminine, et le bracelet ou anneau de cheville à oves pleins et peu proéminents, au milieu du III' ${ }^{\mathrm{s}}$ s. av. J.-C ;

-Armement: le type de suspension de fourreau d'épée, de la deuxième moitié III ${ }^{\mathrm{e}}$ au début $\mathrm{II}^{\mathrm{e}} \mathrm{s}$. av. J.-C ;

- Amphore massaliète : le spécimen muni d'un bord de forme A-MAS bd9, datable entre 300-150 av. J.-C. environ, avec un maximum de fréquence entre 250 et 175 environ ;

- Céramique à vernis noir : la présence très restreinte de l'attique à vernis noir ; celle, également très discrète de l'atelier des petites estampilles, avec le bol PET-EST 2783, datable de 325-225 environ; la suprématie des productions des ateliers de Rosas, qui ont fonctionné entre environ 325 et 200 av. J.-C., avec une période maximum d'exportation entre environ 275 et 225 ; en regard, la rareté de la campanienne $\mathrm{A}$, attestée par un bol CAMP-A 27a-b avec rosette aux pétales très fins, une forme importée dans la région dès le milieu du III ${ }^{\mathrm{e}} \mathrm{s}$. av. J.-C. et qui fait partie des plus anciennes productions de cette catégorie que l'on y rencontre ;

- Céramique grise peinte massaliète : seconde moitié du IV e et III' s. av. J.-C. (Py, Adroher Auroux, Sanchez 2001, p. 1118 et 1121);

- Céramique à pâte claire : la coupe CL-MAS 433 couvre les IV e et III ${ }^{\mathrm{e}}$ s. av. J.-C. (Bats 1988, p. 177 (forme F 434) ; Py, Adroher Auroux, Sanchez 2001, p. 696697) ; le bol CM-MAS 236 apparaît au début du IV ${ }^{\mathrm{e}}$ s., connaît une fréquence maximum au $\mathrm{III}^{\mathrm{e}} \mathrm{s}$. puis disparaît au milieu du II ${ }^{\mathrm{e}}$ s. av. J.-C. (Py, Adroher Auroux, Sanchez 2001, p. 643-646) ; le bol CM-MAS 321 apparaît dès le $\mathrm{V}^{\mathrm{e}} \mathrm{s}$. et disparaît dans le courant du $\mathrm{II}^{\mathrm{e}} \mathrm{s}$. av. J.-C. (Bats 1988, p. 175 ; Py, Adroher Auroux, Sanchez 2001, p. 654-656), mais les exemplaires attestés ici ont une rosette semblable à celle des vases à vernis noir de Rosas.

Les parts relatives des différentes catégories de céramiques à vernis noir, attique, petites estampilles, Rosas et campanienne A, comparées aux courbes de ces séries attestées à Lattes (Py, Adroher Auroux, Sanchez 2001, p. 1160, fig. 177), suggèreraient une fourchette réduite aux deuxième et troisième quarts du $\mathrm{III}^{\mathrm{e}} \mathrm{s}$. av. J.-C. La grande majorité du reste du matériel, céramique, métallique ou en pâte de verre ne la contredit pas. Seules les agrafes de ceinture de suspension d'épée ne sont pas datées avant la deuxième moitié du $\mathrm{III}^{\mathrm{e}} \mathrm{s}$., voire environ 225 av. J.-C., en Gaule intérieure. On remarquera cependant, qu'on dispose là, à Ambrussum, des premiers spécimens de ce type d'agrafes découverts en contexte, avec des céramiques d'importation méditerranéennes autorisant une datation d'apparition peut-être un peu plus ancienne que celle qui est admise jusqu'ici à partir des contextes de Gaule interne.

Concernant le terminus ante quem, on soulignera l'absence de tout reste d'amphores italiques et gréco-italiques, dans cette partie de la nécropole du moins. Si la première catégorie ne semble pas présente dans la région avant le dernier tiers du II ${ }^{\mathrm{s}} \mathrm{s}$. av. J.-C., l'amphore grécoitalique, elle, arrive plus précocement en Languedoc oriental dès le premier quart de ce siècle, et en quantité importante (voir dans ce chapitre, § 13.). Dans le matériel amphorique de cette portion de la nécropole d'Ambrussum, cette double absence et l'exclusivité des productions massaliètes contribuent donc à fixer un terminus ante quem au tournant du $\mathrm{II}^{\mathrm{e}} \mathrm{s}$. av. J.-C.

La datation de ce quartier de la nécropole d'Ambrussum paraît donc comprise entre les environs de 275 et les environs de 200 ou le tout début du $\mathrm{II}^{\mathrm{e}} \mathrm{s}$. av. J.-C. Dans ce laps de temps, est-il possible de préciser la place chronologique de chacune des structures mises au jour? L'exercice semble bien risqué mais mérite d'être tenté néanmoins.

Plusieurs sépultures pourraient être placées plutôt dans la partie ancienne de cette fourchette, vers le second quart et le milieu du $\mathrm{III}^{\mathrm{e}} \mathrm{s}$. av. J.-C., grâce à des éléments particuliers du mobilier: les tombes T2 (fibule), T15 (fibule), T19 (fibule et chaîne-ceinture) et T25 (fibule).

À l'inverse, d'autres tombes pourraient être légèrement plus récentes, dernier quart du $\mathrm{III}^{\mathrm{e}}$ et début du II $\mathrm{e}$. av. J.-C. : les sépultures T11 (bracelet en verre, céramique campanienne A ancienne), T13 (céramique campanienne A ancienne), T18 (crochet de ceinture) et T24 (fibule).

Entre ces deux groupes, soit dans les troisième et quatrième quarts du $\mathrm{III}^{\mathrm{e}} \mathrm{s}$. av. J.-C., pourraient se situer les tombes T5, T6, T12, T14, T17 et T21 et les structures ST1 et ST3.

Enfin, pour une dernière série, les tombes T7, T16, T20, T22 et T23, aucun élément du mobilier ne permet de proposer une quelconque précision à l'intérieur de cette fourchette chronologique. 
Pour sa part, le bûcher crématoire B1 paraît bien fonctionner dès le début de cette période, mais également jusque vers la fin du III ${ }^{\mathrm{e}}$ s. av. J.-C., puisqu'on y retrouve des objets semblables à ceux des tombes T19 et T25, mais aussi T24 ${ }^{19}$.

19 Sur les liens entre les tombes fouillées et ce bûcher, voir infra, chap. $6, \S 6.1$.
On le voit, cette tentative de classement chronologique des diverses structures funéraires reste imprécise et hypothétique. Mieux vaut donc, dans l'étude des pratiques funéraires, envisager ce quartier dans son ensemble, représentant une étape de la nécropole d'Ambrussum, comprise entre le second quart du III' $\mathrm{s}$. et la fin du $\mathrm{III}^{\mathrm{e}} \mathrm{s}$. av. J.-C. ou le tout début du siècle suivant. 



\section{Chapitre 6}

\section{Les pratiques funéraires à Ambrussum Défunts, traitement des corps et des restes osseux, morphologie des tombes et matériel d'accompagnement}

\begin{abstract}
$\mathrm{A}$ vant d'examiner la morphologie des tombes, la constitution des lots d'os humains et leur mode de dépôt, de même que la composition et le traitement des objets et des restes animaux, il convient de se demander qui est admis dans cette portion de cimetière et de s'interroger sinon sur l'identité des individus, du moins sur la composition de ce groupe de défunts en terme d'âge et de sexe, son « recrutement » pour reprendre le mot de Claude Masset (1987).
\end{abstract}

\section{Le recrutement}

Le nombre de sépultures fouillées et de défunts découverts est réduit, 22 tombes ayant livré en tout un nombre minimum de 23 sujets décédés. Malgré la faiblesse numérique de cet ensemble, il est néanmoins possible d'estimer si sa composition est conforme à la mortalité préjenerienne ${ }^{20}$ ou s'il existe des biais pouvant correspondre à des réalités sociales. Ici, pour cela, seul le critère de l'âge au décès peut être pris en compte. Cette détermination de l'âge au décès ne peut être relativement précise que pour les immatures, les moins de 20 ans. Toute précision sur l'âge des adultes étant très rarement obtenue dans un contexte où règne l'incinération. Pour la même raison, la répartition entre hommes et femmes ne peut pas être appréciée du point de vue de l'anthropologie biologique. Elle ne peut être approchée que par la symbolique de certains objets accompagnant éventuellement des défunts adultes ou ayant dépassé l'âge de la puberté.

\section{1. Âge aux décès et âge d'accès au cimetière}

Les âges aux décès dans ce secteur de la nécropole d'Ambrussum sont les suivants :

- Tombe T2 : un adolescent, 15-20 ans ;

- Tombe T3 : un adulte ou adolescent ;

- Tombe T4 : un adulte âgé ;

20 Adjectif formé sur le nom du médecin anglais Edward Jenner (1749-1823), qui ouvrit l'ère de la vaccination.
- Tombe T5 : un grand enfant, 8-12 ans ;

- Tombe T6 : un adulte jeune, 20-30 ans ;

- Tombe T7 : un adulte et un jeune enfant d'environ 1 an;

- Tombe T10 : un adulte ;

- Tombe T11 : un adulte jeune, 20-30 ans ;

- Tombe T12 : un adulte, plus de 30 ans ;

- Tombe T13 : un jeune enfant, 3-5 ans ;

- Tombe T14 : un adulte jeune, 20-30 ans ;

- Tombe T15 : un adulte, plus de 30 ans, mais pas un vieillard ;

- Tombe T16: un adulte ;

- Tombe T17 : un adulte;

- Tombe T18 : un grand enfant, adolescent ou adulte ;

- Tombe T19: un adulte ;

- Tombe T20: un adulte ;

- Tombe T21 : un adulte jeune, 20-30 ans ;

- Tombe T22 : un jeune enfant, 2-4 ans ;

- Tombe T23 : un adulte, plus de 30 ans ;

- Tombe T24 : un grand enfant, 12-14 ans ;

- Tombe T25 : un adulte.

Au total, ce quartier de la nécropole a accueilli un jeune enfant vers 1 an, deux jeunes enfants entre 2 et 5 ans, deux grands enfants entre 8 et 14 ans, un adolescent, quinze adultes, un sujet adolescent ou adulte et un sujet indéterminé, grand enfant, adolescent ou adulte.

Au-delà de ces données brutes, le degré de représentation de chaque classe d'âge des immatures dans cette portion de nécropole peut être précisé en comparant leur distribution à celles que l'on connaît en démographie historique, établies selon une espérance de vie à la naissance déterminée, suivant en cela le modèle mis au point par Pascal Sellier lors de l'étude du tumulus de Courtesoult (Sellier 1996). Pour cela, il convient d'exprimer les effectifs de ces immatures selon les mêmes classes que celles de la démographie historique, des classes d'âge quinquennales, en années révolues, à l'exception des deux premières, respectivement d'une durée d'un an (0-12 mois révolus) et de quatre ans (1-4 ans révolus). Pour chaque classe est calculé le quotient de mortalité (rapport du nombre de décès à la totalité de 
l'effectif de cette classe et des classes plus âgées) de type « aqx » (où « $\mathrm{x}$ » désigne l'âge d'entrée dans la classe, et « $\mathrm{a}$ » la durée de cette classe en années révolues, « $\mathrm{q}$ » signifiant quotient). Ces quotients sont ensuite comparés aux modèles théoriques des tables de mortalité de Ledermann (1969) dont l'espérance de vie à la naissance est comprise entre 25 et 35 ans. On ne connaît en effet aucune société préjennérienne, si désavantagée soit-elle, qui ait une espérance de vie à la naissance inférieure à 20-24 ans ; et, par ailleurs, les chiffres les plus élevés pour les classes les plus favorisées de ces populations n'excèdent pas 36-39 ans (par exemple la noblesse britannique aux XVI ${ }^{\mathrm{e}}-\mathrm{XVII}{ }^{\mathrm{e}}$ s., la «classe dirigeante » de Genève au XVII ${ }^{e}$ s. ou encore la famille des empereurs Ming en Chine) (Sellier 1996, p. 191 et 193). Les écarts à la norme observés peuvent être considérés comme des anomalies dont il convient d'identifier la cause, taphonomie ou pratique funéraire.

Un tel classement introduit parfois des coupures trop strictes qui masquent souvent l'imprécision de l'évaluation de l'âge. Celle-ci est généralement établie sous la forme d'un intervalle entre deux anniversaires qui peut se trouver à cheval sur deux classes d'âge. Dans ce cas, la correspondance entre la détermination de l'âge et l'attribution à une classe est résolue selon le principe de "minimalisation des anomalies" préconisé par P. Sellier (1996, p. 191-192) pour obtenir la distribution la moins éloignée d'une mortalité naturelle de type préjennérien : est choisie alors l'hypothèse qui se conforme le mieux à ce schéma de mortalité archaïque. Ainsi, selon ce principe de conformité, le sujet d'un an environ de la tombe T7 est placé dans la classe des 1-4 ans et celui de 8-12 ans de la tombe T5 dans celle des 5-9 ans.

Pour les six classes d'âge retenues, la répartition des sujets d'Ambrussum est la suivante (fig. 98) :

- 0-12 mois : 0 individu ;

- 1-4 ans : 3 individus (tombes T7, T13 et T22);

- 5-9 ans : 1 individu (tombe T5) ;

- 10-14 ans : 1 individu (tombe T24);

-15-19 ans (adolescents) : 1 individu (tombe T2) ;

-20 ans et plus (adultes) 15 individus (tombes T4,

T6, T7, T10, T11, T12, T14, T15, T16, T17, T19, T20, T21, T23 et T25).

Cette distribution appelle un certain nombre de remarques.

Les défunts de moins d'un an font totalement défaut ici. Une telle absence, ou, selon les cas, un quotient de mortalité extrêmement faible en regard de ceux que l'on connaît dans les sociétés préjennériennes, est un phénomène constant dans le monde indigène protohistorique du Sud de la France. Ces très jeunes morts manquent en effet complètement dans les nécropoles du second Âge du Fer qui ont donné lieu à une étude anthropologique : Ensérune entre la fin du $\mathrm{V}^{\mathrm{e}}$ et la fin du $\mathrm{III}^{\mathrm{e}} \mathrm{s}$. av. J.-C. (Dedet, Schwaller 2010, p. 272), Mourrel-Ferrat à Olonzac, Hérault, dans le dernier quart du $\mathrm{IV}^{\mathrm{e}} \mathrm{s}$. av. J.-C. (Janin et al. 2000) ou Servanes-Cagalou à Mouriès, Bouches-du-Rhône, au I ${ }^{\mathrm{er}}$ s. av. J.-C. (Marcadal, Marcadal, Paillet 2003). À l'évidence, dans ces communautés, nouveau-nés et nourrissons de la première année n'ont pas droit au cimetière villageois. Et il ne s'agit pas là d'une particularité locale puisque ces cimetières se répartissent sur un vaste territoire, des environs de Carcassonne aux Alpilles, et qu'à eux quatre ils couvrent l'ensemble du second Âge du Fer. Cette absence est constatée aussi au I ${ }^{\text {er }}$ s. av. J.-C. dans la nécropole du Paradis à Aramon (Gard), même si le nombre de tombes dont le matériel ostéologique a pu être étudié est très réduit (quatre tombes : T4, 5, 6 et 11 ; Genty, Feugère 1995). Il en va de même dans les sépultures isolées du second Âge du Fer languedocien : partout on a affaire à des sujets adultes ou de taille adulte, comme pour la tombe de Font de la

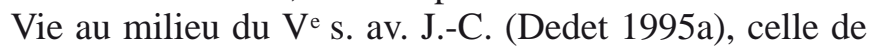
la Roussillonne à Nîmes vers 350-250 av. J.-C. (Dedet, Gauthey 2008), et dans la quinzaine de tombes des $\mathrm{II}^{\mathrm{e}}$ et $\mathrm{I}^{\mathrm{er}} \mathrm{s}$. av. J.-C. de la périphérie nîmoise (Forum des Carmes, Cadereau, Mas des Abeilles, Mas de Vignole, Forum Kinepolis) (Bel et al. 2008). Et ce phénomène est également très net pour les périodes antérieures de la Protohistoire, Bronze final IIIb et premier Âge du Fer, pour lesquelles plus de 3000 défunts ont pu être analysés (Dedet 2008, p. 31-59).

On peut se demander évidemment s'il n'existerait pas, dans chacune de ces nécropoles, un quartier où les tout-petits seraient déposés préférentiellement. Certes, à Ambrussum comme à Mourrel-Ferrat, à Ensérune, à Aramon ou à Servanes-Cagalou ce sont seulement des portions de nécropoles qui ont été fouillées. La question se pose aussi pour les nombreux cimetières du Bronze final IIIb et premier Âge du Fer du Midi méditerranéen dont aucun n'a encore fait l'objet d'une exploration complète et exhaustive. Cependant, sur le nombre de nécropoles protohistoriques fouillées jusqu'ici, l'absence de découverte de tels secteurs, réservés aux défunts de la première année, permet d'écarter cette objection.

À Ambrussum, comme ailleurs, cette absence ne saurait évidemment refléter une mortalité périnatale et néonatale nulle ou très réduite, car, dans une société préjennerienne la mortalité à cet âge est très élevée, les quotients variant de $224 \%$ à $320 \%$ o pour des 


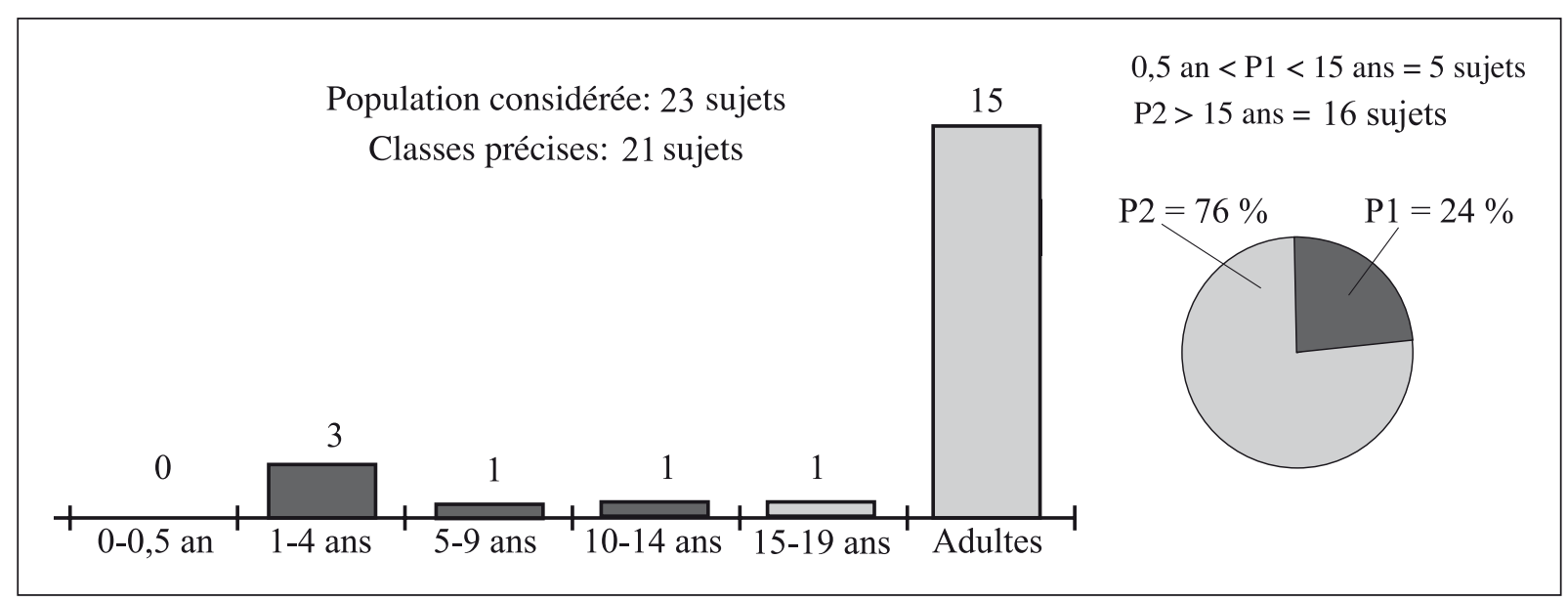

Fig. 98. Classement des défunts d'Ambrussum par grandes classes d'âge : les données brutes.

\begin{tabular}{|c|c|c|c|c|c|}
\hline $\begin{array}{c}\text { TABLES-TYPES } \\
\text { DE LEDERMANN } 1969\end{array}$ & $\begin{array}{c}0-12 \text { mois } \\
1 \mathrm{q} 0\end{array}$ & $\begin{array}{c}1-4 \text { ans } \\
4 q 1\end{array}$ & $\begin{array}{c}5-9 \text { ans } \\
5 q 5\end{array}$ & $\begin{array}{c}10-14 \text { ans } \\
5 q 10\end{array}$ & $\begin{array}{c}15-19 \text { ans } \\
5 q 15\end{array}$ \\
\hline E spérance vie à la naiss. $=25$ ans & 320,4 & 362,76 & 76,89 & 42,62 & 58,44 \\
\hline E spérance vie à la naiss. $=30$ ans & 269,8 & 269,52 & 61,03 & 35,04 & 49,15 \\
\hline Espérance vie à la naiss. $=35$ ans & 224,32 & 195,88 & 47,62 & 28,39 & 40,8 \\
\hline S ITE & $\begin{array}{c}0-12 \text { mois } \\
1 \mathrm{q} 0\end{array}$ & $\begin{array}{c}1-4 \text { ans } \\
4 q 1\end{array}$ & $\begin{array}{c}5-9 \text { ans } \\
5 q 5\end{array}$ & $\begin{array}{c}10-14 \text { ans } \\
5 q 10\end{array}$ & $\begin{array}{c}15-19 \text { ans } \\
5 q 15\end{array}$ \\
\hline \multirow[t]{2}{*}{ AMBRUSSUM } & 0 & 142,85 & 55,56 & 58,82 & 62,50 \\
\hline & ficitaire & & ent normal & & \\
\hline
\end{tabular}

Fig. 99. Quotient de mortalité (en \%) des défunts immatures d'Ambrussum. Pour comparaison, tables-types de Ledermann pour une espérance de vie à la naissance de 25 ans, 30 ans et 35 ans (Ledermann 1969, p. 86-88).

espérances de vie à la naissance comprises entre 25 et 35 ans (fig. 99). Si ces très jeunes morts, périnatals et nourrissons de moins d'un an manquent en ces lieux, c'est bien qu'ils ont été placés ailleurs. En fait, les nombreuses découvertes de tombes ou de restes de squelettes de sujets périnatals et de quelques nourrissons de moins d'un an effectuées au sein même des habitats protohistoriques du Languedoc et des régions voisines, Roussillon, Grands Causses et Provence, apportent une réponse, pour une partie de ceux-ci au moins (Dedet 2008, p. 65-156). $\mathrm{Au}$ demeurant, cette situation est propre à la culture du monde indigène du Sud de la France et ne concerne pas les colonies grecques, notamment celle de Marseille où les sujets périnatals apparaissent normalement représentés dans le cimetière de Sainte-Barbe (Moliner et al. 2003 ; Dedet 2011).

Cette pratique de l'ensevelissement des nouveau-nés dans les maisons n'est pas pour le moment clairement attestée sur l'oppidum d'Ambrussum. L'examen du matériel osseux recueilli au titre de la faune provenant des sondages profonds réalisés entre 1967 et 1979 par J.-L. Fiches dans le secteur I, sous les maisons galloromaines édifiées derrière la tour 4 (Fiches et al. 1976) et dans le secteur IV (Fiches, Gutherz, Roux 1979 ; Fiches 1983), sur une surface cumulée de l'ordre de $100 \mathrm{~m}^{2}$ n'en a fourni aucun vestige ${ }^{21}$. Un seul lot, provenant du décapage 2 du sondage "Sud. IV, 79", a procuré trois os d'un seul sujet (une moitié proximale d'ulna gauche, une moitié distale de fémur droit et un fémur gauche complet symétrique du précédent), appartenant, d'après les équations de Fazekas et Kosa (1978), à un prématuré de 7 à 7,5 mois lunaires de gestation. Mais la datation de cet individu ne peut être précisée entre la fin de l’Âge du Fer (seconde moitié III ${ }^{\mathrm{e}}$ - $^{\mathrm{er}} \mathrm{s}$. av. J.-C.) et l'époque galloromaine (Dedet 2008, p. 71 et 359-360).

21 Il n'a cependant pas été possible de retrouver tous les lots osseux du secteur IV du Dévès (Fiches, Gutherz, Roux 1979). 
La classe suivante, celle des 1-4 ans, est certes bien attestée dans la nécropole d'Ambrussum, contrairement aux tout-petits, mais à l'évidence elle est sous-représentée, montrant un fort déficit par rapport à la proportion attendue. Le quotient de mortalité de près de $143 \%$ o est inférieur de moitié à celui des tables de référence (fig. 99). À Ambrussum, certains de ces jeunes enfants commencent donc à être admis dans le cimetière villageois, mais il en manque environ autant, et on ignore tout du traitement réservé à cette moitié-là. Ici encore, cette situation est celle qu'illustrent les autres cimetières indigènes de la région : le quotient de mortalité pour cette classe est de $131 \%$ à Ensérune, entre la fin du $\mathrm{V}^{\mathrm{e}}$ et la fin du III s. av. J.-C. (Dedet, Schwaller 2010, p. 272273), tandis que dans les nécropoles du Bronze final IIIb et du premier Âge du Fer, il varie selon les lieux de $20 \%$ o à $128 \%$ (Dedet 2008, p. 64).

Un changement d'attitude apparaît chez les habitants d'Ambrussum avec la classe suivante, les enfants de 5 à 9 ans. Ceux-ci sont ici normalement représentés : leur quotient de mortalité de $55 \%$ o correspond à celui d'une espérance de vie entre 30 et 35 ans (fig. 99). Et cela reste dans la lignée de ce qui est remarqué pour le reste du monde indigène languedocien de l'Âge du Fer où, si dans certaines communautés les quotients sont quelque peu inférieurs à ceux qui sont attendus, partout ailleurs ils sont conformes à la mortalité préjennerienne (Dedet 2008, p. 63-64).

À Ambrussum donc, les enfants de cet âge paraissent normalement admis au cimetière villageois, et s'ils sont moins nombreux que les 1-4 ans, c'est uniquement parce que le risque de décès est désormais beaucoup moins grand. Il en va de même pour les deux classes suivantes, les grands enfants (10-14 ans) et les adolescents (1519 ans), et en cela, les habitants d'Ambrussum suivent toujours l'usage régional. Le caractère exceptionnel de ces sujets dans l'échantillon procuré par les fouilles est normal et les quotients de mortalité sont tout à fait conformes à ceux de la démographie archaïque. En définitive, il apparaît donc qu'à Ambrussum, c'est à partir de cinq ans que le défunt est normalement admis dans le cimetière villageois.

\subsection{Homme ou femme, garçon ou fille d'après la symbolique du mobilier}

En l'absence de toute donnée ostéologique permettant de déterminer le sexe biologique des défunts, et pour pallier ce manque, on soulignera l'existence de deux groupes de sépultures d'adolescents et d'adultes pourvus d'objets présentant une symbolique soit masculine soit féminine. La matrice de la fig. $\mathbf{8 8}$ met en effet en évidence deux groupes d'objets faisant partie de l'équipement personnel des défunts jamais associés dans la même tombe individuelle :

- d'une part, la fusaïole, la chaine ceinture à maillons doubles, le pendant d'oreille, le lot de deux bracelets (ou plus), les perles en pâte de verre ou en corail ;

- d'autre part, les armes (pointe et talon de lance, éléments d'épée, de fourreau et/ou de suspension, éléments de bouclier).

La connotation sexuelle de telles pièces a souvent été retenue dans les publications récentes de nécropoles protohistoriques languedociennes. Elle est confortée par le dépôt de ces objets avec des sujets inhumés des tumulus des Garrigues du Languedoc oriental et des Grands Causses, dont le sexe biologique a pu être diagnostiqué d'après les caractères morphologiques de l'os coxal (Dedet 1992, p. 193-197 ; Dedet 2001, p. 312) ${ }^{22}$. La première série d'objets se rapporterait à des individus féminins, la seconde série à des sujets masculins. Cette symbolique concernerait les adultes, les adolescents et les enfants ayant dépassé le cap des environs de 7 ans. Une étude récente portant sur l'ensemble des enfants connus dans le monde indigène protohistorique du Sud de la France montre qu'elle ne s'applique pas aux jeunes enfants de moins de 6-7 ans. En effet ceux-ci, lorsqu'ils sont accompagnés de quelques objets, ne sont pourvus que de pièces du premier groupe, ce qui indiquerait non pas leur sexe mais plutôt l'appartenance de la petite enfance au monde des femmes de la maisonnée (Dedet 2008, p. 234-240).

Ainsi, on aurait donc à Ambrussum :

-5 tombes de femmes: T2 (une fusaïole et deux pendants d'oreille), T6 (une perle), T11 (deux bracelets), T19 (une chaîne ceinture à maillons doubles et un pendant d'oreille), T23 (une fusaïole et deux bracelets) ;

- 4 tombes d'hommes: T12 (éléments de lance et d'épée), T14 (éléments d'épée), T21 (éléments de lance et d'épée), T25 (un bracelet, éléments de lance et d'épée) ;

- 1 tombe de grand garçon, adolescent ou homme : T18 (éléments d'épée);

-2 tombes de filles T5 (8-12 ans) et T24 (12-15 ans) pourvues chacune de deux perles ;

22 À cette base documentaire, on ajoutera le sujet incinéré de la sépulture de Saint-Martin-de-Colombs à Fabrègues (Hérault) dont le sexe anthropologique peut également être déterminé (Dedet, Paya 2006-2007). 
- 1 tombe de très jeune enfant de 2-4 ans, T22, dont le collier de perles en pâte de verre n'indiquerait pas le sexe ;

- 1 tombe d'adolescent, T2, qui associe des pièces à connotation féminine, la fusaïole et une paire de pendants d'oreille avec un objet à symbolique masculine, un petit talon de lance. Par le nombre d'objets, la symbolique féminine domine et il se pourrait que la présence du talon de lance résulte d'un ramassage involontaire sur un bûcher ayant déjà servi pour la crémation d'autres défunts. L'aire crématoire B1, par exemple, a en effet, été utilisée pour brûler des défunts des deux sexes, si l'on en croit le matériel recueilli (voir infra). Un cas similaire a été rencontré à Ensérune, celui de la tombe 5/1988, de la première moitié du III $\mathrm{s}$ s. av. J.-C. (Schwaller et al. 1995, p. 216-220);

-6 tombes d'adultes dont le mobilier ne permet pas de présumer du sexe : T7, T10, T15, T16, T17, T20 ; on notera que l'adulte de $\mathrm{T} 7$ est accompagné d'un très jeune enfant vers 1 an, mais cela ne peut constituer un argument en faveur de la reconnaissance d'une femme.

Si tant est que les objets pris en compte reflètent bien le sexe des défunts auprès desquels ils sont déposés, cet échantillon montre qu'hommes et femmes sont représentés à égalité dans les tombes d'Ambrussum. Cependant, seuls certains adultes ont droit, semble-t-il, à cette symbolique: pour environ un tiers d'entre eux, celle-ci n'existe pas, à moins bien sûr qu'elle ne nous soit pas perceptible d'après les données dont nous disposons.

Une telle répartition des morts adultes en trois ensembles selon le mobilier d'accompagnement, les hommes présumés, les femmes présumées et les indéterminés, est bien connue dans le monde indigène protohistorique du Sud de la France, avec toutefois des variations dans les proportions, selon les lieux et les périodes. Dans la même région qu'Ambrussum mais à une époque antérieure, au premier Âge du Fer, les tumulus des Garrigues du Languedoc oriental, ont livré au total 103 tombes individuelles d'adultes ou d'adolescents qui ont pu faire l'objet d'une détermination ostéologique. Dans cet ensemble, 43 sujets (soit $41,7 \%$ ) possèdent un mobilier à symbolique sexuelle, et sur ce lot 19 (soit $44 \%$ ) ont un mobilier « féminin » ${ }^{23}$ et 24 (soit $56 \%$ ) un mobilier «masculin ${ }^{24}$ (Dedet 1992, p. 193-198).

23 Tumulus Cazevieille C4, D9, E3, G9, J8, K6 et L2, Ravin des Arcs 2, Peyrescanes 3, 6 et 12, Cambous 1 et 13, Frouzet B8, Cazarils 11 et 12 , Viols 2,5 et 8 .

24 Tumulus Cazevieille A2, A5, B5, C1, D14, F2, F6, I1, I5, J1 et G3, Ravin des Arcs 7, Cambous 4 et 15, Frouzet B2 et B4, Cazarils 1, 10 et 17, Saint-Martin A1, Viols 9, Sadoulet 1 et 4 et Serre des Galères 1.
Un peu plus loin à Agde (Hérault), au VII s. av. J.-C. dans la nécropole du Peyrou, sur un total de 99 tombes individuelles d'adultes ou d'adolescents, 67 (soit $68 \%$ ) ont un matériel présentant une connotation sexuelle, parmi lesquelles figurent 40 défunts présumés féminins $^{25}$ (soit $60 \%$ des cas connotés) et 27 présumés masculins ${ }^{26}$ (soit $40 \%$ des cas) (Nickels, Marchand, Schwaller 1989). Au Grand Bassin II à Mailhac (Aude) au siècle suivant, 10 tombes individuelles d'adultes ou d'adolescents sur un total de 13 sont pourvues d'un mobilier à symbolique sexuelle, et dans ce lot 5 ont un mobilier «féminin ${ }^{27}$ et 5 un mobilier «masculin ${ }^{28}$ (Janin et al. 2002). À même époque dans la nécropole de Las Peyros à Couffoulens (Aude), dans 28 tombes individuelles d'adultes ou d'adolescents sur un total de 42 , figurent des pièces à connotation sexuelle, «féminine » pour 9 d'entre elles ${ }^{29}$ (soit $32 \%$ ) et « masculine » pour 19 autres $^{30}$ (soit $68 \%$ ) (Solier, Rancoule, Passelac 1976 ; Passelac, Rancoule, Solier 1981).

\section{Tombe individuelle, tombe partagée}

Une seule des sépultures fouillées dans ce secteur de la nécropole d'Ambrussum, la tombe T7, a livré les restes de deux sujets, au moins, un adulte et un très jeune enfant, vers un an. Pour toutes les autres, le nombre minimum d'individu que révèle l'étude ostéologique est égal à 1 . Certes, l'échantillon est beaucoup trop réduit pour pouvoir affirmer que la tombe individuelle est la règle à Ambrussum pour les adultes et surtout pour les enfants au-delà d'un an. Mais, si on ne peut exclure d'autres exceptions, le dépôt individuel doit correspondre à un usage très majoritaire pour les adultes, qui, au demeurant, constituent l'essentiel du recrutement de cette portion de cimetière.

Cet usage, on le constate à Ensérune à la même époque. Sur les 117 tombes de ce site qui ont bénéficié d'une étude anthropologique, on en dénombre 9 doubles ( $2 \mathrm{du} \mathrm{IVe}$ s. et $7 \mathrm{du} \mathrm{III}{ }^{\mathrm{e}}$ s. av. J.-C.), soit $8 \%$. La majorité d'entre elles associe un adulte et un jeune

25 Tombes 5, 11, 26, 27, 33, 37, 41, 42, 50, 58, 65, 71, 75, 82, 94, $97,107,109,113,116,117,119,120,121,123,127,130,137,146$, 165, 167, 171, 175, 177, 186, 191, 192, 197, 203 et 204 du Peyrou.

26 Tombes 7, 22, 33, 34, 39, 50, 51, 58, 71, 72, 75, 83, 97, 98, $113,114,116,117,121,122,126,130,142,144,149,168$ et 202 du Peyrou.

27 Tombes 3, 21, 24, 27 et 55 du Grand Bassin II.

28 Tombes $1,4,7,14$ et 56 du Grand Bassin II.

29 Tombes 6, 38, 57, 60, 70, 75, 76, 79 et 81 de Las Peyros.

30 Tombes $8,10,13,15,18,21,22,29,30,31,42,43,44,45,50$, 52, 61, 80 et 84 de Las Peyros. 
enfant de 1-6 ans ; six tombes sont dans ce cas et pour une septième, il s'agit d'un jeune ou grand enfant. Deux sépultures seulement sortent de ce schéma, l'une réunissant un adulte et un adolescent (T.153) et l'autre deux adultes (T.175) (Dedet, Schwaller 2010, p. 278-279).

La tombe individuelle pour les adultes est déjà la formule la plus courante dans la région au premier Âge du Fer. Sépultures accueillant deux, voire trois ou quatre, de ces défunts sont alors rares ou même exceptionnelles. Dans toutes les tombes fouillées au Camp de l'Église-Sud à Flaujac-Poujols (Lot) et à Las Peyros à Couffoulens (Aude), soit respectivement 56 et 84 sépultures, ne figurent que des dépôts individuels d'adultes et/ ou adolescents mais aussi, dans ces deux nécropoles, de jeunes et grands enfants. À Agde/le Peyrou I, seulement 8 des 116 adultes et/ou adolescents recensés sont dans des tombes multiples d'adultes et/ou d'adolescents (soit $7 \%$ ). Au Causse à Labruguière (Tarn), seuls 2,1\% des adultes et/ou adolescents sont dans des tombes multiples d'adultes et/ou d'adolescents (6 sur 287 individus). Dans celle de Gourjade à Castres, ce sont 4,5\% des adultes et/ ou adolescents qui partagent la même sépulture (10 sur 221 défunts) et au Martinet, également à Castres, $6 \%$ des adultes et/ou adolescents (4 sur 67 sujets) (Dedet 2008, p. 218-220). Partout, la tombe double ou triple, concerne essentiellement les enfants : c'est en fait une part importante de ces jeunes défunts, soit, globalement pour l'ensemble du monde indigène du Sud de la France, environ un tiers des 1-6 ans comme des 7-14 ans, qui partagent la tombe d'un autre enfant ou d'un adulte (Dedet 2008, p. 218 et 283). Seuls les tumulus des Garrigues du Languedoc oriental offrent une proportion plus forte d'adultes ayant en commun la même sépulture, un quart d'entre-eux, mais il s'agit sans doute d'une coutume propre à une région qui édifie des tombeaux plus grands qu'ailleurs.

À Ambrussum, même si les rares enfants bénéficient d'une sépulture individuelle, à l'exception du nourrisson de la tombe T7, on notera cependant que le loculus contenant les restes d'un enfant de 2-4 ans (tombe T22) et celui qui abrite les os d'un adulte (tombe T23) partagent la même structure commune de recouvrement.

\section{La morphologie de la tombe}

La morphologie de la tombe est intimement liée au seul type de traitement du cadavre en vigueur dans ce quartier de la nécropole d'Ambrussum, la crémation pratiquée sur un bûcher situé en un autre lieu que la sépulture elle-même. Vu les conditions d'enfouissement de cette partie du site sous les alluvions du fleuve, on peut considérer que ce secteur est conservé de manière satisfaisante et qu'il n'a pas subi de dégâts importants après son recouvrement. Le sol d'utilisation de cette nécropole peut être mis en évidence, et la partie aérienne des sépultures, lorsqu'elle existe, peut être reconnue, au moins en partie. De la sorte, les deux types d'architecture sépulcrale présents ici, l'un plus simple que l'autre, doivent bien correspondre à deux catégories de tombes, étant entendu que l'on a considéré comme sépulture tout dépôt secondaire d'os humains brûlés, placé dans une structure plus ou moins élaborée et accompagné d'un nombre plus ou moins important d'objets mobiliers.

Le premier type de tombe, le plus élaboré, comprend deux aménagements, un loculus et une structure de recouvrement (fig. 100, A et fig. 101).

Le loculus est une fosse creusée franchement, de plan à peu près circulaire ou ovale. Le diamètre à l'ouverture des loculus circulaires varie de $50 \mathrm{~cm}$ pour la tombe T17, à $70 \mathrm{~cm}$ pour la tombe 6 , soit des surfaces s'échelonnant entre $0,20 \mathrm{~m}^{2}$ et $0,38 \mathrm{~m}^{2}$. Les loculus ovales ont des dimensions plus importantes à l'ouverture, allant de $65 \mathrm{~cm}$ sur $75 \mathrm{~cm}$ d'axes pour la tombe T13, à $80 \mathrm{~cm}$ sur $140 \mathrm{~cm}$ pour la tombe T23, soit des superficies à l'ouverture comprises entre $0,38 \mathrm{~m}^{2}$ et $0,88 \mathrm{~m}^{2}$. Celui de la tombe T22 se distingue des autres par son plan à l'ouverture, plus irrégulier, s'inscrivant dans un trapèze, et ses dimensions plus importantes, $110 \mathrm{~cm}$ sur $150 \mathrm{~cm}$ d'axes, soit une surface de $1,30 \mathrm{~m}^{2}$.

La profondeur varie aussi d'une tombe à une autre, de $8 \mathrm{~cm}$, pour la tombe 23 , à $36 \mathrm{~cm}$ pour la tombe 22 , avec trois groupes :

- un groupe vers 12-15 cm (tombes T5, T6, T11, T12, T13, T14 et T17);

- un groupe vers $20-25 \mathrm{~cm}$ (tombes T2, T4 et T7);

- un groupe entre 30 et $36 \mathrm{~cm}$ (tombes T21, T22, T24 et $\mathrm{T} 25)$.

La surface à l'ouverture et la profondeur ne sont pas corrélées, puisque parmi les plus grands loculus on trouve le moins profond (tombe T23, profondeur de $8 \mathrm{~cm}$ ) et le plus profond (tombe T22, profondeur de $36 \mathrm{~cm}$ ).

La forme du creusement est également très diversifiée. Les parois peuvent être symétriques, obliques et abruptes avec un fond plat (tombes T11 et T12), un fond arrondi (tombes T5, T6, T7 et T21) ou un fond conique (tombes T22 et T24). Elles peuvent aussi être asymétriques, plus ou moins obliques, avec un fond plat (tombe 
T23) ou un fond arrondi (tombes T13 et T14) (fig. 101). Le creusement peut comporter un ressaut, avec une partie supérieure verticale et une partie inférieure oblique et abrupte et un fond arrondi (tombes T17 et T25).

La structure aérienne de la tombe est constituée d'un léger amoncellement de terre recouvrant le loculus comblé et débordant tout autour sur le sol de circulation. Elle se laisse difficilement percevoir, car elle est composée du même sédiment alluvial apporté par les débordements du fleuve que celui dans lequel sont creusés les loculus, ou la couche qui surmonte la nécropole après son abandon. Seuls plusieurs indices permettent d'en déceler l'existence. C'est d'une part la présence de divers vestiges absents ailleurs dans la couche d'alluvions recouvrant le site : fragments d'os humains incinérés, le plus souvent de petite taille, éparpillés ou parfois regroupés, petits morceaux de charbons de bois, quelques objets, tessons de vases et surtout objets personnels du mort, pièces d'habillement ou de parure ayant subi l'action du feu. D'autre part, des vases ou des portions de vases, coupes et urnes, sont écrasés à plat sur le sol de la nécropole, en bordure même ou à proximité immédiate de l'ouverture des loculus ; or ceux-ci n'auraient pu se conserver in situ sans la protection d'un recouvrement rapide.

Du fait notamment de leur faible épaisseur et de l'absence de toute bordure aménagée, ces structures de recouvrement sont difficilement décelables dans leur ensemble, et leurs limites restent imprécises pour nous. Ce ne sont le plus souvent que des portions plus ou moins importantes qui en ont pu être perçues. Leur épaisseur varie de $2 \mathrm{~cm}$ à $10 \mathrm{~cm}$ selon les cas, avec un maximum de hauteur juste au dessus du comblement du loculus. Le plus souvent cette hauteur maximum n'excède pas 5 ou $6 \mathrm{~cm}$. L'amplitude de ces structures peut atteindre $4 \mathrm{~m} \mathrm{de}$ diamètre ou de grand axe, mais presque toujours, elle se situe entre $2 \mathrm{~m}$ et $3 \mathrm{~m}$.

Dans deux cas, la même structure aérienne recouvre deux loculus voisins, appartenant à deux défunts différents : les tombes T12 et T14 d'une part, et les tombes T22 et T23 d'autre part.

Le second type de sépultures, plus rudimentaire, ne comporte qu'un seul aménagement, une simple dépression ou cuvette creusée dans le sol, sans structure aérienne surmontant son comblement, du moins, sans dispositif de recouvrement perceptible (fig. 100, B) : tombes T10, T15, T16, T18, T19 et T20. Cette fosse est plus ou moins grande à l'ouverture, mais toujours peu profonde. Son amplitude varie de $30 \mathrm{~cm}$ sur $50 \mathrm{~cm}$ d'axes pour la tombe 10 , à $125 \mathrm{~cm}$ sur $145 \mathrm{~cm}$ d'axes pour la tombe
T19. La profondeur va de $2 \mathrm{~cm}$ ou $3 \mathrm{~cm}$ pour les tombes $\mathrm{T} 10$ et $\mathrm{T} 18$, à $13 \mathrm{~cm}$ pour la tombe T19. Les parois sont le plus souvent obliques très peu inclinées, sauf dans le cas de la tombe T19 où elles sont abruptes.

La question se pose, évidemment, de savoir si ce second type, plus sommaire, correspond bien à des tombes, et s'il ne pourrait s'agir de structures annexes, destinées à conserver une partie de la couche de crémation prélevée sur le bûcher. Le cas de la fosse T19 permet de lever cette hypothèque. La masse d'os qu'elle contenait, tout à fait dans la moyenne des tombes de la première classe, et le mobilier parfaitement homogène et bien spécifique d'un défunt dont on a voulu indiquer le sexe, montrent bien qu'il s'agit d'une tombe à part entière. Les autres fosses de cette catégories sont certes moins pourvues en restes humains et en objets, mais pour le reste, elles ne se distinguent pas de cette dernière; et qui plus est, dans les éléments qu'elles renferment, on ne constate pas de doublon avec les tombes voisines.

Le premier groupe de tombes, celles qui sont pourvues d'une structure de recouvrement, est le plus répandu dans ce secteur d'Ambrussum, avec quinze ou seize cas avérés contre cinq pour la seconde série, sans dispositif de couverture. Le choix de l'une ou l'autre de ces deux formes ne semble pas corrélé au sexe du mort, sujets présumés masculins et sujets présumés féminins se rencontrant dans les deux séries, sans exclusive. L'est-il avec son âge ? La question peut se poser car les jeunes enfants ne figurent ici que dans la catégorie avec structure de recouvrement. cependant, on ne saurait en conclure que les sépultures sans dispositif de couverture ne concernent pas ces enfants vu le petit nombre des tombes de cette série et la faible représentation des morts de cet âge. Par ailleurs, le recouvrement commun de deux loculus, constaté ici deux fois, n'apparaît pas spécifique à une catégorie de défunts : il intéresse, dans un cas, une adulte présumé féminin et un jeune enfant (tombes T23 et T22), et, dans l'autre cas, deux adultes pourvus tous deux d'objets personnels à symbolique masculine (tombes T12 et T14). On examinera ci-après s'il existe un lien entre ces deux catégories de sépultures et le dépôt des restes osseux et/ou avec celui des objets accompagnant ces restes.

\section{Le dépôt des os humains}

Aucune tombe à incinération primaire, installée à l'emplacement même du lieu de la crémation, n'est ici attestée ; dans tous les cas, les restes humains brûlés ont été amenés dans la tombe depuis le bûcher. 


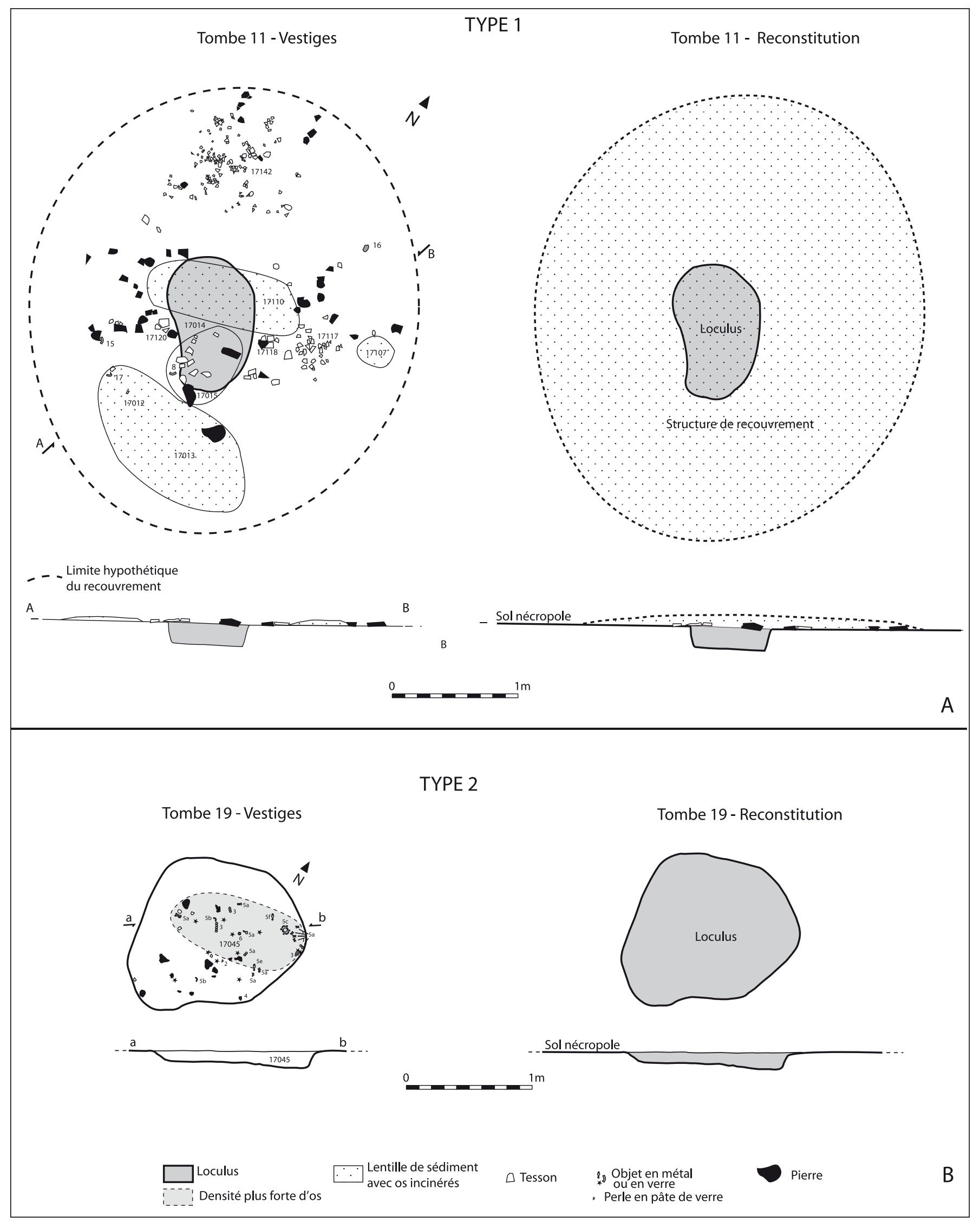

Fig. 100. Typologie de la morphologie des tombes du secteur fouillé de la nécropole d'Ambrussum. 


\begin{tabular}{|c|c|c|c|c|c|c|c|}
\hline TOMBE & & LO & CULUS & & RECOUVR & REMENT & DĖFUNT \\
\hline & $\begin{array}{l}\text { Dimensions } \\
\text { ouverture }\end{array}$ & Superficie & Profondeur & Profil & Dimensions & Hauteur & \\
\hline Т 11 & $110 \times 70 \mathrm{~cm}$ & $0,55 \mathrm{~m}^{2}$ & $15 \mathrm{~cm}$ & $\begin{array}{l}\text { Paroi oblique abrupte } \\
\text { Fond plat }\end{array}$ & $\geq 330 \mathrm{~cm}$ & $6 \mathrm{~cm}$ & $\begin{array}{l}1 \text { adulte } \\
\text { «féminin » }\end{array}$ \\
\hline Т 12 & $130 \times 65 \mathrm{~cm}$ & $0,67 \mathrm{~m}^{2}$ & $15 \mathrm{~cm}$ & $\begin{array}{l}\text { Paroi oblique abrupte } \\
\text { Fond plat }\end{array}$ & \multirow{2}{*}{$\geq 260 \times 200 \mathrm{~cm}$} & \multirow{2}{*}{$5 \mathrm{~cm}$} & $\begin{array}{l}1 \text { adulte } \\
\text { « masculin » }\end{array}$ \\
\hline Т 14 & $60 \times 55 \mathrm{~cm}$ & $0,25 \mathrm{~m}^{2}$ & $12 \mathrm{~cm}$ & $\begin{array}{l}\text { Paroi oblique abrupte } \\
\text { Fond arrondi }\end{array}$ & & & $\begin{array}{l}1 \text { adulte } \\
\text { « masculin » }\end{array}$ \\
\hline Т 13 & $75 \times 65 \mathrm{~cm}$ & $0,38 \mathrm{~m}^{2}$ & $15 \mathrm{~cm}$ & $\begin{array}{l}\text { Paroi oblique abrupte } \\
\text { Fond arrondi }\end{array}$ & non mesurable & non mesurable & $\begin{array}{l}1 \text { enfant } \\
3-5 \text { ans }\end{array}$ \\
\hline T 17 & $50 \times 50 \mathrm{~cm}$ & $0,20 \mathrm{~m}^{2}$ & $12 \mathrm{~cm}$ & $\begin{array}{l}\text { Paroi oblique abrupte } \\
\text { Ressaut } \\
\text { Fond arrondi }\end{array}$ & $\geq 200 \times 150 \mathrm{~cm}$ & $6 \mathrm{~cm}$ & 1 adulte \\
\hline Т 21 & $90 \times 70 \mathrm{~cm}$ & $0,50 \mathrm{~m}^{2}$ & $31 \mathrm{~cm}$ & $\begin{array}{c}\text { Paroi oblique abrupte } \\
\text { Fond arrondi }\end{array}$ & $\geq 200 \times 200 \mathrm{~cm}$ & $5 \mathrm{~cm}$ & $\begin{array}{l}1 \text { adulte } \\
\text { « masculin » }\end{array}$ \\
\hline Т 22 & $150 \times 110 \mathrm{~cm}$ & $1,30 \mathrm{~m}^{2}$ & $36 \mathrm{~cm}$ & $\begin{array}{c}\text { Paroi oblique abrupte } \\
\text { Fond pointu }\end{array}$ & \multirow{2}{*}{ $\pm 300 \times 300 \mathrm{~cm}$} & \multirow{2}{*}{$4 \mathrm{~cm}$} & $\begin{array}{l}1 \text { enfant } \\
2-4 \text { ans }\end{array}$ \\
\hline Т 23 & $140 \times 80 \mathrm{~cm}$ & $0,88 \mathrm{~m}^{2}$ & $8 \mathrm{~cm}$ & $\begin{array}{l}\text { Paroi verticale } \\
\text { à oblique abrupte } \\
\text { Fond plat }\end{array}$ & & & $\begin{array}{c}1 \text { adulte } \\
\text { «féminin » }\end{array}$ \\
\hline Т 24 & $70 \times 70 \mathrm{~cm}$ & $0,40 \mathrm{~m}^{2}$ & $30 \mathrm{~cm}$ & $\begin{array}{c}\text { Paroi oblique abrupte } \\
\text { Fond pointu }\end{array}$ & $400 \mathrm{x} \geq 260 \mathrm{~cm}$ & $2 \mathrm{~cm}$ & $\begin{array}{l}1 \text { enfant } \\
12-15 \text { ans } \\
\text { " féminin » }\end{array}$ \\
\hline Т 25 & $70 \times 65 \mathrm{~cm}$ & $0,35 \mathrm{~m}^{2}$ & $32 \mathrm{~cm}$ & $\begin{array}{c}\text { Paroi verticale } \\
\text { à oblique abrupte } \\
\text { Ressaut. Fond arrondi }\end{array}$ & $\begin{array}{c}180 \mathrm{x} \geq 300 \mathrm{à} \\
400 \mathrm{~cm}\end{array}$ & $10 \mathrm{~cm}$ & $\begin{array}{l}1 \text { adulte } \\
\text { «asculin » }\end{array}$ \\
\hline Т 2 & $56 \mathrm{x} ? \mathrm{~cm}$ & $?$ & $25 \mathrm{~cm}$ & $?$ & $\geq 200 \times 200 \mathrm{~cm}$ & $4 \mathrm{~cm}$ & $\begin{array}{l}1 \text { adolescent } \\
\text { «féminin » }\end{array}$ \\
\hline $\mathrm{T} 4$ & $57 \times 50 \mathrm{~cm}$ & $0,22 \mathrm{~m}^{2}$ & $20 \mathrm{~cm}$ & $?$ & $\geq 200 \times 200 \mathrm{~cm}$ & $15 \mathrm{~cm}$ & $\begin{array}{l}1 \text { adulte } \\
\text { «masculin » }\end{array}$ \\
\hline T 5 & $60 \times 50 \mathrm{~cm}$ & $0,24 \mathrm{~m}^{2}$ & $15 \mathrm{~cm}$ & $\begin{array}{l}\text { Paroi oblique abrupte } \\
\text { Fond arrondi }\end{array}$ & $\geq 200 \times 200 \mathrm{~cm}$ & $20 \mathrm{~cm}$ & $\begin{array}{l}1 \text { enfant } \\
8-12 \text { ans } \\
\text { « féminin » }\end{array}$ \\
\hline T 6 & $70 \times 70 \mathrm{~cm}$ & $0,38 \mathrm{~m}^{2}$ & $12 \mathrm{~cm}$ & $\begin{array}{c}\text { Paroi oblique abrupte } \\
\text { Fond arrondi }\end{array}$ & $\geq 300 \times 200 \mathrm{~cm}$ & 10 à $20 \mathrm{~cm}$ & $\begin{array}{l}1 \text { adulte } \\
\text { « féminin » }\end{array}$ \\
\hline T 7 & $115 \times ? \mathrm{~cm}$ & $?$ & $20 \mathrm{~cm}$ & $\begin{array}{l}\text { Paroi oblique abrupte } \\
\text { Fond arrondi }\end{array}$ & $?$ & $?$ & $\begin{array}{l}1 \text { adulte } \\
\text { et } 1 \text { enfant } \\
\text { vers } 1 \text { an }\end{array}$ \\
\hline
\end{tabular}

Fig. 101. Principales caractéristiques morphologiques des tombes du secteur fouillé de la nécropole d'Ambrussum. 


\subsection{Une quantité d'os variable selon le défunt}

Le poids d'os est variable d'une tombe à une autre, ce qui traduit une absence de constante dans le prélèvement sur le bûcher (fig. 102). Pour certains sujets, ce ramassage concerne une quantité de restes relativement importante, proche de la moitié du poids théorique d'un squelette incinéré, mais pour d'autres, ce n'est qu'une part très réduite. Il varie en fait, d'après les sépultures complètement fouillées ou presque ${ }^{31}$, en fonction de l'âge et du sexe présumé du défunt (fig. 103).

Pour les treize adultes identifiés dont on a la quasi totalité des os déposés, les poids s'échelonnent de $101,8 \mathrm{~g}$ à 980,0 g, et la moyenne est de 442,3 g. C'est pour les hommes présumés que ces poids sont les plus importants, avec une moyenne de 730,3 g par tombe : ils sont compris entre $299,1 \mathrm{~g}$ (T4) et $980 \mathrm{~g}$ (T21) ou même plus de $1000 \mathrm{~g}$ car aux $742 \mathrm{~g}$ du loculus de la T12 on doit ajouter une part des 561,3 g d'os de la couverture partagée avec la T14. En revanche, pour les femmes présumées les quantités sont, en moyenne, moitié moindre (moyenne de 309,4 g), inscrites dans une fourchette comprise entre $157,6 \mathrm{~g}$ et $437,7 \mathrm{~g}$. On a donc ici, en moyenne, 2,3 fois plus d'os pour les hommes que pour les femmes, mais en même temps on constate le même type de représentation des grandes régions anatomiques, des proportions semblables d'éléments provenant de la tête, du tronc et des membres chez les uns comme chez les autres. Cet écart de poids, important, est-il le reflet d'une pratique différente dans le prélèvement des restes osseux en fonction du sexe du défunt adulte ? On recueillerait moins d'os pour une femme que pour un homme ? Ou bien y a-t-il là simplement une cause naturelle ?

Plusieurs études ont montré que la masse osseuse des hommes est plus élevée que celle des femmes (Hermann 1976 ; Mackinley 1993 ; Warren, Maples 1997). Mais, à Ambrussum, cette différence en faveur des hommes présumés va bien au-delà des différences moyennes de poids biologique du squelette constatées entre les deux sexes. Ici le poids moyen d'os incinérés pour les hommes présumés, 730,3 g, représente 39,6\% de la moyenne théorique des os des hommes pour B. Hermann ${ }^{32}, 32 \%$

\footnotetext{
31 Pour chaque sépulture, les valeurs incluent les os du loculus entièrement fouillé et ceux de la structure de recouvrement. Cette dernière a toute chance d'avoir subi une certaine érosion et la totalité de son emprise n'a pas toujours pu être complètement fouillée. Ces poids sont donc minorés par rapport au dépôt réel, mais sans doute de peu, vu la faible densité d'os perçue dans presque toutes les structures de recouvrement fouillées.

32 Soit $1841,6 \mathrm{~g}$.
}

de celle indiquée par J. Mackinley ${ }^{33}$ et $25 \%$ de celle que proposent M. W. Warren et W. R. Maples ${ }^{34}$. Or, pour les adultes présumés féminins la moyenne de 309,4 g est une proportion sensiblement moindre puisqu'elle correspond à $18,2 \%$ de la moyenne établie pour les femmes par B. Hermann ${ }^{35}, 19,1 \%$ par J. Mackinley ${ }^{36}$ et $17 \%$ par M. W. Warren et W. R. Maples ${ }^{37}$.

Cette différence a été mise en relation avec la déminéralisation osseuse due à la ménopause. Une étude expérimentale récente sur une population actuelle a mis en évidence une diminution relative de la masse totale d'os brûlés des adultes en fonction de l'âge au décès et cette baisse est environ deux fois plus importante pour les femmes que pour les hommes (Bass, Jantz 2004, cité par Lenorzer 2009, p. 83-84). De son côté, H. Duday, dans une étude en cours consacrée aux restes humains de la nécropole de Porta Nocera à Pompéi, constate que la plupart des tombes pour lesquelles la masse d'os brûlés contenus dans le réceptacle cinéraire est très faible sont celles de femmes âgées, plusieurs marqueurs de sénescence étant pris en considération conjointement. Il en conclut que «c'est probablement aux troubles endocriniens consécutifs à la ménopause qu'est dû l'allègement considérable de leur squelette ». En moyenne on a, à Pompéi, 1,8 fois plus d'os pour les hommes que pour ces femmes âgées (Van Andringa, Duday, Lepetz 2011). Dans ce secteur de la nécropole d'Ambrussum, la différence de poids pourrait donc aussi relever de cette cause et être imputée à un âge moyen élevé des femmes qui y ont été ensevelies.

Le cas des adultes dont on ne peut soupçonner le sexe semble différent. Pour les quatre adultes indéterminés, le poids d'os s'échelonne de 101,8 g à 413,4 g et la moyenne est de $215,5 \mathrm{~g}$. Celle-ci ne représente plus que $12 \%$ du poids moyen des os d'adultes, hommes et femmes confondus, selon B. Hermann ${ }^{38}$ et $13 \%$ selon J. MacKinley ${ }^{39}$. À Ambrussum, c'est une catégorie d'adultes peu pourvue en matériel d'accompagnement, dont on n'a pas cherché à indiquer symboliquement le sexe par des objets connotés, les deux manifestations étant sans doute liées. Le fait que la quantité d'os qui représente ces défunts soit en moyenne deux à trois fois 


\begin{tabular}{|c|c|c|c|c|c|c|}
\hline TOMBE & $\begin{array}{l}\text { LOCULUS } \\
\text { Masse totale }\end{array}$ & $\begin{array}{l}\text { RECOUVREMENT } \\
\text { Masse totale }\end{array}$ & TOTAL TOMBE & $\begin{array}{c}\text { LOCULUS } \\
\text { Masse moyenne } \\
1 \text { fragment déterminé }\end{array}$ & $\begin{array}{l}\text { RECOUVREMENT } \\
\text { Masse moyenne } \\
1 \text { fragment déterminé }\end{array}$ & DÉFUNT \\
\hline T10 & $190,3 \mathrm{~g}$ & & $190,3 \mathrm{~g}$ & $0,15 \mathrm{~g}$ & & Adulte \\
\hline T11 & $183,7 \mathrm{~g}$ & $100,5 \mathrm{~g}$ & $284,2 \mathrm{~g}$ & $0,22 \mathrm{~g}$ & $0,22 \mathrm{~g}$ & Adulte « féminin » \\
\hline T12 & $742 \mathrm{~g}$ & \multirow{2}{*}{$561,3 \mathrm{~g}$} & & $0,22 \mathrm{~g}$ & \multirow{2}{*}{$0,32 \mathrm{~g}$} & Adulte « masculin » \\
\hline T14 & $282,7 \mathrm{~g}$ & & & $0,50 \mathrm{~g}$ & & Adulte « masculin » \\
\hline $\mathrm{T} 12 / 14$ & & & $1586 \mathrm{~g}$ & & & \\
\hline $\mathrm{T} 13$ & $69,8 \mathrm{~g}$ & & $69,8 \mathrm{~g}$ & $0,09 \mathrm{~g}$ & & Enfant 3-5 ans \\
\hline $\mathrm{T} 15$ & $101,8 \mathrm{~g}$ & & $101,8 \mathrm{~g}$ & $0,33 \mathrm{~g}$ & & Adulte \\
\hline T16 & $156,6 \mathrm{~g}$ & & $156,6 \mathrm{~g}$ & $0,36 \mathrm{~g}$ & & Adulte \\
\hline T17 & $153,4 \mathrm{~g}$ & $260 \mathrm{~g}$ & $413,4 \mathrm{~g}$ & $0,31 \mathrm{~g}$ & $0,33 \mathrm{~g}$ & Adulte \\
\hline $\mathrm{T} 18$ & $121 \mathrm{~g}$ & & $121 \mathrm{~g}$ & $0,39 \mathrm{~g}$ & & Grand Enfant, Ado ou Adulte \\
\hline T 19 & $437,7 \mathrm{~g}$ & & $437,7 \mathrm{~g}$ & $0,32 \mathrm{~g}$ & & Adulte « féminin » \\
\hline T20 & $?$ & $23,1 \mathrm{~g}$ & $23,1 \mathrm{~g}$ & $0,13 \mathrm{~g}$ & & $\begin{array}{l}\text { Adulte } \\
\end{array}$ \\
\hline T21 & $980 \mathrm{~g}$ & $0 \mathrm{~g}$ & $980 \mathrm{~g}$ & $0,52 \mathrm{~g}$ & & Adulte « masculin » \\
\hline T22 & $87,4 \mathrm{~g}$ & $1,5 \mathrm{~g}$ & $88,9 \mathrm{~g}$ & & & Enfant $2-4$ ans \\
\hline T23 & $352,3 \mathrm{~g}$ & $5,6 \mathrm{~g}$ & $357,9 \mathrm{~g}$ & $0,26 \mathrm{~g}$ & & Adulte « féminin » \\
\hline T24 & $319,6 \mathrm{~g}$ & $7,5 \mathrm{~g}$ & $327,1 \mathrm{~g}$ & $0,17 \mathrm{~g}$ & $0,18 \mathrm{~g}$ & Enfant $12-15$ ans « féminin 》 \\
\hline T25 & $765,9 \mathrm{~g}$ & $20,3 \mathrm{~g}$ & $786,2 \mathrm{~g}$ & $0,33 \mathrm{~g}$ & $0,34 \mathrm{~g}$ & Adulte « masculin » \\
\hline $\mathrm{T} 2$ & $?$ & $?$ & $>68 \mathrm{~g}$ & & & Adolescent « féminin » \\
\hline T3 & $?$ & $63,4 \mathrm{~g}$ & $>63,4 \mathrm{~g}$ & & & Adulte \\
\hline T4 & $271,7 \mathrm{~g}$ & $27,4 \mathrm{~g}$ & $299,1 \mathrm{~g}$ & & & Adulte « masculin » \\
\hline T5 & $144,1 \mathrm{~g}$ & $0 \mathrm{~g}$ & $144,1 \mathrm{~g}$ & & & Enfant $8-12$ ans « féminin » \\
\hline T6 & $152,2 \mathrm{~g}$ & $5,4 \mathrm{~g}$ & $157,6 \mathrm{~g}$ & & & Adulte « féminin » \\
\hline T7, sujet 1 & $>299,6 \mathrm{~g}$ & $?$ & $>299,6 \mathrm{~g}$ & & & Adulte \\
\hline T7, sujet 2 & $>9,9 \mathrm{~g}$ & $?$ & $>9,9 \mathrm{~g}$ & & & Enfant vers 1 an \\
\hline
\end{tabular}

Fig. 102. Tableau récapitulatif du poids des os humains livrés par les tombes du secteur fouillé de la nécropole d'Ambrussum, avec indication des parts respectives des loculus et des dispositifs de recouvrement et du poids moyen des fragments d'os déterminés, et notification de la classe d'âge et, éventuellement, du sexe présumé.

plus faible que pour les hommes et les femmes présumés pourrait faire partie de ce traitement modeste.

La masse osseuse déposée pour le grand enfant de 12-15 ans présumé féminin de la tombe T24, avec $327,1 \mathrm{~g}$, se place très proche de la moyenne du poids des présumées femmes. Cela est dans la norme puisque la masse osseuse des immatures recoupe la variabilité des sujets adultes en ce domaine dès l'âge de 12 ans (Trotter, Hixon 1974).

Pour les autres enfants, les poids d'os déposés sont proportionnellement faibles. Le 8-12 ans de la tombe 5, peut-être une fille si l'on en croit le mobilier associé, est attesté par un lot d'os nettement moins important, $141,1 \mathrm{~g}$, ce qui ne représente guère que 13 à $15 \%$ du poids théorique d'os incinéré vers cet âge ${ }^{40}$. Il en va de même des deux jeunes enfants entre 2 et 5 ans des tombes T13 et T22, avec, respectivement 71,5 g et $88,9 \mathrm{~g}$, masses au demeurant très proches l'une de l'autre. Si l'on considère que le poids théorique moyen d'os incinérés est de $259 \mathrm{~g}$ pour un enfant de 2 ans et de 636 g pour celui de 4 ans (Warren, Maples 1997, p. 420-421), c'est donc entre $27 \%$ et $12 \%$ des os brûlés de ces jeunes défunts

40 Entre 3 et 13 ans, la masse osseuse incinérée oscille entre 932,6 et 1132,4 g selon M. Trotter et B.B. Hixon (1974). qui sont mis ici dans la sépulture, soit proportionnellement autant que pour les adultes.

\subsection{Une quantité d'os variable en fonction du type de sépulture}

Pour une même classe d'âge de défunts, la masse d'os déposée varie en fonction du type de sépulture utilisé. La comparaison de ces poids ne peut donc prendre en compte que les tombes d'adultes, cette classe étant la seule attestée dans les tombes de la catégorie des tombes sommaires. Elle montre que les tombes élaborées, à dispositif de recouvrement, ont accueilli en moyenne trois fois plus d'os humains que les tombes rudimentaires, dépourvues de ce dispositif :

- tombes d'adultes de la première classe (tombes $\mathrm{T} 11, \mathrm{~T} 12, \mathrm{~T} 14, \mathrm{~T} 17, \mathrm{~T} 21, \mathrm{~T} 23$ et T25) : les poids varient de $284,2 \mathrm{~g}$ à 980,00 g, soit une moyenne de 629,6 g et un écart-type de 270,95 ;

- tombes d'adultes de la deuxième classe (tombes T10, T15, T16, T18 ${ }^{41}$ et T19) : les poids vont de 101,8 g à $437,7 \mathrm{~g}$, soit une moyenne de $201,48 \mathrm{~g}$ et un écart-type de 136,48 .

41 Cependant pour la tombe 18, l'examen ostéologique ne permet pas de conclure entre grand enfant, adolescent ou adulte. 


\begin{tabular}{|c|c|c|c|c|c|c|}
\hline TOMBE & $\begin{array}{l}\text { Homme } \\
\text { présumé }\end{array}$ & $\begin{array}{c}\text { Femme } \\
\text { présumée }\end{array}$ & $\begin{array}{c}\text { Adulte } \\
\text { indéterminé }\end{array}$ & $\begin{array}{c}\text { Enfant } \\
12-15 \text { ans }\end{array}$ & $\begin{array}{c}\text { Enfant } \\
8-12 \text { ans }\end{array}$ & $\begin{array}{c}\text { Enfant } \\
2-5 \text { ans }\end{array}$ \\
\hline T 12 & $>742 \mathrm{~g}$ & & & & & \\
\hline T14 & $>282,7 \mathrm{~g}$ & & & & & \\
\hline Recouv. T 12/14 & $561,3 \mathrm{~g}$ & & & & & \\
\hline Т 21 & $980 \mathrm{~g}$ & & & & & \\
\hline Т 25 & $786,2 \mathrm{~g}$ & & & & & \\
\hline $\mathrm{T} 4$ & $299,1 \mathrm{~g}$ & & & & & \\
\hline T 11 & & $284,2 \mathrm{~g}$ & & & & \\
\hline Т 19 & & $437,7 \mathrm{~g}$ & & & & \\
\hline Т 23 & & $357,9 \mathrm{~g}$ & & & & \\
\hline T 6 & & $157,6 \mathrm{~g}$ & & & & \\
\hline T 10 & & & $190,3 \mathrm{~g}$ & & & \\
\hline T 15 & & & $101,8 \mathrm{~g}$ & & & \\
\hline T 16 & & & $156,6 \mathrm{~g}$ & & & \\
\hline Т 17 & & & $413,4 \mathrm{~g}$ & & & \\
\hline Т 24 & & & & $327,1 \mathrm{~g}$ & & \\
\hline T 5 & & & & & $144,1 \mathrm{~g}$ & \\
\hline T 13 & & & & & & $71,5 \mathrm{~g}$ \\
\hline T 22 & & & & & & $88,9 \mathrm{~g}$ \\
\hline Moyenne & $730,3 \mathrm{~g} *$ & $309,35 \mathrm{~g}$ & $215,5 \mathrm{~g}$ & & & $80,2 \mathrm{~g}$ \\
\hline
\end{tabular}

A

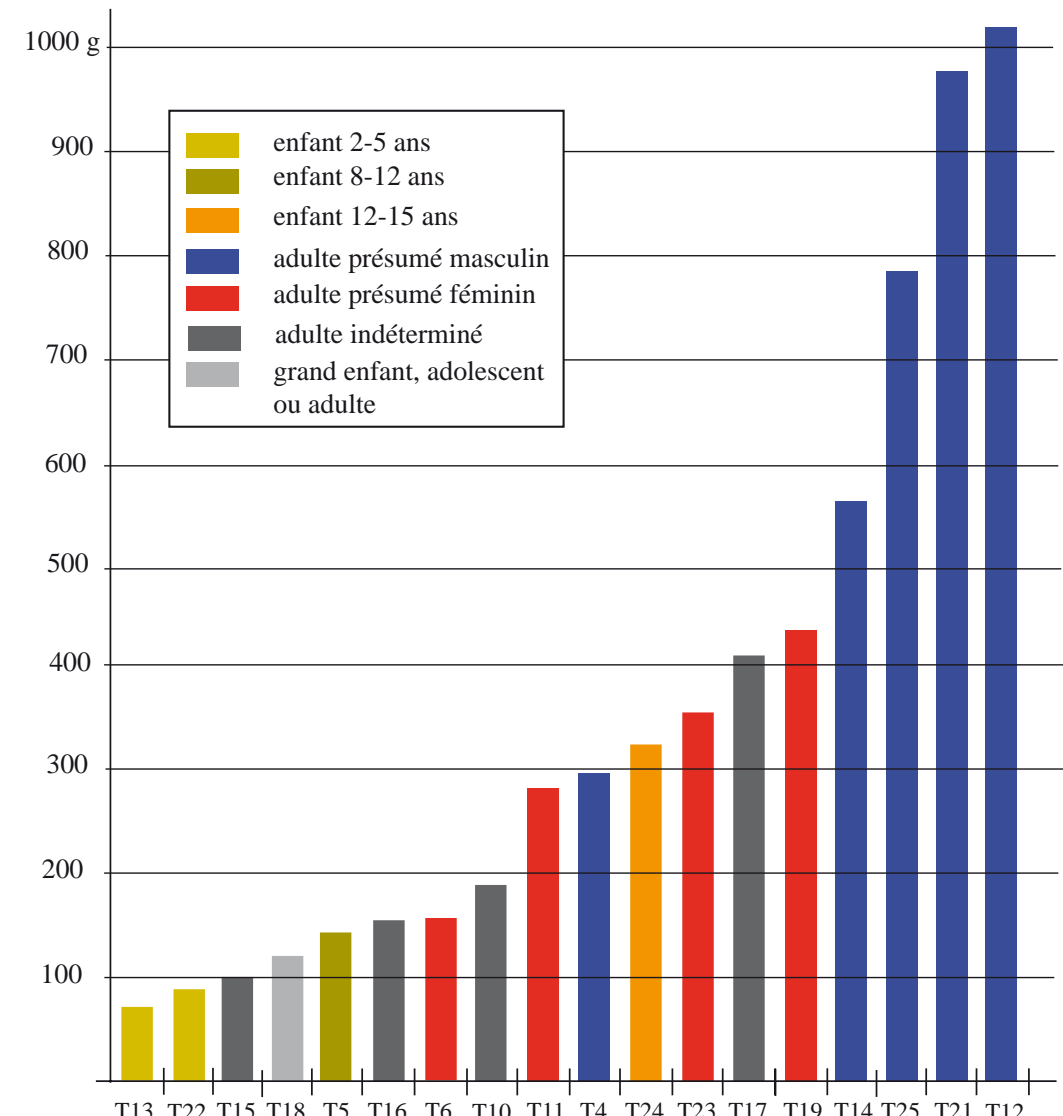

Fig. 103.

A : Tableau récapitulatif du poids des os humains livrés par les tombes du secteur fouillé de la nécropole d'Ambrussum, en fonction du sexe présumé et de l'âge du défunt. Pour les tombes 12 et 14 qui ont un dispositif de recouvrement commun où les os ne peuvent être répartis entre les deux individus, ont été pris en compte les poids totaux des loculus 12 et 14 et du recouvrement 12/14, représentant l'ensemble des deux défunts.

B : Variation du poids des dépôts osseux en fonction de l'âge et du sexe présumé des défunts (la moitié de la masse osseuse du recouvrement commun des tombes 12 et 14 a été attribuée à chacun de ces deux défunts). 


\begin{tabular}{|c|c|c|c|c|c|c|}
\hline \multirow{2}{*}{ TOMBE } & \multirow{2}{*}{ DÉFUNT } & \multirow{2}{*}{ TOTAL } & \multicolumn{2}{|c|}{ LOCULUS } & \multicolumn{2}{|c|}{ RECOUVREMENT } \\
\hline & & & Poids en $\mathrm{g}$ & $\%$ & Poids en $\mathrm{g}$ & $\%$ \\
\hline T11 & Adulte " féminin » & 284,2 & 183,7 & $64,6 \%$ & 100,5 & $35,4 \%$ \\
\hline T17 & Adulte & 413,4 & 153,4 & $37,1 \%$ & 260 & $62,9 \%$ \\
\hline T 22 & Enfant 2-4 ans & 88,9 & 87,4 & $98,5 \%$ & 1,5 & $1,7 \%$ \\
\hline T23 & Adulte « féminin » & 357,9 & 352,3 & $97 \%$ & $5,6 \quad(11,2)$ & $3 \%$ \\
\hline T12 & Adulte « masculin » & & 742 & & \multirow{2}{*}{561,3} & \multirow{2}{*}{$35,3 \%$} \\
\hline T14 & Adulte « masculin " & & 282,7 & & & \\
\hline T 21 & Adulte « masculin » & 980 & 980 & 100 & 0 & $0 \%$ \\
\hline T 24 & Enfant $12-15$ ans « féminin » & 327,1 & 319,6 & $95,5 \%$ & $7,5 \quad(15)$ & $4,5 \%$ \\
\hline T 25 & Adulte « masculin » & 786,2 & 765,9 & $95 \%$ & $20,3 \quad(40,6)$ & $5 \%$ \\
\hline
\end{tabular}

Fig. 104. Part relative des os humains livrés par les loculus et les dispositifs de recouvrement des tombes du secteur fouillé de la nécropole d'Ambrussum, en fonction du sexe présumé et de l'âge du défunt (Pour les recouvrements de T23, T24 et T25, en partie fouillés, figurent les extrapolations).

\subsection{Le mode de dépôt}

Ces restes sont placés directement dans la sépulture, hors de tout contenant et en particulier en dehors de tout vase ossuaire. Le mode de dépôt varie cependant en fonction de la situation dans la tombe.

Dans les tombes de première classe, il convient de distinguer le loculus et le dispositif de recouvrement. Dans le loculus, ce dépôt se compose de deux parties. Un prélèvement du sédiment du bûcher est placé dans le comblement vers le fond ou le centre de la fosse. Il prend la forme d'une ou plusieurs mottes blanchâtres et compactes de cendres et d'os, souvent collés entre eux. Il n'est pas possible de savoir si ces petits amas étaient placés dans un contenant périssable, un petit sac par exemple, ou s'il s'agit d'une simple pelletée, car ils sont recouverts par le comblement de la fosse. Ce dernier est formé par un sédiment argileux issu du substrat local et en son sein sont répartis des morceaux d'os humains débarrassés des résidus de la combustion, en quelque sorte nettoyés. Ces éléments sont dispersés jusque sur les bords du loculus, ce qui indique qu'ils n'étaient pas enfermés dans un contenant disparu. À la densité en os de la première partie du dépôt, s'oppose l'éparpillement des éléments de la seconde partie. Des fragments osseux sont aussi éparpillés dans l'accumulation de terre formant le dispositif de couverture de la tombe.

La part relative d'os déposée dans chacune des deux structures composant ces tombes est très variable selon les cas.

Les trois tombes dont les restes du dispositif de recouvrement ont pu être intégralement fouillés montrent des cas de figure opposés. Pour l'adulte « féminin» de la tombe T11, le loculus a reçu $64,6 \%$ de la masse du lot osseux, et le recouvrement $35,4 \%$. La proportion est exactement inverse pour ce qui concerne l'adulte indéterminé de la tombe T17, avec 37,1\% du lot osseux, en poids, dans le loculus et $62,9 \%$ dans le recouvrement. Et pour le jeune enfant de la tombe T22, la part osseuse éparpillée dans le recouvrement est minime, 1,5\%.

D'une manière générale c'est le loculus qui reçoit la plus grosse part, voire la totalité du lot. Dans la tombe T21, celle d'un adulte « masculin », la moitié du recouvrement, qui seule a pu être fouillée, était dépourvue d'os. Pour l'adulte «masculin» de la tombe T25, là aussi, seule la moitié du recouvrement a pu être étudiée, livrant 20,3 g d'os. Si on extrapole en doublant cette quantité pour la totalité du recouvrement, ce ne serait qu'environ $5 \%$ des os dans cette structure pour $95 \%$ dans le loculus de cette sépulture. On a les mêmes proportions pour le grand enfant présumé féminin de la tombe T24. L'estimation peut aussi être effectuée pour le cas des tombes T12 et T14 dont les loculus voisins ont un dispositif de recouvrement commun, en comparant la quantité d'os du recouvrement avec la somme des os des deux loculus : le dispositif recouvrant ces deux structures a livré $35,3 \%$ du total des os de ces deux tombes. De toutes manières, une conclusion s'impose, la variabilité d'une telle répartition du dépôt osseux n'apparaît pas corrélée avec l'âge des défunts, ni avec leur sexe présumé (fig. 104).

Dans les tombes de seconde classe, dépourvues de dispositif de recouvrement, les os sont le plus souvent dispersés dans le comblement de terre argileuse jaune du loculus très peu profond, sans être accompagnés de résidus de la crémation. C'est le cas des tombes T10, T15, T16 et T18. Seule la tombe T19 fait exception, remplie d'un sédiment prélevé sur le bûcher, gris foncé à noirâtre, plus sombre dans la partie centrale de la fosse. Au demeurant, ce dépôt se distingue des autres de sa catégorie de tombes par sa masse relativement élevée, 437,9 g et l'abondance de son mobilier, alors que les quatre autres sépultures de cette classe ont un 
matériel d'accompagnement très réduit et un poids d'os compris entre $101,8 \mathrm{~g}$ et $190,3 \mathrm{~g}$. Tous ces caractères rapprochent en fait cette tombe T19 de la première classe distinguée.

Un autre point mérite d'être souligné : les poids moyens des fragments osseux déterminés provenant des loculus sont tout à fait semblables à ceux qui sont issus des dispositifs de recouvrement (fig. 102) : respectivement $0,31 \mathrm{~g}$ et $0,33 \mathrm{~g}$ pour l'adulte de la tombe $\mathrm{T} 17$, ou $0,33 \mathrm{~g}$ et $0,34 \mathrm{~g}$ pour celui de la tombe T24 ou encore $0,32 \mathrm{~g}$ et $0,34 \mathrm{~g}$ pour celui de la tombe 21 et aussi $0,17 \mathrm{~g}$ et $0,18 \mathrm{~g}$ pour le grand enfant de la tombe $\mathrm{T} 24 ; 0,22 \mathrm{~g}$ dans les deux structures pour l'adulte de la tombe $\mathrm{T} 11 ; 0,22 \mathrm{~g}$ dans le loculus de l'adulte de la tombe T12, 0,50 g dans le loculus de l'adulte de la tombe T14 et 0,32 $\mathrm{g}$ dans le recouvrement commun aux deux (fig. 102). À ce niveau là, donc, aucune distinction n'existe entre le dépôt osseux du loculus et celui du dispositif de recouvrement.

Concernant ce poids moyen des os, on ne dispose de comparaisons chiffrées que pour le contenu des ossuaires de la nécropole de Gourjade (Castres, Tarn) à une époque plus ancienne, fin du Bronze final et premier Âge du Fer. Dans ces dépôts, on a signalé des poids moyens de $0,20 \mathrm{~g}$ pour les fragments de côtes, $0,78 \mathrm{~g}$ pour les fragments crâniens, $2,43 \mathrm{~g}$ pour ceux des membres supérieurs et $3,36 \mathrm{~g}$ pour ceux des membres inférieurs (Duday, Depierre, Janin 2000, p. 20). Pour le tronc et le crâne, ces valeurs sont sensiblement supérieures à celles que fournit Ambrussum. Et il en va de même pour les membres si l'on compare avec les données, relativement rares, obtenues à Ambrussum quand il a été possible de faire la distinction entre membres supérieurs et membres inférieurs. En effet, dans les tombes de ce site, le poids moyen est de $1,11 \mathrm{~g}$ pour les fragments attribués aux membres supérieurs (de $0,80 \mathrm{~g}$ dans la tombe T12 à 1,95 g dans la tombe T21) et il est de 1,70 g pour les fragments des membres inférieurs (de $1,18 \mathrm{~g}$ dans la tombe T11 à 3,20 $\mathrm{g}$ dans la tombe T14). Mais, l'ossuaire constitue une protection qui peut expliquer cette différence.

\subsection{La composition du dépôt osseux}

\section{La part de la tête}

La valeur théorique de l'indice pondéral crânien est de $20 \%$ environ pour l'adulte. À Ambrussum la valeur observée varie de 0 à $48 \%$, et la moyenne, pour les seize individus adultes et/ou adolescents recensés, s'établit à $19,77 \%$, tout à fait conforme à la normale, avec un écart-type de 10,97 (fig. 105 et 106, A). Pour les deux grands enfants (tombes T5 et T24), cet indice, respectivement 18,4 et $27,4 \%$ entre dans l'écart-type calculé pour les adultes (fig. 105). Il n'en va pas de même pour les enfants plus jeunes.

Les deux enfants entre 2 et 5 ans, tombes T13 et T23, montrent en effet des indices très élevés, respectivement de 50,4 et 64,5\% (fig. 105). Le même fait a été remarqué dans d'autres séries, notamment la nécropole du Peyrou I à Agde, pour le VII ${ }^{\mathrm{e}}$ s. av. J.-C. (Duday 1989, p. 469), ou celles du Castrais, Gourjade, le Martinet et le Causse, pour le Bronze final IIIb et le premier Âge du Fer (Giraud, Pons, Janin dir. 2003, I, p. 194). Or, comme le fait remarquer H. Duday dans son étude du Peyrou I, le volume de la tête rapporté au volume corporel est beaucoup plus élevé chez le jeune enfant que chez l'adulte et cela pourrait suffire à justifier de tels indices anormalement forts et ne reflèterait pas un ramassage sélectif.

\section{La part du tronc}

Pour tous les individus d'Ambrussum le poids relatif du tronc est anormalement bas. Il oscille entre 0 et $10,3 \%$ du poids total d'os attesté dans les sépultures, avec une moyenne de $4,41 \%$ et un écart-type de $3,26 \%$ (fig. 105 et 106, A). À l'exception de l'adulte de la tombe T4, avec l'indice pondéral le plus élevé de $10,3 \%$, tous sont nettement inférieurs à l'intervalle $10-20 \%$ considéré comme «normal», la moyenne théorique étant de $17 \%$ (Duday, Depierre, Janin 2000, p. 21-22). Et sur ce plan, les quatre jeunes ou grands enfants (tombes 5, 13, 22 et 24) ne se différencient pas de leurs aînés (fig. 105).

Ce déficit de la représentation du tronc est un fait couramment constaté dans les sépultures du Sud de la France protohistorique. Il est généralement lié à une mauvaise conservation des vertèbres qui tient sans doute au processus de crémation mis en œuvre habituellement (Duday, Depierre, Janin 2000, p. 22). De fait, dans la sépulture de Saint-Martin-de-Colombs à Fabrègues (Hérault), au VII s. av. J.-C., l'indice pondéral exceptionnellement élevé du tronc, $23 \%$, tient uniquement à la présence de vertèbres bien conservées, alors que les autres os de cette partie du squelette sont presque totalement absents (Dedet, Paya 2006-2007). L'une des rares tombes du Castrais ayant fourni un indice pondéral du tronc exceptionnellement élevé $(25,6 \%)$ se signale par une hyperostose poreuse très évoluée de la colonne vertébrale, pathologie qui a sans doute modifié 


\begin{tabular}{|c|c|c|c|c|}
\hline Tombe & Défunt & Tête & Tronc & Membres \\
\hline T10 & Adulte & 6,9 & 4,4 & 88,7 \\
\hline $\mathrm{T} 11$ & & 24 & 6,2 & 69,8 \\
\hline dont Loculus & Adulte « féminin » & 29,6 & 6,9 & 63,5 \\
\hline et Recouvrement & & 13,2 & 5 & 81,8 \\
\hline T 12 Loculus & Adulte « masculin » & 16,8 & 8,9 & 74,3 \\
\hline T 14 Loculus & Adulte « masculin » & 8,8 & 13,1 & 78,1 \\
\hline T 12/14 Recouvrement & & 29,2 & 4,7 & 66 \\
\hline T 13 & Enfant $3-5$ ans & 50,4 & 5,1 & 44,5 \\
\hline T 15 & Adulte & 14,6 & 1,7 & 83,7 \\
\hline T16 & Adulte & 13,6 & 3,2 & 83,3 \\
\hline T 17 & & 16,6 & 6 & 77,5 \\
\hline dont Loculus & Adulte & 8,7 & 10,8 & 80,5 \\
\hline et Recouvrement & & 21 & 3,2 & 75,8 \\
\hline $\mathrm{T} 18$ & Gd enfant, Ado ou Adulte & 0 & 1,8 & 98,2 \\
\hline T 19 & Adulte « féminin » & 21,1 & 8,7 & 70,2 \\
\hline T 20 & Adulte & 16,1 & 0,8 & 83,1 \\
\hline T 21 & Adulte « masculin » & 22,3 & 6,2 & 71,6 \\
\hline T 22 & Enfant 2-4 ans & 64,5 & 5,6 & 29,9 \\
\hline T23 & Adulte « féminin » & 33,3 & 1,5 & 65,2 \\
\hline T 24 & & 27,4 & 6 & 66,7 \\
\hline dont Loculus & Enfant $12-15$ ans & 27,6 & 6 & 66,4 \\
\hline et Recouvrement & & 16,7 & 3,2 & 79,6 \\
\hline T 25 & & 19,3 & 7,2 & 73,5 \\
\hline dont Loculus & Adulte « masculin» & 19,2 & 7,4 & 73,4 \\
\hline et Recouvrement & & 21,5 & 0,5 & 78 \\
\hline $\mathrm{T} 2$ & Adolescent « féminin » & 11,6 & 0,1 & 88,3 \\
\hline T3 Recouvrement & Adulte & 20,3 & 0 & 79,5 \\
\hline T4 & Adulte « masculin » & 48 & 10,3 & 41,7 \\
\hline T5 & Enfant 8-12 ans & 18,4 & 9,2 & 72,4 \\
\hline T6 & Adulte « féminin » & 29,1 & 4,3 & 66,6 \\
\hline
\end{tabular}

Fig. 105. Tableau récapitulatif des indices pondéraux de chaque grande région anatomique, en $\%$ par rapport au poids total d'os identifiés dans chaque tombe du secteur fouillé de la nécropole d'Ambrussum.

\begin{tabular}{|c|c|c|c|}
\hline & I P Crâne & I P Tronc & I P Membres \\
\hline Nombre & 16 & 16 & 16 \\
\hline Moyenne & 19,77 & 4,41 & 75,82 \\
\hline Écart-type & 10,97 & 3,26 & 12,85 \\
\hline Minimum & 0 & 0 & 41,7 \\
\hline Maximum & 48,0 & 10,3 & 98,2 \\
\hline
\end{tabular}

\begin{tabular}{|c|c|c|c|c|}
\hline Catégorie & Tombe & I P Crâne & I P Tronc & I P Membres \\
\hline \multirow{9}{*}{ 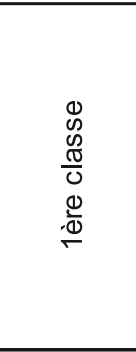 } & T 11 & 24 & 6,2 & 69,8 \\
\hline & T12 Loculus & 16,8 & 8,9 & 74,3 \\
\hline & T 14 Loculus & 8,8 & 13,1 & 78,1 \\
\hline & $\mathrm{T} 17$ & 16,6 & 6 & 77,5 \\
\hline & T 21 & 22,3 & 6,2 & 71,6 \\
\hline & T 23 & 33,3 & 1,5 & 65,2 \\
\hline & T25 & 19,3 & 7,2 & 73,5 \\
\hline & Moyenne & 20,15 & 7,01 & 72,85 \\
\hline & Écart-type & 6,24 & 3,49 & 4,49 \\
\hline \multirow{7}{*}{$\begin{array}{l}0 \\
\mathbb{N} \\
0 \\
\mathbb{D} \\
0 \\
\mathbb{N} \\
\stackrel{N}{N}\end{array}$} & T 10 & 6,9 & 4,4 & 88,7 \\
\hline & T15 & 14,6 & 1,7 & 83,7 \\
\hline & T16 & 13,6 & 3,2 & 83,3 \\
\hline & T 18 & 0 & 1,8 & 98,2 \\
\hline & T19 & 21,1 & 8,7 & 70,2 \\
\hline & Moyenne & 11,24 & 3,96 & 84,8 \\
\hline & Écart-type & 8,05 & 2,87 & 4,38 \\
\hline
\end{tabular}

Fig. 106.

A : Valeurs des indices pondéraux (I P) du crâne, du tronc et des membres pour les tombes d'adultes et/ou d'adolescents du secteur fouillé de la nécropole d'Ambrussum.

B : Comparaison des indices pondéraux de chaque grande région anatomique des adultes et adolescents entre tombes de la première classe et de la seconde classe (en \% par rapport au poids total d'os identifiés livrés par les tombes). 
le comportement de ces os sur le bûcher (Giraud, Pons, Janin dir., 2003, I, p. 196).

\section{La part des membres}

Pour les dix-sept sujets adultes ou adolescents d'Ambrussum, le poids relatif des membres est compris entre 41,7 et 98,2 \% (fig. 105). La moyenne, 75,82 \%, est supérieure à la moyenne théorique de 62,6\%. L'écart-type est de 12,85 (fig. 106, A). Cette part, proportionnellement plus importante des membres compense évidemment le manque au niveau du tronc. Il en va de même pour les deux grands enfants des tombes T5 et T24 dont l'indice est, respectivement, de 72,4 et $66,7 \%$. En revanche, cet indice est très en-dessous de la moyenne théorique pour les deux jeunes enfants des tombes T13 et T22, respectivement 44,5 et $29,9 \%$, contrebalancé dans ces deux cas par une part plus importante des os de la tête qui découle de la morphologie des jeunes enfants.

\section{La variation entre les deux classes de tombes}

La composition du lot osseux des adultes et des adolescents prélevé sur le bûcher et déposé ne paraît guère varier selon que le défunt bénéficie de l'une ou l'autre des deux catégories de sépulture distinguées.

Certes, tête et tronc sont mieux représentés dans la première classe, celle des tombes pourvues d'un dispositif de recouvrement. L'indice pondéral moyen de la tête y est de 20,15\% (écart-type de 6,24) et celui du tronc de 7,01\% (écart-type de 3,49). Pour les tombes sans dispositif de recouvrement, les mêmes indices sont, respectivement $11,24 \%$ (écart-type de 8,05) et de 3,96\% (écart-type de 2,87) (fig. 106, B). Cependant, dans ces dernières, le taux de détermination moyen des os n'est que de $62,98 \%$ de la masse osseuse totale, alors qu'il est de 78,7\% dans les tombes de la première classe et ceci peut expliquer cela. De toutes façons, on retrouve dans les dépôts de seconde classe une répartition tête, tronc, membres voisine de celle qui est constatée dans les tombes de la première classe.

De même, le poids moyen des fragments d'os déterminés provenant des tombes de première classe est tout à fait semblable à celui des restes osseux découverts dans les tombes de deuxième classe : ainsi, pour les adultes, entre $0,22 \mathrm{~g}$ et $0,50 \mathrm{~g}$ pour les premières, et de 0,15 à $0,39 \mathrm{~g}$ pour les secondes (fig. 102).

Ces deux constatations tendent à confirmer que ces structures dépourvues de dispositif de recouvrement sont bien des tombes à part entière et non de simples vidanges de restes de bûchers.

\section{Le matériel accompagnant les défunts}

\subsection{Les objets personnels}

Presque tous les objets personnels retrouvés dans les sépultures portent des traces de feu plus ou moins importantes, simple coloration et/ou début de fusion, et cela, pas seulement les pièces d'habillement ou de parure, comme les fibules, les bracelets, les éléments de ceinture ou les perles, mais aussi les armes et les ustensiles. À l'évidence, ces objets ont été brûlés avec le corps sur le bûcher. Il s'agit de ce qu'il est convenu d'appeler le «mobilier primaire», par opposition au «mobilier secondaire », constitué d'éléments placés après l'incinération dans la structure définitive recevant les restes du mort (Blaizot dir. 2009, p. 126-128).

L'objet personnel le plus volumineux mis dans un de ces dépôts est la pointe de lance de la tombe T12, qui mesure $160 \mathrm{~mm}$ de long, et aucun autre ne dépasse $90 \mathrm{~mm}$. Les pièces métalliques les plus encombrantes, comme les épées, leurs fourreaux ou les éléments de bouclier se retrouvent dans les tombes sous la forme de petits morceaux. Cette fragmentation peut résulter de deux actions, soit le ringardage ${ }^{42}$ lors de la conduite de la crémation, ou bien un bris intentionnel après celle-ci.

Par ailleurs, de ces objets de grande dimension, on n'a mis dans la tombe qu'un nombre restreint de morceaux. Sans doute faut-il y voir l'application du principe bien connu en ethnologie de la partie valant le tout.

Quatre sépultures sont dépourvues de toute trace d'objet personnel du défunt. Il peut s'agir d'adultes, ceux des tombes T10, T16 et T17, comme du jeune enfant entre trois et cinq ans de la tombe 13. Mais il s'agit là d'une minorité de sujets. De tels objets accompagnent en effet seize individus. Ils peuvent être répartis en trois groupes selon que les divers éléments qui les composent sont associés ou non dans les dépôts (fig. 88). Deux de ces catégories ne sont jamais représentées à la fois dans la même tombe, d'une part les armes et le fourniment, d'autre part certaines parures et certains ustensiles. Allusion y a déjà été faite à propos de la symbolique sexuelle dont ces pièces sont chargées (voir supra dans

42 Action de remuer le bûcher ou de modifier la position de parties du corps du défunt durant la crémation au moyen d'un grand tisonnier ou « ringard » (pour un exemple traditionnel au Népal, voir Grévin 2004, p. 49). 
le même chapitre, § 1.2.). La troisième série comprend les objets pouvant être joints à l'une comme à l'autre des deux premières catégories.

\subsubsection{Armes et fourniment}

Armement et fourniment affectent six sépultures, les tombes T2, T12, T14, T18, T21 et T25. Ils figurent aussi dans l'aire crématoire B1 et dans la structure ST1, possible bûcher également (fig. 88).

L'arme le plus souvent concernée est l'épée, dont on trouve des éléments dans cinq de ces sépultures (tombes T12, T14, T18, T21 et T25). En fait, ce n'est pas la lame elle-même qui est placée dans la tombe, sans doute du fait de son encombrement, alors que des morceaux de lames ont été retrouvés dans l'aire de crémation B1, mais de petits éléments que le feu du bûcher a détachés soit de sa poignée soit du système de suspension. Ainsi figurent souvent les rivets fixant la garniture de matière organique de la poignée (tombes T12, T14, T21 et T25), les éléments en bronze ou en fer de la ceinture ou du baudrier, des anneaux, de un à quatre selon les cas (tombes T12, T14, T18 et T21), des passants (tombes $\mathrm{T} 12$ et $\mathrm{T} 14$ ) et des agrafes à crochet (tombes T12, T14, $\mathrm{T} 18$ et $\mathrm{T} 21)$.

Presque aussi souvent attestée que l'épée est la lance, que l'on trouve dans quatre sépultures, trois en association avec l'épée (tombes T12, T21 et T25) et une fois sans autre accompagnement d'arme (tombe T2). Cette arme est représentée soit par sa pointe (tombe T12), soit par son talon (tombes T2, T21 et T25). Comme il s'agit d'objets de dimension réduite, ces éléments sont déposés complets ou peu détériorés.

Le bouclier n'apparaît sûrement qu'une fois, dans la couverture commune des tombes 12 et 13 , et seulement sous la forme de rivets de fixation de l'umbo. Qu'il accompagne le défunt de la tombe T12 ou celui de la tombe T14, il y est associé à des restes d'épée. Il est possible aussi que deux autres rivets se rapportent également à un autre bouclier dans la tombe T25, qui, elle aussi, a reçu des vestiges d'épée, mais cela reste hypothétique.

Quatre des individus équipés d'armement ou de fourniment sont des adultes, dont au moins deux âgés de moins de 30 ans (tombes T14 et T21) et un de plus de 30 ans (tombe T12), l'âge de celui de la tombe 25 ne pouvant être précisé. Un autre défunt (tombe T2) est un adolescent, mais l'âge du sixième individu (tombe T18) ne peut être déterminé, grand enfant, adolescent ou adulte. Ce type de dépôt affecte donc plutôt les classes «jeunes adultes » et « adolescents » que des sujets âgés. Et son attribution à un grand enfant, si tant est que le sujet de la tombe 18 entre dans cette catégorie, ne peut être exclue a priori car au moins trois cas de tombes de grands enfants équipés d'armes sont connues actuellement dans la Protohistoire régionale : la tombe 331 de Negabous à Perpignan, au milieu du VIIe s. (Toledo i Mur dir. 2010, II, p. 242-245 et 505) ${ }^{43}$, le tumulus de l'Agnel 1 à Pertuis dans le Vaucluse, aux environs de 600 et la tombe de Saint-Antoine à Castelnau-deGuers, Hérault, dans le second quart du VI ${ }^{\mathrm{e}}$ s. av. J.-C. (Dedet 2008, p. 255-256 et 277-281). Et de tels dépôts d'armes auprès de grands enfants ne sont pas l'apanage du Midi de la France. On les retrouve par exemple en Castille, aux $\mathrm{VI}^{\mathrm{e}}-\mathrm{V}^{\mathrm{e}} \mathrm{s}$. av. J.-C., dans la nécropole de Carratiermes (tombes 267 et 301), province de Soria (Argente Oliver et al. 2000), près de Bologne en Italie, dans celle de Monte Tamburino (tombes 59, 66, 99 et 117) aux IV ${ }^{\mathrm{e}}-\mathrm{III}^{\mathrm{e}}$ s. av. J.-C. (Vitali dir. 2003), ou encore en Celtique continentale dans la tombe 8 du Chemin de Montereau à Barbey (Seine-et-Marne) au IV ${ }^{\mathrm{e}} \mathrm{s}$. av. J.-C. (Séguier et al. 2010, p. 202 et 209).

Ces six défunts pourvus d'armes forment une part proportionnellement très importante du groupe de tombes fouillées: ils représentent environ $35 \%$ de la population adulte et/ou adolescente (17 sujets), ou encore $30 \%$ des adultes et/ou adolescents et/ou grands enfants (20 sujets). De tels pourcentages ne manquent pas de surprendre. Étant donné que, dans ce quartier de la nécropole d'Ambrussum, le nombre d'adultes présumés masculins équivaut à peu près celui des adultes connotés féminins, ce sont donc environ les deux tiers des hommes qui seraient portés en terre avec de l'armement. Cela pose la question de la raison d'une présence aussi importante de ces objets dans les sépultures de cette communauté.

Bien sûr l'échantillon de population perçu est très réduit. Bien sûr aussi, nous ne connaissons pas la totalité de ce cimetière, et cette fréquence des tombes à armes peut être seulement localisée à une partie de ce lieu. L'hypothèse d'une pareille spécialisation peut d'autant moins être écartée depuis la fouille récente, en 2008, d'un secteur de la nécropole de Beaucaire/Le Sizen Collège Vigne, daté des IV $^{\mathrm{e}}$-III' ${ }^{\mathrm{e}}$ s. av. J.-C., dévolu à des enfants et, semble-t-il d'après le mobilier, à des femmes

43 Richard Donat qui a fait la fouille de l'ossuaire et l'étude anthrologique de ce sujet écrit prudemment « grand enfant ou jeune adolescent » mais pencherait plutôt pour un grand enfant entre 10 et 14 ans (communication orale du 17-11-2010). 
(Carme, Demangeot 2010). Mais ici, à Ambrussum, le «recrutement» des défunts paraît équilibré et cette hypothèse ne semble pas devoir être retenue, d'autant que des armes, peu ou prou contemporaines, provenant peut-être de tombes, ont jadis été découvertes dans le secteur du pont romain, à l'autre extrémité de la terrasse alluviale où est installée la nécropole (voir supra, introduction, § 3.).

La question du statut de ces individus «avec armes » se pose donc. L'hypothèse de «guerriers », de «militaires» semble devoir être éliminée : les traces d'activités économiques qui ont pu être décelées dans les fouilles de l'habitat marquent une population plutôt tournée vers l'agriculture et l'élevage, comme sur les autres oppida régionaux contemporains (Columeau 1979). Dès lors, ces dépôts d'armes signaleraient simplement des tombes d'hommes plutôt jeunes, capables éventuellement d'assurer la défense de la communauté, de ses récoltes et de ses troupeaux. N'oublions pas que cette nécropole correspond à l'époque où l'oppidum d'Ambrussum se structure et se fortifie (Fiches, Mathieu 2002, p. 528-529). À la fin du IV e ou au début du III ${ }^{\mathrm{e}}$ s., cette agglomération est dotée d'un rempart de pierre sèche, équipé de tours quadrangulaires et englobant une superficie d'environ cinq hectares. Loin de tomber en désuétude, cette enceinte est réaménagée dans la seconde moitié du III ${ }^{\mathrm{e}}$ s. av. J.-C., avec des tours de plan arrondi, selon l'évolution de l'architecture des remparts régionaux, et une tour «monumentale », plus importante que les autres, au point culminant du tracé (Arcelin, Dedet 1985). Et, durant le siècle suivant, cette fortification sera encore en usage et fera l'objet de compléments, d'améliorations et de reconstructions.

Ces six dépôts d'armes d'Ambrussum reproduisent probablement la composition de l'équipement de l'homme «en armes » dans cette communauté au $\mathrm{III}^{\mathrm{e}} \mathrm{s}$. av. J.-C., même si, bien sûr, ne prend place dans la sépulture qu'une sélection plus ou moins volontaire de ce qui a accompagné le corps sur le bûcher. Cette panoplie comprend donc une épée, avec son système de suspension, et une lance pour l'offensif, un bouclier pour le défensif ; et un tel prélèvement partiel sur le bûcher par les survivants suffit à expliquer que des éléments de ces trois armes ne figurent pas dans tous les cas ${ }^{44}$. Il reste que, en dehors du bouclier, aucun autre élément de protection du corps n'est attesté, casque, cuirasse ou cnémides. Et cet équipement peut être aussi bien celui de combattants

44 Pour la tombe 2, dont on ne connaît qu'un talon de lance, on tiendra compte aussi du caractère incomplet de la fouille lors des sondages des années 1980 (Fiches dir. 1989). à pied que de cavaliers. En effet, la possible présence de ces derniers est signalée par la découverte de dents d'équidés, peut-être de cheval, dans deux des tombes à arme d'Ambrussum, la tombe T21 et le recouvrement commun aux tombes $\mathrm{T} 12$ et $\mathrm{T} 14$.

\subsubsection{Objets de parure et ustensiles spécifiques des tombes sans armement}

Huit sépultures dépourvues d'arme ou de pièces de fourniment, T2, T5, T6, T11, T19, T22, T23 et T24, contiennent, en dehors des vases ou tessons de vases en céramique, plusieurs catégories d'objets qui, pour leur part, n'apparaissent pas dans les tombes contenant de l'armement : perles et/ou pendants d'oreille, parures d'au moins deux bracelets, ou chaîne ceinture, ou encore un ustensile lestant le fuseau, la fusaïole. À l'exception des pendants d'oreille, de telles pièces sont également attestées dans l'aire de crémation B1 (fig. 88).

Les perles équipent quatre défunts, ceux des tombes T5, T6, T22 et T24. Elles sont presque toujours en pâte de verre ; seules celles de la tombe T5 sont en corail.

Trois de ces tombes n'en ont livré qu'une (tombe T6) ou deux (tombes T5 et T24). Il s'agit soit des grosses perles en pâte de verre bleue à protubérance portant des spirales jaunes (T6 et T24), soit de branches de corail (T5). Dans ces cas, plutôt qu'un véritable collier, sans doute s'agit-il d'un simple sautoir. En revanche, la tombe T22 contenait en grand nombre des petites perles filiformes, cinquante-cinq bleues et une jaune, ainsi qu'une perle moyenne et une grosse perle, l'ensemble constituant un véritable collier auquel pouvait aussi être intégré l'anneau en bronze découvert dans le loculus. Beaucoup de ces objets montrent des traces de feu ; ils ont donc accompagné les corps sur le bûcher.

Deux adultes sont concernés par ce type de parure, ceux des tombes T6 et T19. Les trois autres défunts sont jeunes, un petit enfant de 2-4 ans pour le collier de la tombe T22 et deux grands enfants de 8-12 ans et 12-15 ans pour, respectivement, les tombes T5 et T24. Et les deux plus jeunes ceux des tombes T22 et T5, ne sont d'ailleurs munis d'aucun autre petit objet personnel. Portées en sautoir ou en collier ces perles concernent donc surtout les enfants. Dès lors la question se pose de savoir s'il s'agit de parures ou d'objets prophylactiques. La valeur protectrice des perles en pâte de verre n'est pas assurée, même si elle a été avancée pour la décoration oculée placée sur certaines d'entre-elles (Déchelette 1927, p. 825). Il n'en va pas de même pour les rameaux de corail, comme ceux de la tombe 5, qui, «mis en 
amulette aux enfants passent pour être des préservatifs » selon Pline ${ }^{45}$ (Dasen 2003).

Deux défunts possèdent de petits pendants d'oreille de même forme, en croissant. Le sujet adolescent de la tombe T2 en est équipé d'une paire, en bronze, tandis qu'un seul exemplaire, en argent, accompagne l'adulte de la tombe T19.

Deux adultes sont pourvus de deux ou trois bracelets, ou du moins des morceaux de ceux-ci : deux exemplaires en bronze et un en verre dans la tombe 11, et deux ou trois en bronze dans la tombe T23. Ces objets ont été cassés avant leur dépôt et portent le plus souvent des traces de feu. L'un des bracelets de la tombe T23 a même, sans doute, été brisé avant le passage sur le bûcher, comme l'atteste l'état très différent de deux fragments jointifs. Les exemplaires en bronze sont fort simples, une tige de section en « $\mathrm{D} »$ ou lenticulaire, sans décor visible. Tous les morceaux n'étant pas mis dans la tombe, on ignore le plus souvent s'il s'agit de bracelets ouverts ou fermés, cependant l'un de ceux de la tombe T11, avec extrémité amincie, signale la présence d'un exemplaire ouvert.

La chaîne de ceinture en bronze qualifiée de « féminine », à maillons doubles reliés par des anneaux, à chaînettes accessoires comprenant des pendentifs accrochés à elle, et munie d'un fermoir accompagne deux défunts : l'adulte de la tombe T19, ainsi que l'adulte de la tombe T23 ou l'enfant de la tombe T22, un maillon double ayant été trouvé dans le dispositif de recouvrement commun aux deux loculus T22 et T23.

La fusaïole enfin, instrument du travail féminin du filage de la laine, équipe le sujet adolescent de la tombe $\mathrm{T} 2$ et l'adulte de la tombe T23.

Dans ce groupe de défunts dépourvus d'armement, le mobilier se démarque nettement selon l'âge au décès.

Aux enfants on ne confie que des perles et anneaux. Le collier ou le sautoir est ici le seul objet personnel qui leur soit attribué. C'est un usage traditionnel dans la région, que, pour la Protohistoire, on note dès le Bronze final III. Il s'applique aux nourrissons ayant atteint ou dépassé les six mois d'existence et les matières entrant dans la composition de ces objets, ambre, corail, fer, pourraient avoir une valeur prophylactique si l'on se réfère aux sociétés de l'Antiquité classique. La perle ou le collier équipent encore souvent les jeunes et grands

45 Histoire Naturelle, XXXII, 24. enfants, éventuellement associés à d'autres menus objets, épingle, fibule, coquillage ou fusaïole. Ils peuvent aussi être attribués à des sujets adolescents et adultes munis d'objets personnels à symbolique féminine. Cependant pour les jeunes enfants, ces perles ne marquent pas le sexe du défunt, mais plutôt son appartenance au monde des femmes de la maisonnée (Dedet 2008, p. 154-155, 226-240 et 290). À Ambrussum, c'est sans doute le cas pour le 2-4 ans de la tombe T22, dont le loculus, de surcroît, est placé à proximité immédiate de celui de la tombe T23, abritant un adulte présumé féminin, et tous deux possèdent le même dispositif de couverture. En revanche, pour les grands enfants des tombes T5 et T12, il pourrait s'agir d'un marqueur féminin, à l'instar des adultes des tombes T6 et T19.

Pour leur part, le pendant d'oreille, la parure composée de plusieurs bracelets, la chaîne de ceinture et la fusaïole sont réservés aux adultes et aux adolescents, sans doute des individus féminins si l'on en croit la connotation dont ces pièces sont chargées.

Toutefois, ce ne sont jamais tous les éléments de cet équipement symbolisant les femmes qui apparaissent associés dans ces tombes. La plupart du temps, il s'agit d'un seul bijou: paire de pendants d'oreille dans la tombe T2, parure de bracelets dans les tombes T11 et T23, perle dans la tombe T6, auxquels s'ajoutent parfois la fusaïole, dans les tombes T2 et T23. Un seul de ces adultes, celui de la tombe T19, réunit trois de ces pièces, la ceinture "féminine », le pendant d'oreille en argent et la perle, auxquels il convient d'ajouter un bracelet décoré et une fibule à disque incrusté de corail. Et pour ce défunt, on soulignera la qualité de ces objets : le caractère complexe de la ceinture qui est composée de multiples éléments, la matière semi-précieuse du pendant d'oreille, l'ornementation du bracelet en bronze, qui tranche sur celle des autres bracelets découverts dans ce secteur de la nécropole, et celle de la fibule, qui sans être unique sur ce site appartient à la catégorie la plus élaborée en usage ici. Nul doute que l'on a cherché à mettre cette femme en valeur par le mobilier qui lui est associé, même si la raison nous en échappe complètement.

Cet « équipement féminin » perceptible à Ambrussum se retrouve dans les deux autres nécropoles languedociennes indigènes peu ou prou contemporaines, Ensérune et Mourrel-Ferrat, du moins dans les rares tombes dont le matériel est connu actuellement. Cette similitude réside autant dans la nature des objets déposés que dans leur très faible quantité auprès de chaque individu. Il en va ainsi à Ensérune, dans les tombes T9 avec trois bracelets en bronze et trois fusaïoles (Jannoray 1955, p. 324), 
T55bis avec une fusaïole (ibid., p. 243, fig. 32), T147 avec deux boucles d'oreille en or (Gallet de Santerre 1968, 73), T172-172bis avec sept perles en verre et une fusaïole (ibid. p. 79) et T6-1988 avec une fusaïole (Schwaller et al. 1995, p. 220-222). Un tel équipement figure aussi dans trois tombes de Mourrel-Ferrat: les tombes T2 avec un coquillage (Janin et al. 2000, p. 223), T5 avec une boucle d'oreille (ibid., p. 224, fig. 8, ${ }^{\circ} 54$ et p. 255) et T 21 avec deux ou trois bracelets en bronze et une perle en verre (ibid., p. 235-237).

\subsubsection{Autres objets personnels}

Les défunts d'Ambrussum peuvent aussi être accompagnés de pièces de parure ou d'habillement, fibules et bracelet unique, associés ou non à des éléments des deux précédentes séries d'objets personnels. Ces pièces sont également représentées dans l'aire de crémation B1.

La fibule à pied discoïde orné de corail prend place auprès de quatre défunts :

- l'adulte de la tombe T25, équipé d'arme ;

- l'adulte de la tombe T19 et l'individu adolescent de la tombe $\mathrm{T} 2$, au mobilier à connotation féminine ;

- l'adulte de la tombe T15, dépourvu de matériel à symbolique sexuelle.

La fibule à ressort court, long pied recourbé comportant un nodule et fixé à l'arc, figure dans deux autres tombes :

- avec l'adulte de la tombe T21, pourvu d'armement ;

- avec le grand enfant de la tombe T24, accompagné d'un mobilier à connotation féminine.

La fibule à ressort long, pied recourbé à petit nodule et fixé à l'arc, trouvée sur le sol de la nécropole, ne peut être attribuée à une tombe précise.

Le port d'un seul bracelet concerne l'homme présumé de la tombe T25, la femme présumée de la tombe T19 et l'adulte indéterminé de la tombe T15.

À l'évidence, ici comme ailleurs dans la Protohistoire du Languedoc et de la Provence, ces objets ne constituent pas des marqueurs d'identité sexuelle des défunts.

\subsection{Vases et tessons de vases}

La céramique figure dans l'aire de crémation B1, dans la structure ST1, ainsi que dans toutes les sépultures. Cette présence revêt toutefois des significations différentes selon l'état du récipient et le lieu de découverte.

\subsubsection{La céramique découverte dans l'aire de crémation B1}

Dans l'aire de crémation B1, mettons à part une coupe à vernis noir de l'atelier de Rosas retrouvée brisée mais aux trois quarts complète, et aux morceaux non dispersés. C'est probablement un vase jeté dans un secteur de cette aire de crémation à la manière d'une ultime libation.

Pour le reste, il s'agit uniquement des tessons de vases toujours isolés. Ces morceaux ne paraissent pas faire partie d'un mobilier placé sur le bûcher. Ils semblent plutôt intervenir dans un rite accompagnant la cérémonie de crémation, de même d'ailleurs que les restes animaux, comme des vestiges de repas pris auprès du bûcher, et dont il convient de laisser un témoignage, ou une petite partie symbolique, sur celui-ci.

\subsubsection{La céramique découverte dans les tombes}

Dans la plupart des tombes, la céramique est associée aux différentes catégories d'objets personnels, aussi bien celles qui possèdent une symbolique sexuelle que celles qui en sont dépourvues. Dans trois cas cependant, elle constitue le seul matériel d'accompagnement, et cette éventualité n'est pas réservée à une classe d'âge puisqu'elle concerne deux adultes (tombes T10 et T16), et un jeune enfant de 3-5 ans (tombe T13). Cette présence de la céramique est attestée sous trois grandes formes de dépôt, le vase complet, la portion de vase incomplet et le tesson isolé.

Ces récipients ressortissent à deux grandes catégories fonctionnelles : d'une part les urnes de type pot à cuire ou à conserver les aliments, ainsi que les grandes coupes ou jattes, qui peuvent avoir le même usage, catégorie à laquelle se rattachent les couvercles et coupes-couvercles pour fermer ces urnes; d'autre part les vases liés au service de la boisson, amphores, cruches et œnochoés, coupes et coupelles. Malgré l'aspect quelque peu théorique et simplificateur d'une telle répartition, on dénommera la première série de vases à aliments « vases à solides », et celle qui est dédiée au service de la boisson, « vases à liquides ».

\section{Dépôt de vase complet}

Le dépôt de vase complet est très rare ici, pour ne pas dire exceptionnel, et il est bien particulier à plus d'un titre (fig. 107 et 108).

Il affecte d'abord un seul secteur du quartier de la nécropole fouillé, celui des trois tombes voisines T12, $\mathrm{T} 13$ et T14, dont deux au moins, les tombes T12 et T14, 
possèdent en commun le même dispositif de couverture. Il implique un nombre très restreint de récipients, trois seulement. Dans les trois cas il s'agit de coupes, et ces vases sont d'un certain prix puisque importés de la région de Rosas et d'ateliers du sud de la Gaule fabriquant de la céramique à pâte claire «massaliète ». Enfin ces récipients ne sont pas déposés intacts dans la tombe, mais sont cassés et les morceaux sont répartis en différents lieux :

- une coupe à vernis noir de Rosas (fig. 19, $\mathrm{n}^{\circ}$ 8) dont la plupart des morceaux ont été placés dans le remplissage de la partie basse du loculus de la tombe T12, parmi les restes incinérés, tandis que d'autres tessons ont été intégrés à la structure de recouvrement commune aux loculus des tombes T12 et T14;

- une coupe à pâte claire ma ssaliète (fig. 19, $\mathrm{n}^{\circ} 13$ ) dont deux tessons prennent place dans le loculus de la tombe T12, trois autres dans le recouvrement des tombes $\mathrm{T} 12$ et $\mathrm{T} 14$ et le reste se répartit dans le loculus de la tombe $\mathrm{T} 13$;

- une autre coupe à pâte claire massaliète (fig. 21, $n^{\circ}$ 9) dont sept tessons ont été déposés dans le loculus de la tombe T14, et les autres éléments dans le recouvrement des tombes T12 et T14.

Ces trois coupes établissent un lien et une concomitance entre ces trois tombes et le dépôt des os de ces trois défunts, deux adultes pourvus d'armement, donc sans doute masculins (tombes 12 et 14) et un enfant jeune (tombe 13). Vases à liquide, elles témoignent d'un rituel particulier, sans doute une triple libation commune aux trois trépassés lors du dépôt de leurs restes dans les loculus, avec bris des récipients et rejet des morceaux dans les loculus et le recouvrement.

\section{Dépôt de portion de vase}

Les portions de vases constituent un type de dépôt plus fréquent que le précédent : dix-neuf ensembles ont été recensés (fig. 107 et 108). Ces portions sont plus ou moins importantes. On peut estimer qu'elles représentent, selon les cas, entre 5 et $50 \%$ du récipient, mais guère plus. Elles proviennent de deux grandes catégories fonctionnelles, soit des vases propres à renfermer des aliments solides, l'urne et son couvercle, la grande coupe et la jatte, ou bien des vases destinés aux liquides.

Les vases à aliment solide, au nombre de seize, comptent pour plus des trois quarts de l'ensemble. Ce sont des produits non tournés indigènes, de fabrication locale. L'urne est la plus fréquente, qui figure dans douze cas : trois exemplaires dans la tombe $\mathrm{T} 11$ et un dans chacune des tombes T5, T10, T14, T16, T19, T21, T24, et
T25 et dans le recouvrement commun aux tombes T22 et T23. Les autres formes sont exceptionnelles et apparaissent toujours en complément de l'urne : une jatte dans la tombe T11 et une autre dans la tombe T19; une grande coupe dans la tombe T11 et un couvercle dans la tombe T20. Le plus souvent, ces portions de récipients sont écrasées sur le sol de la nécropole, en bordure même du loculus, et recouvertes, au-dessus du sol, par la structure aérienne de la tombe (tombes T11, T14, T16, T19, T20, T21, T22/23 et T24). Mais parfois on trouve aussi des tessons de ces vases à la fois dans le loculus et dans le recouvrement (tombes T11 et T25).

Les vases à liquide sont beaucoup plus rares que les précédents, au nombre de trois spécimens seulement. Ce sont tous des produits importés sur le site : une portion de coupe grise peinte massaliète, dont les éléments sont répartis dans le loculus et le recouvrement de la tombe T12, une coupe à vernis noir de Rosas dans le recouvrement de la tombe T25, et une autre coupe de la même catégorie dans le loculus et le recouvrement de la tombe T12.

\section{Dépôt de tesson isolé}

Les vases sont le plus souvent représentés par un seul tesson ou un nombre très faible de tessons, quelques unités, même s'il arrive que le nombre précis de récipients soit parfois impossible à déterminer. C'est là le mode de présence de la céramique le plus courant car il concerne toutes les sépultures et, pour chacune de celles-ci, ce sont plusieurs récipients qui sont attestés, voire plusieurs dizaines (fig. 107 et 108). Ces fragments sont généralement de petite taille, quelle que soit la dimension du récipient dont ils proviennent, coupelle ou amphore.

En tout, ce sont quelque 450 vases qui sont ainsi attestés par 490 tessons. Avec 460 tessons, la céramique non tournée est très largement majoritaire $(94 \%)$. Seuls figurent 29 vases importés (6\%). La forme de vase à aliment solide ou à liquide ne peut être précisée que pour une partie de ce lot, 133 tessons.

Les vases à solide sont prépondérants, 100 exemplaires au moins, soit les trois quarts des formes déterminées. Ce sont essentiellement des vases non tournés, et presque tous des urnes, tandis que couvercles, grandes coupes, jattes et dolia sont exceptionnels.

Les vases à liquide, avec 33 spécimens, ne forment qu'un quart environ de l'ensemble des formes évaluées. La céramique non tournée est très peu présente dans cette catégorie, avec quatre vases seulement, soit près de $12 \%$ du total des vases à liquide, uniquement des coupes. 


\begin{tabular}{|c|c|c|c|}
\hline TOMBE & TESSONS ISOLÉS & PORTIONS DE VASES & VASES COMPLETS \\
\hline T 10 & $\begin{array}{l}\text { Loculus : } 16 \text { tessons de } 15 \text { vases } \\
\text { Vase à solide : } 2 \mathrm{CNT} \\
\text { Vase à liquide : } 1 \mathrm{VN} \\
\text { Indéterminé : } 12 \mathrm{CNT}\end{array}$ & $\begin{array}{l}\text { Recouv.: } \\
\text { Vase à solide : } 1 \text { urne CNT (10\%) }\end{array}$ & \\
\hline T 11 & $\begin{array}{l}\text { Loculus : } 17 \text { tessons de } 14 \text { vases } \\
\text { Vase à solide : } 14 \mathrm{CNT} \\
\text { Vase à liquide : } 0 \\
\text { Recouv. : } 96 \text { tessons de } 70 \text { vases env. } \\
\text { Vase à solide : } 5 \mathrm{CNT} \\
\text { Vase à liquide : } 8 \text { ( } 3 \mathrm{VN}, 2 \mathrm{CL} \mathrm{M}, 3 \mathrm{~A} \mathrm{M}) \\
\text { Indéterminé : } \leq 58 \mathrm{CNT}\end{array}$ & $\begin{array}{l}\text { Loculus et Recouv.: } \\
\text { Vases à solide : } 2 \text { urnes CNT (10 et } 50 \% \text { ) } \\
\text { Recouv. : Vases à solide : } \\
2 \text { urnes CNT ( } 10 \text { et } 25 \%) \\
1 \text { grande coupe CNT }(15 \%) \\
1 \text { jatte CNT }(5 \%)\end{array}$ & \\
\hline T 12 & $\begin{array}{l}\text { Loculus : } 19 \text { tessons de } 11 \text { vases } \\
\text { Vase à solide : } 8 \mathrm{CNT} \\
\text { Vase à liquide : } 3(1 \mathrm{CL} \mathrm{M}, 2 \mathrm{~A} \mathrm{M}) \\
\text { Recouv. : } 44 \text { tessons de } \leq 44 \text { vases } \\
\text { Indéterminé }: \leq 44 \mathrm{CNT}\end{array}$ & & $\begin{array}{l}\text { Loculus et Recouv.: } \\
\text { Vase à liquide : } \\
1 \text { coupe VN, } 1 \text { coupe CL M } \\
\text { (même que dans loculus T 13) }\end{array}$ \\
\hline T13 & $\begin{array}{l}\text { Loculus : } 11 \text { tessons de } 8 \text { vases } \\
\text { Vase à solide : } 6 \mathrm{CNT} \\
\text { Vase à liquide : } 2(1 \mathrm{~V} \mathrm{~N}, 1 \mathrm{CL} \mathrm{M})\end{array}$ & & $\begin{array}{l}\text { Loculus: } \\
\text { Vase à liquide : } \\
1 \text { coupe CL M (même que dans T12) }\end{array}$ \\
\hline T 14 & $\begin{array}{l}\text { Loculus : } 4 \text { tessons de } 4 \text { vases } \\
\text { Vase à solide }: 2 \mathrm{CNT} \\
\text { Indéterminé : } 2 \mathrm{CNT} \\
\text { Recouv. : } 70 \text { tessons de } \leq 70 \text { vases } \\
\text { Vase à solide }: 5 \text { ( } 4 \mathrm{CNT}, 1 \mathrm{VN}) \\
\text { Indéterminé : } \leq 65 \mathrm{CNT}\end{array}$ & $\begin{array}{l}\text { Recouv. : } \\
\text { Vase à solide : } 1 \text { urne }(40 \%)\end{array}$ & $\begin{array}{l}\text { Loculus et Recouv.: } \\
\text { Vase à liquide : } \\
1 \text { coupe CL M (même que dans T12) } \\
\text { Recouv. : } \\
\text { Vase à solide : } 1 \text { couvercle CNT }(80 \%)\end{array}$ \\
\hline T15 & $\begin{array}{l}\text { Loculus : } 29 \text { tessons de } 27 \text { vases } \\
\text { Vase à solide : } 4 \mathrm{CNT} \\
\text { Vase à liquide : } 1 \mathrm{VN} \\
\text { Indéterminé : } 22 \mathrm{CNT}\end{array}$ & & \\
\hline T 16 & $\begin{array}{l}\text { Loculus : } 43 \text { tessons de } 39 \text { vases } \\
\text { Vase à solide : } 2 \mathrm{CNT} \\
\text { Vase à liquide }: 1 \mathrm{CL} \mathrm{M} \\
\text { Indéterminé : } 36 \mathrm{CNT}\end{array}$ & $\begin{array}{l}\text { Recouv. : } \\
\text { Vase à solide :1 urne }(10 \%)\end{array}$ & \\
\hline Т 17 & $\begin{array}{l}\text { Recouv. : } 31 \text { tessons de } 29 \text { vases env. } \\
\text { Vase à solide : } 3(2 \mathrm{CNT}, 1 \mathrm{CL} \mathrm{M}) \\
\text { Vase à liquide : } 3(2 \mathrm{VN}, 1 \mathrm{CNT}) \\
\text { Indéterminé : } 23 \mathrm{CNT}\end{array}$ & & \\
\hline $\mathrm{T} 18$ & $\begin{array}{l}\text { Loculus : } 23 \text { tessons de } 21 \text { vases } \\
\text { Vase à solide }: 21 \mathrm{CNT}\end{array}$ & & \\
\hline
\end{tabular}

Fig. 107. Tableau récapitulatif des modalités des dépôts céramiques dans les tombes du secteur fouillé de la nécropole d'Ambrussum ( $C N T=$ céramique non tournée $; \mathrm{VN}=$ vernis noir ; $C L M=$ Claire Massaliète ; $A M=$ amphore Massaliète).

La céramique importée comprend en revanche toutes les catégories de vases liées sinon au banquet, du moins à la consommation du vin : des amphores massaliètes (tessons de huit exemplaires), soit environ le quart des vases importés, des coupes, soit environ les trois quarts de ces vases (15 exemplaires à vernis noir de Rosas et 5 à pâte claire massaliète) et une seule œnochoé à pâte claire massaliète.

\section{Des gestes différents}

Ces trois formes de dépôts de vases ou de tessons illustrent trois sortes de gestes différents.
Les rares vases complets ont été apportés dans les tombes après la crémation des corps. Sur les trois attestés, un seul porte des traces de feu, mais on ne peut pas dire si celles-ci résultent d'un passage sur le bûcher crématoire ou d'une autre action. Coupes pour des liquides, ces trois récipients pourraient donc refléter des libations faites dans les tombes lors de l'ensevelissement des restes incinérés des défunts. Ces actions sont suivies du bris de ces vases et de la répartition des morceaux dans différentes parties des sépultures, loculus et recouvrement, et même de leur partage entre deux défunts.

Les portions de vases marquent un autre rituel. Elles ne semblent pas provenir de vases placés sur le bûcher. 


\begin{tabular}{|c|c|c|c|}
\hline TOMBE & TESSONS ISOLÉS & PORTIONS DE VASES & VASES COMPLETS \\
\hline T 19 & $\begin{array}{l}\text { Loculus } 22 \text { tessons de } 22 \text { vases } \\
\text { Vase à liquide : } 2(1 \mathrm{~V} \mathrm{~N}, 1 \mathrm{~A} \mathrm{IB}) \\
\text { Indéterminé : } 20 \mathrm{CNT}\end{array}$ & $\begin{array}{l}\text { Recouv. : Vases à solide: } \\
1 \text { urne }(5 \%) \\
1 \text { jatte }(5 \%)\end{array}$ & \\
\hline T 20 & $\begin{array}{l}\text { Épandage : } 9 \text { tessons de } 9 \text { vases } \\
\text { Indéterminé : } 9 \mathrm{CNT}\end{array}$ & Vase à solide $: 1$ couvercle $(20 \%)$ & \\
\hline T 21 & $\begin{array}{l}\text { Loculus : } 3 \text { tessons de } 2 \text { vases } \\
\text { Vase à solide : } 1 \mathrm{CNT} \\
\text { Vase à liquide : } 1 \mathrm{CL} M \\
\text { Recouv. : } 2 \text { tessons de } 2 \text { vases } \\
\text { Indéterminé : } 2 \mathrm{CNT}\end{array}$ & $\begin{array}{l}\text { Recouv } \\
\text { Vase à solide : } 1 \text { urne }(15 \%)\end{array}$ & \\
\hline T 23 & $\begin{array}{l}\text { Loculus : } 32 \text { tessons de } 30 \text { vases } \\
\text { Vase à solide }: 4 \mathrm{CNT} \\
\text { Vase à liquide }: 1 \mathrm{AM} \\
\text { Indéterminé }: 30 \mathrm{CNT}\end{array}$ & & \\
\hline T22-23 & $\begin{array}{l}\text { Recouv. : } 5 \text { tessons de } 3 \text { vases } \\
\text { Vase à solide }: 1 \mathrm{CNT} \\
\text { Vase à liquide }: 2 \mathrm{VN} \\
\text { Indéterminé }: 4 \mathrm{CNT} \\
\end{array}$ & $\begin{array}{l}\text { Recouv } \\
\text { Vase à solide :1 urne }(50 \%)\end{array}$ & \\
\hline T 24 & $\begin{array}{l}\text { Loculus : } 2 \text { tessons de } 2 \text { vases } \\
\text { Vase à solide : } 1 \mathrm{CNT} \\
\text { Indéterminé : } 1 \mathrm{CNT} \\
\text { Recouv. : } 40 \text { tessons de } 38 \text { vases env. } \\
\text { Vase à solide }: 6 \mathrm{CNT} \\
\text { Vase à liquide : } 1 \mathrm{CNT} \\
\text { Indéterminé : } 31 \mathrm{CNT}\end{array}$ & $\begin{array}{l}\text { Recouy } \\
\text { Vase à solide : } 1 \text { urne }(50 \%)\end{array}$ & \\
\hline T 25 & $\begin{array}{l}\text { Loculus : } 9 \text { tessons de } 9 \text { vases } \\
\text { Vase à liquide }: 1 \mathrm{VN} \\
\text { Indéterminé }: 8 \mathrm{CNT} \\
\text { Recouv. : } 14 \text { tessons de } 14 \text { vases } \\
\text { Vase à solide : } 2 \text { CNT } \\
\text { Vase à liquide : } 1 \mathrm{AM} \\
\text { Indéterminé : } 11 \mathrm{CNT} \\
\end{array}$ & $\begin{array}{l}\text { Loculus et recouv. : } \\
\text { Vase à solide : } 1 \text { urne }(15 \%) \\
\text { Recouy. } \\
\text { Vase à liquide : } 1 \text { coupe VN }(25 \%)\end{array}$ & \\
\hline T5 & $\begin{array}{l}\text { Loculus : } 3 \text { tessons de } 2 \text { vases } \\
\text { Vase à solide : } 1 \mathrm{CNT} \\
\text { Vase à liquide : } 1 \mathrm{VN}\end{array}$ & $\begin{array}{l}\text { Loculus et/ou recouv. : } \\
\text { Vase à solide : } 1 \text { urne }(50 \%)\end{array}$ & \\
\hline T 6 & $\begin{array}{l}\text { Loculus : } 14 \text { tessons de } 14 \text { vases } \\
\text { Vase à solide : } 12 \mathrm{CNT} \\
\text { Vase à liquide : } 2 \mathrm{CNT} \\
\end{array}$ & $\begin{array}{l}\text { Loculus } \\
\text { Vase à liquide : } 1 \text { coupe VN (25\%) }\end{array}$ & \\
\hline T 7 & $\begin{array}{l}\text { Loculus (incomplet) : tessons de } 7 \text { vases } \\
\text { Vase à liquide }: 2 \mathrm{VN} \\
\text { Indéterminé }: 5 \mathrm{CNT}\end{array}$ & & \\
\hline
\end{tabular}

Fig. 108. Tableau récapitulatif des modalités des dépôts céramiques dans les tombes du secteur fouillé de la nécropole d'Ambrussum (suite).

C'est du moins le cas pour les vases en céramique importée, qui ne portent pas les stigmates du feu crématoire, mais cela est difficilement perceptible pour les vases non tournés car il est impossible de faire la part entre traces laissées par la cuisson originelle, par un usage culinaire préalable ou par un passage sur le bûcher funèbre. Dans leur grande majorité ( $84 \%$ ), ces portions sont issues de récipients à aliment solide, et en particulier d'urnes, et plus rarement $(16 \%)$ de vases à liquide. Elles ont été soit placées dans les loculus, soit, plus souvent, posées à plat sur le sol entourant l'ouverture de ceux-ci, et par la suite elles ont été écrasées et fragmentées par le poids des sédiments. Elles correspondent soit à un panneau
« vertical» du vase, du bord au fond, soit à une partie horizontale, le haut, le milieu ou le fond. Dans le cas de la tombe T24, on peut noter la manière dont l'urne non tournée a été cassée : un coup porté au fond du vase depuis l'extérieur a provoqué une perforation et un large éclatement circulaire, et c'est une moitié «verticale» du vase qui a été ainsi déposée dans la tombe. Aucun vestige du contenu de ces récipients n'a été découvert, notamment piégé sous les panneaux d'urnes écrasés horizontalement sur le sol. Manifestement ce type de dépôt traduit un partage du vase entre la tombe et un autre lieu, ou d'autres lieux. Son contenu a-t-il, aussi, été réparti entre le défunt et d'autres destinataires, bien 
vivants eux ? Ou bien s'agit-il seulement d'abandonner le contenant, ou, du moins, une part de celui-ci.

Les tessons de céramiques isolés se répartissent également entre vases à solide et vases à liquide de manière semblable à celle des portions : environ trois quarts de vases à solide pour un quart de vases à liquide. Ces morceaux, placés dans les loculus et les recouvrements des tombes, semblent provenir directement du bûcher, où ils ont pu être ramassés en même temps que les restes osseux. Deux arguments vont dans ce sens.

D'une part, dans plusieurs cas, les traces d'un feu secondaire sont indubitables. On le constate parfois sur des vases importés : sur les deux tessons des deux coupes à vernis noir de Rosas du recouvrement de la tombe T11, ou le tesson d'amphore massaliète du loculus de la tombe T12, ou encore les fragments de la coupe campanienne du loculus et du recouvrement de la tombe T13. Mais cela apparaît aussi pour la céramique non tournée, lorsque deux tessons jointifs marquent, de part et d'autre de la cassure, une différence très nette de coloration, comme dans les tombes $\mathrm{T} 12$ et $\mathrm{T} 25$.

D'autre part, la proportion entre vases à aliments solides et vases à liquides est tout à fait comparable à celle que l'on a notée dans la répartition des tessons retrouvés dans la couche de fonctionnement de l'aire crématoire B1, pour les premiers $64 \%$ et $36 \%$ pour les seconds. Bien sûr, le rapport direct entre cette aire et les tombes fouillées n'est pas assuré, par exemple, par des recollages d'os ou d'objets. Mais la contemporanéité et la proximité topographique de l'un et des autres, de même que le mobilier et la répartition des défunts par âge et sexe présumé, montrent, à défaut de relation directe, un lien très fort (nous reviendrons infra sur cette question).

Ces tessons isolés rejetés sur le bûcher peuvent être liés aux restes de repas consommés par les assistants aux cérémonies dont il convenait de se débarrasser. Dans cette optique, l'introduction d'une partie d'entre eux dans la sépulture, de manière quelque peu automatique, sinon involontaire, en même temps que l'on prélève les os incinérés, ne marquerait donc pas un rite particulier supplémentaire.

Par ailleurs, on ne peut totalement exclure une inclusion involontaire d'une part de ces tessons dans le remplissage des tombes, parce que ces objets étaient déjà présents sur le sol de la nécropole (voir supra, chap. 1, $\S 1.1$.$) .$

Les vases à liquide sont exclusifs dans la première catégorie de dépôts céramiques, celle des vases complets, et dans les deux autres formules, panneaux et tessons isolés, le nombre de vases à aliments solides domine très largement celui des vases à liquides. Mais pour ces trois modalités, deux absences méritent d'être soulignées, celle des vases à parfum et celle des lampes.

Les sources écrites grecques et romaines témoignent largement de ces substances parfumées répandues sur le mort et sur le bûcher et, plus généralement, fort utilisées dans la sphère religieuse, soit en offrandes aux divinités, soit en rite de purification, soit pour procéder à la toilette du mort ou plus prosaïquement pour masquer les mauvaises odeurs (Scheid 1984, p. 121-122). Manifestement, si l'on en croit l'absence des vases caractéristiques, alabastres et unguentaria, la population d'Ambrussum n'en fait pas usage dans ses cérémonies funéraires, à la différence, par exemple, des habitants des colonies de Marseille (Moliner et al. 2003, p. 189190) et d'Agde à cette époque (Marchand, Schwaller dans Lugand, Bermond, 2001, p. 145-146 ; Dedet 2011), qui suivent en cela des pratiques grecques bien connues d'après les témoignages iconographiques, notamment celui des lécythes à fond blanc (Oakley 2004, passim).

L'absence de lampe à huile dans les sépultures d' Ambrussum, quant à elle, se remarque également dans les niveaux contemporains de l'habitat sis sur l'oppidum (Fiches, Fenouillet, Wujek 1976, p. 33-85; Fiches, Gutherz, Roux 1979 ; Fiches 1983). Pourtant les ateliers de Rosas, dont les exportations sont ici bien présentes, ont produit de tels ustensiles imitant un type attique de la seconde moitié du $\mathrm{IV}^{\mathrm{e}}$ et du premier quart du $\mathrm{III}^{\mathrm{e}} \mathrm{s}$. av. J.-C. (Puig 2006, p. 369).

L'usage de la lampe à huile pour l'éclairage domestique n'est guère attesté, par des exemplaires attiques, de type grec ou d'imitation, que dans les habitats des contrées littorales du Languedoc et de la Provence, ouverts aux apports extérieurs, et ce, dès le $\mathrm{V}^{\mathrm{e}} \mathrm{s}$. av. J.-C. (Ugolini 1993, p. 283-284). À Lattes, par exemple, cette présence est très réduite jusqu'au début du II $\mathrm{s}$. av. J.-C. et ne connaît une très forte augmentation qu'à partir de cette époque (Paterno 2004, p. 346-348). En fait, avant la fin de l'Âge du Fer, l'importance de la lampe semble très inégale selon les sites et cet ustensile n'est adopté dans les maisons que progressivement, à partir de la conquête romaine (Feugère et al. 1998, p. 336).

Il en va de même de l'utilisation de la lampe à huile dans les pratiques funéraires. Le plus ancien témoignage régional actuellement connu, celui de la tombe T1 des Colombes à Beaucaire, ne remonte pas au-delà du dernier quart du II ${ }^{\mathrm{e}}$ s. av. J.-C. (Dedet, Michelozzi, Py 1974, 
p. 65-74). Et cet usage reste cependant peu répandu avant la fin du siècle suivant : les cas se multiplient à partir de ce moment, à Aramon/le Paradis, Beaucaire/ les Marronniers, Saint-Rémy-de-Provence, Mouriès/ Servanes-Cagalou, Le Paradou/l'Arcoule (Bel et al. 2008, p. 291-293). Son adoption témoigne alors très probablement d'une romanisation des usages funéraires, les lumières, lampes, torches, candélabres, jouant un rôle symbolique en rappelant la vieille pratique romaine de célébrer les funérailles de nuit pour éviter que prêtres et magistrats ne puissent rencontrer le cortège et en subir la souillure (Scheid 1984, p. 121-123).

\subsection{Dépôt de monnaie}

La couche de fonctionnement de l'aire de crémation B1 contenait deux oboles de Marseille (fig. 69, $n^{\circ} 832$ et 833), qui ont subi l'action du feu au point de les rendre difficilement reconnaissables. Dans la mesure où le prélèvement des restes de la crémation en vue du dépôt secondaire dans la tombe est toujours très partiel, ces pièces auraient très bien pu figurer dans une ou deux tombes de cette nécropole. Ont-elles été placées là, sur le bûcher, en contact étroit avec un ou deux cadavres sur le point d'être incinéré, à la manière d'un objet personnel, ou bien jetées dans le foyer durant la crémation? Évidemment la pratique crématoire ne permet aucune réponse sur ce point mais, de toutes manières, cette présence dans la nécropole d'Ambrussum revêt une importance non négligeable.

En effet, pour le moment, il s'agit de la plus ancienne attestation de la présence de monnaie en milieu funéraire dans le Midi de la France. En Gaule interne, pour une époque aussi haute, on ne connaît guère que le cas de la tombe 22 de Vevey, sur la rive suisse du lac Léman, datée de la Tène $\mathrm{C} 1$, soit la seconde moitié du III ${ }^{\mathrm{s}} \mathrm{s}$. av. J.-C. : une obole de Marseille avait été placée dans la main droite d'un défunt inhumé, une femme d'après le mobilier associé (Martin-Kilcher 1981, p. 119-120).

Jusqu'ici, le dépôt de monnaie dans une tombe ou une nécropole n'était pas avéré dans le Sud de la Gaule à cette époque ni dans les siècles antérieurs. Un cas est connu à la marge chronologique du secteur fouillé de la nécropole d'Ambrussum, celui de la tombe 3 de Beaucaire/Les Colombes, datée vers 200 av. J.-C., qui contenait également une obole de Marseille (Dedet, Michelozzi, Py 1974, p. 81). Pour le plein second Âge du Fer, les quelque 500 sépultures d'Ensérune n'en ont livré aucune, pas plus que la portion de nécropole fouillée à Mourrel-Ferrat.
Cette absence de monnaie en milieu funéraire dans la sphère indigène affecte aussi les nécropoles grecques d'Agde/Le Peyrou II, de Marseille/Sainte-Barbe et de Marseille/Bassin de Carénage ${ }^{46}$. Certes, le paiement à Charon pour le passage dans l'au-delà est une tradition de la culture grecque, qui se développe par exemple à Athènes à l'époque hellénistique et affecte aussi bien les inhumés, avec dépôt de la pièce dans la bouche ou dans la main, que les incinérés (Kurtz, Boardman 1971, p. 116 et 211). Cependant, il est loin d'être régulier. Par exemple, il est attesté de manière discrète à la fin du $\mathrm{IV}^{\mathrm{e}}$ s. av. J.-C. à Apollonia du Pont, mais beaucoup plus fréquemment à Olynthe (A. Baralis dans Hermary dir. 2010, p. 147). Même contraste en Occident, puisque ce dépôt est absent des tombes d'Aléria (Jehasse, Jehasse 1973) comme de celles de Marseille et d'Agde, mais il est en revanche présent à Ampurias. Dans cette colonie toute proche de la Gaule, quatre des inhumations du secteur Ampurias/Martí, datées de la deuxième moitié du $\mathrm{IV}^{\mathrm{e}}$ et de la première moitié du $\mathrm{III}^{\mathrm{e}} \mathrm{s}$. av. J.-C., en sont pourvues : la pièce est placée dans la bouche du défunt de l'inhumation 36, et elle a été découverte "à la tête" ou "sous le cou" des sujets des inhumations 108 et 109 (Almagro Basch 1953, p. 65, 93 et 98-101). Un peu plus tard, dans le quartier Ampurias/Las Corts, les incinérations 9, 24, 27, 53, 108 et 154, des $\mathrm{II}^{\mathrm{e}}$ et $\mathrm{I}^{\mathrm{er}}$ s. av. J.-C., en renferment également (Almagro Basch 1953, p. 257258, 281-284, 292-297, 315, 351 et 378).

Dans le monde indigène régional cependant, une telle présence de monnaie en milieu funéraire ne va pas tarder à se répandre. Elle est moins exceptionnelle durant la première moitié du $\mathrm{I}^{\text {er }} \mathrm{s}$. av. J.-C., puisque attestée dans les tombes 5 de Beaucaire/Les Colombes (Dedet, Michelozzi, Py 1974, p. 99-100) et 7 de Mouriès/ Servanes (Bouches-du-Rhône) (Marcadal, Marcadal, Paillet 2003, p. 263-264). Et elle devient plus fréquente à partir de la deuxième moitié du $\mathrm{I}^{\text {er }} \mathrm{s}$. av. J.-C. et au siècle suivant (Bel et al. 2008, p. 334, fig. 283). Elle est aussi bien attestée dans plusieurs inhumations datant du Haut-Empire de la nécropole marseillaise de SainteBarbe, avec plusieurs cas de pièce de monnaie dans la bouche du mort, huit sûrs et six probables (Moliner et al. 2003, p. 208-209). L'adoption progressive de cet usage dans le Midi de la France à partir du dernier siècle avant notre ère est sans doute un des premiers indices de romanisation dans les pratiques funéraires.

46 Pour les tombes d'époque grecque découvertes au Bassin de Carénage dans la première moitié du $\mathrm{XIX}^{\mathrm{e}} \mathrm{s}$., ce fait est bien souligné par N. Toulouzan, responsable de la commission des fouilles (cité par Rothé, Tréziny 2005, p. 659). 
La présence de ces monnaies dans la nécropole d'Ambrussum, avant la fin du III ${ }^{\mathrm{e}} \mathrm{s}$. av. J.-C., ne semble donc pas pouvoir être attribuée à une influence funéraire massaliète, influence qui d'ailleurs n'apparaît aucunement dans tous les autres aspects des pratiques funéraires du monde indigène régional du second Âge du Fer (voir infra, chap. 7 et Dedet 2011). La datation s'oppose aussi à l'hypothèse d'un signe de romanisation. Il semble plus raisonnable de penser que c'est pour leur valeur intrinsèque, en offrande, que ces deux oboles ont ici accompagné des défunts. Et la situation d'Ambrussum, en bordure même de la grande voie protohistorique reliant l'Italie à l'Espagne, préfigurant la via Domitia, y favorise le commerce et la présence de numéraire dans la population locale. Une situation favorable aux échanges a également été soulignée pour le cas de Vevey, au débouché des cols alpins vers le Plateau suisse (Kaenel 1990, p. 276 et 298) ${ }^{47}$. Au demeurant, c'est aussi une telle intention d'offrande monétaire qui paraît ressortir de la présence de nombreuses oboles massaliètes accompagnant les dépôts de restes crâniens humains et d'armes sur le site du Cailar dans le Gard, à la même époque qu'Ambrussum et non loin de là (Roure 2010, p. 73-74). Et d'ailleurs, pour la Grèce même ou d'autres colonies grecques, telle Apollonia du Pont, on a évoqué que de telles monnaies aient été déposées dans les tombes pour ce qu'elles valent en elles-mêmes, plus que selon le rite de "l'obole à Charon" (Kurtz, Boardman 1971, p. 211 ; Hermary dir. 2010, p. 259-260).

\subsection{Un objet singulier : le clou}

La présence du clou en fer forgé de la tombe 23 , cas unique dans ce secteur de la nécropole, est difficile à interpréter. De par ses dimensions importantes, $69 \mathrm{~mm}$ de long, avec une tête de $21 \mathrm{~mm}$ de diamètre, il ne paraît pas pouvoir provenir d'un objet, par exemple un meuble ou un coffret, qui aurait accompagné le défunt sur le bûcher, ou plutôt sans doute dans ce cas, la défunte, ni d'un réceptacle ayant pu servir à enfermer les os brûlés dans la tombe, éventualité que dément d'ailleurs la dispersion de ces restes dans le loculus. Deux explications peuvent être avancées.

La première hypothèse est celle de la magie: il s'agirait de fixer l'esprit du défunt en le "clouant" symboliquement en ce lieu pour l'empêcher de revenir tourmenter les vivants. C'est l'interprétation retenue par

47 L'inhumée de Vevey a aussi été interprétée, à cause de cette monnaie, comme une étrangère (Polenz 1982 cité par Kaenel 1990, p. 298).
P. Galliou (1989, p. 49 et 71) pour nombre de tombes à incinération d'Armorique romaine qui contenaient un clou en fer. À moins qu'il ne s'agisse, à l'inverse, de protéger les restes du mort contre toute atteinte, le clou étant, dans la Rome antique, symbole de préservation de ce qui est "irrévocablement fixé" (Saglio dans Daremberg, Saglio 1877-1918, vº clavus, p. 1240-1242).

La seconde hypothèse est toute prosaïque. On peut imaginer que ce clou ait servi, sur le bûcher, soit à fixer des éléments de celui-ci, soit à accrocher une offrande ou une décoration. D'autres clous en fer, moins importants, ont d'ailleurs été découverts dans le niveau de fonctionnement de l'aire de crémation B1.

\subsection{La présence des restes d'animaux}

Des os d'animaux sont attestés dans toutes les tombes fouillées à Ambrussum entre 1999 et 2003. Ils prennent place toujours dans les loculus, mais aussi dans presque tous les dispositifs de recouvrement.

Il convient tout d'abord de mettre à part les restes de microfaune et de malacofaune livrés par plusieurs tombes, qui se trouvaient très probablement dans le sédiment constituant la terrasse ou sur le sol de celle-ci avant le creusement des loculus, et qui ont été introduits involontairement dans le comblement de ceux-ci. C'est le cas notamment des morceaux de coquilles d'escargots des tombes T10, T13 et T14, et des deux fragments de coquillage marin des tombes T16 et T17, qui ne portent pas de trace de feu. De ce fait, on ne saurait charger d'une symbolique sexuelle la présence de ces vestiges auprès des défunts concernés, comme c'est le cas pour les valves de cardium ou de pecten que l'on trouve dans un certain nombre de tombes du Midi protohistorique.

Pour le reste, ces vestiges animaux se présentent sous deux formes : l'os isolé qui est le plus fréquent, et, plus rare, la portion de squelette. Ces deux formules illustrent deux gestes différents, peut-être restes de repas partagés par les survivants auprès du bûcher dans le premier cas, et, dans le second, sacrifice non consommé destiné à la personne décédée (fig. 121) (voir infra, Annexe 2 par A. Gardeisen).

Le plus souvent donc, on a affaire à un os, une dent, ou un fragment de ceux-ci, isolé, brûlé ou non. Ces restes proviennent surtout de moutons et/ou chèvres, pour $69,3 \%$ du total. Les porcs occupent la seconde place, avec 16,3\%. Bœufs, chevaux et chiens sont beaucoup plus rares, $4 \%$ pour chacun, tandis que, avec $2 \%$ 
du total d'os, la catégorie oiseau galliforme est exceptionnelle. Les restes osseux non déterminés précisément mais rapportables à des animaux de petite taille, comme les moutons, les chèvres et les suidés, ou de grande taille, comme les bovidés, et les équidés, renvoient la même image : douze individus de petite taille pour quatre de grande taille.

Le nombre d'animaux attestés par tombe est compris entre un (tombe T10) et dix-neuf (tombe T11) ${ }^{48}$. Les quantités varient cependant très sensiblement en fonction de l'âge et du sexe présumé du défunt, ce qui montre que ces os ne proviennent pas de ramassages aléatoires de restes rejetés sur le bûcher, mais qu'il y a choix délibéré de placer tel élément dans la sépulture.

Pour les douze défunts adultes, ce sont 4,5 animaux qui sont attestés en moyenne par tombe, avec une fourchette de 1 à 19. Les mieux lotis sont les femmes présumées, avec une moyenne de 8,3 animaux (tombe T11: 19; tombe T19: 5 ; tombe T23:1). Les hommes supposés en ont moitié moins, avec 3,8 animaux par tombe en moyenne (ensemble tombes T12 et T14 : 13 individus ; tombes T21 et T25 : 1 chacune). Quant aux adultes indéterminés, cette moyenne n'est plus que de 1,8 (tombes T10 et T20: 1 chacune; tombes T15 et T16:2; tombe $\mathrm{T} 17: 3)$. C'est une moyenne semblable à cette dernière qui concerne les deux tombes de jeunes enfants (tombe T22: 1 ; tombe T13:2). Avec les restes de six animaux, le seul grand enfant attesté, celui de la tombe T24, se rapproche en ce domaine du score moyen des adultes pourvus d'une symbolique féminine (fig. 121).

Les restes d'équidés ne prennent place qu'auprès de défunts particuliers, des adultes connotés masculins, pourvus de pièces d'armement : celui de la tombe T21 et celui de la tombes $\mathrm{T} 12$ ou celui de la tombe $\mathrm{T} 14^{49}$. Les dépôts de ces extrémités de patte ou dents doivent être considérés comme symboliques puisqu'ils sont dépourvus de toute valeur alimentaire. Et si l'espèce, cheval ou âne, ne peut être précisée dans les deux cas, ces dépôts de restes d'équidés sont, semble-t-il, le seul indice de faune différenciée en fonction du sexe du défunt. En effet, les autres espèces suffisamment représentées comme le porc et les moutons/chèvres accompagnent pareillement hommes et femmes présumés ; il en va de même de la seconde catégorie de dépôt de faune dont nous allons parler.

48 Seules sont prises en compte les sépultures découvertes dans les fouilles de 1999 à 2003.

49 Cet élément a en effet été découvert dans le recouvrement commun aux deux loculus.
Cette seconde formule concernant la présence de restes animaux dans les sépultures d'Ambrussum consiste dans le dépôt d'une portion de squelette incomplètement prélevée sur un bûcher ou un foyer où elle a d'abord séjourné. Contrairement à la précédente, cette catégorie de restes n'affecte que quatre tombes, où d'ailleurs le premier type de dépôt est aussi attesté. Il peut s'agir d'un crâne de porcelet juvénile, dans les tombes T12 et T23, d'un crâne de capriné adulte dans la tombe T24, d'une patte de capriné juvénile dans la tombe T10 ou encore d'une partie de gril costal de capriné juvénile, à nouveau dans la tombe T12. Ce type de dépôt intéresse les trois catégories d'adultes distingués, tout autant l'homme présumé de la tombe T12, que la femme supposée de la tombe T23, ou encore l'adulte sans symbolique sexuelle de la tombe T10, mais aussi le grand enfant de la tombe T24, connoté féminin.

Quelle que soit la forme de cette présence animale dans ce quartier de la nécropole d'Ambrussum, il s'agit toujours d'espèces élevées, les mêmes que celles qui ont été rencontrées dans les couches d'habitat de l'oppidum contemporaines (Columeau 1979). Ce sont donc des animaux proches des gens et de leurs activités vivrières qui ont été préférés, plutôt que des produits de la chasse. Au demeurant, cette dernière paraît occuper une place assez discrète dans l'économie vivrière, d'après les vestiges osseux retrouvés dans l'habitat.

\section{Quelques éléments sur l'organisation de la nécropole}

Dans le cadre de cette fouille, seule une portion de cette nécropole a été appréhendée et aucune limite de l'espace funéraire n'a, semble-t-il, été atteinte. Toutefois, la manière dont les vestiges mis au jour se répartissent permet de formuler quelques constatations sur l'organisation de ce secteur. Évidemment, le groupement des tombes en deux ensembles de part et d'autre du chenal fluviatile qui traverse la zone fouillée du nord-ouest au sud-est, ne correspond peut-être pas à la réalité originelle, car cet écoulement, daté du II ${ }^{\mathrm{e}}$ s. av. J.-C., a pu détruire des structures situées à son emplacement.

\subsection{Bûchers et tombes}

Dans cette nécropole, il n'y a pas un secteur réservé à la crémation des défunts et un autre à l'ensevelissement de leurs restes. Si la structure ST1 correspond bien aux vestiges d'une aire de crémation, deux bûchers distants de 25 mètres, prendraient ainsi place parmi les tombes 
de cette partie de la nécropole couvrant une superficie de moins de $1000 \mathrm{~m}^{2}$.

Les tombes sont installées à proximité de ces bûchers. L' espace entourant la structure ST1 n'a pas été fouillé, mais la tombe T25 qui est la plus proche connue se trouve à environ $5 \mathrm{~m}$ de celle-ci et on ne peut exclure la présence d'autre(s) tombe(s) entre elles. On a une meilleure connaissance des environs immédiats de l'aire de crémation B1, pour leur part, du moins vers le nord et vers l'ouest. Ce bûcher n'est distant que de 1,2 m environ de la couverture de la sépulture la plus proche, la tombe T11, et de 2,2 $\mathrm{m}$ de son loculus ; cependant, un espace relativement vaste et vide de tombes l'entoure vers le nord et le sud-ouest.

Cette insertion des bûchers parmi les tombes et la contemporanéité des deux ensembles de structures permettent de poser la question du lien entre les premiers et les secondes. Faute d'une fouille complète cette relation ne peut guère être appréhendée pour la structure ST1. Il n'en va pas de même pour ce qui concerne l'aire de crémation B 1. Certes, aucun recollage entre fragments osseux ou mobiliers n'atteste avec sûreté que des défunts ensevelis dans les tombes ont été incinérés en ce lieu même. Cependant plusieurs faits indiquent un rapport bien réel.

C'est d'abord la proximité topographique entre les tombes et l'aire de crémation B 1, même si la situation de cette dernière en périphérie de la fouille, laisse penser qu'elle a pu aussi fonctionner pour des défunts dont les sépultures se trouvent plus au sud ou plus à l'est.

D'autre part, des pièces semblables figurent dans ce bûcher et dans les tombes fouillées, qui ont pu équiper un même objet en partie détruit ou dissocié par le feu crématoire, comme une fibule, un collier ou une ceinture, et ces objets tissent un réseau assez dense de relations entre le premier et les secondes (fig. 109) :

- éléments de corail décorant les disques de fibules : lien avec le loculus de la tombe T19;

- maillons doubles en bronze de ceinture dite féminine : liens avec le loculus de la tombe T19 et le recouvrement des tombes $\mathrm{T} 22$ et $\mathrm{T} 23$;

- petites perles fines en pâte de verre bleue : lien avec le loculus de la tombe T22;

- perles moyennes en pâte de verre bleue : lien avec le loculus de la tombe T25;

- grosses perles cylindriques en pâte de verre bleu, à trois rangs de protubérances ornées d'un filet blanc ou jaune opaque, en spirale : lien avec le loculus de la tombe T24 ;
- passants en fer se rapportant à des ceintures et ceinturons vraisemblablement destinés à la suspension de fourreaux d'épée : liens avec le recouvrement des tombes T12 et T14, et le loculus de la tombe T14.

Par ailleurs, la population des défunts qu'évoque cette aire de crémation $\mathrm{B} 1$ correspond parfaitement à celle dont témoignent les tombes voisines. Cette structure a été utilisée pour incinérer des corps accompagnés d'objets personnels à connotation masculine, comme le bouclier et l'épée dans son fourreau avec sa suspension, ou à connotation féminine, fusaïole, collier de perles, chaîne de ceinture, deux séries de pièces qui figurent ensuite, mais bien séparées, soit dans les tombes d'hommes supposés ou soit dans celles de femmes présumées.

D'autre part, les classes d'âge des défunts repérés dans les restes osseux de cette aire B1 correspondent à celles des sujets ensevelis dans les tombes, adulte, adolescent et jeune enfant (fig. 110). On mettra à part évidemment le fotus de cinq à sept mois lunaires attesté dans le bûcher : sa présence relève plutôt de la crémation d'une femme morte enceinte ou en couches que d'un traitement funéraire spécifique, car ces très jeunes défunts sont absents des tombes d'Ambrussum.

Enfin, on l'a déjà souligné (supra, chap. $3, \S 2.4$.), les tombes fouillées dans ce secteur de la nécropole et l'aire d'incinération B1 montrent une très grande similitude aussi bien dans la représentation des différentes régions anatomiques des squelettes que dans les poids moyens des fragments osseux (fig. 65).

Pour toutes ces raisons, il semble donc bien que la structure d'incinération $\mathrm{B} 1 \mathrm{a}$ servi à brûler au moins une partie des individus dont les restes ont été déposés dans les sépultures de ce quartier de la nécropole.

\subsection{L'organisation de la nécropole}

La répartition topographique de ces tombes ne semble pas répondre à un plan préétabli. Certaines de ces structures pourraient paraître s'aligner selon plusieurs axes parallèles de direction nord-sud. Il en va ainsi des alignements des tombes T20-T21-T3, T17-T18-T19, T15-T16-T5, T11-T22-T23-T8.

Mais d'autres directions pourraient tout aussi bien être soupçonnées, par exemple des axes parallèles ouestest, avec les tombes T25-T21-T19, T20-T18-T16 ou T25-T5-T22-T10. En fait, aucun ordonnancement préférentiel ne se dégage particulièrement. 


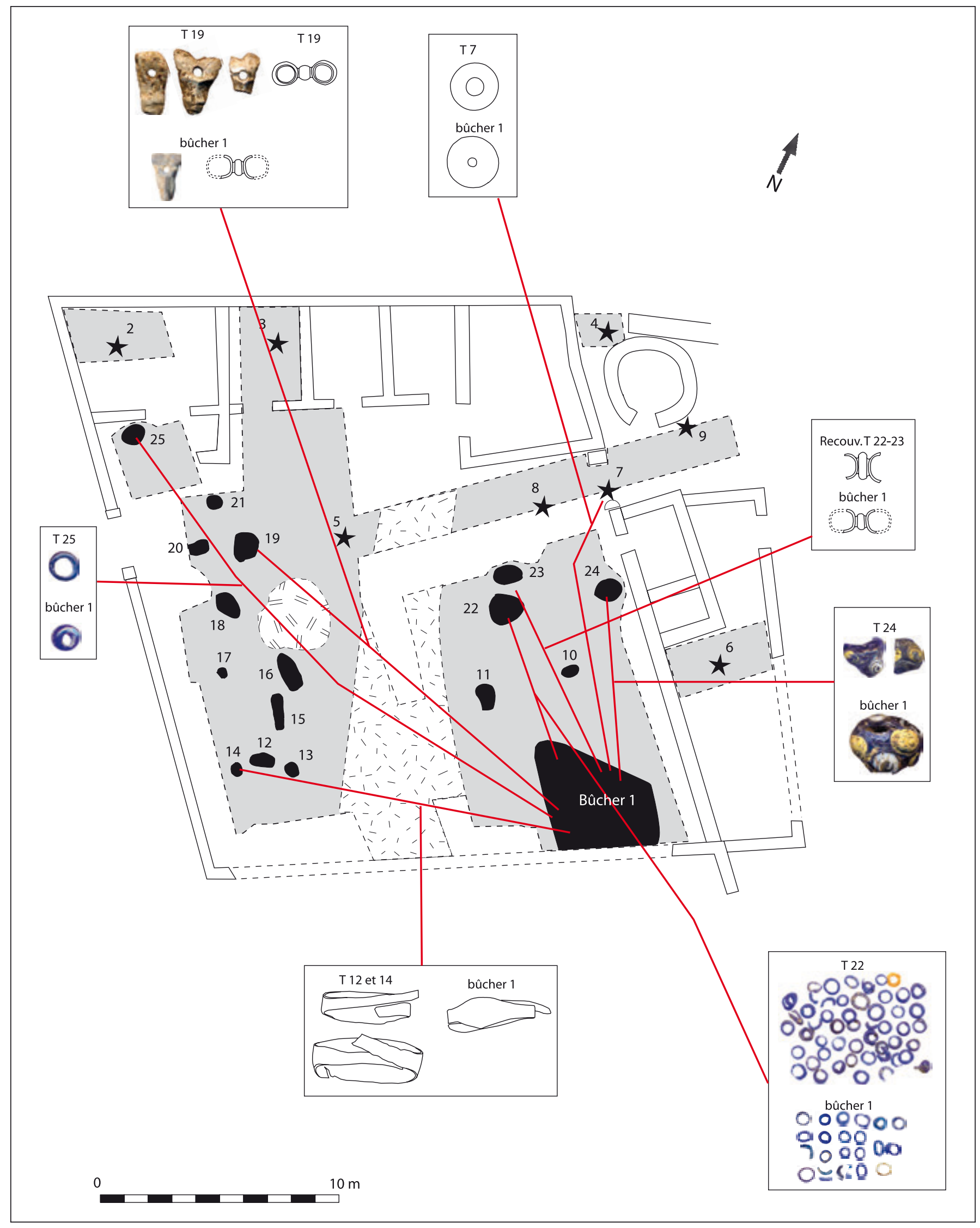

Fig. 109. Les liens entre le bûcher B1 et les tombes environnantes du secteur fouillé de la nécropole d'Ambrussum : les objets. 


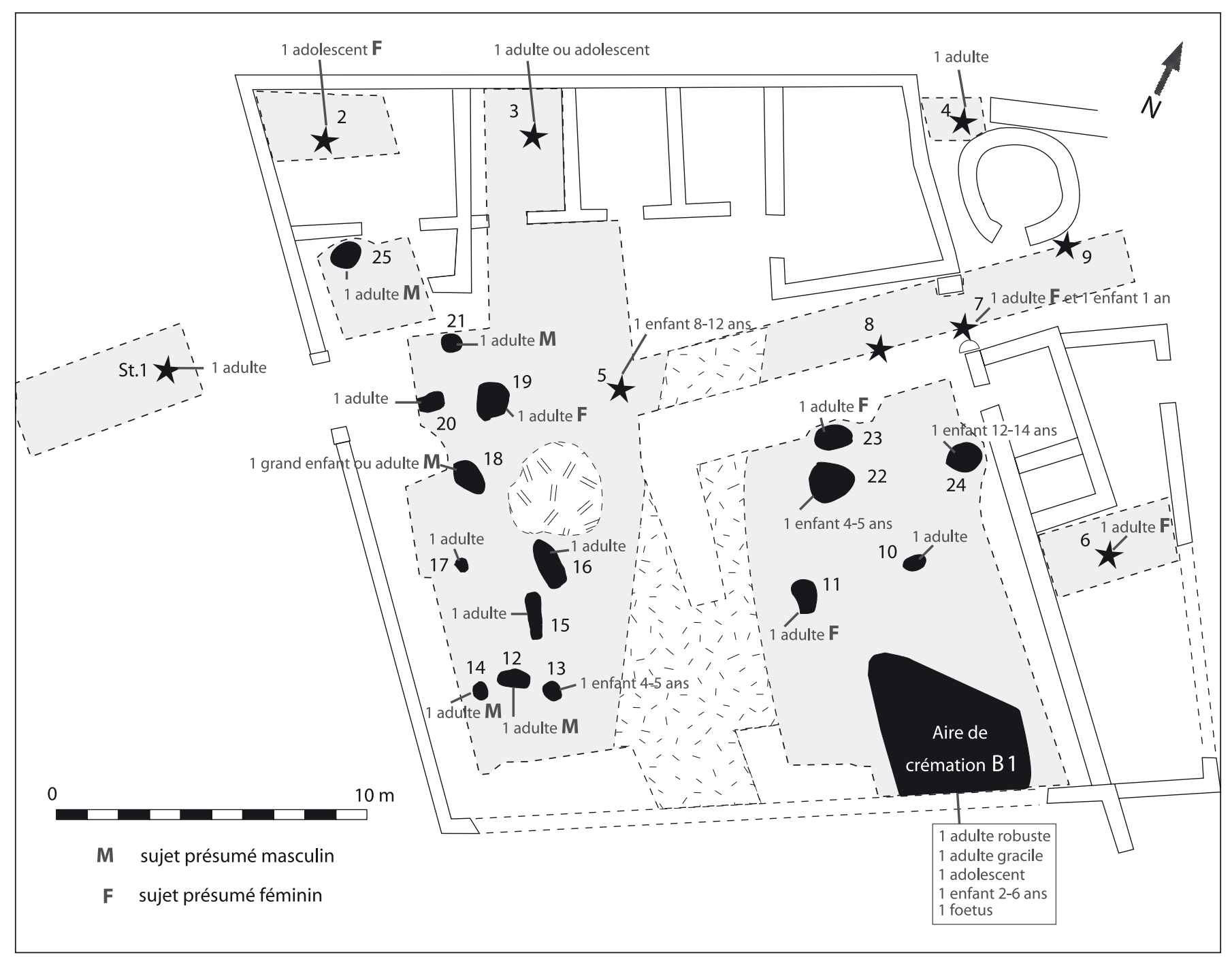

Fig. 110. Les liens entre le bûcher B1 et les tombes environnantes du secteur fouillé de la nécropole d'Ambrussum : les âges des défunts.

Ces sépultures sont très proches les unes des autres. Pour la plupart d'entre elles, la distance entre les loculus, de bord à bord, est comprise entre $1,3 \mathrm{~m}$, entre les loculus 19 et 21 , et 3,5 m entre les loculus T21 et T25 ou T12 et $\mathrm{T} 17$. Il en résulte que les dispositifs de recouvrement sont évidemment très rapprochés : malgré l'incertitude concernant leurs limites, la distance entre deux recouvrements varie de $0,8 \mathrm{~m}$, entre les tombes T11 et T22/ $\mathrm{T} 23$, et 2,4 m entre les tombes T12 et T17. L'estimation de la densité de sépultures ne peut être qu'approximatif : pour $10 \mathrm{~m}^{2}$, elle varie de 2 à 2,5 tombes dans le secteur Ouest, à 1,5 tombes dans le secteur Est, en ne prenant pas en compte les abords du bûcher B1 dépourvus de toute tombe et les zones détruites.

Mais dans deux secteurs, les loculus sont beaucoup plus rapprochés et le recouvrement est commun à deux loculus. Ainsi, les loculus des tombes T12 et T14 sont à $0,4 \mathrm{~m}$ seulement l'un de l'autre, distance semblable à celle qui sépare également les loculus des tombes T22 et T23. Dans ces deux cas, le même dispositif recouvre les deux fosses. Une telle couverture est cependant, semble-t-il, absente du loculus T13, pourtant creusé à $0,25 \mathrm{~m}$ seulement du loculus de la tombe T12. De telles dispositions, rapprochement des loculus et communauté du recouvrement, ont sans doute une raison familiale : dans chaque cas c'est un jeune enfant (tombes T13 et T22) qui est placé à proximité immédiate de la tombe d'un adulte présumé masculin (tombe T12) ou féminin (tombe T23) ; un même recouvrement concerne ce jeune enfant de la tombe T22 et cet adulte présumé féminin de la tombe T23. En revanche, ce sont deux adultes présumés masculins, ceux des tombes T12 et T14, que l'on a placés très proches l'un de l'autre et sous un même recouvrement, comme si le décès avait une même cause, par exemple dans un combat. 


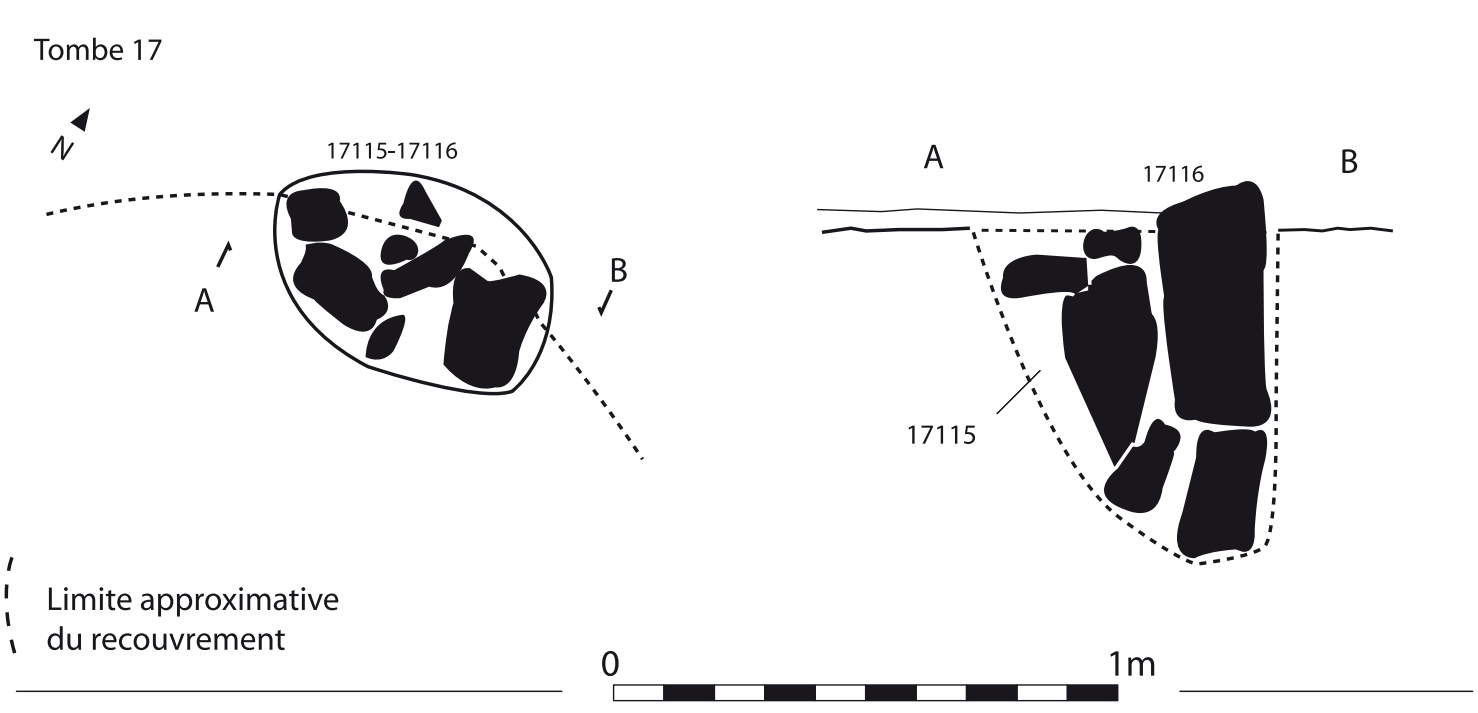

Tombes 22 et 23
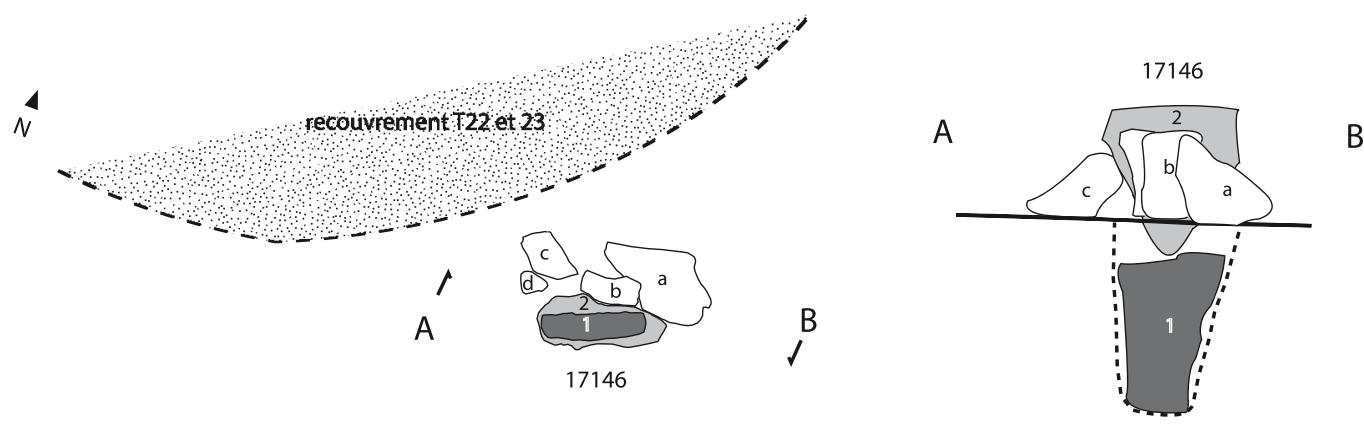

Fig. 111. Les deux dispositifs annexes du secteur fouillé de la nécropole d'Ambrussum ; plans et coupes.

Hormis la proximité de ces deux jeunes enfants avec des adultes, on ne remarque aucun autre disposition particulière des tombes en fonction de l'âge au décès. Aucun secteur n'est réservé à une classe d'âge : jeunes enfants, grands enfants et adolescents ne sont pas regroupés, mais au contraire disséminés parmi les adultes (fig. 110).

Adultes et adolescents ne semblent pas non plus montrer une répartition différenciée selon qu'ils sont accompagnés d'objets présumés masculins ou féminins. Certes, dans la partie orientale de la fouille, les seuls pour lesquels s'affiche une symbolique sont marqués féminins (tombes T6, T7, T11 et T23). Cependant, dans ce même secteur, deux autres adultes ne sont accompagnés d'aucun objet à connotation sexuelle, et surtout, dans la partie occidentale, les sujets présumés féminins (tombes T2 et T19) sont mêlés aux individus présumés masculins (tombes T12, T14, T18, T21 et T25). Si l'on en croit ces signes, hommes et femmes ne seraient donc pas séparés dans ce cimetière (fig. 110).

\subsection{Les dispositifs "parafunéraires"}

Dans le secteur fouillé de la nécropole se trouvent aussi deux structures de conception semblable, distantes de 12,5 m, ST17115-17116 auprès de la tombe T17 et ST17146, auprès de la tombe T22. Leur fonction n'est pas élucidée, mais vu le contexte, on les qualifiera de parafunéraires.

Chacun de ces dispositifs se compose de deux pierres de calcaire local, celui de la colline portant l'oppidum, pierres non travaillées, de forme oblongue allongée, disposées verticalement et superposées. Dans les deux cas, cela forme une sorte de pilier haut de $62 \mathrm{~cm}$ pour la ST17146 et de $73 \mathrm{~cm}$ pour la ST17115-17116 (fig. 111). 
Dans les deux cas, l'un des blocs est complètement enterré et celui qui le surmonte émerge du sol de la nécropole de peu de hauteur, $8 \mathrm{~cm}$ pour ST17029 et $22 \mathrm{~cm}$ pour ST17115-17116. Ces grands éléments sont calés par des pierres plus petites, destinées à leur maintien vertical dans l'étroite fosse qui les a accueillis. Cette dernière n'a reçu aucun dépôt perceptible, os humain ou animal, charbons de bois ni objet ayant laissé des traces. Ces deux dispositifs sont essentiellement souterrains, du moins dans leur forme actuelle.

L'utilité de ces deux structures semblables est problématique. Les morts concernés par ces aménagements ne se distinguent en rien des autres, du moins pour nous, ni dans leur identité, ni dans le matériel qui les accompagne : un adulte dépourvu de tout objet à connotation sexuelle dans le cas du dispositif ST17115-17116 de la tombe T17, et un jeune enfant et un adulte présumé féminin dans celui du dispositif ST17146 proche du recouvrement des tombes T22 et T23. Ces aménagements sont situés à la périphérie immédiate du recouvrement de chacune des deux tombes concernées, mais ils ne participent pas d'une quelconque bordure de ce dispositif. S'agit-il de stèles grossières dont la partie supérieure aurait été cassée après l'utilisation de la nécropole ? Le cas est avéré, par exemple, sur le "sanctuaire" des Touriès à Saint-Jean-et-Saint-Paul, Aveyron, au premier Âge du Fer (Gruat 2011, p. 106-107). L'incertitude demeure pour le dispositif proche de la tombe T22; en revanche, pour celui qui jouxte la tombe T17, le sommet de la pierre qui émerge du sol est relativement régulier et ne paraît avoir été cassé après sa mise en place.

Plutôt que de chercher à signaler ces tombes, y-a-t-il eu la volonté de privilégier, en terme de dimensions, la partie enfouie et cachée dans la terre ? Cela renverrait alors à une intention symbolique que nous ne pouvons pas identifier dans le registre du rituel funéraire.

\section{Conclusion}

On le voit, les pratiques en usage dans ce quartier de la nécropole d'Ambrussum au III ${ }^{\mathrm{e}} \mathrm{s}$. av. J.-C. témoignent d'une certaine variété. Des différences se marquent dans la composition du matériel d'accompagnement en fonction des critères naturels que sont l'âge au décès et, pour les adultes, les adolescents et peut-être les grands enfants, le sexe. À l'intérieur de la classe d'âge des adultes, des différences sont notables également dans la quantité du mobilier ou encore dans la morphologie de la tombe. Ces variations peuvent impliquer d'autres critères sociaux non naturels, comme la place qu'occupait, de son vivant, le mort dans la communauté, à moins qu'il ne s'agisse des circonstances du décès ou de l'idée que s'en font les survivants, suivant le système de la "bonne" ou de la "mauvaise" mort, bonne mort parce que jugée féconde pour eux, ou mauvaise car stérile et dangereuse tant pour la société que pour le décédé. Les funérailles comme le tombeau, ainsi que le devenir de l'individu décédé, varient en conséquence. Ce principe est très répandu dans les sociétés anciennes ou traditionnelles (par exemple Hertz 1928, p. 78-83, pour les Dayak de Bornéo, ou Thomas 1982, p. 101-108, pour l'Afrique Noire), et bons et mauvais morts peuplent également le monde gréco-romain (Jobbé-Duval 1924 [2000] ; Gnoli, Vernant dir. 1982).

Quelle que soit leur raison d'être, les variations que l'on perçoit entre sépultures, tant au niveau de la morphologie des tombes que des matériels d'accompagnement, restent dans une mesure limitée. En particulier, on remarque l'absence ici de toute sépulture ou dépôt ostentatoire. Si ostentation il y eût, peut-être celle-ci s'est-elle plutôt exercée par des cérémonies autour du foyer crématoire, dont pourraient témoigner les restes céramiques et animaux retrouvés dans l'aire de crémation B1. 




\section{Chapitre 7}

\section{Ambrussum dans le contexte funéraire du Midi méditerranéen au début et au milieu du second Âge du Fer}

\section{La documentation funéraire contemporaine en Languedoc et en Provence}

$\mathrm{N}$ ous l'avons souligné au début de cette étude, les nécropoles et les tombes peu ou prou contemporaines de celles qui ont été fouillées à Ambrussum, et suffisamment bien connues pour permettre la comparaison sont fort peu nombreuses, pour le moment, en Languedoc et en Provence (fig. 112).

En ce domaine, l'essentiel de nos connaissances sur le monde indigène provient actuellement du Languedoc occidental et surtout de deux nécropoles, celles d'Ensérune et de Mourrel-Ferrat (Hérault).

À Ensérune, sur quelque 520 sépultures mises au jour, s'échelonnant du milieu du $\mathrm{V}^{\mathrm{e}}$ et au tournant du $\mathrm{III}^{\mathrm{e}}$ avec le $\mathrm{II}^{\mathrm{e}}$ s. av. J.-C., environ 300 se rapportent à la période allant de la fin du $\mathrm{IV}^{\mathrm{e}}$ à la fin du $\mathrm{III}^{\mathrm{e}} \mathrm{s}$. (Schwaller, Marchand 1993, p. 225-226). Il s'agit toutefois essentiellement de travaux anciens, menés entre 1909 et 1966, pour lesquels les observations et les données sont très lacunaires et, au demeurant, en grande partie inédites. Seules six tombes, fouillées en 1988 et 2000, sont bien connues, cinq du premier quart du III $\mathrm{s}$. av. J.-C. (tombes 1, 2, 3, 5 et 6-1988) et une de l'extrême fin de ce siècle (SP1004), ainsi que les restes d'un ustrinum contemporain de cette phase de la nécropole (Schwaller et al. 1995, p. 210-220; Bel et al. à paraître; Jallet et al. 1998). À Mourrel-Ferrat, treize sépultures et les restes de plusieurs ustrina de la fin du $\mathrm{IV}^{\mathrm{e}}$ ou du tout début du III ${ }^{\mathrm{e}}$ s. av. J.-C. ont été étudiés (Janin et al. 2000). D'autres tombes de cette époque ont été repérées dans cette région, à Saint-Julien (Pézenas, Hérault) (Dedet et al. 2003, p. 170) et aux Oubiels (Sigean, Aude) (Anwar 2010), mais elles étaient en grande partie détruites par des travaux agricoles.

Le Languedoc oriental et la Provence étaient, jusqu'ici, encore moins bien lotis : à l'exception de la tombe de la Roussillonne à Nîmes, de la deuxième moitié du $\mathrm{IV}^{\mathrm{e}}$ ou du III ${ }^{e}$ s. av. J.-C.(Dedet, Gauthey 2008), les autres sépultures ne sont connues que de manière imparfaite, comme la tombe 5 des Colombes à Beaucaire (Gard), de l'extrême fin du $\mathrm{III}^{\mathrm{e}} \mathrm{s}$. ou du tout début du $\mathrm{II}^{\mathrm{e}} \mathrm{s}$. av. J.-C. (Dedet, Michelozzi, Py 1974, p. 75-83), les quatre sépultures de la première moitié du $\mathrm{III}^{\mathrm{e}} \mathrm{s}$. av. J.-C. des Conques à Cucuron (Vaucluse), dont les restes osseux humains n'ont pas été étudiés (Dumoulin 1962) et la tombe supposée de Préville à Uzès (Gard) (Saint-Venant 1897). Cette lacune est en passe d'être en partie comblée grâce à la fouille récente de 112 tombes des $\mathrm{IV}^{\mathrm{e}}-\mathrm{III}^{\mathrm{e}} \mathrm{s}$. av. J.-C. au Sizen-Collège Vigne à Beaucaire, actuellement en cours d'étude (Carme, Demangeot 2010).

Dans les Alpes du Sud, plusieurs sépultures explorées au $\mathrm{XIX}^{\mathrm{e}} \mathrm{s}$. se rapportent aussi à cette phase du deuxième Âge du fer, comme, par exemple, celles des Mâts ou du Serre des Béraud à Jausiers (Alpes-de-Haute-Provence) (Bérard 1997, p. 227-236), ou de Peyre-Haute à Guillestre (Hautes-Alpes) (Willaume 1991, p. 205-211). Cependant les données sont peu précises, aussi bien pour ce qui concerne la morphologie des tombes, que les défunts et les assemblages de mobiliers.

Pour leur part, les pratiques funéraires des colonies grecques du Midi gaulois ne peuvent être appréhendées avec précision qu'à Marseille, essentiellement grâce à la fouille de 96 tombes s'échelonnant du $\mathrm{IV}^{\mathrm{e}}$ au milieu du $\mathrm{II}^{\mathrm{e}}$ s. av. J.-C. sur le site de Sainte-Barbe (Moliner et al. 2003 ; Dedet 2011). La connaissance des 28 sépultures de cette époque découvertes au Peyrou à Agde, en cours d'étude, reste encore imprécise (Marchand, Schwaller dans Lugand, Bermond 2001, p. 145-146).

\section{L'accès au cimetière villageois}

À Ambrussum tous les morts n'ont pas accès au cimetière villageois, en particulier avant l'âge d'environ cinq ans. Mis à part le fotus de l'aire crématoire B1, très probablement brûlé avec sa mère décédée avant ou pendant l'accouchement, les tout-petits de moins d'un an en sont complètement absents. Seule une part des enfants de 1 à 4 ans y est admise, environ la moitié ou le tiers selon le taux de mortalité attendu. Ce n'est qu'avec la classe 


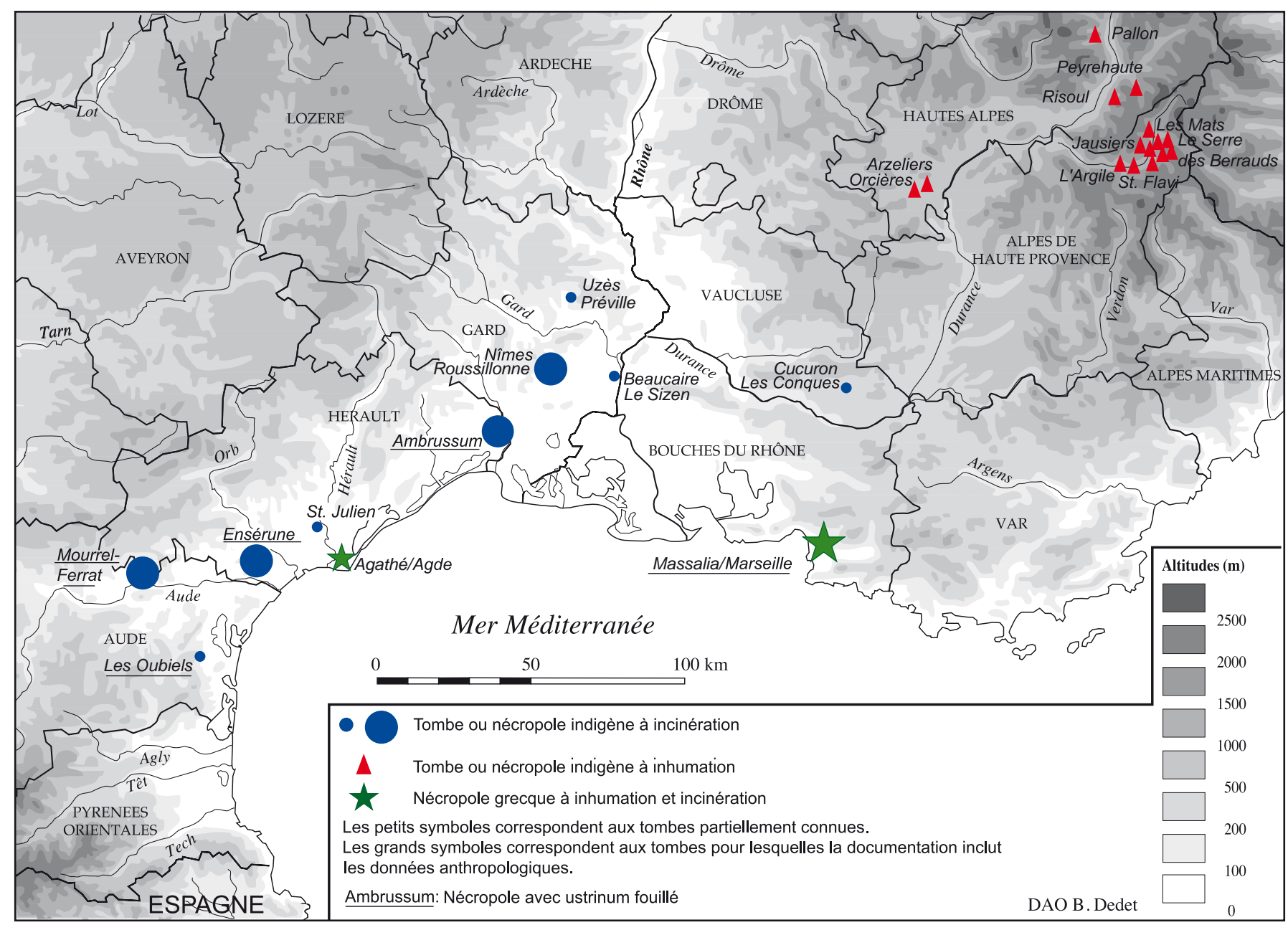

Fig. 112. Localisation des nécropoles et tombes des IVe et III s. av. J.-C. en Languedoc, Provence et Alpes méridionales.

des 5-9 ans que le recrutement de la nécropole paraît conforme à une mortalité archaïque. Des usages semblables ont alors cours à Mourrel-Ferrat et à Ensérune. À Mourrel-Ferrat, si les déterminations ostéologiques n'ont pas permis de cerner les jeunes enfants, les moins d'un an manquent totalement (Janin et al. 2000). Il en va de même à Ensérune. Et sur ce site, une grande part des 1-4 ans et une part encore non négligeable des 5-9 ans font aussi défaut (Dedet, Schwaller 2010, p. 272-273).

Cette exclusion des plus jeunes individus et leur admission progressive au sein de cet espace socialisé qu'est le cimetière villageois sont alors des coutumes traditionnelles dans le monde indigène de la région puisqu'on les observe, dans tout le Midi de la France, depuis la fin de l'Âge du Bronze (Dedet 2008). En revanche, elles sont en total contraste avec les pratiques en cours, en ce domaine, dans les colonies grecques voisines, à Marseille ou, pour ce qu'on en connaît, à Agde. En effet, dans le cimetière marseillais de Sainte-Barbe, du début du $\mathrm{IV}^{\mathrm{e}}$ au milieu du II ${ }^{\mathrm{e}}$ s. av. J.-C., sur un échantillon d'une centaine de défunts, les moins d'un an sont normalement représentés et les 1-4 ans ne montrent qu'un déficit réduit (Moliner et al. 2003, p. 83). Au Peyrou II, à Agde, sont signalés de «très jeunes enfants » inhumés en amphore massaliète, sans doute, ici aussi, des sujets périnatals ou de moins d'un an (Nickels 1982, p. 278).

Pour les autres classes d'âge, grands enfants, adolescents et adultes, il est impossible de savoir si tous les morts bénéficient d'une sépulture à Ambrussum, comme ailleurs dans le monde indigène méridional. Au premier Âge du Fer, la rareté et la dispersion des tombes tumulaires des Garrigues languedociennes et provençales laissent penser que, alors, seuls certains de ces défunts plus âgés bénéficiaient d'un traitement solennel de la mort et qu'un autre procédé ne laissant pas de traces, ou des vestiges moins visibles, a pu exister pour une partie d'entre eux (Dedet 2000, p. 178). Nonobstant la constitution de vastes groupements de tombes comme 
celui d'Ambrussum, une séparation de ce type, entre sépultures durables et pratiques funéraires fugaces, a pu persister au second Âge du Fer dans la région. Mais de surcroît, on a aussi la preuve d'autres destins pour d'autres morts adultes ou adolescents en Languedoc à cette époque.

En effet, l'habitat du Cailar (Gard), voisin et exactement contemporain d'Ambrussum, a livré de nombreux restes humains d'adultes, essentiellement crâniens, accompagnés d'armes. Ce sont là les traces d'une pratique d'exposition en plein air, près du rempart (Roure 2007 ; Girard, Roure 2009). Au total, ce n'est pas moins d'une quarantaine d'individus qui a été recensée après le fouille de 2010, sur une surface réduite qui ne représente qu'une petite partie du lieu où prennent place ces installations. Sur ce site, cette pratique est contemporaine des tombes fouillées à Ambrussum; elle couvre tout le $\mathrm{III}^{\mathrm{e}} \mathrm{s}$. av. J.-C. Et si, pour le moment, aucune semblable concentration de tels vestiges n'a été découverte sur un autre habitat de la région, des os épars d'adultes et d'adolescents y sont souvent signalés en contexte résiduel dans des agglomérations du milieu de l'Âge du Fer, comme dans l'Aude, au Carla (Bouriège), à l'Agréable (Villasavary), à Pech Maho (Sigean), dans l'Hérault à La Ramasse (Clermont-l'Hérault) et à Ensérune, ou dans le Gard à Vié-Cioutat (Mons); et sur l'oppidum d'Ambrussum même, des os d'un ou deux adolescents proviennent d'une couche d'occupation d'une maison datée du dernier quart du III s. av. J.-C. (Dedet, Schwaller 1990, p. 147-148). Quelle que soit l'interprétation que l'on donne à la présence de ces os humains, traces de sanctuaires avec exposition de trophées comme au Cailar, « reliques » de certains défunts, têtes coupées prélevées sur des ennemis vaincus selon la pratique régionale rapportée par les auteurs anciens eux-mêmes (Strabon, IV, 4.5 et Diodore de Sicile, V, 29, 4.5), ce sont là autant de morts ayant dépassé l'enfance qui donc n'ont pas été accueillis dans une nécropole. Ambrussum n'échappe sans doute pas à de tels usages.

Au Cailar, le nombre d'individus concernés n'est pas négligeable, mais évidemment on ne saurait généraliser cette donnée à l'ensemble de la région.

\section{La pratique de l'incinération}

Le dépôt secondaire de crémation est la norme dans la nécropole d'Ambrussum. C'est aussi alors la pratique en vigueur presque partout dans le Midi de la France pour les défunts admis au cimetière villageois, quel que soit leur âge au décès (fig. 112). On la constate ainsi aux
IV $^{\text {e- III }}{ }^{\mathrm{e}}$ s. av. J.-C. aussi bien non loin d'Ambrussum, à Nîmes/La Roussillonne comme à Beaucaire/Le SizenCollège Vigne, qu'en Provence à Cucuron/Les Conques, ou en Languedoc occidental, à Mourrel-Ferrat, Ensérune, Saint-Julien, Les Oubiels. Seuls font exception à cette règle le Sud des Alpes et les colonies grecques de la côte (Dedet 2004).

Dans les Alpes méridionales sont encore attestées des sépultures à inhumation au moins jusqu'au $\mathrm{III}^{\mathrm{e}} \mathrm{s}$. av. J.-C. Certes, s'agissant de découvertes anciennes, les modalités sont mal connues, mais ce sont bien des squelettes qui sont évoqués dans les publications pour plusieurs cas à Jausiers (les Mâts, la Rochette, le Serre des Bérauds, Lans), à Laragne-Montéglin (Arzeliers) ou à Risoul (Bérard 1997). Il n'est pas précisé s'il s'agit de dépôts primaires ou secondaires, cependant les structures parfois décrites entourant ces squelettes pourraient nous orienter vers la première possibilité. Un adulte en dépôt primaire sur le dos est même clairement figuré sur le plan publié d'une tombe de Peyre-Haute à Guillestre, datée de la fin du IV ${ }^{\mathrm{e}} \mathrm{s}$. ou du début du III' ${ }^{\mathrm{e}}$ s. av. J.-C., et c'est là la seule information précise sur ce sujet (Chantre 1878).

Dans les colonies de Marseille et d'Agde, aux IVe, $\mathrm{III}^{\mathrm{e}}$ et II ${ }^{\mathrm{e}}$ s. av. J.-C., crémation et inhumation se côtoient, comme c'est d'ailleurs l'usage souvent dans nombre de cités grecques (Kurtz, Boardman 1971, p. 71, 91 et 162 ; Étienne, Müller, Prost 2006, p. 157). À Marseille/ Sainte-Barbe les enfants de moins de dix ans sont toujours inhumés, alors que grands enfants, adolescents et adultes sont soit concernés par l'inhumation primaire soit incinérés, et le partage entre les deux pratiques est tout à fait équitable au $\mathrm{III}^{\mathrm{e}} \mathrm{s}$. av. J.-C. (Moliner et al. 2003, p. 34-36). La situation semble plus contrastée au Peyrou II d'Agde où figurent vingt-quatre inhumations pour quatre incinérations (Marchand, Schwaller dans Lugand, Bermond 2001, p. 145-146).

Pour les indigènes du Languedoc oriental, et en particulier les habitants d'Ambrussum, au III s. av. J.-C., cette pratique de la crémation est alors traditionnelle, remontant au début du premier Âge du Fer. Elle est introduite à cette époque, dans cette région où règne alors sans partage l'inhumation, primaire ou secondaire, depuis le Bronze final II. Ce mouvement se fait sans doute depuis l'ouest du Languedoc. En effet, l'incinération est la règle au Bronze final III en Languedoc occidental et en Roussillon, et son adoption dans les territoires situés à l'est du fleuve Hérault est progressive, de l'ouest vers l'est. L'incinération remplace donc peu à peu les différentes formes d'inhumation durant le VII ${ }^{e} s$. av. J.-C. entre fleuves Hérault et Rhône, et au cours du 
siècle suivant en Provence (Dedet 2004). Dès le début du $\mathrm{VI}^{\mathrm{e}}$ s. av. J.-C. l'inhumation a disparu du Languedoc oriental, du moins pour les morts «normaux », ceux qui ont accès au cimetière. Elle ne reste en vigueur que pour les très jeunes morts, périnatals et certains nourrissons, enterrés dans les habitats (Dedet 2008, p. 79-156).

\section{Le bûcher crématoire}

Comme ici à Ambrussum, dans ce monde indigène du milieu du second Âge du Fer, les trépassés sont brûlés sur un bûcher aménagé au sein même de la nécropole, et une partie des restes du corps et de la crémation est ensuite prélevée pour être transportée dans la tombe. C'est ce que montrent les cas connus aussi bien à Ensérune qu'à Mourrel-Ferrat, pour la même période.

Le bûcher d'Ensérune, daté de la première moitié du III ${ }^{\mathrm{e}}$ s. av. J.-C., offre de nombreuses similitudes avec celui d'Ambrussum, même si ce n'est finalement qu'une petite portion qui en a pu être soigneusement fouillée, la majeure partie ayant été largement détruite par les recherches des années 1960 (Jallet et al. 1998). Là aussi, il s'agit d'une vaste structure, d'au moins $15 \mathrm{~m}^{2} \mathrm{de}$ superficie, ayant servi pour des crémations successives. La couche de fonctionnement repose sur des nappes discontinues de sable calcaire, rapportées pour constituer une vaste plate-forme. Elle renferme, en quantité, éléments osseux humains, tessons de vases et objets personnels des défunts, perles et morceaux d'objets métalliques fondus.

Mais ce bûcher d'Ensérune marque aussi plusieurs nettes différences avec celui d'Ambrussum, traduisant des pratiques funéraires quelque peu distinctes également. À Ensérune, la céramique qui y a été découverte diffère de celle des tombes : les tessons appartiennent pour une large part à des vases non tournés, catégorie de vaisselle proportionnellement beaucoup moins présente dans les sépultures elles-mêmes. Sur le bûcher, ces récipients n'ont peut-être pas la même fonction que dans les tombes : alors que dans ces dernières, ces vases contiennent presque toujours un dépôt de volaille entière, sur le bûcher ils ont peut-être servi à contenir des liquides car les restes animaux sont totalement absents.

Les deux bûchers fouillés à Mourrel-Ferrat, S11 et S15, sont quelque peu différents, bien qu'installés, là aussi, sur une nappe de cailloux et de blocs. Parmi ces éléments ont été prélevés des charbons de bois, des nodules d'argile cuite, des fragments céramiques et métalliques parfois brûlés, ainsi que des os humains incinérés qui ne sont pas en position anatomique (Janin et al. 2000, p. 237-241). Ces bûchers sont plus petits, occupant une surface réduite de un ou deux mètres de large sur deux mètres de long environ, et chacun pourrait n'avoir servi que pour un seul défunt, adulte ou de taille adulte. C'est ce que laissent supposer la masse des restes osseux découverts, $1339,1 \mathrm{~g}$ pour S11 et $1476,4 \mathrm{~g}^{50}$ pour S15, et l'absence de doublons parmi ce matériel. Ces deux structures s'accompagnent de plusieurs trous pour des poteaux qui ont peut-être servi à suspendre un brancard funéraire au-dessus du feu. Enfin, une tombe d'individu de taille adulte est installée à quelques centimètres seulement de chacun de ces bûchers, la tombe 17 près du bûcher $\mathrm{S} 11$ et la tombe 18 près du bûcher $\mathrm{S} 15$.

Cependant, le matériel livré par ces deux structures de Mourrel-Ferrat, en plus d'objets personnels des défunts, des tessons isolés de vases et des os d'animaux, pourraient signaler, comme à Ambrussum, des repas pris en marge de la crémation, avec bris des vases ayant été utilisés à cette occasion et rejet de quelques tessons ainsi que de quelques restes animaux dans le bûcher. Ici, le nombre plus limité de restes, 15 tessons isolés et 7 os de faune dans le bûcher S11, 6 tessons isolés, une portion d'urne et 2 os dans le bûcher S15, pourrait simplement indiquer, s'agissant de structures plus petites, des cérémonies de moindre ampleur et qui ont laissé moins de témoignages.

Dans la région, de telles aires de crémation ne sont pas une nouveauté au second Âge du Fer. Plusieurs cas de forme et dimension semblables à ceux de MourrelFerrat sont connus dans le cimetière du Moulin à Mailhac, datés de la transition Âge du Bronze - Âge $\mathrm{du}$ Fer, se rapportant chaque fois à un groupe réduit de tombes (Janin 1993, p. 49-50).

Une autre formule, qui n'apparaît pas à Ambrussum, a peut-être aussi existé à Mourrel-Ferrat. En effet, sur ce site, une dizaine de poteaux circulaires, certains pourvus de pierres de calage, se trouvent tout près d'autres sépultures. Il ne peut s'agir d'éléments signalant les tombes puisqu'ils ont brûlé ; sans doute participent-ils plutôt du bûcher lui-même et ils seraient alors les seules traces de crémations qui auraient précédé le creusement des tombes à l'emplacement même de l'ustrinum. Cette formule de sépultures installées dans les restes même du bûcher est de toutes façons déjà attestée antérieurement dans la région, aux $\mathrm{VII}^{\mathrm{e}}$ et $\mathrm{VI}^{\mathrm{e}} \mathrm{s}$. av. J.-C., comme, par exemple, dans le tumulus B1 du Frouzet à Saint-Martinde-Londres (Hérault), celui de l'Agnel 1 à Pertuis

50 Pour le poids théorique d'un adulte brûlé, voir supra, chap. 2, $\S 2.4 .1$. 
(Vaucluse), celui de la Guérine 1 à Cabasse et la tombe 1 de Gros-Ped aux Arcs-sur-Argens (Var). Mais elle reste alors rarement, sinon exceptionnellement, mise en œuvre : elle concerne en effet des individus qui sortent très nettement de l'ordinaire, si l'on en croit le mobilier associé (Dedet à paraître).

Ces deux types de bûchers se retrouvent dans la colonie grecque de Marseille entre le $\mathrm{IV}^{\mathrm{e}}$ et le $\mathrm{II}^{\mathrm{e}}$ s. av. J.-C., avec quelques variations toutefois. Dans la nécropole de Sainte-Barbe, quatre aires de crémation sans sépulture sont installées au milieu des tombes mais elles sont quelque peu distinctes de celles du monde indigène. Ici point d'aménagement de base ; il s'agit simplement de l'empreinte au sol d'une aire quadrangulaire ou circulaire, de $1,25 \mathrm{~m}^{2}$ à $4,50 \mathrm{~m}^{2}$, ayant subi l'action du feu et couverte de cendres et de charbons. Et, d'après la faible quantité d'os humains recueillis chaque fois, entre 27 et $207 \mathrm{~g}$, ces bûchers ne sont pas collectifs mais individuels, à condition bien sûr qu'ils n'aient pas été nettoyés (Moliner et al. 2003, p. 35). Vers la même époque, des bûchers semblables ont aussi leur place dans les enclos funéraires de la Bourse (Bertucchi 1992, p. 133). Mais il semble aussi exister à Sainte-Barbe la formule du bûcher individuel incluant la sépulture elle-même. Un tel bûcher est installé dans une fosse et les restes ont ensuite été percés par un loculus accueillant un ossuaire : ce serait le cas des tombes 55 et 252 (Moliner et al. 2003, p. 35, 257 et 272 ).

\section{Le mode de dépôt des restes osseux}

La mise en place des os brûlés du défunt directement dans le loculus, en dehors de tout contenant durable, et, éventuellement pour une petite partie du lot, dans la structure de recouvrement, est la seule formule de dépôt en usage à Ambrussum.

Le dépôt direct des os dans le loculus, sans réceptacle, est bien attesté vers la même époque dans la région. On le note à Cucuron/Les Conques (Dumoulin 1962) et à Beaucaire/Le Sizen-Collège Vigne (Carme, Demangeot 2010). Cette pratique est traditionnelle en Languedoc oriental. Cela est en continuité avec ce qui se faisait déjà dans cette contrée au premier Âge du Fer (Dedet 1992, p. 61-64) : dans les tumulus à incinération secondaire des Garrigues, les os étaient éparpillés dans une aire à peu près centrale du monument, ellemême parfois délimitée par un aménagement de pierres, comme en témoignent, par exemple, les tumulus gardois de Sadoulet 2 à Pompignan (Gascó 1980, p. 58-63) ou celui de Peyraube 6 à Lamelouze (Dedet, Gauthey 1994, p. 113-124). On la voit aussi mise en œuvre dans l'Hérault au VII ${ }^{\mathrm{e}} \mathrm{s}$. av. J.-C., tout près d'Ambrussum, dans les tombes de Montpellier/Gallière (Dedet, Lisfranc 2005), aux VI $\mathrm{I}^{\mathrm{e}}$ et $\mathrm{V}^{\mathrm{e}} \mathrm{s}$. av. J.-C. dans la nécropole de Castelnaule-Lez/Mermoz (Ott et al. 2010) et dans la tombe isolée de Font-de-la-Vie à Saint-Bauzille-de-Montmel au milieu du V ${ }^{\mathrm{e}}$ s. av. J.-C. (Dedet 1995a). Dans cette dernière, c'est du sédiment provenant du bûcher, sorte de magma cendreux enrobant des morceaux d'os brûlés, que l'on dépose dans le loculus, comme à Ambrussum.

Cette portion de la nécropole d'Ambrussum ignore l'usage du vase-ossuaire, bien présent alors en Languedoc oriental. À Beaucaire/Le Sizen-Collège Vigne, les tombes à ossuaire côtoient les sépultures à dépôt direct, mais sont moins nombreuses toutefois. Le vase-ossuaire est d'ailleurs présent aussi tout à côté du Sizen, dans la nécropole de Beaucaire/Les Colombes, et notamment dans la tombe 5 datée du dernier quart du III ${ }^{\mathrm{e}}$ ou du premier quart du II ${ }^{\mathrm{e}}$ s. av. J.-C. (Dedet, Michelozzi, Py 1974, p. 75-83). On le retrouve aussi, non loin d'Ambrussum et à même époque, dans la tombe de Nîmes/La Roussillonne (Dedet, Gauthey 2008) (fig. 113). Le vaseossuaire était déjà employé dans la région littorale du Languedoc oriental dans les siècles antérieurs, comme à Fabrègues/Saint-Martin-de-Colombs au VII ${ }^{\mathrm{s}} \mathrm{s}$. av. J.-C. (Dedet, Paya 2006-2007), à Pérols/La Pailletrice vers 500 av. J.-C. (Daveau, Dedet 2010), ou à Nîmes/Vignole VII dans la première moitié $\mathrm{du} \mathrm{V}^{\mathrm{e}} \mathrm{s}$. av. J.-C. (Séjalon, Dedet 2003), et aussi, concurremment au dépôt direct dans le loculus, à Castelnau-le-Lez/Mermoz (fig. 113).

Cette diversité n'est pas réservée à la seule partie orientale du Languedoc. Les dépôts en fosse sans ossuaire marquent également la fin du premier Âge du Fer et le début du second en Languedoc occidental, dans un milieu où jusque là, la tombe à vase-ossuaire était la règle. C'est ce que montrent les tombes les plus récentes du Grand Bassin II à Mailhac et quelques sépultures de la nécropole de Couffoulens/Las Peyros, dans l'Aude, datées de la fin du $\mathrm{VI}^{\mathrm{e}}$ ou du début du $\mathrm{V}^{\mathrm{e}} \mathrm{s}$. av. J.-C. (Janin et al. 2002 ; Passelac, Rancoule, Solier 1981). Et pour la seconde moitié du $\mathrm{V}^{\mathrm{e}} \mathrm{s}$., cette formule est également attestée dans l'Hérault. à Ensérune, Cesseras/les Bosquets, et Siran/la Martelle (Dedet, Schwaller 2010 ; Rancoule 1983 ; Rancoule 1989) (fig. 114).

Le vase-ossuaire est la règle à Ensérune, au $\mathrm{III}^{\mathrm{e}} \mathrm{s}$. av. J.-C., mais il existe alors aussi dans cette région un procédé que l'on pourrait qualifier de mixte : le loculus renferme un ossuaire mais aussi des résidus du bûcher incluant des os humains versés directement en dehors de ce contenant (Dedet, Schwaller 2010, p. 275). 


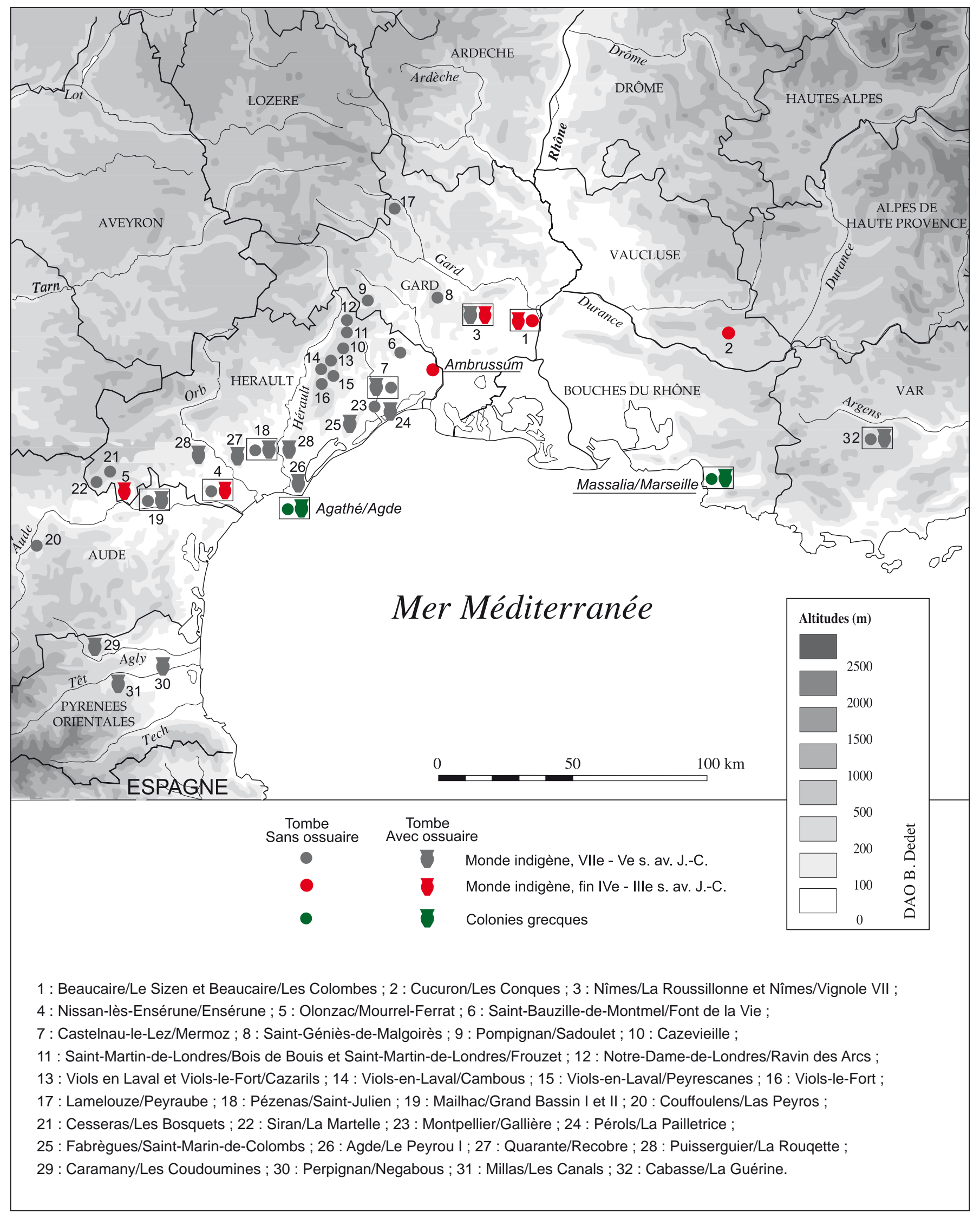

Fig. 113. Répartition des tombes sans ossuaire ou avec ossuaire. 
À Mourrel-Ferrat, fin $\mathrm{IV}^{\mathrm{e}}$-début $\mathrm{III}^{\mathrm{e}}$ s. av. J.-C. se rencontre la même pratique mixte, avec même, dans la moitié des cas, une masse d'os du comblement des fosses plus importante que celle de l'ossuaire : ainsi dans la tombe 18 , qui possède le lot osseux le plus volumineux découvert sur le site $(1350 \mathrm{~g})$, ce sont $95,7 \%$ des os qui se trouvent dans la fosse, hors de l'ossuaire (Janin et al. 2000, p. 232-234) (fig. 113).

Mais la fouille d'Ambrussum met aussi en évidence l'existence d'un autre geste, la mise en place, ou la dispersion, d'une partie des os du défunt prélevés sur le bûcher dans le sédiment terreux du dispositif de recouvrement de la sépulture. Cette pratique n'est pas inconnue dans la Protohistoire régionale. Elle avait déjà été discrètement signalée dans trois nécropoles du premier Âge du Fer. D'abord au Grand Bassin I de Mailhac: « Les ultimes vestiges de l'incinération, soigneusement recueillis sur l'ustrinum étaient déversés sur le tas de pierres qui recouvrait la tombe. C'est ainsi qu'on trouve parmi les pierres du tumulus des fragments de bronze parfois à moitié fondus (...), de petites mottes de terre rougie, des charbons, parfois un peu de cendres, des esquilles d'os brûlés » (Louis, Taffanel, Taffanel, 1958, p. 34). Ensuite aux Coudoumines à Caramany (Pyrénées-Orientales) : «Seulement deux tombes possédaient leur dalle de fermeture en place. Elles étaient recouvertes de sédiment mêlé à des cendres, de menus charbons de bois et des esquilles d'os humains calcinés » (Porra 1995, p. 459). Puis pour une des tombes de Pradines à Causses-etVeyran (Hérault), la T36, où l'argile composant l'amas surmontant la tombe «contient de très nombreux os humains brûlés et des charbons de bois » (Mazière 2002, p. 127 et p. 149, note 11). Dans tous ces cas, nul doute que l'observation de cet usage ne soit favorisée par une conservation satisfaisante de cette structure superficielle ou d'une partie de celle-ci. Cette condition est, somme toute, assez rarement remplie et la fréquence de cet usage est donc difficile à apprécier à l'échelle de la région. Cependant tout récemment, c'est pour un nombre important de recouvrements de sépultures du premier Âge du Fer que pareille pratique vient d'être remarquée dans la nécropole du Causse à Labruguière (Tarn), lors de la fouille préventive conduite en 2010 par L. Buffat (Société Mosaïques Archéologie), tandis que, à l'inverse, dans le secteur du premier Âge du Fer de Pradines, particulièrement bien conservé, sur une quarantaine de tombes fouillées, une seule est concernée.

Les deux usages qui ont cours dans le monde indigène, les dépôts des os humains avec ossuaire ou sans ossuaire, se retrouvent aussi à Marseille et à Agde, aux $\mathrm{IV}^{\mathrm{e}}$-III ${ }^{\mathrm{e}}$ s. av. J.-C. À Marseille/Sainte-Barbe, dans le lot des 29 sépultures à incinération, le dépôt dans un contenant, le plus souvent dans une urne, mais parfois dans une amphore ou dans un vase en plomb, est le plus fréquent (18 cas), tandis que le versement direct dans la fosse concerne 11 tombes (Moliner et al. 2003, p.34-35). Dans les tombes des terrasses de la Bourse, toutes ces formules à l'exception de l'amphore sont attestées, mais les réceptacles métalliques paraissent plus fréquemment utilisés, parfois insérés dans une cuve en pierre. À Agde/ Le Peyrou II, sur les quatre tombes à incinération fouillées, trois disposent d'un ossuaire (Marchand, Schwaller dans Lugand, Bermond 2001, p. 146) (fig. 113).

\section{Le poids des os}

Dans le monde indigène comme dans la colonie grecque de Marseille, la variabilité du poids des os prélevés sur le bûcher traduit une absence de constante, et cela, quel que soit le mode de dépôt dans la tombe. Pour certains sujets, ce ramassage concerne une grande quantité de restes, proche de la moitié du poids théorique d'un squelette incinéré, mais pour d'autres ce n'est qu'une infime part qui est placée dans la sépulture. On le remarque bien à Ambrussum, mais aussi dans les autres nécropoles peu ou prou contemporaines.

À Mourrel-Ferrat, les poids totaux concernant les adultes, ossuaire et versement direct dans le loculus, s'échelonnent de 107 à $1350 \mathrm{~g}$ avec un regroupement autour de $200 \mathrm{~g}$, et les contenus des ossuaires seuls varient de 57,7 à 240,8 g, avec un regroupement entre 58 et $65 \mathrm{~g}$. Dans les tombes à dépôt sans ossuaire d'Ensérune, les poids varient de 10 à $210 \mathrm{~g}$, et le plus grand nombre ne renferme que 30 à $40 \mathrm{~g}$, mais en l'absence de tamisage ces valeurs n'ont qu'un intérêt limité. Dans la même nécropole, les poids d'os placés dans les ossuaires s'échelonnent de 42 à 1026 g, la moyenne est de 268 g, et la plupart des dépôts se situe entre 150 et 300 g. Pour les tombes mixtes de ce site, la quantité d'os présents dans le loculus reste incertaine du fait des conditions de fouilles anciennes (Dedet, Schwaller 2010, p. 277).

Ce sont là des valeurs proches de celles d'Ambrussum où, pour les quatorze adultes identifiés, les différences entre défunts vont de un à dix, avec des poids compris entre de 101,8 et 980,0 g, et une moyenne de 391,6 $\mathrm{g}$. L'ossuaire de la Roussillonne, avec ses 719,2 g d'os, se place, lui, dans le haut de fourchette des dépôts sans ossuaire d'Ambrussum (Dedet, Gauthey 2008).

À Marseille/Sainte-Barbe, les mêmes pratiques concernent les douze tombes individuelles d'adultes 
incinérés, jugées complètes lors de la fouille. Les deux dépôts complets en fosse, sans réceptacle, sont très éloignés l'un de l'autre, mais ils entrent dans une fourchette de poids très proche de celle qui a été constatée à Ambrussum (172,7 g pour la tombe 255 et $771,9 \mathrm{~g}$ pour la tombe 97). En revanche, le volume des restes des dix adultes placés dans un récipient est sensiblement plus important : les poids sont compris entre 52,1 et 1921,4 g, pour une moyenne de $867,3 \mathrm{~g}$, soit globalement le double d'Ambrussum (Moliner et al. 2003, p. 90). Sur ce point, on retrouve dans la colonie grecque la même tendance qu'en milieu indigène : la masse osseuse mise dans un ossuaire est plus importante, en moyenne, que celle qui est déposée directement dans le loculus.

\section{La morphologie de la tombe}

La morphologie des sépultures à crémation secondaire sans ossuaire peut présenter plusieurs formes dans le monde autochtone du Midi méditerranéen (fig. 114).

Le premier type d'Ambrussum, que nous avons qualifié « d'élaboré » par rapport à un deuxième type appelé «rudimentaire » (fig. 114, no 5), est illustré à SaintBauzille-de-Montmel/Font-de-la-Vie environ 200 ans plus tôt (Dedet 1995a). Cette tombe est formée d'une dépression de plan circulaire de $1,10 \mathrm{~m}$ de diamètre, n'excédant pas $10 \mathrm{~cm}$ de profondeur, aménagée dans le sol terreux sans entamer le substrat rocheux calcaire. Elle inclut, dispersés dans son comblement, les os mêlés à des restes du foyer et à ceux du mobilier très fragmenté. En bordure de cette fosse, vers le nord, une urne ou une portion d'urne non brûlée a été posée sur le sol antique. La conservation de cet ensemble implique une structure de recouvrement disparue, de terre et/ou de pierres, à l'image de celle que l'on retrouve à Ambrussum.

D'autres formes existent cependant aussi dans la région, comme à Cucuron/Les Conques, dans le Vaucluse ou à Cesseras/Les Bosquets à l'extrémité occidentale de l'Hérault.

La tombe B des Conques, datée du VI ${ }^{e}$ s. av. J.-C., comprend une fosse ovale de 0,85 sur $0,65 \mathrm{~m}$ à 1 'ouverture et $0,20 \mathrm{~m}$ de profondeur (Dumoulin 1962, p. 324-326). Deux modalités la distinguent fortement de celles d'Ambrussum : le fond de cette fosse est bordé par un cordon de blocs de grès non taillés; par ailleurs les os calcinés, les bijoux brûlés et les offrandes sont répartis à l'intérieur de cette structure en des tas bien distincts (fig. 114, $\mathrm{n}^{\circ}$ 2).
Une formule quelque peu différente se rencontre aux Bosquets, dans la seconde moitié du V $\mathrm{e}$ s. av. J.-C., comprenant plusieurs éléments d'après les cas les mieux conservés, les sépultures B2 et B3: une grande fosse profonde, 1 à $1,5 \mathrm{~m}$ de long sur $0,7 \mathrm{~m}$ de large pour 0,4 à $0,5 \mathrm{~m}$ de profondeur, remplie de cendres, de terre rougie et de blocs de grès ayant subi l'action du feu; les restes ramassés sur le bûcher, charbons, os humains incinérés et éléments très fragmentés du mobilier sont déversés sur le dessus du comblement de cette fosse et dans une petite dépression adjacente de $0,5 \mathrm{~m}$ de diamètre pour 0,10 à $0,15 \mathrm{~m}$ de profondeur. L'ensemble est recouvert par des blocs de grès (Rancoule 1983) (fig. 114, $\mathrm{n}^{\circ} 1$ ).

Le second type de tombe d'Ambrussum, constitué d'une simple fosse de faibles dimensions, enfermant des résidus du bûcher et dépourvue, semble-t-il, de structure apparente en surface, est attesté pour la même époque dans les fouilles récentes de Beaucaire/Le Sizen-Collège Vigne (Carme, Demangeot 2010).

La forme de ces deux catégories de sépultures à dépôt direct des os dans le loculus, bien documentées à Ambrussum, est différente de celle des tombes contemporaines à vase-ossuaire. À Mourrel-Ferrat, l'ossuaire occupe le centre d'un loculus tronconique étroit et peu profond, et, dans le cas de la tombe 21 , le creusement est limité à l'emprise du vase (Janin et al. 2000) (fig. 114, $\mathrm{n}^{\circ}$ 3). À Ensérune, les cinq tombes du III ${ }^{\mathrm{e}} \mathrm{s}$. av. J.-C. fouillées en 1988, ont une fosse oblongue pouvant atteindre $1,40 \mathrm{~m}$ sur le grand axe, creusée dans un conglomérat surmontant le substrat rocheux dont les ressauts sont utilisés pour poser des objets ; une couverture de deux épaisseurs de blocs accuse un pendage important vers le centre de la fosse et témoigne d'un espace sous-jacent originellement vide. La dimension du loculus dépasse toujours plus ou moins largement l'encombrement de l'ossuaire et du mobilier conservé, indice de dépôt d'objets périssables et/ou de résidus provenant du bûcher (Schwaller et al. 1995) (fig. 114, n 4). Des stèles rudimentaires en pierre, sans inscription ni décor, signalent ces sépultures à Ensérune (Schwaller 1994a), mais peut-être aussi à Mourrel-Ferrat.

Tout autres sont les tombes de Marseille et d'Agde. À Marseille/Sainte-Barbe les restes du trépassé, brûlés ou non, sont placés en pleine terre directement ou dans un contenant, urne, amphore, cercueil, coffrage de bois ou, beaucoup plus rarement, sarcophage. La fermeture du tombeau peut se faire de diverses manières : des planches, des morceaux de panses d'amphores, un amoncellement de pierres, de tessons et de matériaux de récupération, ou encore des dalles couchées. 


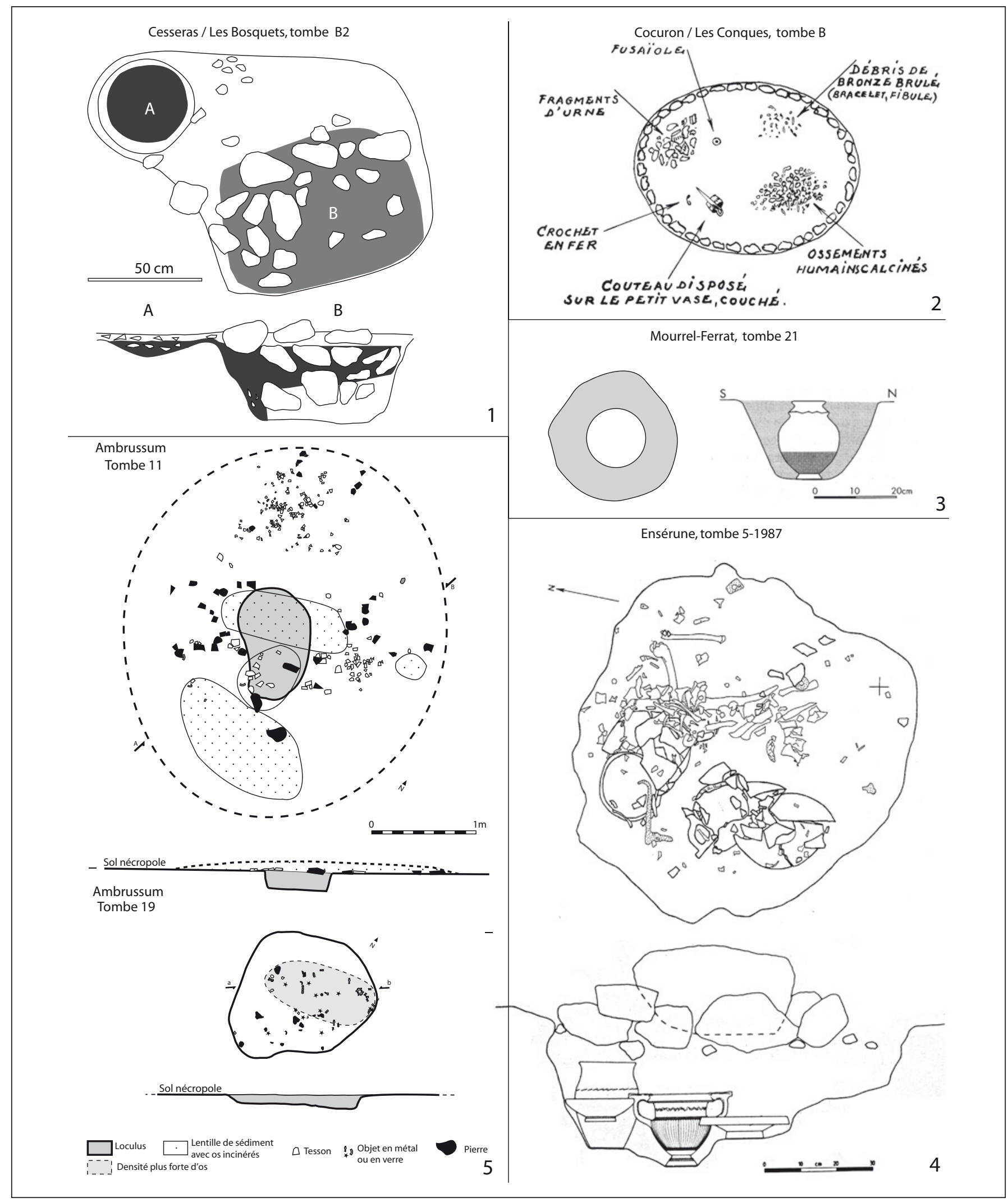

Fig. 114. Exemples de tombes du monde indigène languedocien et provençal de la fin du IVe et du IIIe $\mathrm{S}$. av. J.-C. 1 : Cesseras (Hérault), tombe B2 des Bosquets (d'après Rancoule 1983) ; 2 : Cucuron (Vaucluse), tombe B des Conques (d'après Dumoulin 1962) ; 3 : Olonzac (Hérault), tombe 21 de Mourrel Ferrat (d'après Janin et al. 2000) ; 4 : Nissan-lès-Ensérune, tombe 5-1987 d'Ensérune (d'après Schwaller et al. 1995) ; 
Qu'il s'agisse d'incinération ou d'inhumation, beaucoup de tombes, mais peut-être était-ce le cas pour toutes, sont marquées en surface par une pierre de taille fruste, souvent dégrossie en pyramide, de 0,3 à $0,4 \mathrm{~m}$ de haut, placée dans l'emprise de la fosse, jamais en dehors de celle-ci, et dans le cas des inhumations, plantée plus particulièrement vers l'extrémité où se trouve la tête (Moliner et al. 2003, p. 72-74). Le sarcophage constitue l'usage exclusif à la rue du Tapis-Vert, du moins dans la partie qui a pu être fouillée (Chabot, Féraud 1959). Et ces sépultures apparaissent somme toute modestes en regard de celles, monumentales, des deux terrasses de la Bourse, soigneusement bâties à la mode grecque, en grand appareil et décorées de bossages ou de triglyphes, incluant une série de tombes à incinération dans des logettes (Bertucchi 1992).

Dans les tombes à inhumation d'Agde/Le Peyrou II, un aménagement périphérique de blocs sur chant borde le corps et un lit de pierres recouvre l'ensemble. Pour leur part, les tombes à incinération montrent toujours la trace d'une couverture de blocs, malgré un mauvais état de conservation (Dedet, Schwaller 2010, p. 283).

\section{Le matériel d'accompagnement}

À Ambrussum, le matériel accompagnant le défunt des tombes sans ossuaire est fragmenté et incomplet, et il montre souvent des traces de passage sur le bûcher (fig. 115). Il en va de même dans le monde indigène languedocien et provençal, où, le plus souvent, bris et caractère incomplet des objets mis dans la tombe, notamment des vases, vont de pair avec le dépôt des restes humains hors de tout vase-ossuaire. C'est le cas vers la même époque en Provence à Cucuron/Les Conques : deux bracelets, une fibule et une pendeloque dans la tombe A, une petite coupe et des tessons d'une urne incomplète, en céramique non tournée, des débris de bracelet et de fibule en bronze, un passant en fer, un couteau et une fusaïole dans la tombe B, qui a peut-être accueilli deux défunts (?), car couteau et fusaïole s'excluent d'habitude; une fibule et des tessons de deux urnes dans la tombe $\mathrm{C}$; une pointe de lance dans la tombe $\mathrm{D}$ (Dumoulin 1962). Déjà, antérieurement, ce type de dépôt avait cours, en Languedoc oriental, non loin d'Ambrussum, Saint-Bauzille-de-Montmel/Font-de-la-Vie au milieu $\mathrm{du} \mathrm{V}^{\mathrm{e}} \mathrm{s}$. av. J.-C. ou à Montpellier/Gallière au VII ${ }^{\mathrm{e}} \mathrm{s}$. av. J.-C. (Dedet 1995 ; Dedet, Lisfranc 2005). C'était aussi le cas dans les tertres des Garrigues et des Cévennes au premier Âge du Fer, comme par exemple dans le tumulus 6 de Peyraube à Lamelouze (Dedet, Gauthey 1994, p. 113-124), ainsi que dans les nécropoles du Languedoc occidental, à Mailhac/Grand Bassin II et à Couffoulens/ Las Peyros, à la fin du $\mathrm{VI}^{\mathrm{e}}$ et au début du $\mathrm{V}^{\mathrm{e}} \mathrm{s}$. (Janin et al. 2002 ; Passelac, Rancoule, Solier 1981).

Le mobilier des tombes à vase ossuaire de la fin du IV ${ }^{\mathrm{e}}$ et de début du $\mathrm{III}^{\mathrm{e}} \mathrm{s}$. av. J.-C. présente deux éventualités au voisinnage d'Ambrussum. Dans certaines sépultures de la nécropole du Beaucaire/Le Sizen-Collège Vigne, le vase-réceptacle n'est accompagné d'aucun objet. Dans d'autres tombes du Sizen ou encore dans la tombe de Nîmes/La Roussillonne l'accompagnement est très limité. Au Sizen ces pièces d'accompagnement peuvent être, mais rarement, placées dans le loculus à côté de l'ossuaire, ou, plus fréquemment, sont déposées dans ce vase même au sommet de l'amas osseux (Carme, Demangeot 2010). À la Roussillonne seule une petite coupe a été ajoutée au dépôt, posée sur le dessus du paquet d'os dans l'ossuaire (Dedet, Gauthey 2008). À la fin du III s. av. J.-C. ou au début du suivant, la tombe 3 de Beaucaire/Les Colombes est beaucoup mieux pourvue et il n'est pas certain que l'ensemble du matériel ait pu être récupéré : l'urne ossuaire, qui contient aussi une fibule et une monnaie, est posée dans la courbure d'une épée encore dans son fourreau, qui ont été ployés ; deux plats à vernis noir et un en céramique non tournée sont alignés d'un côté (Dedet, Michelozzi, Py 1974, p.75-83). Ce cas est-il exceptionnel alors à Beaucaire ? S'agissant de la seule tombe de cette époque connue sur ce site, il est impossible de se prononcer.

Cette variation dans la quantité et dans l'état du matériel mis dans la tombe en fonction de la forme que prend le dépôt osseux humain se retrouve à la même époque en Languedoc occidental. Ainsi à Mourrel-Ferrat, c'est dans seulement la moitié des tombes à ossuaire que figure du matériel d'accompagnement, soit un vase entier, soit des tessons de sept ou huit récipients incomplets. Les sépultures sans ossuaire ne contiennent pas de récipient complet, mais seulement des tessons de plusieurs vases, et objets en métal et restes animaux sont plus nombreux dans les tombes à ossuaire (Janin et al. 2000). À Ensérune, dans les cinq tombes fouillées en 1988, si les objets personnels du mort, pièces de parure et d'habillement, ustensiles, armes, coffrets décorés d'incrustations en os, passent sur le bûcher avec le cadavre et se retrouvent déformés ou à l'état de fragments dans le loculus, les vases d'accompagnement et les offrandes alimentaires ne sont pas brûlés et sont déposés intacts (Schwaller et al. 1995, p. 224).

Dans cette partie du Languedoc, commeà Ambrussum, les quantités de matériel déposé auprès du mort sont, pour leur part, très variables. Elles sont faibles dans les 
tombes dites «à simple ossuaire », où seuls quelques objets personnels et des restes d'une offrande animale sont joints aux restes osseux. Par exemple la tombe 21 de Mourrel-Ferrat n'a livré qu'une fibule et un bracelet en bronze ainsi qu'une perle en pâte de verre (Janin et al., 2000, p. 235-237). C'est le cas aussi à Ensérune comme dans la tombe 6/1988, avec des perles de collier, des éléments de tabletterie de coffret, une chaîne-ceinture ou une fibule, une fusaïole et un dépôt de faune (Schwaller et al., 1995, 220-222). Et ce bagage peut encore être plus réduit, comme dans la tombe $1 / 1988$ du même site, avec une patte de porc (ibid., p. 207-208). Mais plus souvent ce matériel est abondant et les armes sont fréquentes, ces dernières formant parfois de véritables panoplies, comme dans certaines tombes d'Ambrussum. Ainsi dans trois des cinq tombes d'adultes d'Ensérune fouillées en 1988 (tombes 2, 3 et 5), dans celle qui l'a été en 2000, ainsi que de la tombe $161^{51}$, toutes datées du III $\mathrm{s}$. av. J.-C., figurent deux à dix vases d'accompagnement, l'équipement plus ou moins complet d'un guerrier, épée dans son fourreau, fer de lance et bouclier, des fibules, des éléments de tabletterie en os et des restes animaux (Schwaller et al., 1995, p. 210-220 ; Bel et al., à paraitre ; Rapin, Schwaller 1987). Cependant, à la différence d'Ambrussum, beaucoup de ces objets, même s'ils ont séjourné au préalable sur le bûcher, comme les épées, ne sont pas réduits à l'état de petits morceaux. Disposer et exposer dans la tombe vases et armes complets participe ici d'une forme d'ostentation manifestement absente à Ambrussum.

La connotation sexuelle, bien visible pour une part des adultes d'Ambrussum, est également perceptible ailleurs à cette époque, notamment à Ensérune. Dans cette nécropole, sur vingt-neuf tombes découvertes entre 1954 et 1965, neuf contiennent des objets présumés masculins, essentiellement des armes (tombes 146, 150/151, $157,158,163,170,171,175$ et 178), et deux, des pièces présumées féminines, fusaïole ou boucles d'oreille (tombes 147 et 172) (Gallet de Santerre 1968, p. 73-83); et parmi les cinq sépultures fouillées en 1988 figurent deux dépôts avec armes et un avec fusaïole (Schwaller et al. 1995).

La coutume de placer des restes animaux dans la sépulture est, pour sa part, bien présente en Languedoc au milieu du second Âge du Fer, soit de la même manière qu'à Ambrussum, soit sous une forme bien différente. La plupart des tombes de Mourrel-Ferrat contiennent des os

51 Il s'agit là d'une des tombes les moins mal connues parmi celles qui ont été fouillées anciennement sur ce site. d'animaux isolés ${ }^{\mathbf{5}}$ (Janin et al. 2000). Ceux-ci sont également bien présents à Ensérune au $\mathrm{III}^{\mathrm{e}} \mathrm{s}$. av. J.-C., mais cette nécropole montre aussi une autre coutume constituée par le dépôt de volailles entières et de quartiers de caprinés et de porcs non brûlés (Schwaller et al. 1995, notamment p. 226-229). À la différence d'Ambrussum, c'est là de la viande préparée et non consommée qui a accompagné le défunt dans son tombeau.

Relevée à Ambrussum, la présence de restes d'équidés, et en particulier de cheval, est très rarement attestée dans les sépultures de la région pendant la Protohistoire, mais, même si elle est exceptionnelle, c'est une pratique ancienne. On en trouve le témoignage dans les tombes 10 de Mourrel-Ferrat et 43 d'Ensérune pour le second Âge du Fer (Janin et al. 2000, p. 225-227 et p. 246), la tombe 1 de Gros-Ped aux Arcs-sur-Argens, Var, au milieu du VIe s. av. J.-C. (Bérato, Dugas, Dutour 1991, p. 129), la tombe 248 de Saint-Julien à Pézenas au milieu du VII ${ }^{e}$ s. av. J.-C. (étude en cours), la tombe 220 du Moulin à Mailhac au Bronze final IIIb ou à la transition Bronze - Fer (Taffanel, Janin 1998, p. 181) et dans le tumulus IV du Freyssinel à Balsièges, Lozère, au Bronze final IIIa (Morel 1968, p. 40 ; Dedet 2001, p. 52-54).

Si l'on en croit leurs contextes, ces dépôts de restes équins semblent cependant refléter des préoccupations diverses. Le défunt de Saint-Julien concerné, un grand enfant, adolescent ou adulte, et celui de Gros-Ped, un adulte robuste, très probablement masculin, se signalent par des armes, comme à Ambrussum, et l'individu de Gros-Ped est un mort insigne, enseveli avec un très riche mobilier sous le bûcher lui-même, pratique fort peu répandue durant la Protohistoire méridionale (Dedet à paraître). À Mourrel-Ferrat, le défunt, adulte ou adolescent, est dépourvu d'arme ou de tout autre objet à connotation sexuelle perceptible. Celui du Moulin de Mailhac, dont l'âge ne peut être précisé, aurait possédé un mobilier très réduit, notamment une fusaïole, symbole féminin, mais cette sépulture a été découverte « entièrement soulevée par la charrue » (Taffanel, Janin 1998, p. 181), ce qui incite à considérer ce voisinage avec réserve. Autre temps, autre mœurs, dans le tumulus IV du Freyssinel, ce sont trente-trois dents de cheval qui sont signalées « réparties toutes au même niveau, à peu

52 Sur ce site, ces vestiges sont interprétés comme « des offrandes primaires (c'est-à-dire placées sur le bûcher) dont la présence dans la tombe ne relève finalement que du curage du bûcher » (Janin et al. 2000 , p. 246). Nous avons vu supra, chap. 6, qu'il ne peut en être ainsi à Ambrussum où ce qui accompagne le défunt dans la tombe paraît bien spécifique. 
près au centre du monument, sur une surface de deux mètres carrés, environ » (Morel 1968, p. 40).

À Marseille/Sainte-Barbe, dans le cas des sépultures à incinération, le matériel a pu être brûlé avec le cadavre, et notamment les objets montrent souvent les stigmates du passage sur le bûcher. D'autres objets ont été placés dans la tombe après la crémation, lors de l'ensevelissement ; cependant la distinction entre les deux séries est souvent impossible à faire. Ces pièces sont généralement peu nombreuses : la majorité des dépôts, quinze d'entre eux, ne comptent qu'un ou deux éléments, soit en tout 48 pièces pour 21 tombes et une moyenne de 2,3 objets par tombe. Ce matériel est plus fréquent dans les tombes à incinération ( 15 cas) que dans les tombes à inhumation (6 cas) : les incinérés sont les défunts le plus souvent accompagnés d'objets et aussi ceux qui en sont le plus pourvus.

À la différence du milieu indigène, rares semblent être les objets personnels des défunts dans cette nécropole massaliète. Les dépôts se composent essentiellement de vases à huile et à parfum, de strigiles et d'éléments en terre cuite de couronnes florales, autant d'objets qui évoquent la toilette mortuaire et des libations, et des personnes s'inscrivant dans des mœurs grecques. Et, dans aucun cas, ces pièces ne permettent de soupçonner s'il s'agit d'un homme ou d'une femme, contrairement à la culture indigène contemporaine et en particulier aux pratiques en usage à Ambrussum.

De surcroît, dans ce cimetière de Sainte-Barbe une forte proportion d'adultes, 19 sur 44 , soit $43 \%$, sont dépourvus de tout mobilier. Même si cette pratique concerne surtout les inhumés, 19 sur 25, soit les trois quarts d'entre eux et, plus rarement les incinérés, 4 sur 19 soit un cinquième seulement, les Grecs de Marseille ne répugnent pas à ensevelir les restes de leurs morts adultes sans aucun matériel d'accompagnement. Il n'en va pas de même chez les Indigènes, partout en Provence et en Languedoc, et Ambrussum ne déroge pas à cette règle.

\section{Les tombes à armes}

\subsection{La fréquence des armes}

On l'a déjà souligné (cf supra chap. $6, \S 5$.), ce secteur de la nécropole d'Ambrussum a accueilli six défunts accompagnés de pièces d'armement, ceux des tombes 2 , $12,14,18,21$ et 25 ), ce qui constitue une proportion très importante des défunts adultes découverts, environ le tiers. Et des éléments d'armes figurent également dans l'aire crématoire B1 et dans la structure ST1 qui est peut-être aussi un autre bûcher.

En ce domaine, les trois autres nécropoles languedociennes contemporaines connues, Ensérune et Mourrel-Ferrat dans l'Hérault, ainsi que Le SizenCollège Vigne à Beaucaire, dans le Gard, montrent des situations diverses vers la même époque. À Ensérune, " un comptage rapide permet d'avancer un pourcentage de l'ordre de $20 \%$ des tombes concernées par un équipement militaire relativement complet» (Rapin, Schwaller 1987, p. 181). Il s'agit sans doute là d'une proportion proche de celle d'Ambrussum, compte tenu de la différence de taille des deux échantillons de population (quelque 500 sépultures connues à Ensérune). En revanche, les armes sont absentes des douze tombes et des bûchers de la fin du IV ${ }^{\mathrm{e}} \mathrm{s}$. av. J.-C. fouillés à MourrelFerrat, de même que des 112 sépultures de Beaucaire/ le Sizen-Collège Vigne, datées pour l'immense majorité d'entre elles de la deuxième moitié du $\mathrm{IV}^{\mathrm{e}}$ et de la première moitié du $\mathrm{III}^{\mathrm{e}} \mathrm{s}$. av. J.-C. (Janin et al. 2000 ; Carme, Demangeot 2010). Cependant, dans les deux cas, il pourrait ne pas s'agir là d'un usage local qui priverait les hommes de leur armement dans la tombe. En effet, à Mourrel-Ferrat, le mobilier semble indiquer des tombes présumées féminines et seul serait donc connu un quartier de nécropole réservé aux femmes ; à Beaucaire/le Sizen-Collège Vigne, la zone fouillée est dévolue aux enfants et aux femmes car, pour les adultes, la seule symbolique sexuelle attestée est féminine. D'ailleurs, dans ces deux lieux, ces secteurs occupent une surface très réduite, où les sépultures sont très densément groupés.

Dans le contexte régional, une telle présence massive d'armement dans les tombes est une nouveauté. En Languedoc oriental, au premier Âge du Fer, seulement $4 \%$ des tumulus des Garrigues sont affectés par le dépôt d'armes (Dedet 1992, p. 184). Et parmi les rares tombes du $\mathrm{V}^{\mathrm{e}} \mathrm{s}$. av. J.-C. attestées, seule la sépulture isolée de Font-de-la-Vie à Saint-Bauzille de Montmel, Hérault, contenait une pièce d'armement (Dedet 1995a). Dans les régions voisines, les chiffres varient selon les lieux et l'époque, mais restent cependant bien en deçà de la fréquence observée à Ambrussum : $14 \%$ dans les tumulus des Grands Causses au premier Âge du Fer (Dedet 2001, p. 317) ; autour de $2 \%$ des tombes en Roussillon au début du premier Âge du Fer (Dedet, Marchand 2010, p. 92); entre 1,8 \% au Peyrou I à Agde au VII $\mathrm{s}$. av. J.-C., $1 \%$ et $14 \%$ à Mailhac (Aude) respectivement dans les secteurs du Grand Bassin I, VII ${ }^{\mathrm{e}}$ s., et du Grand Bassin II, VIe s. av. J.-C. (Dedet 2009, p. 219) ; $20 \%$ des 
dépôts à Saint-Julien de Pézenas, Hérault, aux VII ${ }^{\mathrm{e}}-\mathrm{VI}{ }^{\mathrm{e}} \mathrm{s}$. av. J.-C., et $26 \%$ à Las Peyros à Couffoulens, Aude, au VI ${ }^{\mathrm{e}}$ s. av. J.-C. (Dedet, Marchand, à paraître).

Cette proportion élevée des défunts à armement constatée à Ambrussum et à Ensérune est un phénomène qui concerne aussi la Gaule intérieure à pareille époque. On l'observe, par exemple, en Auvergne à partir de la fin du $\mathrm{IV}^{\mathrm{e}}$ et au III ${ }^{\mathrm{e}}$ s. av. J.-C.(Mennessier-Jouannet et al. 2010, p. 247), mais aussi en Bourgogne, où les armes représentent près de $30 \%$ des objets placés dans les tombes à La Tène B2 et environ $20 \%$ à La Tène $\mathrm{C} 1$ et C2 (Baray, Chaume, Millet 2007, p. 216, fig. 29). En Sénonais, dans la nécropole de la Haute-Grève à Gouaix (Seine-et-Marne), c'est au moins un homme sur trois qui se voit attribuer un équipement militaire au début ou dans la première moitié du $\mathrm{III}^{\mathrm{e}} \mathrm{s}$. av. J.-C, « ce qui signifie que, pour cette période, les sépultures à armes sont plus nombreuses que les sépultures masculines ordinaires » (Séguier et al. 2010, p. 196). Dans une étude de synthèse concernant le Bassin parisien, G. Bataille, J. Kaurin et S. Marion notent que $33 \%$ des tombes datées de la Tène $\mathrm{B} 2$, et encore $14 \%$ de celles de la Tène $\mathrm{C} 1$ en sont pourvues ${ }^{53}$. Si on fait abstraction des tombes d'enfants et si l'on admet que, généralement, on compte à peu près autant de sépultures «masculines » que de sépultures « féminines », on retrouve là une situation semblable à celle d'Ambrussum.

Dans un autre contexte culturel, celui des Grecs des colonies de Gaule méridionale, l'armement n'apparaît pas dans les dépôts funéraires. Ainsi, aucune arme n'est signalée dans les 96 sépultures d'époque grecque du cimetière de Sainte-Barbe à Marseille, du $\mathrm{IV}^{\mathrm{e}}$ au milieu du $\mathrm{II}^{\mathrm{e}}$ s. av. J.-C. (Moliner et al. 2003). Il en va de même dans les 28 tombes datées entre le milieu du IV e et le début du II ${ }^{\mathrm{e}}$ s. av. J.-C. du cimetière du Peyrou II à Agde (Nickels 1982; Marchand, Schwaller dans Lugand, Bermond 2001, p. 145-146). Le statut des armes ou de ceux qui les portent serait donc ici bien différent de celui du monde indigène (Dedet 2011).

\subsection{Le reflet de la panoplie}

Épées et leurs accessoires, lances et boucliers sont les seules armes figurant dans les tombes d'Ambrussum. Ce reflet de la panoplie de l'habitant de l'oppidum

53 Communication de G. Bataille, J. Kaurin et S. Marion intitulée «Une archéologie de la guerre au second âge du Fer», présentée au colloque pré-protohistoire du $136^{\mathrm{e}}$ Congrès national des sociétés historiques et scientifiques, Perpignan, 2011.
d'Ambrussum est-il conforme à ce que l'on connaît ailleurs dans le monde indigène du Sud de la France à la même époque ? Deux sources permettent d'en juger.

Sur un plan strictement funéraire la nécropole d'Ensérune est pratiquement la seule du monde indigène qui fournisse des données. Ce sont actuellement 18 sépultures pourvues de ces mêmes catégories d'armes, qui y sont connues pour la période comprise entre la fin du $\mathrm{IV}^{\mathrm{e}}$ et le début du $\mathrm{II}^{\mathrm{e}} \mathrm{s}$. av. J.-C. :

- épée (et/ou fourreau et éléments de suspension), pointe et/ou talon de lance, et élément(s) d'un bouclier, 7 tombes : T 146, T 151, T 158, T 170 (Gallet de Santerre 1968, p. 73-75 et 83), T 163 (Rapin, Schwaller 1987), T 3-1988 (Schwaller et al. 1995, p. 212-216) et T 157 (Schwaller et al. 2001, p. 180-182) ;

- épée (et/ou fourreau et éléments de suspension) et élément(s) d'un bouclier, 5 tombes : T 43 (Jannoray 1955, p. 234-235 et 242), T 175, T 178 (Gallet de Santerre 1968, p. 79-82), T 5-1988 (Schwaller et al. 1995, p. 216-219) et T 1001 (Bel et al. à paraitre) ;

- épée (et/ou fourreau et éléments de suspension) et pointe et/ou talon de lance, 3 tombes : T 121 (Jannoray 1955, p. 234-235), T 13 et T IB29 (Schwaller et al. 2001, p. 177-179);

- pointe et/ou talon de lance, 2 tombes : T 171 (Gallet de Santerre 1968, p. 79-82) et T IB71 (Schwaller et al. 2001, p. 177-178);

- élément(s) d'un bouclier, 1 tombe: T 2-1988 (Schwaller et al. 1995, p. 210-212).

À Ensérune comme à Ambrussum, règne donc la même triade, épée, lance, bouclier.

En dehors d'Ensérune, dans cette fourchette chronologique, seule la tombe 3 des Colombes à Beaucaire, datée vers la fin du $\mathrm{III}^{\mathrm{e}} \mathrm{s}$. ou dans le premier quart du $\mathrm{II}^{\mathrm{e}}$ s. av. J.-C., contient de l'armement, une épée dans son fourreau, et confirme cette image ; cependant il n'est pas sûr que tous les objets déposés nous soient parvenus (Dedet et al. 1974, p. 75-83). Par ailleurs, si tant est qu'il s'agit bien de sites funéraires, ce sont de telles armes que recélaient les dépôts en grottes de Provence orientale : au moins deux épées dans leurs fourreaux et trois pointes de lances dans l'aven Bernard à Vallauris (Vindry 1978, p. 35-37 et p. 74, fig. 37) et une épée dans l'aven de la Lauve à Gourdon, Alpes-Maritimes (Fulconis 2004, p. 112).

Dans un autre registre, celui du sanctuaire, les dépôts du III $\mathrm{s}$. av. J.-C. récemment mis au jour dans l'habitat gardois du Cailar montrent la même panoplie que dans les tombes languedociennes. Les fouilles en cours sur ce site livrent en effet, en abondance, épées avec leur 


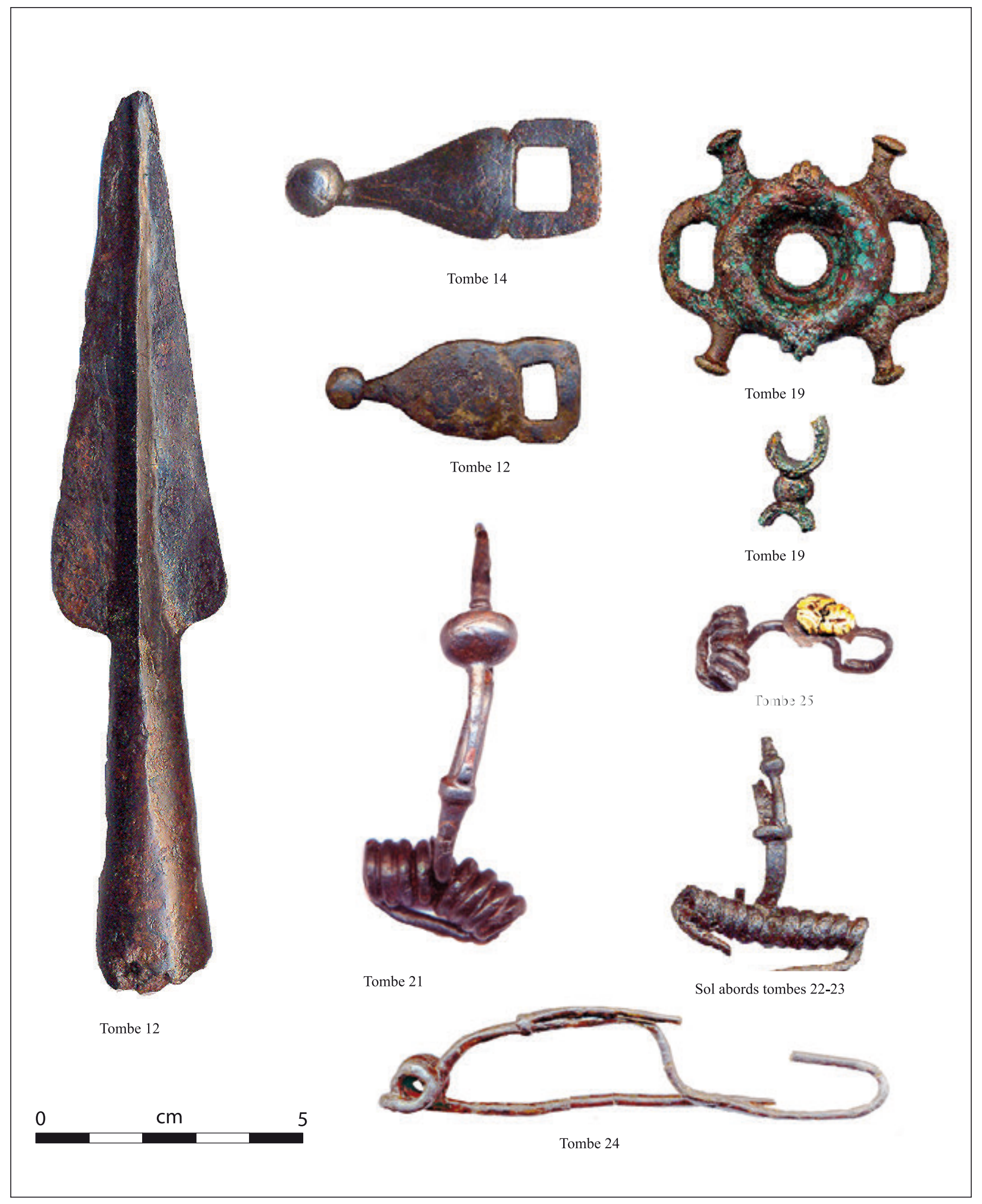

Fig. 115. Pointe de lance de la tombe T12 (fer); agrafes de ceinturon des tombes T12 et T14 (fer) ; éléments de ceinture de la tombe T19 (bronze) ; fibule de la tombe T25 (fer et corail) ; fibule de la tombe 24 (fer) ; fibule de la tombe T21 (fer) ; fibule du sol aux abords des tombes T22 et T23 (fer). 
système de suspension, plaques et bouterolles de fourreau, pointes de lance, umbos et orles de bouclier. Ces armes, qui portent des traces caractéristiques de mutilations, sont associées à des restes de têtes coupées d'adultes portant des perforations d'enclouage. Ce sont là des vestiges de trophées exposés puis démontés et rejetés au sol (Roure 2007 ; Girard, Roure 2009), mais ces dépouilles, même s'il s'agit de celles d'ennemis vaincus, reflètent, elles aussi, l'armement du guerrier de la région.

À l'évidence ici et là, l'épée, le bouclier et la lance, composent la panoplie standard de l'indigène « en arme » du Midi méditerranéen au $\mathrm{III}^{\mathrm{e}}$ s. av. J.-C.

Cet armement n'est pas, en lui même, original. Il est tout à fait conforme à celui qui a cours à la même époque en Gaule non méditerranéenne, par exemple en basse-Auvergne (Deberge, Orengo 2007, p. 352), en Bourgogne (Baray, Chaume, Millet 2007, p. 218), en Île de France (Marion 1987, p. 108 et 111-112), en Champagne septentrionale et dans l'Aisne (Demoule 1999, p. 188) ou dans la partie orientale du Bassin parisien (Baray 2003, p. 259, tab. XXXVII, étapes VA, VB et VIA de l'auteur).

De cet équipement tripartite de l'homme armé méridional, casque et cuirasse paraissent absents, ou presque. Deux seuls casques de cette époque sont actuellement connus en Languedoc. L'un, en fer, décoré d'appliques en bronze, provient de l'oppidum d'Ensérune, sans doute la nécropole, mais son contexte n'est pas connu (Schwaller 1994b, p. 90-91). L'autre a été découvert à Montlaurès, Aude, dans le secteur de la source lors du décapage de surface préalable à la fouille de l'habitat. C'est un exemplaire d'apparat, en bronze et en fer, richement orné de corail (de Chazelles, Feugère, Ferré 1994). Sa situation originelle reste inconnue; le lieu de la trouvaille semble permettre d'écarter un contexte funéraire courant mais pas, a priori, un lieu cultuel. Une telle fonction cultuelle du lieu de découverte est évoquée pour le précieux casque des Perrats à Agris (Charente), proche par le style de celui de Montlaurès et tout aussi exceptionnel, provenant d'une grotte (Ducongé, Gomez de Soto 2007, p. 480-486). Au demeurant, ces armes défensives existent bien alors dans la région mais figurées dans la pierre. Elles semblent dévolues à des combattants exceptionnels, personnages ou héros honorés, entre autres, par des statues qui les représentent et qui sont placées dans des sanctuaires (Arcelin, Rapin 2003, p. 207-209). Casques et cuirasses seraient ainsi des pièces réservées à une «élite ». Et cela ne va pas sans rappeler la situation signalée dans d'autres régions de Gaule, par exemple l'Aisne et la Marne, où cuirasses et casques ne prennent place que dans les tombes à char (Demoule 1999, p. 187).

Il s'agit d'un changement en ce domaine par rapport au premier Âge du Fer et en particulier la fin de cette période. En effet, les tombes à armes du $\mathrm{VI}^{\mathrm{e}} \mathrm{s}$. av. J.-C. contiennent souvent deux armes d'hast au lieu d'une et, parfois, des placages de cuirasse ou, exceptionnellement, le casque complètent la panoplie. Plusieurs tombes de Saint-Julien à Pézenas, Hérault (étude en cours), de las Peyros à Couffoulens, Aude (Solier, Rancoule, Passelac 1976 ; Passelac, Rancoule, Solier 1981) en sont des exemples ${ }^{54}$. Cependant, dans ces cimetières, mêlés aux autres défunts, ce ne sont que de très rares individus qui possèdent un tel équipement défensif.

54 L'objet de la sépulture de Corno-Lauzo à Pouzols-Minervois, Aude, publié comme un possible casque (Taffanel, Taffanel 1960, p.) s'est révélé en fait, après restauration, être un plat (aimable renseignement d'Odette Taffanel, avril 2011). 



\section{Conclusion}

$\mathrm{V}$

ingt-deux sépultures accueillent, en tout, vingt-trois défunts, une aire de crémation est utilisée pour brûler au minimum quatre individus, dont une femme enceinte ou en couches, peut-être ceux pour lesquels plusieurs de ces tombeaux constituent la dernière demeure, un second foyer crématoire existe sans doute aussi, et, dans ce quartier de la nécropole d'Ambrussum, figurent également deux dispositifs annexes plutôt énigmatiques, l'ensemble inscrit entre le second quart du $\mathrm{III}^{\mathrm{e}} \mathrm{s}$. et le tournant des $\mathrm{III}^{\mathrm{e}}$ et $\mathrm{II}^{\mathrm{e}} \mathrm{s}$. av. J.-C.

Le bilan de cette recherche peut paraitre modeste si l'on considère qu'il s'agit d'une seule portion d'un cimetière sans doute beaucoup plus vaste, celui de l'un des oppida majeurs du second Âge du Fer languedocien, et dont l'usage a dû débuter plus tôt, au $\mathrm{V}^{\mathrm{e}} \mathrm{s}$. av. J.-C. lorsque les hommes vinrent habiter sur la colline du Dévès.

Étant donné le nombre réduit de sépultures mises au jour ici, les conclusions ne peuvent être que provisoires et méritent confirmation. Néanmoins l'intérêt de cet échantillon est loin d'être limité puisque c'est la première fois qu'une nécropole de cette époque est découverte et partiellement explorée en Languedoc oriental et dans la région bas-Rhôdanienne, et, pour l'ensemble du sud de la France, la fouille d'une aire de crémation de cette importance est en quelque sorte une première, dépassant largement le cadre régional.

Cette aire de crémation B1 a permis de brûler successivement plusieurs personnes, indifféremment hommes et femmes adultes si l'on en croit la symbolique de certains objets personnels, adolescents et enfants. Après chaque crémation, le prélèvement des restes pour l'ensevelissement dans la tombe, tant au niveau des os des défunts eux-mêmes que du mobilier personnel brûlé avec le corps, a été partiel mais soigné. En effet, ces vestiges n'apparaissent jamais mélangés dans les diverses sépultures : à l'exception d'un adulte et d'un très jeune enfant, celles-ci livrent chaque fois les restes d'un seul individu, du moins si l'on en croit l'absence de doublon et d'incompatiblité parmi les pièces osseuses, et les objets présumés masculins ou féminins ne sont pas non plus mêlés dans les tombes. Tessons isolés de vases et os de faune, également isolés, et dont les répartitions sur le bûcher diffèrent de celles des os des défunts et de leurs objets personnels, paraissent témoigner d'autres gestes, peut-être des repas cérémoniels pris par les survivants aux abords de cette structure durant la crémation ou en fin de celle-ci, et dont l'issue serait marquée par le bris des vases et l'abandon symbolique des restes céramiques et animaux sur le bûcher, mais aussi dans la tombe elle-même.

Pour leur part, les sépultures fouillées à Ambrussum permettent d'expliquer, au moins partiellement, le manque de connaissances, qui existait avant cette découverte, concernant les pratiques funéraires de la première moitié du second Âge du Fer en Languedoc, plus spécialement dans la partie orientale de cette région, et en Provence. La mise en évidence de leurs vestiges suppose en effet des conditions bien particulières. De telles structures, fragiles, peuvent disparaître au fil du temps, au gré de l'érosion ou des travaux agricoles et autres actions humaines. Dépourvues de disposition architecturale remarquable et de dépôts d'objets complets, vases ou pièces métalliques, elles n'attirent guère l'attention en cas de mise au jour fortuite. Masquées par une épaisse couche alluviale, elles ne peuvent être décelées par une prospection de surface. Et n'oublions pas que leur découverte à Ambrussum est tout à fait inopinée, résultat de sondages profonds consécutifs aux recherches sur la station routière gallo-romaine postérieure qui les surmonte. Le récent dégagement de tombes souvent tout aussi ténues à Beaucaire en 2008 sur le site du Sizen-Collège Vigne confirme bien les causes de cette lacune : l'adoption alors, dans ce Midi méditerranéen situé à l'est du fleuve Hérault, de coutumes funéraires ne laissant que des traces modestes. Et de prime abord, le contraste est d'autant plus fort avec ce que l'on connaît, pour le moment, de la nécropole d'Ensérune qui, jusqu'ici constituait la référence pour le Midi de la France à cette époque. Cette recherche fournit donc un éclairage précis sur la gestion de la mort et des morts au $\mathrm{III}^{\mathrm{e}} \mathrm{s}$. av. J.-C. dans une communauté indigène 
du Languedoc oriental. Et les coutumes funéraires de ces habitants de l'oppidum d'Ambrussum marquent trois enseignements principaux.

En premier lieu il apparaît qu'une grande part de ces usages s'inscrit dans la tradition régionale. C'est d'abord l'accès au cimetière, qui est réglementé en fonction de l'âge au décès : les plus jeunes, ceux qui sont morts en phase périnatale ou durant leur première année d'existence, n'y sont pas admis ; seulement une partie des jeunes enfants de un à six ans, de l'ordre de la moitié d'entre eux, peut y accéder. Par ailleurs, si l'on en croit la symbolique des objets accompagnant les morts adultes, y sont accueillis en nombre équivalent les hommes et les femmes. Pour ces défunts bénéficiant de tombes «normales », l'incinération que l'on constate à Ambrussum est le mode de traitement du corps exclusif dans cette région depuis le $\mathrm{VI}^{\mathrm{e}} \mathrm{s}$. av. J.-C., soit depuis quelque trois siècles. La présence, parmi les tombes, d'un bûcher crématoire utilisé à plusieurs reprises est bien attestée depuis la fin de l'Âge du Bronze en Languedoc. Le mode de dépôt des os humains, directement dans le loculus, hors de tout contenant, est tout aussi traditionnel dans cette région. Cette formule n'est cependant pas exclusive en Languedoc, au cours des siècles antérieurs, mais côtoie un autre procédé majoritaire dans la plupart des nécropoles plus anciennes, mais ici non usité, l'emploi du vase ossuaire. Et il n'est pas jusqu'à la mise en place d'une part des restes osseux du défunt dans le dispositif de recouvrement des tombeaux qui ne soit également attesté plus anciennement dans le Midi de la France. Il en va de même de l'accompagnement du défunt. Pourvoir le mort de ses objets personnels plus ou moins complets, brûlés avec lui et fragmentés, va de pair, dans le Midi depuis le $\mathrm{VI}^{\mathrm{e}}$ s., avec le dépôt des restes humains dans le loculus hors de tout contenant. Mettre aussi dans la tombe un matériel différencié selon l'âge et le sexe est un usage qui plonge également ses racines dans le passé régional.

Certaines de ces pratiques dont témoigne Ambrussum peuvent n'avoir qu'une implantation locale, telle l'exclusivité du mode de dépôt des restes humains en pleine terre, sans vase-ossuaire. En effet, vers la même époque, à $25 \mathrm{~km}$ de là, à Nîmes, pour la tombe de la Roussillone, on utilise l'ossuaire, et, un peu plus loin, à Beaucaire, dans la nécropole du Sizen-collège Vigne, tombes avec ou sans ossuaire se côtoient. Autre particularisme local à Ambrussum, ces dépôts de petites portions de squelettes de porcs, de chèvres ou de moutons, incomplètement prélevées sur le bûcher, qui se distinguent fortement des volailles entières et des quartiers de moutons, de chèvres et de porcs non brûlés qui figurent à Ensérune.
Mais d'autres caractéristiques apparaissent comme des nouveautés en Languedoc oriental, ou du moins tranchent nettement par rapport à ce que l'on connaissait pour le premier Âge du Fer.

Cette portion de la nécropole d'Ambrussum marque d'abord un traitement solennel de la mort désormais ouvert à un plus grand nombre de défunts ayant dépassé la petite enfance qu'auparavant. Au premier Âge du Fer, les tumulus des Garrigues du Languedoc oriental, comme ceux des Grands Causses du sud du Massif central, de Provence et des Alpes méridionales, répartis en petits groupes ou disséminés sur de vastes espaces, n'accueillaient finalement qu'un nombre restreint de sujets. Ici à Ambrussum, on a affaire à une agglomération d'un nombre important de sépultures modestes et d'encombrement réduit sur un petit espace, à la différence des tumulus antérieurs. Et, pour une autre communauté du Languedoc oriental, les récentes fouilles de la nécropole de Beaucaire/Le Sizen-Collège Vigne fournissent une image semblable (Carme, Demangeot 2010, p. 69). À cet égard, la comparaison d'Ambrussum au $\mathrm{III}^{\mathrm{e}} \mathrm{s}$. av. J.-C. avec La Pailletrice à Pérols, près de Montpellier vers 500 av. J.-C., dans le même contexte de plaine littorale, est éloquente. Alors que dans la partie fouillée du complexe tumulaire de la Pailletrice quatre tombes sont groupées sur une surface de $4000 \mathrm{~m}^{2}$ (Daveau, Dedet 2010), à Ambrussum ce sont vingt-deux sépultures et vingt-trois défunts qui se répartissent sur une superficie environ dix fois moindre. Cette densité accrue va de pair avec une surface et une architecture fortement amoindries, puisqu'on passe d'enclos en périphérie des tertres de 13 à 17,8 m de diamètre à la Pailletrice, à des recouvrements n'excédant pas un diamètre de $3 \mathrm{~m}$ à Ambrussum.

Certes, cette concentration de tombes sur un espace limité et situé à proximité de l'agglomération des vivants est bien connue en Languedoc occidental depuis le Bronze final III, comme par exemple à Mailhac, mais, à l'est du fleuve Hérault, c'est une nouveauté au second Âge du Fer et la nécropole de Castelnau-le-Lez/Mermoz en usage aux $\mathrm{V}^{\mathrm{e}}-\mathrm{IV}^{\mathrm{e}} \mathrm{s}$. av. J.-C., à deux kilomètres de l'oppidum de Sextantio (Ott et al. 2010) annonce la situation d'Ambrussum.

Autre fait nouveau en ce milieu de l'Âge du Fer du Midi de la France, c'est le nombre important de tombes à arme : $35 \%$ des adultes de cette portion de la nécropole d'Ambrussum en sont pourvus. Comme adultes présumés masculins et féminins s'équilibrent ici, une telle fréquence de dépôts de ce type d'objets pourrait signifier que tous les hommes en âge de combattre emportent 
des armes dans leur tombe. Mais, de ce point de vue, le cas d'Ambrussum n'apparaît pas exceptionnel au second Âge du Fer et n'est pas isolé en Languedoc, la proportion d'armes livrées par la nécropole d'Ensérune en fait foi (voir supra chap. 7, § 9.).

Cet accroissement de la quantité des tombes à armement peut être rapproché de plusieurs autres faits régionaux qui se produisent la fin $\mathrm{du}^{\mathrm{IV}} \mathrm{IV}^{\mathrm{e}} \mathrm{s}$. et au $\mathrm{III}^{\mathrm{e}} \mathrm{s}$. av. J.-C.

C'est d'abord une période de construction de grands remparts monumentaux, non seulement sur l'oppidum d'Ambrussum même mais aussi sur de nombreux autres habitats du Languedoc oriental, comme par exemple ceux de Nages et de Roquecourbe.

C'est aussi celle de la découverte de restes d'armes dans les habitats languedociens et provençaux contemporains, éléments d'épées, de fourreaux et de leur suspension, de lances et de boucliers, semblables à ceux trouvés dans les tombes. Ces objets, très exceptionnels dans les habitats de la région jusqu'à la fin du $\mathrm{IV}^{\mathrm{e}} \mathrm{s}$. deviennent beaucoup moins rares au III ${ }^{\mathrm{e}} \mathrm{s}$. av. J.-C., et cela en dehors de tout contexte cultuel comme celui que montrent les dépôts de têtes humaines coupées du Cailar, dans le Gard (Girard, Roure 2009). Cette augmentation est notable, par exemple, dans l'habitat de l'île à Martigues (Rétif 2000, p. 178-181) ou encore dans celui de Lattes. Ainsi, sur ce dernier site, la présence de ces objets dans les maisons est multipliée par sept au $\mathrm{III}^{\mathrm{e}} \mathrm{s}$. av. J.-C. par rapport au siècle précédent : alors qu'on ne compte que 0,2 armes pour 1000 tessons de vases au $\mathrm{IV}^{\mathrm{e}} \mathrm{s}$. av. J.-C., cette proportion passe à 1,4 armes au siècle suivant (Paterno 2004, p. 355-357 et fig. 10).

C'est également le moment d'une déprise humaine importante dans tout l'arrière-pays languedocien, de la basse-Ardèche au Lauragais, indiquée par la désertion d'un grand nombre d'agglomérations. Ce phénomène est d'ailleurs bien marqué dans les environs proches d'Ambrussum, par exemple sur les habitats gardois de Villevieille et de Gailhan, en amont dans le bassin du Vidourle, ou à La Madeleine (Tornac) et à Vié-Cioutat (Mons) un peu plus loin dans celui du Gard.

Cet ensemble de faits paraît souligner une époque moins sûre qu'auparavant, peut-être troublée, et un besoin accru de protection. On n'en déduira pas pour autant des populations vivant sur le pied de guerre et ces tombes à arme ne sont sans doute pas celles de « guerriers » stricto sensu. L'accompagnement d'armes ne relève probablement pas d'un statut dominant, d'une «classe » affichant les instruments de son pouvoir. Il s'agit sans doute plutôt de marquer tout simplement dans les tombes la présence d'hommes capables de défendre, de leur vivant, le village et la communauté villageoise, ses terroirs, ses récoltes et ses troupeaux, lorsque les circonstances le nécessitent.

D'ailleurs, une certaine uniformité caractérise ces sépultures à arme ; peu de différences dans la quantité et la qualité des objets y sont sensibles. Rien n'évoque ici les individus pourvus de signes d'opulence particulière, les nombreux objets et instruments de «banquet » qui accompagnaient autrefois les dépôts d'armes de certaines tombes languedociennes et provençales, par exemple dans la région de Mailhac aux $\mathrm{VII}^{\mathrm{e}}$ et au $\mathrm{VI}^{\mathrm{e}} \mathrm{s}$. av. J.-C., avec les défunts de la tombe 68 du Grand Bassin I et de celle de Corno-Lauzo (Taffanel, Taffanel 1960 ; Taffanel, Taffanel 1962), ou dans les Garrigues montpelliéraines, avec le tumulus du Frouzet B1 au $\mathrm{VI}^{\mathrm{e}}$ s. et encore au siècle suivant, la tombe de Font de la Vie (Dedet 1995a ; Dedet 1995b).

Bien évidemment, la prolifération de tombes modestes et l'augmentation du nombre de défunts armés dépassent le cadre strict des usages funéraires puisqu'ils sont le reflet de modifications sans doute profondes dans la société, sur le plan social, économique et politique. Or le rôle de Marseille est prépondérant dans l'évolution des populations de la région, de leurs activités économiques, de la structuration et de la forme de leur habitat, bref de leur cadre de vie. Malgré cela, aucun des usages funéraires des Grecs des colonies de Marseille ou d'Agde, qui pour leur part restent marqués du sceau de l'hellénisme, n'a d'influence sur la gestion de la mort chez les Indigènes d'Ambrussum, et ce, dans cette région parcourue par la voie Héracléenne et particulièrement ouverte aux contacts avec les marchands méditerranéens (Dedet 2011). Au demeurant, une telle imperméabilité entre ces deux milieux culturels coexistant dans le Midi méditerranéen de la France au second Âge du Fer n'est pas le propre du seul domaine des tombes ; elle peut également être constatée dans la sphère religieuse non strictement mortuaire (Golosetti 2009).

Les rites funéraires massaliètes reflètent bien plutôt les coutumes grecques de l'époque, accueillant les morts périnatals au cimetière de la cité, bien souvent à l'intérieur d'un vase, inhumant les enfants, inhumant certains adultes, incinérant d'autres adultes, ne plaçant dans la tombe que très peu de matériel, souvent même rien du tout, et généralement simplement les objets souillés ayant servi à la toilette du mort, aux actions liées à la cérémonie des adieux, à des libations et à des offrandes de 
couronnes de fleurs (Moliner et al. 2003 ; Dedet 2011). Cette simplicité que manifestent les vestiges rejoint l'impression que donne Valère Maxime des obsèques marseillaises : «on amène les morts à leur sépulture en les transportant sur un chariot, sans lamentations ni plaintes. Le deuil ne dure que le jour des obsèques, avec un sacrifice groupant les gens de la maison, accompagné d'un banquet qui rassemble toutes les relations » (Valère Maxime, Faits et dits mémorables, II, 6-7) ${ }^{55}$.

De leur côté, les usages funéraires des indigènes d'Ambrussum sont traditionnels, et ne paraissent ni transformés ni seulement modifiés au contact des influences grecques. Cette imperméabilité entre les deux milieux culturels en ce domaine s'explique sans doute parce que l'on se situe au plus profond des préoccupations humaines, et elle doit sans doute refléter deux conceptions de la mort fondamentalement différentes.

Pour les massaliètes des $\mathrm{IV}^{\mathrm{e}}$, $\mathrm{III}^{\mathrm{e}}$ et $\mathrm{II}^{\mathrm{e}}$ s. av. J.-C., comme pour le commun des mortels de la Grèce d'alors, en dehors des cercles intellectuels ou philosophiques, la mort c'est d'abord l'arrêt des plaisirs de la vie, et un séjour vague au royaume des ombres, l'Hadès, sans repère ni espoir d'aucun accomplissement, une mort sans horizon.

Au contraire, pour les indigènes, la mort n'est pas une fin de l'existence, mais un au-delà où le défunt peut

55 Traduction R. Combès, Paris, les Belles Lettres (coll. CUF), 2003. entrer pour survivre sous différentes conditions et échapper en quelque sorte à elle. Elle lui ouvre la porte d'un monde autre où le double du défunt va survivre avec le double des objets qui ont symbolisé son existence terrestre. Dans le texte sur plomb déposé dans une sépulture de la nécropole de l'Hospitalet-du-Larzac en Aveyron, on trouve notamment mention en langue gauloise, $\mathrm{du}$ monde visible (vodercos), de la mort (nepos) et du monde invisible de l'outre-tombe (antumnos) (Vernhet 1995). Certes, ce document date du $\mathrm{I}^{\mathrm{er}}$ S. ap. J.-C., mais il fournit des termes et des notions religieuses indigènes, et issu d'un Larzac éloigné des centres urbains, il concerne un milieu autochtone, héritier direct du passé local. Non seulement les morts ont une autre vie dans cet au-delà, mais en plus les «nouveau-morts » peuvent leur transmettre des messages à ces morts plus anciens et à des divinités, moyennant le passage sur le bûcher d'objets matériels. Et d'ailleurs Diodore de Sicile, décrivant les mœurs des Gaulois de Gaule du Sud dans la première moitié du Irr $\mathrm{s}$. av. J.-C., ne laisse aucun doute à ce sujet : « au cours des funérailles, ils jettent dans le feu des lettres écrites à des parents déjà morts, comme si ces derniers pouvaient les lire » (Diodore de Sicile, Bibliothèque historique, $\mathrm{V}, 28,6)^{56}$. En fait, dans le monde indigène de la région nîmoise et du bas-Rhône, il faut attendre la fin du Irr s. av. J.-C. pour qu'apparaisse une transformation progressive du rituel concernant la mort des adultes attestant une intégration de pratiques en usage dans l'Empire romain.

56 Traduction J.-L. Brunaux 1996, p. 190. 


\section{Annexe 1}

\section{Analyse anthracologique de l'aire de crémation B1 de la nécropole d'Ambrussum}

\author{
Auteurs : Carine CENZON SALVAYRE ${ }^{57}$ \\ et Aline DURAND ${ }^{58}$
}

I mplanté sur la rive droite du Vidourle, à Villetelle près de Lunel, le site appartient à l'étage mésoméditerranéen, série du chêne vert. Cependant, le chêne pubescent occupe une place proche sur les versants nord. Classiquement, les forêts caducifoliées sont considérées comme caractéristiques d'un étage supraméditerranéen, qu'elles définissent en se développant au-dessus des forêts sclérophylles de type eu-méditerranéen (Ozenda 1975 ; Quezel 1976), le chêne vert étant limité vers le nord par une bande de végétation qui se mélange de chênes pubescent et de buis (BraunBlanquet 1936). Ces forêts caducifoliées se localisent de préférence sur les sols profonds des combes alors que les chênaies vertes préfèrent les sols secs et rocheux calcaires des collines de l'arrière-pays languedocien ${ }^{59}$.

Dans un premier temps, l' analyse anthracologique des charbons de bois vise à définir l'usage du bois dans le cadre précis de l'acte de crémation. La problématique se concentre sur plusieurs points capitaux : tenter de comprendre la pratique crématoire au travers de la reconnaissance de gestes; appréhender les milieux forestiers dans lesquels l'homme a pu s'approvisionner et, par ce biais, enfin, essayer de distinguer le matériel ligneux ayant servi à la combustion de celui pouvant être déposé sur le bûcher comme dépôt d'offrande.

De manière générale, les échantillons provenant de structures spécialisées type fours, telle la structure funéraire à étudier, ne permettent pas une interprétation paléo-écologique des taxons. En effet, la nature des unités stratigraphiques prélevées ne remplit pas

57 LAMM UMR 6572 et CCJ UMR 6573.

58 LAMM UMR 6572.

59 Le site d'Ambrussum, habitat et nécropole, a déjà fait l'objet de deux études anthracologiques par Lucie Chabal (dans Fiches et al. 1989 , p. 33-35 et 180-191). les conditions décrites notamment par L. Chabal pour autoriser une interprétation de ce type (Heinz 1990 ; Badal-Garcia 1990 ; Chabal 1997). Ces conditions sont les suivantes : les charbons de bois doivent provenir de bois de feu domestique, et les vidanges successives de foyers doivent s'être déroulées sur la longue durée, la stratigraphie devant témoigner de cette longue durée d'utilisation. Ainsi les charbons se présentent de manière dispersée et non concentrés. Au contraire, dans notre cas, les charbons sont concentrés et nous ne pouvons prouver non plus la durée de cette action, même si l'aire de crémation a servi à plusieurs reprises. Notre approche répond donc à une vision ethno-botanique.

Les déductions paléo-environnementales ne sont données qu'à titre d'hypothèse.

\section{Matériel et méthodes}

L'intégralité du sédiment du bûcher B1 a été prélevée par les fouilleurs et tamisée à l'eau à la maille $0,5 \mathrm{~mm}$. L'échantillonnage que nous avons effectué n'a pas porté sur la totalité des charbons recueillis, mais sur ceux de trois unités stratigraphiques du bûcher B1, fouillées en 2002 et 2003 : l'US 17132, couche de fonctionnement rouge, localisée dans une dépression centrale de la structure ; les US 17130 et 17164 correspondant à la couche noire de fonctionnement de cette structure. Il compte 779 charbons de bois.

Le sédiment et les charbons, ont été prélevés par unités stratigraphiques et par carrés de $20 \mathrm{~cm}$ de côté. Cette démarche est utilisée en anthropologie afin de replacer spatialement les restes osseux dans le bûcher. L'application de ce protocole à l'anthracologie a pour but de tenter de comprendre le déroulement de la crémation. V. Bel en a souligné la nécessité (Bel 1996). Cette méthode, largement éprouvée, a été appliquée ici pour les prélèvements anthracologiques du résidu des crémations.

En laboratoire, les 779 charbons de bois ont été observés au microscope à réflexion, selon les trois plans 


\begin{tabular}{|c|c|c|c|c|}
\hline \\
\hline \multicolumn{2}{|c|}{$\begin{array}{l}\text { Chronologie deuxième Age du fer } \\
\text { E chantillon }\end{array}$} & US 17132 & US 17164 & US 17130 \\
\hline \multicolumn{2}{|l|}{ Taxons } & & & \\
\hline Noms scientifiques & Noms vernaculaires & & & \\
\hline Acer campestre/monspessulanum & E rable champêtre & & 2 & \\
\hline Buxus sempervirens & Buis & & 1 & 1 \\
\hline Quercus f.c & Chêne caducifolié cf. pubescent & 111 & 171 & 161 \\
\hline Quercus coccifera/ilex & Chêne vert-kermès & 29 & 4 & 8 \\
\hline Quercus-castanea & Chêne-châtaignier & 15 & 24 & 34 \\
\hline Quercus. & Chênes & 38 & 37 & 42 \\
\hline Indéterminé & & 8 & 7 & 6 \\
\hline Indéterminable & & 25 & 20 & 19 \\
\hline Total & & 226 & 263 & 270 \\
\hline
\end{tabular}

Fig. 116. Tableau regroupant l'ensemble des identifications anthracologiques.

\begin{tabular}{|l|c|}
\hline & Nbre fragments \\
\hline 1: Peu de vitrification & \\
\hline 2: Vitrification sur les parois de cellules uniquement & 30 \\
\hline 3: Vitrification jusqu'à fusion des cellules & 130 \\
\hline 4: Vitrification avec fusion des cellules abondantes & 33 \\
\hline 5: Vitrification rendant la fusion des cellules quasi exclusive sur le plan d'observation & 5 \\
\hline
\end{tabular}

Fig. 117. Présence d'éléments vitrifiés sur les charbons de bois. Selon une échelle de vitrification établie par Christophe Vaschalde.

\begin{tabular}{|c|c|c|c|c|}
\hline & US 17132 & US 17164 & US 17130 & TOTAL \\
\hline Thylles & 41 & 64 & 35 & 140 soit $18,5 \%$ \\
\hline
\end{tabular}

Fig. 118. Occurrence des thylles dans le Chêne (Quercus FC).

anatomiques du bois obtenus par cassure à la main ou au moyen d'un scalpel. La détermination des taxons a été faite en s'aidant d'ouvrages spécialisés sur l'anatomie du bois (Schweingruber 1990 ; Jacquiot, Trenard, Dirol 1973) et de la collection de référence de bois actuels du Laboratoire d'Archéologie Médiévale Méditerranéenne d'Aix-en-Provence (UMR 6572). L'analyse a respecté la répartition des carrés de fouilles, mais aucune organisation spatiale des vestiges ligneux carbonisés n'a pu être reconnue. Nous en discuterons dans l'interprétation.

\section{Identification et remarques anatomiques}

Pour l'US 17132, deux taxons ont été identifiés, le chêne caducifolié méditerranéen (Quercus f.c.) et les chênes sempervirents, chêne vert et ou kermès (Quercus coccifera/ilex). Le châtaignier ne se différencie des chênes caducifoliés que par l'absence de rayon multisérié et la présence de rayons bisériés Castanea satival Quercus f.c. Aussi, sur les échantillons de petite taille, la diagnose n'a pu être menée au niveau spécifique. Pour l'heure, il n'est pas possible non plus de discriminer, à l'exception notable de Quercus suber, les chênes sempervirents à l'espèce en microscopie à réflexion classique. Ce n'est réalisable qu'à l'aide d'un analyseur d'images moyennant des mesures précises d'éléments vasculaires $\mathrm{du}$ bois qui sont extrêmement chronophages. Ainsi seulement le chêne vert peut être distingué du chêne kermès. Ce protocole, extrêmement long et fastidieux, ne peut actuellement être mis en œuvre qu' au Centre de Bioarchéologie et Écologie UMR 5059 de l'Institut de Botanique à Montpellier. Par conséquent, il est possible qu'une partie des chênes qualifiés de sempervirents soit des chênes kermès.

Les US 17130 et 17164 fournissent les mêmes résultats à ceci prés que deux autres taxons apparaissent, le buis (Buxus sempervirens) et l'érable (Acer cf.campestre). En ce qui concerne l'érable, la différenciation entre espèces est délicate. Mais sur la base de la taille des rayons ligneux, deux groupes sont néanmoins discriminés : un groupe à petits rayons, rassemblant Acer campestre, Acer opulifolium et Acer platanoïdes, et un groupe à gros rayons, supérieurs à 6-7 cellules de large, comprenant Acer monspessulanum et Acer 


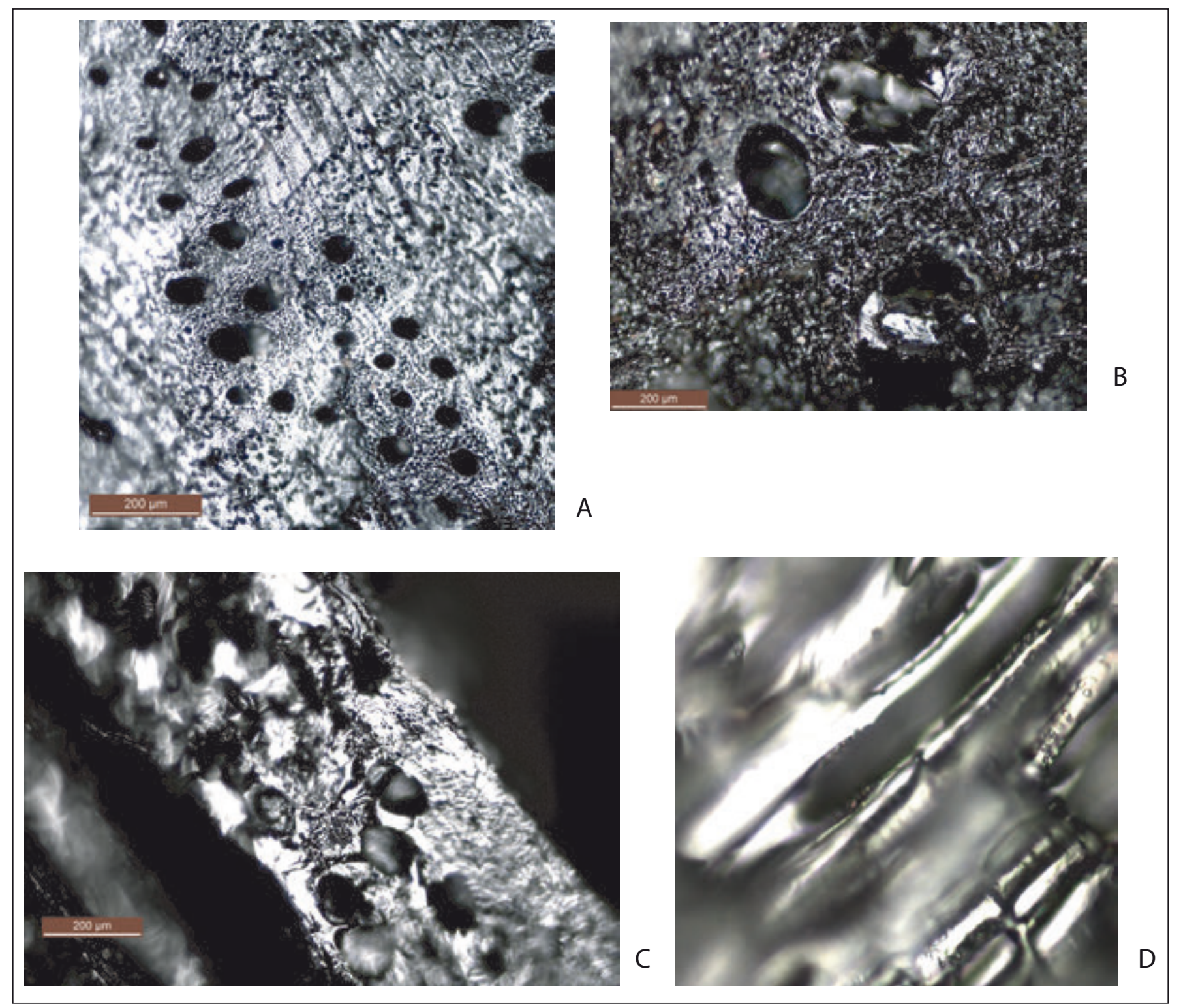

Fig. 119. A : Chêne vert- kermès (Quercus coccifera ilex), coupe transversale ;

B : Chêne à feuillage caduc (Quercus FC), coupe transversale, présence de thylles dans les vaisseaux ; C : Chêne à feuillage caduc (Quercus FC), coupe transversale, présence de vitrification (stade 3).

D : Coupe radiale, perforations scalariformes du buis (Buxus sempervirens) (clichés C.Cenzon-Salvayre - LAMM-UMR 6572).

pseudoplanatus. Sur les échantillons observés, la taille des rayons était inférieure à 6-7 cellules. Étant donné la situation biogéographique du site, il est probable que les charbons de bois d'érable soient donc à rapporter au seul érable champêtre.

Sans grande surprise dans le cadre d'un gisement de charbons concentrés, comme celui-ci, les variations de représentation des taxons dans les différentes unités stratigraphiques sont faibles. La proportion des taxons est nettement en faveur du chêne caducifolié (77\%) (fig. 116).

\section{Identification des charbons toutes US confondues}

La majorité des charbons de bois présente de nombreuses déformations anatomiques. Ces dégradations semblent, a priori, provenir de conditions de combustion avancées. En effet, ces charbons présentent des traces de vitrification qui correspondent à une fusion variable des éléments anatomiques du bois (fig. 117). À l'heure actuelle, les anthracologues ne savent pas interpréter correctement ce phénomène multifactoriel dans lequel les conditions de combustion jouent sans doute un rôle important (Marguerie, Hunot 2007). Cependant, depuis 
trois ans, Christophe Vaschalde (doctorant-LAMM) inclut, dans ses études anthracologiques, une quantification systématique de la vitrification. Pour ce faire, il a mis en place une échelle de quantification (encore inédite), permettant d'évaluer l'intensité de ce phénomène, à laquelle nous faisons désormais systématiquement appel dans nos analyses. Lors de la présente analyse anthracologique, aucune morphologie remarquable du bois, type bûches ou brindilles, n'a pu être observée.

\section{La présence de thylles}

Les thylles sont des excroissances cellulaires produites par les cellules vivantes du parenchyme bordant les vaisseaux (Biologie et Multimédia- Université Pierre et Marie Curie). L'arbre stocke, en un sens, ces déchets dans les vaisseaux larges du duramen, et, de fait, ceux-ci ne sont plus fonctionnels (Zimmermann 1979). Leur formation peut être naturelle chez certaines essences. Dans d'autres cas, elle répond à certaines blessures mécaniques, comme celles qui sont causées par l'élagage (Sun, Rost, Matthews 2006), ou encore à des attaques d'agents pathogènes comme les microorganismes, pour en limiter l'extension. Dans ce dernier cas, le processus est réversible et les thylles peuvent entièrement se résorber. Chez les sujets âgés, leur présence dans le bois parfait, ou duramen, par opposition à l'aubier, ou bois juvénile, est quasi systématique et le bois perd alors son rôle fonctionnel. Une tendance générale signale que les thylles apparaissent dans les bois à zone poreuse, mais cela peut varier selon les espèces et les conditions du milieu (Saitoh, Ohtani, Fukazawa 1993). Dans le cas d'une observation non pathologique, les thylles s'observent seulement dans le bois de cœur (Kuroda 2011, p.427).

Nous avons quantifié cette présence au sein des charbons de bois analysés. Les thylles n'ont été observées que sur le bois de Quercus F.C., ce qui signalerait uniquement la présence en nombre de bois de cœur (duramen) (fig. 118).

\section{Critères d'identification anatomique des charbons de bois et écologique des taxons identifiés (fig. 119)}

Le chêne à feuillage caduc, Quercus F.C.(Fagacées) : Bois hétéroxylé à zone poreuse. Cernes annuels distincts, 1 à 2 rangs de pores du bois initial de 200 à $350 \mu$, répartition dendritique et flammée des pores du bois final. Vaisseaux isolés et nombreux. Rayons ligneux homogènes en majorité unisériés et bas, plurisériés larges et hauts de plusieurs centimètres. Perforations simples et grandes ponctuations intervasculaires. Espèce chef de file de l'étage supraméditerranéen qui préfère les sols frais et humides.

Le chêne vert ou kermès, Quercus cocciferal ilex (Fagacées) :

Bois hétéroxylé à pores diffus ou semi-poreux. Cernes annuels peu distincts, répartition radiale des pores, isolés et peu nombreux. Vaisseaux à parois épaisses de 50 à $100 \mu \mathrm{m}$ de diamètre dans le bois initial diminuant progressivement de 30 à $80 \mu \mathrm{m}$ dans le bois final ; perforations simples, grandes ponctuations inter- et radiovasculaires. Rayons ligneux homogènes, en majorité unisériés, de 4-12 cellules de hauteur, et très nombreux ; rayons ligneux plurisériés larges d'environs $300-500 \mu \mathrm{m}$ et hauts de 3 à $10 \mathrm{~mm}$. Parenchyme axial très abondant. Les chênes méditerranéens supportent des sols secs et trouvent leur plein développement dans l'étage mésoméditerranéen de végétation.

\section{Le buis, Buxus sempervirens (Buxacées) :}

Bois à pores diffus, de petites tailles $(<40 \mu)$ et majoritairement solitaires. Prédominance de rayons bi- et tri-sériés hétérogènes de type I. Présence de perforations scalariformes de 5 à 10 barreaux épais. Tissu ligneux uniquement formé de fibres trachéides. Espèce thermophile de demi-ombre, il pousse sur sols très secs à frais, il se trouve associé à la chênaie pubescente et préférera les parties nord (chênaie-buxaie des phytosociologues). Son optimum est reconnu à l'étage supra-méditerranéen, résistant au feu, il bénéficie de la dégradation de la couverture forestière.

L'érable champêtre, Acer, cf. campestre/monspessulanum (Acéracées) :

Bois homogène à pores diffus solitaires ou accolés radialement par 2-6 ou $6(50-100 \mu)$. Rayons ligneux homogènes 2 à 8 sériés suivant les espèces. Présence d'épaississements spiralés fins et réguliers. Perforations simples et ponctuations intervasculaires circulaires à elliptiques souvent disposées en quinconce. Tissu ligneux majoritairement formé de fibres libriformes. Espèce héliophile ou de demi-ombre, à l'étage supraméditerranéen, il est associé au Quercus pubescens ${ }^{60}$.

\section{Résultats et interprétation}

La crémation entraine des gestes techniques qui répondent à une construction bien précise permettant la disparition des chairs, comme le montrent les différentes

60 Données écologiques : Rameau, Mansion, Dumé 2008. 
études ethnoarchéologiques réalisées en Inde notamment par Gilles Grévin (Grévin 2009). De plus, les observations de terrain témoignent, en majorité, que le corps du défunt est placé au dessus du bois afin d'exploiter au maximum l'air ascendant (Blaizot 2005). C'est cet ensemble de gestes que les études anthracologiques essayent de retrouver au travers de la répartition spatiale des essences.

Ici, c'est un prélèvement partiel des os brulés et/ ou des résidus de crémation qui a été effectué, pour un dépôt en d'autres lieux (dépôts secondaires). La fonction même d'une telle structure pose quelques questions d'ordre taphonomique. En effet, l'aire a servi à plusieurs crémations, consécutives ou non, et peut être considérée comme une aire de travail. Cela implique certainement un nettoyage de l'aire du bûcher. Ce nettoyage a déjà été observé sur ce type de structure à Ensérune pour la même période (Jallet et al. 1998).

Dès lors, prélever les charbons de bois dans ce contexte particulier implique une réflexion sur la signification des échantillons. En effet, les assemblages de charbons peuvent subir des perturbations, celles-ci peuvent être perçues pro parte au travers de l'étude des processus taphonomiques. Lucie Chabal et Isabelle Théry, dans un article récent, définissent ce processus et l'appliquent aux assemblages de charbons, notamment en mettant en avant la part de choix culturel, "Archaeology has a wider definition of taphonomy, including not only the natural processes which modify the thanatocoenose, but also all the cultural choices and gestures which have an impact on the plant, animal or human materials, from their natural environment to their fossilization » (ThéryParisot et al. 2010, p. 142).

Ce facteur humain intervient dans la configuration même de l'aire de crémation qui suppose un nettoyage. L'étude des places de charbonnière, notamment celle menée par L. Fabre, ressemble en terme d'approche taphonomique à la situation produite par la réutilisation et le nettoyage d'une aire de crémation. Dans sa thèse, L. Fabre (1996, p. 84) présente les charbonnières comme des structures qui reçoivent un nettoyage de la faulde avant réemploi ; la fonction même d'un bûcher amené à être réutilisé entraîne de nouvelles perturbations, et, malheureusement, l'acte de nettoyage détruit toute tentative de reconstruction du bûcher funéraire tel qu'il pouvait être lors de la dernière crémation. De plus, ces aires de crémation subissent les aléas du vent ou de la pluie qui contribuent également à perturber la répartition spatiale des charbons. Et comme l'a montré l'archéologie expérimentale, après la crémation, les restes du bûcher sont très pauvres (Lambot, Friboulet, Méniel 1994 ; Pautreau 1994). Ces structures sont en effet différentes des bûchers individuels qui apparaissent en masse au Haut-Empire dans le Sud de la France (fosse-bûcher ou tombe-bûcher), et qui supposent un seul acte de crémation, scellé par la suite. Pour la majorité d'entre-elles, les restes de crémation sont souvent bien conservés et permettent d'approcher les modalités de crémation. (Blaizot et al. 2009, p. 93). Ces perturbations entrainent donc un biais dans une étude de la répartition spatiale des différentes essences utilisées dans la crémation. Les résultats de l'analyse anthracologique confirment cette hypothèse : en effet les taxons, très peu nombreux, sont indifféremment répartis.

\section{L'utilisation majoritaire d'une essence : Quercus f.c.}

Les résultats de l'anthraco-analyse révèlent la présence majoritaire du taxon Quercus F.C. Le chêne semble donc avoir été choisi principalement pour la combustion des corps. Ce taxon se retrouve fréquemment dans les études anthracologiques du sud de la France. À notre connaissance, pour la période protohistorique et dans le sud de la France, deux études anthracologiques funéraires seulement sont publiées :

- Sur ce même site d'Ambrussum, L. Chabal a étudié près d'un millier de fragments provenant des Tombes 3 , $4,6,7,8$ et de la structure ST9. De cette étude ressort une dominance de chênes méditerranéens (Chênes cf. pubescent, chênes cf. vert et chêne vert ou chêne kermès) et 8 autres taxons. Cet excellent combustible a fait l'objet d'un ramassage pour cette pratique (Fiches et al. 1989) ;

- Sur les combustibles de cinq tombes à incinération du deuxième Age du Fer à Ensérune dont une structure qualifiée d'ustrinum, le chêne à feuillage caduc et le chêne vert et/ou kermès représentent respectivement $95,4 \%$ et $99,1 \%$ des fréquences dans chaque tombe. L'auteur explique : «Des raisons sans rapport avec leurs propriétés combustibles ont ainsi pu placer ces espèces en tête des choix possibles : ainsi, des contraintes d'approvisionnement, par exemple liées à leur abondance naturelle, à une facilité d'exploitation »(Chabal 1995).

Lors du colloque d'Antibes ${ }^{61}$, une étude récente, menée par Carmen Mensua Calzado dans la péninsule ibérique, présente une aire de crémation proche de celle d'Ambrussum en termes de chronologie

61 Des hommes et des plantes: Exploitation du milieu et gestion des ressources végétales de la Préhistoire à nos jours, $\mathrm{XXX}^{\mathrm{e}}$ rencontres internationales d'archéologie et d'histoire d'Antibes, palais des congrès d'Antibes - Juan-les-Pins, 22-24 octobre 2009. 
et de morphologie. Les résultats révèlent, comme à Ambrussum, que l'essence Quercus F.C. est majoritaire.

Dans les incinérations du Sud de la France, les chênes méditerranéens dominent donc largement pour l'utilisation de combustible en contexte funéraire, comme à Ensérune (Chabal 1995) ou pour la période antique à Soumaltre (Fabre, Pernaud, Thiébault 2003). Une des explications fréquemment retenue par les auteurs est la prédominance de l'approvisionnement dans la végétation locale. L'homme interagit avec son milieu et s'adapte à celui-ci. Allant très largement dans ce sens, il faut encore ajouter à ce corpus, les résultats de l'anthraco-analyse menée sur plusieurs structures à crémation du Haut-Empire sur le site de Richeaume XIII (Puyloubier, Bouches-du-Rhône), où la majorité du combustible est représentée par le pin d'Alep, bûches en place y compris, tandis que celui-ci est largement dominant dans les diagrammes anthracologiques de la villa voisine (Mocci, Granier, Dumas 2009). Pour les besoins liés à la construction ou à la combustion, les essences semblent donc être choisies en fonction de leur abondance dans le milieu environnant, mais aussi en raison de leur morphologie (fabrication de bûches, de bois de construction).

\section{Combustible ou objets?}

La fonction de deux autres espèces présentes, l'Érable champêtre (Acer sp, cf. campestre) et le Buis (Buxus sempervirens) pose question : s'agit-il de combustible ou de dépôts d'objets manufacturés ? Dans une étude récente que nous avons menée sur les crémations en contexte gallo-romain de Richeaume XIII (Mocci et al., 2009), un objet en bois manufacturé, dont la fonction reste inconnue, a été façonné dans de l'érable (Acer sp.). Le bois d'Érable est connu dans l'Antiquité pour l'élégance de son ouvrage : "Acer eiusdem fere amplitudinis, operum elegantia ac subtilitate citro secundum » (Pline l'Ancien, Hist. Nat., 16, 2).

De même, les exemples de petits objets façonnés à partir du buis sont nombreux notamment pour la période gallo-romaine. A Lattes, un peigne à double rangée de dents a été retrouvé, gorgé d'eau, dans un puits. Le buis, bois dense, est «apprécié pour la finesse de son grain » (Chabal, Feugère 2005). Pour la période protohistorique, L. Chabal fait l'hypothèse que le buis retrouvé dans les tombes d'Ensérune aurait pu être utilisé comme bois d'œuvre (Chabal 1995). Cependant, ces propositions ne peuvent être définitives. En effet, le buis est commun dans l'aire du Chêne pubescent et celui-ci aurait pu être utilisé comme simple combustible au même titre que l'érable (Braun-Blanquet 1936).

\section{Choix du chêne et éléments de paléo-écologie}

Comme précisé ci-dessus, les structures spécialisées type fours, et ici funéraire, ne permettent pas une interprétation paléo-écologique des taxons. Néanmoins les quelques essences reconnues sont indicatrices du milieu végétal exploité et celui-ci, dans le cas qui nous occupe, semble local. En effet, les différentes études de bûchers funéraires pour la Protohistoire comme pour l'Antiquité révèlent que le combustible utilisé pour la crémation est récolté localement. L'homme semble plutôt s'adapter à son environnement et rechercher des bois à usage funéraire en fonction de critères de combustibilité et de morphologie des essences (Chabal 1995; Fabre, Pernaud, Thiébault 2003 ; Mocci, Granier, Dumas 2009).

Revenons à l'étude de L. Chabal sur l'habitat d'Ambrussum : «il ressort nettement de l'ensemble du diagramme une évolution de la chênaie, avec raréfaction relative du Chêne cf. C. pubescent au profit du Chêne cf. C. vert» (dans Fiches et al. 1989, p. 184). Cette étude ne bénéficiait pas, alors, de gisements anthracologiques pour les Âges du Bronze et du Fer, et L. Chabal s'interrogeait sur une possible régénération de la chênaie aux alentours d'Ambrussum. Certes, comme nous l'avons précisé plus haut, notre étude ne peut entrer dans le cadre statistique d'une étude paléoécologique. Parler d'une régénération de la forêt conduirait à sur-interpréter les résultats. Cependant on ne peut faire abstraction de ces données et il faut les comparer aux diagrammes obtenus en 1989, où la situation de la chênaie d'Yeuse était inversée, le chêne vert représentant en moyenne 70 à $80 \%$ des fragments de charbons de bois étudiés que ce soit pour la période néolithique ou pour la période romaine. Tout en ne réduisant pas les dynamiques végétales à l'augmentation ou la diminution d'une essence dans une couche de structure archéologique, nous pouvons toutefois admettre que l'utilisation majoritaire du chêne à feuillage caduc à des fins crématoires témoigne de sa présence relative dans la végétation locale et que celuici ne faisait pas l'objet d'attention et/ou d'économie. La prédominance de la chênaie d'Yeuse se manifeste plus tard dans les couches archéologiques d'époque romaine analysées par L. Chabal : à cette époque l'Yeuse est majoritaire, ce qui reflète l'évolution d'ensemble de la végétation vers des formations plus sclérophiles et xérophiles. Il est possible que les deux chênes aient eu une répartition un peu hétérogène sur les reliefs environnant le site, et que des espaces différents aient été exploités pour la crémation et pour le combustible domestique, reflétant tour à tour plutôt une espèce ou l'autre de chêne. Nous n'en connaissons pas la raison sociale, mais il nous semble possible d'écarter une explication liée à 
des préférences et aux propriétés combustibles des deux chênes. En effet, les comportements au feu en sont d'une part extrêmement proches, et d'autre part beaucoup plus influencés par le calibre ou la refente des bûches (et leur degré d'humidité) que par la nature de l'espèce. C'est là un résultat bien démontré en anthracologie (Chabal 1997, Théry-Parisot 2001, Théry-Parisot et al. 2010, p. 144). Mais en l'absence de résultats anthracologiques concernant les calibres des bois brûlés lors des crémations et de données objectives susceptibles de révéler une quelconque préférence symbolique ou religieuse, il n'est pas possible d'aller plus avant dans l'interprétation des données obtenues pour argumenter sur les raisons du choix éventuel d'une des deux espèces de chênes comme combustible funéraire et donc sur la collecte préférentielle de chêne caducifolié méditerranéen, majoritairement présent dans les contextes analysés.

Il convient de souligner aussi la quasi-absence d'espèces de ripisylve, mis à part l'érable champêtre dont ce n'est toutefois pas la situation optimale. En effet, la nécropole se situe à proximité immédiate du Vidourle où peuvent croître des espèces hygrophiles à mésophiles ; ces espèces sont également peu présentes dans les diagrammes anthracologiques de l'époque romaine (Chabal dans Fiches et al. 1989, p. 187). Cette remarque plaide également en faveur de l'hypothèse d'un choix spécifique dirigé vers une certaine formation boisée. Dans une analyse proposée avec le recul de l'étude de nombreux autres sites languedociens, L. Chabal pense que la couverture forestière des basses vallées fluviales riche en frêne et orme (qui sont encore actuellement les espèces potentiellement dominantes de la basse plaine), s'est formée entre la fin de l'Âge du Bronze et l'Âge du Fer, à la faveur de l'alluvionnement naturel lié à la fin de la remontée marine (Chabal 1997). Il est donc normal au Néolithique Ferrières de ne pas percevoir la forêt alluviale, dans un contexte fluvial plus encaissé : la chênaie s'étend alors beaucoup plus près du fleuve. Durant l'Âge du Fer et à la période romaine, cette forêt (qu'aucun prélèvement n'a permis de refléter pour ce site) aurait été défrichée puisqu'elle occupait les terres les plus fertiles. Elle ne subsistait alors plus qu'en ripisilve. Actuellement, le frêne connaît une reconquête dans les friches, alors que les populations d'orme, malades, ne subsistent guère que sous forme de haies (L. Chabal, communication orale).

\section{Conclusion}

Les données obtenues sur le bûcher B1 d'Ambrussum révèlent l'existence d'un mode d'approvisionnement choisi en conséquence d'un environnement donné. La fonction même de ce type de structure, servant à plusieurs reprises, engendre une représentativité statistique peu fiable. La présence majoritaire du chêne $c f$. pubescent ne reflète certainement pas l'intégralité du combustible utilisé. L'étude des aires de crémations ayant servi à plusieurs reprises se révèle peu porteuse d'informations en termes de reconnaissance des gestes et des pratiques crématoires, contrairement à celle des bûchers à usages uniques. Cependant les problèmes taphonomiques soulevés ont permis d'interroger ce matériel de manière cohérente, et au-delà de sa fonction dans la pratique funéraire. La comparaison avec d'autres données obtenues sur le site d'Ambrussum par L. Chabal, a conduit à compléter les résultats acquis et à proposer quelques jalons sur la végétation locale et, dans une moindre mesure, sur son évolution. 



\section{Annexe 2}

\section{Les restes animaux dans les pratiques funéraires à Ambrussum}

\section{Auteur : Armelle GARDEISEN ${ }^{62}$}

\section{Analyse des assemblages fauniques issus de la nécropole, fouilles 1999-2003}

$\mathrm{L}$ 'étude archéozoologique de la nécropole protohistorique d'Ambrussum porte sur les restes provenant des sols recouvrant l'ensemble de la surface ayant livré seize tombes (secteur Est et secteur Ouest), de ces tombes (différencié en plusieurs contextes tels que loculus, dispositifs de recouvrement, zones d'épandage), et de l'ustrinum B1 (ou aire de crémation B1) subdivisé en deux niveaux fonctionnels (un socle ou plateforme d'aménagement et une couche de fonctionnement).

Les restes fauniques sont comptabilisés en nombre de restes déterminés (NRD) ou indéterminés (indét.). Dans certains cas, un élément cassé est constitué de plusieurs fragments appariés entre eux : c'est alors le nombre d'éléments, ou nombre initial de restes qui est comptabilisé en NRD, et le nombre de fragments (NF) constituant cet élément est simplement signalé. Lorsque l'os a été brûlé, on a relevé la couleur blanche, grise, noire ou bleue de sa surface. Parfois, seul l'environnement de la combustion, et par conséquent l'action d'une forte chaleur mais sans contact direct avec les flammes, est observé. Les décomptes des restes indéterminés précisent à quelles catégories d'esquilles ils appartiennent : les microesquilles signalent des esquilles de moins de $10 \mathrm{~mm}$. Leur état de carbonisation est également noté.

\subsection{Le sol de la nécropole}

La nécropole a été fouillée sur la surface correspondant approximativement à la zone 1 du quartier bas d'Ambrussum. Cette zone étant traversée par un chenal fluviatile, deux secteurs, Est et Ouest, ont été distingués

62 UMR 5140, CNRS et Université Paul Valéry, Montpellier 3. de manière artificielle, de part et d'autre de ce chenal. Il n'y a pas de lien avéré entre le sol de la nécropole, dans lequel ont été creusés les loculus, et les tombes ellesmêmes du point des vue des assemblages fauniques. Le matériel osseux y est extrêmement fragmenté et éparpillé : il est constitué d'une cinquantaine de fragments provenant d'espèces domestiques (fig. 120). Si une partie de la fragmentation observée s'est produite in situ, il est néanmoins probable que les assemblages fauniques issus de cette sédimentation soient en position secondaire (épandage au-dessus de la nécropole de sédiments exogènes ayant introduit quelques fragments osseux). Il n'y a dans ce lot aucun reste faunique brûlé, à l'inverse de ceux collectés dans les tombes ou leurs recouvrements. Enfin, en l'absence d'ossements découpés, il n'y a pas lieu de soulever la question d'éventuelles pratiques alimentaires en relation avec la mise en place des sépultures. En conclusion, le sol de la nécropole ne semble avoir aucun lien direct avec les pratiques funéraires.

\subsection{Assemblages fauniques issus des tombes}

\subsubsection{Observations}

La liste des restes fauniques par sépulture a été fournie dans l'étude de chaque sépulture (supra chap. 2). Les restes issus des loculus ont été différenciés et inventoriés indépendamment de ceux qui proviennent des superstructures recouvrant les tombes.

L'inventaire distingue les restes déterminés des restes indéterminés tout en faisant la part entre les différents degrés de combustion observés et la longueur des esquilles, classées en esquilles ou en microesquilles. Les déterminations zoologiques comprennent deux classes supplémentaires pour les animaux de petite taille (caprinés, suidés, canidés) ou de grande taille (équidés, bovidés), pour lesquels il n'a pas été possible de désigner une espèce.

Un tableau récapitulatif rassemble les dénombrements par tombe, en fonction de la nature des contextes 
(fig. 120). Dans certains cas, il a été possible de faire des remontages, des collages, ou des appariements. Ainsi, en fonction de la répartition des restes, de leur état de combustion, de leurs analogies ostéologiques, il a été possible de repérer ce qui était probablement, à l'origine, des dépôts spécifiques (selon la définition donnée par l'auteur dans Gardeisen 2002). Malheureusement, dans la plupart des cas, la dispersion des fragments osseux et leur fragilité liée à la carbonisation, doublées d'un processus de mise en place variable, font que la plupart des restes ont été retrouvés à l'état isolé et sont très fragmentaires. La conséquence directe de tels phénomènes se traduit par un faible taux de détermination, seulement $15,7 \%$ des restes.

Les restes fauniques sont de manière générale épars, fragmentés, et souvent altérés. On constate que le spectre des espèces est large, comparativement au nombre de restes, ceci en relation avec des phénomènes de pollutions probables ${ }^{63}$ cumulés aux processus de rejet ou de dépôt en plusieurs étapes (fig. 120). De plus, seules des espèces domestiques ont été identifiées : le choix des animaux se serait porté sur des individus directement accessibles et disponibles, puisqu'il s'agit des espèces régulièrement attestées dans tous les sites protohistoriques de la région et même au-delà.

Lorsque les microesquilles sont observées, elles constituent l'essentiel des restes indéterminés. Les processus d'altération dus aux divers facteurs anthropiques, funéraires ou climatiques, font que des éléments préalablement fragilisés par le feu ont d'autant plus réagi aux agressions post-dépositionnelles. Les assemblages perdent alors une grande part de leur potentiel d'interprétation au niveau comportemental puisqu'il est avéré qu'ils ont été fortement modifiés.

Dans bien des cas, les vestiges fauniques évoquent un mélange d'assemblages d'origines distinctes, aussi bien dans le loculus que dans l'organisation de la superstructure. Toutefois, des dépôts dits spécifiques (Gardeisen 2002), constitués d'une portion squelettique particulière, ont été identifiés dans six tombes (fig. 121). A l'exception d'une extrémité distale de membre de capriné (tombe T10), tous ont été carbonisés à blanc. Il n'est guère surprenant de constater que ces portions proviennent de porc ou de capriné, dont les proportions sont largement majoritaires à l'échelle de la nécropole, surtout si on cumule leur comptage avec celui des animaux

63 Sont concernés ici les restes de malacofaune, de microfaune, de lagomorphes, et peut-être aussi ceux d'oiseaux ou de chiens. de petite taille : on obtiendrait alors 88 restes soit $69 \%$ de l'assemblage total de restes déterminés.

La présence d'un ossement d'équidé provenant du loculus de la tombe T21 est notable : il s'agit d'un métacarpien droit reconstitué à partir de 24 fragments osseux. L'extrémité proximale est en partie conservée ${ }^{64}$, avec des portions de la diaphyse et un fragment de l'articulation distale. L'os est brûlé de façon irrégulière, certaines zones étant carbonisées alors que d'autres ne montrent que des effets de la chaleur. Cet os soulève la question de la méthode de prélèvement sur le bûcher : il semblerait qu'il ait été déposé complet, puis brûlé et en partie cassé sur le feu, à la suite de quoi seuls quelques éléments ont été transférés, intentionnellement ou non, dans le loculus. Il paraît peu probable que l'os ait été placé complet dans la tombe : les conditions taphonomiques n'expliqueraient pas la quasi absence de la diaphyse qui, par nature, est une partie extrêmement résistante chez cette espèce. C'est donc bien la méthode de prélèvement sur le bûcher qui est en cause ici : une pratique soignée, mais non exhaustive. Comme dans le cas des restes d'équidés retrouvés dans les structures des tombes $\mathrm{T} 12$ et T14, on remarquera ici que le défunt, était accompagné d'armes, donc sans doute un homme, ce qui constitue sans doute un lien indéniable entre le statut du défunt et les offrandes ou le mobilier l'accompagnant.

Le choix de la portion anatomique (s'il y en a un), sans être systématique, se porte préférentiellement sur la tête, l'extrémité d'un membre, et dans un cas seulement, d'un gril costal. Ce dernier cas désigne une portion consommable, à l'inverse des têtes et des extrémités de pattes dont la valeur alimentaire est habituellement considérée de moindre intérêt. Les allusions au repas funéraire ne manquent pas dans la littérature protohistorique, et, ici encore, quelques indices nous amènent à soulever la question de la destination des portions squelettiques absentes, et par conséquent potentiellement consommées par les vivants (?) ${ }^{65}$. On citera l'exemple du dépôt d'un crâne de porcelet d'environ 3 mois dans la tombe T12, animal dont on peut imaginer la consommation à l'exclusion de la tête. Ce crâne a été brûlé, et selon l'intensité subie par les divers éléments osseux qui se sont disloqués, on observe des traces de feu allant de la couleur noire à la couleur blanche. Le lot est constitué d'un total de 66 restes crâniens parmi lesquels ceux issus du neurocrâne $(\mathrm{NF}=4)$, des deux

64 Mesures du métacarpien : DT proximal $=44,5 \mathrm{~mm}$, et DAP proximal $=29,8 \mathrm{~mm}$.

65 Hypothèse qui rejoint les attestations de repas funéraires célébrés à l'occasion des funérailles. 
mandibules $(\mathrm{NF}=9)$, de dents lactéales isolées $(\mathrm{NF}=31)$ ainsi que de microesquilles osseuses présentant le même stade de carbonisation. Les os crâniens montrent ici une vulnérabilité particulière à l'action du feu et à celle de la dispersion des restes (perte probable de ces éléments au moment du prélèvement de la tête calcinée sur le bûcher). Ce crâne de porcelet était accompagné du gril costal d'un jeune capriné juvénile, également carbonisé. Le gril est représenté par 27 fragments de côtes carbonisées à blanc provenant d'une même série de cinq côtes latéralisées à droite. Il s'agit, avec cette tombe T12, de la seule attestation de deux dépôts associés dont divers fragments ont également été retrouvés dans la structure de recouvrement commune à cette tombe et à sa voisine, la tombe $\mathrm{T} 14^{66}$.

Ces restes étaient mélangés à 391 fragments d'os brûlés à des degrés divers parmi lesquels on a également retrouvé des fragments du crâne de porcelet ainsi que des esquilles des côtes d'agneau (ou de chevreau). Il est ainsi possible de proposer l'hypothèse de deux dépôts différenciés et bien caractérisés : un crâne de porcelet et un gril costal de jeune capriné, carbonisés et mêlés à une grande quantité d'esquilles et de microesquilles brûlées qui suggèrent la présence d'autres portions animales sur le bûcher. Toutefois, on ne peut exclure que ces éléments proviennent en grande partie d'épandages de sédiments en provenance du bûcher, mais rien, au niveau ostéologique, ne nous permet de les distinguer avec certitude.

Les tombes $\mathrm{T} 12$ et $\mathrm{T} 14$ possédaient une structure de recouvrement commune qui a également fourni des restes fauniques parmi lesquels d'autres éléments brûlés provenant du crâne de porcelet et du gril costal de capriné. Il y aurait donc dépôt ou dispersion des restes recueillis sur le bûcher à différentes étapes de la mise en place de la sépulture. Par ailleurs, la présence, dans cette structure, de dents d'équidés isolées est intéressante à noter, du fait là encore ${ }^{67}$ de sa relation avec l'identification d'un défunt adulte accompagné d'armes. Le crâne dont pourraient provenir ces deux dents aurait été détruit par l'action du feu, et seuls quelques fragments auraient été prélevés, pour un dépôt à caractère symbolique ${ }^{68}$. Il y a fort à parier que les autres fragments crâniens auront été délaissés, car la conservation de la tête d'un porcelet suggère que les conditions de combustion puis de conservation auraient épargné des fragments crâniens d'équidés. Ce fait souligne la pratique différentielle de

66 Les autres dépôts identifiés sont isolés dans leur tombe.

67 Cas observé dans la tombe T21 (cf plus haut).

68 On imagine mal en effet la disparition intégrale des autres fragments crâniens et dentaires pour cette espèce. mise en place de dépôts, entiers dans le loculus, et prélevés donc dispersés et retrouvés à l'état isolé dans les dispositifs de recouvrement des tombes.

Deux autres tombes ont livré un dépôt, ou plus précisément les restes cassés et brûlés de dépôt crânien. Les tombes T23 et T24 contenaient, respectivement, un crâne de porc juvénile et un neurocrâne de capriné. Dans les deux cas, un lot d'esquilles ou de microesquilles leur était associé. À signaler également que la tombe T23 est la seule à avoir fourni un reste de chien (dent inférieure non brûlée). Le défunt, adulte, de cette tombe T23 serait une femme, si l'on en croit les objets déposés (fig. 121).

\subsubsection{Processus de dépôts de portions animales dans les tombes}

Sur l'ensemble des 16 tombes fouillées entre 1999 et 2003, 907 restes fauniques ont été collectés dont 24,5\% (soit 160 NRD) ont été déterminés, et plus de la moitié sont carbonisés à des degrés divers de combustion, allant de la simple « chauffe» à la carbonisation totale (couleur blanche) (NR brûlés $=582$ soit $64,5 \%)$.

Parmi les 160 restes déterminés, on note l'importance des caprinés, avec 77 restes, présents dans 12 tombes, puis des suidés, présents dans 6 tombes (essentiellement sous forme de restes crâniens), ainsi que des bovidés, équidés ou canidés, respectivement dans deux tombes. Le spectre faunique s'élargit de façon anecdotique par la trouvaille ponctuelle de lagomorphe et d'oiseau (fig. 120).

Il est intéressant de signaler, en parallèle, la part régulière que prennent les restes de microfaune et de malacofaune, respectivement retrouvés dans 7 et 6 tombes, c'est-à-dire avec une fréquence équivalente à celle des restes de porcs. Toutefois, en dépit de l'aspect fragmentaire et altéré du matériel, on remarque que les oiseaux, lapins, chiens, microfaune et malacofaune ne sont jamais carbonisés, à l'inverse des ossements de caprinés, suidés, bovidés et équidés, qui, eux, le sont majoritairement. Ces constatations nous amènent à considérer deux causes possibles à la présence des assemblages fauniques, causes qui traduisent deux comportements opposés : accidentel ou volontaire. L'un résulte d'activités antérieures à la mise en place des dépôts : il s'agit des pollutions de fragments osseux ou dentaires isolés, dispersés et introduits dans les structures au cours du remblaiement de ces dernières (microfaune, malacofaune, oiseau, lapin et parfois des ossements d'animaux domestiques). L'autre comportement, de nature funéraire, consiste à déposer sur le bûcher des portions 

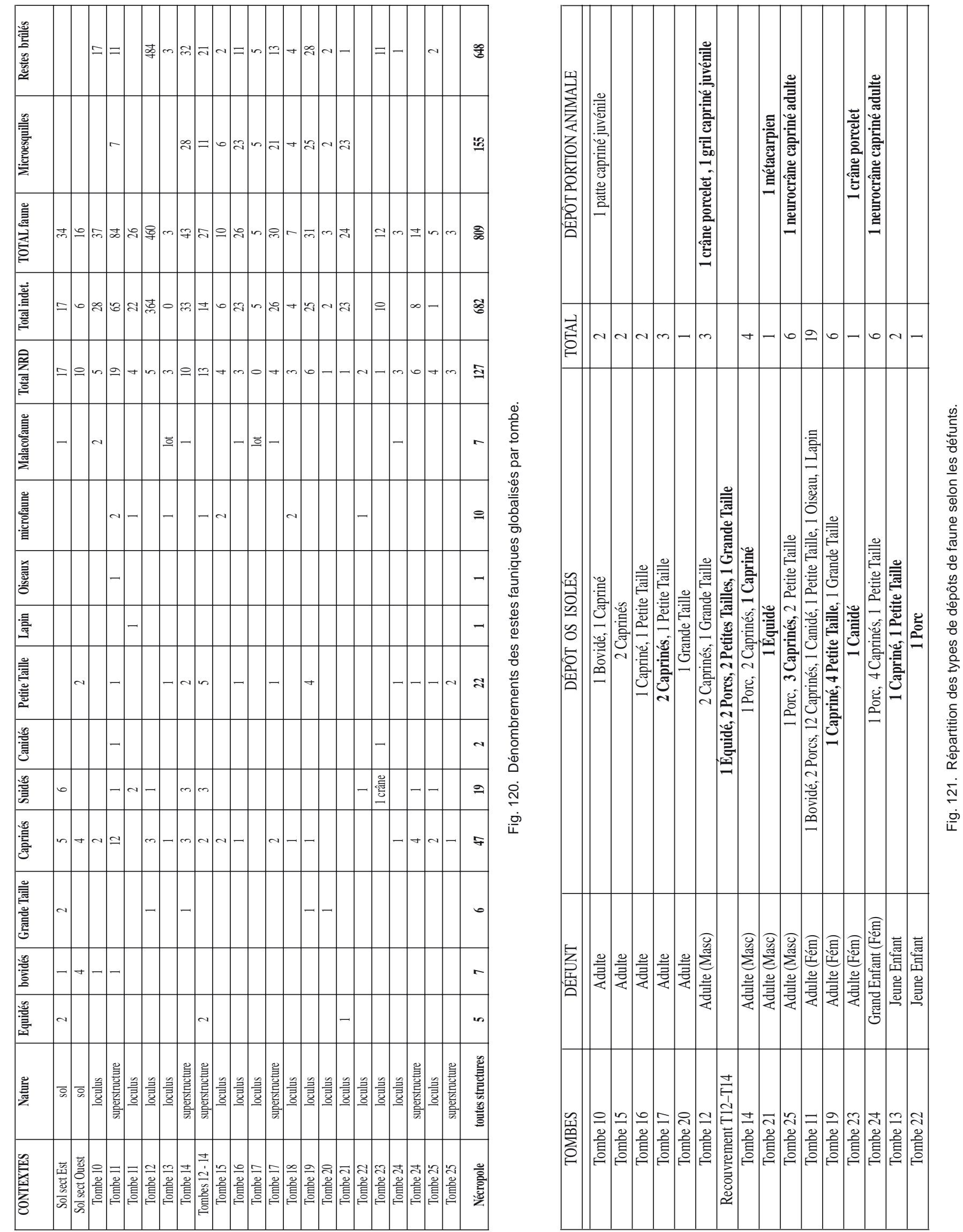
animales qui sont ensuite prélevées, jamais intégralement cependant, et placées dans ou sur la tombe, au moment de la mise en terre des cendres du défunt, accompagné symboliquement par des « offrandes » (animales, armes, bijoux, etc). A cela s'ajoute les cas d'ossements isolés de mammifères domestiques qui ne sont pas associés à un dépôt de type « dépôt spécifique », et dont la provenance est incertaine : pollutions en provenance d'autres sédiments, dépôts symboliques évoquant le repas funéraire (sur le même modèle que pour les fragments isolés de céramique); la question reste ouverte.

Les dépôts caractérisés retrouvés dans les loculus des tombes correspondent à des éléments prélevés sur le bûcher (tombes T12 et T21). Il n'y a qu'un seul exemple, incertain, de dépôt spécifique dit d'offrande viatique, caractérisé par des portions anatomiques plus ou moins complètes et non carbonisées, dans la tombe T10: il s'agirait d'un acropode antérieur de capriné juvénile représenté par un os carpien et des phalanges proximales, intermédiaires et distales.

Dans tous les cas de figure, les portions sont incomplètes, soit parce qu'elles n'ont pas fait l'objet d'un dépôt intégral mais plutôt d'un prélèvement, soit parce qu'elles proviennent du bûcher et ont été fragmentées à la suite de la combustion et leurs fragments dispersés. Enfin, le ramassage aléatoire fait qu'une partie des ossements a été perdue. Il faut envisager, en parallèle, la présence de certains restes comme accidentelle, les ossements de faune ayant été introduits avec les sédiments utilisés lors du comblement des tombes ou de leur recouvrement.

D'un point de vue général, les portions animales utilisées au cours des pratiques funéraires, quelle que soit leur destination (bûcher, offrande viatique, offrandes sur le bûcher), sont constituées par des éléments squelettiques divers et plus particulièrement de crânes, d'extrémités de membres ou d'éléments du squelette axial, comme des côtes ou des vertèbres. Ces portions proviennent majoritairement de caprinés ou de porcs, la plupart d'entre eux étant juvéniles.

Des relations ostéologiques entre le contenu du loculus et celui de la superstructure de recouvrement de la tombe ont été établies. En effet, quelques associations ou appariements ont été effectués : crâne de porcelet et gril costal de capriné de la tombe T12 complétés par des fragments complémentaires issus de la superstructure recouvrant les tombes $\mathrm{T} 12$ et $\mathrm{T} 14$; similitude des microesquilles du loculus et du recouvrement de la tombe T22 ; neurocrâne de capriné adulte dans le loculus de la tombe T24 et présence d'une dent isolée dans le dispositif de recouvrement.

Un prélèvement «global » aurait été réalisé sur le bûcher puis des échantillons auraient été déposés dans et sur la tombe au fur et à mesure de sa mise en place, en accompagnement au défunt, mais aussi au cours de la réalisation de la sépulture. Ce fait est également observable avec d'autres éléments du mobilier : voir les petits objets 2 et 7 de la tombe T22 qui se trouvaient dans le dispositif 17136 de recouvrement commun aux loculus T22 et T23. De la même manière, des pierres parsèment l'intérieur et le dessus de la tombe, sans que l'on puisse leur attribuer une nature de « dépôt ». Il s'agit, comme dans le cas de la faune dispersée, de phénomènes d'intrusion par l'apport de sédiments provenant potentiellement des abords du bûcher. Le même phénomène fait que l'on retrouve, ici et là, des restes isolés et fragmentaires de coquillages marins (tombes T14, T16, T17 et T24). Un dernier cas d'intrusion est également à signaler : celui des ossements de très petits animaux classés en microfaune. Il s'agit de restes isolés de reptiles, de batraciens et de divers petits mammifères inclus dans les sédiments, qui ont également été introduits de manière accidentelle dans ou sur les tombes (tombes T11, T13, T15, T18, T22, et superstructure des tombes T12-T14). Leur fréquence souligne un phénomène récurrent de pollution par des sédiments extérieurs. Il semble raisonnable d'exclure la possibilité d'introduction dans les tombes d'animaux vivants qui y auraient été piégés et seraient morts sur place : dans ce cas de figure, improbable compte tenu du colmatage des espaces, les squelettes originellement complets auraient été mieux conservés et collectés presque intégralement compte tenu des méthodes de fouilles et de tamisage pratiqués par les archéologues.

\section{Analyse des assemblages fauniques issus de l'aire de crémation $B 1$}

\subsection{Protocole d'analyse}

L'étude des restes fauniques exhumés lors de la fouille de l'aire de crémation B1 a été réalisée en adéquation avec celle des restes humains. En premier lieu, deux assemblages ont été distingués, interprétés comme provenant de deux niveaux fonctionnels bien individualisés au cours de la fouille :

- Le socle d'aménagement (cinq unités regroupées : US17121, US17122, US17123, US17134, UD17172) comportant des mobiliers archéologiques divers 
prélevés dans des couches de sédimentation humaine d'habitat tels que des os, pierres, tessons de poteries, éléments divers comme fragments de chenets de terre cuite ou de sole de foyer. Il se présente comme une sorte de substruction du «foyer » et correspond à une phase d'aménagement.

- Une couche de fonctionnement (US17109, US17113, US17114, US17130, US17130, US17132), correspondant aux différentes crémations. Le mobilier faunique était en effet associé à des fragments osseux et dentaires humains attribués à plusieurs individus (adultes, adolescents et enfants). Ainsi, l'hypothèse de plusieurs crémations successives réalisées entre 275 et 200 avant notre ère est retenue, auxquelles étaient associés divers autres mobiliers archéologiques.

Les mobiliers archéologiques, en général, et les ossements animaux en particulier, ont été prélevés par carrés de 20 centimètres de côté. Le tamisage des sédiments a été effectué à la maille de $0,5 \mathrm{~mm}$ par les archéologues. Les restes ont été dénombrés en fonction de leur détermination anatomique spécifique, de leur état de fragmentation, de leur état de combustion, et, pour finir, ils ont été pesés. Un inventaire complet a été dressé sur un fichier Excel qui rassemble la totalité des observations réalisables. L'étude s'est toutefois heurtée à une difficulté de diagnose anatomique et spécifique liée à l'état du matériel osseux, soit qu'il ait été fragmenté, soit qu'il ait été carbonisé. Ainsi, le taux de détermination des restes fauniques est particulièrement faible : 8,2 \% pour le socle, et $26,8 \%$ pour la couche de fonctionnement (fig. 122).

Les déterminations étant rares et souvent imprécises, le matériel a été traité et dénombré par grandes catégories. Au niveau spécifique, moutons et chèvres sont groupés en caprinés. Lorsque la distinction s'est avérée impossible, un groupe dit de «petite taille» a été créé : il s'agit de restes appartenant soit à des caprinés, soit à des suidés. Le même type de regroupement a été réalisé pour les bovidés et équidés, sous le terme " grande taille ». la microfaune pas plus que l'avifaune n'a été déterminée au niveau spécifique.

En ce qui concerne les portions anatomiques présentes, on a eu recours aux catégories suivantes :

Crâne : cheville osseuse, os crânien, dent, mandibule, maxillaire, hyoïde ;

Tronc : vertèbres, côtes, sternèbres ;

Membre antérieur: scapula, humérus, radius, ulna, os carpiens ;
Membre postérieur: coxal, fémur, tibia, fibula, patella, os malléolaire, os tarsiens ;

Membre indéterminé : os long (diaphyses ou articulations), métapodes indéterminés, phalanges, sésamoïdes ;

Esquilles: fragments indéterminés de plus de $10 \mathrm{~mm}$;

Microesquilles : fragments indéterminés de moins de $10 \mathrm{~mm}$.

L'état de conservation et, en particulier pour les couches de fonctionnement, de crémation, n'a pas permis de déterminer de classes d'âges valides. Néanmoins on a constaté la présence d'un certain nombre d'individus juvéniles, identifiés grâce à des fragments dentaires ou des épiphyses non soudées ${ }^{69}$. Leur nombre est trop faible pour les comptabiliser en tant que tels.

Le dernier critère retenu dans la caractérisation des restes fauniques est le degré de carbonisation. Celui-ci consiste en une différenciation entre os ayant subi l'action du feu mais de façon indirecte (os chauffé) et os effectivement brûlé. Dans ce dernier cas, la couleur de la corticale est notée : marron, noire, blanche, bleue et mixte (indiquant ainsi différents degrés de crémation ou carbonisation).

Au total, 1370 fragments osseux ou dentaires ont été examinés et décrits, formant une masse de 1706,35 g (fig. 122).

Les deux assemblages, socle et fonctionnement, sont nettement différenciés : d'un point de vue quantitatif tout d'abord, du point de vue de la fragmentation et du taux de détermination, et enfin du point de vue de l'état de conservation. Le socle, en effet, ne contient que $4,5 \%$ de restes brûlés contre $63,7 \%$ dans les couches de fonctionnement. Un rapport simple entre les nombres de fragments et leur masse correspondante met en évidence une différence remarquable de la masse moyenne des restes fauniques : $8,1 \mathrm{~g}$ pour le socle, et $0,36 \mathrm{~g}$ pour le fonctionnement. Un biais comportemental et taphonomique très important souligne la différence dans l'accumulation et la mise en place de ces deux assemblages.

Il y a une forme d'analogie entre le contenu faunique du socle et celui du sol de la nécropole : dans les deux cas, il semble que les restes fauniques ne soient

69 Trente six restes ont en effet été attribués à des animaux juvéniles sur un ensemble de 105 fragments dont l'âge (sous forme de classe) a pu être estimé. Rappelons ici que le nombre total des restes fauniques des couches de fonctionnement de l'ustrinum est de 1213 restes. 


\begin{tabular}{|c|c|c|c|c|c|c|c|c|c|}
\hline \multirow[t]{2}{*}{ BÜCHER B1 } & \multicolumn{2}{|c|}{ SOCLE } & \multicolumn{2}{|c|}{ FONCTIONNEMENT } & \multicolumn{5}{|c|}{ FONCTIONNEMENT } \\
\hline & NR & M asses (gr) & NR & M asses (gr) & & NR & $\% N R$ & M asses (gr) & masse moy/frag \\
\hline Total & 157 & 1724,25 & 1213 & 432,1 & Total & 213 & & 432,1 & 0,36 \\
\hline Déterminés & 13 & 376,05 & 325 & 255,88 & Déterminés & 325 & $26,8 \%$ / total & 255,88 & 0,79 \\
\hline Indéterminés & 144 & 898,2 & 888 & 171,72 & Indéter minés & 888 & $73,2 \%$ / total & 171,72 & 0,19 \\
\hline Brûlés & 7 & 162,3 & 773 & 176,7 & Brûlés & 773 & $63,7 \%$ / total & 176,7 & 0,23 \\
\hline Bøuf & & & 3 & 11,6 & Chauffés & 155 & & 101,87 & 0,68 \\
\hline Caprinés & 9 & 71,4 & 62 & 79,75 & noirs & 428 & 55,4 \% / brûlés & 85,96 & 0,2 \\
\hline M outon & 2 & 60,5 & & & mixtes & 101 & 13,1 \%/ brûlés & 37,72 & 0,37 \\
\hline Chèvre & 1 & 75,6 & & & marrons & 247 & $32 \%$ / brûlés & 117,27 & 0,47 \\
\hline Petite taille & 1 & 34,9 & 26 & 24,8 & gris & 27 & 3,5 \%/ brûlés & 11,35 & 0,42 \\
\hline Grande taille & & & 3 & 6,8 & bleus & 7 & 0,9 \%/ brûlés & 1,1 & 0,16 \\
\hline Cochon & 2 & 75,5 & 31 & 88,15 & blancs & 103 & 13,3 \%/ brûlés & 22,57 & 0,21 \\
\hline Equidés & & & 2 & 43 & & & & & \\
\hline Carnivore & 1 & 25,9 & & & Crâne & 110 & $33,8 \% /$ det & 111,46 & 1,01 \\
\hline Lapin & 1 & 4,4 & & & Tronc & 33 & $10,2 \% /$ det & 18,37 & 0,56 \\
\hline Oiseau & 1 & 5,2 & 7 & 0,51 & M embre ant & 24 & $7,4 \% /$ det & 24,3 & 1,01 \\
\hline Microfaune & & & 16 & 0,37 & M embre post & 21 & $6,5 \% /$ det & 86,57 & 4,1 \\
\hline Coquillages & 2 & 3,8 & 4 & 0,9 & Membre indet & 80 & $24,6 \% /$ det & 38,78 & 0,48 \\
\hline & & & & & & & & & \\
\hline Masse totale (gr) & 1274,25 & & 432,1 & & Esquilles & 185 & $20,8 \%$ / indet & 82,4 & 0,45 \\
\hline masse moyenne/frag & 8,1 & & 0,36 & & Microesquilles & 757 & $79,2 \%$ / indet & 78,47 & 0,1 \\
\hline
\end{tabular}

Fig. 122. Dénombrements des restes fauniques de l'aire de crémation B1 : récapitulatif.

pas en position primaire mais qu'ils aient été apportés avec le sédiment.

\subsection{Le socle de l'aire de crémation $B 1$}

L'assemblage faunique du socle se présente comme un lot hétérogène, très fragmenté, observation paradoxalement accrue par le soin apporté au tamisage des sédiments au moment de la fouille. La répartition horizontale des restes fauniques est appréhendée sans distinction d'espèce ou de détermination mais en fonction de la masse osseuse répertoriée par carré (fig. 123) :

Classe A : moins de $0,1 \mathrm{~g}$;

Classe B : de 0,1 à $0,9 \mathrm{~g}$;

Classe $\mathrm{C}:$ de 1,0 à $2,9 \mathrm{~g}$;

Classe D : de 3,0 à $4,9 \mathrm{~g}$;

Classe E : de 5,0 à 9,9 g ;

Classe $\mathrm{F}$ : plus de $10 \mathrm{~g}$.

Le matériel, en faible quantité (fig. 122), est réparti sur une surface localisée à l'ouest de la fouille et de la limite des unités stratigraphiques. Cela correspond en réalité à la zone d'épandage de l'unité stratigraphique 17121, qui est celle qui a livré 117 restes fauniques sur les 157 restes globalement collectés dans la masse de ce socle. Le complément provient de l'US17122 localisée sur les carrés AA10, AA11 et AA12 qui n'ont pas été collectés par sous carrés. Et enfin dans une moindre mesure les quelques restes de l'US 17123 répartis sur AB13 (fig. 123). Les 7 fragments brûlés sont isolés dans divers carrés (C10, B10, A10, A11, AA10, AA13, AB13). Cette répartition, peu significative, semble aléatoire et certainement liée à l'épandage de terre lors de l'aménagement préliminaire au fonctionnement du bûcher.

Aucune relation ostéologique n'a été retrouvée entre les divers fragments : absence de collage, connexion, ou appariement. Enfin, rien n' associe le contenu du socle à celui du fonctionnement du bûcher : il s'agit donc bien de deux ensembles différenciés et indépendants. Les mobiliers provenant du socle se rapportent au mobilier habituel retrouvé en habitat de cette époque.

\subsection{Le niveau de fonctionnement du bûcher B1, correspondant aux activités de crémation}

\subsubsection{La couche de "terre rouge»}

La répartition horizontale par masse présentée sur la fig. 124 a été réalisée sans tenir compte des déterminations anatomiques ou spécifiques. Cette couche est localisée dans une légère dépression, au niveau des carrés AA11, AA12, AB11, AB12, AB13. Les restes fauniques y sont moins denses que les os humains et légèrement plus étalés. Les trois restes de bœuf ainsi que les trois coquillages et un os d'oiseau signalés dans le dénombrement du fonctionnement (fig. 122) proviennent de cette couche. La majorité des vestiges sont brûlés à divers degrés, surtout carbonisés, de couleur noire, ou bien ont 
subi l'action du feu mais sans contact direct avec les flammes. Les animaux domestiques de petite taille, avec en particulier des caprinés et des porcs, y sont dominants mais l'ensemble reste peu significatif avec un total de 119 restes dont 35 strictement indéterminés, classés à hauteur égale entre esquilles et microesquilles. Il n'y a pas de concentration osseuse particulière observée.

\subsubsection{La couche de «terre noire »}

Les répartitions par masse pour chaque espèce n'indiquent rien de particulier si ce n'est qu'il y a de tout partout, et aucune distribution particulière en fonction des portions anatomiques n'est observée. Les ossements et dents de faune s'étalent sur toute la surface fouillée, sans qu'une zone de concentration particulière ne soit visible. La surface correspondant à la concentration maximum des os humains ne présente aucune particularité au niveau de la répartition de la faune. Nous donnons néanmoins ici, sous la forme de figures de répartitions successives, les localisations des restes identifiés ou indéterminés (fig. 125 à 131). Seules les esquilles et microesquilles indiquent une répartition relativement homogène sans concentration notable, mais cela tient au fait qu'elles sont particulièrement nombreuses (fig. 122). Il y a donc une différence notable entre la position des restes humains et des mobiliers (bijoux, armes) qui sont localisés très majoritairement dans la partie centrale ${ }^{70}$, les tessons de vase déportés sur le bord est de cette zone de crémation, et enfin les restes de faune dont la répartition est homogène sur l'ensemble de la surface du bûcher fouillée.

Les dénombrements par portion anatomique et par espèce n'apportent pas davantage d'informations, mais ceci est en partie dû à la faiblesse numérique des ossements déterminés. De fait, les échantillons utilisables sont toujours très limités quantitativement.

Il reste donc, comme seule interprétation plausible de la répartition des restes fauniques, l'hypothèse d'un prélèvement régulier des offrandes brûlées sur le bûcher, les fragments laissés sur le bûcher se retrouvant altérés et réduits à de simples microesquilles au cours des crémations suivantes. Peut-être faut-il ajouter à ce scénario, le probable étalement des restes de crémation sur la surface même du bûcher, après que les éléments symboliques du défunt, de ses effets personnels et de ses offrandes aient été prélevés afin d'être déposés dans les loculus des tombes et sur leurs dispositifs de recouvrement.

70 Zone délimitée en pointillés et tiretés sur les figures 124 à 129.

\section{Conclusion}

L'exploration archéologique de la nécropole d'Ambrussum offre une documentation exceptionnelle pour la compréhension des ensembles funéraires du $\mathrm{IIII}^{\mathrm{e}} \mathrm{s}$. avant notre ère en Gaule méridionale (-275/-200). Les divers contextes explorés représentent un ensemble original qui combine un habitat proche, des surfaces d'aménagement, de creusement et d'installation des tombes ainsi qu'un ustrinum. Cette conjonction de contextes permet à l'archéozoologue de situer la part animale et d'examiner avec une acuité renforcée la place des animaux dans les pratiques funéraires.

Les techniques de fouilles ont donné la possibilité d'aborder les répartitions stratigraphiques et spatiales, et, ainsi, ont mis en évidence un certain nombre d'indices sur les comportements et les gestes impliquant des portions animales. En dépit de contraintes taphonomiques importantes, notamment celles découlant de l'action du feu et des réaménagements, et les altérations d'origine climatique, les assemblages osseux éclairent un nouvel aspect des pratiques funéraires jusque-là incomplètement documenté. La nécropole d'Ambrussum se présente donc comme un exemple original par rapport à d'autres nécropoles régionales comme celle d'Ensérune par exemple. Les restes fauniques se caractérisent, à Ambrussum, par un aspect très fragmentaire et altéré. A cela s'ajoute la question des pollutions ou des intrusions éventuelles d'os qui n'ont pas de relation directe avec les pratiques funéraires : les coquillages, la microfaune, dans certains cas les oiseaux ou les lagomorphes, et parfois certains restes fauniques appartenant à des mammifères domestiques identifiés parmi les offrandes ou les déchets culinaires associés au repas funéraire.

Il apparaît néanmoins assez clairement que des portions animales ont été déposées sur le bûcher au moment de la crémation, que certaines d'entre elles ont été prélevées avec application pour être déposées dans la tombe, accompagnant ainsi le défunt au même titre que ses effets personnels ou des tessons de vases. Le caractère incomplet confère à ces dépôts un aspect symbolique, d'autant que parfois les dépôts initiaux se trouvent éparpillés dans le loculus et dans le recouvrement de la tombe. La mise en évidence de crémations successives suggère que des mélanges ont pu se produire, au même titre que l'apport de sédiments au moment des remplissages des loculus a pu introduire des fragments osseux sans lien direct avec le rituel. De plus, la différence de répartition entre os humains et animaux sur le bûcher indique que leur traitement était différent. Il est ainsi envisagé, au vu des éparpillements des restes fauniques dans la couche 


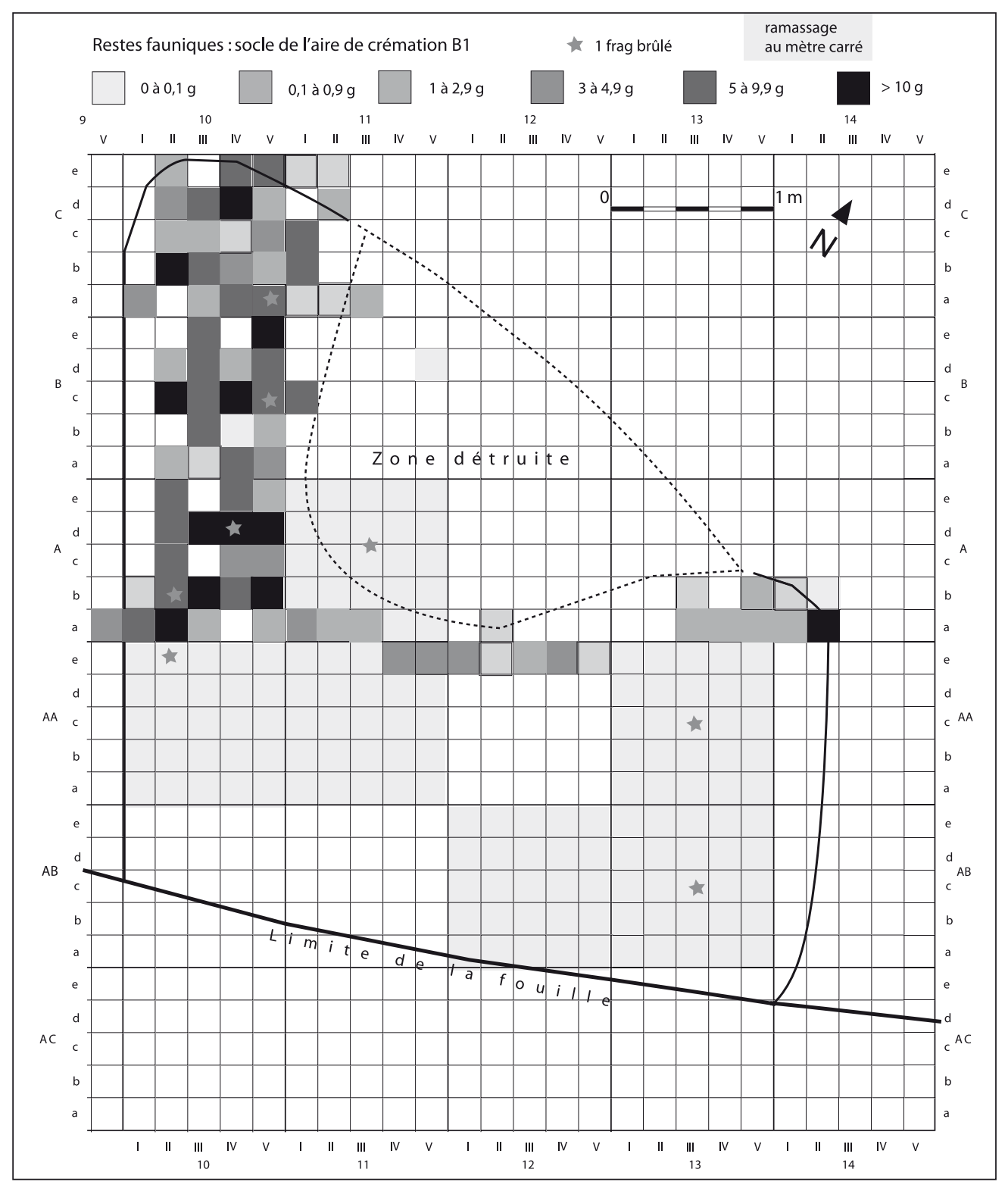

Fig. 123. Répartition des restes fauniques sur le socle de l'aire de crémation B1 en fonction de leur masse.

de fonctionnement de l'ustrinum, que chaque crémation ait été précédée par un épandage sur place des cendres de la crémation précédente, provoquant ainsi un étalement homogène des fragments de faune.

Du point de vue des offrandes animales, Ambrussum se caractérise par l'absence de portions de viande non brûlées et plus ou moins en connexion, habituellement interprétées comme offrandes viatiques, comme c'est le cas à Ensérune (Gardeisen 1994 ; 1995). Les restes fauniques sont le plus souvent brûlés ou fragmentés, et jamais observés en connexion : il n'y a donc pas eu de dépôt faisant suite à la mise en pièce d'un membre ou d'une portion anatomique non consommée. Les portions animales retrouvées proviennent essentiellement du bûcher, pour ce qui est de celles qui sont carbonisées. Pour les autres, les fragments retrouvés n'évoquent pas vraiment les restes d'une portion animale complète originellement, mais plutôt un dépôt à caractère symbolique de quelque reliquat pouvant, par exemple, provenir de repas. Mais rien ne permet, au niveau ostéologique, d'identifier concrètement les déchets de ce qui est régulièrement interprété comme le repas funéraire ; ce cas n'est évoqué ici que par l'absence d'ossements ${ }^{71}$ provenant de parties consommables. C'est le cas des porcelets dont la tête est brûlée puis déposée dans la tombe, mais dont le reste du corps est totalement absent.

71 Avec tous les risques que cet exercice comporte... 
Aire de Crémation $\mathrm{B} 1$, fonctionnement : couche rouge - répartition des masses de faune

......... limite de la zone de densité maximum des restes humains

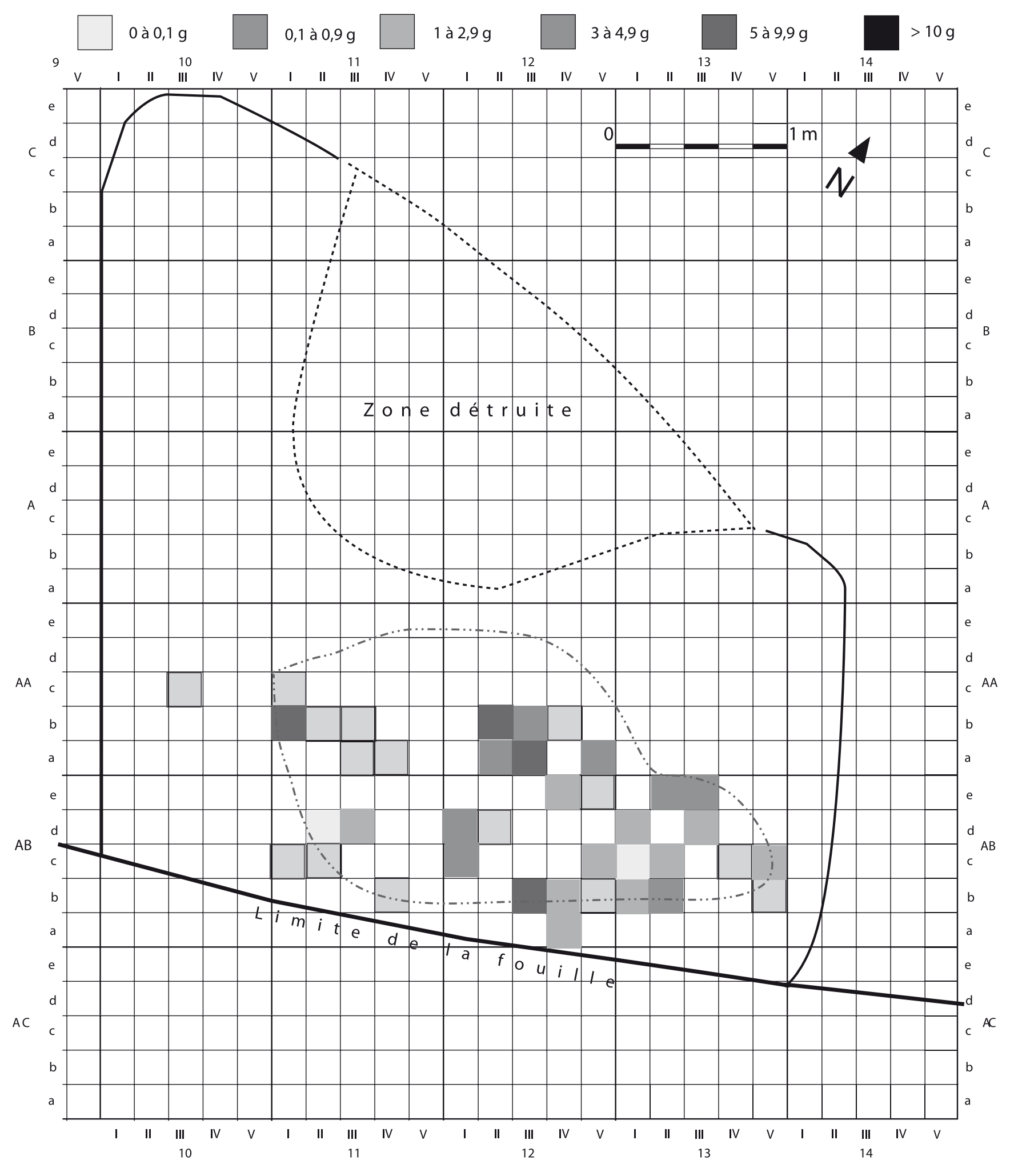

Fig. 124. Répartition des restes fauniques de la couche rouge (US17132) de l'aire de crémation B1 en fonction de leur masse. 


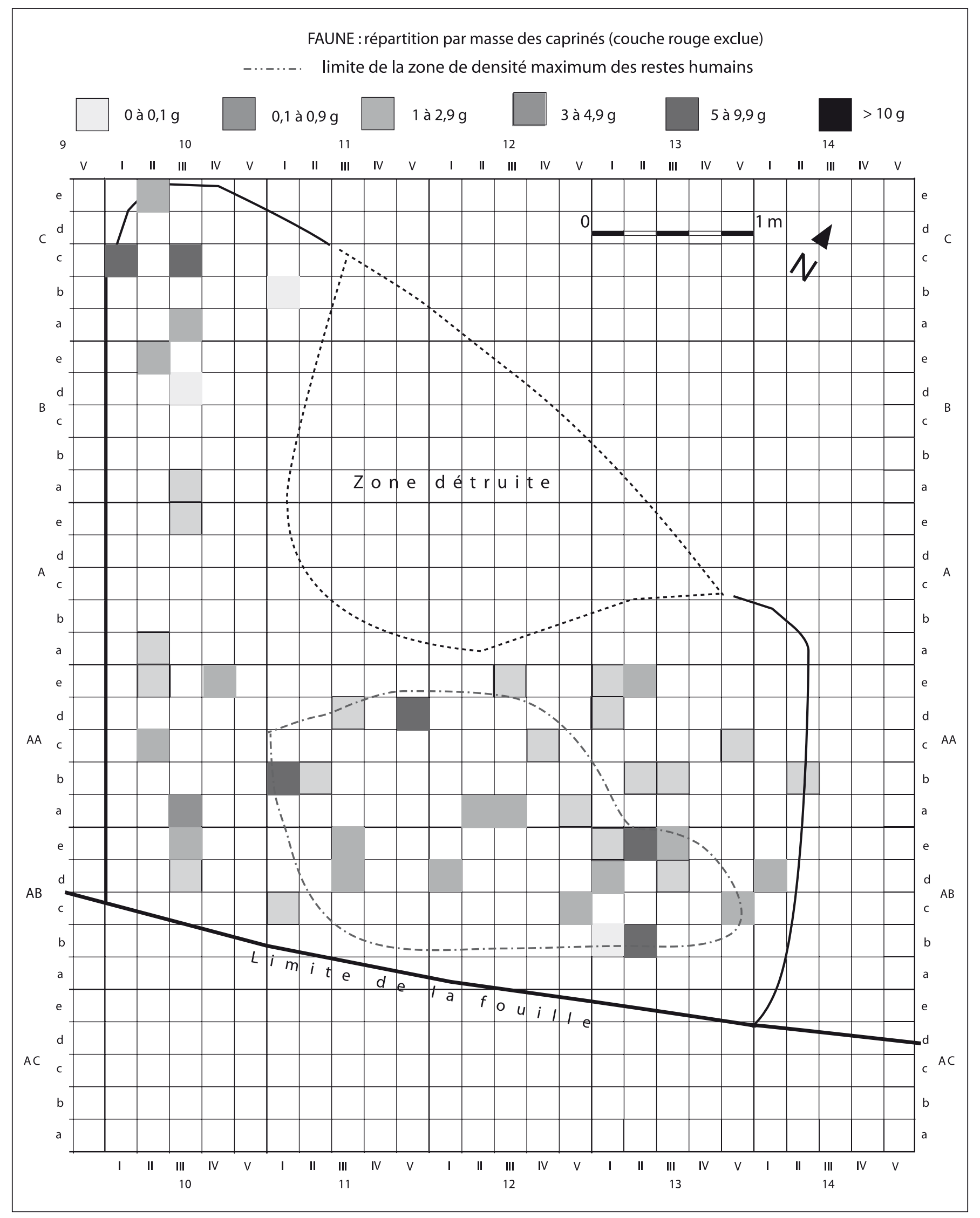

Fig. 125. Répartition des restes de caprinés en fonction de leur masse dans le niveau de fonctionnement de l'aire de crémation B1. 
FAUNE : répartition par masse des porcs (couche rouge exclue) ... -...- limite de la zone de densité maximum des restes humains

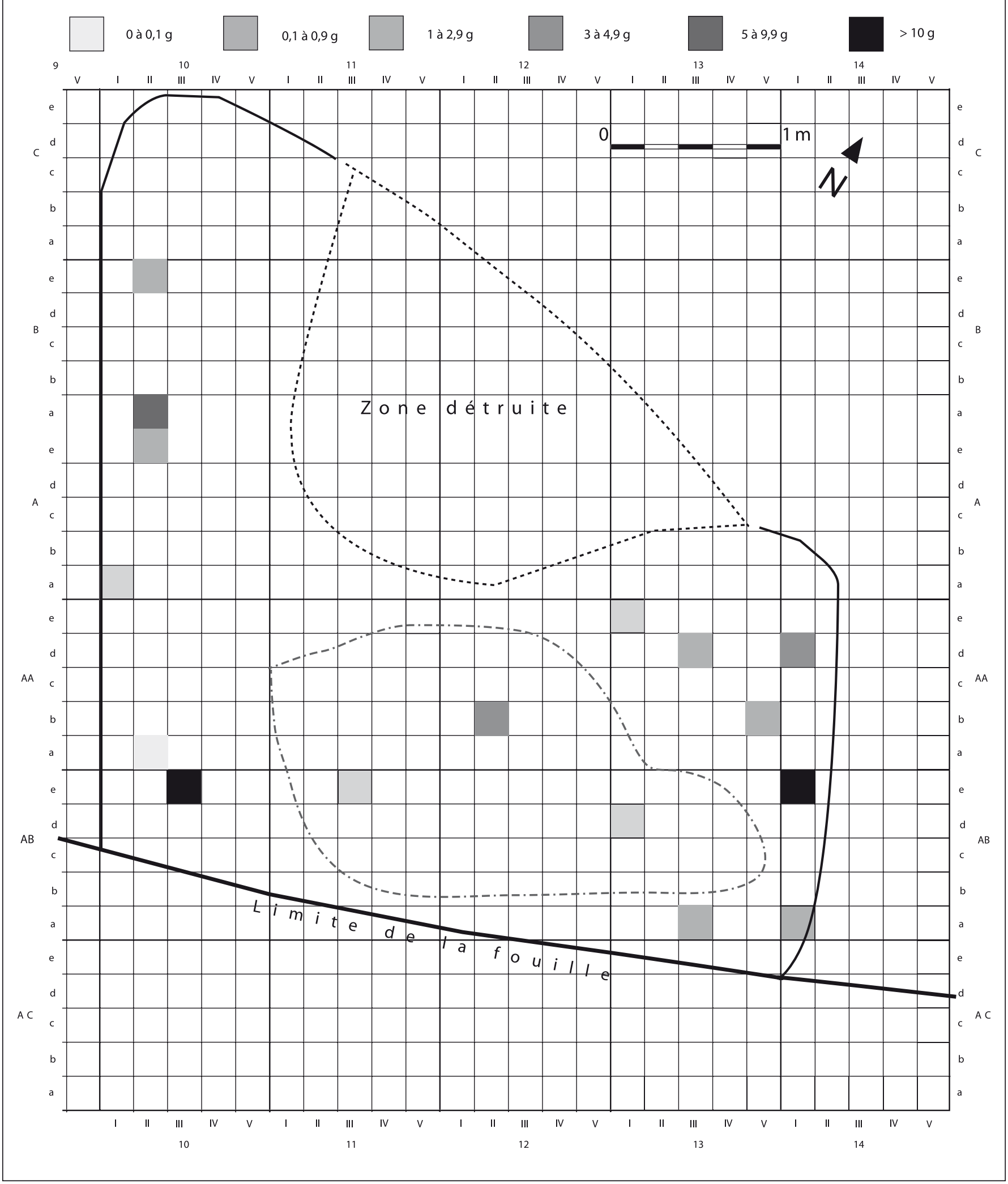

Fig. 126. Répartition des restes de porcs en fonction de leur masse dans le niveau de fonctionnement de l'aire de crémation B1. 


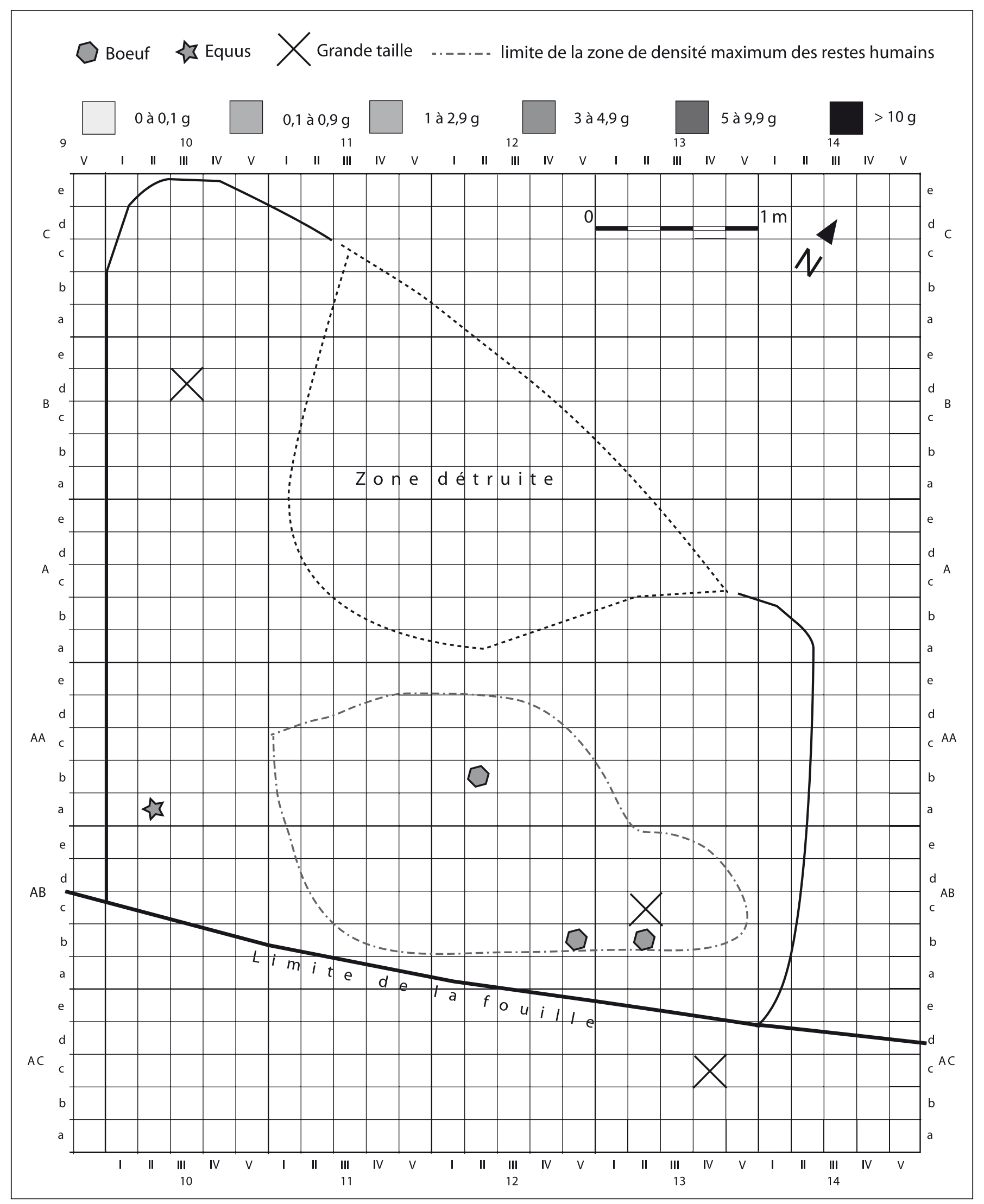

Fig. 127. Répartition des restes de bœufs, d'équidés et d'animaux de grande taille en fonction de leur masse dans le niveau de fonctionnement de l'aire de crémation B1. 


\section{Coquillage Oiseau}

\section{-..-..-- limite de la zone de densité maximum des restes humains}

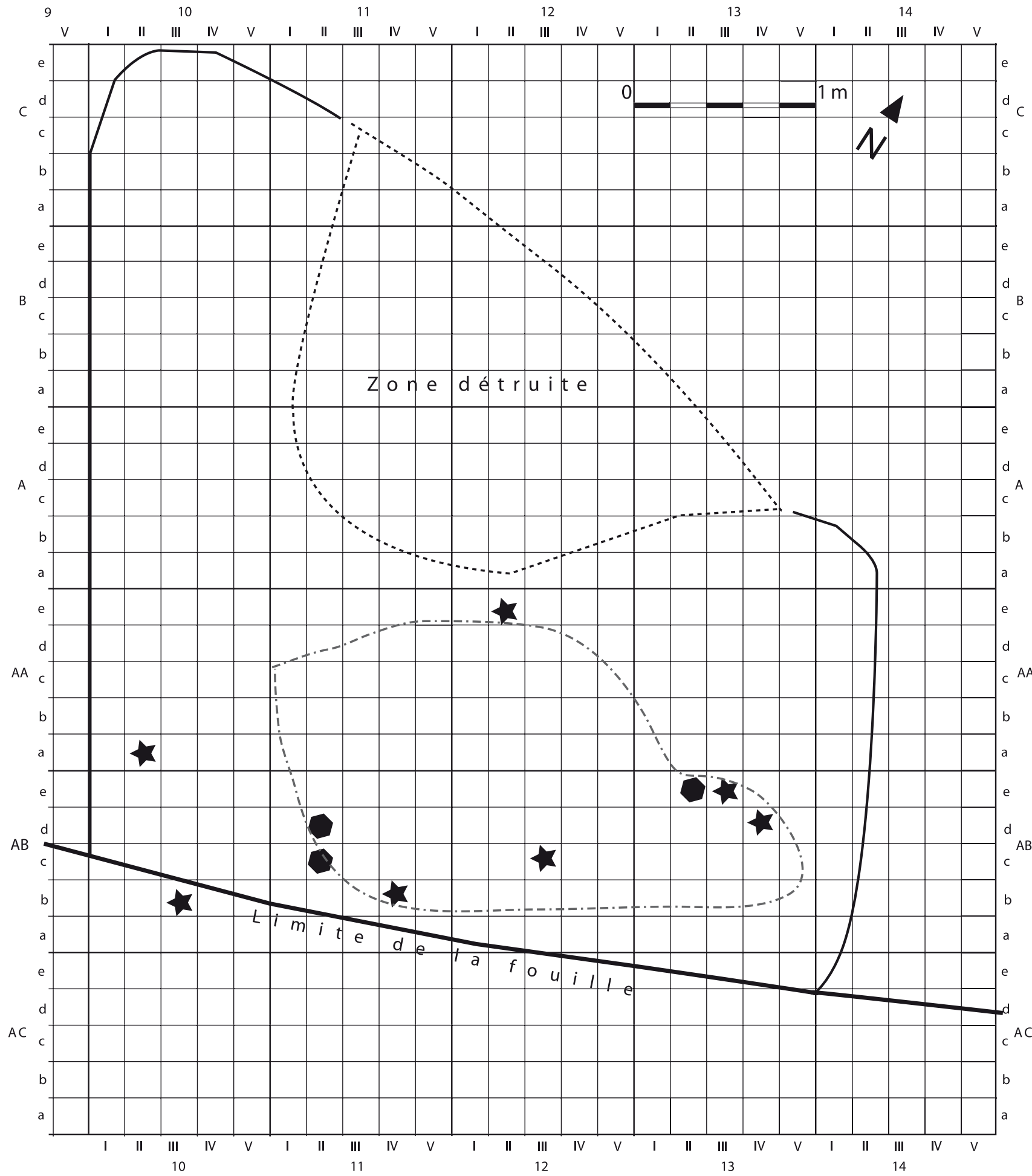

Fig. 128. Répartition des restes d'oiseau et de coquillages en fonction de leur masse dans le niveau de fonctionnement de l'aire de crémation B1. 


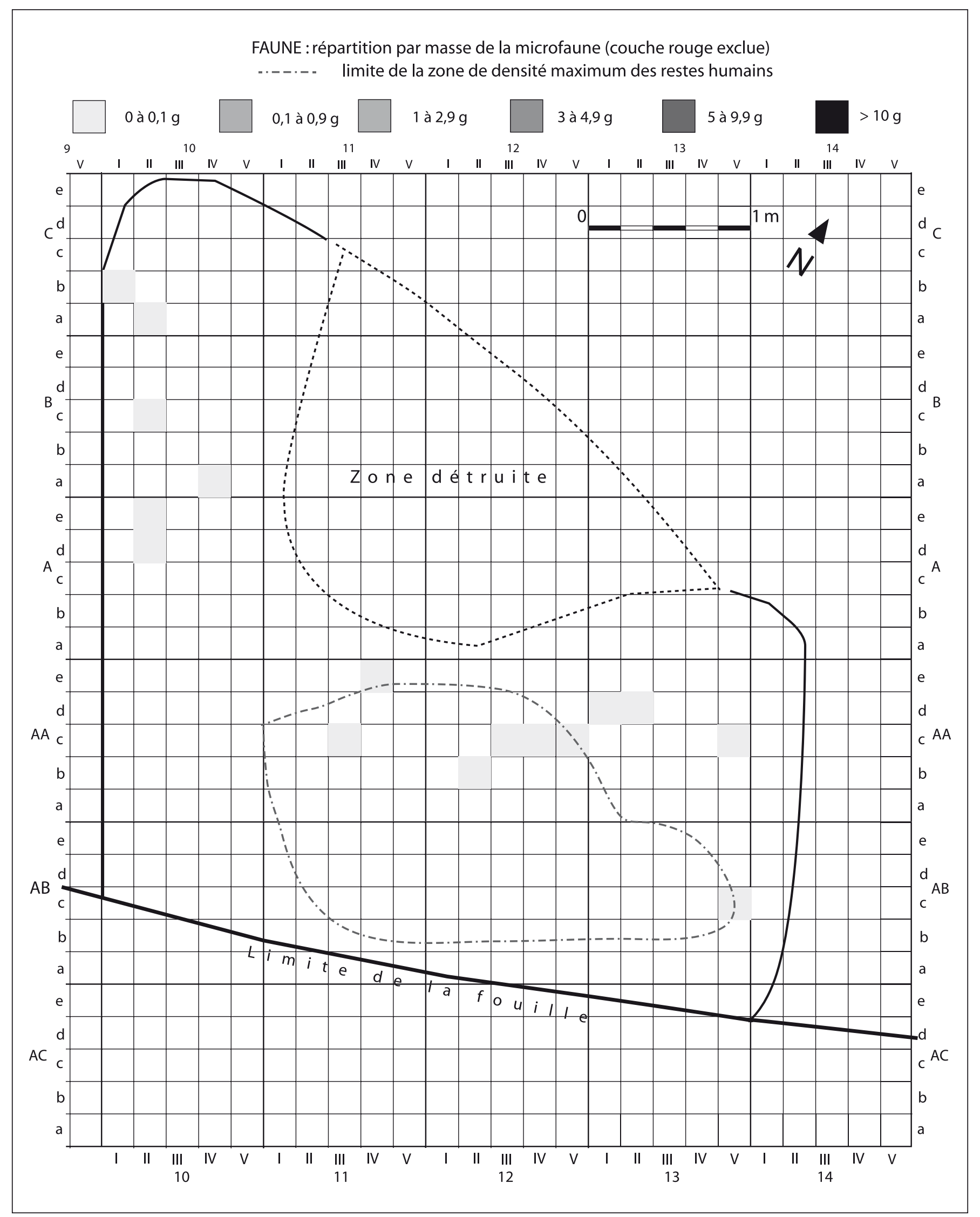

Fig. 129. Répartition des restes de microfaune en fonction de leur masse dans le niveau de fonctionnement de l'aire de crémation B1. 


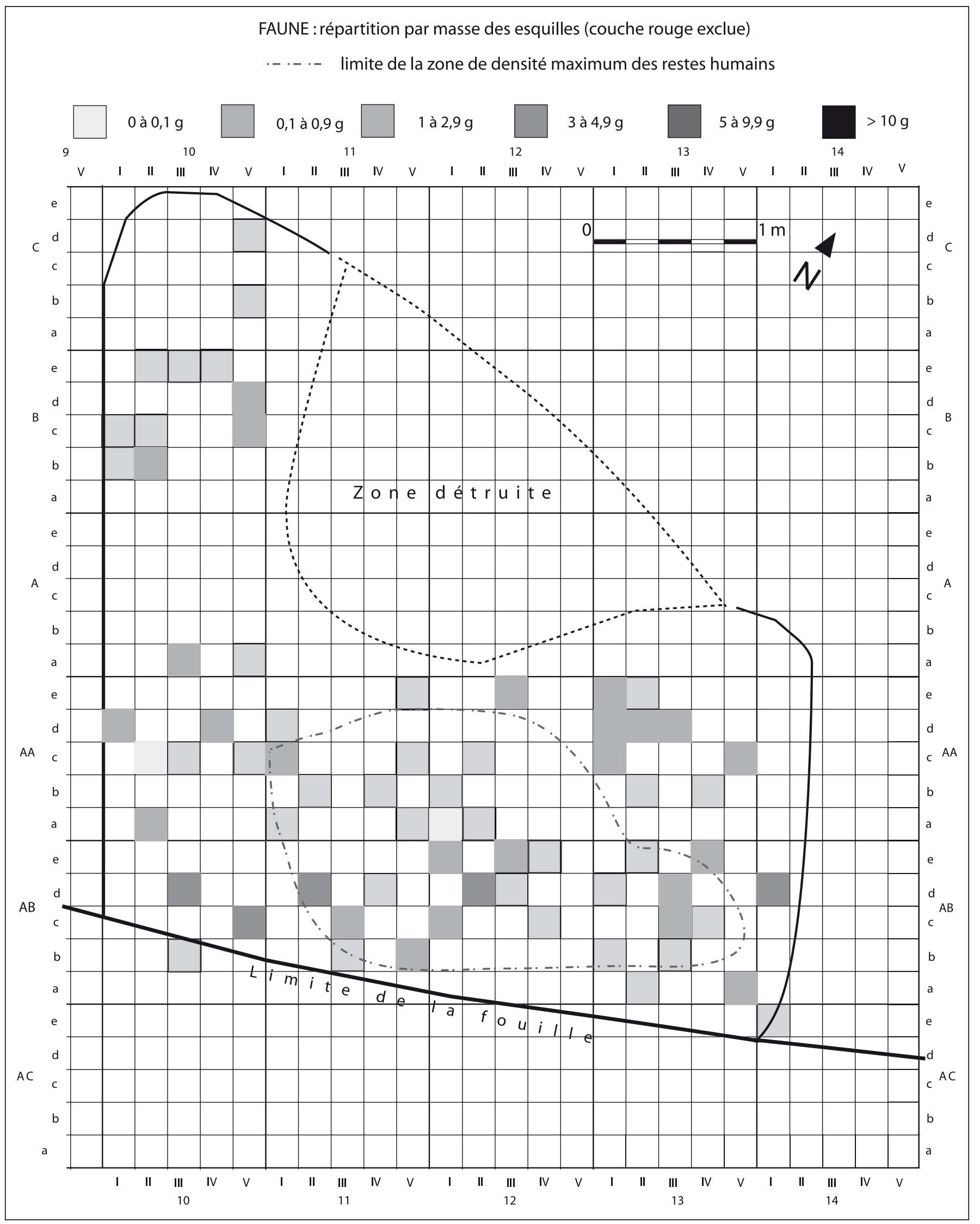

Fig. 130. Répartition des restes d'esquilles en fonction de leur masse dans le niveau de fonctionnement de l'aire de crémation B1. 


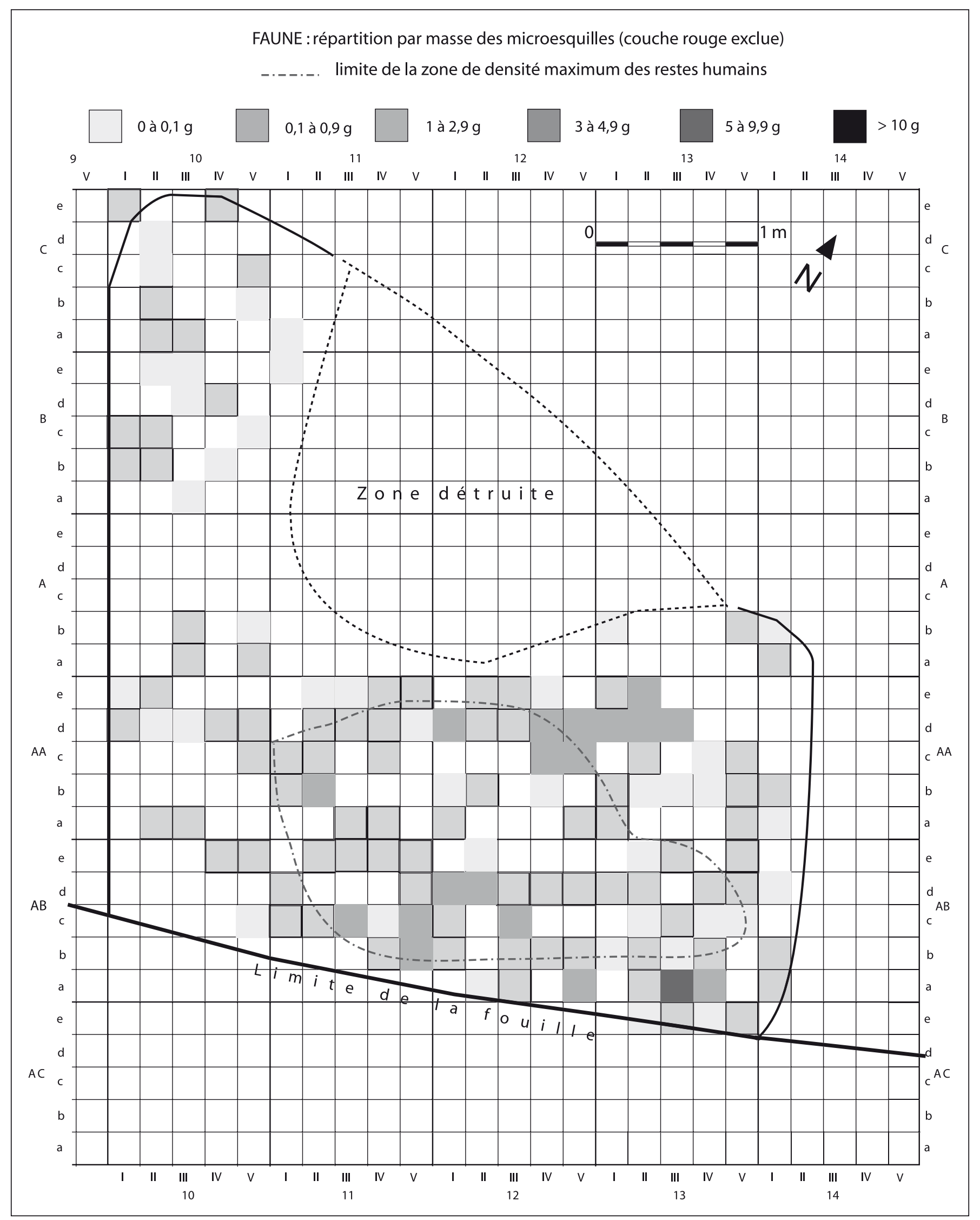

Fig. 131. Répartition des restes de microesquilles en fonction de leur masse dans le niveau de fonctionnement de l'aire de crémation B1. 


\begin{tabular}{|c|c|c|c|c|c|c|c|c|}
\hline & & & & & \multicolumn{3}{|c|}{ Mesures (mm) } & \multirow{2}{*}{ trace de feu } \\
\hline & US & carré & reste & $\operatorname{taxon}$ & M1 & M2 & M3 & \\
\hline \multirow{41}{*}{ 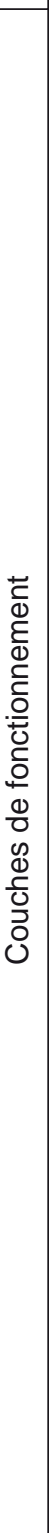 } & \multirow[t]{7}{*}{17109} & $\mathrm{~B} 10 \mid \mathrm{C}$ & vertèbre $n^{\circ} 1$ & cf. Perca fluviatilis & 2 & & 2,6 & $X$ \\
\hline & & $\mathrm{B} 10 \mathrm{II} \mathrm{a}$ & frag. de côte & indéterminé & & & & \\
\hline & & \multirow[t]{2}{*}{ B10 II e } & acanthotrich & indéterminé & & & & \\
\hline & & & acanthotrich & indéterminé & & & & \\
\hline & & B10 IV d & acanthotrich & indéterminé & & & & \\
\hline & & $\mathrm{C} 10 \mathrm{Ib}$ & acanthotrich & indéterminé & & & & \\
\hline & & berne sud & molaire réniforme & Sparus aurata & & 6,7 & & $X X$ \\
\hline & \multirow[t]{6}{*}{17113} & AA11 Id & dent caniniforme & Sparidés & & & & \\
\hline & & AA11 $\| \mathrm{e}$ & dent molariforme & Sparidés & & & & $\mathrm{XX}$ \\
\hline & & AA11 II e & dent molariforme & Sparidés & & & & $X X$ \\
\hline & & AA11 V d & molaire réniforme & Sparus aurata & & 5 & & $X$ \\
\hline & & AA12 III C & vertèbre caudale & cf. Perca fluviatilis & 1,9 & 2,1 & 2,3 & $X$ \\
\hline & & AA12 III e & dent molariforme & Sparidés & & & & $X X$ \\
\hline & \multirow[t]{5}{*}{17114} & $\mathrm{AA} 13 \mid \mathrm{d}$ & dent molariforme & Sparidés & & & & $\mathrm{XX}$ \\
\hline & & \multirow[t]{4}{*}{ AA13 II d } & vertèbre caudale & Anguilla anguilla & 2,6 & & 3,7 & \\
\hline & & & dent molariforme & Sparidés & & & & $X X$ \\
\hline & & & dent molariforme & Sparidés & & & & \\
\hline & & & acanthotrich & indéterminé & & & & \\
\hline & \multirow[t]{2}{*}{17130} & AA12 I C & frag. de dentaire & Sparus aurata & & & & $\mathrm{X}$ \\
\hline & & AB12 III e & dent caniniforme & Sparidés & & & & \\
\hline & \multirow[t]{21}{*}{17132} & AA12 III b & frag de dentaire/prémaxillaire & cf. Sparus aurata & & & & \\
\hline & & $\mathrm{AA} 12 \mathrm{Vb}$ & frag de prémaxillaire (droit) & Sparus aurata & & & & $X$ \\
\hline & & AA13 I a & dent molariforme & Sparidés & & & & $\mathrm{X}$ \\
\hline & & AA13 II a & dent molariforme & Sparidés & & & & $X X$ \\
\hline & & \multirow[t]{4}{*}{ AA13 III b } & esquille indéterminé & indéterminé & & & & $X$ \\
\hline & & & dent molariforme & Sparidés & & & & $\mathrm{X}$ \\
\hline & & & côte & indéterminé & & & & $\bar{X}$ \\
\hline & & & côte & indéterminé & & & & $X$ \\
\hline & & \multirow[t]{2}{*}{ AA13 IV a } & côte & indéterminé & & & & $\mathrm{X}$ \\
\hline & & & dent molariforme & Sparidés & & & & $X X$ \\
\hline & & \multirow[t]{2}{*}{ AB12 III d } & molaire réniforme & Sparus aurata & & 6,5 & & $\mathrm{XX}$ \\
\hline & & & acanthotrich & indéterminé & & & & \\
\hline & & \multirow[t]{3}{*}{ AB13 II C } & vertèbre $n^{\circ} 2$ & Dicentrarchus labrax & 5,3 & 5,9 & 5,6 & $\mathrm{X}$ \\
\hline & & & frag. de vertèbre thoracique & cf. Dicentrarchus labrax & & 5,6 & & $\mathrm{X}$ \\
\hline & & & frag. d'otolithe & indéterminé & & & & $X$ \\
\hline & & \multirow[t]{5}{*}{ AB13 V b } & molaire réniforme & Sparus aurata & 12,1 & 6,9 & & $X X$ \\
\hline & & & molaire réniforme & Sparus aurata & 7,8 & 5,4 & & $X$ \\
\hline & & & frag. de vertèbre & indéterminé & & & & $\bar{X}$ \\
\hline & & & frag. de prémaxillaire & Sparus aurata & & & & $\mathrm{X}$ \\
\hline & & & acanthotrich & indéterminé & & & & \\
\hline & & AB13 V d & frag. de vertèbre & indéterminé & & & & $X$ \\
\hline \multirow{11}{*}{ 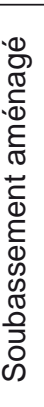 } & \multirow[t]{3}{*}{17121} & A10 I a & vertèbre $7-8$ & Mugilidés & & & 6,1 & \\
\hline & & A10 II C & molaire réniforme & Sparus aurata & 18,6 & 11,9 & & $\mathrm{XX}$ \\
\hline & & $\mathrm{C} 11 \| \mathrm{d}$ & molaire réniforme & Sparus aurata & 8,4 & 6 & & \\
\hline & 17122 & A10 II/V a & vertèbre caudale & Cyprinidés & 1,7 & 1,8 & 2,3 & \\
\hline & & & dent molariforme & Sparidés & & & & \\
\hline & & & dent molariforme & Sparidés & & & & \\
\hline & & & dent molariforme & Sparidés & & & & \\
\hline & & & acanthotrich & indéterminé & & & & \\
\hline & & & écaille & indéterminé & & & & \\
\hline & & & esquille d'os crânien & indéterminé & & & & \\
\hline & & A11 II a & dent caniniforme & Sparidés & & & & \\
\hline
\end{tabular}

Fig. 132. Inventaire de l'ichtyofaune de l'aire de crémation B1 [Mesures des vertèbres : M1= hauteur max. du centrum, M2=largeur max. du centrum, M3= diamètre antéro-postérieur max. du centrum ; Mesures des molaires réniforme de daurade : M1= diamètre antéro-postérieur max., M2= largeur max ; Traces de feu : $X=$ brûlé (couleur noir), XX= brûlé (couleur gris-bleu)]. 


\section{Annexe 3}

\section{Les restes de poissons de la nécropole d'Ambrussum}

\author{
Auteur : Gaël PIQUÈS ${ }^{72}$
}

L e tamisage du remplissage des tombes à incinération et des couches de fonctionnement du bûcher funéraire B1de la nécropole $(-275 /-200)$ a fourni au total une centaine de restes d'ichtyofaune. Dans ce contexte funéraire, la question a été de déterminer si ces restes de poissons pouvaient correspondre à des offrandes.

\section{L'ichtyofaune du bûcher funéraire $B 1$}

Les couches de soubassement et de fonctionnement du bûcher ont été prélevées par carré et tamisées dans leur intégralité à l'aide de tamis d'une maille minimale de $0,5 \mathrm{~mm}$.

Le soubassement aménagé a livré seulement 11 restes qui se répartissent entre les couches 17121 et 17122 (fig. 132). Il s'agit principalement de dents isolées de Sparidés pouvant être attribuées à de la daurade royale (Sparus aurata), représentée ici par deux molaires réniformes. À cela s'ajoutent une vertèbre de muge (famille des Mugilidés), une vertèbre de Cyprinidés ainsi qu'une écaille, une épine de nageoire (acanthotrich) et une esquille indéterminées. À noter qu'aucun de ces restes n'est brûlé à l'exception d'une des deux molaires réniformes de daurade qui présente une couleur gris-bleu. Compte tenu de sa composition, ce matériel ne peut être assimilé à un dépôt primaire mais plutôt à des restes épars rapportés avec le sédiment ayant servi à l'aménagement du soubassement du bûcher.

Le matériel des couches de fonctionnement du bûcher (Us 17109, 17113, 17114, 17130, 17132) se compose quant à lui de 39 restes. Si l'on fait abstraction des dents isolées de Sparidés, des épines de nageoires et des côtes indéterminées, il se réduit à seulement 11 restes :

72 Ingénieur d'études au CNRS (UMR 5140, Montpellier-Lattes).
- une vertèbre d'anguille, Anguilla anguilla ;

- deux vertèbres de loup, Dicentrarchus labrax, pouvant appartenir au même individu ;

- deux vertèbres de perche, Perca fluviatilis, également attribuable à un même individu ;

- trois restes de daurade, un fragments de dentaire, un de prémaxillaire et un autre de dentaire ou prémaxillaire ;

- un fragment d'otolithe et une esquille d'os crânien indéterminés.

Pour la daurade, on obtient un nombre minimum de deux individus d'après le décompte et la mesure des molaires réniformes isolées. Il s'agit de daurades dont la longueur totale est de 500 à $600 \mathrm{~mm}$ ( 2 à $3 \mathrm{~kg}$ ) et de 350 à $400 \mathrm{~mm}(0,5 \mathrm{à} 1 \mathrm{~kg})$. Les autres poissons représentés sont de petits spécimens, d'environ $150 \mathrm{~mm}(0,05 \mathrm{~kg})$ pour la perche et de $320 \mathrm{~mm}$ (environ $0,3 \mathrm{~kg}$ ) pour le loup.

Globalement l'ichtyofaune des niveaux de fonctionnement du bûcher se trouve en dehors des concentrations d'os humains, là où les tessons de céramiques sont les plus nombreux. Des déplacements post-dépositionnels sont observés. En l'occurrence à partir des fragments de dentaires et prémaxillaires de daurades, circonscrits au carré AA12, mais dont les dents sont éparpillées en périphérie sur un rayon d'1,50 m (fig. 133). Enfin la majorité des restes montre des traces de feu, plus ou moins légères, qui n'arrivent toutefois pas au stade de la carbonisation (fig. 134). Aucun d'entre eux ne présente de couleur blanc bleuté ou blanc crayeux qui indiquerait, comme pour les os humains, une température de chauffe de plus de $350^{\circ} \mathrm{C}$ (Bonucci, Graziani 1975, Piquès 2004). L'hypothèse d'offrandes de poissons sur le bûcher au moment de la crémation peut donc être exclue. Il pourrait s'agir en revanche de restes de repas jetés sur le foyer presque éteint. Toutefois aucune portion anatomique, que ce soit de la tête ou du corps, n'est représentée par plus de deux restes. Cela implique dans cette hypothèse le prélèvement d'une partie des ossements, à l'occasion peut être d'un nettoyage du foyer ou d'un ramassage des cendres. Le fait est que leur disparition par combustion semble peu probable compte tenu du faible degré de chauffe des os conservés. 


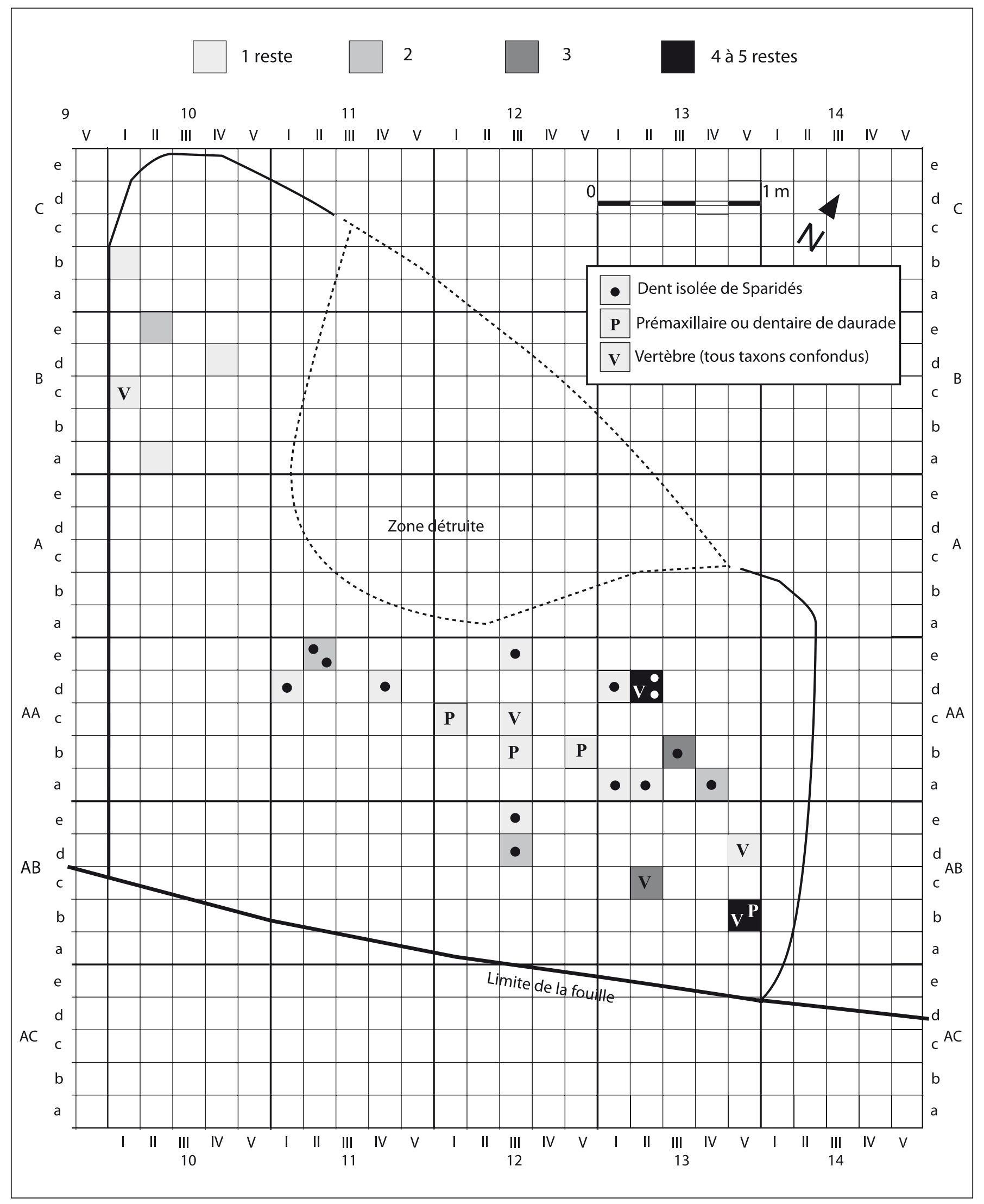

Fig. 133. Répartition spatiale des restes d'ichtyofaune des couches de fonctionnement de l'aire de crémation B1 (Us 17019, 17113, 17114, 17130, 17132). 


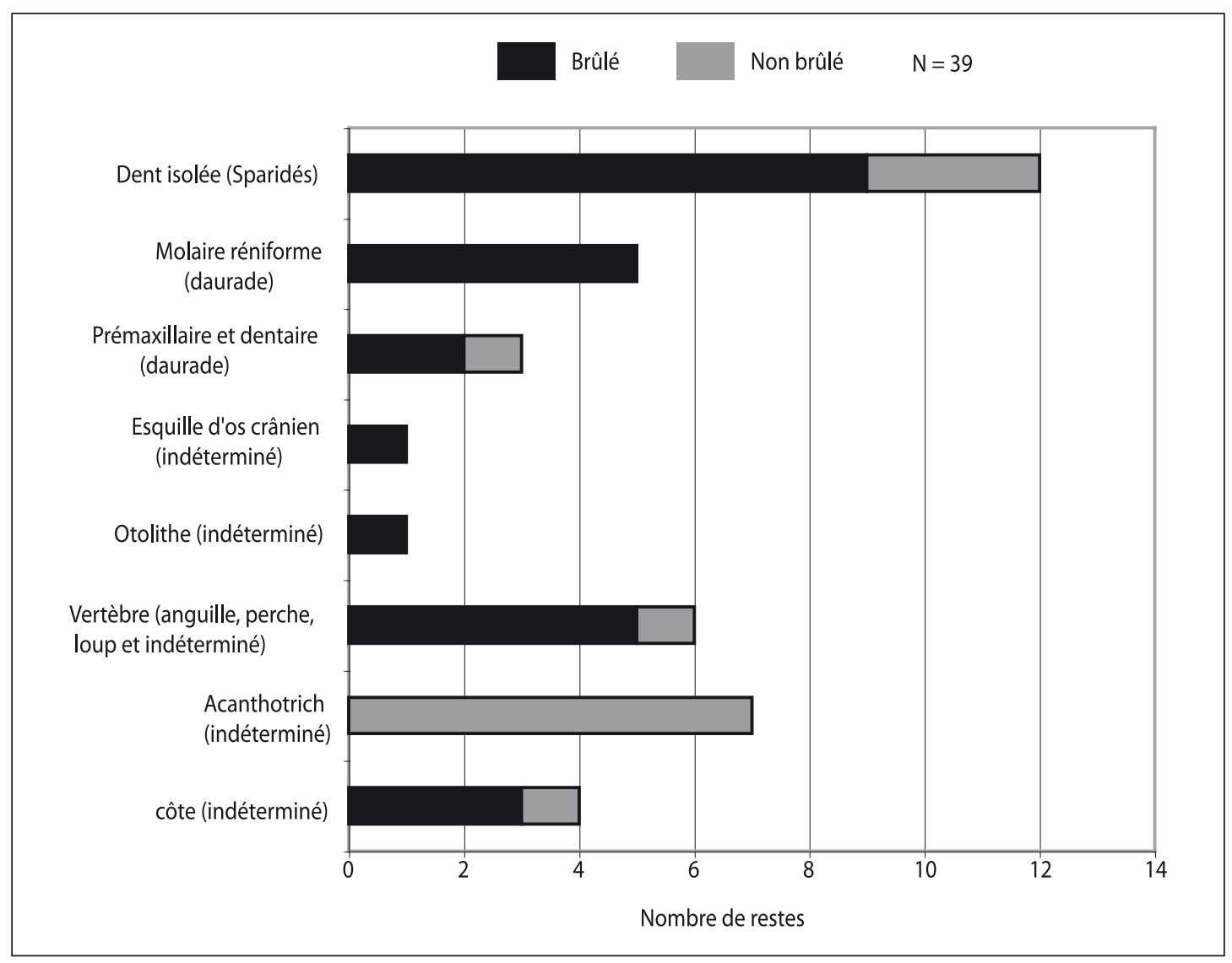

Fig. 134. Inventaire des restes brûlés et non brûlés des couches de fonctionnement de l'aire de crémation B1.

\section{L'ichtyofaune des tombes}

Le loculus de chacune des tombes ainsi que leur superstructure a été tamisé à une maille minimale de $0,5 \mathrm{~mm}$. Quelques restes de poissons ont ainsi été recueillis dans le loculus des tombes $\mathrm{n}^{\circ} 12,13,16$ et 18. Ces os qui ne sont pas brûlés ne constituent pas des assemblages pouvant évoquer une offrande. Il s'agirait plutôt de restes de poissons rapportés avec le sédiment ayant servi à combler le loculus. En voici l'inventaire :

- Tombe 12 : une épine de nageoire ;

- Tombe 13: deux vertèbres de Sciaenidés pouvant être attribués au même individu ;

- Tombes 16: quatre épines de nageoires et un lépidotriche ;

- Tombes 18 : une écaille, un fragment de vertèbre, un lépidotriche et une côte.

En conclusion, aucun témoignage évident d'offrande de poisson n'est attesté ici, que ce soit dans les tombes ou dans les couches de fonctionnement du bûcher. Quant au rejet de restes de consommation sur le bûcher, rien ne nous certifie qu'il s'agit d'une pratique rituelle en relation avec les funérailles du défunt.

Au-delà de ce contexte funéraire, il faut souligner que ces échantillons sont les seules données ichtyofauniques antérieures à la période romaine dont on dispose pour Ambrussum. Le reste de la documentation étant issu pour l'essentiel des niveaux du Haut-Empire de l'agglomération routière (Piquès 2009).

Malgré leur faible nombre, les quelques restes d'ichtyofaune de la nécropole nous renseignent tout au moins sur l'origine des poissons consommés au III $\mathrm{s}$. av. n. è. Il s'agit en partie du produit d'une pêche locale pratiquée dans le fleuve Vidourle dont les représentants sont ici la perche, les cyprinidés et vraisemblablement l'anguille. À cela s'ajoute la consommation d'espèces marines ou lagunaires, comme le muge et le loup qui remontent toutefois assez haut les fleuves et qui, à l'instar de l'anguille, pouvaient être pêchés dans le Vidourle. La daurade royale et les Sciaenidés, en revanche, témoignent sans ambiguïté de l'acheminement de produits marins ou lagunaires pêchés à un peu plus de $20 \mathrm{~km}$ du site. 



\section{Annexe 4}

\section{Les restes carpologiques de la nécropole d'Ambrussum : intrusions ou offrandes ?}

\section{Auteur : Núria ROVIRA ${ }^{73}$}

\section{Introduction}

$\mathrm{L}$ a nécropole d'Ambrussum (275-200 av. n. è.), comprenant environ deux douzaines de tombes et un ustrinum, a fait l'objet d'un échantillonnage systématique. La présence de restes carpologiques étant assez rare dans les deux types de structures, la question se pose de savoir s'il s'agit d'offrandes brûlées en même temps que les corps ou bien d'intrusions accidentelles de graines.

\section{Matériels et méthode}

L'échantillonnage de l'ustrinum et des tombes a été réglé par la méthode de fouille employée. Ainsi, concernant l'ustrinum, 309 échantillons correspondant aux différents carrés des unités stratigraphiques de fonctionnement fouillées ont été prélevés et tamisés à l'eau sur une maille de $0,5 \mathrm{~mm}$. Au total, 573,75 litres de sédiment ont été tamisés. Seuls 21 prélèvements ont livré des restes carpologiques (Us 17109, 17113, 17114, 17130,17132 et 17164).

Parmi les vingt-trois tombes attestées, seules douze ont fait l'objet d'un prélèvement et d'un tamisage systématiques de la totalité du sédiment, tant du loculus que de la superstructure. Un total de 55 échantillons a été tamisé (mailles de 4, 2 et $0,5 \mathrm{~mm}$ ), ce qui correspond à 2307,3 litres de sédiment. Les seules tombes ayant livré des restes carpologiques sont la 12, 14, 16, 17, 18, 21 et 22 , ce qui correspond à 10 prélèvements.

73 Archéobotaniste (carpologue). Associée à l'équipe Archéologie des Milieux et des Ressources, UMR 5140 Archéologie des Sociétés Méditerranéennes. 390, avenue de Pérols, 34970 Lattes (France). E-mail : nuriarovirab@yahoo.es
Tous les carpo-restes sont carbonisés et généralement assez fragmentés. Néanmoins, leur bon état de conservation général a permis une détermination taxonomique assez précise pour la plupart d'entre eux. L'identification des carpo-restes a été réalisée à l'aide d'une collection de référence de semences actuelles personnelle, ainsi que d'atlas taxonomiques spécialisés (Brouwer, Stählin 1975 ; Beijerinck 1976; Cappers, Bekker, Jans 2005).

\section{Résultats de l'analyse carpologique}

Au total, 94 carpo-restes ont été collectés, dont 63 dans les tombes et 31 dans l'ustrinum. De façon globale, douze taxons végétaux ont été identifiés, la plupart appartenant au groupe des plantes cultivées (céréales, légumineuses et fruits). Il est cependant intéressant de noter que, même en nombre très réduit, les principales espèces économiques méditerranéennes de l'Âge du Fer sont présentes sur le site (Marinval-Ruas 1991 ; Buxó 1992; Alonso, Buxó, Rovira 2008 ; Alonso, Rovira 2010 ; Bouby 2010).

\section{Les céréales}

Parmi les céréales, trois espèces sont attestées : l'orge vêtue (Hordeum vulgare), le blé commun (Triticum aestivum/durum) et le millet commun (Panicum miliaceum). Le faible nombre de restes ainsi que le nombre réduit d'attestation, ne permettent pas de juger de leur importance, mais les deux premières espèces sont assez récurrentes.

\section{Les légumineuses}

Le groupe des légumineuses est représenté essentiellement par deux taxons, la lentille (Lens culinaris) et la vesce (Vicia sp.). Deux autres carpo-restes ont été déterminés comme Vicia/Pisum en raison de leur grande taille, mais ils ne conservent pas suffisamment de critères morphologiques pour permettre de préciser leur identification. 


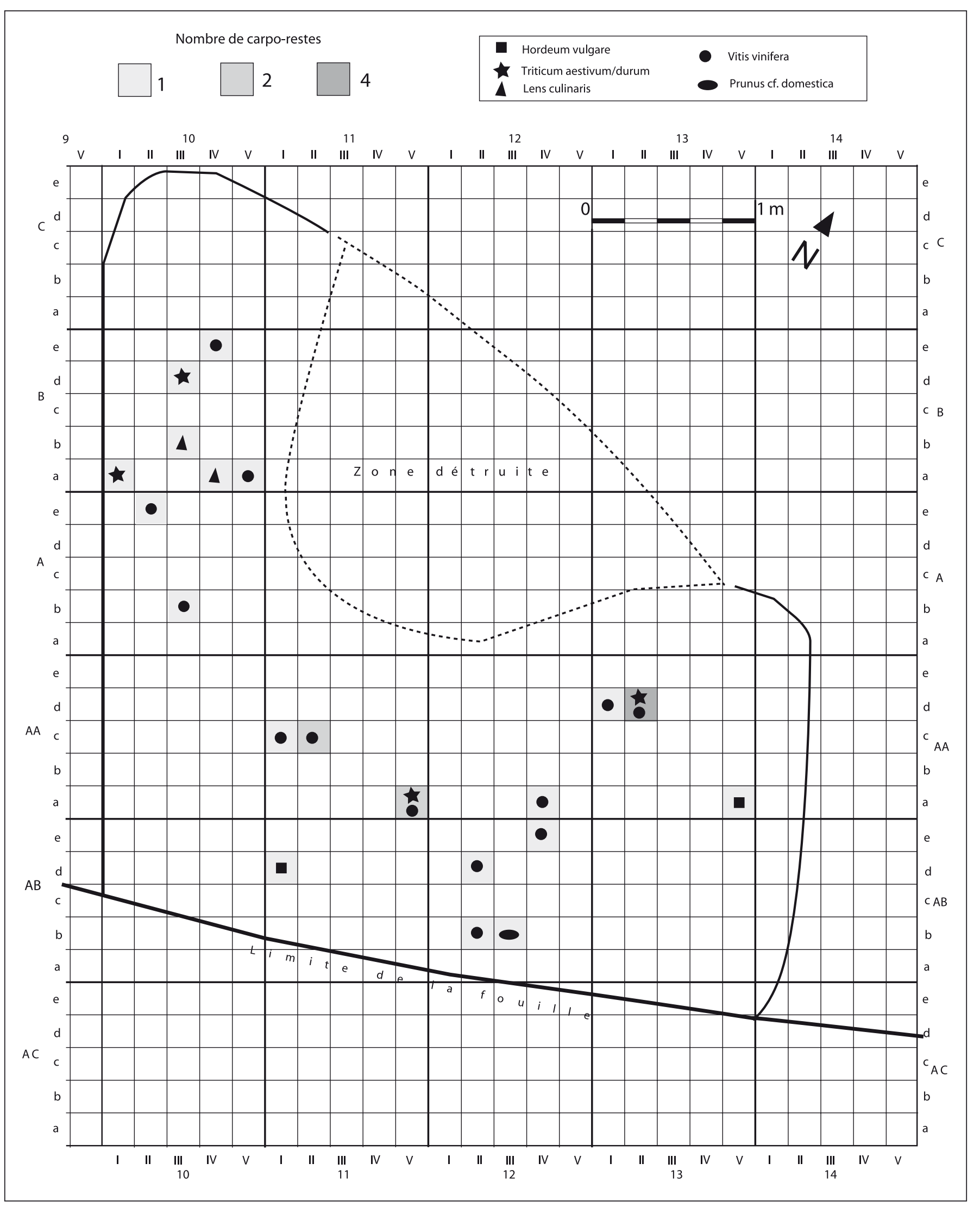

Fig. 135. Distribution dans la couche de fonctionnement de l'aire de crémation B1 des taxons végétaux issus de l'analyse des restes carpologiques. Les symboles correspondent aux taxons identifiés et la couleur au nombre de restes par carré. 


\section{Les fruits}

Au total, cinq taxons font partie de la catégorie des fruits: le raisin (Vitis vinifera), la cornouille (Cornus mas), la noisette (Corylus avellana), le gland (Quercus sp.) et la prune (Prunus cf. domestica). Le raisin est le seul taxon que l'on peut attribuer sans aucun doute au groupe des plantes cultivées. Le prunier et le noisetier ont pu être également cultivés mais le faible nombre de restes ne permet pas de l'affirmer. En revanche, le cornouiller mâle est une espèce exploitée par ses fruits, mais qui a priori n'aurait pas fait l'objet d'une mise en culture. Quant aux restes de Quercus sp., espèce prédominante dans le bûcher funéraire (Cenzon, Durand dans ce volume), seule une cupule a été collectée et aurait pu arriver sur le bûcher en même temps que le combustible. À l'exception du raisin, tous les autres taxons ne sont attestés que de façon ponctuelle.

\section{Plantes rudérales}

Un seul taxon, le chardon aux ânes (Onopordum acanthium), fait partie des espèces rudérales qui poussent dans les milieux ouverts et anthropisés.

\section{Discussion : les carpo-restes et leur contexte d'attestation}

Afin de répondre à la question initialement posée sur l'éventualité d'un dépôt d'offrandes végétales avec le défunt ou bien sur le caractère intrusif des carpo-restes attestés dans la nécropole d'Ambrussum, une analyse différenciée entre les tombes et le bûcher est proposée.

\section{L'ustrinum}

Un total de cinq taxons végétaux a été identifié dans le niveau de fonctionnement de l'ustrinum : l'orge vêtue, le blé commun, la lentille, le raisin et la prune (fig. 135). En général, le nombre de carpo-restes par carré est très faible (de 1 à 4 restes). Le volume de sédiment tamisé par carré varie en moyenne entre 0,5 et 10 litres. La plupart des carrés n'ont livré qu'un seul carpo-reste, ce qui correspond donc à un seul taxon. Leur répartition spatiale est plutôt aléatoire et aucune concentration de taxons n'est attestée.

Concernant le socle de l'ustrinum, l'orge vêtue, le blé commun et une légumineuse indéterminée (Vicia/Pisum) ont été identifiés. Ces attestations suivent la même tendance observée dans la couche de fonctionnement de cette structure.
En définitive, aucun dépôt volontaire de graines ou de produits végétaux ne peux être identifié. L'hypothèse que ces carpo-restes soient des intrusions provenant soit de la matrice sédimentaire, soit de leur rejet dans le feu au cours de la combustion semble à retenir. Dans ce dernier cas, il pourrait s'agir de produits végétaux consommés lors du rituel d'incinération qui ont été jetés dans le bûcher, mais rien ne permet de l'affirmer.

\section{Les tombes}

Les carpo-restes attestés dans les tombes sont également peu nombreux (fig. 136). On note la présence de trois céréales (orge vêtue, millet commun et blé commun), d'une légumineuse (vesce), de trois fruits (cornouille, noisette et gland) et d'une espèce rudérale (chardon aux ânes).

En général, les tombes présentent entre 1 et 3 restes par structure. La seule exception est la tombe 14, avec 21 restes dans les deux couches de la superstructure et 31 restes dans le loculus. Il s'agit pour la plupart de caryopses de céréales et de pépins de raisin. Aucun élément archéologique observé ou collecté dans cette tombe semble la distinguer du reste. De ce fait, la présence plus abondante de restes carpologiques pourrait être simplement fruit du hasard.

En définitive, concernant les activités qui sont à l'origine de ces restes, aucun élément ne permet d'affirmer une fois de plus qu'ils soient issus d'une activité volontaire liée à des pratiques cultuelles. Ainsi, il semble envisageable que ces carpo-restes étaient contenus dans la matrice sédimentaire dans laquelle les tombes (loculus) ont été creusées et qui a servi également à leur recouvrement (superstructure). Il s'agirait donc de déchets de consommation.

\section{Conclusions}

À notre connaissance, l'utilisation de produits végétaux dans les pratiques funéraires de l'âge du Fer en France méditerranéenne reste rare. Le seul exemple connu est celui de la nécropole de Peyraube (Lamelouze, Gard), plus exactement du tumulus de Peyraube 6 (Dedet, Gauthey 1994). Le dépôt correspondait à un amas de sédiment foncé situé à proximité de la région où reposait le défunt. L'analyse chimique des composants organiques montre qu'il ne s'agit pas de résidus de combustion, mais de produits végétaux décomposés sur place : une gerbe de graminées (sauvages ou cultivées ?) 


\begin{tabular}{|c|c|c|c|c|c|c|c|c|c|c|c|}
\hline & \multirow{3}{*}{$\begin{array}{c}12 \\
\mathrm{SE} \\
17028\end{array}$} & \multicolumn{3}{|c|}{14} & \multirow{3}{*}{$\begin{array}{c}16 \\
L \\
17030\end{array}$} & \multicolumn{2}{|c|}{17} & \multirow{3}{*}{$\begin{array}{c}18 \\
\frac{L}{17035}\end{array}$} & \multirow{3}{*}{$\begin{array}{c}21 \\
L \\
17047\end{array}$} & \multirow{3}{*}{$\begin{array}{c}22 \\
\frac{L}{17138}\end{array}$} & \multirow[b]{4}{*}{ Total } \\
\hline Partie & & \multicolumn{2}{|c|}{ SE } & \multirow{2}{*}{$\frac{\mathrm{L}}{17050}$} & & \multirow{2}{*}{\begin{tabular}{|c|} 
SE \\
17029
\end{tabular}} & \multirow{2}{*}{$\frac{\mathrm{L}}{17053}$} & & & & \\
\hline & & 17026 & 17027 & & & & & & & & \\
\hline Céréales & & & & & & & & & & & \\
\hline 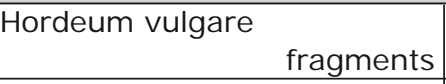 & & $\begin{array}{l}2 \\
1\end{array}$ & 1 & & 1 & & & & & & $\begin{array}{l}4 \\
1\end{array}$ \\
\hline Panicum miliaceum & & & & 2 & & & & & & & 2 \\
\hline $\begin{array}{r}\text { Triticum aestivum/durum } \\
\text { fragments }\end{array}$ & & $\begin{array}{l}2 \\
2\end{array}$ & 3 & 2 & & & & & & & $\begin{array}{l}7 \\
2\end{array}$ \\
\hline $\begin{array}{ll}\text { Triticum sp. } & \text { frag. } \\
\end{array}$ & & & & 1 & & & & & & & 1 \\
\hline Hordeum/Triticum frag. & & 1 & 3 & 2 & 1 & & & 1 & & & 8 \\
\hline Légumineuses & & & & & & & & & & & \\
\hline Vicia sp. & & & & & & 1 & & & & & 1 \\
\hline Vicia/Pisum & & & & & & & & & & 1 & 1 \\
\hline Fruits & & & & & & & & & & & \\
\hline Vitis vinifera & & 3 & $\begin{array}{l}1 \\
2\end{array}$ & $\begin{array}{c}8 \\
14\end{array}$ & & & 2 & & & & $\begin{array}{l}11 \\
19\end{array}$ \\
\hline Bois et haies & & & & & & & & & & & \\
\hline Cornus mas & & & & 1 & & & & & & & 1 \\
\hline Corylus avellana & & & & & & & & & 1 & & 1 \\
\hline Quercus sp. & 1 & & & & & & & & & & 1 \\
\hline Rudérales & & & & & & & & & & & \\
\hline Onopordum acanthium & & & & 1 & & & & & & & 1 \\
\hline I ndéterminées & & & & & & & & & & & \\
\hline Indéterminées & & & & & & & & $\begin{array}{l}1 \\
1\end{array}$ & & & $\begin{array}{l}1 \\
1\end{array}$ \\
\hline Nb restes & 1 & 11 & 10 & 31 & 2 & 1 & 2 & 3 & 1 & 1 & 63 \\
\hline Nb litres & 78 & 116 & 50 & 30 & 23 & 166 & 13 & 110 & 130 & 290 & 1006 \\
\hline
\end{tabular}

Fig. 136. Taxons végétaux identifiés dans les tombes ( $\mathrm{SE}=$ superstructure; $\mathrm{L}=$ loculus).

ou bien un tissu (en lin ?). Ce tumulus est daté entre le $\mathrm{VIII}^{\mathrm{e}}$ et la première moitié du $\mathrm{VI}^{\mathrm{e}} \mathrm{s}$. avant notre ère.

Une seconde offrande végétale de ce type, cette fois-ci dans le Nord de la France, a été identifiée sur la nécropole d'Esvres (Indre-et-Loire) dans une tombe d'enfant datée de la fin de l'âge du Fer (Verdin 2010). Dans ce cas, l'analyse des phytolithes a permis de mettre en évidence un probable dépôt d'aiguilles de conifères dans un vase, de millet dans un autre, puis d'un possible coussin de millet sous la tête du défunt. En parallèle, le corps aurait pu reposer sur une litière de paille.

En ce qui concerne les dépôts d'offrandes végétales alimentaires, en particulier de graines, de fruits, de préparations culinaires (dont des pains/galettes) ou de boissons, quelques exemples existent pour l'âge du Bronze (Marinval 1986). Dans l'Est de la France, un dépôt de millet commun a été retrouvé dans une sépulture de la nécropole de Dampierre (Doubs) et un amas constitué de blé amidonnier, blé tendre/dur, orge vêtue et avoine rude est issu du tertre funéraire de Maisod (Jura) ; dans le Nord-Ouest, il faut noter la découverte de noisettes dans le caveau sous le cairn de Kernonen (Finistère). En fait, il faut attendre la période gallo-romaine pour que ce type d'offrandes soit répandu et abondant, surtout en contexte de crémation (Marinval 1993, 2004 ; Pradat 1994 ; Bouby, Marinval 2004 ; Preiss, Matterne, Latron 2005 ; Ruas, Bouby, Pradat 2006).

Pour conclure, dans le cas de la nécropole de la fin du III' s. av. n. è. d'Ambrussum, l'analyse des restes carpologiques ne permet pas d'affirmer l'utilisation de produits végétaux comme offrandes pour les défunts dans les tombes ou la crémation volontaire de végétaux dans le bûcher. 




\section{Bibliographie}

\begin{abstract}
Almagro Basch 1953 : ALMAGRO BASCH (M.) - Las necrópolis de Ampurias. I. Introducción y necrópolis griegas. Barcelona, Diputación provincial de Barcelona-Consejo superior de investigaciones científicas 1953, 399 p. et XVIII pl. HT (coll. Monografías Ampuritanas III).
\end{abstract}

Alonso, Rovira 2010 : ALONSO (N.), ROVIRA (N.) - Consommation et traitement des produits végétaux à Lattara entre -475 et -350 . In : Janin (T.) dir. - Premières données sur le cinquième siècle avant notre ère dans la ville de Lattara. Lattara, 21, 2010, p. 329-388.

Alonso, Buxó, Rovira 2008 : ALONSO (N.), BUXÓ (R.), ROVIRA (N.) Archéobotanique des semences et des fruits de Lattara: bilan des recherches. In : Janin (T.), Py (M), La ville portuaire de Lattara (Lattes, Hérault) et son territoire : nouveaux acquis, nouvelles questions. Gallia, 65, 2008, p. 193-200.

Anwar 2010: ANWAR (N.) - La nécropole à incinération des Oubiels (Sigean, Aude) : le mobilier non céramique des $\mathrm{IV}^{\mathrm{e}}-\mathrm{III}^{\mathrm{e}}$ s. av. J.-C. In : Barral (P.), Dedet (B.), Delrieu (F.), Giraud (P.), Le Goff (I.), Marion (S.), Villard (A.) dir., Gestes funéraires en Gaule au Second Âge du Fer, Actes du 33e colloque de l'AFEAF, Caen 2009. Besançon, Presses Universitaires de Franche-Comté, 2010, p. 303-309 (Annales littéraires, n 883 ; Série «Environnement, sociétés et archéologie », n 14).

Arcelin, Arcelin 1975 : ARCELIN (P.), ARCELIN (C) - Les sépultures préromaines de Saint-Rémy-de-Rovence. Revue Archéologique de Narbonnaise, VIII, 1975, p. 67-135

Arcelin, Dedet 1985 : ARCELIN (P.) et DEDET (B.) - Les enceintes protohistoriques du Midi méditerranéen des origines à la fin du II ${ }^{\mathrm{e}}$ s. av. J.-C. In : Dedet (B.), Py (M.) dir., Les enceintes protohistoriques de Gaule méridionale. Caveirac, Association pour la Recherche Archéologique en Languedoc Oriental, 1985, p. 11-37 (Cahier 14).

Arcelin, Rapin 2003 : ARCELIN (P.), RAPIN (A.) - Considérations nouvelles sur l'iconographie anthropomorphe de l'âge du Fer en Gaule méditerranéenne. In : Buchsenschutz (O.), Bulard (A.), Chardenoux (M.-B.), Ginoux (N.) éd., Décors, images et signes de l'âge du Fer européen, Actes du XXVI ${ }^{\mathrm{e}}$ colloque de l'AFEAF, Paris - Saint-Denis, 2002. Tours, FERACF, 2003, p. 183-219 (Supplément à la Revue Archéologique du Centre de la France, 24)

Argente Oliver et al. 2000 : ARGENTE OLIVER (J.-L.), DÍAZ DÍAZ (A.), BESCÓS CORRAL (A.) - Tiermes V. Carratiermes, necrópolis celtibérica. Valladolid, ed. de la Junta de Castilla y León, 2000 (Arqueología en Castilla y León, Memorias, 9).

Augier et al. 2007 : AUGIER (L.), MENNESSIER-JOUANNET (C.), MILCENT (P.-Y.), ORENGO (L.), RIQUIER (S.) - La France centrale aux $\mathrm{IV}^{\mathrm{e}}-\mathrm{III}^{\mathrm{e}}$ s. av. n. ère (Auvergne, Berry et Orléanais). In : MennessierJouannet (C.), Adam (A.-M.), Milcent (P.-Y.) dir., La Gaule dans son contexte européen aux IV et $I I I^{e}$ s. av. n. è. Actes du XXVII e colloque de l'AFEAF, Clermont-Ferrand 2003, thème spécialisé. Lattes, Association pour le Développement de l'Archéologie en Languedoc-Roussillon, 2007, p. 117-176 (Monographies d'Archéologie Méditerranéenne).

Badal García 1990 : BADAL GARCÍA (E.) - Aportaciones de la antracologia al estudio del paisaje vegetal y su evolucion en le cuaternario reciente, en la costa mediterranea del Pais Valenciano y Andalucia (18000-3000 BP). Thèse de doctorat, Universitat de Valencia, Facultad de Geografia e Historia, 1990, 385 p. (dactylographié).

Baray 2003 : BARAY (L.) - Pratiques funéraires et sociétés de l'Âge du fer dans le Bassin parisien (fin du VII ${ }^{e}$ s. - troisième quart du II ${ }^{e}$ s. avant J.-C.). Paris, éd. du CNRS, 2003, 446 p. et un cédérom (Suppléments à Gallia, 56).
Baray, Chaume, Millet 2007 : BARAY (L.), CHAUME (B.), MILLET (E.) - Culture matérielle et pratiques funéraires en Bourgogne du nord aux IV et III ${ }^{\mathrm{e}}$ s. av. J.-C. In : Mennessier-Jouannet (C.), Adam (A.-M.), Milcent (P.-Y.) dir., La Gaule dans son contexte européen aux IVe et III ${ }^{e}$ s. av. n. è. Actes du XXVII ${ }^{e}$ colloque de l'AFEAF, Clermont-Ferrand 2003, thème régional. Lattes, Association pour le Développement de l'Archéologie en LanguedocRoussillon, 2007, p. 187-225 (Monographies d'Archéologie Méditerranéenne). Bass, Jantz 2004 : BASS (W.M.), JANTZ (R.L.) - Cremation weights in east Tennessee. Journal of Forensic Sciences, 49, 5, september 2004, p. 901-904. Beijerinck 1976: BEIJERINCK (W.) - Zadenatlas der Nederlandsche Flora. Amsterdam, Backhuys \& Meesters, 1976.

Bel 1996 : BEL (V.) - Étude spatiale de sept incinérations primaires galloromaines de la région lyonnaise. Bulletins et Mémoires de la Société d'anthropologie de Paris, Nouvelle Série 8, 3-4, 1996, p. 207-222.

Bel et al. 2008: BEL (V.), BARBERAN (S.), CHARDENON (N.), FOREST (V.), RODET-BÉLARBI (I.), VIDAL (L.) - Tombes et espaces funéraires de la fin de l'Âge du Fer et du début de l'époque romaine à Nîmes (Gard). Lattes, Association pour le Développement de l'Archéologie en LanguedocRoussillon, 2008, 519 p. (Monographies d'Archéologie Méditerranéenne, 24). Bel et al., à paraître : BEL (V.), GARDEISEN (A.), MARCHAND (G.), SCHWALLER (M.) - Au tournant des $\mathrm{III}^{\mathrm{e}}$ et II ${ }^{\mathrm{e}}$ s. av. J.-C. : une tombe singulière à Ensérune (Montady, Hérault), à paraître.

Bérard 1997 : BÉRARD (G.) - Les Alpes-de-Haute-Provence. Paris, Maison des Sciences de l'Homme, 1997, 567 p. (coll. Carte Archéologique de la Gaule, 04). Bérato, Dugas, Dutour 1991 : BÉRATO (J.), DUGAS (F.), DUTOUR (O.) - Les tombes protohistoriques de Gros Ped, Les Arcs-sur-Argens (Var). Documents d'Archéologie Méridionale 14, 1991, p. 125-140.

Berger et al. 2004 : BERGER (J.-F.), FICHES (J.-L.), GAZENBEEK (M.) La gestion du risque fluvial à Ambrussum durant l'Antiquité par les riverains du Vidourle. In : Burnouf (J.), Leveau (P.) dir., Fleuves et marais, une histoire au croisement de la nature et de la culture. Sociétés préindustrielles et milieux fluviaux, lacustres et palustres : pratiques sociales et hydrosystèmes. Paris, CTHS, 2004, p. 419-435.

Bertucchi 1992 : BERTUCCHI (G.) - Nécropoles et terrasses funéraires à l'époque grecque. Bilan sommaire des recherches. In : Bats (M.), Bertucchi (G.), Congès (G.), Tréziny (H.), Marseille grecque et la Gaule, actes du Colloque international d'Histoire et d'Archéologie et $d u V^{e}$ Congrès archéologique de Gaule méridionale, Marseille, 1990, Lattes/Aix-en-Provence, ADAM éditions/ Université de Provence, 1992, p. 123-137 (Études Massaliètes, 3).

Blaizot 2005 : BLAIZOT (F.) - Contribution à la connaissance des modes de dislocation et de destruction du squelette pendant la crémation : l'apport du bûcher funéraire en fosse du Néolithique final à Reichstett-Mundolsheim (Bas-Rhin). Bulletins et mémoires de la Société d'Anthropologie de Paris, 17, 1-2, 2005, p. 13-35.

Blaizot dir. 2009 : BLAIZOT (F.) dir. - Pratiques et espaces funéraires de la Gaule durant l'Antiquité. Gallia, 66-1, 2009, 387 p.

Bonnet 1905 : BONNET (É.) - Antiquités et monuments du département. In : Géographie générale du département de l'Hérault, III, 2. Montpellier, Société languedocienne de géographie, 1905, p. 199-753.

Bonucci, Grazziani 1975 : BONUCCI (E.), GRAZZIANI (G.) - Comparative thermogravimetric, $\mathrm{x}$-ray diffraction and electron microscope investigations of burnt bones from recent, ancient and prehistoric age. Academia Nazionale dei Lincei, Rendiconti della Classe di scienze fisiche, matematiche e naturali, série 8, 59, 5, 1975, p. 518-533. 
Bouby 2010 : BOUBY (L.) - Agriculture dans le bassin du Rhône du Bronze final à l'Antiquité. Agrobiodiversité, économie, cultures. Thèse de doctorat, EHESS, Toulouse-Le Mirail, 2010.

Bouby, Marinval 2004 : BOUBY (L.), MARINVAL (P.) - Fruits and seeds from Roman cremations in Limagne (Massif central) and the spatial variability of plant offering in France. Journal of Archaeological Science, 31, 2004, p. 77-86.

Boyer,Dedet,Marchand 2006 : BOYER(R.),DEDET(B.),MARCHAND (G.) - L'aven sépulcral de Plérimond à Aups, Var (VI' siècle av. J.-C.). Gallia, 63, 2006, p. 171-209.

Braun-Blanquet 1936 : BRAUN-BLANQUET (J.) - La Chênaie d'Yeuse méditerranéenne (Quercion ilicis), Monographie phytosociologique. MariLavit, Montpellier,1936, 148 p.

Brouwer, Stählin 1975 : BROUWER (W.), STÄHLIN (A.) - Handbuch der Samenkunde für Landwirschaft, Gartenbau und Forstwirtschaft. DLG Verlag. Frankfurt, 1975.

Brunaux 1996 : BRUNAUX (J.-L.) - Les religions gauloises. Rituels celtiques de la Gaule indépendante. Paris, Errance, 1996, 216 p.

Brunaux, Lambot 1987 : BRUNAUX (J.-L.), LAMBOT (B.) - Guerre et armement chez les Gaulois 450-52 av. J.-C. Paris, Errance, 1987, 220 p.

Brunaux, Rapin 1988 : BRUNAUX (J.-L.), RAPIN (A.) - Gournay II. Boucliers et lances, dépôts et trophées. Paris, Revue Archéologique de Picardie/éd. Errance, 1988, 245 p.

Buxó 1992 : BUXÓ (R.) - Cueillette et agriculture à Lattes: les ressources végétales d'après les semences et les fruits. Lattara, 5, 1992, p. 45-90.

Cappers, Bekker, Jans 2006 : CAPPERS (T.J.), BEKKER (M.), JANS (J.E.A.) - Digitale Zadenatlas van Nederland. Barkhuis, Groningen, 2006.

Carme, Demangeot 2010 : CARME (R.), DEMANGEOT (C.) - Beaucaire, Collège Eugène Vigne. Bilan Scientifique de la Région Languedoc-Roussillon 2008. Paris, Ministère de la Culture, 2010, p. 68-71.

Chabal 1995 : CHABAL (L.) - Les combustibles de cinq tombes à incinération du deuxième Age du fer à Ensérune (Nissan-lez-Ensérune, Hérault). In : Arcelin (P.), Bats (M.), Garcia (D.), Marchand (G.), Schwaller (M.) éd. Sur les pas des Grecs en Occident. Hommages à André Nickels. Paris/Lattes, Errance/ADAM éditions, 1995, p. 231-236 (Études massaliètes 4).

Chabal, Feugère 2005 : CHABAL (L.), FEUGÈRE (M.) - Le mobilier organique des puits antiques et autres contextes humides de Lattara. Lattara 18, Lattes, Association pour le Développement de l'Archéologie en LanguedocRoussillon, 2005, p. 137-188.

Chabal 1997 : CHABAL (L.) - Forêts et sociétés en Languedoc (Néolithique final, Antiquité tardive). L'anthracologie, méthode et paléoécologie. Paris, Maison des sciences de l'Homme, 1997, 189 p. (Documents d'archéologie Française 63).

Chabot 1983 : CHABOT (L.) - L'oppidum de La Cloche aux PennesMirabeau (Bouches-du-Rhône) (synthèse des travaux effectués de 1967 à 1982). Revue Archéologique de Narbonnaise, XVI, 1983, p. 39-80.

Chabot, Féraud 1959 : CHABOT (L.), FÉRAUD (J.-B.) - La nécropole de la rue du Tapis-Vert à Marseille, Cahiers Ligures de Préhistoire et d'Archéologie, 8, p. 63-86.

Chantre 1878 : CHANTRE (E.) - Les nécropoles du premier Âge du Fer dans les Alpes françaises. Matériaux pour l'Histoire primitive et naturelle de l'Homme, XIV e année, $2^{\mathrm{e}}$ série, IX, 1878, p. 1-15.

Charpy 1991 : CHARPY (J.-C.) - La Champagne. In : Les Celtes, Bompiani, Milan 1991, p. 245-250.

Charpy 1995 : CHARPY (J.-C.) - Les fibules dites de Münsingen en Champagne. In: Charpy (J.-C.), L'Europe celtique du $V^{e}$ au III $I^{e}$ siècle avant J.-C., Contacts, échanges et mouvements de populations. Actes du $2^{\mathrm{e}}$ Symposium International d'Hautvillers, 1992. Sceaux, éd. Kronos, 1995, p. 335-390.

Chazelles et al. 1984: CHAZELLES (C.-A. de), FICHES (J.-L.), GENIS-ARMADA (M.-T.), MANNIEZ (Y.), ROUX (J.-C.) - Recherches archéologiques dans le quartier bas d'Ambrussum (Villetelle, Hérault). 4. La fouille de sauvetage en 1983. A.R.A.L.O. Caveirac, Association pour la Recherche Archéologique en Languedoc Oriental, 1984, 43 p. (Dossier 6). Chazelles, Feugère, Ferré 1994 : CHAZELLES (C.-A. de), FEUGÈRE (M.), FERRÉ (M.) - Découverte d'un casque celtique à décor de corail sur l'oppidum de Montlaurès (Narbonne, Aude). Bulletin de la Commission Archéologique et Littéraire de Narbonne, 45, 1994, p. 113-115.

Columeau 1979: COLUMEAU (P.) - Sondage au sommet de la colline d'Ambrussum (Villetelle, Hérault). II : étude de la faune. Documents d'Archéologie Méridionale, 2, 1979, p. 51-52.

Daremberg, Saglio dir. 1877-1918 : DAREMBERG (C.), SAGLIO (E.) dir. Dictionnaire des antiquités grecques et romaines. Paris, Hachette, 1877-1918. Dasen 2003 : DASEN (V.) - Protéger l'enfant: amulettes et crepundia. In : Gourevitch (D.), Moirin (A.), Rouquet (N.) dir., Maternité et petite enfance dans l'Antiquité romaine. Catalogue d'exposition. Muséum d'Histoire Naturelle. Bourges, éd. de la ville de Bourges, 2003, p. 172-177.

Daveau et al. 2008 : DAVEAU (I.) dir., DEDET (B.), GUERRE (J.), RÉMY (I.), RASCALOU (P.), RAUX (S.), HENRY (É.), JORDA (C.), MARTIN (S.), CAROZZA (L.), PELLÉ (R.) - Enclos funéraires de l'Âge du fer et voies romaines à «La Pailletrice » à Pérols (Hérault), Rapport final d'opération, Nîmes, Inrap, 2008, 224 p.

Daveau, Dedet 2010 : DAVEAU (I.), DEDET (B.) - Découverte de tumulus à enclos du dernier quart du $\mathrm{VI}^{\mathrm{e}} \mathrm{s}$. et du premier quart du $\mathrm{V}^{\mathrm{e}} \mathrm{s}$. dans la plaine littorale languedocienne à Pérols (Hérault). In : Barral (P.), Dedet (B.), Delrieu (F.), Giraud (P.), Le Goff (I.), Marion (S.), Villard (A.) dir., Gestes funéraires en Gaule au Second Âge du Fer. Actes du $33^{e}$ colloque de l'AFEAF, Caen 2009, thème spécialisé. Besançon, Presses universitaires de Franche-Comté, 2010, p. 297-302 (Annales littéraires, n 883 ; Série «Environnement, sociétés et archéologie », $\left.\mathrm{n}^{\circ} 14\right)$.

Deberge, Orengo 2007 : DEBERGE (Y.), ORENGO (L.) - Les mobiliers en contexte funéraire en Basse-Auvergne (du $\mathrm{III}^{\mathrm{e}}$ au ${ }^{\mathrm{er}} \mathrm{s}$. avant notre ère) : nouvel état des connaissances. In : Mennessier-Jouannet (C.), Deberge (Y.) éd., L'archéologie de l'Âge du Fer en Auvergne. Actes du XXVII ${ }^{\mathrm{e}}$ colloque international de l'Association Française pour l'Étude de l'Âge du Fer, Clermont-Ferrand, 2003, thème régional. Lattes, Association pour le Développement de l'Archéologie en Languedoc-Roussillon, 2007, p. 333-364 (Monographies d'Archéologie Méditerranéenne).

Deberge et al. 2007: DEBERGE (Y.), ORENGO (L.), LOUGTHON (M.), VERRIER (G.) - La culture matérielle de la Grande Limagne d'Auvergne du III ${ }^{\mathrm{e}}$ au I ${ }^{\text {er }}$ s. av. J.-C. In: Mennessier-Jouannet (C.), Deberge (Y.) éd., L'archéologie de l'Âge du Fer en Auvergne. Actes du XXVII colloque international de l'Association Française pour l'Étude de l'Âge du Fer, Clermont-Ferrand, 2003, thème régional. Lattes, Association pour le Développement de l'Archéologie en Languedoc-Roussillon, 2007, p. 167-204 (Monographies d'Archéologie Méditerranéenne).

Déchelette 1927 : DÉCHELETTE (J.) - Manuel d'archéologie préhistorique et celtique. 4, second âge du Fer, époque de la Tène. Paris, Picard 1927, p. 417-1163.

Dedet 1992: DEDET (B.) - Rites funéraires protohistoriques dans les Garrigues languedociennes. Paris, éd. du CNRS, 1992, 413 p. (Suppléments à la Revue Archéologique de Narbonnaise, 24).

Dedet 1995a : DEDET (B.) - Une illustration de l'évolution des pratiques funéraires en Languedoc oriental à l'Age du Fer : la tombe de Font de la Vie à Saint-Bauzille-de-Montmel, Hérault, V V s. av. J.-C. Gallia, 52, 1995, p. $145-163$.

Dedet 1995b : DEDET (B.) - Étrusques, Grecs et Indigènes dans les Garrigues du languedoc oriental au premier Age du Fer : habitats et sépultures. In : Arcelin (P.), Bats (M.), Garcia (D.), Marchand (G.), Schwaller (M.) éd. - Sur les pas des Grecs en Occident, Hommages à André Nickels. Paris/ Lattes, Errance/ADAM éditions, 1995, p. 277-307 (Études massaliètes, 4).

Dedet 2000 : DEDET (B.) - Pratiques funéraires et société au premier Age du Fer dans les Garrigues languedociennes. In: Gascó (J.), Claustre (F.), Habitats, économies et sociétés du Nord-Ouest méditerraéen de l'Âge du Bronze au premier Âge du Fer. XXIV e congrès préhistorique de France, Carcassonne, 1994. Paris, Société Préhistorique Française, 2000, p. 175-189. Dedet 2001 : DEDET (B.) - Tombes et pratiques funéraires protohistoriques des Grands Causses du Gévaudan. Paris, Maison des sciences de l'Homme, 2001, 356 p. (Documents d'Archéologie Française, 84).

Dedet 2004 : DEDET (B.) - Variabilité des pratiques funéraires protohistoriques dans le sud de la France : défunts incinérés, défunts non brûlés. Gallia, 61, 2004, p. 193-222. 
Dedet 2008 : DEDET (B.) - Les enfants dans la société protohistorique. L'exemple du Sud de la France. Rome, École française de Rome, 2008, 400 p. (coll. de l'École française de Rome, 396).

Dedet 2009: DEDET (B.) - Sépultures et société dans le Sud-Est de la France au bronze final IIIb et au premier âge du Fer. In : Guilaine (J.) dir., Sépultures et sociétés : du Néolithique à l'Histoire. Séminaire du Collège de France. Paris, Errance, 2009, p. 197-224.

Dedet 2011 : DEDET (B.) - Les Gaulois du Midi et Marseille grecque : deux mondes funéraires. Gallia, 68-2, 2011, p. 1-45.

Dedet à paraître : DEDET (B.) - Tombes sur bûcher et dépôts secondaires d'incinération en Languedoc oriental et en Provence au premier Âge du Fer. In : Rovira Hortalà (M.C.), López Cachero (F.J.), Mazière (F.) dir., Les necròpolis de incineració entre l'Ebre i el Tíber. Taula rodona internacional, Barcelona, Museu d'Arqueologia de Catalunya, 2008, sous presse.

Dedet $\boldsymbol{e}$ t al. 2003 : DEDET (B.), JANIN (T.), MARCHAND (G.), SCHWALLER (M.) - Canthares, bassins et amphores pour l'au-delà : la nécropole de Saint Julien en Languedoc (Pézenas, Hérault). In : Landes (C.) éd., Les Étrusques en France. Archéologie et collections. Catalogue d'exposition. Lattes, Musée archéologique Henri Prades, 2003, p 169-182.

Dedet, Gauthey 1994 : DEDET (B.), GAUTHEY (J.) - La nécropole de Peyraube (Lamelouze, Gard) au premier Âge du Fer. Documents d'Archéologie Méridionale, 17, 1994, p. 101-151.

Dedet, Gauthey 2008 : DEDET (B.), GAUTHEY (J.) - Tombe du second âge du Fer de La Roussillone à Nîmes, Gard. Documents d'Archéologie Méridionale, 31, 2008, p. 213-228.

Dedet, Lisfranc 2005 : DEDET (B.), LISFRANC (R.) - Les trois tombes du premier âge du Fer de Gallière à Montpellier (Hérault). Documents d'Archéologie Méridionale, 28, 2005, p. 91-104.

Dedet, Marchand 2009 : DEDET (B.), MARCHAND (G.) - Deux dépôts avec armes du VI ${ }^{\mathrm{e}}$ s. av. J.-C. en Provence orientale : les Clues de Verdaches à Auzet (Alpes-de-Haute-Provence) et la source du Noyer à Roquefort-les-Pins (Alpes-Maritimes). Gallia, 66, 2009, p. 1-28.

Dedet, Marchand 2010 : DEDET (B.), MARCHAND (G.) - Les tombes à arme du Roussillon et des terres avoisinantes durant la Protohistoire. In : Des vases pour l'Éternité. La nécropole de Negabous et la Protohistoire du Roussillon. Catalogue d'exposition. Conseil général des Pyrénées orientales, Perpignan 2010, p. 89-102.

Dedet, Marchand, à paraître : DEDET (B.), MARCHAND (G.) - Armes et tombes de guerriers en Languedoc et en Provence au Bronze final et au premier Age du Fer : équipement, représentation et symbolique. À paraître.

Dedet, Michelozzi, Py 1974 : DEDET (B.), MICHELOZZI (A.), PY (M.) - La nécropole des Colombes à Beaucaire (Gard), $\mathrm{II}^{\mathrm{e}}-\mathrm{I}^{\mathrm{er}} \mathrm{s}$. av. J.-C. Revue Archéologique de Narbonnaise, VII, 1974, p. 59-118.

Dedet, Paya 2006-2007 : DEDET (B.), PAYA (D.) - La tombe du premier Âge du Fer de Saint-Martin-de-Colombs à Fabrègues (Hérault). Documents d'Archéologie Méridionale, 29-30, 2006-2007, p. 25-32.

Dedet, Schwaller 1990 : DEDET (B.), SCHWALLER (M.) - Pratiques cultuelles et funéraires en milieu domestique sur les oppidums languedociens. Documents d'Archéologie Meridionale, 13, 1990, p.137-163.

Dedet, Schwaller 2010 : DEDET (B.), SCHWALLER (M.) - Les pratiques funéraires en Languedoc et en Provence du $\mathrm{V}^{\mathrm{e}}$ au milieu du $\mathrm{II}^{\mathrm{e}} \mathrm{s}$. av. J.-C. In : Barral (P.), Dedet (B.), Delrieu (F.), Giraud (P.), Le Goff (I.), Marion (S.), Villard-Le Tiec (A.) dir., Gestes funéraires en Gaule au Second Âge du Fer. Actes du 33 $3^{\mathrm{e}}$ colloque de l'AFEAF, Caen 2009, thème spécialisé. Besançon, Presses universitaires de Franche-Comté, 2010, p. 269-290 (Annales littéraires, ${ }^{\circ} 883$; Série « Environnement, sociétés et archéologie », $\left.\mathrm{n}^{\circ} 14\right)$.

Demoule 1999 : DEMOULE (J.-P.) - Chronologie et société dans les nécropoles celtiques de la culture Aisne-Marne du VI ${ }^{e}$ au III ${ }^{e}$ siècle avant notre ère. Revue Archéologique de Picardie, $\mathrm{N}^{\circ}$ spécial 15, 1999, 406 p.

Dubosse 2007 : DUBOSSE (C.) - Ensérune (Nissan-lez-Ensérune, Hérault). Les céramiques grecques et de type grec dans leurs contextes ( $V I^{e}-I V^{e} s$. av. n. e.). Lattes, Association pour le Développement de l'Archéologie en Languedoc-Roussillon, 2007, 567 p. (Monographies d'Archéologie Méditerranéenne, 23).

Ducongé, Gomez de Soto 2007 : DUCONGÉ (S.), GOMEZ DE SOTO (J.) Les dépôts à caractère cultuel en milieux humides et dans les cavités naturelles du Centre-Ouest de la France à l’Âge du Fer. In : Barral (P.), Daubigney (A.), Dunning (C.), Kaenel (G.), Roulière-lambert (M.-J.) dir. - L'âge du Fer dans l'arc jurassien et ses marges. Dépôts, lieux sacrés et territorialité à l'âge $d u$ Fer. Actes du XXIXe colloque international de l'AFEAF, Bienne, 2005. Besançon, Presses universitaires de Franche-Comté, 2007, vol. 2, p. 477-492 (Annales littéraires ; série « Environnement, sociétés et archéologie »).

Duday 1989 : DUDAY (H.) - La nécropole du Peyrou à Agde (Hérault). Étude anthropologique. In : Nickels (A.), Marchand (G.), Schwaller (M.), Agde, la nécropole du premier Age du Fer. Paris, éd. du CNRS, 1989, p. 459472 (Suppléments à la Revue Archéologique de Narbonnaise, 19).

Duday, Depierre, Janin 2000 : DUDAY (H.), DEPIERRE (G.), JANIN (T.) - Etude anthropologique des sépultures secondaires à incinération : approche méthodologique. In : Dedet (B.), Gruat (P.), Marchand (G.), Py (M.), Schwaller (M.) éd., Archéologie de la mort, archéologie de la tombe au Premier Age du Fer. Actes du XXI colloque international de l'AFEAF, Conques 1997. Lattes, Association pour la Recherche Archéologique en Languedoc Oriental, 2000, p. 7-29 (Monographies d'Archéologie Méditerranéenne, 5).

Duday, Laubenheimer, Tillier 1995 : DUDAY (H.), LAUBENHEIMER (F.), TILLIER (A.-M.) - Sallèles d'Aude. Nouveau-nés et nourrissons galloromains. Paris, Les Belles Lettres, 1995, 146 p. (Annales Littéraires de l'université de Besançon, 563).

Dumoulin 1962 : DUMOULIN (A.) - Les fosses funéraires de Cucuron (Vaucluse). Gallia, XX, 1962, p. 323-333.

Duval 1971 : DUVAL (A.) - Le cimetière Tène Ic - Tène II de la Hourgnotte, commune de Liry (Ardennes). Antiquités Nationales, 1971-3, p. 53-66.

Duval 1976 : DUVAL (A.) - Aspects de la Tène Moyenne dans le Bassin Parisien. Bulletin de la Société Préhistorique française, 73, 1976, p. 457-484. Étienne, Müller, Prost 2006 : ÉTIENNE (R.), MÜLLER (C.), PROST (F.) Archéologie historique de la Grèce antique. Paris, Ellipses, 2006 (2e édition), $399 \mathrm{p}$.

Fabre 1996 : Fabre (L.) - Le charbonnage historique de la chênaie à Quercus ilex L. (Languedoc, France) : conséquences écologiques. Thèse de Doctorat de Sciences, Université de Montpellier II, 1996, 446 p. (dactylographié).

Fabre, Pernaud, Thiébault 2003 : FABRE (L.), PERNAUD (J.-M.), THIÉBAULT (S.) - Feu sacré ? Revue archéologique de Picardie, ${ }^{\circ}$ spécial 21, 2003, p. 139-146.

Fazekas, Kosa 1978 : FAZEKAS (I.-G.), KOSA (F.) - Forensic fetal osteology. Budapest : Akademiai Kiado, 1978, $414 \mathrm{p}$.

Ferembach, Schwidetzky, Stloukal 1979: FEREMBACH (D.), SCHWIDETZKY (I.), STLOUKAL (M.) - Recommandations pour déterminer l'âge et le sexe sur le squelette. Bulletins et Mémoires de la Société d'anthropologie de Paris, 6, série XIII, 1979, p. 7-45.

Feugère 1990a : FEUGÈRE (M.) - Les petits objets de l'îlot 3. In : Py dir., Fouilles dans la ville antique de Lattes. Les îlots 1, 3 et 4-nord du quartier Saint-Sauveur. Lattara, 3, Lattes, Association pour la Recherche Archéologique en Languedoc Oriental, 1990, p. 191-203.

Feugère 1990b : FEUGÈRE (M.) - Petits mobiliers, faciès et comparaisons. In : Py (M.) dir., Fouilles dans la ville antique de Lattes. Les îlots 1, 3 et 4-nord du quartier Saint-Sauveur. Lattara, 3, Lattes, Association pour la Recherche Archéologique en Languedoc Oriental, 1990, p. 357-375.

Feugère 1992 : FEUGÈRE (M.) - Le verre préromain en Gaule méridionale : acquis récents et questions ouvertes. Revue Archéologique de Narbonnaise, 25, 1992, p. 151-176.

Feugère, Py 1989 : FEUGÈRE (M.), PY (M.) - Les bracelets en verre de Nages (Gard) (Les Castels, fouilles 1958-1981). In : Feugère (M.) dir., Le verre préromain en Europe occidentale. Montagnac, éd. M. Mergoil, 1989, p. 153-167.

Feugère et al. 1994 : FEUGÈRE (M.), DEDET (B.), LECONTE (S.), RANCOULE (G). - Les parures du $\mathrm{V}^{\mathrm{e}}$ au $\mathrm{II}^{\mathrm{e}}$ s. av. J.-C. en Gaule méridionale : composantes indigènes, ibériques et celtiques. In : L'Âge du Fer en Europe sud-occidentale. Actes du XVI e colloque de l'AFEAF, Agen, 1992. Aquitania, XII, 1994, p. 237-281.

Feugère et al. 1998 : FEUGÈRE (M.), PASSELAC (M.), PELLECUER (C.), GARMY (P.), BEL (V.), BESSAC (J.-C.), de CHAZELLES (C.-A.), FICHES (J.-L.), MAUNÉ (S.), MONTEIL (M.), ROTH CONGÈS (A.), 
SABRIÉ (M.), SABRIÉ(R.) - Signes de la romanisation. Revue Archéologique de Narbonnaise, 31, 1998, p. 299-353.

Fiches, Fenouillet, Wujek 1976 : FICHES (J.-L.), FENOUILLET (M.), WUJEK (C.) - Sept ans de recherches à Ambrussum, oppidum relais de la voie domitienne (1968-1974). Caveirac, Association pour la Recherche Archéologique en Languedoc Oriental, 1976, 122 p. (Cahier 4).

Fiches, Gutherz, Roux 1979 : FICHES (J.-L.), GUTHERZ(X.), ROUX(J.-C.) - Sondage au sommet de la colline d'Ambrussum (Villetelle, Hérault). I : étude archéologique. Documents d'Archéologie Méridionale, 2, 1979, p. 27-50.

Fiches, Roux 1981 : FICHES (J.-L.), ROUX (J.-C.) - Recherches archéologiques dans le quartier bas d'Ambrussum (Villetelle, Hérault). 1. La fouille de sauvetage en 1980. Caveirac, Association pour la Recherche Archéologique en Languedoc Oriental, 1981, 39 p. (Dossier 1).

Fiches, Roux 1982 : FICHES (J.-L.), ROUX (J.-C.) - Recherches archéologiques dans le quartier bas d'Ambrussum (Villetelle, Hérault). 1. La fouille de sauvetage en 1981. Caveirac, Association pour la Recherche Archéologique en Languedoc Oriental, 1982, 38 p. (Dossier 3).

Fiches 1983 : FICHES (J.-L.) - L'occupation préromaine d'Ambrussum après la fouille du secteur IV. Documents d'Archéologie Méridionale, 6, 1983, p. 79-100.

Fiches dir. 1989 : FICHES (J.-L.) dir. - L'oppidum d'Ambrussum et son territoire. Fouilles au quartier du Sablas (Villetelle, Hérault), 1979-1985. Paris, éd. du CNRS, 1989, 286 p. (Monographie du CRA, 2).

Fiches, Mathieu 2002 : FICHES (J.-L.), MATHIEU (V.) - Ambrussum, Villetelle (Hérault). In : Fiches (J.-L.) dir.-Les agglomérations gallo-romaines en Languedoc-Roussillon, 2. Lattes, Association pour le Développement de l'Archéologie en Languedoc-Roussillon, p. 521-557 (Monographies d'Archéologie Méditerranéenne, 14).

Fiches et al. 2007 : FICHES (J.-L.), BARBÉRAN (S.), BERDEAUX-LE BRAZIDEC (M.-L.), CHABAL (L.), GAFA (R.), GARDEISEN (A.), GARCIA (L.), GAZENBEEK (M.), MATHIEU (V.), ROVIRA (N.) - Un enclos cultuel sur la berge du Virdourle à Ambrussum (Villetelle, Hérault). Revue Archéologique de Narbonnaise, 40, 2007, p. 47-116.

Fulconis 2004 : FULCONIS (S.) - Gars, Gourdon, Grasse, Saint-Cézaire : prospections. Bilan Scientifique Régional de Provence-Alpes-Côte d'Azur, 2004, p. 112-114.

Gallet de Santerre 1968 : GALLET DE SANTERRE (H.) - Fouilles dans le quartier ouest d'Ensérune (Insula ${ }^{\circ} \mathrm{X}$ ). Revue Archéologique de Narbonnaise, I, 1968, p. 39-83.

Galliou 1989 : GALLIOU (P.) - Les tombes romaines d'Armorique. Essai de sociologie et d'économie de la mort. Paris, Maison des sciences de l'Homme, 1989, 204 p. (Documents d'Archéologie Française, 17).

Ganet 1995 : GANET (I.) - Les Hautes-Alpes. Paris, Maison des Sciences de l'Homme, 1995, 188 p. (coll. Carte Archéologique de la Gaule, 05).

García 1993 : GARCÍA (D.) - Entre Ibères et Ligures. Lodévois et moyenne vallée de l'Hérault protohistoriques. Paris, CNRS, 1993, 355 p. (Suppléments à la Revue Archéologique de Narbonnaise, 26).

Gardeisen 1994 : GARDEISEN (A.) - Étude de la faune des tombes 1, 2, 3, 5 et 6 de la nécropole d'Ensérune (Hérault). In : Arcelin (P.), Bats (M.), Garcia (D.), Marchand (G.), Schwaller (M.) éd. - Sur les pas des Grecs en Occident. Hommages à André Nickels. Paris/Lattes, Errance/ADAM éditions, 1995, p. 226-229 (Études massaliètes 4).

Gardeisen 1995: GARDEISEN (A.) - Premiers résultats archéozoologiques de tombes des troisième et premier siècles avant J.C. en Languedoc. In : L'Homme et animal dans l'Antiquité romaine. Actes du colloque de Nantes 1991, Tours, Centre de recherches A. Piganiol, 1995, p. 115-129 (Caesarodunum, Hors série).

Gardeisen 2001: GARDEISEN (A.) - Des animaux dans des tombes: archéozoologie dans les Grands Causses du Gévaudan au premier âge du Fer. In : Dedet (B.), Tombes et pratiques funéraires protohistoriques des Grands Causses du Gévaudan.Paris, Maison des sciences del'Homme, 2001,p.337-343 (Documents d'Archéologie Française, 84).

Gardeisen 2002 : GARDEISEN (A.) - Interprétation des restes fauniques dans les tombes protohistoriques du sud de la France. In : Carozza (L.), Dedet (B.), Passelac (M.), Valdeyron (N.) dir., Pratiques funéraires protohistoriques entre Massif Central et Pyrénées. Hommage à Jean-François Salinier. Actes du colloque de Puylaurens, 2000. Castres, Comité Départemental d'Archéologie du Tarn, 2002, p. 211-215 (Archéologie Tarnaise, 12).

Gardeisen 2003 : GARDEISEN (A.) - La faune. In : Giraud (J.-P.), Pons (F.), Janin (T.) dir., Nécropoles protohistoriques de la région de Castres (Tarn); Le Causse, Gourjade, Le Martinet. Vol. 1, Études et synthèses. Paris, Maison des sciences de l'Homme, 2003, p. 211-232 (Documents d'Archéologie Française, 94).

Garmy 1974: GARMY (P.) - L'oppidum protohistorique de Roque de Viou. Caveirac, Association pour la Recherche Archéologique en Languedoc Oriental, 1974, 165 p. et 80 pl. h. t. (Cahier 1).

Gascó 1980 : GASCÓ (Y.) - Fouille de deux tumulus de la nécropole du Sadoulet à Pompignan (Gard). Documents d'Archéologie Méridionale, 3, p. $45-64$.

Gebhard 1989 : GEBHARD (R.) - Le verre à Manching : données chronologiques et apport des analyses. In : Feugère (M.) dir., Le verre préromain en Europe occidentale. Montagnac, éd. M. Mergoil, 1989, p. 101-106.

Gebhard 1991: GEBHARD (R.) - Die Fibeln aus dem Oppidum von Manching. Römisch-Germanische Kommission des Deutschen Archäologischen Instituts zu Francfort am Main. Stuttgart, Steiner, 1991, 224 p. et 86 pl. (Die Ausgrabungen in Manching, Bd. 14).

Genty, Feugère 1995 : GENTY (P.-Y.), FEUGERE (M.) - Aramon (Gard). La nécropole du $\mathrm{I}^{\mathrm{er}} \mathrm{s}$. avant notre ère. Documents d'Archéologie Méridionale, 18, 1995, p. 143-195.

Girard, Roure 2009 : GIRARD (B.), ROURE (R.) - Le mobilier métallique du dépôt du Cailar (Gard) : Quantification, composition et traces de manipulations destructives. In : Honegger (M.) et al. dir., Le site de La Tène : bilan des connaissances - état de la question. Actes de la table ronde internationale de Neuchâtel. 2007, Neuchâtel, Archéologie Neuchâteloise 43, 2009, p. 197-205. Giraud, Pons, Janin dir. 2003 : GIRAUD (J.-P.), PONS (F.), JANIN (T.) dir. - Nécropoles protohistoriques de la région de Castres (Tarn). Le Causse, Gourjade, Le Martinet. Paris, Maison des sciences de l'Homme, 2003, vol. 1 : Études et synthèses, 275 p., vol. 2: Catalogue des ensembles funéraires, 268 p., vol. 3 : Planches du mobilier, 231 p. (Documents d'Archéologie Française, 94).

Gnoli, Vernant dir. 1982 : GNOLI (G.), VERNANT (J.-P.) dir. - La mort, les morts dans les sociétés anciennes. Cambridge University Presse, Paris, Maison des Sciences de l'Homme, 1982, 505 p.

Golosetti 2009 :GOLOSETTI (R.) - Dépôts rituels de la Protohistoire récente en Gaule méditerranéenne: définition et questions méthodologiques. In : Bonnardin (S.), Hamon (C.), Lauwers (M.), Quilliec (B.), Du matériel au spirituel. Réalités archéologiques et historiques des « dépôts » de la Préhistoire à nos jours. Actes des XXIX ${ }^{e}$ rencontres internationales d'Archéologie et d'Histoire d'Antibes, 2008. Antibes, Éditions APDCA, p. 293-302.

Grévin 2004 : GRÉVIN (G.) - L'ethnologie au secours des archéologues. L'étude des crémations sur bûchers. Archéologia, 408, 2004, p. 44-51.

Grévin 2009 : GRÉVIN (G.) - Apport archéologique et médico-légal de l'étude de la crémation sur bûcher en Inde et au Népal. In : Études sur la mort, 2, 2009, p. 23-28.

Gruat 2011 : GRUAT (P.) - Les Touriès, Saint-Jean-et-Saint-Paul, Aveyron. In : Roure (R.), Pernet (L.) dir., Des rites et des Hommes. Les pratiques symboliques des Celtes, des Ibères et des Grecs en Provence, Languedoc et Catalogne. Catalogue d'exposition. Paris, Errance, 2011, p. 104-111.

Guillaumet, Rapin 2000 : GUILLAUMET (J.-P.), RAPIN (A.) - L'art des Gaulois du Midi, In : Chausserie-Laprée (J.) dir., Le temps des Gaulois en Provence. Martigues, Musée Ziem, 2000, p. 79-83.

Haevernick 1960 : HAEVERNICK (T.E.) - Die Glasarminge und Ringperlen der Mittel- und Spätlatènezeit auf dem europäischen Festland. Bonn, 1960, 272 p., 6 tab., 35 pl.

Hatt, Roualet 1977 : HATT (J.-J.), ROUALET (P.) - La chronologie de la Tène en Champagne. Revue Archéologique de l'Est et du Centre-Est, XXVIII, 1-2, 1977, p. 7-36.

Heinz 1990 : HEINZ (C.) - Dynamique des végétations holocènes en Méditerranée nord-occidentale d'après l'anthracoanalyse de sites préhistoriques : méthodologie et paléoécologie. Paléobiologie continentale, $16, \mathrm{n}^{\circ} 2$, $212 \mathrm{p}$. 
Hermann 1976: HERMANN (B.) - Neuere Ergebnisse zur Beurteilung menschlicher Brandknochen. Z. Rechtmedizin , 77, 1976, p. 7-29.

Hermary dir. 2010 : HERMARY (H.) dir., Apollonia du Pont (Sozopol). La nécropole de Kalfata (V $V^{e}-I I I^{e}$ s. av. J.-C.). Fouilles franco-bulgares (20022004). Paris/Aix-en-Provence, Errance/Centre Camille Jullian, 2010, 300 p. et $129 \mathrm{pl}$. h.-t. (Bibliothèque d'Archéologie Méditerranéenne et Africaine, 5). Hertz 1907 réed. 1928 : HERTZ (R.) - Contribution à une étude sur la représentation collective de la mort. In : Sociologie religieuse et folklore. Paris,

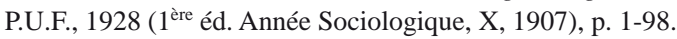

Jacquiot, Trenard, Dirol 1973 : JACQUIOT, (C.), Y. TRENARD (Y.), DIROL (D.) - Atlas d'anatomie des angiospermes (essences feuillues). Paris, Centre Technique du Bois, 1973.

Jallet et al. 1998 : JALLET (F.), JANIN (T.), MARCHAND (G.), ORLIAC (D.), POUPET (P.), SCHWALLER (M.) - Un ustrinum du deuxième âge du Fer à Ensérune (Nissan-lez-Ensérune, Hérault). Documents d'Archéologie Méridionale, 21, 1998, p. 197-210.

Janin 1993 : JANIN (T.) - Mailhac, nécropole du Moulin. Bilan Scientifique Régional du Languedoc-Roussillon, 1993, p. 48-50.

Janin et al. 2000 : JANIN (T.), DE BOUBY (J.), BOISSON (H.), CHARDENON (N.), GARDEISEN (A.), MARCHAND (G.), MONTECINOS (A.), SÉJALON (P.) - La nécropole du second âge du Fer de Mourrel-Ferrat à Olonzac (Hérault). Documents d'Archéologie Méridionale, 23, 2000, p. 219-248.

Janin $\boldsymbol{e}$ t $\boldsymbol{a}$. 2002 : JANIN (T.), TAFFANEL (O.), TAFFANEL (J.), BOISSON(H.), CHARDENON (N.), GARDEISEN (A.), HERUBEL (F.), MARCHAND (G.), MONTECINOS (A.), ROUQUET (J.) - La nécropole protohistorique du Grand Bassin II à Mailhac (Aude), VI $\mathrm{VI}^{\mathrm{e}}$ s. av. n. è. Documents d'Archéologie Méridionale, 25, 2002, p. 65-122.

Jannoray 1955 : JANNORAY (J.) - Ensérune, contribution à l'étude des civilisations pré-romaines de la Gaule méridionale. Paris, De Boccard, 1955, 490 p. (Bibliothèque des Écoles Françaises d'Athènes et de Rome, 181).

Jehasse, Jehasse 1973 : JEHASSE (J.), JEHASSE (L.) - La nécropole préromaine d'Aléria, 1960-1968. Paris, éd. du CNRS, 1973, 632 p., V et 184 pl. ht. (supplément à Gallia, XXV).

Jobbé-Duval 1924, réed. 2000 : JOBBÉ-DUVAL (E.). - Les morts malfaisants (larvae, lemures) d'après le droit et les croyances populaires des romains. Chambéry, Exergue, 2000 (1éd. Paris 1924), 201 p.

Kaenel 1990 : KAENEL (G.) - Recherches sur la période de la Tène en Suisse occidentale. Analyse des sépultures. Lausanne, Cahiers d'Archéologie Romande 50, 1990, $457 \mathrm{p}$.

Krämer 1985: KRÄMER (W.) - Die Grabfunde von Manching und die Latènezeitlichen Flachgräber in Südbayern. Römisch-Germanische Kommission des Deutchen Archäologischen instituts zu Frankfurt am Main, Stuttgart, Steiner 1985, 196 p et 126 pl. HT.

Krogman 1978 : KROGMAN (W.M.) - The human skeleton in Forensic Medicine. Springfield, 1978.

Kruta 1985 : KRUTA (V.) - Le port d'anneaux de cheville en Champagne et le problème d'une immigration danubienne au $\mathrm{III}^{\mathrm{e}}$ siècle avant J.-C. Études Celtiques, XXII, 1985, p. 27-51.

Kurtz, Boardman 1971 : KURTZ (D.C.), BOARDMAN (J.) - Greek burial customs. London-Southampton, Thames and Hudson, 1971, $354 \mathrm{p}$.

Lagrand, Thalmann 1973 : LAGRAND (C.), THALMANN (J.-P.) - Les habitats protohistoriques du Pègue (Drôme). Le sondage $n^{\circ} 8$ (1957-1971). Grenoble, Centre de documentation de la Préhistoire alpine, 1973, 158 p.

Lamboglia 1952 : LAMBOGLIA (N.) - Per una classificazione preliminare della ceramica campana. In : Actes du premier Congrès International d'Études Ligures, Monaco-Bordighera-Gênes 1950. Bordighera, Institut International d'Études Ligures, 1952, p. 139-206.

Lambot 1994 : LAMBOT (B.) - Le bûcher expérimental d'Acy-Romance, 11-12 août 1989. In : Lambot (B.), Friboulet (M.), Méniel (P.) dir., Le site protohistorique d'Acy-Romance (Ardennes). II, Les nécropoles dans leur contexte régional (Thugny-Trugny et tombes aristocratiques). Mémoires de la Société archéologique champenoise, 8, supplément au bulletin n ${ }^{\circ}$ 2, 1994, p. 250-261. Leconte 1990-1991: LECONTE (L.) - Les nécropoles laténiennes de Saint-Maur-des-Fossés (Val-de-Marme). Antiquités Nationales, 22/23, 1990/1991, p. 43-80.
Ledermann 1969 : LEDERMANN (S.) - Nouvelles tables-types de mortalité. Paris, INED, 1969, 260 p. (Travaux et documents, cahier ${ }^{\circ} 53$ ).

Lejars 1994 : LEJARS (T.) - Gournay III. Les Fourreaux d'épée. Le sanctuaire de Gournay-sur-Aronde et l'armement des Celtes de la Tène moyenne. Paris, Errance 1994, 234 p.

Le Mort et al. 2001: LE MORT (F.), ERIM-ÖZDOGAN (A.), ÖZBEK (M.), YILMAZ (Y.) - Feu et archéo-anthropologie au Proche-Orient (Épipaléolithique et Néolithique). Le lien avec les pratiques funéraires. Données nouvelles de Çayönü (Turquie). Paléorient, 26/2, 2001, p. 37-50.

Lenorzer 2009 : LENORZER (S.) - La crémation dans les sociétés protohistoriques du sud de la France. Lattes, Association pour le Développement de l'Archéologie en Languedoc-Roussillon, 2009, 282 p. (coll. Monographies d'Archéologie Méditerranéenne, 25).

Lepetz, Van Andringa 2008 : LEPETZ (S.), VAN ANDRINGA (W.) Archéologie du rituel. Méthode appliquée à l'étude de la nécropole de la Porta Nocera à Pompéi. In : Scheid (J.), Pour une archéologie du rite. Nouvelles perspectives de l'archéologie funéraire. Rome, École française de Rome, 2008, p. 105-126 (coll. de l'École française de Rome, 407).

Louis, Taffanel, Taffanel 1958: LOUIS (M.), TAFFANEL (O.), TAFFANEL (J.) - Le premier Âge du Fer languedocien. II, Les nécropoles à incinération. Bordighera/Montpellier, Institut International d'Études Ligures, 1958, 262 p.

Lugand, Bermond 2001 : LUGAND (M.), BERMOND (I.) - Agde et le Bassin de Thau. Paris, Maison des Sciences de l'Homme, 2001, 448 p. (coll. Carte Archéologique de la Gaule, 34/2 ).

MacKinley 1993 : MACKINLEY (J.I.) - Bone fragment size and weiths of bone from modern british cremation and the implications for the interpretation of archaeological cremations. International Journal of Osteoarchaeology, 3, 1993, p. 283-287.

MacKinley 1994 : MACKINLEY (J.I.) - Taille des fragments d'os dans les incinérations britanniques et conséquences sur les techniques et rituels de crémation. Journal of Archaeological Science, 21, 1994, p. 339-342.

Marcadal, Marcadal, Paillet 2003 : MARCADAL (N.), MARCADAL (Y.), PAILLET (J.-L.) - La nécropole protohistorique et gallo-romaine de ServanesCagalou ( ${ }^{\text {er }}$ s. av. J.-C. - $\mathrm{III}^{\mathrm{e}}$ s. ap. J.-C.) à Mouriès (Bouches-du-Rhône) : sépultures et monuments funéraires. Documents d'Archéologie Méridionale, 26, 2003, p. 251-348.

Marguerie, Hunot 2007 : MARGUERIE (D.), HUNOT (J.-Y.) - Charcoal analysis and dendrology: data from archaeological sites in north-western France. Journal of Archaeological Science 34, 9, 2007, p. 1417-1433.

Marinval 1986: MARINVAL (P.) - Présence de macro-restes végétaux (semences et fruits) en contexte funéraire protohistorique français. In : Duday (H.), Masset (C.), Anthropologie physique et archéologie. Méthodes d'étude des sépultures. Actes du colloque de Toulouse, 4-6 Novembre 1982. Editions du CNRS, Paris, 1986, p. 333-342.

Marinval 1993 : Marinval (P.) - Études carpologiques d'offrandes alimentaires végétales dans les sépultures gallo-romaines : réflexions préliminaires. In : Ferdière (A.) dir., Monde des morts, monde des vivants en Gaule rurale. Revue Archéologique du Centre de la France, 6, 1993, p. 45-65.

Marinval 2004 : Marinval (P.) - Offrandes alimentaires d'origine végétale en contexte funéraire gallo-romain. Nouveau regard. In : Baray (L.) éd., Archéologie des pratiques funéraires. Approches critiques. Bibracte, 9, 2004, p. 203

Marion 2007 : MARION (S.) - Les $\mathrm{IV}^{\mathrm{e}}$ et $\mathrm{III}^{\mathrm{e}} \mathrm{s}$. avant notre ère en Île-deFrance. In: Mennessier-Jouannet (C.), Deberge (Y.) éd., La Gaule dans son contexte européen aux $I V^{e}$ et $I I I^{e}$ s. av. n. è. Actes du XXVII ${ }^{\mathrm{e}}$ colloque international de l'Association Française pour l'Étude de l'Âge du Fer, Clermont-Ferrand, 2003, thème spécialisé. Lattes, Association pour le Développement de l'Archéologie en Languedoc-Roussillon, 2007, p. 91-115 (Monographies d'Archéologie Méditerranéenne).

Martin-Kilcher 1981 : MARTIN-KILCHER (S.) - Das keltische Gräberfeld von Vevey VD. Jahrbuch der schweizerischen Gesellschaft für Ur- und Frühgeschichte, 64, 1981, p. 107-156.

Masset 1987 : MASSET (C.) - Le « recrutement » d'un ensemble funéraire. In : Duday (H.), Masset (C.) dir., Anthropologie physique et archéologie. Méthodes d'étude des sépultures. Actes du colloque de Toulouse, 1982. Paris, éd. du CNRS, 1987, p. 11-126. 
Mazière 2002 : MAZIÈRE (F.) - Contribution des nécropoles du premier âge du Fer de la vallée de l'Orb (Hérault) à l'étude des pratiques funéraires et des dynamiques du peuplement protohistorique en Languedoc occidental. In : Carozza (L.), Dedet (B.), Passelac (M.), Valdeyron (N.) dir., Pratiques funéraires protohistoriques entre Massif Central et Pyrénées. Actes du colloque en hommage à Jean-François Salinier, Puylaurens, 2000. Castres, Comité départemental d'archéologie du Tarn, 2002, p. 121-151 (Archéologie Tarnaise 12).

Ménard 1750 : MÉNARD (L.) - Histoire civile, ecclésiastique et littéraire de la ville de Nîmes, avec des preuves, 7 volumes, 1744 - 1758.

Mennessier-Jouannet et al. 2010: MENNESSIER-JOUANNET (C.), BLAIZOT (F.), DEBERGE (Y.), NECTOUX (É.) - Espaces funéraires et pratiques liées au traitement du défunt et au mobilier en Auvergne au Second Âge du Fer. In : Barral (P.), Dedet (B.), Delrieu (F.), Giraud (P.), Le Goff (I.), Marion (S.), Villard-Le Tiec (A.) dir., Gestes funéraires en Gaule au Second Âge du Fer. Actes du 33 $3^{\mathrm{e}}$ colloque de l'AFEAF, Caen 2009, thème spécialisé. Besançon, Presses universitaires de Franche-Comté, 2010, p. 231-251 (Annales littéraires, $\mathrm{n}^{\circ} 883$; Série «Environnement, sociétés et archéologie », $\left.\mathrm{n}^{\circ} 14\right)$.

Mocci, Granier, Dumas 2009 : MOCCI (F.), GRANIER (G.), DUMAS (V.) - Richeaume XIII (Puyloubier, 13). Rapport Final d'Opération archéologique programmée 2007-2009. Aix-en-Provence, Service Régional de l'Archéologie, PACA, 2009, $409 \mathrm{p}$.

Moliner et al. 2003 : MOLINER (M.), MELLINAND (P.), NAGGIAR (L.), RICHIER (A.), VILLEMEUR (I.) - La nécropole de Sainte-Barbe à Marseille (IVe s. av. J.-C. $-I I^{e}$ s. ap. J.-C.). Aix-en-Provence, Édisud/Centre Camille Jullian, 491 p. (Études Massaliètes, 8).

Moorrees, Fanning, Hunt 1963a: MOORREES (C.F.A.), FANNING (E.A.), HUNT (E.E.) - Formation and resorption of three deciduous teeth in children. American Journal of Physical Anthropology, 21, 1963, p. 205-213. Moorrees, Fanning, Hunt 1963b : MOORREES (C.F.A.), FANNING (E.A.), HUNT (E.E.) - Age variation of formation stages for ten permanent teeth. Journal of Dental Research, 42, 1963, p. 1490-1502.

Mordant 1977 : MORDANT (C.) - Les récentes découvertes de La Tène dans la Bassée et la région du confluent Seine-Yonne. In : Les Sénon avant la conquête à la lumière des dernières découvertes; habitats, commerce, sépultures. Actes du colloque de Sens, 1977. Sens, Société Archéologique de Sens, 1977, p. 45-53.

Morel 1968: MOREL (Ch.) - Sépultures tumulaires de la région du Freyssinel (Causse de Sauveterre). Revue du Gévaudan, 14, 1968, p. 13-77.

Nickels 1982 : NICKELS (A.) - Agde grecque : les recherches récentes. In : I Focei dall Anatolia all'Oceano. La Parola del Passato, CCIV-CCVII, 1982, p. 269-279.

Nickels, Marchand, Schwaller 1989 : NICKELS (A.), MARCHAND (G.), SCHWALLER (M.) - Agde, la nécropole du premier Age du Fer. Paris, éd. du CNRS, 1989, 498 p. (Suppléments à la Revue Archéologique de Narbonnaise, 19).

Oakley 2004: OAKLEY (J. H.) - Picturing death in classical Athens : the evidence of the white lekythoi. New York, Cambridge University press, 2004, 268 p. et VIII p. de pl. (Coll. Cambridge studies in classical art and iconography).

Ott et al. 2010 : OTT (M.), BEL (V.), CHARDENON (N.), SÉJALON (P.) - L'ensemble funéraire protohistorique de la «ZAC Mermoz » à Castelnaule-Lez, Hérault ( $\mathrm{VI}^{\mathrm{e}}-\mathrm{IV}^{\mathrm{e}} \mathrm{s}$. av. J.-C.). In : Barral (P.), Dedet (B.), Delrieu (F.), Giraud (P.), Le Goff (I.), Marion (S.), Villard (A.) dir., Gestes funéraires en Gaule au Second Âge du Fer, Actes du 33 ${ }^{\mathrm{e}}$ colloque de l'AFEAF, Caen 2009. Besançon, Presses Universitaires de Franche-Comté, 2010, p. 291-296 (Annales littéraires, n 883 ; Série «Environnement, sociétés et archéologie », $\left.\mathrm{n}^{\circ} 14\right)$.

Ozenda 1975 : OZENDA (P.) - Sur les étages de végétation dans les montagnes du bassin méditerranéen. Documents de cartographie écologique. Vol. 16. Grenoble, Laboratoire de biologie végétale de l'Université Grenoble I, 1975, p. 1-31.

Paris 1998 : PARIS (P.), avec la coll. de LEJARS (T.), BEN NCER (A.) - Les sépultures à incinération de la Tène moyenne de la «ZAC de Ther » à Allonne (Oise). Revue Archéologique de Picardie, 1998, 1/2, p. 271-329.
Passelac, Rancoule, Solier 1981 : PASSELAC (M.), RANCOULE (G.), SOLIER (Y.) - La nécropole de "Las Peyros" à Couffoulens (Aude) : découverte d'un nouveau groupe de tombes. Revue Archéologique de Narbonnaise, XIV, 1981, p. 1-53.

Paterno 2004: L. Paterno, Les petits objets du quartier 30-35 dans leur contexte lattois. In: Py (M.) dir., Le quartier 30-35 de la ville de Lattara (fin III ${ }^{e}-I^{e r}$ s. av. n. ̀̀.). Regards sur la vie urbaine à la fin de la Protohistoire. Lattara 17, Lattes, Association pour le Développement de l'Archéologie en Languedoc-Roussillon, 2004, p. 345-359.

Pautreau 1994 : PAUTREAU (J.-P.) - Quelques aspects des crémations contemporaines en Asie du Sud-Est. In : Lambot (B.), Friboulet (M.), Méniel (P.) dir., Le site protohistorique d'Acy-Romance (Ardennes). II, Les nécropoles dans leur contexte régional (Thugny-Trugny et tombes aristocratiques). Mémoires de la Société archéologique champenoise, 8, supplément au bulletin $\mathrm{n}^{\circ} 2$, 1994, p. 306-315.

Peyer 1991 : PEYER (S.) - L'Âge du Fer en Valais (Suisse) (1) : de l'époque de Hallstatt à la Tène moyenne. In : Duval (A.) éd., Les Alpes à l'Âge du Fer. Actes du Xe colloque de l'AFEAF, Chambéry 1986. Paris, CNRS 1991, p. 333347 (Suppléments à la Revue Archéologique de Narbonnaise, 22)

Piquès 2004 : PIQUÈS (G.) - Ichtyofauna from the funerary urns : analysis, appraisal and prospects. In : Aubet (M.-E.) dir., The Phoenician Cemetery of Tyre-Al Bass. Excavations 1997-1999. BAAL, Hors série I, 2004, p.441-446. Piquès 2009 : PIQUÈS (G.) - Consommation et modes d'approvisionnement en poisson à partir de l'analyse de l'ichtyofaune. In : Fiches (J.-L.) dir., Une maison de l'agglomération routière d'Ambrussum (Villetelle, Hérault). Fouille de la zone 9 (1995-1999). Lattes, Association pour le Développement de l'Archéologie en Languedoc-Roussillon, 2009, p. 205-209 (Monographies d'Archéologie Méditerranéenne, 26).

Polenz 1982: POLENZ (H.) - Münzen in latènezeitlichen Gräbern Miteleuropas aus der Zeit zwischen 300 und 50 v.Chr. Geburt. Bayerische Vorgeschichtsblätter, 47, 1982, p. 27-222.

Porra 1995 : PORRA (V.) - Premières données sur la nécropole à incinération protohistorique des Coudoumines à Caramany (P.-O.). In : Cultures $i$ medi de la prehistoria à l'edat mitjana. Actes del $\mathrm{X}^{\mathrm{e}}$ col.loqui internacional d'arquelogia de Puigcerdà, 1994. Puigcerdà i Osseja, 1995, p. 459-463.

Pradat 1994 : Pradat (B.) - Les offrandes alimentaires végétales dans les tombes antiques : exemples d'incinérations à Lyon et à Marseille. DEA, univ. Paris 1, 1994.

Preiss, Matterne, Latron 2005 : Preiss (S.), Matterne (V.), Latron (F.) - An approach to funerary rituals in the Roman provinces: plant remains from a Gallo-Roman cemetery at Faulquemont (Moselle, France). Veget Hist Archaeobot, 14, 2005, p. 362-372.

Puig 2006 : PUIG (A. M.) - El taller ceràmic de Roses. In : Puig (A.M.), Martin (A.) dir., La colònia grega de Rhode (Roses, Alt Empordà). Girona, Museu d'Arqueología de Catalunya, 2006, p. 295- 559 (série monogràfica 23). Py 1978 : PY (M.) - L'oppidum des Castels à Nages (Gard) (fouilles 19581974). Paris, éd. du CNRS, 1978, 361 p. (Suppléments à Gallia, XXXV).

Py 1983 : PY (M.) - La tombe d'Atila (Sernhac, Gard, II ' s. av. n. è.). Revue Archéologique de Narbonnaise, XVI, 1983, p. 367-376.

Py 1990a : PY (M.) - Culture, économie et société protohistoriques dans la région nimoise. Rome, École française de Rome 1990, 957 p. (collection de l'École française de Rome 131).

Py 1990b : PY (M.) — La céramique de l'îlot 1. In : Py dir., Fouilles dans la ville antique de Lattes. Les îlots 1, 3 et 4-nord du quartier Saint-Sauveur. Lattara, 3, Lattes, Association pour le Développement de l'Archéologie en Languedoc-Roussillon, 1990, p. 71-98.

Py 1994a : PY (M.) - Les céramiques d'époque protohistorique (IV ${ }^{\mathrm{e}}-\mathrm{II}^{\mathrm{e}} \mathrm{s}$. avant notre ère). In: Garcia (D.) dir. - Exploration de la ville portuaire de Lattes. Lattara 7, Lattes, Association pour le Développement de l'Archéologie en Languedoc-Roussillon, 1994, p. 205-332.

Py 1994b : PY (M.) - Catalogue des petits objets. In : Garcia (D.) dir. Exploration de la ville portuaire de Lattes. Lattara 7, Lattes, Association pour le Développement de l'Archéologie en Languedoc-Roussillon, 1994, p. 373-422.

Py, Lebeaupin 1989: PY (M.), LEBEAUPIN (D.), avec la coll. de DUDAY (H.), FABRE (V.), TILLIER (A.-M.) - Stratigraphie du Marduel 
(Saint-Bonnet-du-Gard), IV, les niveaux des IV ${ }^{\mathrm{e}}$ et IIII ${ }^{\mathrm{e}}$ s. av. n. è. sur le chantier central. Documents d'Archéologie Méridionale, 12, 1989, p. 121-190.

Py dir. 1993 : PY (M.) - Dicocer. Dictionnaire des céramiques antiques (VII s. av. n.è̀. - VII e s. de n. è. Lattara 6, Lattes, Association pour le Développement de l'Archéologie en Languedoc-Roussillon, 1993, 622 p.

Py, Adroher Auroux, Sanchez 2001 : PY (M.), ADROHER AUROUX (A.), SANCHEZ (C.) - Dicocer 2, Corpus des céramiques de l'âge du Fer de Lattes (fouilles 1963-1999). Lattara 14, Lattes, Association pour le Développement de l'Archéologie en Languedoc-Roussillon, 2001, 1306 p.

Py 2006 : PY (M.) - Les monnaies préaugustéennes de Lattes et la circulation monétaire protohistorique en Gaule méridionale. Lattara 19, Lattes, Association pour le Développement de l'Archéologie en LanguedocRoussillon, 2006, $1270 \mathrm{p}$.

Py 2006-2007 : PY (M.) - La zone H de l'oppidum des Castels (Nages-etSolorgues, Gard). Documents d'Archéologie Méridionale, 29-30, 2006-2007, p. 277-344.

Rameau, Mansion, Dumé 2008: RAMEAU (J.-C.), MANSION (D.), DUMÉ (G.) - Flore forestière française : guide écologique illustré. Forêt privée française, Idf, 2008, $2421 \mathrm{p}$.

Rancoule 1983 : RANCOULE (G.) - Tombes à incinération du début du deuxième Âge du fer à Cesseras, Hérault, Bulletin de la Société d'Études scientifiques de l'Aude, LXXXIII, 1983, p. 41-50.

Rancoule 1989: RANCOULE (G.) - Usages funéraires dans l'Aude au premier Âge du Fer et au début du second, Documents d'Archéologie Méridionale, 12, 1989, p. 41-49.

Rancoule, Solier 1972 : RANCOULE (G.), SOLIER (Y.) - La Cité de Carcassonne à l'Âge du Fer. Note préliminaire sur les découvertes archéologiques de l'enclos Saint-Nazaire Bulletin de la Société d'Études scientifiques de l'Aude, LXXII, 1972, p. 133-161.

Rapin 1990 : RAPIN (A.) - L'armement, fil conducteur des mutations du second Âge du Fer. Revue Archéologique de l'Ouest, supplément 3, 1990, p. 287-297.

Rapin, Schwaller 1987 : RAPIN (A.), SCHWALLER (M.) - Contribution à l'étude de l'armement celtique : la tombe 163 d'Ensérune (Hérault). Revue Archéologique de Narbonnaise, 20, 1987, p. 155-183.

Raux 1999 : RAUX (S.) - Les objets de la vie quotidienne à Lattes au $\mathrm{IV}^{\mathrm{e}} \mathrm{s}$. avant notre ère. In : Py (M.) dir., Recherches sur le quatrième siècle avant notre ère à Lattes. Lattara 12, Lattes, Association pour le Développement de l'Archéologie en Languedoc-Roussillon, 1999, p. 439-518.

Raynaud et al. 1998 : Raynaud (C.), Berger (J.-F.), Fiches (J.-L.), Géoarchéologie d'un paysage méditerranéen. Rapport de PCR, 1998 (dactylographié).

Rétif 2000 : RÉTIF (M.) - Le mobilier métallique de l'habitat protohistorique de l'Ile de Martigues, B. du Rh. (V ${ }^{\mathrm{e}}-\mathrm{II}$ e s. av. J.-C.). Documents d'Archéologie Méridionale, 23, 2000, p. 157-208.

Rothé, Tréziny 2005 : ROTHÉ (M.-P.), TRÉZINY (H.) - Marseille et ses alentours. Paris, Maison des Sciences de l'Homme, 2005, 925 p. (coll. Carte Archéologique de la Gaule, 13/3).

Roure 2007 : ROURE (R.) - Armes et têtes coupées au Cailar (Gard) : premiers éléments de réflexion sur un dépôt rituel en Gaule méditerranéenne. In : Barral (P.), Daubigney (A.), Dunning (C.), Kaenel (G.), RoulièreLambert (M.-J.) dir., L'âge du Fer dans l'arc jurassien et ses marges. Dépôts, lieux sacrés et territorialité à l'âge du Fer. Actes du XXIXe colloque international de l'AFEAF, Bienne, 2005. Besançon, Presses universitaires de Franche-Comté, 2007, vol. 2, p. 653-658 (Annales littéraires; série "Environnement, sociétés et archéologie").

Roure 2010: ROURE (R.) - Le Cailar, Place de la Saint-Jean. Bilan Scientifique de la Région Languedoc-Roussillon 2008. Paris, Ministère de la Culture, 2010, p. 71-74.

Ruas, Bouby, Pradat 2006 : RUAS (M.-P.), BOUBY (L.), Pradat (B.) - Les restes de fruits dans les dépôts archéologiques du Midi de la France ( $\mathrm{V}^{\mathrm{e}}-\mathrm{XVI}^{\mathrm{e}} \mathrm{s}$.). In : Ruas (M.-P.) dir., Cultures des fruits et lieux des cultures de l'Antiquité, du Moyen Âge et de l'époque Moderne. Des savoirs en pratique, des mots et des images. Actes du séminaire de Toulouse 31 mars- $1^{\mathrm{er}}$ avril 2005. Archéologie du Midi Médiéval, 23-24, 2006, p. 145-193.

Ruas, Marinval 1991 : RUAS (M.-P.), MARINVAL (P.) - Alimentation végétale et agriculture d'après les semences archéologiques (de 9000 av. J.-C. au $\mathrm{XV}^{\mathrm{e}} \mathrm{s}$.). In : Guilaine (J.) - Pour une Archéologie Agraire. À la croisée des sciences de l'homme et de la nature. Paris, Armand Colin, 1991, p. 409-439. Saint-Venant 1897 : SAINT-VENANT (J. de) - Les derniers Arécomiques, traces de la civilisation celtique dans la région du bas-Rhône, spécialement dans le Gard. Bulletin Archéologique du Comité des travaux historiques, 1897, p. 481-531.

Saitoh, Ohtani, Fukazawa 1993: SAITOH (T.), OHTANI (J.), FUKAZAWA (K.) - The occurrence and morphology of tyloses and gums in the vessels of Japanese hardwoods. International Association of Wood Anatomists Journal, 14, 1993, p. 359-371.

Sanmartí Grego 1978: SANMARTí GREGO (E.) - La cerámica campaniense de Emporion y Rhode, Barcelona, 1978, 2 vol., 713 p. (coll. Monografies Emporitanes, IV).

Scheid 1984 : SCHEID (J.) - Contraria facere : renversements et déplacements dans les rites funéraires. Annali dell'Istituto Orientale di Napoli, VI, 1984, p. 117-139.

Schwab 1995 : SCHWAB (H.) - Deux nécropoles Laténiennes à Gumefens (canton de Fribourg, Suisse). In : Charpy (J.-J.) éd., L'Europe celtique du $V^{e}$ au III ${ }^{e}$ s. av. J.-C. Contacts, échanges et mouvements de populations. Actes du $2^{e}$ symposium international d'Hautvillers. Sceaux, Kronos, 1995, p. 239-358 (Mémoire n 9 de la Société Archéologique Champenoise).

Schwaller 1994a : SCHWALLER (M.) - Structures de couverture et de signalisation des tombes du deuxième Âge du fer en Languedoc occidental, Documents d'Archéologie Méridionale, 17, 1994, p. 69-73.

Schwaller 1994b : SCHWALLER (M.) - Ensérune, carrefour de civilisations protohistoriques. Paris, Imprimerie Nationale, 1994, 107 p. (coll. Guides archéologiques de la France).

Schwaller, Marchand 1993 : SCHWALLER (M.), MARCHAND (G.) - La phase tardive de la nécropole d'Ensérune (Hérault). In : Cliquet (D.), RémyWatte (M.), Guichard (V.), Vaginay (M.) éd., Les Celtes en Normandie. Les rites funéraires en Gaule (III ${ }^{e} I^{e r}$ siècle avant J.-C.). Actes du $14^{e}$ colloque de l'Association Française pour l'Étude de l'Âge du Fer, Évreux, 1990. Rennes 1993, p. 225-229 (Suppléments à la Revue Archéologique de l'Ouest, 6).

Schwaller et al. 1995 : SCHWALLER (M.), DUDAY (H.), JANIN (T.), MARCHAND (G.). - Cinq tombes à incinération du deuxième âge du Fer à Ensérune (Nissan-lez-Ensérune, Hérault). In: Arcelin (P.), Bats (M.), Garcia (D.), Marchand (G.), Schwaller (M.) éd. - Sur les pas des Grecs en Occident. Hommages à André Nickels. Paris/Lattes, Errance/ADAM éditions, 1995, p. 205-230 (Études massaliètes 4).

Schwaller et al. 2001: SCHWALLER (M.), MARCHAND (G.), LEJARS (T.), ORLIAC (D.), RAPIN (A.), SANMARTí (E.) - Échanges, influences, productions dans la nécropole du deuxième âge du Fer d'Ensérune (Hérault). Documents d'Archéologie Méridionale, 24, 2001, p. 173-184.

Schweingruber 1990 : SCHWEINGRUBER (F.H.) - Anatomy of European woods. Berna, éd. Paul Haupt, 1990, 800 p.

Séguier et al. 2010 : SÉGUIER (J.-M.), DELATTRE (V.), GRATUZE (B.), PEAKE (R.), VIAND (A) - Les nécropoles protohistoriques de "La haute Grève » à Gouaix (Seine-et-Marne). Tours, FERACF, 2010, 258 p. (Supplément à la Revue Archéologique du Centre de la France, 37).

Séjalon, Dedet 2003 : SÉJALON (P.), DEDET (B.) - Trois enclos funéraires $\mathrm{du} \mathrm{V}^{\mathrm{e}} \mathrm{s}$. av. J.-C. au mas de Vignole (Nimes, Gard). Documents d'Archéologie Méridionale, 26, p. 43-61.

Sellier 1996 : SELLIER (P.) - La mise en évidence d'anomalies démographiques et leur interprétation : population, recrutement et pratiques funéraires du tumulus de Courtesoult. In : Piningre (J.-F.) dir. - Nécropoles et société au premier âge du Fer : le tumulus de Courtesoult (Haute-Saône). Paris, Maison des sciences de l'Homme, 1996, p. 188-202 (Documents d'Archéologie Française, 54).

Solier, Rancoule, Passelac 1976: SOLIER (Y.), RANCOULE (G.), PASSELAC (M.) - La nécropole de "Las Peyros", VI s. av. J.-C., à Couffoulens (Aude). Paris, De Boccard 1976, 117 p. (Supplément à la Revue Archéologique de Narbonnaise, 6).

Sun, Rost, Matthews 2006 : SUN (Q.), ROST (T. L.), MATTHEWS (M. A.) - Pruning-induced tylose development in stems of current-year shoots of Vitis vinifera (Vitaceae). American journal of botany 93, no. 11, 2006, p. $1567-1576$. 
Taffanel, Taffanel 1960 : TAFFANEL (O.), TAFFANEL (J.) - Deux tombes de chefs à Mailhac (Aude). Gallia, XVIII, 1960, p. 1-37.

Taffanel, Taffanel 1962 : TAFFANEL (O.), TAFFANEL (J.) - Deux tombes de cavaliers du premier Âge du Fer à Mailhac (Aude). Gallia, XX, 1962, p. 3-32.

Taffanel, Janin 1998 : TAFFANEL (O), TAFFANEL (J.), JANIN (T.) - $L a$ nécropole du Moulin à Mailhac (Aude). Lattes, Association pour la Recherche Archéologique en Languedoc Oriental, 1998, 393 p. (Monographies d'Archéologie Méditerranéenne, 2).

Tendille 1978 : TENDILLE (C.) - Fibules protohistoriques de la région nîmoise. Documents d'Archéologie Méridionale, 1, 1978, p. 77-112.

Tendille 1979 : TENDILLE (C.) - Mobiliers métalliques protohistoriques de la région nîmoise : les bracelets. Documents d'Archéologie Méridionale, 2, 1979, p. 61-79.

Tendille 1980 : TENDILLE (C.) - Mobiliers métalliques protohistoriques de la région nimoise : autres objets de parure et d'habillement (III). Documents d'Archéologie Méridionale, 3, 1980, p. 95-124.

Tendille, Manniez 1990 : TENDILLE (C.), MANNIEZ (Y.) - Les petits objets de l'îlot 1. In : Py dir., Fouilles dans la ville antique de Lattes. Les îlots 1, 3 et 4-nord du quartier Saint-Sauveur. Lattara, 3, Lattes, Association pour la Recherche Archéologique en Languedoc Oriental, 1990, p. 99-108.

Théry-Parisot, Chabal, Costamagno 2010: THÉRY-PARISOT (I.), CHABAL (L.), COSTAMAGNO (S) - Taphonomie de la combustion des résidus organiques et des structures de combustion en contexte archéologique. Actes de la table ronde, 27-29 mai 2008, CEPAM. Vol. 2. Revue bilingue de Préhistoire, 2010.

Thomas 1982 : THOMAS (L.-V.) - La mort africaine. Idéologie funéraire en Afrique Noire. Paris, Payot, 1982, 272 p.

Thomas 1998 : THOMAS (Y.) - Perle à décor oculé spiralé du Second Âge du Fer à Bouzanville «la Comtasse» (Meurthe-et-Moselle). Antiquités Nationales, 30, 1998, p. 107-109.

Toledo i Mur dir. 2010 : TOLEDO I MUR (A.) dir. - Perpignan, PyrénéesOrientales, Le site de Negabous, de la Protohistoire à l'époque moderne. II - La nécropole protohistorique à incinération. Rapport final d'opération, Inrap Méditerranée, 2010, 2 vol. 646 p.

Trotter, Hixon 1974 : TROTTER (M.), HIXON (B.B.) - Sequential changes in weight, density and percentage ash weight of human squeletons from an early fetal period through Old Age. The Anatomic Record, 179, 1974, p. 1-18. Ubelaker 1978 : UBELAKER (D.H.) - Human skeletal remains. Excavation, analysis, interpretation. Washington, Taraxacum, 1978, $119 \mathrm{p}$.
Ugolini 1993 : UGOLINI (D.) - Lampes grecques et de type grec de Béziers. Utilisation et diffusion de la lampe grecque dans le Midi entre le $\mathrm{VI}^{\mathrm{e}}$ et le $\mathrm{IV}^{\mathrm{e}} \mathrm{s}$. avant J.-C. Documents d'Archéologie Méridionale, 16, 1993, p. 279-293.

Van Andringa, Duday, Lepetz à paraître: VAN ANDRINGA (W.), DUDAY (H.), LEPETZ (S.) et al. - Mourir à Pompéi. Fouille d'un quartier funéraire de la nécropole romaine de Porta Nocera (2003-2007). vol. 1: Analyse des contextes archéologiques et synthèses générales; vol. 2 : Artefacts et écofacts en contexte funéraire. Analyses et synthèses par type de matériel archéologique. Rome, École française de Rome, 2011 (coll. de l'École française de Rome).

Verdin 2010 : VERDIN (P.) - Offrandes végétales et aménagement de sépulture d'une tombe gauloise d'enfant de la nécropole d'Esvres-sur-Indre. Résultats d'une analyse de phytolithes. In : Delhon (C.), Théry-Parisot (I.), Thiébault (S.), Des hommes et des plantes. Exploitation et gestion des ressources végétales de la Préhistoire à nos jours. Actes des $\mathrm{XXX}^{\mathrm{e}}$ Rencontres internationales d'archéologie et d'histoire d'Antibes. 22-24 octobre 2009, Antibes. Anthropobotanica, 1, 2010, [En ligne] http://www.mnhn.fr/museum/fof-fice/science/science/DocScientifique/ publica

Vernhet 1995: VERNHET (A.) - Une inscription magique en langue gauloise. Le plomb de La Vayssière, L'Hospitalet-du-Larzac . In : Dix ans d'archéologie en Aveyron. Montrozier, Musée du Rouergue, p. 267-269 (coll. Guide d'Archéologie, 3).

Vindry 1978 : VINDRY (G.) - Un siècle de recherches préhistoriques et protohistoriques en Provence orientale (1875-1975). La Protohistoire. Documents d'Archéologie Méridionale, 1, 1978, p. 7-76.

Vitali dir. 2003 : VITALI (D.) dir. — La necropoli di Monte Tamburino a Monte Bibele. Bologna, Gedit, 2003, 525 p. et 280 p.

Warren, Maples 1997 : WARREN (M.W), MAPLES (W.R.) - The anthropometry of contemporary commercial cremation. Journal of Forensic Science, 42, 3, 1997, p. 417-423.

Willaume 1991 : WILLAUME (M.) - Les sépultures du second Âge du Fer. In : Archéologie dans les Hautes-Alpes. Gap, Musée départemental de Gap, 1991, p. 205-215.

Zepezauer 1989 : ZEPEZAUER (M.-A.) - Perles à décor oculé spiralé de la Tène moyenne et finale. In : Feugère (M.) dir., Le verre préromain en Europe occidentale. Montagnac, éd. M. Mergoil, 1989, p. 107-120.

Zimmermann 1979 : ZIMMERMANN (M. H.) - The discovery of tylose formation by a Viennese lady in 1845. IAWA Bulletin 2, no. 3, 1979, p. $51-56$. 


\section{PUBLICATIONS DU CENTRE CAMILLE JULLIAN}

http://sites.univ-provence.fr/ccj/spip.php?rubrique79

\section{Disponibles gratuitement en ligne :}

Revue Antiquités africaines, $n^{\circ} 1$ (1967) à 29 (1993), sur le portail Persée :

(http://www.persee.fr/web/revues/home/prescript/revue/antaf)

Collection Archaeonautica, ${ }^{\circ} 1$ (1977) à 14 (1998), sur le portail Persée :

(http://www.persee.fr/web/revues/home/prescript/revue/nauti)

Barrière mobile 3 ans.

Collection Etudes massaliètes, $n^{\circ} 1$ (1986) à 9 (2007), sur le site du CCJ :

(http://ccj.univ-provence.fr/spip.php?rubrique83)

ou sur celui du Centre de Conservation du Livre à Arles :

(http://www.e-corpus.org/search/search.php?search=search\&page=1\&q=études+massaliètes\&search=Rechercher)

Bibliothèque d'Archéologie Méditerranéenne et Africaine (BiAMA) :

A partir de 2013 (barrière mobile 3 ans) sur le site Revues.org 


\section{BIBLIOTHÈQUE D'ARCHÉOLOGIE MÉDITERRANÉENNE ET AFRICAINE (BiAMA)}

Editions Errance, 7 rue Jean-du-Bellay, 75004 Paris. http://www.librairie-epona.fr/ La BiAMA prend la suite des Travaux du Centre Camille Jullian
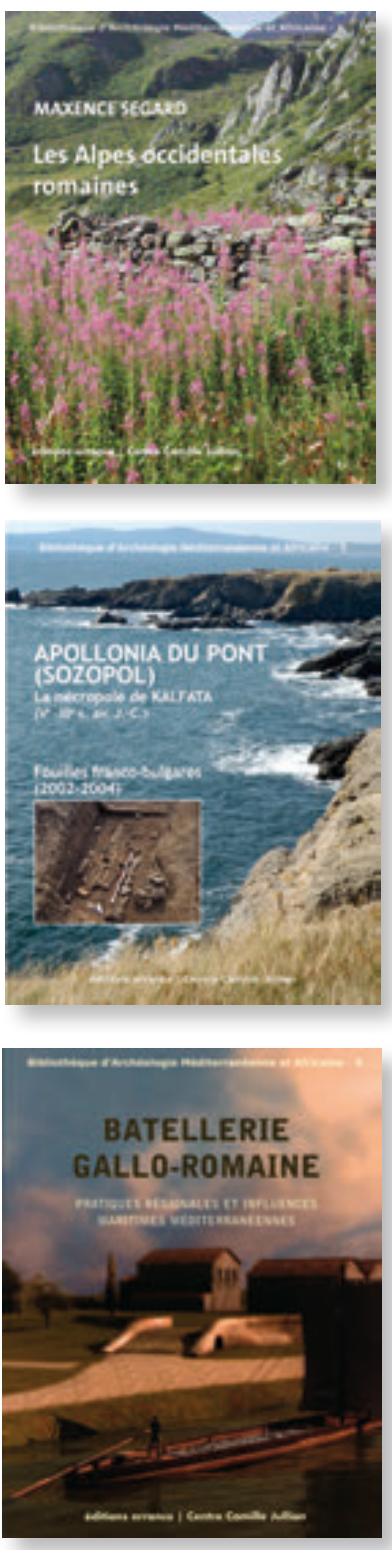
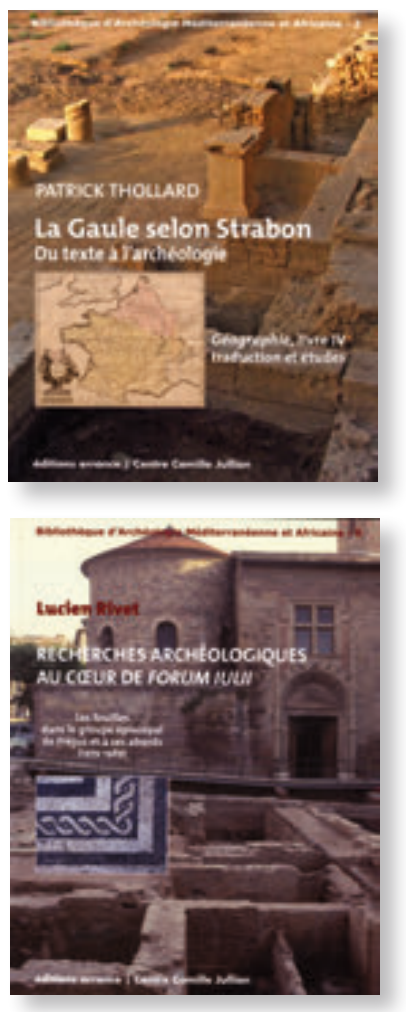

1. M. Segard, Les Alpes Occidentales à l'époque romaine, Développement urbain et exploitation des ressources des régions de montagne (Gaule Narbonnaise, Italie, provinces alpines), Paris 2009, 288 p.

2. Patrick Thollard, La Gaule selon Strabon : du texte à l'archéologie (Géographie livre IV). Traduction et études, Paris 2009, 265 p.

3. Grecs et indigènes de la Catalogne à la mer Noire, actes des rencontres du programme européen Ramses (2006-2008), édités par H. Tréziny, Paris 2010, 716 p.

4. Archéologie de la montagne européenne. Actes de la table ronde internationale de Gap (29 septembre- - $^{\text {er }}$ octobre 2008), textes réunis par Stéfan Tzortzis et Xavier Delestre, avec la collaboration de Jennifer Greck, Paris 2010, 333 p.

5. A. Hermary (éd.), Apollonia du Pont (Sozopol) La nécropole de Kalfata (Ve $V^{e} I^{e} s$. av J.-C.) - Fouilles franco-bulgares (2002-2004), 2010, 432 p.

6. L. Rivet, Recherches archéologiques au coeur de Forum Iulii - Les fouilles dans et autour du groupe cathédral de Fréjus (1979-1989), 2010, 420 p.

7. Sous la direction de Marc Bouiron, Françoise Paone, Bernard Sillano, Colette Castrucci et Nadine Scherrer, Fouille à Marseille, la ville médiévale et moderne, (ÉtMassa 10), 2011, 463 p.

8. P. Excoffon, Ville et campagne de Fréjus romaine. La fouille préventive de «Villa Romana » 2011, $306 \mathrm{p}$.

9. Sous la direction de Giulia Boetto, Patrice Pomey, André Tchernia, Batellerie gallo-romaine : pratiques régionales et influences maritimes méditerranéennes, 2011,191 p.

10. F. Sacchetti, Les amphores grecques dans le Nord de l'Italie. Echanges commerciaux entre les Apennins et les Alpes aux époques archaïque et classique (sous presse).

11. B. Dedet, Une nécropole du second Âge du Fer à Ambrussum, Hérault, 2012, 288 p.

12. L'enfant et la mort dans l'Antiquité. III. Le matériel associé aux tombes d'enfants, Actes du colloque international organisé à la Maison Méditerranéenne des Sciences de l'Homme (MMSH) d'Aix-en-Provence, 20-22 janvier 2011, édités par A. Hermary et C. Dubois (sous presse). 


\section{COLLECTION ÉTUDES MASSALIÈTES (EtMassa)}
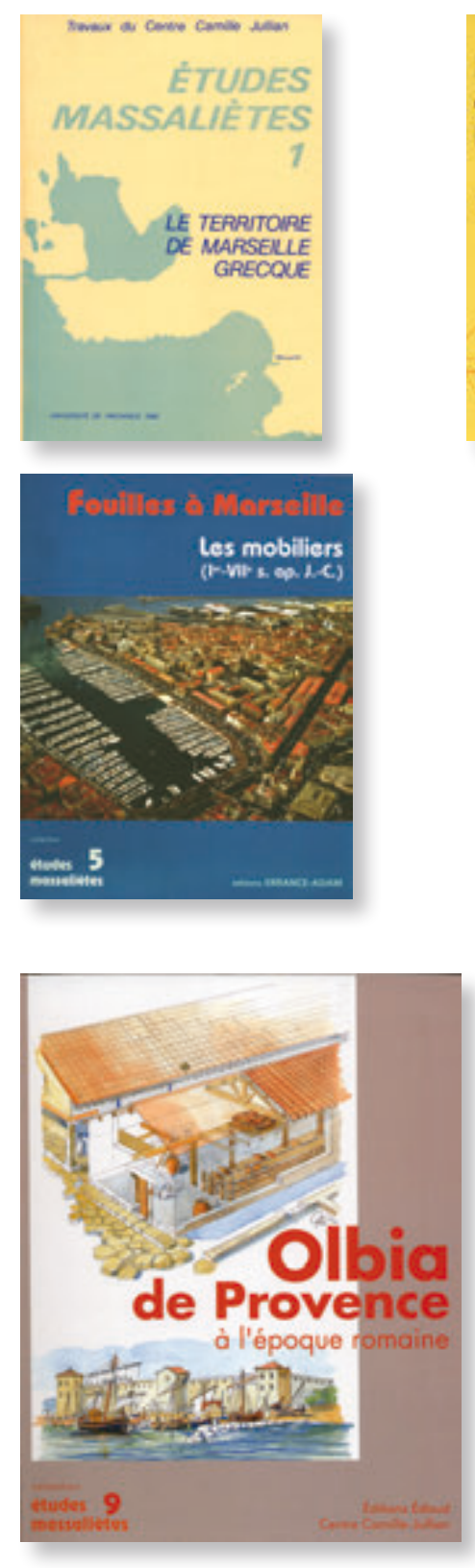
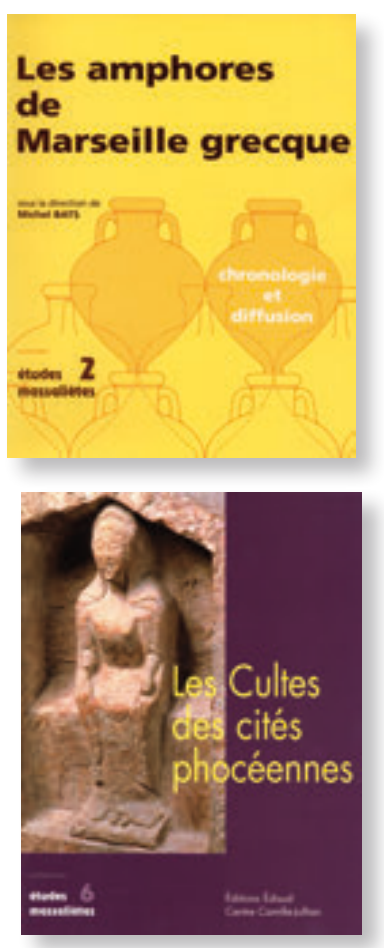
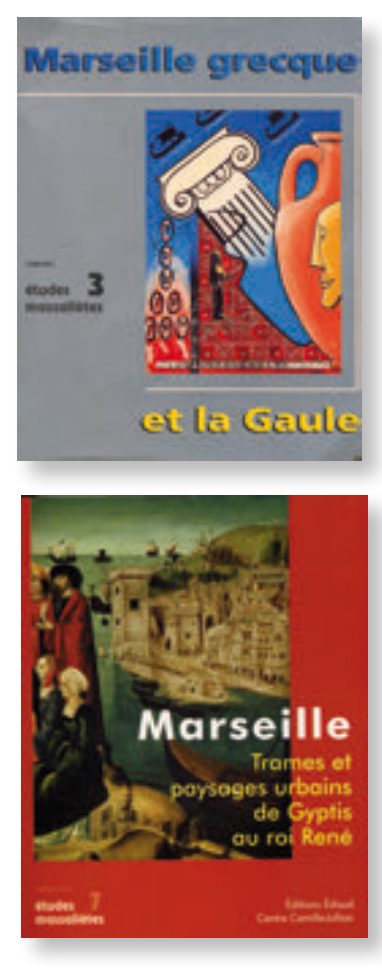
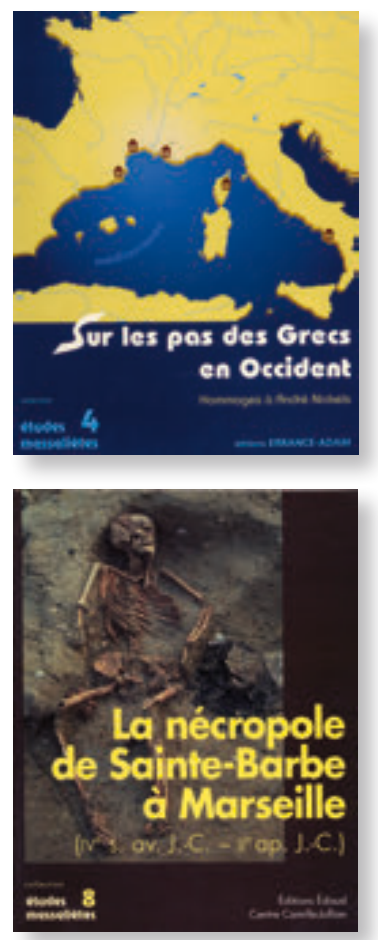

1. Le territoire de Marseille grecque, actes de la table ronde d'Aix-en-Provence, 1985, édités par M. Bats et H. Tréziny, Université de Provence, Aix-en-Provence, 1986.

2. Les amphores de Marseille grecque, actes de la table ronde de Lattes, 1988, édités par M. Bats, Université de Provence/ADAM éditions, Aix-en-Provence/ Lattes, 1990.

3. Marseille grecque et la Gaule, actes des colloques de Marseille et Aix-enProvence, 1990, édités par M. Bats, G. Bertucchi, G. Congès, H. Tréziny, Université de Provence / ADAM éditions, Aix-en-Provence / Lattes, 1992.

4. Sur les pas des Grecs en Occident. Hommages à André Nickels, édités par P. Arcelin, M. Bats, G. Marchand, M. Schwaller, éditions Errance / ADAM éditions, Paris-Lattes 1995.

5. Fouilles à Marseille. Les mobiliers (I ${ }^{e r}-V I I^{e}$ s. ap. J.-C.), vol. collectif sous la direction de M. Bonifay, M.-Br. Carre et Y. Rigoir, éditions Errance / ADAM éditions, Paris-Lattes 1998.

6. Les cultes des cités phocéennes, actes du coll. d'Aix-en-Provencel Marseille, juin 1999, édités par A. Hermary et H. Tréziny, Édisud/Centre C. Jullian, Aix-en-Provence, 2000.

7. Marseille. Trames et paysages urbains de Gyptis au Roi René, Actes du colloque international d'archéologie, Marseille, 3-5 novembre 1999, textes réunis et édités par M. Bouiron et H. Tréziny, B. Bizot, A. Guilcher, J. Guyon et M. Pagni, Édisud/Centre C. Jullian, Aix-en-Provence, 2001.

8. La nécropole de Sainte-Barbe à Marseille (IV s. av. J.-C. - II e s. ap. J.-C.), vol. collectif sous la direction de M. Moliner, Édisud/Centre C. Jullian, Aix-en-Provence, 2003.

9. Olbia de Provence à l'époque romaine, vol. collectif sous la direction de Michel Bats, Édisud/Centre C. Jullian, Aix-en-Provence, 2007.

10. M. Bouiron et al. (éd.), Fouilles à Marseille. Approche de la ville médiévale et moderne, 2011, 464 p. (= BiAMA 7).

Les volumes sont disponibles en format pdf sur : http://sites.univ-provence.fr/ccj/spip.php?rubrique83, grâce au soutien du Centre de conservation du livre à Arles (e-corpus). 


\section{REVUE ANTIQUITÉS AFRICAINES,}

CNRS Editions, 15 rue Malebranche, 75005 Paris - http://www.cnrseditions.fr

Les volumes 1 (1967) à 29 (1993) de la revue sont accessibles sur le portail Persée à l'adresse :

http://www.persee.fr/web/revues/home/prescript/revue/antaf

Dernier volume paru, t. 45, 2009

\section{COLLECTION ÉTUDES D'ANTIQUITÉS AFRICAINES}

CNRS Editions, 15 rue Malebranche, 75005 Paris - http://www.cnrseditions.fr

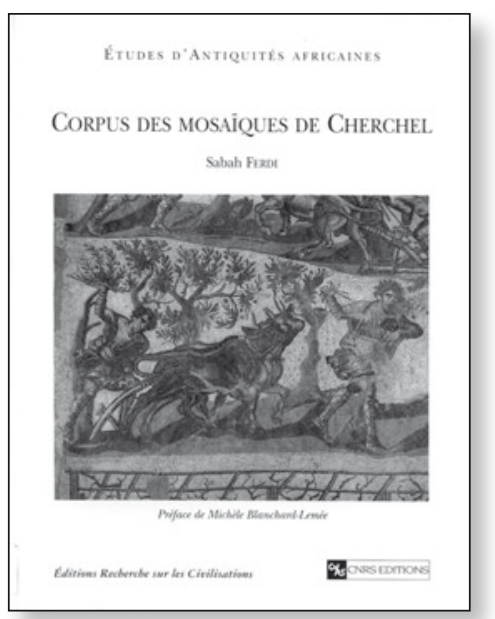

- Sabah Ferdi, Corpus des mosä̈ques de Cherchel, 2005.

- Lieux de cultes : aires votives, temples, églises, mosquées. IXe Colloque international sur l'histoire et l'archéologie de l'Afrique du Nord antique et médiévale (Tripoli, 19-25 février 2005), 2008.

- Jean-Marie Lassère, Maisons de Clupea. Exemples de l'architecture domestique dans un port de l'Afrique proconsulaire. Les maisons de l'Ecole de pêche, avec une étude de la céramique par Jean Piton, 2010.

\section{COLLECTION ARCHAEONAUTICA}

CNRS Editions, 15 rue Malebranche, 75005 Paris - http://www.cnrseditions.fr

\section{Archaeonautica}

$16 \mid 2010$

Les épaves de Saint-Georges

Lyon $-\mathrm{I}^{\mathrm{er}}-\mathrm{XVIII} \mathrm{I}^{\mathrm{e}}$ siècles

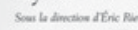

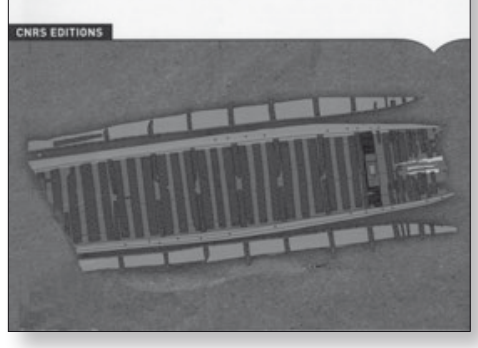

Derniers volumes parus :

14. P. Pomey, E. Rieth (dir.), Construction navale, maritime et fluviale. Approches archéologiques, historique et ethnologique Actes du Septième Colloque International d'Archéologie Navale - Proceedings of the Seventh International Symposium on Boat and ship Archaeology, Ile Tatihou 1994 (Saint-Vaast-la-Hougue). Paris 1998, $335 \mathrm{p}$.

15. 2008, L'archéologie maritime et navale de la Préhistoire à l'époque contemporaine, Paris 2009.

16. E. Rieth (dir.) Les épaves de Saint-Georges - Lyon (Ir-XVIII ${ }^{e}$ s.) : analyse architecturale et études complémentaires, Paris 2010. 335 p.

La collection $(1,1977$ - 14, 1998) est disponible sur le portail Persée (barrière mobile à 3 ans) 


\section{TRAVAUX DU CENTRE CAMILLE JULLIAN}

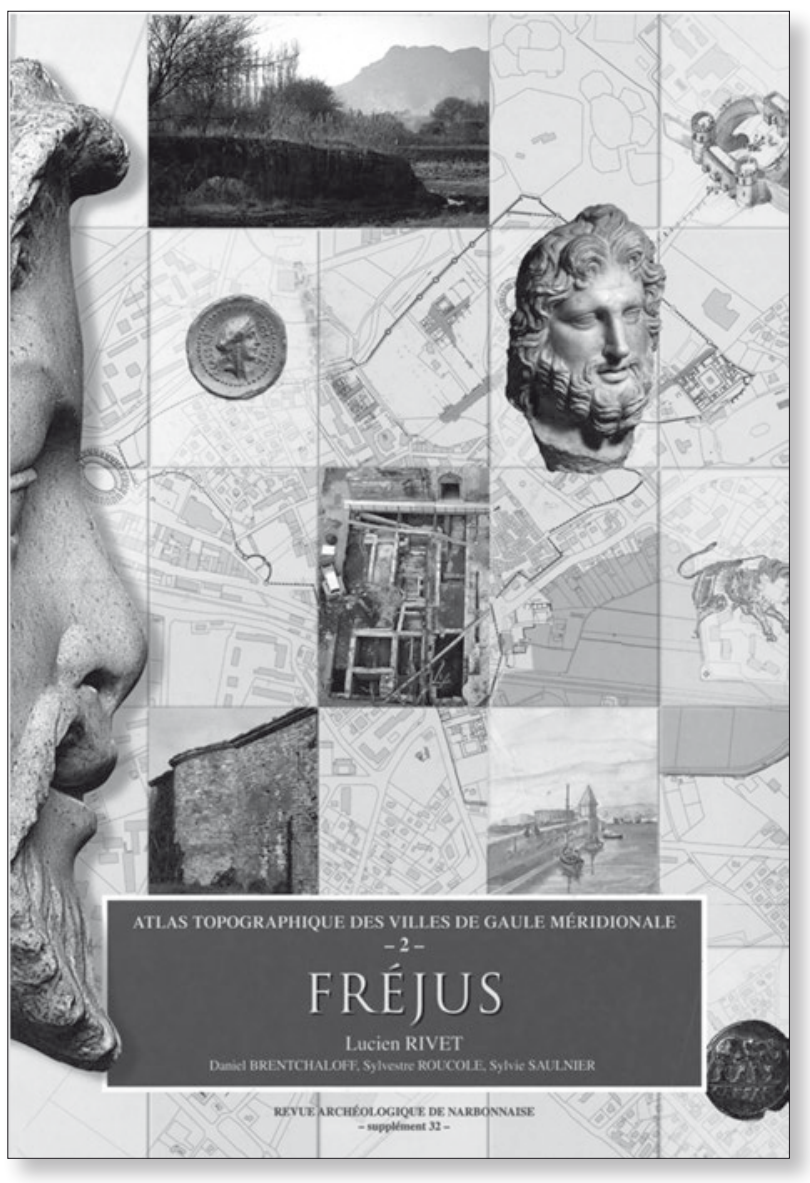

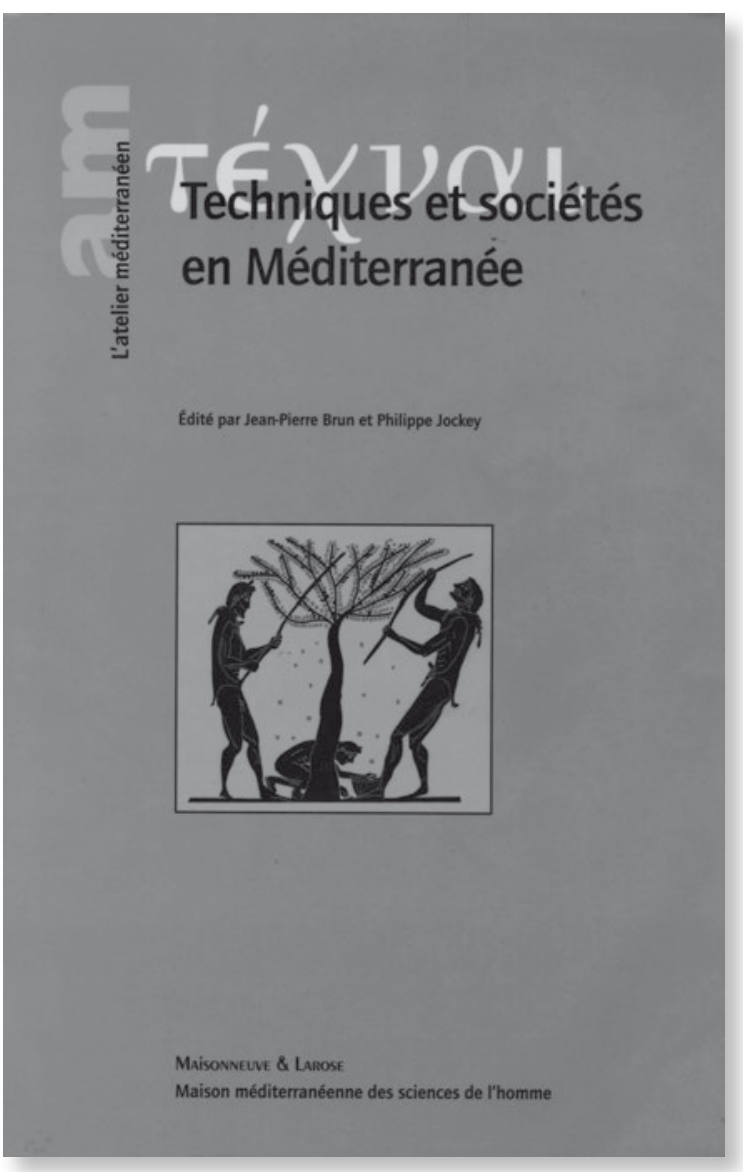

Derniers volumes parus :

21. Techniques et économie antiques et médiévales. Le temps de l'innovation, actes du colloque d'Aix-en-Provence (mai 1996), réunis par D. Garcia et D. Meeks, éd. Errance, Paris, 1997, 1 vol., 240 p.

22. Fouilles à Marseille. Les mobiliers ( $I^{e r}-V I I^{e}$ s. ap. J.-C.), ouvrage collectif sous la direction de M. Bonifay, M.-Br. Carre et Y. Rigoir (Ét. massa. 5), éd. ADAM-Errance, Lattes/Paris, 1998, 1 vol., 443 p.

23. J. Guyon, N. Nin, L.Rivet, S. Saulnier, Atlas topographique des villes de Gaule méridionale. 1, Aix-en-Provence, Montpellier, 1998 (Supplément 30 à la R.A.N.)

24. B. Sabattini, dir. La céramique attique du IVe siècle en Méditerranée occidentale, Actes du Colloque International d'Arles (7-9 décembre 1995), Naples, Centre Jean Bérard, 2000 (= Collection du Centre Jean Bérard, 19).

25. J.-P Morel, C. Rondi-Costanzo et D. Ugolini, éd., Corallo di ieri, corallo di oggi, Actes du Colloque International du Centre Universitaire Européen pour les Biens Culturels, Ravello, Italie (13-15 décembre 1996), Bari, Edipuglia, 2000 (= CUEBC, Scienze e materiali del patrimonio culturale, 5).

26. P. Leveau et J.-P. Saquet, éd., Milieu et sociétés dans la Vallée des Baux. Études présentées au colloque de Mouriès. Montpellier, 2000 (= Suppl. 31 à la R.A.N.).

27. L. Rivet, D. Brentchaloff, S. Roucole, S. Saulnier, Atlas topographique des villes de Gaule méridionale 2. Fréjus, Montpellier, 2000 (= Suppl. 32 à la R.A.N.).

28. P. Lévêque et J.-P. Morel, dir., Céramiques hellénistiques et romaines. III, Paris, 2001.

29. Ph. Columeau, Alimentation carnée en Gaule du Sud: VII ${ }^{e}$ s. av. J.-C.-XIVe s., éditions Université de Provence, Aix-en-Provence 2002.30. J.-P. Brun et Ph. Jockey, éd., TECHNAI. Techniques et sociétés en Méditerranée, Hommage à M.-Cl. Amouretti, Paris, Maisonneuve et Larose, 2001 (MMSH, coll. L'atelier méditerranéen), Aix-en-Provence 2001.

30. J.-P. Brun et Ph. Jockey, éd., TECHNAI. Techniques et sociétés en Méditerranée, Hommage à M.-Cl. Amouretti, Paris, Maisonneuve et Larose, 2001 (MMSH, coll. L'atelier méditerranéen), Aix-en-Provence 2001. 
Achevé d'imprimer en Février 2012 par Corlet Imprimeur à Condé-sur-Noireau

Dépôt légal : Mars 2012 $\mathrm{n}^{\circ} \mathrm{d}$ 'imprimeur :

Imprimé en France 